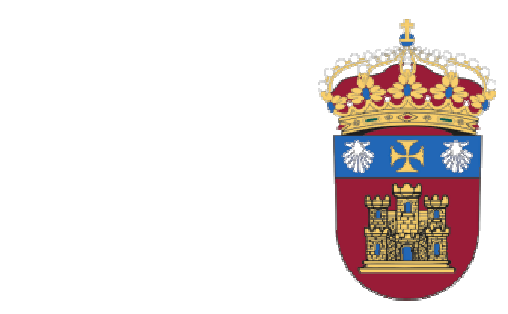

UNIVERSIDAD DE BURGOS

FACULTAD DE CIENCIAS

DEPARTAMENTO DE BIOTECNOLOGÍA Y CIENCIA DE LOS ALIMENTOS ÁREA DE INGENIERÍA QUÍMICA

\title{
SEPARACIÓN DE AMINOÁCIDOS Y DERIVADOS UTILIZANDO RESINAS IMPREGNADAS DE EXTRACTANTE
}

TESIS DOCTORAL

ANA ISABEL HORTA RONDA

Febrero 2008 



\section{SEPARACIÓN DE AMINOÁCIDOS Y DERIVADOS UTILIZANDO RESINAS IMPREGNADAS DE EXTRACTANTE}

Memoria que para optar al grado de Doctor por la Universidad de Burgos presenta la licenciada

ANA ISABEL HORTA RONDA

Burgos, Febrero 2008 



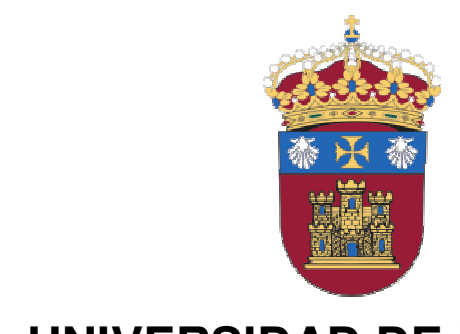

\section{UNIVERSIDAD DE BURGOS}

FACULTAD DE CIENCIAS

SECRETARÍA

La presente Tesis Doctoral queda registrada en el folio $\mathrm{n}^{\circ}$ del correspondiente Libro de Registros, con el no

Burgos, a de de 2008

El Encargado del Registro 



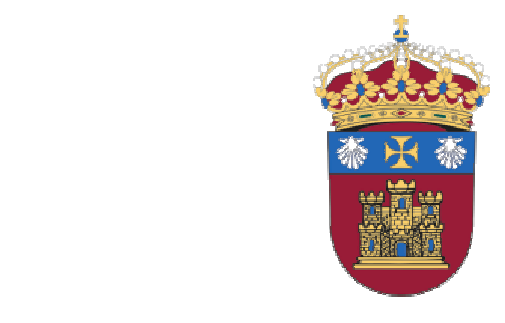

\title{
UNIVERSIDAD DE BURGOS \\ FACULTAD DE CIENCIAS \\ DEPARTAMENTO DE BIOTECNOLOGÍA \\ Y CIENCIA DE LOS ALIMENTOS \\ ÁREA DE INGENIERÍA QUIIMICA
}

\begin{abstract}
DRA. MARÍA OLGA RUIZ PÉREZ,
PROFESOR DOCTOR CONTRATADO FIJO DEL ÁREA DE INGENIERÍA QUÍMICA

DE LA UNIVERSIDAD DE BURGOS
\end{abstract}

\author{
DRA. MARIA ISABEL ESCUDERO BARBERO, \\ PROFESOR TITULAR DEL ÁREA DE INGENIERÍA QUIIMICA \\ DE LA UNIVERSIDAD DE BURGOS
}

\section{CERTIFICAN:}

Que la memoria titulada «SEPARACIÓN DE AMINOÁCIDOS Y DERIVADOS UTILIZANDO RESINAS IMPREGNADAS DE EXTRACTANTE», que para optar al grado de Doctor por la Universidad de Burgos presenta Dña. ANA ISABEL HORTA RONDA, ha sido realizada bajo nuestra dirección en el Área de Ingeniería Química del Departamento de Biotecnología y Ciencia de los Alimentos de la Universidad de Burgos.

Y para que así conste, firmo el presente certificado en Burgos a 29 de febrero de 2008.

Fdo. Dra. Dª. María Olga Ruiz Pérez

Fdo. Dra. $D^{\mathrm{a}} \cdot \mathrm{M}^{\mathrm{a}}$ Isabel Escudero Barbero 



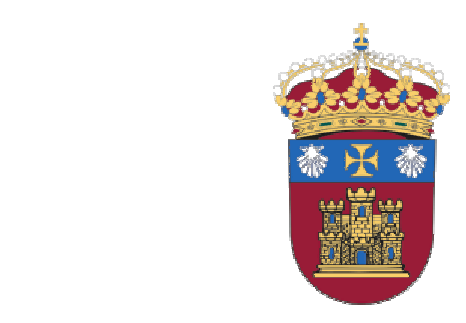

\title{
UNIVERSIDAD DE BURGOS \\ DEPARTAMENTO DE BIOTECNOLOGÍA \\ Y CIENCIA DE LOS ALIMENTOS
}

\begin{abstract}
D. MANUEL PÉREZ MATEOS CATEDRÁTICO Y DIRECTOR DEL DEPARTAMENTO DE BIOTECNOLOGÍA Y CIENCIA DE LOS ALIMENTOS DE LA UNIVERSIDAD DE BURGOS
\end{abstract}

CERTIFICA:

Que la memoria titulada «SEPARACIÓN DE AMINOÁCIDOS Y DERIVADOS UTILIZANDO RESINAS IMPREGNADAS DE EXTRACTANTE », que para optar al grado de Doctor por la Universidad de Burgos presenta Dña. ANA ISABEL HORTA RONDA, ha sido realizada en el Área de Ingeniería Química del Departamento de Biotecnología y Ciencia de los Alimentos de la Universidad de Burgos, bajo la dirección de las Doctoras María Olga Ruiz Pérez y María Isabel Escudero Barbero.

Burgos a 29 de febrero de 2008

Fdo. Dr. D. Manuel Pérez Mateos

Director del Departamento 



\section{AGRADECIMIENTOS}

\section{$\cos$}

A la Dra. Maria Olga Ruiz Pérez directora de esta Tesis Doctoral por su apoyo y constante seguimiento del trabajo, ofreciéndome su opinión y conocimiento a través de intensas horas de trabajo en equipo, y gracias a lo cuál, he tenido la oportunidad de tener distintos puntos de vista para la mejor realización de esta memoria.

A la Dra. Maㅗ Isabel Escudero Barbero directora de esta Tesis Doctoral por ofrecerme la oportunidad de trabajar en un proyecto de alto interés científico, por su colaboración y ayuda en el desarrollo del mismo.

A mis amigos y compañeros del Área de Ingeniería Química y del Laboratorio de Salud Pública por su amistad y ayuda, y por los buenos momentos compartidos juntos.

A la Universidad de Burgos, al Ministerio de Educación y Ciencia y a la Junta de Castilla y León por haber financiado este trabajo.

A mis amigas de la Universidad de Burgos por su constante apoyo y amistad durante todos estos años de estudio y trabajo; y por compartir gratos momentos y experiencias juntas.

A mi familia y especialmente a mis padres, por estar apoyándome siempre que lo he necesitado, por sus consejos, su constante e inestimable ayuda y cariño recibido. 



\section{$\underline{\text { INDICE }}$}

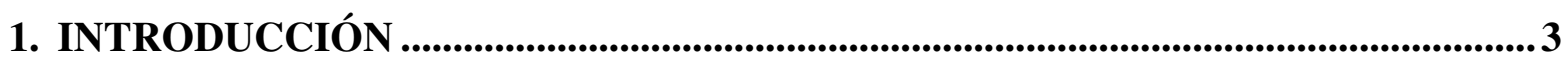

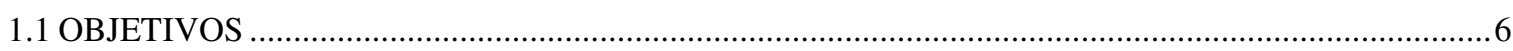

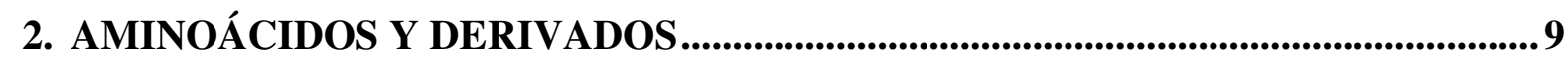

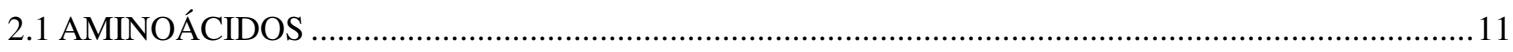

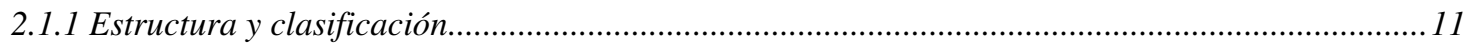

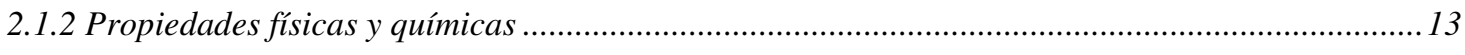

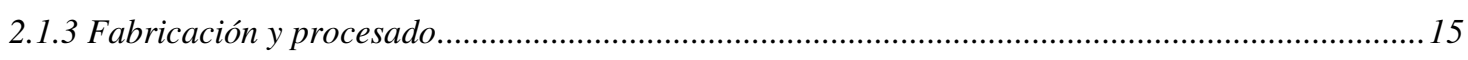

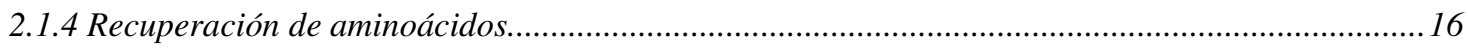

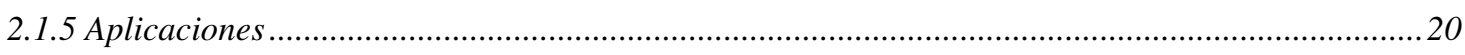

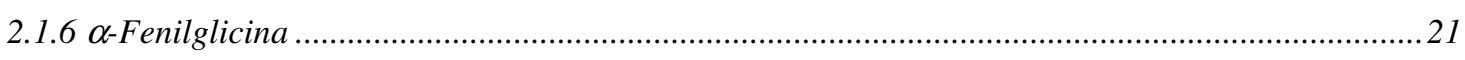

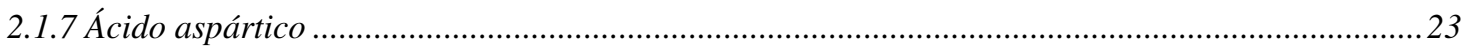

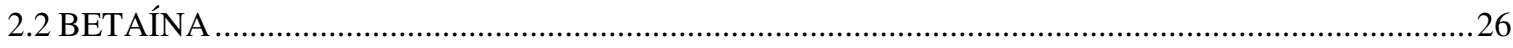

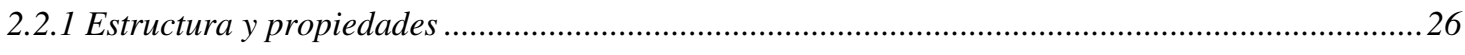

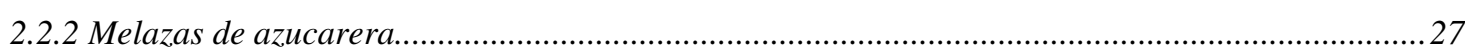

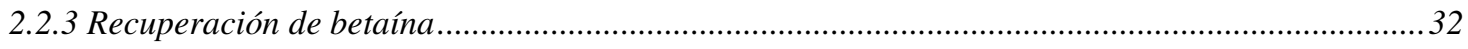

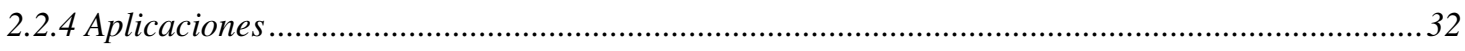

3. EXTRACCIÓN LÍQUIDO-LÍQUIDO ........................................................................35

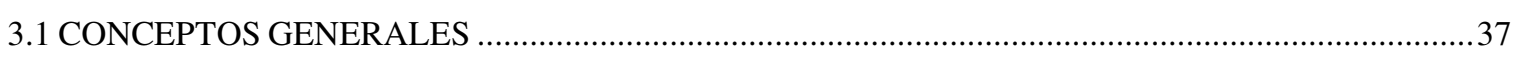

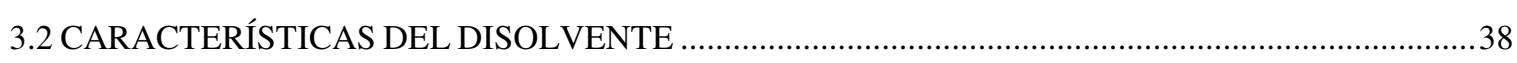

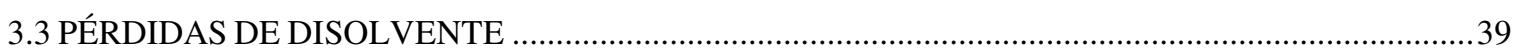

3.4 EQUILIBRIOS DE EXTRACCIÓN DE AMINOÁCIDOS Y BETAÍNA ……………...............................40

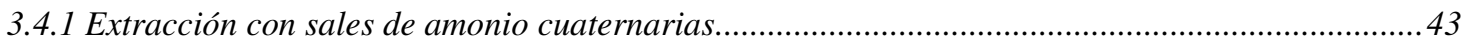

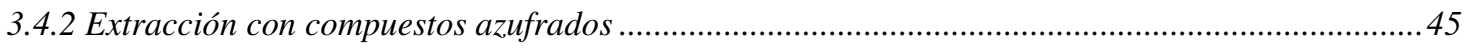

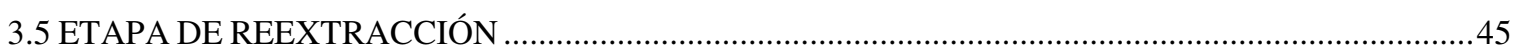

4. SEPARACIÓN CON RESINAS....................................................................................47

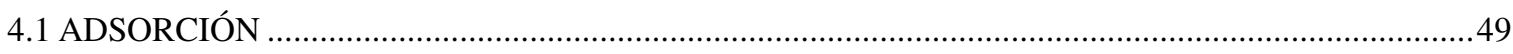

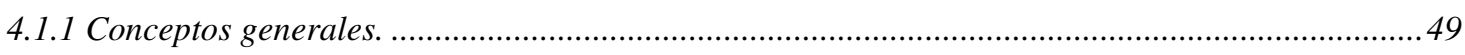

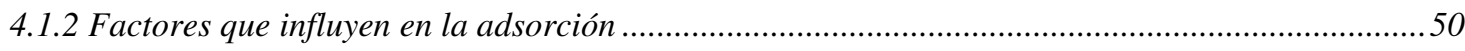

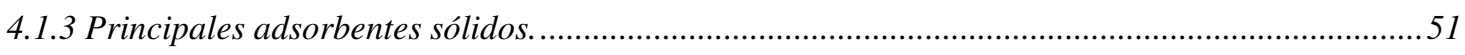

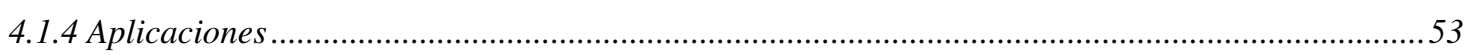

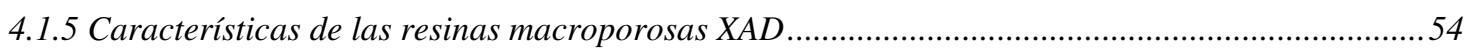

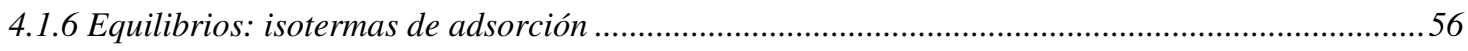

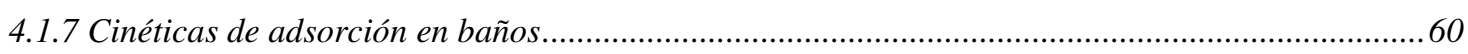

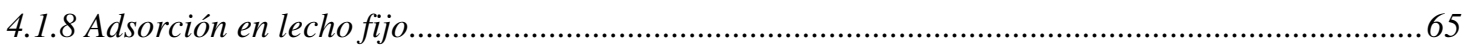


4.1.9 Desorción y regeneración del adsorbente ................................................................................69

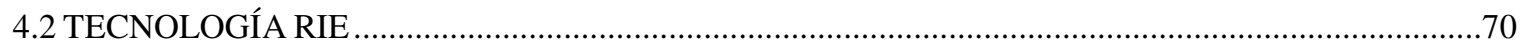

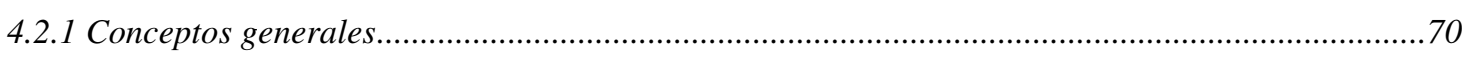

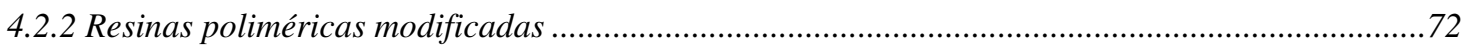

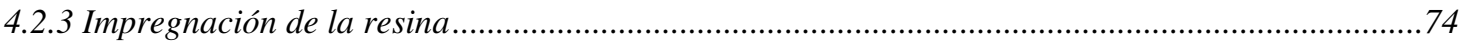

5. RECUPERACIÓN DE AMINOÁCIDOS............................................................................77

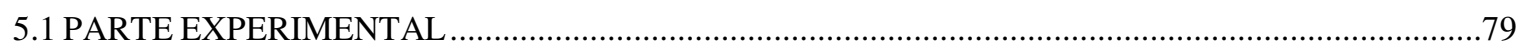

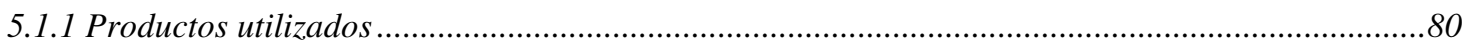

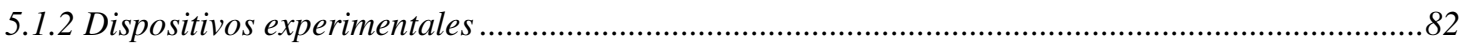

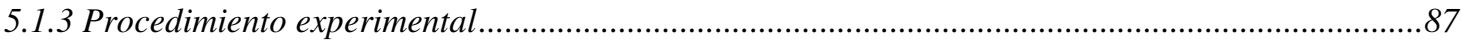

5.2 RESULTADOS Y DISCUSIÓN: EQUILIBRIOS DE EXTRACCIÓN ….............................................96

5.2.1 Impregnación de Amberlita XAD-4 con TOMAC .........................................................................96

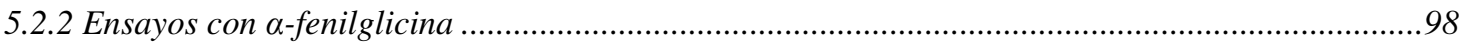

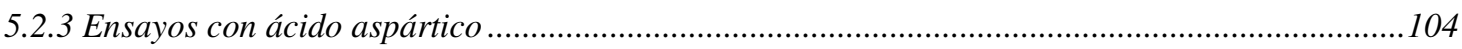

5.2.4 Ensayos con mezclas binarias de ácido aspártico y $\alpha$-fenilglicina ..............................................113

5.2.5 Comparación de los equilibrios de extracción individual y conjunta de ácido aspártico y $\alpha$ -

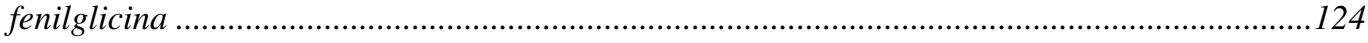

5.3 RESULTADOS Y DISCUSIÓN: CINÉTICAS DE EXTRACCIÓN EN BAÑOS AGITADOS .............127

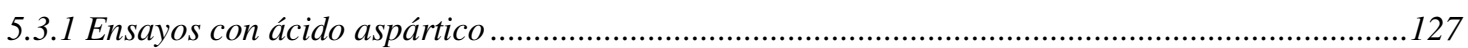

5.3.2 Ensayos con mezclas binarias de ácido aspártico y $\alpha$-fenilglicina ............................................144

5.3.3 Comparación de las cinéticas de la extracción individual y conjunta de ácido aspártico y $\alpha$ -

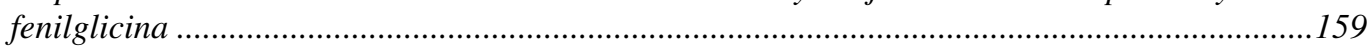

5.4 RESULTADOS Y DISCUSIÓN: EXTRACCIÓN EN COLUMNAS DE LECHO FIJO.......................162

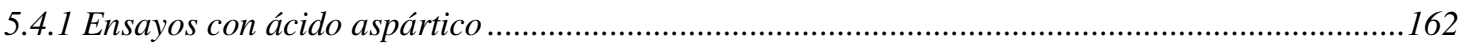

5.4.2 Ensayos con mezclas binarias de ácido aspártico y $\alpha$-fenilglicina .............................................172

5.4.3 Modelo dinámico para la estimación de las curvas de ruptura ......................................................178

5.4.4 Extracción-reextracción en un sistema con dos columnas de RIE en serie...................................186

6. RECUPERACIÓN DE BETAÍNA ...............................................................................193

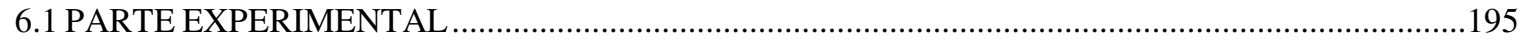

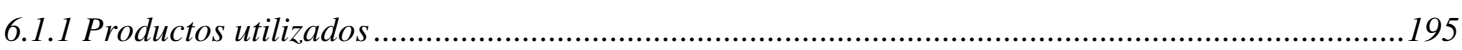

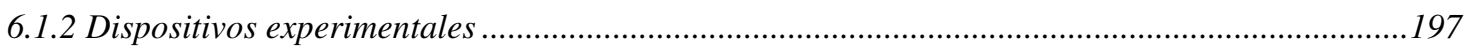

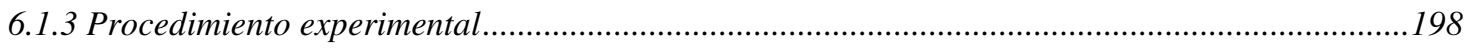

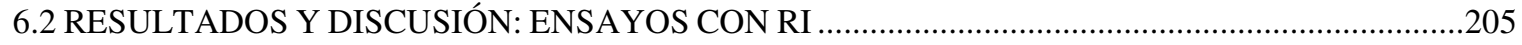

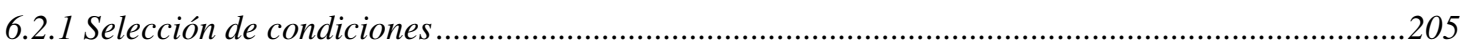

6.2.2 Equilibrios de extracción de betaína con Amberlyst 15 ...............................................................209

6.2.3 Equilibrios de extracción de mezclas binarias de betaína y sacarosa con Amberlyst 15..............210

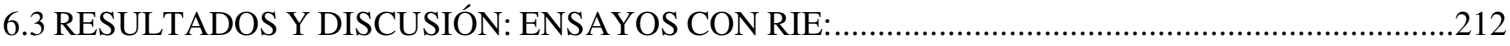

6.3.1 Ensayos de equilibrio de extracción líquido-líquido: selección del extractante ...........................212 
6.3.2 Lavado e impregnación de RIE.

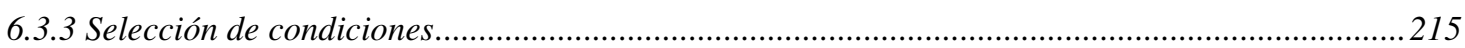

6.3.4 Equilibrios de extracción de betaína con RIE.............................................................................2216

6.3.5 Equilibrios de extracción de mezclas binarias de betaína y sacarosa con RIE ...........................220

6.3.6 Cinéticas de extracción de betaína en baños agitados.....................................................................222

6.3.7 Extracción de betaína en columnas de lecho fijo ............................................................................2229

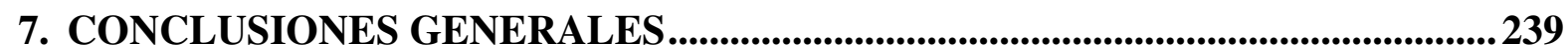

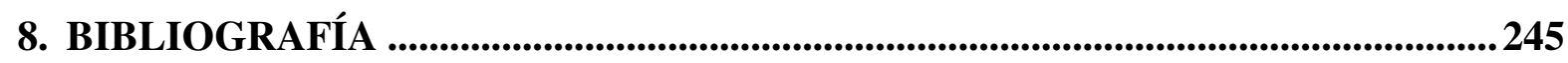

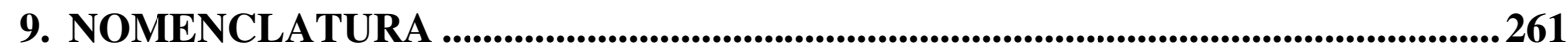

10. APÉNDICES

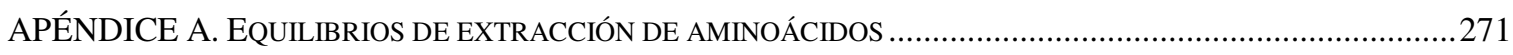

APÉNDICE B. CINÉTICAS DE EXTRACCIÓN DE AMINOÁCIDOS EN BAÑOS AGITADOS ..................................282

APÉNDICE C. EXTRACCIÓN DE AMINOÁCIDOS EN LECHOS FIJOS DE RIE ..................................................300

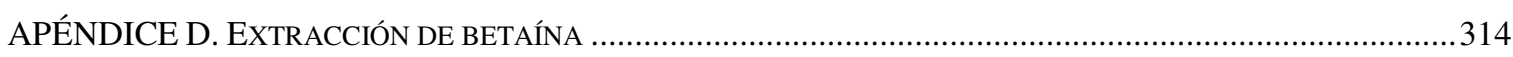





\section{RESUMEN}

En esta Tesis Doctoral se analiza la separación de biocompuestos de interés alimentario y farmaceutico como son los aminoácidos (a-fenilglicina y ácido aspártico) y derivados (betaína) mediante una novedosa tecnología de extracción con resinas impregnadas de extractante (RIE), demostrando que es una alternativa adecuada a los procesos de separación convencionales.

Estos biocompuestos de elevado consumo industrial se utilizan habitualmente como materias primas en la elaboración de alimentos, cosméticos, analgésicos y fármacos. El interés de su recuperación de caldos de fermentación o de corrientes residuales reside en su elevado valor potencial, tanto alimentario como farmacológico, a la vez que se disminuyen los riesgos medioambientales asociados a la emisión de nitrógeno en su vertido. En concreto, el aminoácido a-fenilglicina se emplea como precursor en la síntesis de antibióticos $\beta$-lactámicos, tales como las cefalosporinas. El ácido aspártico se emplea principalmente en la síntesis de aspartamo, edulcorante artificial hipocalórico de amplio uso alimentario y farmacéutico. La betaína se emplea como protector de la mucosa gástrica, para reducir los niveles de homocisteína, como aditivo en pastas de dientes ya que evita la sequedad bucal, en productos cosméticos para pacientes con dermatitis y en piensos.

La tecnología con RIE es una tecnología híbrida capaz de reunir en un solo proceso la elevada capacidad y selectividad que ofrecen las técnicas de extracción líquido-líquido, con las ventajas que ofrecen los procesos de separación con matrices sólidas de intercambio iónico, que permiten procesar disoluciones altamente diluidas utilizando equipos sencillos como son los lechos porosos y fluidizados. En este estudio se ha empleado como soporte polimérico Amberlita XAD-4 y como extractante cloruro de trialquilmetilamonio (Tomac) para la separación selectiva de los aminoácidos y ácido dinonilnaftalensulfónico (DNNSA) para la de betaína.

La investigación recogida en esta memoria de Tesis Doctoral se ha llevado a cabo mediante la consecución de las siguientes etapas:

- Estudios de impregnación del soporte polimérico con el extractante.

- Determinación experimental y modelización de los equilibrios de extracción de afenilglicina y ácido aspártico, separados y mezclados, con RIE bajo diferentes condiciones iniciales de concentración de aminoácido y de $\mathrm{pH}$. Se ha desarrollado un modelo matemático sencillo que permite evaluar los mecanismos implicados en el proceso de extracción y que es necesario para el diseño del proceso dinámico de separación empleando lechos fijos de RIE.

- Estudio cinético de extracción en tanques agitados y modelización de los resultados. Se ha determinado experimentalmente la velocidad de separación individual y conjunta de ácido aspártico y a-fenilglicina con RIE. La modelización de los resultados permite cuantificar los parámetros cinéticos necesarios para el cambio de escala, así como las resistencias implicadas o más limitantes en el proceso de transferencia de materia.

- Estudio del proceso dinámico de separación de ácido aspártico y de a-fenilglicina utilizando lechos fijos rellenos de RIE. Determinación experimental y modelización de las curvas de ruptura de extracción y de reextracción de ácido aspártico solo o mezclado con $\alpha$-fenilglicina: efecto de la concentración de la alimentación, del pH, 
de la concentración de Tomac en la RIE y de la velocidad superficial, así como de los ciclos sucesivos de extracción-reextracción. En base a estos resultados, se ha diseñado el proceso de extracción-reextracción utilizando dos lechos fijos de RIE en serie con el objetivo fundamental de conseguir el fraccionamiento de los aminoácidos estudiados de sus mezclas binarias.

- Evaluación de la separación de betaína sola y mezclada con sacarosa de disoluciones acuosas empleando RIE y resinas de intercambio iónico comerciales. Diseño de un proceso de pretratamiento - extracción y de reextracción. Modelización y optimización del proceso en lechos fijos de resina impregnada de extractante. 


\begin{abstract}
The separation of amino acids ( $\alpha$-phenylglycine and aspartic acid) and by-products (betaine), as they are biocompounds of food and pharmaceutical interest, was carried out with a new extraction technology using extractant-impregnated resins. This study demonstrates that this new technology is an alternative to the conventional separation processes.
\end{abstract}

Biocompounds are extensively used as raw materials in the chemical, pharmaceutical, food and health industries. It is important to recover them from fermentation broths or process effluents for economic and environment reasons in order to minimize water pollution. $\alpha$-Phenylglycine is an important precursor in pharmaceutical industry in the production of $\beta$-lactam antibiotics, such as cephalosporines. Aspartic acid and phenylalanine are mainly used in the synthesis of the low-calorie sweetener, aspartame. Betaine is used as a digestive aid being particularly helpful for persons with insufficient acid production in the stomach, it is also used to reduce homocysteine levels, as an ingredient in toothpaste, in cosmetic products and in feeds.

Extraction with impregnated resins (EIR) is a novel hybrid technology which combines the high capacity and selectivity of liquid-liquid extraction technique, with the advantages of separation processes with ion exchange resins, which allow to process high quantities of diluted solutions, using simple and low cost equipments, such as fixed or fluidized beds. In this work separation of amino acids was investigated by impregnation of Amberlite XAD-4 resin with tri-alkylmethylammonium chloride (TOMAC) and for betaine separation the same resin was impregnated with dinonilnaftalensulfonic acid (DNNSA).

Research was carried out by the following steps:

- Impregnation study of the polymeric support with the extractant.

- Experimental determination of a-phenylglycine and aspartic acid extraction equilibria, isolated or in binary mixtures with EIR, under different initial amino acid concentrations and $\mathrm{pH}$. Equilibrium models which take account of the simultaneous reactive extraction of the amino acids or hydroxyl ions with the extractant are performed in order to design separation dynamic process with EIR fixed beds.

- Kinetics studies in a batch stirred tank. The sorption rates of $\alpha$-phenylglycine and aspartic acid isolated and in binary mixtures with EIR have been investigated. Kinetic models were used for the determination of the rate-controlling steps and diffusion coefficients values.

- Extraction and back-extraction of a-phenylglycine and aspartic acid in fixed bed packed with EIR were studied. The effects of the feed flow rate, amino acid concentration in the feed solution, $\mathrm{pH}$ and extractant concentration in the impregnated resin on the breakthrough curves, were investigated. A dynamic model that considers intraparticle diffusion and external liquid film diffusion as limiting steps in mass transfer rates is applied. It was also designed an extraction and back-extraction process with two fixed beds packed with EIR for fractionation 
of amino acids in mixtures.

- Separation of betaine isolated or in mixtures with sucrose from aqueous solutions using impregnated resins (EIR) or ion exchange resins was studied. An extraction and back-extraction process was designed in fixed beds packed with EIR. 


1. INTRODUCCIÓN 

El trabajo de investigación que configura la presenteTesis Doctoral se ha centrado en el estudio de una nueva tecnología híbrida de extracción que utiliza resinas macroporosas no iónicas impregnadas con un extractante selectivo, aplicado a la separación de aminoácidos (ácido aspártico y a-fenilglicina) y derivados (betaína) de disoluciones diluidas. La finalidad de esta investigación ha sido avanzar en el conocimiento científico y tecnológico, analizando no sólo la viabilidad técnica del proceso de recuperación selectiva de aminoácidos y derivados, sino la evaluación crítica de las ventajas tecnológicas que presenta para configurarse como un proceso alternativo a los procesos convencionales de separación utilizados a nivel industrial, como son principalmente la extracción líquido-líquido o el uso de resinas de intercambio iónico.

Los aminoácidos y derivados son biocompuestos de elevado consumo industrial, se utilizan habitualmente como materias primas en la preparación de alimentos, cosméticos, analgésicos y fármacos. El interés de su recuperación de caldos de fermentación, de corrientes de proceso o de corrientes residuales donde se encuentran presentes en baja concentración reside su valor potencial, tanto alimentario como farmacológico, a la vez que se disminuyen los riesgos medioambientales asociados a la emisión de nitrógeno en los vertidos, nutriente que puede producir la eutrofización del cauce receptor (crecimiento de algas provocando la asfixia masiva de la vida acuática).

En concreto, el aminoácido fenilglicina se emplea como precursor en la síntesis de antibióticos $\beta$-lactámicos, tales como las cefalosporinas y penicilinas sintéticas, uno de los grupos con mayor volumen de producción del sector farmacéutico. El ácido aspártico se emplea en la preparación de medios de cultivo, en detergentes, fungicidas y germicidas y principalmente en la síntesis de aspartamo, edulcorante artificial hipocalórico de amplio uso en bebidas refrescantes, alimentos, caramelos y fármacos. La betaína, también conocida como N,N,N-trimetilglicina, se emplea como protector de la mucosa gástrica, para reducir los niveles de homocisteína que es un tóxico que promueve la arterosclerosis y la osteoporosis, como aditivo en pastas de dientes en pacientes con sequedad bucal, en preparados vitamínico-minerales, en productos cosméticos (champús, geles y preparados de limpieza de la piel) para pacientes con dermatitis. Además, actúan como "donantes de grupos metilo" necesario para un funcionamiento hepático correcto, la replicación celular y las reacciones de desintoxicación. También se usa en piensos, principalmente de pollos y peces, y para mejorar la adaptación de los peces a concentraciones salinas más elevadas y para la fabricación de materiales biodegradables de aplicación en la producción de papel y en la formación de nuevos plásticos transparentes. En este estudio se ha evaluado la recuperación de betaína de residuos industriales de las azucareras en donde se encuentra presente en alta concentración, hasta un $7 \%$ en las melazas de remolacha y hasta un $4 \%$ en las vinazas de fermentación.

El interés del presente trabajo reside en las ventajas que aporta la tecnología de extracción con Resinas Impregnadas de Extractante (Tecnología RIE) frente a los procesos convencionales, con el fin de disminuir los costes de operación y mejorar el rendimiento de la separación y purificación de los aminoácidos y derivados. Esta tecnología híbrida es capaz de reunir en un solo proceso las ventajas que ofrecen los procesos de adsorción sobre matrices poliméricas sólidas, aplicables a disoluciones muy diluidas, con la elevada capacidad y selectividad que ofrecen las técnicas de extracción con disolventes, utilizando además un equipo sencillo y barato como son los lechos porosos o fluidizados, propio de la tecnología de intercambio iónico con resinas sólidas. Esta tecnología además, se puede englobar dentro de las "tecnologías limpias", ya que minimiza el uso de disolventes orgánicos, los costes energéticos son relativamente bajos, 
no se precisa cambio de estado y la recirculación de las fases conlleva un aprovechamiento casi total de las corrientes implicadas, con pérdidas de compuestos en el sobrante prácticamente despreciables, contribuyendo así a la sostenibilidad del medio ambiente.

Además del interés de su aplicación, esta investigación cubre un amplio estudio fundamentado en los principios que gobiernan la transferencia de materia. Dicho estudio abarca los aspectos básicos relacionados con el equilibrio entre fases, el estudio de las etapas físicas que condicionan la operación, la velocidad de transferencia de materia y su modelización de cara al diseño del proceso integrado de extracción - reextracción en lechos fijos y su posible cambio de escala para la aplicación industrial.

\subsection{OBJETIVOS}

El presente trabajo está enfocado al estudio de la separación de $\alpha$-fenilglicina, ácido aspártico y betaína de disoluciones acuosas diluidas utilizando la tecnología híbrida de extracción reactiva con resinas impregnadas de extractante, tratando de cubrir los objetivos que se citan a continuación:

\section{A Estudiar la viabilidad técnica de la tecnología híbrida de extracción con resinas impregnadas de extractante (RIE) aplicada a la separación de aminoácidos de disoluciones acuosas diluidas.}

Este objetivo conlleva la consecución de las siguientes etapas:

1. Evaluación de las condiciones óptimas de impregnación de la resina Amberlita XAD-4 con Tomac.

2. Estudio del equilibrio y de las cinéticas en baños agitados de extracción individual y conjunta de ácido aspártico y fenilglicina con resina impregnada de extractante, bajo diferentes condiciones de operación. Modelización de resultados.

3. Evaluación del proceso dinámico de extracción y reextracción de los aminoácidos fenilglicina y ácido aspártico empleando columnas de lechos fijos rellenas de resina impregnada: Determinación y modelización de las curvas de ruptura de los aminoácidos, estudiando el efecto del caudal, temperatura, $\mathrm{pH}$, carga de Tomac en la RIE y concentración de la alimentación. Estudios de reextracción - regeneración del lecho y evaluación del agotamiento en ciclos sucesivos. 
4. Diseño de un proceso dinámico de fraccionamiento de los aminoácidos $\alpha$ fenilglicina y ácido aspártico empleando dos lechos fijos de resina impregnada: selección de condiciones.

\section{B Estudiar la recuperación de betaína utilizando la tecnología híbrida de extracción con resinas impregnadas de extractante (RIE).}

Este objetivo conlleva las siguientes etapas:

1. Selección de los agentes de separación: extractantes, diluyentes, resinas de intercambio iónico, resinas modificadas, etc.

2. Estudio del equilibrio de extracción de betaína sola y mezclada con sacarosa con resinas de intercambio iónico comerciales y con resina impregnada de extractante, bajo diferentes condiciones de operación. Modelización de resultados. Selección de las condiciones.

3. Determinación experimental y modelización de los resultados cinéticos de extracción de betaína en baños agitados con resina impregnada de extractante, bajo diferentes condiciones de operación.

4. Diseño de un proceso de pretratamiento - extracción y reextracción: modelización y optimización del proceso en lechos fijos de resina impregnada de extractante. 



\section{AMINOÁCIDOS Y DERIVADOS}





\subsection{AMINOÁCIDOS}

Desde el punto de vista de la química de los alimentos, los aminoácidos, péptidos y proteínas, proporcionan los elementos necesarios para la síntesis proteica y contribuyen en la estructura y cualidades organolépticas de los alimentos. En concreto, los aminoácidos y los péptidos contribuyen directamente en su sabor y son precursores de los componentes aromáticos y de las sustancias coloreadas que aparecen en la obtención, preparación, maduración y almacenamiento de los mismos; mientras que las proteínas tienen capacidad para formar o estabilizar geles, espumas, masas, emulsiones y estructuras fibrilares que son esenciales en los alimentos (Belitz H. D. et al., 1997; Linden G. et al., 1996).

Los aminoácidos son las unidades básicas que componen las proteínas. Aproximadamente 20 aminoácidos las constituyen habitualmente. En 1806, fue descubierto el primer aminoácido, la L-asparagina, y cien años más tarde, en 1935 se aisló el vigésimo, la L-treonina. Todos estos a-aminoácidos de configuración $L$ se obtienen por hidrólisis completa (ácida, alcalina o enzimática) de las proteínas.

\subsubsection{Estructura y clasificación}

Los aminoácidos contienen, por lo menos, un grupo amino primario $\left(-\mathrm{NH}_{2}\right)$ y un grupo carboxilo $(-\mathrm{COOH})$. En los aminoácidos derivados de las proteínas el grupo amino primario ocupa una posición $\alpha$ con relación al grupo carboxilo. Los $\alpha$ - aminoácidos naturales tienen la estructura siguiente:

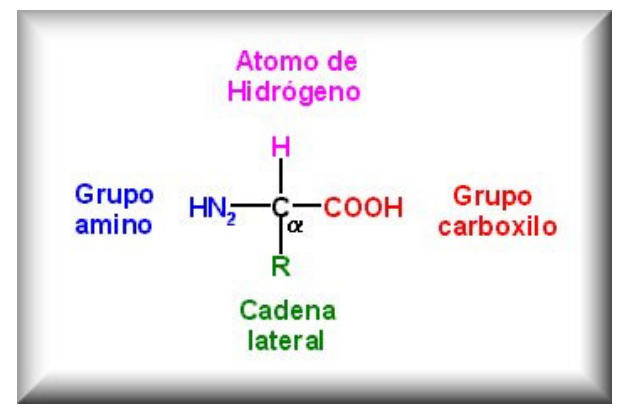

donde $\mathrm{R}$ es la cadena lateral de los aminoácidos, que puede ser desde un protón, como en el caso del aminoácido más sencillo la glicina, hasta un resto alifático, aromático o heterocíclico portador de otros grupos funcionales.

Los aminoácidos se diferencian sólo en la naturaleza química de la cadena lateral o grupo $\mathrm{R}$, las propiedades físico-químicas, como la carga neta, la solubilidad, la reactividad química y las posibilidades de establecer puentes de hidrógeno de los 
aminoácidos dependen de la naturaleza química de la cadena lateral. Las proteínas naturales contienen hasta 20 aminoácidos primarios, unidos vía enlaces amida. Sin embargo, el número total de aminoácidos existente en la naturaleza es del orden de 200 (Fennema O. R, 2000; Belitz H. D. et al., 1997).

Desde el punto de vista de la polaridad de la cadena lateral se puede realizar la siguiente clasificación de los aminoácidos (Cheftel J. C. et al., 1989):

- Aminoácidos con las cadenas laterales apolares o hidrófobos: glicina, alanina, isoleucina, leucina, metionina, prolina, fenilalanina, triptófano, valina. Son menos solubles en el agua que los aminoácidos polares. La hidrofobicidad aumenta con la longitud de la cadena lateral.

- Aminoácidos con cadenas laterales polares y sin carga (hidrófilos): serina, treonina, cisteína, tirosina, asparagina, glutamina. Tienen grupos funcionales neutros y polares que son capaces de formar enlaces hidrógeno con algunas moléculas, tales como el agua, por ejemplo. La polaridad de la serina, treonina y tirosina depende de su grupo hidrófilo $(-\mathrm{OH})$, la polaridad de la asparragina y glutamina de su grupo amida $\left(-\mathrm{CO}-\mathrm{NH}_{2}\right)$ y la polaridad de la cisteína de su grupo tiol (-SH). La glicina se incluye, a veces, en este grupo; la cisteína y tirosina poseen los grupos funcionales más polares de esta clase, porque los grupos tiol y fenol pueden sufrir una ionización parcial a pH próximos a la neutralidad. Además, se pueden oxidar dos grupos tiol de dos moléculas de cisteína y entonces se forma una molécula de cistina. Cuando en una proteína se produce este fenómeno, aparece entonces un enlace disulfuro.

La asparragina y la glutamina se hidrolizan fácilmente en presencia de un ácido o de una base para formar, respectivamente, los ácidos aspártico y glutámico.

- Aminoácidos con cadena lateral cargada negativamente (a pH próximo a 7): ácido aspártico, ácido glutámico.

- Aminoácidos con cadena lateral cargada positivamente (a pH próximo a 7): histidina, lisina, y arginina. El grupo $\epsilon-\mathrm{NH}_{2}$ es el responsable de la carga de la lisina y el grupo guanadina en la argina. El $10 \%$ de los grupos amidazol de la histidina resultan protonizados a $\mathrm{pH}=7$ y el $50 \%$ a $\mathrm{pH}=6$.

Desde el punto de vista nutricional los aminoácidos se pueden clasificar como:

- Aminoácidos esenciales que deben ser ingeridos en la dieta: valina, leucina, isoleucina, fenilalanina, triptófano, metionina, treonina, histidina, lisina, arginina.

- Aminoácidos no esenciales pero sí necesarios para el buen funcionamiento del organismo: glicina, alanina, prolina, serina, cisteína, tirosina, asparagina, glutamina, ácido aspártico, ácido glutámico.

Los valores nutricionales de una proteína se mejoran agregando los aminoácidos esenciales que la proteína posea en baja concentración. 


\subsubsection{Propiedades físicas y quimicas}

Los aminoácidos son sólidos, con estructuras cristalinas muy variadas, tienen puntos de fusión elevados entre 200 y $300^{\circ} \mathrm{C}$, y generalmente se descomponen antes de alcanzar el punto de fusión.

Estereoquímica de los aminoácidos. Con la excepción de la glicina, todos los $\alpha$ aminoácidos contienen al menos un átomo de carbono asimétrico, lo que quiere decir que son distintos los cuatro grupos a él unidos y se les puede caracterizar por su capacidad para hacer girar la luz a la derecha (+) o a la izquierda (-), dependiendo del disolvente y del grado de ionización. Por lo tanto, todos los aminoácidos excepto la glicina, tienen dos isómeros enantiómeros ópticamente activos designados por $\mathrm{D}$ y $\mathrm{L}$, esta denominación se refiere únicamente a la configuración absoluta del aminoácido y no tiene nada que ver con el sentido de giro del plano de la luz polarizada (Cheftel J. C. et al., 1989). Así, según la representación de Fisher y por analogía con el $D$ y L-gliceraldehído, los esteroisómeros de los aminoácidos de forma general se pueden representar como:

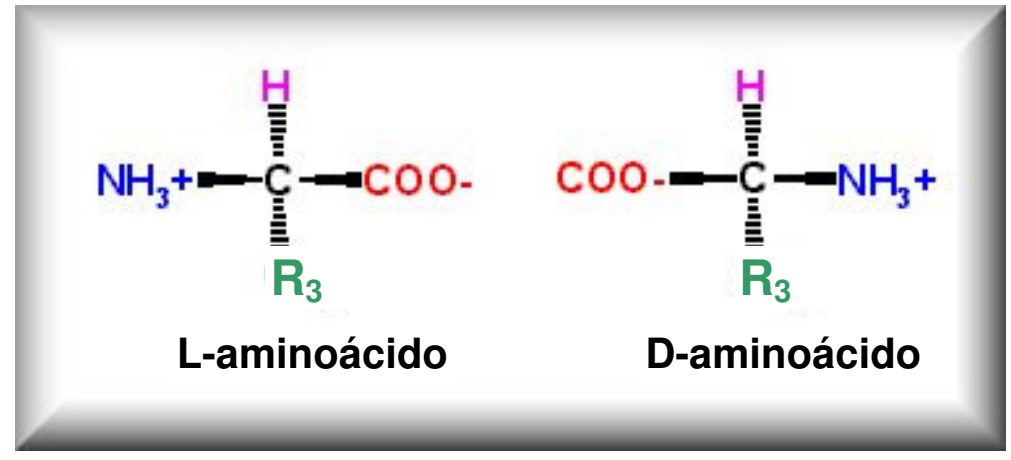

Los aminoácidos que constituyen las proteínas son todos de la forma $\mathrm{L}$, debido a que las células poseen enzimas estereoespecíficas que sintetizan únicamente estos esteroisómeros, eliminándose si existen los esteroisómeros $D$ vía renal y evitando así una posible síntesis de péptidos tóxicos. A pesar de todo, en las células existe una cierta cantidad remanente de D-aminoácidos (Herrera E., 1993).

Propiedades ácido-base. Ionización. Los a-aminoácidos en disolución acuosa debido a su carácter anfotérico, sufren una disociación dependiente del $\mathrm{pH}$ como se muestra a continuación:<smiles>[R]C([NH3+])C(=O)O</smiles>

forma catiónica (ácido)<smiles>[R]C([NH3+])C(=O)OC1CCCC1</smiles><smiles></smiles> 
Las constantes de disociación de los aminoácidos se pueden obtener mediante las siguientes relaciones de equilibrio:

$$
\begin{gathered}
\mathrm{K}_{\mathrm{a} 1}=\frac{\left[\mathrm{H}^{+}\right]\left[\mathrm{H}_{3} \mathrm{~N}^{+} \mathrm{CH}(\mathrm{R}) \mathrm{COO}^{-}\right]}{\left[\mathrm{H}_{3} \mathrm{~N}^{+} \mathrm{CH}(\mathrm{R}) \mathrm{COOH}\right]} \\
\mathrm{K}_{\mathrm{a} 2}=\frac{\left[\mathrm{H}^{+}\right]\left[\mathrm{H}_{2} \mathrm{NCH}(\mathrm{R}) \mathrm{COO}^{-}\right]}{\left[\mathrm{H}_{3} \mathrm{~N}^{+} \mathrm{CH}(\mathrm{R}) \mathrm{COO}^{-}\right]}
\end{gathered}
$$

Generalmente, se expresan en términos de $\mathrm{pK}$, y pueden tener dos o más pKs dependiendo del número de grupos de disociación en la molécula.

Muchos aminoácidos en solución están presentes en su forma anfotérica, es decir con carga eléctrica neta cero. El punto isoeléctrico $(\mathrm{pl})$ es el $\mathrm{pH}$ al cual la carga eléctrica neta de una molécula de aminoácido es cero. Para un aminoácido que no tenga grupos cargados en la cadena lateral, se puede calcular:

$$
\mathrm{pI}=\frac{\mathrm{pK}_{\mathrm{a} 1}+\mathrm{pK}_{\mathrm{a} 2}}{2}
$$

Para los aminoácidos que contengan un grupo ácido en la cadena lateral, o un grupo básico en la cadena lateral, el pl se calcula según las expresiones (2.4) y (2.5), respectivamente:

$$
\begin{aligned}
& \mathrm{pI}=\frac{\mathrm{pK}_{\mathrm{a} 1}+\mathrm{pK}_{\mathrm{a} 3}}{2} \\
& \mathrm{pI}=\frac{\mathrm{pK}_{\mathrm{a} 2}+\mathrm{pK}_{\mathrm{a} 3}}{2}
\end{aligned}
$$

donde los subíndices 1, 2 y 3 se refieren a los grupos carboxilo, amino, y los ionizables de la cadena lateral, respectivamente (Fennema O. R, 2000; Herrera E., 1993).

La solubilidad de los aminoácidos en agua es muy variada, depende del $\mathrm{pH}$ de la disolución siendo mínima en su pl y aumenta al aumentar la temperatura. La adición de ácidos o álcalis por lo general, aumenta la solubilidad del aminoácido por formación de sales, al igual que también aumenta en presencia de otros aminoácidos. Los aminoácidos que tienen grupos polares adicionales, por ejemplo $-\mathrm{OH},-\mathrm{SH},-\mathrm{COOH},-\mathrm{NH}_{2}$, son generalmente más solubles en agua.

Debido a su carácter anfótero, los aminoácidos tienen características tanto de ácidos como de bases orgánicas, dando las reacciones ordinarias de los ácidos carboxílicos y aminas. Desde el punto de vista de la preparación de alimentos (cocción, asado o fritura) tienen gran importancia e interés el estudio de las reacciones que ocurren a temperaturas elevadas de $100-200^{\circ} \mathrm{C}$, dónde se desarrollan aromas característicos vía reacción Maillard y que son compuestos derivados especialmente de cisteína, metionina, ornitina y prolina (Belitz H. D. et al., 1997). 


\subsubsection{Fabricación y procesado}

La alimentación, en el mundo actual, plantea problemas tanto cuantitativos como cualitativos. Debido al creciente volumen de la población, la problemática del hambre es uno de los más graves. Esto ha obligado a desarrollar nuevas fuentes de proteínas (Ej: microorganismos), aminoácidos y péptidos que complementan las fuentes tradicionales de proteínas vegetales y animales (agricultura, ganadería o pesca).

La producción de aminoácidos se realiza mediante un amplio abanico de tecnologías que incluyen la extracción de hidrolizados de proteínas, la síntesis química, la biotransformación de precursores mediante células o enzimas y la fermentación directa (Ward O.P., 1989). Tradicionalmente, la mayoría de los aminoácidos se obtienen por extracción a partir de los hidrolizados de proteínas. El método de extracción de aminoácidos a partir de sustancias naturales, generalmente desechos orgánicos (cabellos humanos, residuos del tratamiento de pieles, plumas de aves, etc), sigue siendo competitivo. Este es el caso de la L-cistina y la L-tirosina, aminoácidos poco solubles en agua, que pueden separarse de aminoácidos hidrosolubles durante el procesado de los hidrolizados de proteínas de origen animal o vegetal (Linden G. et al., 1996). Sin embargo, todavía es difícil el aislamiento en su forma pura al estar en presencia de un gran número de compuestos orgánicos similares.

Para la síntesis química de $\alpha$-aminoácidos se han establecido diversos métodos químicos, por ejemplo, la aminación de ácidos carboxílicos $\alpha$-halogenados o de $\alpha$ cetoácidos. De esta manera, se han sintetizado químicamente aminoácidos como: DLalanina, glicina y DL-metionina. Sin embargo, en muchos casos, es necesario realizar procesos de resolución óptica para separar la mezcla racémica DL. El proceso de resolución óptica es complejo y como alternativa, la separación puede realizarse por métodos físico-químicos que aplican las propiedades de los estereoisómeros (métodos cromatográficos, cristalización, etc.) o por métodos biológicos (fermentación, enzimáticos, etc.) basados en el comportamiento característico de los aminoácidos en las células vivas en presencia de enzimas (Kirk-Othmer, 1992).

En cuanto a la obtención de aminoácidos mediante los procesos enzimáticos, los substratos sintetizados químicamente se convierten en el aminoácido correspondiente por acción catalítica de un enzima. Se emplean enzimas microbianos libres 0 inmovilizados sobre un soporte. Esta técnica se ha empleado para obtener el ácido Laspártico a partir del ácido fumárico, L-alanina a partir del ácido L-aspártico, etc. Este método es de gran potencial industrial por realizarse en una sola etapa. Su principal inconveniente es la pérdida progresiva de la actividad del enzima, resultando activa durante una semana, pierde más del $75 \%$ de la actividad en periodos de 20-25 días. Además, los procesos enzimáticos no proporcionan elevados rendimientos y no siempre se obtienen aminoácidos de la pureza adecuada (Linden G. et al., 1996).

Otra alternativa es la producción de aminoácidos por fermentación basada en el conocimiento de los circuitos metabólicos, la utilización de cepas eficaces y mutantes, y la existencia de reacciones de retro-inhibición. El principal inconveniente es que se requieren elevados tiempos de aislamiento, y la necesidad de técnicas de purificación para la obtención de los aminoácidos en forma pura, generándose además subproductos con elevados riesgos medioambientales. (Linden G. et al., 1996; Brown C. M. et al., 1992). En la actualidad, gracias a los avances en genética microbiana y en ingeniería genética, se pueden producir todos los aminoácidos microbiológicamente, en cantidades rentables, excepto para la glicina, L-cisteína y la L-cistina. 


\subsubsection{Recuperación de aminoácidos}

Los aminoácidos se encuentran presentes en caldos de fermentación o en corrientes de procesado, en baja concentración y en presencia de otros compuestos químicos similares. Su separación y purificación son etapas cruciales en la optimización del proceso productivo de las industrias biotecnológicas.

El número de etapas necesarias para la recuperación de aminoácidos y bioproductos depende de la materia prima utilizada, de la concentración, de las propiedades físicoquímicas del producto y del grado de purificación necesario. Las operaciones unitarias de recuperación de aminoácidos pueden agruparse en las siguientes categorías (Blanch H.W. et al., 1996; Liddell J.M., 1994):

- Etapas iniciales. Se realiza la separación de materiales insolubles, tales como la biomasa celular o las proteínas agregadas, empleando como operaciones físicas de separación la sedimentación, centrifugación y filtración.

- Etapas intermedias. Consisten en el aislamiento del producto de interés, eliminando las impurezas. En esta categoría se emplean operaciones físicas de extracción, ultrafiltración, intercambio iónico, adsorción, cromatografía, diálisis y electrodiálisis.

- Purificación final. En esta etapa se requieren operaciones químicas de cristalización y precipitación, llevadas a cabo por modificación del pH del medio, adición de sales o de disolventes orgánicos, que producen una variación drástica de la solubilidad del aminoácido. El proceso de purificación finaliza con el secado del producto.

A continuación, se describen brevemente alguna de las técnicas más utilizadas para la separación y purificación de aminoácidos:

\subsubsection{Extracción con Disolventes}

Esta técnica, ampliamente utilizada para la separación de aminoácidos, se expone detalladamente en el apartado 3. Conlleva la transferencia desde los caldos de fermentación o procesado hacia una fase orgánica, que contiene un extractante selectivo, seguida de la reextracción y concentración del producto en una fase acuosa de reextracción, donde se obtiene el producto concentrado. La recuperación final se lleva a cabo normalmente mediante precipitación, cristalización o evaporación. Algunos ejemplos de la utilización de esta tecnología para la recuperación de aminoácidos son: extracción de fenilglicina, utilizando TOMAC como agente extractante (Ruiz M.O. et al., 2002-a; González M. J. et al., 2006), extracción de L-fenilalanina con Aliquat 336 (Haensel $R$. et al., 1986; Uddin M. S. et al., 1990; Calvario L. et al., 1992; Chan C.C. et al., 1993; Escalante H. et al., 1998; Nelly N. A. et al., 1998; Scarpello J.T.et al., 2000), extracción de ácido aspártico y fenilalanina con D2EHPA (Lin S. H. et al., 2006).

Otra aplicación de la extracción con disolventes es la extracción mediante micelas inversas. Las micelas inversas son microgotas de disolución acuosa, dispersas en una fase orgánica continua y estabilizada por un surfactante. Esta tecnología ha sido aplicada 
a la extracción de proteínas (Goto M. et al., 1997) y de aminoácidos (Dzygiel P. et al., 2000; Nishiki T. et al., 2000).

Las unidades de procesado industrial donde se realiza convencionalmente la extracción son baterías de mezcladores-sedimentadores o torres de extracción. Uno de los requisitos necesarios en estos equipos es la existencia de una diferencia de densidades entre las fases de contacto para que se produzca la separación de las mismas.

La extracción con disolventes por contacto directo de las fases presenta la limitación de la formación de emulsiones estables que evita la posterior separación de las fases, provocando la pérdida del producto de interés en la formación de terceras fases. Además, en las torres de extracción existen problemas relacionados con la inundación de la torre y la formación de caminos preferentes.

Como alternativa a este proceso convencional se pueden utilizar procesos híbridos de extracción con resinas impregnadas. Esta última técnica es utilizada en este estudio de investigación y está ampliamente detallada en el apartado 4.2.

\subsubsection{Electrodiálisis}

En este proceso se utilizan membranas intercambiadoras de iones para eliminar solutos cargados de disoluciones acuosas. Entre el ánodo y el cátodo se colocan de forma alterna un número determinado de membranas intercambiadoras de aniones y de cationes. Estos sistemas utilizan una corriente eléctrica para transportar los iones a través de la membrana.

La electrodiálisis se aplica a la separación de aminoácidos. Debido a su carácter anfotérico, a pH alto los aminoácidos tienen carga negativa y migrarán hacia el ánodo y a $\mathrm{pH}$ bajo los aminoácidos cargados positivamente migrarán hacia el cátodo. Si el pH es igual al punto isoeléctrico del aminoácido, el aminoácido no migrará. Así, los diferentes aminoácidos pueden ser separados ajustando el $\mathrm{pH}$ de la disolución que los contiene (Mulder M., 1991).

Esta tecnología ha sido aplicada a la separación de ácido glutámico, metionina y L-lisina utilizando dos tipos de membranas cargadas iónicamente (Kikuchi et al., 1995).

El principal inconveniente de la electrodiálisis es que las membranas tienden a presentar problemas de hinchamiento permitiendo, así, el paso de solutos a través de las membranas por mecanismos de difusión. Otro problema habitual es el inherente a la electrolisis del agua, disminuyendo la eficacia de la separación. Además, las membranas deben tener elevada conductividad eléctrica junto con una buena resistencia mecánica, lo que eleva los costos del proceso.

\subsubsection{Precipitación}

La precipitación es una técnica comúnmente utilizada en la purificación de proteínas, aminoácidos, antibióticos y biopolímeros. 
La tendencia de los aminoácidos y proteínas a precipitar depende de varios factores, como son el disolvente (concentración de sal, constante dieléctrica, $\mathrm{pH}, \ldots$ ), la temperatura, la forma, tamaño y carga de la proteína (Blanch H.W. et al., 1996).

Una de las estrategias más comunes de producir la precipitación de aminoácidos y proteínas es alterando las propiedades del disolvente. Los métodos de precipitación más comunes se describen a continuación:

\section{a) Variación del pH del medio}

El $\mathrm{pH}$ del medio es un factor decisivo en la solubilidad. Para valores de $\mathrm{pH}$ superiores o inferiores al punto isoeléctrico, la molécula de aminoácido se encuentra cargada y las moléculas de agua reaccionan con estas cargas favoreciendo la solubilización. Cuando el $\mathrm{pH}$ del medio se encuentra próximo al punto isoeléctrico las interacciones con el agua y sus cargas netas son mínimas, pudiendo producir su precipitación (Cheftel J. C. et al., 1989).

La etapa final de recuperación de aminoácidos puede llevarse a cabo por precipitación, llevando la disolución a pHs cercanos al punto isoeléctrico, donde la solubilidad es mínima, y el aminoácido precipita.

\section{b) Salting-out}

Foster P.R. (1994) estudió el efecto de la adición de sales a disoluciones de proteínas, comprobando que a bajas concentraciones la solubilidad de las proteínas en disoluciones acuosas aumentaba por efecto salting-in y disminuía para elevadas concentraciones, por efecto salting-out. Las sales neutras tienen, en general una doble influencia sobre la solubilidad. A concentraciones bajas actúan disminuyendo las interacciones electrostáticas aminoácido-aminoácido y aumentando la solubilidad. A concentraciones más altas, las sales neutras disminuyen la solubilidad de los aminoácidos y proteínas como consecuencia de la tendencia de los iones salinos a la hidratación.

\section{c) Reducción de la constante dieléctrica del medio}

Uno de los métodos para precipitar aminoácidos y proteínas ha sido mediante adición de disolventes orgánicos, como etanol y acetona, los cuales disminuyen su solubilidad (Foster P.R., 1994).

La capacidad del etanol para precipitar aminoácidos y proteínas se debe a los cambios que produce en la constante dieléctrica del medio, aumentando las interacciones electrostáticas al disminuir la constante dieléctrica debido a la adición de etanol (Cohn E.J., 1943). Este aumento de las interacciones electrostáticas se ha relacionado con el aumento de las interacciones aminoácido-aminoácido, lo que conduce a su precipitación (Foster P.R., 1994).

Entre las principales técnicas de análisis y separación de mezclas de aminoácidos, se encuentran: 


\subsubsection{Cromatografía en capa fina y electroforesis}

El uso de la cromatografía en capa fina o de la electroforesis son adecuados para averiguar el número y la cantidad relativa de los diferentes aminoácidos presentes en una muestra (análisis cualitativo), aunque para los análisis cuantitativos es necesaria la cromatografía o un analizador de aminoácidos.

Una importante aplicación de la cromatografía en capa fina es la de servir como guía para el desarrollo de las condiciones óptimas para realizar separaciones por cromatografía de líquidos en columna. Las ventajas de este procedimiento son la rapidez y el bajo coste de los ensayos experimentales.

La electroforesis es un proceso en el cual las especies cargadas (iones o partículas coloidales) se separan en función de su distinta velocidad de migración en un campo eléctrico. Desde los años cincuenta, las separaciones electroforéticas fueron la piedra angular de gran parte de la investigación de químicos y biólogos moleculares relacionada con la separación y análisis de proteínas, polinucleótidos y otros biopolímeros. Estas separaciones han sido, y continúan siendo, muy eficientes y de una extensa aplicación, pero por desgracia, son unas técnicas muy lentas y laboriosas que tienen tendencia a ser poco reproducibles. A mediados de los ochenta, esta situación cambió espectacularmente con la aparición de aparatos comerciales para realizar electroforesis analíticas a microescala en columnas capilares (electroforesis capilar). El hecho de que los distintos aminoácidos transporten diferentes cargas netas a un $\mathrm{pH}$ particular, permite separarlos de una mezcla mediante la electroforesis de alto o bajo voltaje.

\subsubsection{Cromatografía de gases.}

Se han hecho muchos ensayos para aprovechar la velocidad y sensibilidad que ofrece la cromatografía de gases, pero aunque se han realizado considerables progresos en el desarrollo de tales métodos, aún no se utiliza de forma rutinaria para el análisis de aminoácidos en muestras biológicas. La razón de esto radica en el hecho de que los aminoácidos, aunque similares, son compuestos químicamente heterogéneos y además no son suficientemente volátiles a menos que se conviertan en algún derivado apropiado.

\subsubsection{Analizador automático de aminoácidos - HPLC.}

Existen dos técnicas para la determinación de aminoácidos a través de cromatografía líquida: cromatografía de reparto en fase reversa y cromatografía de intercambio iónico.

- La cromatografía de líquidos de alta resolución es la técnica de separación más ampliamente utilizada. Las razones más importantes son su sensibilidad, su fácil adaptación a las determinaciones cuantitativas exactas, su idoneidad para la separación de especies no volátiles o termolábiles y, sobre todo, su gran aplicabilidad a aminoácidos que son de primordial interés en la industria.

- Cromatografía de reparto en fase reversa. La cromatografía en fase reversa consiste en un disolvente fundamentalmente polar como fase móvil y una cadena 
hidrocarbonada ligada como fase estacionaria. Algunas de las ventajas más sustanciales de esta alternativa son su gran reproducibilidad, tiempos de retención cortos, velocidad de muestreo alta, sistema cromatográfico simple y amplio campo de aplicación. Por todo ello, las aplicaciones son cada vez más numerosas.

- Cromatografía de intercambio iónico. La cromatografía iónica está relacionada con los métodos modernos y eficaces para la determinación de iones que se basan en el uso de resinas de intercambio iónico. Existen métodos automatizados para la separación y detección de aminoácidos y otras especies iónicas en mezclas complejas. El analizador de aminoácidos, con el que se lleva a cabo la cuantificación de los aminoácidos se basa en esta técnica.

- Analizador automático de aminoácidos. La separación de aminoácidos fue el primer proceso cromatográfico automatizado con derivatización post-columna. La separación fue llevada a cabo por Moore, Spackman y Stein (1958), mediante un intercambio iónico, seguido de su cuantificación de cada componente eluido de la columna por reacción con ninhidrina y posterior detección en el visible. Este método se ha realizado durante más de treinta años, en cualquier laboratorio de proteínas. Las interacciones no iónicas entre los aminoácidos y la resina también influyen en la secuencia de elución, permitiendo que algunos aminoácidos que tienen un comportamiento similar se eluyan de forma separada.

\subsubsection{Aplicaciones}

Los aminoácidos se utilizan como materias primas en la industria alimentaría, farmacéutica, química, cosmética y de alimentación animal.

En la industria alimentaria se emplean los aminoácidos y sus derivados para edulcorar, salar, modificar o aumentar el sabor de los alimentos. Cada aminoácido tiene un sabor característico: dulce, amargo, agrio, salado. El D-glutamato es insípido y los ésteres de metil o etil glicina poseen un sabor muy salado. La glicina y L-alanina son débilmente dulces, pero el aspartamo (éster de metil L-aspartil-L-fenilalanina) es 200 veces más dulce que la sacarosa, utilizándose como edulcorante artificial hipocalórico en fármacos, alimentos o bebidas refrescantes. Recientemente, ha aumentado el consumo de Lfenilalanina y ácido L-aspártico como materias primas para la síntesis de dicho éster. Además, la D-alanina junto con el ácido aspártico forman un edulcorante 12 veces más dulce que el aspartamo (Kirk-Othmer, 1992).

También se utilizan en piensos como suplementos alimenticios en la dieta animal ya que mejoran su contenido en aminoácidos esenciales necesarios para el crecimiento equilibrado de los animales. Los más frecuentes son: DL-metionina, L-lisina, L-treonina (Kirk-Othmer, 1992).

En medicina, en pre- y post-operatorios, se están utilizado transfusiones de aminoácidos para mantener el nivel de nitrógeno necesario para el funcionamiento metabólico. Además, se han desarrollado distintas mezclas de aminoácidos especiales para el tratamiento de muchas enfermedades (Kirk-Othmer, 1992). 
En la industria farmacéutica se utilizan para distintas aplicaciones, como por ejemplo: la L-glutamina y sus derivados se utilizan como remedio en úlceras de estómago o duodenales, el L-DOPA (L-3-(3,4-dihidroxifenil)alanina) es una droga muy efectiva en el tratamiento del Parkinson, el L-triptófano y el 5-hidroxi-L-triptófano se emplean como antidepresivos, el aspartato de potasio se utiliza para mejorar el equilibrio salino del metabolismo y el aspartato de calcio para suplir las deficiencias de calcio en el organismo. La p-hidroxi-D-fenilglicina, D-fenilglicina, D-cisteina y el ácido D-aspártico son importantes como precursores de antibióticos de las familias de penicilinas 0 cefalosporinas (Kirk-Othmer, 1992, 1995; Nitta H. et al., 1997; Youshko M. I., et al., 2001). Además, el desarrollo reciente de nuevos fármacos y antibióticos ha fomentado el consumo de los aminoácidos.

En la industria de cosméticos, los aminoácidos y sus derivados se utilizan para controlar o neutralizar las variaciones de $\mathrm{pH}$ en la piel y los efectos bacterianos. Por ejemplo, la serina se utiliza en cremas o lociones faciales y el glutamato de glucosa se emplea en champús y cremas como compuesto humectante del pelo y de la piel (Kirk-Othmer, 1992).

En la industria química los aminoácidos se emplean en campos muy diversos. Actualmente, en relación a la protección del medioambiente, se presta especial atención a los poli-aminoácidos, que son polímeros biodegradables. Entre otras utilidades estos polímeros se utilizan en la producción del cuero sintético y los polímeros biodegradables poli-(L-ácido aspártico-co-PEG) con aplicación en el campo de la biomedicina. Algunos derivados de aminoácidos se emplean como agentes de limpieza, por ejemplo en la eliminación de aceites de efluentes industriales se emplea un derivado del ácido glutámico. (Kirk-Othmer, 1992).

\subsection{6 $\alpha$-Fenilglicina}

La $\alpha$-fenilglicina o ácido $\alpha$-aminofenilácetico, es un aminoácido de fórmula molecular $\mathrm{C}_{8} \mathrm{H}_{9} \mathrm{NO}_{2}$ y cuya fórmula estructural es:

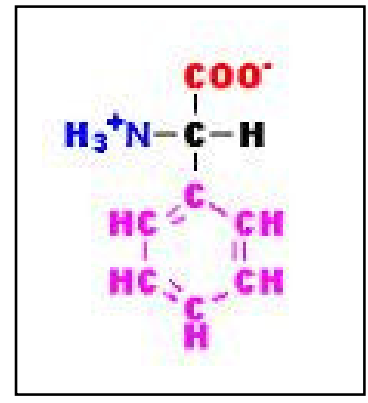

A temperatura ambiente es un sólido de color blanco, de peso molecular 151,16 g/mol, que contiene un $63,56 \%$ de carbono, un $6,00 \%$ de hidrógeno, $9,27 \%$ de nitrógeno y un $21,17 \%$ de oxígeno. 
En disolución acuosa el aminoácido $\alpha$-fenilglicina, como todos los aminoácidos, sufre una disociación dependiente del $\mathrm{pH}$ que se puede representar por el siguiente equilibrio químico:

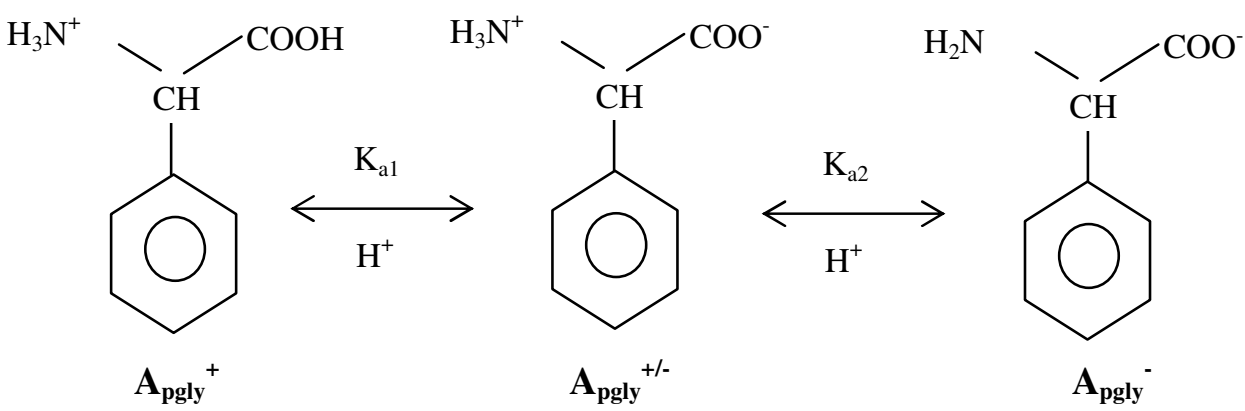

donde $\mathrm{K}_{\mathrm{a} 1}$ y $\mathrm{K}_{\mathrm{a} 2}$ son las constantes de disociación del aminoácido definidas en las Ecs. (2.6) y (2.7) y cuyos valores en términos de $\mathrm{pK}$ son de $\mathrm{pK}_{\mathrm{a} 1}=1,71$ y $\mathrm{pK}_{\mathrm{a} 2}=9,00$ (Ruiz M. O., 2000).

$$
\begin{aligned}
\mathrm{K}_{\mathrm{a} 1 \text { (pgly) }} & =\frac{\left[\mathrm{A}_{\mathrm{pgly}}^{+/-}\right]\left[\mathrm{H}^{+}\right]}{\left[\mathrm{A}_{\mathrm{pgly}}^{+}\right]} \\
\mathrm{K}_{\mathrm{a} \text { (pgly) }} & =\frac{\left[\mathrm{A}_{\mathrm{pgly}}^{-}\right]\left[\mathrm{H}^{+}\right]}{\left[\mathrm{A}_{\mathrm{pgly}}^{+/-}\right]}
\end{aligned}
$$

Así, la concentración total de $\alpha$-fenilglicina, es suma de la concentración de las tres especies presentes en disolución acuosa:

$$
\mathrm{C}_{\mathrm{A}}=\left[\mathrm{A}_{\mathrm{pgly}}^{+}\right]+\left[\mathrm{A}_{\mathrm{pgly}}^{+/-}\right]+\left[\mathrm{A}_{\mathrm{pgly}}^{-}\right]
$$

La concentración de las especies iónicas $A^{+}, A^{+-}$y $A^{-}$del aminoácido $\alpha$-fenilglicina presentes en disolución acuosa para cualquier valor de $\mathrm{pH}$ se puede determinar combinando las Ecs. (2.6), (2.7) y (2.8) obteniendo las siguientes expresiones:

$$
\begin{aligned}
& {\left[\mathrm{A}_{\mathrm{pgly}}^{+}\right]=\frac{\mathrm{C}_{\mathrm{A}(\mathrm{pgly})}\left[\mathrm{H}^{+}\right]^{2}}{\left[\mathrm{H}^{+}\right]^{2}+\mathrm{K}_{\mathrm{a} 1}\left[\mathrm{H}^{+}\right]+\mathrm{K}_{\mathrm{a} 1} \mathrm{~K}_{\mathrm{a} 2}}} \\
& {\left[\mathrm{~A}_{\mathrm{pgly}}^{+/-}\right]=\frac{\mathrm{C}_{\mathrm{A}(\mathrm{pgly})}\left[\mathrm{H}^{+}\right] \mathrm{K}_{\mathrm{a} 1}}{\left[\mathrm{H}^{+}\right]^{2}+\mathrm{K}_{\mathrm{a} 1}\left[\mathrm{H}^{+}\right]+\mathrm{K}_{\mathrm{a} 1} \mathrm{~K}_{\mathrm{a} 2}}}
\end{aligned}
$$




$$
\left[\mathrm{A}_{\mathrm{pgly}}^{-}\right]=\frac{\mathrm{C}_{\mathrm{A}(\mathrm{pgly})} \mathrm{K}_{\mathrm{a} 1} \mathrm{~K}_{\mathrm{a} 2}}{\left[\mathrm{H}^{+}\right]^{2}+\mathrm{K}_{\mathrm{a} 1}\left[\mathrm{H}^{+}\right]+\mathrm{K}_{\mathrm{a} 1} \mathrm{~K}_{\mathrm{a} 2}}
$$

La contribución de la forma aniónica del aminoácido es despreciable en disoluciones acuosas con un $\mathrm{pH}$ menor que el $\mathrm{pK}_{\mathrm{a} 1}$ y la catiónica es despreciable cuando el $\mathrm{pH}$ es mucho mayor que el $\mathrm{pK}_{\mathrm{a} 2}$.

El aminoácido DL-fenilglicina sublima a $255{ }^{\circ} \mathrm{C}$. Su miscibilidad en agua es limitada y depende de la temperatura de operación y del pH. Además, es levemente soluble en disolventes orgánicos y soluble en álcalis.

Se dispone comercialmente de los isómeros $\mathrm{D}$ y $\mathrm{L}$, así como de su mezcla racémica (DL).

El aminoácido $\alpha$-fenilglicina se produce industrialmente por hidrólisis de $\alpha$ aminofenilacetonitrilo con ácido clorhídrico diluido o por fermentación. Además, con métodos de fermentación adecuados se obtiene el isómero $D$ de $\alpha$-fenilglicina a partir de la mezcla racémica (DL) (Kirk-Othmer, 1992; Kim M.G. et al., 1996). Por síntesis químicaenzimática se obtiene el esteroisómero D de $\alpha$-fenilglicina a partir de D,L-fenilhidantoína (Roche Molecular Biochemicals, 2000; Rai R. et al., 1998; Sudge S.S. et al., 1998).

El principal consumo de $\alpha$-fenilglicina se atribuye a la industria farmacéutica para la producción de antibióticos $\beta$-lactámicos tipo penicilinas o cefalosporinas (Guijarro J. I. et al., 1995; Roche Molecular Biochemicals, 2000; Kende A. S. et al., 1995; Margreth A. W. et al., 2001). Actualmente, se está empleando también en tratamientos odontológicos (Kirk-Othmer, 1992; Kim M.G. et al., 1996; Tambe A.S., 1996; Youshko M.I. et al., 2001; Schroën C.G.P.H. et al., 2000).

\subsection{7 Ácido aspártico}

El ácido aspártico, ácido asparaguínico o ácido aminosuccínico, es un aminoácido de fórmula molecular $\mathrm{C}_{4} \mathrm{H}_{7} \mathrm{NO}_{4}$, cuya fórmula estructural es:

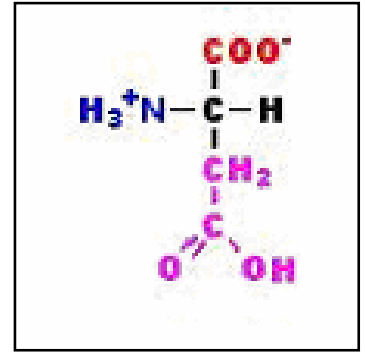

A temperatura ambiente es un sólido en forma de cristales incoloros, con un peso molecular de $133,11 \mathrm{~g} / \mathrm{mol}$, un punto de fusión de $280 \stackrel{\circ}{\circ} \mathrm{C}$, que contiene un $36,09 \%$ de carbono, un 5,30\% de hidrógeno, un 10,52 \% de nitrógeno y un $48,08 \%$ de oxígeno. 
En disolución acuosa el ácido aspártico, como todos los aminoácidos, sufre una disociación dependiente del $\mathrm{pH}$ que se puede representar por el siguiente equilibrio químico:

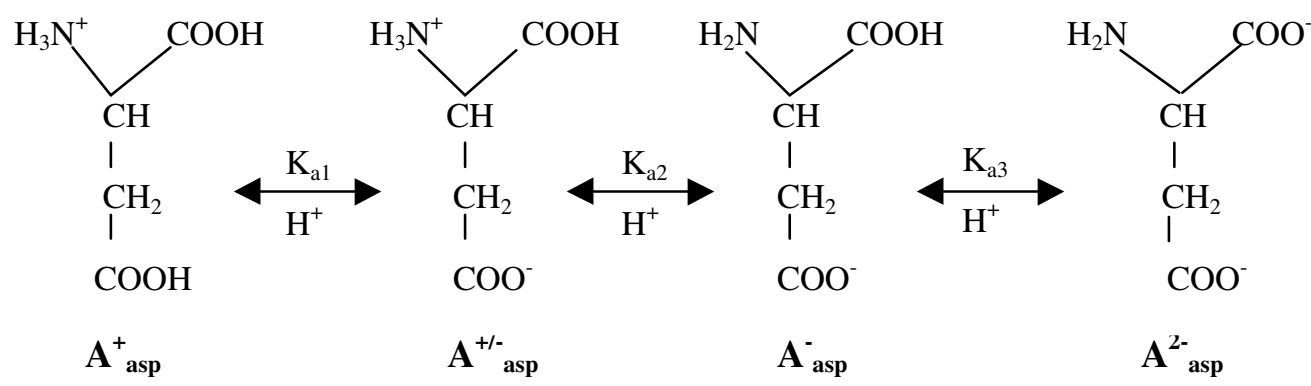

donde $\mathrm{K}_{\mathrm{a} 1}, \mathrm{~K}_{\mathrm{a} 2}$ y $\mathrm{K}_{\mathrm{a} 3}$ son las constantes de disociación del ácido aspártico definidas en las Ecs. (2.12)-(2.14) y cuyos valores en términos de $\mathrm{pK}$ son $\mathrm{pK}_{\mathrm{a} 1}=2,1 ; \mathrm{pK}_{\mathrm{a} 2}=3,9$ y $\mathrm{pK}_{\mathrm{a} 3}=$ 9,8. (Cascaval D. et al., 2001).

$$
\begin{aligned}
& \mathrm{K}_{\mathrm{a} 1 \text { (asp) }}=\frac{\left[\mathrm{A}_{\text {asp }}^{+/-}\right]\left[\mathrm{H}^{+}\right]}{\left[\mathrm{A}_{\text {asp }}^{+}\right]} \\
& \mathrm{K}_{\mathrm{a} 2 \text { (asp) }}=\frac{\left[\mathrm{A}_{\text {asp }}^{-}\right]\left[\mathrm{H}^{+}\right]}{\left[\mathrm{A}_{\text {asp }}^{+/-}\right]} \\
& \mathrm{K}_{\mathrm{a} 3 \text { (asp) }}=\frac{\left[\mathrm{A}_{\text {asp }}^{2-}\right]\left[\mathrm{H}^{+}\right]}{\left[\mathrm{A}_{\text {asp }}^{-}\right]}
\end{aligned}
$$

Así, la concentración total de ácido aspártico, es suma de la concentración de las cuatro especies presentes en disolución acuosa:

$$
\mathrm{C}_{\mathrm{A}}=\left[\mathrm{A}_{\text {asp }}^{+}\right]+\left[\mathrm{A}_{\text {asp }}^{+/-}\right]+\left[\mathrm{A}_{\text {asp }}^{-}\right]+\left[\mathrm{A}_{\text {asp }}^{2-}\right]
$$

La concentración de las especies iónicas $A^{+}, A^{+/-}, A^{-}$y $A^{2-}$ del ácido aspártico presentes en disolución acuosa para cualquier valor de $\mathrm{pH}$ se puede determinar combinando las Ecs. (2.12), (2.13), (2.14) y (2.15) obteniendo las siguientes expresiones:

$$
\left[\mathrm{A}_{\text {asp }}^{+}\right]=\frac{\mathrm{C}_{\mathrm{A}(\text { (asp })}\left[\mathrm{H}^{+}\right]^{3}}{\left[\mathrm{H}^{+}\right]^{3}+\mathrm{K}_{\mathrm{a} 1}\left[\mathrm{H}^{+}\right]^{2}+\mathrm{K}_{\mathrm{a} 1} \mathrm{~K}_{\mathrm{a} 2}\left[\mathrm{H}^{+}\right]+\mathrm{K}_{\mathrm{a} 1} \mathrm{Ka}_{2} \mathrm{~K}_{\mathrm{a} 3}}
$$




$$
\begin{aligned}
& {\left[\mathrm{A}_{\text {asp }}^{+/-}\right]=\frac{\mathrm{C}_{\mathrm{A}(\text { asp })}\left[\mathrm{H}^{+}\right]^{2} \mathrm{~K}_{\mathrm{a} 1}}{\left[\mathrm{H}^{+}\right]^{3}+\mathrm{K}_{\mathrm{a} 1}\left[\mathrm{H}^{+}\right]^{2}+\mathrm{K}_{\mathrm{a} 1} \mathrm{~K}_{\mathrm{a} 2}\left[\mathrm{H}^{+}\right]+\mathrm{K}_{\mathrm{a} 1} \mathrm{Ka}_{2} \mathrm{~K}_{\mathrm{a} 3}}} \\
& {\left[\mathrm{~A}_{\mathrm{asp}}^{-}\right]=\frac{\mathrm{C}_{\mathrm{A}(\text { asp })}\left[\mathrm{H}^{+}\right] \mathrm{K}_{\mathrm{a} 1} \mathrm{~K}_{\mathrm{a} 2}}{\left[\mathrm{H}^{+}\right]^{3}+\mathrm{K}_{\mathrm{a} 1}\left[\mathrm{H}^{+}\right]^{2}+\mathrm{K}_{\mathrm{a} 1} \mathrm{~K}_{\mathrm{a} 2}\left[\mathrm{H}^{+}\right]+\mathrm{K}_{\mathrm{a} 1} \mathrm{Ka}_{2} \mathrm{~K}_{\mathrm{a} 3}}} \\
& {\left[\mathrm{~A}_{\mathrm{asp}}^{2-}\right]=\frac{\mathrm{C}_{\mathrm{A}(\text { asp })} \mathrm{K}_{\mathrm{a} 1} \mathrm{~K}_{\mathrm{a} 2} \mathrm{~K}_{\mathrm{a} 3}}{\left[\mathrm{H}^{+}\right]^{3}+\mathrm{K}_{\mathrm{a} 1}\left[\mathrm{H}^{+}\right]^{2}+\mathrm{K}_{\mathrm{a} 1} \mathrm{~K}_{\mathrm{a} 2}\left[\mathrm{H}^{+}\right]+\mathrm{K}_{\mathrm{a} 1} \mathrm{Ka}_{2} \mathrm{~K}_{\mathrm{a} 33}}}
\end{aligned}
$$

La contribución de cada especie depende únicamente del pH del medio acuoso. Así, la forma aniónica con dos cargas negativas es despreciable en disoluciones acuosas con un $\mathrm{pH}$ al menos de un orden menor que el $\mathrm{pK}_{\mathrm{a} 1}$ y la catiónica es despreciable cuando el $\mathrm{pH}$ es mayor que el $\mathrm{pK}_{\mathrm{a} 2}$.

El ácido aspártico presenta una elevada solubilidad en agua y es altamente insoluble en disolventes orgánicos comunes tales como alcohol y éter. La mezcla racémica DL del aminoácido presenta una densidad de $1,663 \mathrm{~g} / \mathrm{cm}^{3}$ a $12 \stackrel{\circ}{\circ} \mathrm{C}$ y un punto de fusión de 278$280 \stackrel{\circ}{\circ}$. El punto de fusión de la forma $L$ del aminoácido es de $251^{\circ} \mathrm{C}$ y de $269{ }^{\circ} \mathrm{C}$ el de la forma $D$.

Se dispone comercialmente de los isómeros $D$ y $L$, así como de su mezcla racémica (DL).

Las fuentes naturales de producción del ácido aspártico, son la caña y la remolacha azucarera y habitualmente se obtiene como isómero $L$ (Hawley, 1993). Sin embargo, el ácido aspártico es industrialmente producido por vía química de la hidrólisis de asparagina con amoniaco y fumarato de dietilo, y por vía enzimática a partir de fumarato de amonio utilizando aspartasa microbiana soportada sobre un gel de poliacrilamida que permite la producción del aminoácido en continuo (Linden G. et al., 1996).

Este aminoácido se utiliza en la preparación de medios de cultivo, en detergentes, fungicidas y germicidas (Nath M. et al., 1998). En el campo alimentario se emplea como materia prima junto con el aminoácido $\alpha$-fenilalanina para la síntesis de aspartamo, edulcorante artificial hipocalórico ampliamente utilizado en la preparación de alimentos, fármacos y de bebidas refrescantes (Linden G. et al., 1996, Lin S. H. et al., 2006).

En la industria farmacéutica, el ácido aspártico se emplea también en la producción de aspartato cálcico y de potasio (Nitta H. et al., 1997). Además, se utiliza en la síntesis de polímeros biodegradables para la producción de cuero sintético y en los polímeros biodegradables poli-(L-ácido aspártico-Co-PEG) con aplicación en el campo de la biomedicina (Liu Z. H., et al., 1998; Won C. et al., 1998). 


\subsection{BETAÍNA}

La betaína fue aislada por primera vez (Scheibler, 1869) de la savia de azúcar de remolacha (Beta vulgaris), de la cuál tiene como origen su nombre, es un derivado del aminoácido esencial glicicina, que está presente en los residuos industriales de las azucareras, hasta un $6 \%$ en las melazas de remolacha y hasta un $4 \%$ en las vinazas de fermentación, representando aproximadamente del $0,8 \%$ al $1,6 \%$ de peso en seco de azúcar de remolacha (Thalasso $F$. et. al., 1999). En las melazas de caña de azúcar la presencia de betaína no constituye una cantidad significativa.

La betaína es un compuesto muy versátil con un amplio espectro de aplicaciones: en suplementos alimenticios, productos cosméticos (champús, geles, pastas de dientes, etc.), farmacéuticos, dentales y en fermentación, debido a su actividad reguladora de la presión osmótica y por su función donadora de grupos metilo.

La función donadora de grupos metilo de la betaína es muy importante para el correcto funcionamiento del hígado y riñones, para la reproducción celular y para reacciones de desintoxificación. La colina es un precursor de la betaína, que al donar uno de sus grupos metilo se transforma en betaína, y esta al donar otro grupo metilo a la homocisteina se transforma en metionina. (Koc H. et. al., 2002).

\subsubsection{Estructura y propiedades}

La Betaína, (nombre sistemático: sal interna de (carboximetil)trimetilamonio), también conocida como N,N,N-trimetilglicina, es un compuesto nitrogenado, soluble, de fórmula molecular $\mathrm{C}_{5} \mathrm{H}_{11} \mathrm{NO}_{2}$, cuya fórmula estructural es:

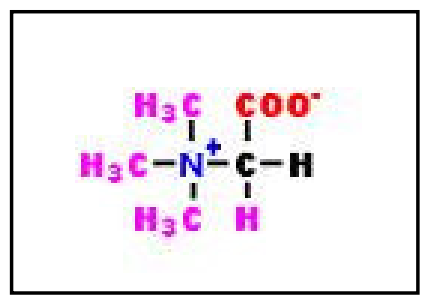

A temperatura ambiente es un sólido blanco, con un peso molecular de $117,15 \mathrm{~g} / \mathrm{mol}$, que contiene un $51,26 \%$ de carbono, un $9,46 \%$ de hidrógeno, un $11,96 \%$ de nitrógeno y un $27,32 \%$ de oxígeno.

En disolución acuosa la betaína sufre una disociación dependiente del $\mathrm{pH}$, similar a la de los aminoácidos, que se puede representar por el siguiente equilibrio químico:<smiles>[B-][N+](C)(C)CC(=O)O</smiles>

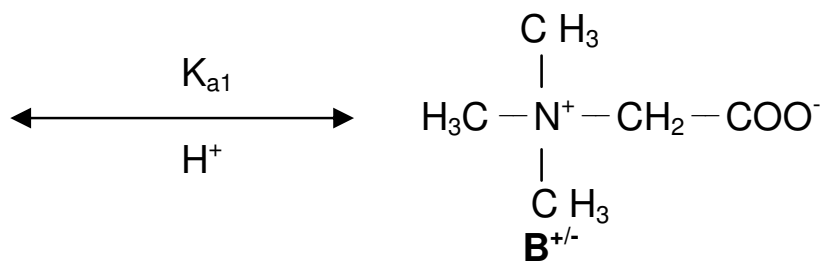


donde $\mathrm{K}_{\mathrm{a} 1}$ es la constante de disociación de la betaína, calculada mediante la Ec. (2.20) y cuyo valor en términos de $\mathrm{pK}$ es de $\mathrm{pK}_{\mathrm{a} 1}=1,81$ (Lunderg. $P$ et. al., 1995).

$$
\mathrm{K}_{\mathrm{a} 1}=\frac{\left[\mathrm{B}^{+/-}\right]\left[\mathrm{H}^{+}\right]}{\left[\mathrm{B}^{+}\right]}
$$

Así, la concentración total de betaína es suma de la concentración de las dos especies presentes en disolución acuosa.

$$
\mathrm{C}_{\mathrm{B}}=\left[\mathrm{B}^{+}\right]+\left[\mathrm{B}^{+/-}\right]
$$

La concentración de las especies iónicas $\mathrm{B}^{+}$y $\mathrm{B}^{+/-}$de la betaína presentes en disolución acuosa para cualquier valor de $\mathrm{pH}$ se puede determinar combinando las Ecs. (2.20) y (2.21) obteniendo las siguientes expresiones:

$$
\begin{gathered}
{\left[\mathrm{B}^{+}\right]=\frac{\mathrm{C}_{\mathrm{B}}\left[\mathrm{H}^{+}\right]}{\left[\mathrm{H}^{+}\right]+\mathrm{K}_{\mathrm{a} 1}}} \\
{\left[\mathrm{~B}^{+/-}\right]=\frac{\mathrm{C}_{\mathrm{B}} \mathrm{K}_{\mathrm{a} 1}}{\left[\mathrm{H}^{+}\right]+\mathrm{K}_{\mathrm{a} 1}}}
\end{gathered}
$$

La contribución de cada especie depende únicamente del pH del medio acuoso. En concreto, la especie catiónica es predominante cuando el $\mathrm{pH}$ es menor que el $\mathrm{pK}_{\mathrm{a} 1}$.

La betaína tiene sabor dulce. Presenta una elevada solubilidad en agua de $160 \mathrm{~g} / 100 \mathrm{~g}$ agua, en metanol tiene una solubilidad de $55 \mathrm{~g} / 100 \mathrm{~g}$ metanol, en etanol tiene una solubilidad de $8,7 \mathrm{~g} / 100 \mathrm{~g}$ etanol y es poco soluble en eter. El punto de fusión es de $310^{\circ} \mathrm{C}$.

\subsubsection{Melazas de azucarera}

Las melazas son la parte no cristalizable del azúcar. Es un líquido viscoso de color castaño oscuro que se obtiene como producto secundario en la fabricación del azúcar. Formada por un $30-60 \%$ de sacarosa y por un $4,5-5,5 \%$ de betaína, junto con algo de glucosa y fructosa entre otros componentes. En concreto, las melazas de la azucarera Ebro (empresa que colabora con el grupo de investigación y que se inserta en estos proyectos con Ref. PPQ 2003-09207 y Ref. CTQ 2006-03032, subvencionados por el Ministerio de Educación y Ciencia) tienen una composición aproximada: $570 \mathrm{mg} / \mathrm{ml}$ de sacarosa, 5,6\% de betaína como principales componentes, además de agua, ceniza (ricas en cloro, sodio, potasio magnesio, calcio) y otros carbohidratos (Ghazi l. et. al., 2006). La melaza negra es el producto de melazas refinadas de azúcar de remolacha o caña. 
La calidad del azúcar de remolacha y la economía del proceso de producción dependen de la composición química del tubérculo. Así, se han hecho estudios de investigación, sobre la distribución de la sacarosa, materia seca, potasio, sodio, compuestos a-amino, compuestos solubles de N, nitrato, betaína, azúcares reductores, glucosa y rafinosa; para así poder calcular su influencia en las pérdidas de azúcar por melazas. El componente esencial de la remolacha es la sacarosa, mientras que los compuestos que no son azúcares dificultan el proceso de obtención del azúcar. La mayor pérdida de azúcar en el proceso, se debe a las melazas. Así, el potasio, sodio, la rafinosa, los compuestos nitrogenados y la betaína aumentan las pérdidas por melazas, mientras que los azúcares invertidos y la glutamina dan lugar a la formación de color durante las etapas de evaporación y cristalización. Todo ello hace que disminuya la calidad del azúcar blanco (Mahn. K. et. al., 2002).

La composición de los compuestos nitrogenados en la remolacha consiste en: aminoácidos (entre $40 \%-30 \%$ ), betaína (30\%), nitratos (6\%) y compuestos nitrogenados no identificados (25\% aproximadamente). Dentro de los aminoácidos presentes están: la glutamina (GLN) que es el aminoácido mayoritario: 31\% del total de los aminoácidos presentes, seguido del ácido $\mathrm{y}$-aminobutírico con un 13\% (GABA) y del ácido aspártico (Asp) con un 12\%, Glu, Ser, y ASN están en porcentajes entre 6-8\% del total de aminoácidos. En la industria azucarera, sólo la concentración de los compuestos nitrogenados amino es determinada para predecir las pérdidas de azúcar por melazas. Sin embargo, todos los compuestos nitrogenados influyen en esta pérdida. Tampoco es posible predecir la composición de los compuestos nitrogenados a partir de la concentración de betaína, debido a que ambos parámetros varían independientemente (Mahn. K. et. al., 2002). En algunos estudios de investigación, se ha observado que en función del genotipo y de la zona dónde se obtenga, el contenido de betaína en la remolacha aumenta cuando hay un nivel bajo de los demás compuestos nitrogenados manteniendo estable la composición total de estos compuestos (Hoffmann. C et. al., 2005). También se ha comprobado, que en épocas de sequía la concentración de betaína y de compuestos nitrogenados en la remolacha aumenta (Mäck G. et. al., 2006).

\subsubsection{Aplicaciones de melazas}

La principal aplicación de las melazas es en alimentación animal, siendo fuentes baratas de carbohidratos, sales, proteínas, vitaminas, etc. pudiéndose utilizar directamente o mezcladas con otros alimentos. También se utilizan en las destilerías para la fabricación de alcoholes, como el ron, en procesos de fermentación para la fabricación de ácido acético, de ácido cítrico, lisina, en la obtención de glutamato, como levaduras para la panificación, etc. (Kirk O. et. al., 1997).

Se ha estudiado la posibilidad de utilizar melazas como fuentes de bajo coste de sacarosa para la producción de Fructo-oligosacáridos (FOSs) para la alimentación animal, ya que estos compuestos tienen propiedades prebióticas que ayudan a prevenir enfermedades, regulan los niveles de calcio, y contribuyen a reducir el consumo de antibióticos (Ghazi l. et. al., 2006). 


\subsubsection{Proceso de producción de azúcar}

La sacarosa o comúnmente llamada azúcar pertenece a la familia de los glúcidos o hidratos de carbono. Es un disacárido formado por glucosa y fructosa de fórmula molecular $\mathrm{C}_{12} \mathrm{H}_{22} \mathrm{O}_{11}$ y de fórmula estructural:

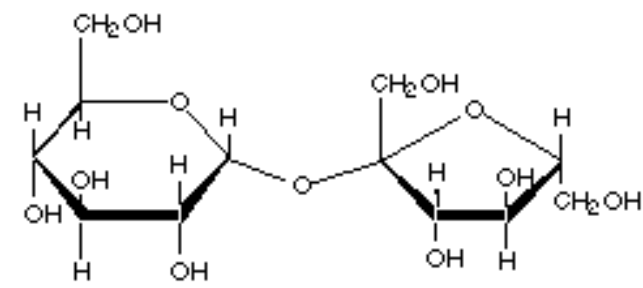

Se extrae comercialmente de la remolacha o de la caña de azúcar, aunque existen otras fuentes.

AZÚCAR DE REMOLACHA. En Europa se produce la mayor parte del azúcar de remolacha $(40 \%)$. El proceso de producción generalmente se compone de las siguientes etapas mostradas esquemáticamente en la Figura 1:

1.- Lavado y troceado de las remolachas. Inicialmente, las remolachas después de lavadas (por captadores de piedras, captadores de raicillas y lavadores) son cortadas en tiras (4-10 cm de largo y 3-5 $\mathrm{mm}$ de grosor), que se denominan peladuras.

2.- Extracción del azúcar. Se realiza por difusión mediante la acción de agua caliente entre $50-70{ }^{\circ} \mathrm{C}$ en contra corriente con la masa de remolacha. El fenómeno de difusión consiste en un movimiento lento y regular de los componentes solubles que se encuentran en el interior de las células. Es importante dirigir el proceso de difusión de forma que se reduzca la extracción de los componentes no azucarados. El líquido azucarado procedente de la difusión, constituye el llamado jugo sin refinar.

3.- Depuración del jugo. Su objetivo es la eliminación de las sustancias no azucaradas que se encuentran disueltas en el jugo azucarado que sale de la difusión. Normalmente, el jugo de azúcar sin refinar se trata con una disolución acuosa de hidróxido de calcio. Tras el tratamiento con cal se suele realizar un paso de carbonatación para precipitar carbonato cálcico junto con sales de calcio de ácidos orgánicos, para coagular proteínas, coloides y partículas suspendidas. Las filtraciones se realizan por medio de decantadores, filtros de vacío, filtros de bujías, filtros prensa, etc. Con esta 
purificación, conseguimos eliminar los componentes tanto suspendidos como disueltos que no son azúcares, para así aumentar la calidad del azúcar, llegándose a conseguir una pureza de aproximadamente el $88 \%$.

4.- Evaporación del jugo. El jugo procedente de la depuración hay que concentrarlo para que tenga lugar la cristalización del azúcar por sobresaturación. La evaporación se realiza mediante vapor a baja presión procedente por ejemplo del escape de los turboalternadores de producción de energía eléctrica. El jugo saliente de la evaporación recibe el nombre de jugo concentrado ó jarabe, con una pureza del 90\%, aproximadamente.

5.- Cocimientos del jarabe y cristalización del azúcar. Para facilitar y provocar la formación de cristales de azúcar, cuando se ha alcanzado un grado de sobresaturación óptimo, se inyecta, dentro de los aparatos donde se lleva a cabo la cocción, una pequeña proporción de polvo de azúcar. La masa que se forma al final de la cocción es la masa de relleno, que pasa desde los aparatos de cocción a unas máquinas estrujadoras. Con un enfriamiento constante de la masa, se modifica la sobresaturación, con lo cual los cristales de azúcar siguen creciendo.

6.- Etapas adicionales. El azúcar blanco se produce en la primera etapa de cristalización. Pero la cristalización del líquido madre no da lugar a azúcares de alta calidad. Por ello, el azúcar de baja calidad se recircula continuamente y se mezcla con el jugo concentrado de azúcar formando un líquido estándar. Debido a la presencia de gran cantidad de impurezas, el flujo de recirculación de azúcar debe ser al menos del 70-80\% del flujo de la alimentación.

7.- $\quad$ Recuperación de azúcares a partir de melazas. Las melazas constituyen el 8-10\% del total de azúcar que entra en la fábrica. Por ello, muchas empresas de Europa, Japón y de EEUU utilizan un proceso de separación por cromatografía para enriquecer la fracción de azúcar (extracto) y la fracción de componentes que no son azúcar (refinado). Normalmente, se utilizan resinas de intercambio catiónico sulfonadas como fase estacionaria, las cuales tienen una ligera afinidad por los azúcares, una afinidad un poco mayor por la betaína y nada o muy poca afinidad por la mayoría de los demás iones. El modo de operación es por pulsos o bien SMB (Simulated Moving Bed). (Kirk O. et. al., 1997).

AZUCAR DE CAÑA. La caña de azúcar se cultiva principalmente en países tropicales. El proceso de obtención de azúcar es bastante laborioso. Se inicia con la transformación de la caña, por molienda y presión, en pasta. A continuación, debido a la gran cantidad de impurezas que contiene se hace necesaria su depuración. Posteriormente, los procesos finales de obtención del azúcar son semejantes a los de la remolacha. 


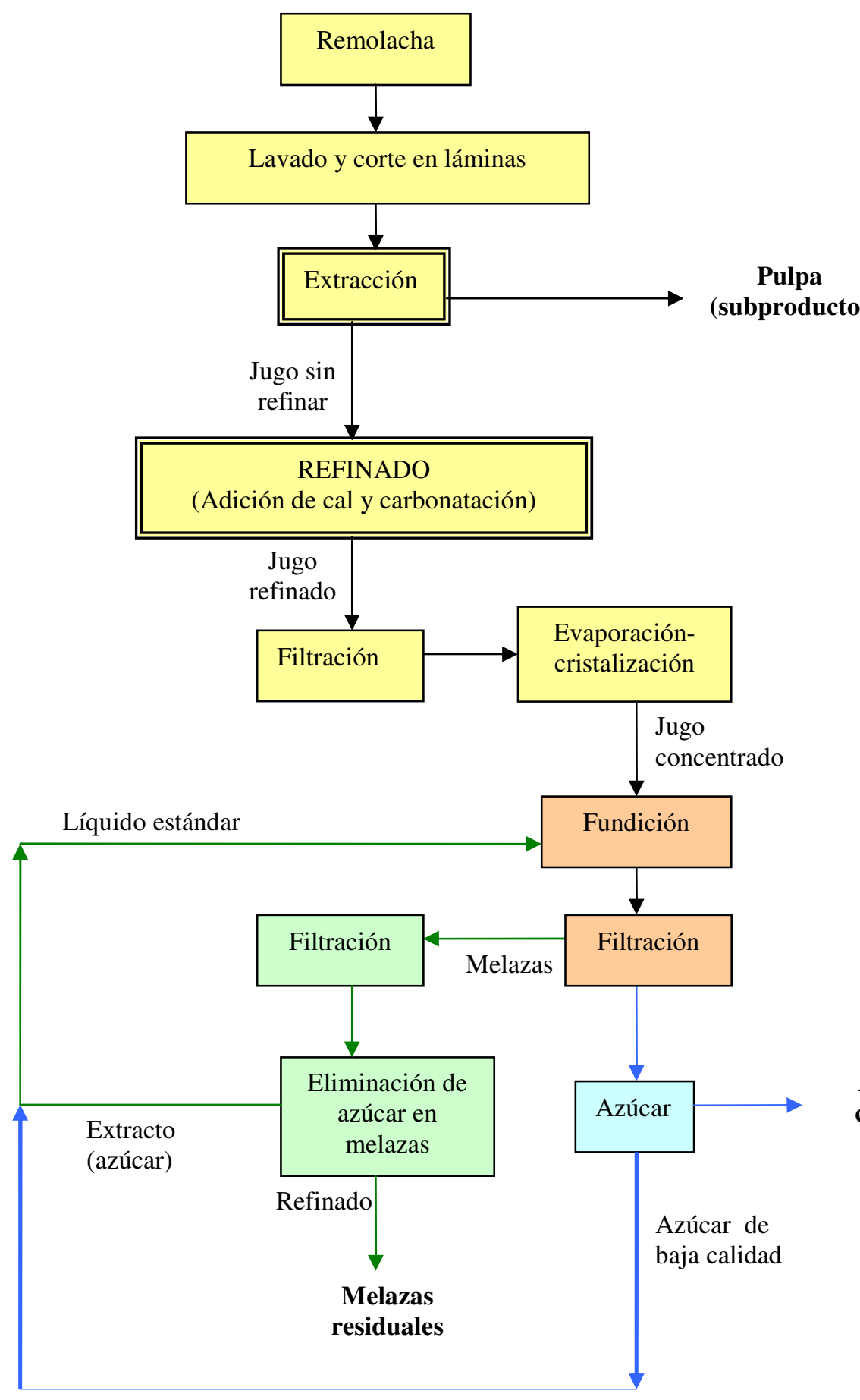

Azúcar para comercializar

Figura 1. Diagrama del proceso de azúcar de remolacha. 


\subsubsection{Recuperación de betaina}

La recuperación de betaína de las melazas de la industria azucarera, para un posterior uso en otros procesos es de gran interés debido al valor potencial de la betaína, tanto farmacológico como tecnológico.

En un estudio reciente se investigó la separación de mezclas de sacarosa-betaína y de sacarosa-sal mediante una planta piloto dónde se emplea un equipo de separación cromatográfica compuesto de 8 columnas cromatográficas conectadas en serie y termostatizadas. Los resultados demuestran la posible aplicación de este proceso a escala industrial tras una etapa de estudio e investigación en mayor profundidad. (Bubnik Z. et. al., 2004). En la bibliografía aparecen algunas patentes (Paananen $H$. et al., 2001; Paananen H. et al., 2007; Heikkila H. et al., 1989; Heikkila H. et al., 1992; Heikkila H. et al., 2000) que siguen las investigaciones de recuperación de betaína con el uso de resinas de intercambio iónico comerciales.

Como alternativa a los estudios con resinas comerciales de intercambio iónico, se propone como objetivo de esta Tesis Doctoral el estudio comparativo de recuperación de betaína empleando la novedosa tecnología de extracción con resinas impregnadas de extractante, haciendo uso especialmente de extractantes catiónicos.

\subsubsection{Aplicaciones}

La betaína es un protector de la mucosa gástrica, y tanto la betaína pura como el clorhidrato de betaína y el palmitato de betaína, se utilizan en la industria farmacéutica en preparados vitamínico-minerales, para la reducción de la acidez gástrica y como aditivo en pastas de dientes para pacientes con sequedad bucal. Se utiliza en la industria de cosmética en champús, geles y preparados de limpieza de la piel recomendados a pacientes con dermatitis alérgica. Además, la betaína es un tensioactivo anfotérico. Se ha estudiado recientemente la formación de nuevas micelas alquilbetaínas capaces de solubilizar cantidades importantes de liposomas, proteínas y vitamina $E$, que en forma de vesículas pueden servir de porteadores estables de moléculas biológicas y médicas. Asimismo, es de resaltar el uso potencial de los ésteres de betaína como materiales biodegradables de aplicación en la producción de papel, en sustitución de los ésteres catiónicos habituales, y en la formación de nuevos plásticos transparentes (Granö H. et. al., 2000).

Una aplicación cada vez más creciente, es la utilización de la betaína en la alimentación animal principalmente en piensos para peces y pollos. (Esteve-Garcia E. et. al., 2000). Esto se debe a sus propiedades de "donador de grupo metilo" a la homocisteína para dar lugar a la metionina en el hígado y es utilizado por el riñón como protector osmótico, manteniendo el balance de agua. Los grupos metilo son esenciales en los sistemas nervioso, inmunológico, renal, y cardiovascular. Algunos estudios de investigación demuestran que la ingestión de betaína vía oral de rumiantes hace que aumente el rendimiento de la producción de leche y de su contenido en grasa durante el periodo de lactancia. Por otro lado, los parámetros físico-químicos de la leche no estuvieron afectados (Fernández C. et. al., 2004). 
En humanos, la betaína se puede adsorber a través de la ingestión de alimentos, o bien, sintetizarse endógenamente a través del catabolismo de la colina en el hígado. La concentración de betaína en el plasma humano está altamente regulada, aunque puede ser inferior a la deseada en enfermos con afecciones renales o diabéticos. Diversos estudios han probado que niveles altos de homocisteína en el plasma humano aumentan el riesgo de padecer enfermedades vasculares, en este caso la betaína actua terapéuticamente reduciendo estos niveles de homocisteína en sangre ( $Z$ wart $F$. J et. al., 2003; Lawson-Yuen A. et. al., 2006). 

3. EXTRACCIÓN
LÎQUIDO-LÍQUIDO 



\subsection{CONCEPTOS GENERALES}

La extracción líquido-líquido, también denominada extracción con disolventes, es una técnica de separación ampliamente utilizada, tanto a nivel de laboratorio como industrial, para la separación y concentración de bioproductos de procesos de fermentación y corrientes residuales (Hanson C., 1979; Eyal A.M. et al., 1995; Kertes A.S. et al., 1986; Tamada J.A. et al., 1990 a-c). Se emplea cuando es el único proceso posible o bien resulta el más económico. Su uso queda restringido a las separaciones que no pueden llevarse a cabo de forma adecuada en una única etapa, ya que esta técnica precisa de una segunda etapa de separación para recuperar los componentes extraídos de la fase disolvente. (Hampe M. J., 1986; Kertes A. S. et al., 1986). Las ventajas de utilizar un proceso de extracción con disolventes dependen de encontrar un disolvente selectivo para el producto de interés que implique, además, mínimas pérdidas del mismo en la fase de refinado, seguido de un proceso adecuado para su recuperación desde la fase de extracto, con el menor coste económico.

En este proceso de separación, una mezcla o disolución líquida denominada alimentación se pone en contacto con un segundo líquido inmiscible o parcialmente miscible denominado disolvente, provocando que ciertos componentes de la alimentación se transfieran al disolvente. A continuación, ambas fases se decantan, el producto rico en disolvente se llama extracto, y el líquido residual de donde se separa el soluto es el refinado. Posteriormente, los compuestos extraídos se separan del extracto mediante destilación, reextracción con otro disolvente u otras técnicas.

La distribución de un soluto $A$ entre dos fases líquidas en equilibrio, puede expresarse mediante el coeficiente de reparto, $\mathrm{K}$, definido de la siguiente manera:

$$
\mathrm{K}=\frac{\mathrm{C}_{\mathrm{A}(\mathrm{o})}}{\mathrm{C}_{\mathrm{A}(\mathrm{w})}}
$$

donde $C_{A(0)}$ es la concentración del soluto en el extracto o fase orgánica, $C_{A(w)}$ en el refinado o fase acuosa.

Con aquellos disolventes que proporcionan coeficientes de distribución menores de la unidad se precisan relaciones elevadas de disolvente / alimentación. Para alcanzar la separación, resulta por tanto más ventajoso que los valores de $\mathrm{K}$ sean razonablemente elevados, empleando una relación volumétrica disolvente / alimentación menor que la unidad y permitiendo simultáneamente la separación y concentración de los productos extraídos. (King C.J. et al., 1988; Cockrem M.C.M. et al., 1989).

El fundamento de la extracción con disolventes es la interacción, en mayor o menor grado, entre el soluto y el disolvente. Según esta interacción se pueden clasificar en dos grandes categorías:

- Interacciones físicas, que implican puentes de hidrógeno o interacciones dipolodipolo. La recuperación del soluto del extracto se realiza generalmente por un método físico, destilación normalmente, o reextracción y precipitación.

- Interacciones químicas, que suponen la formación de uno o más compuestos químicos de estequiometría definida. Hay una limitación en el grado de extracción (o cantidad máxima que puede ser extraída con una cantidad dada de disolvente) 
que corresponde al agotamiento del disolvente. La recuperación del soluto exige invertir la interacción o desplazar el equilibrio de reacción, lo que suele llevarse a cabo modificando las condiciones químicas, por ejemplo, poniendo en contacto el extracto con una fase acuosa de diferente $\mathrm{pH}$ o bien modificando la temperatura, siendo este último más económico.

\subsection{CARACTERÍSTICAS DEL DISOLVENTE}

Es difícil encontrar un disolvente puro que reúna la capacidad de extraer selectivamente al soluto de interés y las propiedades físicas necesarias para producir una separación adecuada de las fases y la posterior reextracción del soluto (Munson C.L. et al., 1984). Por tanto, el disolvente a utilizar puede ser una especie química sencilla, pero no es el caso más frecuente en extracción líquido-líquido.

La especie activa normalmente se emplea disuelta en otro líquido, denominándose extractante al compuesto activo y diluyente a la sustancia que lo disuelve. La disolución de extractante en el diluyente es el disolvente y constituye la fase orgánica (Tamada J.A. et al., 1990 c; Baldwin W.H. et al., 1974).

El diluyente debe disolver selectivamente, no sólo al extractante, sino también a la especie soluto-extractante formada durante la extracción, evitando la aparición de terceras fases, emulsiones o espumas. La formación de estas depende de las características del extractante, del diluyente y del soluto a extraer y, en cualquier caso, es más frecuente que se produzca a valores elevados de soluto en el disolvente. En el caso que este problema no pueda evitarse mediante la elección de otro diluyente, es posible adicionar un tercer componente que mejore la solubilidad y que se conoce con el nombre de modificador (Hartl J. et al., 1990).

Un parámetro de gran importancia en sistemas multicomponentes es la selectividad del extractante, de forma que no es suficiente un disolvente con elevada capacidad de extracción, sino que éste ha de proporcionar además cierto grado de separación o purificación del producto de interés con respecto a otros solutos presentes. La selectividad del extractante por un soluto $A$ frente a otro $B$ se mide mediante el factor de separación, $\beta$ :

$$
\beta=\frac{\mathrm{K}_{\mathrm{A}}}{\mathrm{K}_{\mathrm{B}}}
$$

este factor de separación varia significativamente con las concentraciones de los solutos.

En base a lo expuesto, algunos de los parámetros que deben considerarse en la selección de disolvente son los siguientes:

- Coeficiente de reparto, Ec. (3.1). Aunque no es necesario que tenga valores mayores de 1, cuanto más grande sea su valor, menos disolvente se necesita en la extracción. 
- Selectividad, Ec. (3.2). El disolvente debe ser selectivo por el soluto de interés, es decir presentar valores de selectividad mayores de 1, evitando la coextracción de impurezas. Así se reduce o elimina la etapa de lavado de la fase extracto.

- Insolubilidad. El disolvente y el complejo disolvente-soluto deben ser insolubles o poco solubles en el refinado y evitar además, la formación de terceras fases.

- Recuperabilidad. Debe ser posible invertir el proceso de extracción para recuperar el soluto de interés y el disolvente, bien sea por métodos físicos o químicos. Desde el punto de vista económico, este parámetro es importante.

- Densidad. Es necesaria una diferencia en las densidades de las fases líquidas implicadas en el proceso de extracción. Cuanto mayor sea la diferencia mejor será la separación de las fases.

- Disponibilidad. El disolvente debe estar disponible en cualquier momento y tener más de un suministrador.

- $\quad$ Reactividad química. El disolvente debe ser químicamente inerte a los materiales del sistema de operación y a los demás componentes del sistema.

- Propiedades físicas. Un valor razonablemente elevado de la tensión superficial mejora la separación de las fases. Por otro lado, una viscosidad baja facilita la transferencia de materia y la separación de las fases, reduciendo, además, la energía requerida para el bombeo de las fases. La presión de vapor y punto de congelamiento deben ser bajos para facilitar el manejo y el almacenamiento.

- $\quad$ Toxicidad, inflamabilidad y coste son también parámetros a tener en cuenta.

\subsection{PÉRDIDAS DE DISOLVENTE}

Se requiere que el valor del disolvente perdido en la fase de refinado sea bastante inferior al valor del soluto. Algunos autores de forma clásica, cuantifican este dato en un $5 \%$ (Cockrem M.C.M. et al., 1989).

Para reducir las pérdidas de disolvente en la fase refinado es necesario que el disolvente sea poco soluble en agua. En general, la solubilidad de una sustancia orgánica en agua aumenta con la polaridad de la molécula. Hay que tener en cuenta que cuando existen fuertes interacciones entre un extractante y un soluto, la solubilidad del complejo puede ser mayor que la del disolvente puro en agua.

El estudio realizado por Cockrem et al. sobre la extracción de distintos solutos de disoluciones acuosas, indica que es posible relacionar la miscibilidad de las fases con la solubilidad del disolvente en agua y con la selectividad, demostrando que cuando las pérdidas de disolvente son bajas, es decir para disolventes poco solubles en agua, la solubilidad del agua en el disolvente es también baja y por tanto el coeficiente de distribución para el agua será pequeño, y la selectividad elevada. También demuestra 
que las pérdidas de disolvente, el coeficiente de distribución para el soluto y la selectividad son los factores principales a considerar en la selección del disolvente (Cockrem M.C.M. et al., 1989).

La recuperación del disolvente contenido en la fase de refinado se puede realizar por diversos métodos. Los más frecuentes se exponen a continuación brevemente:

- Desorción con vapor de agua a presión atmosférica. Se utiliza cuando el disolvente es suficientemente volátil, obteniéndose una corriente por cabezas que es una solución acuosa concentrada en el disolvente, apta para ser recirculada al proceso de extracción.

- Desorción con vapor de agua empleando vacío. El coste extra del proceso a vacío puede ser compensado por la economía que supone el no precalentar el refinado, como en el caso anterior. Su uso está justificado porque frecuentemente la volatilidad relativa de los disolventes respecto del agua, es mayor a baja temperatura.

- Desorción con gas inerte. Evita el consumo energético que supone el proceso con vapor.

- Reextracción con un disolvente no polar. Requiere un nuevo proceso de extracción con un nuevo disolvente que presente baja solubilidad con el agua, pero elevada capacidad por el primer disolvente.

\subsection{EQUILIBRIOS DE EXTRACCIÓN DE AMINOÁCIDOS Y BETAÍNA}

La clasificación de los sistemas de extracción para la recuperación de aminoácidos y derivados, como es la betaína, de corrientes acuosas diluidas puede hacerse en función de la naturaleza del extractante y del tipo de interacciones que éste ocasiona:

- Extracción mediante solvatación con agentes hidrocarbonados que poseen átomos de oxígeno en su molécula. Se incluyen dentro de esta categoría los hidrocarburos alifáticos y aromáticos, dada la similitud de los procesos involucrados. Se dan enlaces donadores (por solvatación del soluto).

- Extracción mediante solvatación con extractantes organofosforados que poseen átomos de oxígeno en su molécula. Estos extractantes son óxidos de fosfina, fosfinatos, fosfonatos, fosfatos y ésteres fosfóricos, fosfónicos y fosfínicos. Producen enlaces solvatantes fuertes y específicos, pudiéndose considerar la existencia de una reacción química con el soluto de interés (Abbasian K. et al., 1989). 
- Extracción mediante formación de pares iónicos (transferencia de protones) o por reacción química. Los extractantes, en el primer caso, son aminas alifáticas de elevado peso molecular (aminas primarias, secundarias, terciarias de cadena larga), y en el segundo, son sales de amonio cuaternarias y compuestos azufrados catiónicos.

Algunos estudios publicados indican que los sistemas convencionales de extracción que utilizan agentes hidrocarbonados como alcoholes, cetonas o ésteres inmiscibles en agua, son relativamente ineficaces para la recuperación de aminoácidos de disoluciones acuosas diluidas. Esto se debe a que los aminoácidos no pueden extraerse eficazmente con disolventes no polares o de baja polaridad, ya que en fase acuosa las especies de los aminoácidos presentan carga, positiva la especie catiónica, negativa la especie aniónica o ambas la especie anfótera, reduciéndose considerablemente la solubilización del aminoácido en el disolvente no polar (Kertes A.S. et al., 1986; Schügerl K. et al., 1992). Nuevos extractantes consistentes en macrociclos hidrocarbonados se están estudiando para la recuperación de aminoácidos, a estos extractantes se les introduce grupos funcionales para crear interacciones específicas con las moléculas que se van a extraer. El inconveniente es que es necesario crear el ester del aminoácido para su posterior complejación con el extractante. Ej: $\mathrm{Oct}[6] \mathrm{CH}_{2} \mathrm{COOH}$ para extraer ésteres de aminoácido (Oshima T. et al., 2004).

Además, los aminoácidos prácticamente no se extraen con aminas alifáticas primarias, secundarias o terciarias, ya que el mecanismo de extracción implica la transferencia previa del protón y posteriormente la extracción del anión del aminoácido, proceso imposibilitado por el carácter anfotérico de los aminoácidos en disolución acuosa. Así, el único enlace de hidrógeno que puede formar el átomo de nitrógeno de la amina y el grupo ácido del aminoácido, sin previa transferencia del protón, es demasiado débil para producir la transferencia del aminoácido de la fase acuosa a la orgánica (Schügerl $K$. et al., 1992).

Es de vital importancia en el desarrollo de nuevos procesos de extracción, la identificación de nuevos y más potentes extractantes. En este grupo se pueden incluir los compuestos azufrados, compuestos organofosforados, y las sales de amonio cuaternarias, estos últimos desarrollados inicialmente para la separación de metales en la industria nuclear (Baldwin W.H. et al., 1974) y de uso reciente en la recuperación de ácidos carboxílicos (Clark G.A. et al., 1987; Ruiz M.O., 2000; Qin W. et al., 2003), en la eliminación de contaminantes de efluentes industriales y de alcantarillado (Salazar $E$. et al., 1992) y en la extracción de aminoácidos (Schügerl K. et al., 1992; Escalante H. et al., 2000; Ruiz M.O., 2002; Lin S. H. et al., 2006). Las principales ventajas de utilizar estos extractantes (Schügerl K., 1987) son:

- La capacidad de carga del disolvente puede incrementarse considerablemente permitiendo el uso de menores relaciones de flujo disolvente / agua.

- La selectividad de la recuperación puede aumentar.

- Las velocidades de extracción son elevadas, requiriéndose equipos de menor tamaño y obteniendo buenos rendimientos.

- Los productos de interés pueden concentrarse hasta un punto que haga económicamente más rentable su purificación posterior. 
Una ventaja adicional introducida por algunos extractantes (Amberlita LA-2, Tomac, TBP, TOPO, Alamina 336, etc...) es su baja solubilidad en agua, que evita un tratamiento térmico o químico adicional del refinado de extracción (Golob J. et al., 1981).

Por lo general, los aminoácidos en estudio en este trabajo de investigación y la betaína en disolución acuosa a pH menor o igual al $\mathrm{pK}_{\mathrm{a} 1}$ se pueden extraer con extractantes catiónicos, produciéndose en la interfase una reacción de intercambio iónico entre la forma catiónica del soluto (aminoácido o derivado) y el protón del extractante catiónico. Entre estos extractantes catiónicos se encuentran:

- Extractantes organofosforados siempre que simultáneamente exista transferencia de protones como por ejemplo el ácido di-(2-etilhexil)fosfórico (D2EHPA).

- Extractantes azufrados como el ácido dinonilnaftalensulfónico (DNNSA).

- Extractantes organofosforados-azufrados como por ejemplo el ácido di-(2etilhexil)monotiofosfórico (D2EHPA(S)).

Algunos estudios publicados recientemente muestran que la extracción de aminoácidos con extractantes catiónicos es posible, resultando mayor con extractantes azufrados que con compuestos organofosforados-azufrados y mucho menor con extractantes organofosforados (Itoh H. et al., 1990; Kelly N.A. et al., 1998; Cascaval D. et al., 2001). A pHs intermedios, donde predomina la forma anfótera del aminoácido, se pueden extraer con extractantes básicos como los fosfatos (Schügerl K. et al., 1992), cumpliéndose la misma secuencia de extracción.

Por otra parte, los aminoácidos monocarboxílicos o dicarboxílicos en disolución acuosa a un $\mathrm{pH}$ mayor a su $\mathrm{pK}_{\mathrm{a} 2} \mathrm{O} \mathrm{pK}_{\mathrm{a} 3}$ se encuentran preferentemente en su forma aniónica monovalente o divalente. Por tanto, su extracción puede realizarse con extractantes aniónicos, como son las sales de amonio cuaternarias, produciéndose en la interfase una reacción de intercambio iónico entre la forma aniónica del aminoácido y el catión correspondiente del extractante aniónico (Ruiz M. O. et. al., 2002).

Recientemente, también se está iniciando el estudio de la posible separación enantioselectiva de aminoácidos mediante la utilización de extractantes aniónicos o catiónicos junto a un co-extractante enantioselectivo como son: el ácido $\mathrm{O}, \mathrm{O}^{\prime}$-dibenzoil(2S, 3S)-tartárico (DBTA) o el ácido O, O'-dibenzoil- (2S, 3S)-4-toluoil-tartárico (DTTA) (Tan B. et al., 2006; Tan B. et al., 2007).

En general, en la extracción por reacción química se supone la formación de uno o más compuestos químicos de estequiometría definida. Normalmente, se obtienen isotermas de reparto del tipo que se representa en la Figura 2. La limitación en el grado de extracción (o cantidad máxima que puede ser extraída con una cantidad dada de disolvente) se corresponde con el agotamiento del disolvente. 


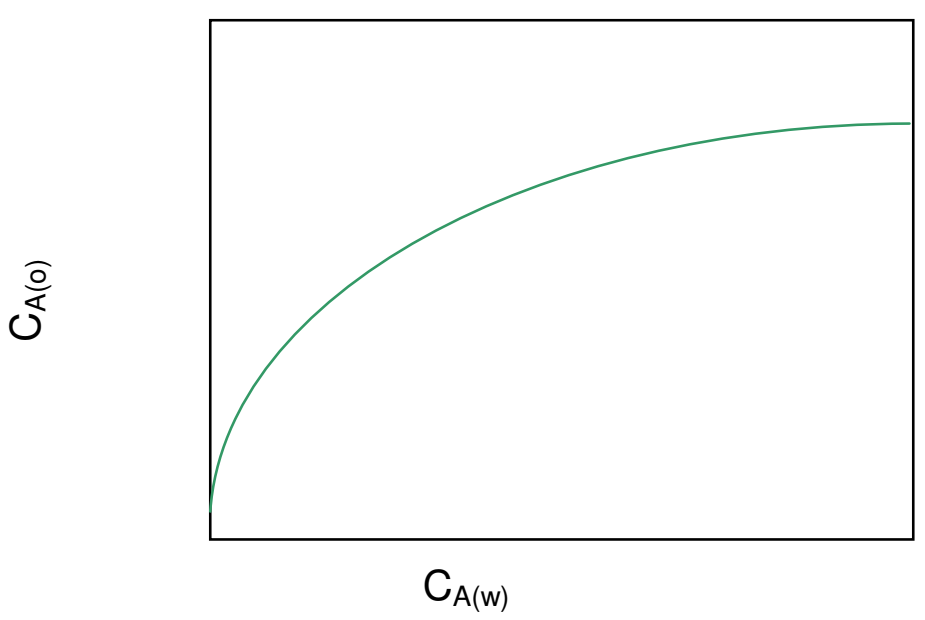

Figura 2. Isoterma de extracción con disolventes

\subsubsection{Extracción con sales de amonio cuaternarias}

Las sales de amonio son extractantes aniónicos, altamente insolubles en agua que mediante reacciones de intercambio iónico, son eficientes en la recuperación de especies aniónicas tales como $\mathrm{Cl}^{-}, \mathrm{Br}^{-}$, vanadio, iridio, sales de ácidos minerales, enzimas, hormonas. (Galan B. et al., 1994) y aminoácidos (Schügerl K. et al., 1992; Haensel R. et al.,1986; Thien M.P. et al., 1988; Chan C.C. et al., 1993, Escalante H. et al., 1998; Uddin M.S. et al., 1990; Uddin M S. et al., 1992, Ruiz M.O., 2002; González M. J. et al., 2006). Generalmente, poseen baja selectividad, ya que pueden producir varias reacciones de intercambio iónico simultaneas con diferentes especies aniónicas presentes en la fase acuosa (Salazar E. et al., 1992).

La extracción de especies aniónicas, con sales de amonio, depende de la concentración de extractante-diluyente, de la temperatura del proceso y especialmente del $\mathrm{pH}$ y de la concentración total de soluto en fase acuosa. Los aminoácidos en disolución acuosa sufren una disociación dependiente del pH y es la variable principal que permite dirigir, en función del pK del soluto, la afinidad del extractante por un soluto determinado (Salazar E. et al., 1992). Así, a pH menor o igual a su $\mathrm{pK}_{\mathrm{a} 1}$ los aminoácidos se encuentran preferentemente en forma catiónica y a $\mathrm{pH}$ mayor a su $\mathrm{pK}_{\mathrm{a} 2}$ preferentemente en su forma aniónica.

Es aconsejable, que el valor del pH de la fase acuosa, en todo el proceso de extracción, sea al menos dos unidades superior al $\mathrm{pK}_{\mathrm{a} 2}$ del aminoácido monocarboxílico (Schügerl $\mathrm{K}$. et al., 1992) para asegurarnos que la especie iónica predominante sea la aniónica. Por tanto, es necesario tamponar o basificar la disolución acuosa y obtener mayoritariamente la especie aniónica del aminoácido para que la reacción de intercambio iónico tenga lugar con este tipo de extractantes aniónicos. 
Algunos autores (Schügerl K. et al., 1992; Haensel R. et al., 1986; Galan B. et al., 1994; Ruiz M.O., 2002; Escalante $H$. et al., 1998) consideran que el proceso de extracción de un aminoácido monocarboxílico $A^{+-}$, con una sal de amonio, $R^{+} X^{-}$, consta de las siguientes etapas:

i) Ionización del soluto en fase acuosa tamponada o basificada a pH superior al $\mathrm{pK}_{\mathrm{a} 2}$ :

$$
\mathrm{A}^{+/-}(\mathrm{w}) \leftrightarrow \mathrm{H}_{(\mathrm{w})}^{+}+\mathrm{A}_{(\mathrm{w})}^{-}
$$

ii) Reacción de intercambio iónico del soluto con el extractante:

$$
\mathrm{R}^{+} \mathrm{X}_{(\mathrm{o})}^{-}+\mathrm{A}_{(\mathrm{w})}^{-} \leftrightarrow \mathrm{R}^{+} \mathrm{A}_{(\mathrm{o})}^{-}+\mathrm{X}_{(\mathrm{w})}^{-}
$$

iii) Coextracción de los iones hidroxilo $\left(\mathrm{OH}^{-}\right)$o de otras especies aniónicas $\left(\mathrm{P}^{-}\right)$ presentes en la fase acuosa:

$$
\mathrm{R}^{+} \mathrm{X}_{(\mathrm{o})}^{-}+\mathrm{P}_{(\mathrm{w})}^{-} \leftrightarrow \mathrm{R}^{+} \mathrm{P}_{(\mathrm{o})}^{-}+\mathrm{X}_{(\mathrm{w})}^{-}
$$

Las constantes de equilibrio de las Ecs. (3.4) y (3.5) se expresan en función de las actividades de las especies como:

$$
\begin{aligned}
& \mathrm{K}_{\mathrm{ep}}=\frac{\mathrm{a}_{\mathrm{R}^{+} \mathrm{A}_{(\mathrm{o})}^{-}} \mathrm{a}_{\mathrm{X}_{(\mathrm{w})}^{-}}}{\mathrm{a}_{\mathrm{R}^{+} \mathrm{X}_{(\mathrm{o})}^{-}} \mathrm{a}_{\mathrm{A}_{(\mathrm{w})}^{-}}} \\
& \mathrm{K}_{\mathrm{eh}}=\frac{\mathrm{a}_{\mathrm{R}^{+} \mathrm{P}_{(\mathrm{o})}^{-}} \mathrm{a}_{\mathrm{X}_{(\mathrm{w})}^{-}}}{\mathrm{a}_{\mathrm{R}^{+} \mathrm{X}_{(\mathrm{o})}^{-}} \mathrm{a}_{\mathrm{P}_{(\mathrm{w})}^{-}}}
\end{aligned}
$$

Algunos trabajos recogidos en la bibliografía (Haensel $R$. et al., 1986; Calvarin L. et al., 1992; Ruiz M.O., 2002; Molinari R. et al., 1992; Yang S.T. et al., 1991) suponen que las actividades de las especies orgánicas son proporcionales a las concentraciones, por tanto, los coeficientes de actividad permanecen constantes y pueden englobarse en la constante de equilibrio. En este supuesto, las constantes de equilibrio aparentes para las reacciones globales de extracción pueden escribirse en términos de concentración como se muestra en las Ecs. (3.8) y (3.9).

$$
\begin{gathered}
\mathrm{K}_{\mathrm{ep}}=\frac{\left[\mathrm{R}^{+} \mathrm{A}^{-}\right]_{(\mathrm{o})}\left[\mathrm{X}^{-}\right]_{(\mathrm{w})}}{\left[\mathrm{R}^{+} \mathrm{X}^{-}\right]_{(\mathrm{o})}\left[\mathrm{A}^{-}\right]_{(\mathrm{w})}} \\
\mathrm{K}_{\mathrm{eh}}=\frac{\left[\mathrm{R}^{+} \mathrm{P}^{-}\right]_{(\mathrm{o})}\left[\mathrm{X}^{-}\right]_{(\mathrm{w})}}{\left[\mathrm{R}^{+} \mathrm{X}^{-}\right]_{(\mathrm{o})}\left[\mathrm{P}^{-}\right]_{(\mathrm{w})}}
\end{gathered}
$$

donde $\mathrm{K}_{\mathrm{ep}} \mathrm{y} \mathrm{K}_{\mathrm{eh}}$ son las constantes de equilibrio expresadas en términos de concentración. 


\subsubsection{Extracción con compuestos azufrados}

Los compuestos azufrados son extractantes catiónicos, generalmente ácidos sulfónicos unidos a cadenas alifáticas largas como por ejemplo: el ácido dinonilnaftalensulfónico (DNNSA) empleado en este trabajo de investigación.

Estos extractantes son altamente insolubles en agua y muy solubles en hidrocarburos aromáticos y alifáticos. Son eficientes en la recuperación de especies catiónicas, tales como aminoácidos (Kelly N.A. et al., 1998). La principal desventaja de su uso es la formación de emulsiones estables y de terceras fases que ralentiza o imposibilita la etapa de separación, y hace necesario la utilización de modificadores en el proceso de extracción líquido-líquido.

Un análisis crítico del proceso de extracción de aminoácidos en su forma catiónica $\left(A^{+}\right)$o de la betaína con el extractante sulfonado $\left(\mathrm{RSO}_{3}{ }^{-} \mathrm{H}^{+}\right)$consta de las siguientes etapas:

i) Ionización del soluto en fase acuosa a pH ácido:

$$
\mathrm{A}^{+}{ }_{(\mathrm{w})} \leftrightarrow \mathrm{H}_{(\mathrm{w})}^{+}+\mathrm{A}_{(\mathrm{w})}^{+/-}
$$

ii) Reacción de intercambio iónico del soluto con el extractante:

$$
\mathrm{RSO}_{3}^{-} \mathrm{H}_{(\mathrm{o})}^{+}+\mathrm{A}_{(\mathrm{w})}^{+} \leftrightarrow \mathrm{RSO}_{3}^{-} \mathrm{A}_{(\mathrm{o})}^{+}+\mathrm{H}_{(\mathrm{w})}^{+}
$$

La constante de equilibrio de la Ec. (3.11) se expresa en términos de concentración como:

$$
\mathrm{K}_{\mathrm{ep}}=\frac{\left[\mathrm{RSO}_{3}^{-} \mathrm{A}^{+}\right]_{(\mathrm{o})}\left[\mathrm{H}^{+}\right]_{(\mathrm{w})}}{\left[\mathrm{RSO}_{3}^{-} \mathrm{H}^{+}\right]_{(\mathrm{o})}\left[\mathrm{A}^{+}\right]_{(\mathrm{w})}}
$$

\subsection{ETAPA DE REEXTRACCIÓN}

Un proceso práctico de recuperación de un soluto, empleando como técnica de separación la extracción con disolventes, se ha de realizar, al menos, en dos etapas. La primera corresponde a la extracción del soluto para obtener un extracto cargado con el soluto, y un refinado acuoso relativamente libre de soluto. La segunda etapa es la reextracción y consiste en transferir el soluto desde el extracto a otra fase producto (stripping), regenerándose la fase disolvente que se recircula a la etapa anterior.

Cuando se utilizan como extractantes sales de amonio cuaternarias, el aminoácido se puede reextraer de la fase orgánica por reacción química. La sal de amonio del aminoácido $\left(\mathrm{R}^{+} \mathrm{A}^{-}\right)$presente en la fase orgánica puede sufrir una reacción de intercambio iónico con un ácido fuerte, según la reacción: 


$$
\mathrm{R}^{+} \mathrm{A}^{-}+\mathrm{B}^{-} \leftrightarrow \mathrm{R}^{+} \mathrm{B}^{-}+\mathrm{A}^{-}
$$

donde $\mathrm{B}^{-}$es la especie no protonada de un ácido fuerte. La reextracción del soluto de interés y la regeneración del extractante es simultánea empleando ácidos fuertes que posean el contra-ion de la sal de amonio.

En trabajos anteriores realizados en nuestro laboratorio se ha estudiado la reextracción de $\alpha$-fenilglicina y de ácido aspártico de disoluciones orgánicas, donde se encuentra en forma de sal de amonio, utilizando ácido clorhídrico como agente de reextracción (Ruiz M.O., 2000; Burgos L., 2001; Sanchez P., 2006). El proceso de reextracción tiene lugar mediante intercambio del anión cloruro por el aminoácido en forma aniónica según la siguiente reacción:

$$
\mathrm{Q}^{+} \mathrm{A}_{(\mathrm{o})}^{-}+\mathrm{Cl}_{(\mathrm{s})}^{-} \leftrightarrow \mathrm{A}_{(\mathrm{s})}^{-}+\mathrm{Q}^{+} \mathrm{Cl}_{(\mathrm{o})}^{-}
$$

Debido al pH ácido del medio, simultáneamente tiene lugar la protonación del aminoácido pasando este a su forma catiónica:

$$
\mathrm{A}_{(\mathrm{s})}^{-} \stackrel{\mathrm{H}^{+}}{\longrightarrow} \mathrm{HA}^{+/-} \stackrel{\mathrm{H}^{+}}{\longrightarrow} \mathrm{A}_{(\mathrm{s})}^{+}
$$

donde los subíndices s y o hacen referencia a la fase acuosa de reextracción y orgánica, respectivamente.

La formación de la especie catiónica del aminoácido favorece el proceso de reextracción, ya que hace desaparecer la forma aniónica del medio, desplazando el equilibrio hacia la reextracción. A su vez, por contener la disolución de reextracción el contraión cloruro se regenera simultáneamente el agente de extracción Tomac.

Con extractantes catiónicos sulfonados (derivados del ácido sulfónico), el aminoácido o la betaína se pueden reextraer de la fase orgánica por reacción química. La sal $\left(\mathrm{RSO}_{3}{ }^{-} \mathrm{A}^{+}\right)$ presente en la fase orgánica puede sufrir una reacción de intercambio iónico con una sal, un ácido o una base fuerte que presente un catión $\mathrm{B}^{+}$según la reacción:

$$
\mathrm{RSO}_{3}^{-} \mathrm{A}_{(\mathrm{o})}^{+}+\mathrm{B}_{(\mathrm{w})}^{+} \leftrightarrow \mathrm{RSO}_{3}^{-} \mathrm{B}_{(\mathrm{o})}^{+}+\mathrm{A}_{(\mathrm{w})}^{+}
$$




\section{SEPARACIÓN CON RESINAS}



En este apartado se describe la técnica de separación empleando resinas macroporosas sobre las que se inmoviliza el extractante. Se han realizado también ensayos de recuperación de los aminoácidos con la resina sin impregnar. La separación en este caso es un proceso de adsorción. Es por ello, que a continuación, se indican los fundamentos de los equilibrios y cinéticas de separación (adsorción/extracción) necesarios para el tratamiento de los datos experimentales.

\subsection{ADSORCIÓN}

\subsubsection{Conceptos generales.}

La adsorción es una operación básica en Ingeniería Química, consistente en la retención en la superficie de un sólido, de moléculas contenidas en una mezcla líquida o gaseosa, como resultado de fuerzas atractivas en la superficie del sólido de mayor magnitud que la energía cinética de las moléculas de soluto (adsorbato) en la fase fluida. La adsorción ocurre en la interfase sólido - fluido. El soluto adsorbido puede formar una capa sobre la superficie del absorbente de una o varias moléculas de espesor (Gusler G.M., 1993; Treybal R.E., 1980; Coulson J.M. et al., 1988; McCabe W.L. et al., 1991). Los adsorbentes con carácter poroso, como las resinas sintéticas, producen adsorciones más complejas y no únicamente superficiales sino también de llenado de los poros con la fase fluida (Gusler G.M. et al., 1993).

Según la naturaleza de la interacción entre ambas fases se puede distinguir entre dos tipos de adsorción:

- $\quad$ Adsorción física, se da cuando la superficie es relativamente inerte. Las moléculas de adsorbato se fijan físicamente a las moléculas de adsorbente debido a diferencias de energía y/o a fuerzas atractivas eléctricas débiles de tipo Van der Waals. Este tipo de adsorción se caracteriza por la formación de capas moleculares superpuestas, siendo el número de capas proporcional a la concentración de soluto en la fase fluida (Camporro A., 1991). Por lo general, suelen ser procesos muy rápidos, excepto cuando el adsorbente presenta poros muy pequeños.

- Adsorción química o quimisorción, se produce una verdadera reacción o enlace químico entre las moléculas de adsorbente y adsorbato (Grant M.T. et al., 1990). Al contrario de lo que ocurre con la adsorción física, la quimisorción es específica, teniendo lugar solamente en determinadas zonas que se denominan centros activos formándose, en consecuencia, una única capa de moléculas adsorbidas. Los calores de adsorción son del mismo orden de magnitud que los de reacción química.

En la práctica existen muchos casos de adsorción intermedia que no pueden ser incluidos en ninguno de los dos tipos anteriores (Ruthven D.M., 1984).

La adsorción puede ser reversible si las fuerzas atractivas entre el adsorbato y el adsorbente son débiles, como ocurre en el caso de la adsorción física. Esta propiedad puede ser muy importante en la práctica, ya que permite la recuperación del soluto y la 
purificación y reutilización del adsorbente. La quimisorción, sin embargo, en muchos casos es irreversible (Cheremisnoff P.N. et al., 1978; Hasanain M.A. et al., 1981).

Entre las características que diferencian los dos tipos de adsorción se encuentran:

- El calor de adsorción, es bajo para la adsorción física, próximo a los calores de licuefacción $(2-6 \mathrm{Kcal} / \mathrm{mol})$, mientras que para la quimisorción alcanzan valores altos $(>15 \mathrm{Kcal} / \mathrm{mol})$ del orden de las reacciones químicas.

- Velocidad de adsorción, es instantánea para la adsorción física, mientras que la quimisorción puede ser lenta, requiriendo una energía de activación, como ocurre en una reacción química.

- Temperatura, la adsorción física va bien a temperaturas bajas o presiones relativamente altas, próximas al punto de ebullición del adsorbible. La quimisorción suele tener lugar a temperaturas más altas y puede actuar bien a P/Po muy bajas.

- Especificidad, la adsorción física no es específica, la capa de adsorbato puede asimilarse a una película de líquido, con varias capas moleculares de espesor. Por el contrario, la quimisorción es específica, se da sólo en sistemas adsorbato/adsorbentes concretos, tiene lugar en centros concretos de la superficie, por lo que sólo puede formarse una monocapa.

\subsubsection{Factores que influyen en la adsorción}

En todo proceso de adsorción influyen numerosos factores, entre ellos se encuentran:

- Características físicas y químicas del adsorbente: superficie específica, tamaño de poro, distribución de tamaños de poro, tamaño de las partículas, distribución de tamaños de partícula, composición química, etc. Todos estos factores físicos y químicos del adsorbente pueden influir drásticamente en la velocidad y capacidad de adsorción.

- Características físicas y químicas del adsorbato: peso molecular, polaridad, solubilidad, composición química, etc. Por lo general, el aumento del peso molecular disminuye la posibilidad de acceso del adsorbato al interior de la estructura porosa del adsorbente disminuyendo el grado de adsorción.

- Los estereoisómeros no muestran regla fija en cuanto a su diferente capacidad de adsorción, mientras que los isómeros ópticos presentan idénticas características. Los compuestos anfóteros que tienen la capacidad de actuar como ácido o bases presentan con resinas apolares una adsorción máxima en el punto isoeléctrico o cuando su carga neta es cero, esto concuerda con la adsorción máxima de las especies neutras. 
- La solubilidad del soluto en el disolvente es un factor determinante del grado de adsorción y generalmente se puede considerar inversamente proporcional a la solubilidad del adsorbato en el adsorbente. Por tanto, cuanto mayor sea la solubilidad del soluto en el disolvente, menor es el grado de adsorción.

- La concentración del adsorbato en la fase fluida y la interacción entre solutos presentes en la fase fluida pueden aumentar la adsorción, actuar como especies relativamente independientes 0 interferirse mutuamente. Generalmente, los diferentes adsorbatos compiten por los mismos lugares de la superficie, por lo que el grado de adsorción de un soluto disminuye en presencia de otros. Sin embargo, es necesario el estudio de cada sistema en concreto, ya que a veces se aumenta la adsorción de un soluto en presencia de otros.

- La naturaleza y características del disolvente: naturaleza química, tensión superficial, $\mathrm{pH}$, temperatura, etc.

- Generalmente, los procesos de adsorción suelen ser exotérmicos, por lo que el grado de adsorción suele aumentar al disminuir la temperatura.

- El tiempo de residencia del sistema.

El rendimiento de adsorción en una aplicación dada depende de cuatro factores principales:

- La capacidad máxima de adsorción del soluto por el adsorbente.

- El equilibrio entre fases.

- La velocidad efectiva de adsorción.

- El tipo de proceso elegido.

\subsubsection{Principales adsorbentes sólidos.}

Los adsorbentes sólidos por lo general se utilizan de forma granular, son materiales naturales o sintéticos de estructura microcristalina, caracterizados por su elevada superficie interna por unidad de peso, accesible a una combinación selectiva de compuestos, y por su elevada porosidad, por lo que la caracterización física es generalmente más importante que la química (Parrish J.R., 1977). Mediante técnicas estandarizadas se determina el volumen de poros, la distribución de tamaños de poros y el área superficial (Parrish J.R., 1977; Browne T.E. et al., 1993). Desde un punto de vista práctico, se consideran otras propiedades como densidad, hidrofobicidad, resistencia a la abrasión, etc. 
Los principales adsorbentes de uso general se enumeran esquemáticamente a continuación:

- Tierras de Fuller. Son arcillas naturales, principalmente son silicatos de aluminio y magnesio. Se utilizan para decolorar, neutralizar y secar aceites vegetales y animales, lo mismo que productos del petróleo como aceites lubricantes, querosenos y gasolinas.

- $\quad$ Arcillas activadas. Se activan por tratamiento químico con ácido sulfúrico o ácido clorhídrico. Se utilizan en la decoloración de productos del petróleo.

- Bauxita. Es una forma de alúmina hidratada natural que debe activarse por tratamiento térmico. Es utilizada en el secado de gases y para decolorar productos del petróleo.

- Alúmina activada. Es un óxido de aluminio hidratado que se activa por calentamiento. Su gran afinidad por el agua permite una importante aplicación industrial en el secado de gases y líquidos y en la eliminación de $\mathrm{HCl}$ del hidrógeno.

- Silica gel. Es una sílice amorfa sintética que como la alúmina activada se emplea en el secado de gases, refrigerantes, disolventes orgánicos, fraccionamiento de hidrocarburos, etc.

- Zeolitas. Son aluminosilicatos metálicos altamente porosos y cristalinos aplicables sobre todo a la separación de gases.

- Resinas sintéticas. Son perlas esféricas porosas compuestas por microesferas. Fabricadas a partir de compuestos aromáticos insaturados como estireno o divinilbenceno. Son útiles para la adsorción de orgánicos no polares a partir de disoluciones acuosas. Comienzan a ser utilizadas a escala industrial. Se emplean en la purificación de agua, incluyendo la eliminación de fenol, cetonas, alcoholes, antibióticos etc. En la recuperación y purificación de esteroides y aminoácidos, en la separación de ácidos grasos de agua y tolueno, etc.

- $\quad$ Carbones activos. El hecho de poseer una superficie no polar o débilmente polar como resultado de grupos funcionales superficiales con oxígeno e impurezas inorgánicas, le confiere al carbón activo ventajas frente a otros adsorbentes. Se utilizan en la separación de líquidos miscibles y sólidos disueltos en líquidos, particularmente a bajas concentraciones. Son útiles para fraccionar compuestos acetilénicos, alcoholes, ácidos orgánicos, cetonas, aldehídos y muchos otros.

- Carbón de hueso. Se obtiene mediante la destilación destructiva de huesos pulverizados y secos a temperaturas de 600 a $900^{\circ} \mathrm{C}$. Se utiliza principalmente en la refinación del azúcar.

La disponibilidad de adsorbentes se ha multiplicado ampliamente en la segunda mitad del siglo XX. Los adsorbentes tradicionales (carbón activo, arcillas, sílice y alúmina) se han extendido a una enorme variedad de materiales carbonosos y de silicoaluminatos sintéticos, consiguiendo aumentar el potencial de la adsorción como técnica de separación.

La preparación de zeolitas sintéticas de tamaño de poro uniforme abrió la posibilidad de efectuar separaciones basadas en la geometría de los canales (esférica o por exclusión) 
y en la cinética de difusión. La mayor parte de las operaciones de separación comerciales por adsorción utilizan estas zeolitas, que podemos llamar convencionales. A partir de la década de los 70 se han desarrollado muchos materiales buscando tamaños de poro mayores, para permitir el acceso a moléculas de mayor tamaño. Así, se han logrado múltiples materiales microporosos, mesoporosos y macroporosos, en general muy costosos de obtener. Esto hace que todavía la mayor parte de las aplicaciones utilicen adsorbentes convencionales (carbones activos y zeolitas clásicas).

El requisito principal para que un proceso de separación sea económicamente rentable es que el adsorbente posea una selectividad, capacidad y vida útil lo suficientemente alta.

En la Ec. (4.1) se define la selectividad del material adsorbente por el soluto A frente a otro B (Ruthven D.M., 1984):

$$
\beta_{\mathrm{AB}}=\frac{\mathrm{X}_{\mathrm{A}} \mathrm{Y}_{\mathrm{B}}}{\mathrm{X}_{\mathrm{B}} \mathrm{Y}_{\mathrm{A}}}
$$

donde $\mathrm{X}$ y $\mathrm{Y}$ son las composiciones de equilibrio del adsorbato en el adsorbente y en la fase fluida respectivamente, expresadas en fracción molar.

\subsubsection{Aplicaciones}

La adsorción se emplea en procesos de secado para la eliminación de trazas de humedad de corrientes gaseosas o líquidas, utilizando columnas rellenas de adsorbente hidrofílico (Cheremisinoff $P$. N. et al., 1978). A gran escala se emplea para la eliminación de impurezas, tales como $\mathrm{H}_{2} \mathrm{~S}$ y mercaptanos del gas natural y contaminantes orgánicos del agua (Ruthven D.M., 1984). Estos procesos se clasifican como procesos de purificación ya que los componentes que adsorbe el sólido poroso están presentes en baja concentración.

La aplicación del proceso de adsorción como técnica de separación en mezclas de dos o más componentes, es reciente. En los años 50 se empleó para la recuperación de hidrocarburos, en los años 60 para la separación de parafinas lineales de isómeros ramificados y cíclicos, y en los años 70 , en sustitución de la destilación. Sin embargo, para que un proceso de adsorción se pueda desarrollar a escala industrial, se requiere la disponibilidad de grandes cantidades de adsorbente de coste no elevado (Ruthven D.M., 1984).

El diseño y aplicación de la adsorción a escala industrial abarca múltiples aspectos entre los que pueden señalarse:

1. Elección y diseño del adsorbente.

2. Elección y diseño del equipo para llevar a cabo la operación. Los más utilizados son: tanques agitados, lechos fijos o fluidizados, lechos móviles y lechos móviles simulados. Además de la etapa de adsorción, es preciso considerar la regeneración del adsorbente para su posterior reutilización y la recuperación de los solutos adsorbidos. 
En la actualidad, la adsorción se aplica para separar selectivamente componentes o impurezas de mezclas líquidas o gaseosas. A continuación, se citan las aplicaciones industriales más frecuentes:

- Separación de gases de mezclas gaseosas: se emplea en la eliminación de gases tóxicos.

- Separación de vapores de gases: se emplea en la recuperación de disolventes, en el secado de gases y en la deshumidificación del aire.

- Separación de solutos en disolución: se utiliza en la decoloración y clarificación de líquidos, de gran importancia en el tratamiento de vinos, vinagre, cervezas, aceites, etc.

- Fraccionamiento de mezclas de gases, de vapores, de sólidos disueltos o de líquidos: se suelen utilizar tamices moleculares por su alta selectividad. Una aplicación es la separación de parafinas lineales de queroseno, nafta y gasoil.

- Separación de iones de disoluciones: se emplea en la concentración de metales, en la eliminación de compuestos inorgánicos, en la recuperación de residuos, en la desmineralización y ablandamiento de aguas.

- Separación de gases disueltos o sólidos suspendidos en líquidos: se emplea en el tratamiento de aguas residuales y potables para la eliminación de olor y sabor.

- Catálisis química: debido a la gran superficie específica que presentan los adsorbentes, pueden actuar como soporte de catalizadores impregnados o sin impregnar.

- Purificación de productos químicos y farmacéuticos: mejora la calidad del producto y disminuye el coste de fabricación. Se emplea en la obtención del ácido cítrico, ácido fosfórico, ácido glutámico, ácido láctico, cafeína, estreptomicina, glicerina, etc.

En base a lo expuesto, en todos los procesos industriales de adsorción hay que considerar: las propiedades y estructura del adsorbente, la interacción adsorbenteadsorbato (equilibrio de adsorción), las propiedades cinéticas en los lechos de partículas y en el interior de las partículas, los sistemas de contacto entre adsorbente y adsorbible y los modos de desorción o regeneración del adsorbente, para obtener procesos económicamente rentables a nivel industrial y de alta efectividad.

\subsubsection{Caracteristicas de las resinas macroporosas XAD}

Son polímeros sintéticos macroporosos. Están formadas por una matriz polimérica aromática o alifática, diferenciándose de las resinas de intercambio iónico por la ausencia de grupos funcionales iónicos. La preparación de éstas resinas se realiza mediante polimerización de un monómero en suspensión (estireno o mezclas estirenodivinilbenzeno) y un agente reticulante en presencia de un disolvente y determinados catalizadores de la reacción. Se consiguen así partículas bastante homogéneas, con una 
elevada área superficial. Las características superficiales y la distribución de tamaños de poro son controlables durante el proceso de fabricación (Maity N. et al., 1991).

Por tanto, cada partícula de adsorbente polimérico XAD está formada por un conjunto de microesferas (idealmente esféricas) que pueden ser porosas o no, según el tipo de resina, y entre las microesferas aparecen unos macroporos intracristalinos tal como se indica en la Figura 3.

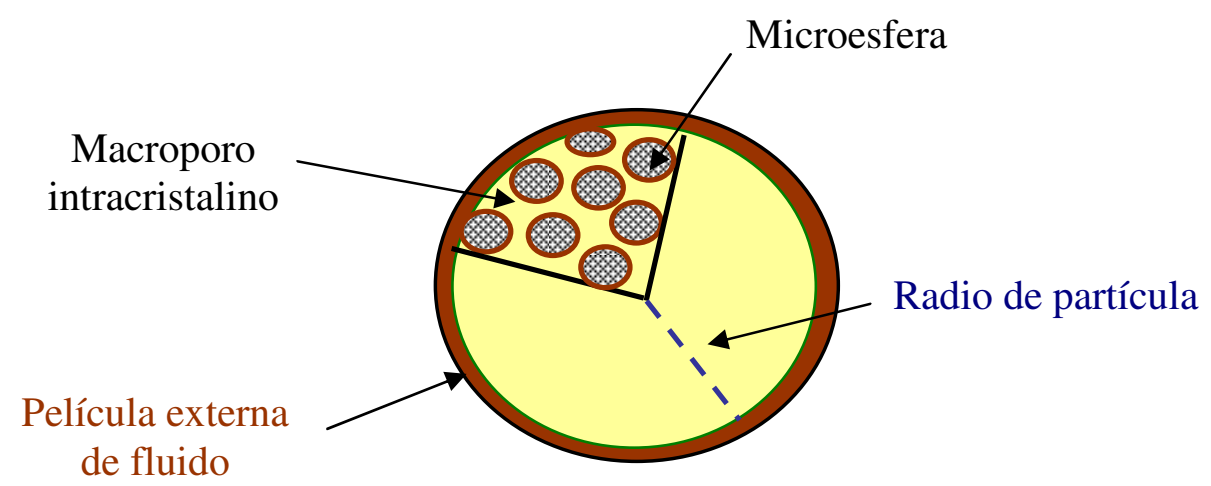

Figura 3: $\quad$ Esquema de una partícula de Amberita XAD.

Así, la superficie del sólido, el microporo de la microesfera y el macroporo de la partícula ofrecen resistencias específicas a la transferencia de materia. Estas resistencias pueden variar ampliamente y su importancia relativa en el proceso de adsorción debe evaluarse en cada caso en concreto, ya que dependen del sistema disolución - adsorbato y de las condiciones de operación (Ruthven D.M., 1984).

Las principales características de los adsorbentes poliméricos macroporosos son:

- Facilidad de regeneración mediante disolventes apropiados, recuperables posteriormente.

- No se producen adsorciones irreversibles.

- Elevada porosidad.

- Presentan una amplia variedad de polaridades, según el tipo, lo que implica una mayor selectividad en sus aplicaciones.

- Buena homogeneidad de su superficie adsorbente.

- Presentan excelentes características hidráulicas en sistemas de flujo ascendente y descendente convencionales.

- Operan en un amplio intervalo de pH de (1-14) debido a que son adsorbentes totalmente orgánicos con propiedades físicas y químicas estables.

- Gran estabilidad térmica, pudiendo utilizarse incluso a temperaturas de $250 \stackrel{\circ}{ } \mathrm{C}$. 
Entre sus características estructurales destacan su elevada superficie específica, que oscila entre 100 y $800 \mathrm{~m}^{2} / \mathrm{g}$, con diámetros de poro entre 5 y $50 \mathrm{~nm}$ y con distribuciones de los mismos mucho más estrechas que en el caso de los carbones activos. Estos dos parámetros, superficie específica y dimensiones de poro, afectan significativamente a la capacidad de adsorción de las resinas XAD. En adsorciones con adsorbentes de igual tamaño de poro, la capacidad de adsorción aumenta con la superficie específica de la partícula.

Las resinas Amberlita XAD se utilizan en la adsorción de solutos orgánicos de disoluciones acuosas o de disolventes polares. Se emplean en la recuperación de ácidos carboxílicos de disoluciones acuosas diluidas, presentando una disminución de la capacidad de adsorción con el aumento de la hidrofilidad del ácido, por ejemplo el ácido cítrico es adsorbido únicamente a altas concentraciones (Juang R.S. et al., 1995 a). Las resinas Amberlita XAD-2 y XAD-16 se emplean en la eliminación de detergentes de soluciones proteicas y la resina Amberlita XAD-16 en los procesos de separación de cefalosporina-C, antibiótico comúnmente utilizado en la industria farmacéutica. Las resinas Amberlita XAD-4 y XAD-2 se emplean en procesos de depuración de aguas (Gusler G.M. et al., 1993; Hasanain M.A. et al., 1981) y para la separación y concentración de aminoácidos de disoluciones acuosas, observándose un aumento de la capacidad de adsorción de la resina al aumentar la hidrofobicidad de la cadena hidrocarbonada del aminoácido (o la disminución de la hidrofilidad de la parte hidrofílica del aminoácido). Los procesos de adsorción de aminoácidos con estas resinas, se ven afectados por el $\mathrm{pH}$, por la temperatura y por la presencia de otros aminoácidos en solución (Doulia D. et al., 2001).

La clasificación comercial específica muestra que la resina Amberlita XAD-2 proporciona elevadas capacidades de extracción para compuestos altamente hidrofóbicos. Para adsorciones de solutos de bajo peso molecular se aconseja el uso de la resina tipo XAD4, para solutos de peso molecular medio la resina tipo XAD-16 y para solutos orgánicos de alto peso molecular la resina XAD-1180. La única resina Amberlita XAD moderadamente polar es la XAD-7 empleada para la recuperación de compuestos noaromáticos de disolventes polares.

Su empleo como materiales adsorbentes, aunque es más reducido que el de los carbones activos, es cada vez mayor a escala industrial.

El principal inconveniente de estos adsorbentes sintéticos es su elevado precio, unas cinco veces superior que el carbón activo. Sin embargo, la clave de que puedan competir en determinadas aplicaciones reside en la facilidad de regeneración que presentan, evitándose el gran consumo energético y la pérdida de material que supone el mismo proceso con carbón activo.

\subsubsection{Equilibrios: isotermas de adsorción}

El fenómeno de adsorción se produce como consecuencia de la transferencia de materia desde la fase fluida hacia la superficie externa del adsorbente, donde las moléculas de adsorbato se distribuyen hasta que se alcanza el estado de equilibrio, esto es, cuando no se produce más acumulación de adsorbato sobre la superficie del adsorbente. La distribución del adsorbato entre ambas fases en condiciones de equilibrio representa el equilibrio de adsorción, que depende de la concentración del soluto en la fase fluida, de la 
concentración y naturaleza de los solutos competidores, de la naturaleza del disolvente y del adsorbente, del $\mathrm{pH}$ y de la temperatura del proceso.

A diferencia de lo que ocurre con la adsorción en fase sólido-gas, los fundamentos teóricos en fase sólido-líquido son más limitados, debido a las interacciones en las que interviene el disolvente. Es interesante destacar que cuando un adsorbente sólido se pone en contacto con una disolución que contiene el disolvente y el adsorbato tiene lugar la adsorción de ambos componentes. No es posible medir la adsorción total ya que no se puede distinguir entre la fracción ocluida en los poros y la fracción adsorbida, pero se puede determinar la adsorción relativa o aparente del soluto (Treybal R. E., 1980).

Se define Isoterma de adsorción como la relación de equilibrio entre la concentración en la fase fluida y la concentración en las partículas de adsorbente a una presión y temperatura constante. Estos datos de equilibrio que forman la isoterma de adsorción se pueden ajustar a una ecuación matemática sencilla, característica de cada sistema, y que se muestra a continuación:

$$
q=f\left(C_{A}\right)
$$

donde se relaciona la concentración de soluto en el sólido y en el fluido en el equilibrio, mediante una función, $\mathrm{f}$, más o menos compleja.

Desde el punto de vista práctico, los datos que componen una isoterma de equilibrio se obtienen fácilmente poniendo en contacto el líquido, de concentración conocida en el soluto A, con una cantidad determinada de sólido, a temperatura y presión constante. Transcurrido el tiempo suficiente para alcanzar el equilibrio, se mide la concentración de soluto en el fluido, $\mathrm{C}_{\mathrm{A}}$, y mediante un balance de materia se calcula la cantidad retenida por el sólido, q, expresada como cantidad de soluto A adsorbido por unidad de peso de adsorbente. La isoterma queda definida por la representación gráfica o analítica de los puntos obtenidos $\left(\mathrm{C}_{\mathrm{A} 1}, \mathrm{q}_{1}\right)$.

Existen diversas clasificaciones de las isotermas de equilibrio atendiendo a la forma del tramo inicial y del tramo final de las curvas. La forma de la isoterma de adsorción aporta información sobre el mecanismo de la adsorción.

La clasificación de las isotermas de equilibrio con las formas más usuales, se simplifica dividiéndose en los cinco tipos siguientes que se representan en la Figura 4 (Treybal R.E., 1980; McCabe W.L. et al., 1991; Coulson J.M. et al., 1993; Ruthven D.M., 1984):

- Isoterma de equilibrio lineal. Se caracteriza por presentar una relación constante entre la concentración en la fase adsorbida y líquida, hasta alcanzar un máximo a partir del cual se transforma en una línea horizontal. Las condiciones que favorecen este tipo de isotermas son: un adsorbente poroso, con moléculas deformables y zonas con diferente grado de cristalización, y un adsorbato con mayor afinidad por el adsorbente que por el disolvente y que difunde más rápidamente hacia el interior del sólido que dicho disolvente. La linealidad indica que el número de centros activos de la superficie permanece constante, es decir, se crean centros a medida que se va adsorbiendo soluto. Se debe de cumplir que la derivada segunda de la función $\mathrm{f}\left(\mathrm{C}_{\mathrm{A}}\right)$, definida en la Ec. (4.2), es nula.

- Isoterma de equilibrio favorable. El adsorbente presenta una elevada capacidad de adsorción incluso a bajas concentraciones de soluto en la fase líquida. La curva es convexa hacia arriba como se muestra en la Figura 4. Su forma indica 
que la adsorción se dificulta al aumentar la concentración de soluto en la fase líquida como consecuencia de la disminución de centros activos disponibles en la superficie del sólido. Esto implica una orientación horizontal de las moléculas adsorbidas, o bien, una competencia pequeña con el disolvente. Se debe de cumplir que la derivada segunda de la función $f\left(C_{A}\right)$, definida en la Ec. (4.2), es menor de cero.

- Isoterma de equilibrio desfavorable. El adsorbente presenta una pequeña capacidad de adsorción a bajas concentraciones de soluto en la fase líquida. La curva es cóncava hacia arriba como se muestra en la Figura 4. Su forma indica que la adsorción se facilita a medida que aumenta la concentración de soluto en la fase líquida. Se debe de cumplir que la derivada segunda de la función $f\left(C_{A}\right)$, definida en la Ec. (4.2), es mayor de cero.

- Isoterma de equilibrio con punto de inflexión. El adsorbente presenta dos zonas de adsorción bien diferenciadas. La curva es convexa hasta que se alcanza una determinada concentración de soluto en la fase líquida a partir de la cual la curva se transforma en cóncava como se muestra en la Figura 4. El adsorbente presenta un comportamiento similar al de la isoterma favorable hasta el punto de inflexión y superado este el comportamiento es similar al de la isoterma desfavorable.

- Isoterma de equilibrio irreversible. La capacidad de adsorción no varía con la concentración. Así, en todo el intervalo de concentración en la fase fluida, $\mathrm{C}_{\mathrm{A}}$, la concentración en la fase sólida es igual a la capacidad máxima de adsorción del sólido expresada por $Q_{S}\left(q=Q_{S}\right)$.

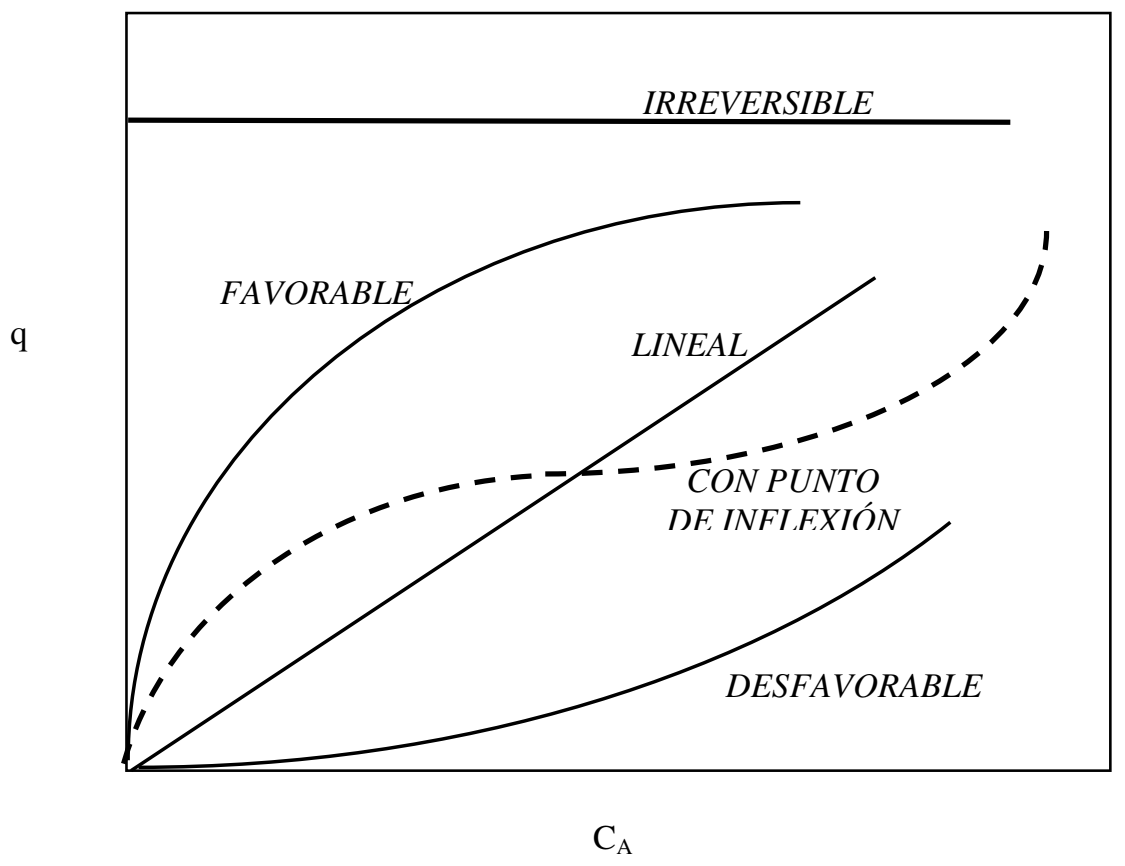

Figura 4: Isotermas de adsorción 


\subsubsection{Modelos matemáticos.}

Existen un gran número de modelos termodinámicos encaminados a representar el equilibrio de adsorción. Generalmente, estos modelos o ecuaciones desarrolladas teóricamente tales como isoterma de Langmuir, Freundlich o la isoterma de BET, se ajustan a alguno de los tipos de isotermas mostrados en la Figura 4.

Las ecuaciones más utilizadas para ajustar las isotermas de adsorción son las siguientes (Treybal R.E., 1980; Coulson J.M. et al., 1988; McCabe W.L. et al., 1991; Perry R.H., 1984):

- Isoterma de Langmuir. Definida en 1918 por Langmuir para adsorción en monocapa en superficies homogéneas, supone que las moléculas adsorbidas se mantienen en lugares localizados, siendo la energía de adsorción constante y sin existir interacción entre los adsorbatos vecinos.

$$
\mathrm{q}=\mathrm{Q}_{\mathrm{S}} \frac{\mathrm{KC}_{\mathrm{A}}}{1+\mathrm{KC}_{\mathrm{A}}}
$$

donde $q$ y $\mathrm{C}_{\mathrm{A}}$ son las concentraciones de soluto en el equilibrio en el sólido y en la disolución respectivamente, $Q_{S}$ es la capacidad máxima de adsorción del sólido y $\mathrm{K}$ es una constante característica del sistema y de las condiciones de equilibrio.

- Isoterma de Freundlich. Es una ecuación empírica que tiene en cuenta la heterogeneidad de la superficie. Supone que la energía de adsorción varía de forma exponencial con el recubrimiento y que existen fuerzas de interacción entre las moléculas de adsorbato.

$$
\mathrm{q}=\mathrm{k} \mathrm{C} \mathrm{C}_{\mathrm{A}}^{\mathrm{n}}
$$

donde $\mathrm{q}$ y $\mathrm{C}_{\mathrm{A}}$ son las concentraciones de soluto en el equilibrio en el sólido y en la disolución respectivamente y $\mathrm{k}$ y $\mathrm{n}$ son las constantes características del sistema y de las condiciones de equilibrio.

- Isoterma de B.E.T. Desarrollada por Brunauer, Emmet y Teller para generalizar el tratamiento de Langmuir y tener en cuenta la posibilidad de adsorción en multicapa. Se emplea principalmente en adsorción gas-sólido y es uno de los métodos más utilizados para el cálculo de superficies específicas de adsorbente. Esta ecuación describe también la isoterma con punto de inflexión mostrada en la Figura 4. Su expresión matemática es la siguiente:

$$
y=\frac{x(1-a)(1-a+k a)}{(1-a x)(1-a x+k a x)}
$$

Esta ecuación está expresada en términos de concentraciones adimensionales,

$$
\mathrm{y}=\frac{\mathrm{q}_{\mathrm{A}}}{\mathrm{q}_{\mathrm{Ai}}}
$$




$$
\begin{aligned}
& x=\frac{C_{A}}{C_{A i}} \\
& a=\frac{C_{A i}}{C_{s}}
\end{aligned}
$$

donde $C_{A}$ y $q_{A}$ son la concentración de soluto en la fase fluida y sólida en el equilibrio, respectivamente, $\mathrm{C}_{\mathrm{Ai}}$ es la concentración del soluto inicial en la fase fluida, $\mathrm{q}_{\mathrm{Ai}}$ es la concentración de la fase sólida en equilibrio con $\mathrm{C}_{\mathrm{Ai}}$ y $\mathrm{C}_{\mathrm{s}}$ la concentración máxima de soluto en el fluido (solubilidad).

\subsubsection{Cinéticas de adsorción en baños}

La velocidad en los procesos de adsorción depende de la concentración de soluto, $\left(\mathrm{C}_{\mathrm{A}}\right)$; del recubrimiento superficial; de las características de la superficie (tamaño de partícula, distribución de tamaño de poros, porosidad, etc...); de la temperatura (Ec. de Arrhenius $\mathrm{k}=\mathrm{A} \exp (-\mathrm{E} / \mathrm{RT}))$, etc. En el caso de adsorbentes porosos, la velocidad efectiva de adsorción está determinada por el mecanismo de transporte que actúa en varias etapas consecutivas (Perry R.H., 1984; Ruthven, D.M., 1984):

I. Transferencia de materia desde el seno de la fase fluida hasta la superficie externa de las partículas de adsorbente (difusión de película).

II. Transferencia de materia por el interior de las partículas de adsorbente (difusión intrapartícula: poro y superficie).

III. La etapa de adsorción propiamente dicha.

Debido a la naturaleza porosa del adsorbente, el transporte hacia el interior de las partículas (intrapartícula) es tratado generalmente como un proceso de difusión en el poro y en la superficie del mismo (Do D. D. et al., 1987; Do D. D. et al., 1991; Komiyama H. et al., 1974 a-b; Liapis A. I. et al., 1977; Ma Z. et al., 1996; Robinson S. M. et al., 1994; Ruthven D. M., 1984; Yoshida H. et al., 1985; Yoshida H.et al, 1984; Yoshida H. et al., 1994; Yang S. A. et al., 1999):

- Difusión en el poro. Difusión a través del fluido que llena los poros de las partículas.

- Difusión en la superficie. Migración de las moléculas previamente adsorbidas, a lo largo de las paredes del poro sin producirse una desorción completa.

La diferencia esencial entre las etapas de difusión de poro y difusión superficial es que están separadas por la etapa de adsorción propiamente dicha y por tanto ocurren en fases diferentes. 
En el caso de adsorción física, la velocidad de la etapa de adsorción es muy rápida comparada con las etapas de transferencia de materia siendo estas etapas las que controlan el proceso. Las ecuaciones que se definen a continuación son aplicables al caso de la adsorción de un soluto en partículas esféricas de adsorbente de tamaño uniforme.

La contribución de la etapa de transferencia de materia desde el seno de la fase fluida hasta la superficie externa de las partículas de adsorbente depende del tipo de equipo seleccionado y de las condiciones de proceso. En general, se define una ecuación de velocidad caracterizada por un coeficiente global de transferencia de materia, $\mathrm{k}_{\mathrm{f}}$, que depende de las características del sistema:

$$
\mathrm{N}_{\mathrm{A}}=\mathrm{k}_{\mathrm{f}}\left(\mathrm{C}_{\mathrm{A}}-\mathrm{C}_{\mathrm{A}}^{*}\right)
$$

siendo $N_{A}$ la densidad de flujo de adsorbato $A$ desde el seno de la disolución a la superficie del sólido a través de la capa límite de fluido que rodea las partículas, $C_{A}$ la concentración de adsorbato en el seno de la disolución y $\mathrm{C}_{\mathrm{A}}{ }^{*}$ la concentración de adsorbato en la disolución en equilibrio con el sólido.

Las densidades de flujo de adsorbato debidas a la difusión de poro y a la difusión superficial, $J_{A p}$ y $J_{A s}$, se caracterizan por los coeficientes de difusión $D_{p}$ y $D_{s}$. Considerando a las partículas como esferas porosas, las densidades de flujo difusivo en el poro y en la superficie del poro en coordenadas esféricas quedan expresadas, para disoluciones diluídas mediante la primera ley de Fick (Barre R.M., 1987; Do D.D. et al., 1991):

$$
\begin{aligned}
& J_{A p}=-\varepsilon_{p} D_{p} \frac{d C_{A p}}{d r} \\
& J_{A s}=-\left(1-\varepsilon_{p}\right) D_{s} \frac{d q_{A}}{d r}
\end{aligned}
$$

donde $C_{A p}$ y $q_{A}$ son las concentraciones del adsorbato $A$ en la fase líquida que rellena los poros y en la superficie de los poros, respectivamente, $\varepsilon_{p}$ es la porosidad de la partícula y $r$ es la coordenada radial.

Los valores de los coeficientes de difusión son diferentes a los observados en difusión molecular libre, debido al menor volumen de los poros y a la tortuosidad de los mismos. (Ruthven D.M., 1984, Camporro A., 1991).

El análisis de la etapa de difusión macroporosa en sistemas binarios o multicomponentes no presenta problemas, debido a que las propiedades de transporte de uno de los componentes no se ven afectadas directamente por los cambios de concentración de los otros componentes. En el caso del análisis de la etapa de adsorción es más complejo, debido a posibles cambios en la movilidad, en el gradiente de potencial químico de cada componente, etc. (Ruthven D.M., 1984).

Para describir el proceso de adsorción de un sistema dado se supone que una o varias de las etapas descritas anteriormente son etapas controlantes del proceso de 
transferencia de materia. Se pueden hacer múltiples combinaciones de los mecanismos básicos de transporte, de modo que a cada una le corresponde un modelo. El desarrollo matemático de estos modelos considera balances de materia, relaciones de equilibrio, ecuaciones cinéticas y condiciones límite. (Do D. D. et al., 1987; Do D. D. et al., 1991; Komiyama H. et al., 1974 a-b; Liapis A. I. et al., 1977; Ma Z. et al., 1996; Robinson S. M. et al., 1994; Ruthven D. M., 1984; Yoshida H. et al., 1984; Yoshida H. et al., 1985; Yoshida H. et al., 1994;: Yang S. A. et al., 1999)

Los modelos matemáticos más utilizados aplicados a partículas esféricas de adsorbentes parten de las siguientes suposiciones:

- La velocidad neta de adsorción en la superficie externa de la partícula, es más rápida que la difusión en el poro y en la superficie del poro,

- Se alcanza el equilibrio local de forma instantánea de tal forma que las concentraciones de adsorbato en el líquido que llena los poros y la adsorbida en la superficie de los mismos están en equilibrio y por tanto relacionadas por la isoterma de equilibrio $q_{A}=f\left(C_{A}\right)$,

- La concentración de adsorbato en el adsorbente es función de la coordenada radial y del tiempo

\subsubsection{Modelo homogéneo.}

La fase sólida se considera un medio homogéneo e isotrópico. Las moléculas de adsorbato se adsorben en la superficie externa de la partícula y difunden hacia el interior de la misma. No tiene en cuenta la estructura de la partícula. El balance de materia al soluto en estado no estacionario aplicado a la macropartícula esférica conduce a la ley de Fick expresada en coordenadas esféricas mediante la siguiente ecuación (Costa C. et al., 1985 a):

$$
\frac{\partial \mathrm{q}_{\mathrm{A}}}{\partial \mathrm{t}}=\frac{1}{\mathrm{r}^{2}} \frac{\partial}{\partial \mathrm{r}}\left(\mathrm{r}^{2} \mathrm{D}_{\mathrm{e}} \frac{\partial \mathrm{q}_{\mathrm{A}}}{\partial \mathrm{r}}\right)
$$

Si la difusividad es constante la Ec. (4.12) se transforma en la siguiente expresión:

$$
\frac{\partial \mathrm{q}_{\mathrm{A}}}{\partial \mathrm{t}}=\mathrm{D}_{\mathrm{e}}\left(\frac{\partial^{2} \mathrm{q}_{\mathrm{A}}}{\partial \mathrm{r}^{2}}+\frac{2}{\mathrm{r}} \frac{\partial \mathrm{q}_{\mathrm{A}}}{\partial \mathrm{r}}\right)
$$

donde $D_{e}$ es la difusividad efectiva del soluto $A$ dentro de la partícula, $r$ es la posición radial en la partícula, $t$ el tiempo y $q_{A}$ la concentración de soluto en la fase resina a tiempo t.

Considerando las siguientes condiciones límites e inicial:

i) La partícula está inicialmente libre de adsorbato:

$$
\mathrm{q}_{\mathrm{A}}=0 \quad \mathrm{t}=0
$$


ii) En el centro de la partícula:

$$
\frac{\partial \mathrm{q}_{\mathrm{A}}}{\partial \mathrm{r}}=0 \quad \mathrm{r}=0 \quad \mathrm{t}>0
$$

iii) En la superficie de la partícula se alcanza el equilibrio:

$$
q_{A}=f\left(C_{A}\right) \quad r=a \quad t>0
$$

donde $C_{A}$ es la concentración de soluto en el seno de la fase fluida en equilibrio con $q_{A}$ en función del tiempo y 'a' es el radio de la partícula de adsorbente. Esta condición límite supone despreciable la resistencia a la transferencia de materia en la película líquida externa.

La función $f\left(\mathrm{C}_{\mathrm{A}}\right)$ debe ser conocida en cada caso con el estudio previo del equilibrio de adsorción.

Resolviendo conjuntamente las Ecs. (4.13)-(4.16) se puede obtener el valor del coeficiente de difusión efectiva $D_{e}$.

\subsubsection{Modelo heterogéneo.}

Considera independientemente la fase fluida que llena los poros y la adsorbida en la superficie de los mismos. Se subdivide en las siguientes categorias:

- Modelo de difusión en los poros. El balance de materia al soluto, considerando la difusión en el poro como etapa controlante del transporte de materia, proporciona la siguiente ecuación en coordenadas esféricas (Costa C. et al., 1985 a; Komiyama H. et al., 1974 a; Liapis A. I. et al., 1977; Yang S. A. et al., 1999):

$$
\varepsilon_{\mathrm{p}} \frac{\partial \mathrm{C}_{\mathrm{Ap}}}{\partial \mathrm{t}}+\left(1-\varepsilon_{\mathrm{p}}\right) \frac{\partial \mathrm{q}_{\mathrm{A}}}{\partial \mathrm{t}}=\varepsilon_{\mathrm{p}} \mathrm{D}_{\mathrm{p}}\left(\frac{\partial^{2} \mathrm{C}_{\mathrm{Ap}}}{\partial \mathrm{r}^{2}}+\frac{2}{\mathrm{r}} \frac{\partial \mathrm{C}_{\mathrm{Ap}}}{\partial \mathrm{r}}\right)
$$

donde $D_{p}$ es el coeficiente de difusión del soluto en el poro, $\varepsilon_{p}$ la porosidad de la partícula de adsorbente, $\mathrm{q}_{\mathrm{A}}$ es la concentración de adsorbato adsorbida en el sólido y $\mathrm{C}_{\mathrm{Ap}}$ la concentración de adsorbato en el fluido que llena los poros.

Resolviendo conjuntamente la Ec. (4.17) con las condiciones limites e inicial mostradas en las Ecs. (4.14)-(4.16) se obtiene el valor del coeficiente de difusión en el poro, $D_{p}$.

- Modelo de difusión superficial. En este caso la etapa controlante de la transferencia de materia es la velocidad de difusión en la superficie de los poros. 
El balance de materia se representa mediante la siguiente ecuación (Komiyama H. et al., 1974 b; Liapis A. I. et al., 1977; Yang S. A. et al., 1999):

$$
\varepsilon_{\mathrm{p}} \frac{\partial \mathrm{C}_{\mathrm{Ap}}}{\partial \mathrm{t}}+\left(1-\varepsilon_{\mathrm{p}}\right) \frac{\partial \mathrm{q}_{\mathrm{A}}}{\partial \mathrm{t}}=\mathrm{D}_{\mathrm{s}}\left(\frac{\partial^{2} \mathrm{q}_{\mathrm{A}}}{\partial \mathrm{r}^{2}}+\frac{2}{\mathrm{r}} \frac{\partial \mathrm{q}_{\mathrm{A}}}{\partial \mathrm{r}}\right)
$$

siendo $D_{s}$ el coeficiente de difusión del soluto $A$ en fase sólida. Esta ecuación es equivalente a la descrita en el caso de modelo homogéneo considerando que la concentración de adsorbato en fase líquida es despreciable respecto a la concentración de soluto adsorbido.

Resolviendo conjuntamente la Ec. (4.18) con las condiciones limites e inicial, Ecs. (4.14)-(4.16), se obtiene el valor del coeficiente de difusión en la superficie, $D_{s}$.

- Modelo de difusión en paralelo. Considera que tanto la difusión en el poro como en la superficie son controlantes del proceso de difusión y ambos flujos difusionales suceden en paralelo. El balance de materia en estado no estacionario conduce a la siguiente ecuación (Costa C. et al., 1985 a; Do D. D. et al., 1987; Do D. D. et al., 1991; Liapis A. I. et al., 1977; Ma Z. et al., 1996; Robinson S. M. et al., 1994; Ruthven D. M., 1984; Yoshida H. et al., 1985; Yoshida H. et al., 1984; Yoshida H. et al., 1994; Yang S. A. et al., 1999):

$$
\varepsilon_{\mathrm{p}} \frac{\partial \mathrm{C}_{\mathrm{Ap}}}{\partial \mathrm{t}}+\left(1-\varepsilon_{\mathrm{p}}\right) \frac{\partial \mathrm{q}_{\mathrm{A}}}{\partial \mathrm{t}}=\varepsilon_{\mathrm{p}} \mathrm{D}_{\mathrm{p}}\left(\frac{\partial^{2} \mathrm{C}_{\mathrm{Ap}}}{\partial \mathrm{r}^{2}}+\frac{2}{\mathrm{r}} \frac{\partial \mathrm{C}_{\mathrm{Ap}}}{\partial \mathrm{r}}\right)+\left(1-\varepsilon_{\mathrm{p}}\right) \mathrm{D}_{\mathrm{s}}\left(\frac{\partial^{2} \mathrm{q}_{\mathrm{A}}}{\partial \mathrm{r}^{2}}+\frac{2}{\mathrm{r}} \frac{\partial \mathrm{q}_{\mathrm{A}}}{\partial \mathrm{r}}\right)
$$

Resolviendo conjuntamente la Ec. (4.19) con las condiciones limites e inicial, Ecs. (4.14)-(4.16), se obtienen los valores de los coeficientes de difusión en el poro, $D_{p}$ y de difusión en la superficie $D_{s}$.

- Modelo de difusión en serie o de biporos. Considera la partícula de adsorbente macroporosa formada por esferas microporosas uniformes. Se considera un coeficiente de difusión superficial en los microporos, $D_{m}$ además de los coeficientes de difusión en el macroporo $\left(D_{p}\right)$ y en la superficie $\left(D_{s}\right)$ (Robinson $S$. M. et al., 1994).

- Modelo de difusión de partícula dual. Se suponen dos zonas diferenciadas de microporos en las partículas adsorbentes. La adsorción en las dos regiones es caracterizada por isotermas distintas. Se definen coeficientes de difusión superficial en ambas zonas, $D_{s 1}$ y $D_{s 2}$ (Camporro A., 1991). 


\subsubsection{Adsorción en lecho fijo}

Es el dispositivo principal instalado a escala industrial. Un lecho fijo o poroso consiste en una torre o columna rellena de material adsorbente. Es un dispositivo semicontinuo en el que se lleva a cabo el proceso de adsorción en régimen no estacionario. Un esquema del mismo se muestra en la Figura 5.

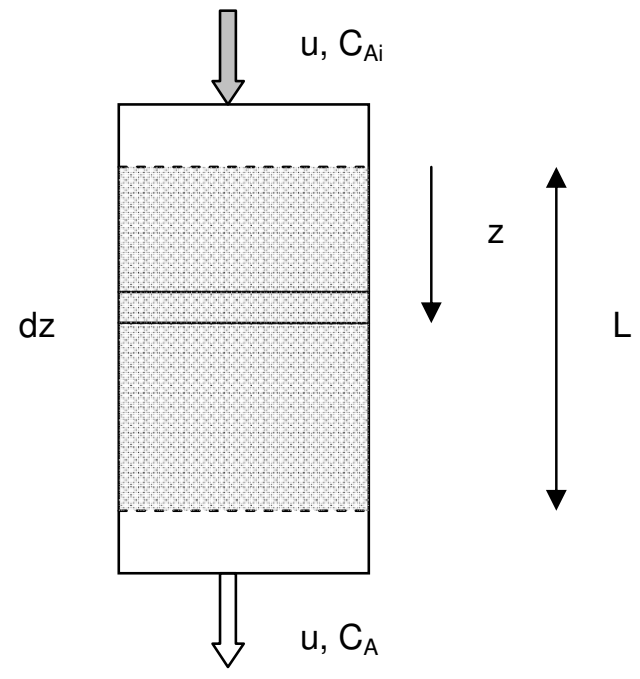

Figura 5: $\quad$ Esquema de un proceso de adsorción en lecho fijo.

La velocidad de adsorción en un lecho fijo cuando una corriente de fluido lo atraviesa con una determinada velocidad, es función de la caída de presión en el lecho y del tiempo de residencia necesario para que se produzca la saturación del lecho.

La adsorción en lecho fijo responde a una curva típica de adsorción dinámica en la que se representa la concentración del adsorbato en fase fluida frente al tiempo como se observa en la Figura 6-a.

Al principio, el adsorbato es extraído totalmente a lo largo de una longitud finita de columna de adsorbente (inicialmente libre de soluto) llamada zona de adsorción o de transferencia de materia, donde la concentración de adsorbato en fase fluida disminuye notablemente obteniéndose un efluente prácticamente libre de soluto. Posteriormente, cuando se llega a una determinada concentración en el adsorbente, la concentración de adsorbato en el efluente comienza a aumentar, alcanzándose el llamado punto de ruptura. A partir de este instante la concentración de soluto en el efluente aumenta con rapidez hasta que alcanza una concentración muy próxima a la de la alimentación, esta zona corresponde a la curva de inflexión. Por último la concentración de adsorbato se iguala a la existente en la corriente de entrada (punto S) alcanzándose la saturación del lecho ya que se supone que el lecho está en equilibrio con la disolución de alimentación (Treybal R. E., 1980). 


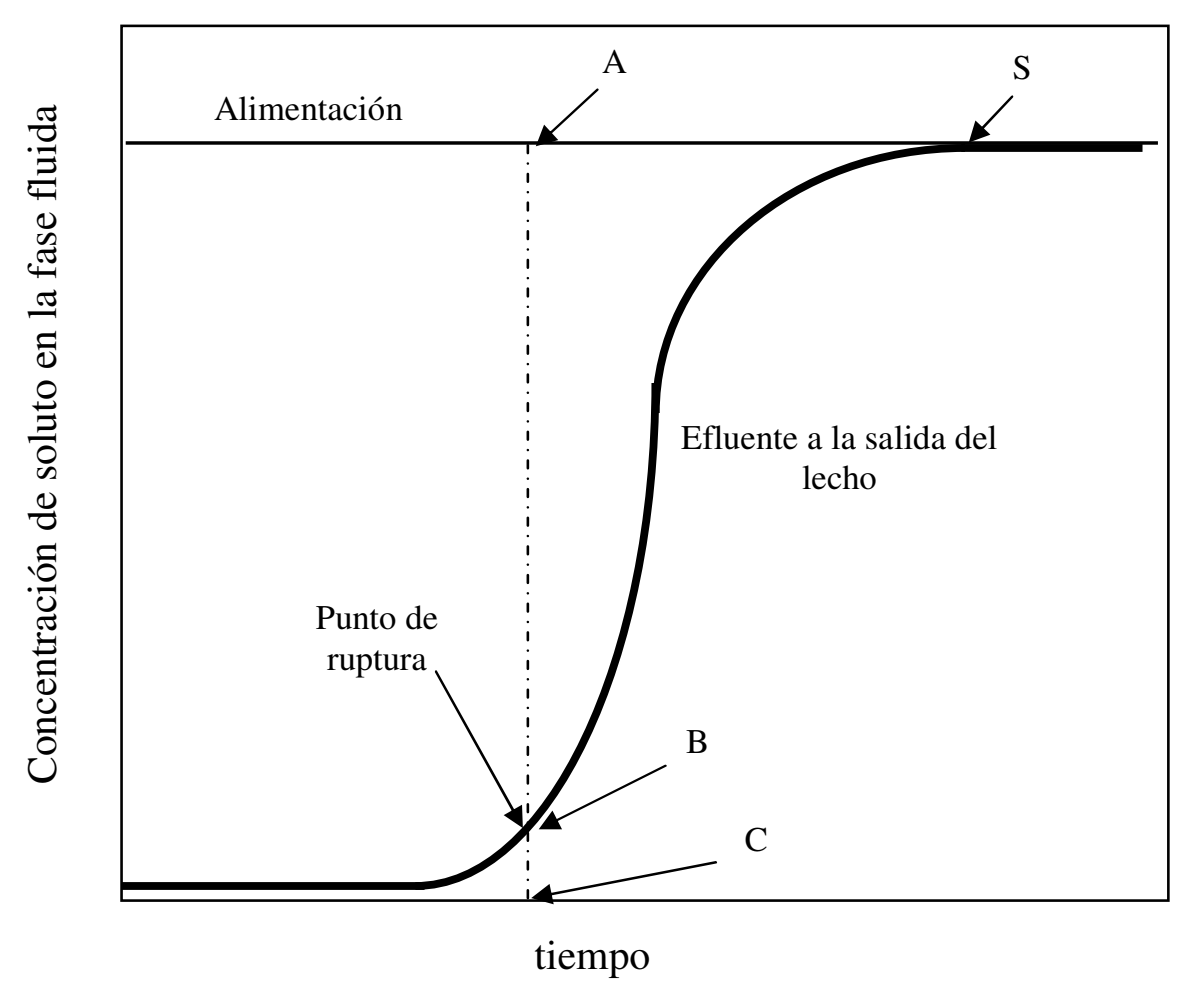

Figura 6-a: Curva de adsorción dinámica en lecho fijo.

Además, del estudio de la cantidad de soluto retenido en el sólido adsorbente (concentración en el adsorbente), hay que tener en cuenta la eficacia del lecho que se expresa como la relación $\mathrm{AB} / \mathrm{AC}$ (Figura 6-a) y representa en cada punto de la curva la relación entre la cantidad retenida y la de la corriente de alimentación. Hasta el punto de ruptura, la eficacia es próxima al 100\%, superado este punto la eficacia disminuye hasta hacerse cero en el punto $S$, debido a que en $S$ prácticamente todo el lecho está en equilibrio con la corriente de alimentación.

La eficacia del lecho se expresa mediante la capacidad en el punto de ruptura, que se define mediante la relación existente entre la cantidad de sustancia adsorbida hasta dicho punto y la cantidad de adsorbente utilizado.

La forma de la curva varía según el tipo de sistema adsorbente - adsorbato. Generalmente, estas curvas tienen forma de $S$ como se muestra en la Figura 6-a, pero pueden tener una gran pendiente o ser relativamente planas $y$, en algunos casos, considerablemente distorsionadas. Si el proceso de adsorción fuese infinitamente rápido, la zona de la curva de inflexión sería una línea vertical recta. La rapidez real y el mecanismo del proceso de adsorción, la naturaleza del equilibrio de adsorción, la velocidad del fluido, la concentración de soluto en la alimentación y la longitud del lecho adsorbedor, en particular si la concentración de soluto en la alimentación es elevada, determinan la forma de la curva (Treybal R.E., 1980).

Habitualmente, en las adsorciones en lecho fijo se suele representar la relación $C_{A} / C_{A o}$ frente al tiempo, siendo $\mathrm{C}_{\mathrm{Ao}}$ y $\mathrm{C}_{\mathrm{A}}$ la concentración de soluto a la entrada y a la salida del lecho, respectivamente. De estas representaciones se obtiene una curva en forma de $S$ denominada curva de ruptura del lecho que se muestra en la Figura 6-b. 


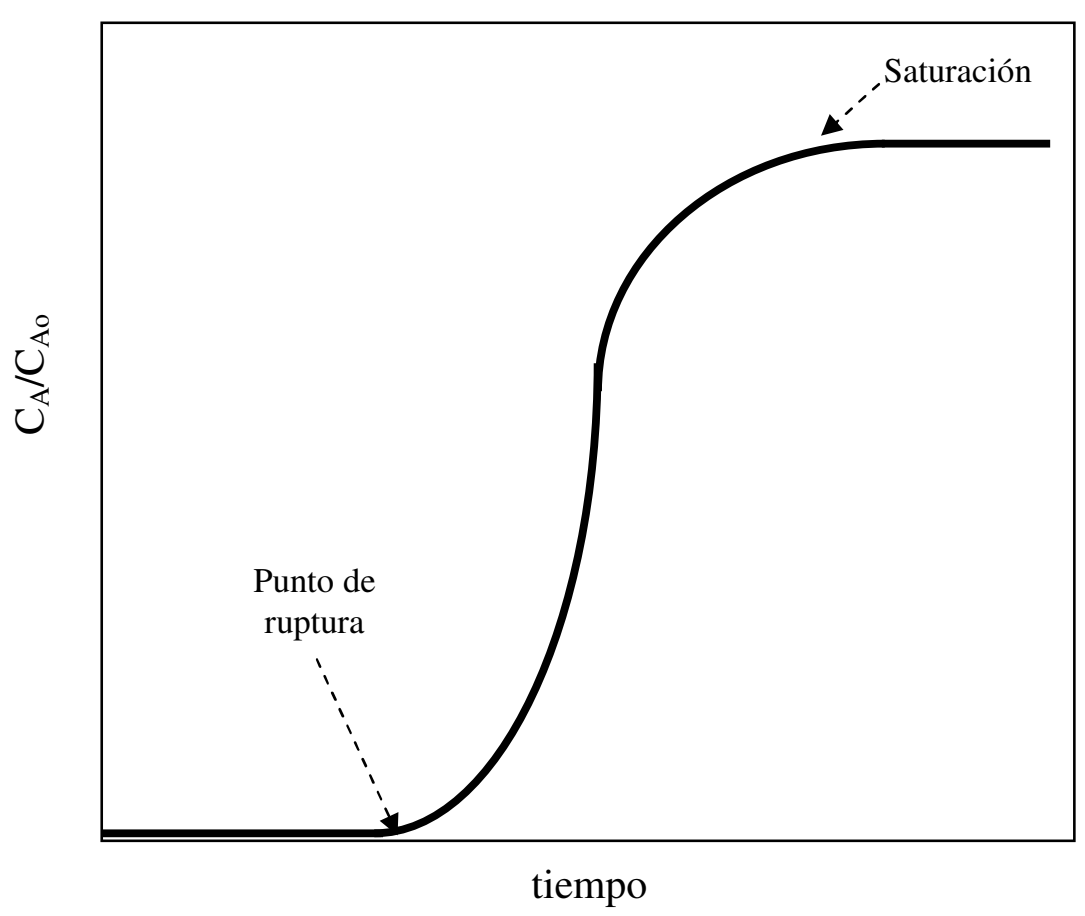

Figura 6-b: Curva de ruptura en lechos fijos.

Los factores a controlar en el funcionamiento de las instalaciones de adsorción en lecho fijo son:

- La presión. En corrientes gaseosas, la capacidad de adsorción aumenta con el aumento de la presión total del sistema debido a que también supone un aumento de la presión parcial del adsorbato.

- Temperatura. A presión constante, el grado de adsorción en un proceso de adsorción física disminuye cuando aumenta la temperatura. Este aumento de temperatura se producirá si el calor generado por la adsorción no es eliminado, repercutiendo negativamente sobre la eficacia del lecho.

- Tamaño de partícula. Debido a que la adsorción mejora al aumentar la superficie de contacto entre adsorbente y adsorbato, interesa trabajar con tamaños de partículas pequeños ya que proporcionan altas superficies de contacto pero evitando las elevadas caídas de presión a través del lecho que proporcionarían tamaños excesivamente pequeños. Además, la forma esférica de las partículas hace posible el llenado del lecho regular y uniforme.

- Velocidad del fluido. Es una variable importante debido a su relación directa con el tiempo de contacto. Los valores de esta variable están comprendidos entre dos límites: el máximo que corresponde al límite de fluidización, en caso de flujo ascendente, y el mínimo impuesto por la transición de flujo turbulento a laminar. 
El diseño de un adsorbedor de lecho fijo se basa en el balance de materia a un elemento diferencial de volumen que debe ser integrado con las condiciones límites e iniciales establecidas en el proceso. Generalmente, se considera que:

- La fase fluida que atraviesa el lecho lleva flujo de pistón

- La operación es isotérmica

- Existe equilibrio instantáneo entre la fase fluida y la fase sólida, en cada punto del lecho

- La caída de presión es despreciable.

La expresión del balance de materia y la ecuación de equilibrio se reflejan en las siguientes ecuaciones (Ruthven D.M., 1984):

$$
\begin{aligned}
& D \frac{\partial^{2} C_{A}}{\partial z^{2}}=u \frac{\partial C_{A}}{\partial z}+\frac{\partial C_{A}}{\partial t}+\frac{1-\varepsilon_{L}}{\varepsilon_{L}} \frac{\partial q}{\partial t} \\
& q=f\left(C_{A}\right)
\end{aligned}
$$

siendo $D$ el coeficiente de dispersión axial (generalmente se considera cero debido a que se asume flujo de pistón), z la posición axial en el lecho, u la velocidad intersticial, t la variable tiempo, $\mathrm{C}_{\mathrm{A}}$ la concentración de soluto en la fase fluida, $\mathrm{q}$ la concentración de soluto en la fase sólida referida a volumen de sólido y $\varepsilon_{\mathrm{L}}$ la porosidad del lecho.

De la combinación de las Ecs. (4.20) y (4.21) se obtiene la siguiente expresión:

$$
\mathrm{u}_{\mathrm{c}}=\frac{\partial \mathrm{z}}{\partial \mathrm{t}}=\frac{\mathrm{u}}{1+\frac{1-\varepsilon_{\mathrm{L}}}{\varepsilon_{\mathrm{L}}} \frac{\mathrm{dq}}{\mathrm{dC}_{\mathrm{A}}}}
$$

La Ec. (4.22) muestra la velocidad, $u_{C}$, con que se propaga la concentración $C_{A}$ a través del lecho y refleja su dependencia con la pendiente puntual de la isoterma de equilibrio. Así para sistemas con isotermas de equilibrio lineales, y siempre que la velocidad intersticial $(\mathrm{u})$ permanezca constante, $\mathrm{u}_{\mathrm{c}}$ adquiere un valor constante (Ruthven D.M., 1984).

Con las condiciones límite e iniciales, que dependen de las resistencias controlantes del proceso de transferencia de materia, del equilibrio y de las condiciones de operación, se obtienen las distintas soluciones analíticas de la Ec. (4.20) (Ruthven D M., 1984; Costa C. et al., 1985 b; Saunders M.S. et al., 1989; Yoshida H. et al., 1984).

Estas soluciones analíticas de diseño y predicción de las curvas de ruptura, presentan gran complejidad de cálculo, además resulta necesario un estudio preliminar de equilibrio y cinético para determinar las resistencias controlantes a la transferencia de materia, así como los parámetros de equilibrio que correlacionan las concentraciones en fase acuosa y en fase resina (Costa C. et al., 1985 b; Neretnieks I. et al., 1976; Saunders M.S. et al., 1989; Yoshida $H$. et al., 1983). En la Tabla 1 se muestra la combinación posible de etapas para la obtención de las distintas soluciones analíticas de diseño y predicción de las curvas de ruptura. 
Tabla 1. Combinación de etapas para la obtención de las soluciones analíticas de diseño y predicción de las curvas de ruptura

\begin{tabular}{|c|c|}
\hline $\begin{array}{l}\text { MODELO DE } \\
\text { FLUJO }\end{array}$ & $\begin{array}{lc}\text { Sin dispersión axial } & 0=u \frac{\partial \mathrm{C}_{\mathrm{A}}}{\partial \mathrm{z}}+\frac{\partial \mathrm{C}_{\mathrm{A}}}{\partial \mathrm{t}}+\frac{1-\varepsilon_{\mathrm{L}}}{\varepsilon_{\mathrm{L}}} \frac{\partial \mathrm{q}}{\partial \mathrm{t}} \\
\text { Con dispersión axial } & D \frac{\partial^{2} \mathrm{C}_{\mathrm{A}}}{\partial \mathrm{z}^{2}}=u \frac{\partial \mathrm{C}_{\mathrm{A}}}{\partial \mathrm{z}}+\frac{\partial \mathrm{C}_{\mathrm{A}}}{\partial \mathrm{t}}+\frac{1-\varepsilon_{\mathrm{L}}}{\varepsilon_{\mathrm{L}}} \frac{\partial \mathrm{q}}{\partial \mathrm{t}}\end{array}$ \\
\hline $\begin{array}{l}\text { ISOTERMAS DE } \\
\text { EQUILIBRIO }\end{array}$ & $\begin{array}{l}\text { Lineal } \\
\text { No Lineal }\end{array}$ \\
\hline $\begin{array}{c}\text { ETAPAS } \\
\text { CONTROLANTES } \\
\text { DE LA } \\
\text { TRANFERENCIA } \\
\text { DE MATERIA }\end{array}$ & $\begin{array}{l}\text { Película líquida externa }\left(k_{f}\right) \\
\text { Difusión intrapartícula }\left(D_{e}\right) \\
\text { Película líquida externa y difusión intrapartícula }\left(k_{f}, D_{e}\right) \\
\text { Película líquida externa, difusión superficial y en el poro }\left(k_{f}, D_{p} \text {, }\right. \\
\left.D_{s}\right)\end{array}$ \\
\hline
\end{tabular}

\subsubsection{Desorción y regeneración del adsorbente}

Una vez finalizada la operación de adsorción, el adsorbente se somete a desorción que consiste en la reextracción de las moléculas de soluto adsorbidas y en la regeneración del sólido con objeto de recuperar su capacidad de adsorción.

La etapa de regeneración requiere un cambio en las condiciones de operación que favorezca la desorción de las sustancias retenidas. Los procedimientos más habituales son:

- $\quad$ Regeneración por aporte de calor. La adsorción es un proceso exotérmico. Así, sometiendo al adsorbente a una temperatura suficientemente elevada, se produce la desorción de las moléculas adsorbidas, que pueden eliminarse pasando una corriente de gas. Permite obtener el producto desorbido con una concentración elevada.

- $\quad$ Regeneración por variación de presión. El método se basa en la disminución de la capacidad de adsorción al pasar un gas a través del lecho que origina una disminución de la presión parcial del adsorbato y éste es arrastrado por la corriente gaseosa. No es aplicable al caso de mezclas líquidas. Es adecuado si las sustancias se adsorben débilmente.

- $\quad$ Regeneración por desplazamiento. La regeneración se lleva a cabo mediante el lavado del adsorbente con un fluido que contiene moléculas de un soluto que compiten activamente con el adsorbato por los centros activos del adsorbente. 
Así, al pasar el fluido a través del adsorbente se producirá el desplazamiento del adsorbato por el soluto del fluido.

- $\quad$ Regeneración química. La regeneración se realiza haciendo pasar a través del lecho una disolución que contiene una sustancia regenerante que por reacción química elimina el soluto del adsorbente, como se explicó anteriormente en el apartado 3.5.

- $\quad$ Arrastre con un fluido inerte, no adsorbible. Sirve para arrastrar el adsorbato. Suele utilizarse en combinación con ciclo térmico.

\subsection{TECNOLOGÍA RIE}

\subsubsection{Conceptos generales}

La tecnología híbrida de adsorción-extracción reactiva con Resinas Impregnadas de Extractante (RIE) es una alternativa a los procesos convencionales de separación. Por lo general, los procesos de precipitación resultan poco eficaces en cuanto al grado de separación, en la extracción reactiva con disolventes se producen elevadas pérdidas del disolvente en el refinado además de la formación de emulsiones estables o terceras fases (Rovira M. et al., 1999), los procesos con resinas de intercambio iónico suelen presentar baja selectividad, y las resinas quelantes producen procesos de extracción lentos, y son caras debido a la dificultad de su fabricación (Akita S. et al., 1990).

Como respuesta a estos inconvenientes se está iniciando el desarrollo de una tecnología híbrida de extracción con resinas impregnadas de extractante (RIE) que es capaz de reunir, en un solo proceso, la elevada capacidad y selectividad que ofrecen las técnicas de extracción reactiva con disolventes, con las ventajas que ofrecen los procesos de separación con matrices sólidas, que permiten procesar grandes cantidades de muestras diluidas, utilizando equipos sencillos y baratos, como son los tanques agitados y los lechos porosos y fluidizados (Ruiz M.O et al., 2002; Ruiz M.O et al., 2006), lo cuál es de gran importancia debido a que el coste final del producto reside en la facilidad para su separación, concentración y purificación.

Las principales ventajas que presenta esta tecnología frente a otras técnicas de separación convencionales son:

- No existe mezcla violenta de fases, ni formación de emulsiones, ni de terceras fases (Juang R-S. y Chang H-L., 1995).

- Se evita la pérdida de extractante ya que se inhibe el proceso de solubilización del mismo en la fase acuosa, aumentando la capacidad de extracción al emplear el extractante puro, sin disolver.

- Alto grado de eficacia en la separación y la reutilización de todos los productos, y por lo tanto, la obtención de menos residuos y menos contaminantes que con los procesos convencionales. 
- Los equipos industriales son tanques agitados, lechos porosos y fluidizados, (Bart $H$-J. y Schöneberger A., 2000), que son equipos baratos y sencillos de diseñar y mantener.

La bibliografía especializada muestra que una característica fundamental de las resinas impregnadas es que el extractante está físicamente adsorbido en los poros o macroporos de la resina, presentando el mismo comportamiento de extracción que si estuviese disuelto en un disolvente orgánico. Por consiguiente, en la tecnología RIE puede existir un doble mecanismo de separación, adsorción debida al soporte polimérico y extracción reactiva debida al extractante impregnado en los poros:

- $\quad$ Adsorción del soluto debida al soporte polimérico de la resina impregnada de extractante, que cumple las leyes y principios fundamentales de la adsorción detallados en al capítulo 4.1 de esta memoria.

- Extracción reactiva del soluto debida al extractante impregnado en la RIE, que cumple los principios básicos de la extracción líquido-líquido recogidos en el capítulo 3 de esta memoria.

Se puede concluir que las propiedades específicas de la RIE dependen del extractante y de la matriz polimérica utilizada (Akita S. et al., 1990).

La extracción con RIE se ha aplicado extensamente a la separación de metales de corrientes siderometalúrgicas utilizando como extractantes derivados del ácido fosfórico y aminas alifáticas de cadena larga (Akita S. et al., 1990; Akita S. et al., 1992; Juang R.S. et al., 1992 a-b; Juang R S. et al., 1995 b-c; Juang R S. et al., 1996 b; Shiau C. Y. et al, 2005; Kabay N. et al., 2005; Liu J. S. et al., 2006). La aplicación de esta técnica a la recuperación de ácidos orgánicos es reciente (Akita S. et al., 1990; Jones I. et al., 1993 ab; Juang R.S. et al., 1995 a; Juang R.S. et al., 1995 c; Juang R.S. et al., 1996 a; Ruiz M.O. et al., 2001; Ruiz M.O. et al., 2006) al igual que se está empezando a investigar para aldehidos y separaciones selectivas de enantiómeros (Babić K. et al., 2006; Babić K. et al., 2007).

En este trabajo, se evaluará la extracción de aminoácidos y derivados empleando resinas poliméricas macroporosas sobre las que se inmoviliza el extractante reactivo. Se utilizaron dos tipos de extractantes: el cloruro de tri-alquilmetilamonio (Tomac) que es una sal de amonio cuaternaria de elevado peso molecular ampliamente utilizado en los procesos de extracción reactiva líquido-líquido como extractante de tipo aniónico, y el ácido dinonilnaftalensulfónico (DNNSA) extractante con grupo sulfónico de tipo catiónico.

Conceptualmente hablando, la extracción reactiva de aminoácidos y derivados es más compleja que la extracción de metales porque los aminoácidos son moléculas más grandes, frágiles, con densidades de carga menos concentradas que en metales, con grupos funcionales menos accesibles y con la posibilidad que tienen los aminoácidos de existir en varias formas iónicas según el pH (Nelly N. A. et al. 1998). Es por ello que hasta ahora, apenas hay aplicación práctica de esta tecnología con RIE para la recuperación de aminoácidos de corrientes residuales, ni se han realizados los estudios fundamentales de equilibrio y cinéticas, ni la modelización de los mismos necesaria para llevar a cabo el cambio de escala y su aplicación a nivel industrial.

Se puede concluir que la tecnología de extracción con RIE se presenta como un novedoso proceso híbrido entre extracción reactiva con disolventes y adsorción. El grado 
de innovación se centra en los beneficios científico - técnicos y económicos que esta tecnología híbrida puede aportar a la industria.

1. Puede solventar los problemas que plantean las técnicas convencionales para la separación de bioproductos, como son la extracción por contacto directo o el uso de resinas de intercambio iónico comerciales. La extracción con disolventes presenta la limitación de la formación de emulsiones o de terceras fases, la inundación de la torre bajo ciertas condiciones de operación y la necesidad de un proceso posterior de re-extracción, generalmente caro y con elevado consumo de reactivos. El uso de resinas de intercambio iónico, además del elevado precio, presenta la limitación de necesitar un excesivo pre-tratamiento de la resina y de la alimentación y la escasa capacidad de la operación.

2. Esta tecnología híbrida de adsorción-extracción es capaz de reunir en un sólo proceso las ventajas de su simplicidad de operación y su aplicación a corrientes altamente diluidas, con la elevada capacidad y selectividad que ofrecen las técnicas de extracción reactiva utilizando extractantes selectivos. Esta técnica de separación puede suponer un beneficio económico, ya que puede aumentar, bajo ciertas condiciones de operación, la eficacia de la separación, reduciendo los costes de producción, el coste de capital, el consumo energético y las pérdidas en el sobrante.

3. Es una tecnología limpia, que implica bajo consumo energético y de reactivos, lográndose un alto grado de eficacia en la separación y la reutilización de todos los productos, obteniéndose residuos menos contaminantes que con los procesos convencionales.

4. Su aplicación se orienta a la separación selectiva de aminoácidos o bioproductos de corrientes de procesado, caldos de fermentación, licores enzimáticos o de corrientes residuales, donde se encuentran como subproductos en concentraciones muy bajas. Al ser productos de alto valor añadido, los beneficios económicos pueden cubrir inmediatamente los costes de instalación y operación. Su aplicación se dirige, fundamentalmente, al sector farmacéutico, alimentario (antibióticos, aminoácidos, péptidos, edulcorantes, saborizantes, preparados vitamínicos y digestivos, jabones terapéuticos, etc.), y de alimentación animal (piensos).

\subsubsection{Resinas poliméricas modificadas}

Las partículas porosas son muy utilizadas como sólidos adsorbentes porque tienen una alta capacidad de adsorción al tener mayor superficie de sólido que una partícula no porosa. A escala industrial, estos procesos con sólidos adsorbentes porosos, están teniendo un especial interés al ser eficaces para conseguir la separación, purificación y recuperación de aminoácidos (Moreira $M$. J. et al., 2005). Sin embargo, la existencia de poros en las partículas da una serie de problemas en los procesos de separación (Martín C. et al., 2004):

- Son procesos lentos porque el movimiento del fluido dentro de la partícula es de difusión. 
- Los poros de las partículas no son selectivos pudiéndose ensuciar con otras sustancias no deseadas presentes en el fluido a separar, disminuyendo su capacidad de adsorción en sucesivas aplicaciones del adsorbente. Además, este ensuciamiento puede provocar la desorción y contaminación del producto final.

- Es más difícil la limpieza de poros que una limpieza superficial.

Durante las tres últimas décadas, el número posible de aplicaciones de las resinas poliméricas se ha incrementado constantemente debido al desarrollo de nuevas resinas modificadas que mejoran algunas de las propiedades de las resinas clásicas. Entre los grupos más destacados se encuentran:

A) Resinas de intercambio iónico: la superficie del sólido adsorbente tiene ligandos consistentes en grupos funcionales de moléculas para conseguir separaciones más específicas del producto deseado. Pueden ser anfotéricas (ácido-base), catiónicas (ácidas) o aniónicas (básicas) fuertes ó débiles. Las resinas de intercambio iónico macroreticulares presentan varias ventajas con respecto a las de tipo gel: se contaminan menos con compuestos orgánicos, son menos frágiles físicamente, y se pueden usar en disoluciones no polares porque estas pueden penetrar en el interior de las resinas macroporosas. Por todo ello, las resinas de intercambio iónico macroreticulares son ampliamente utilizadas en la industria para separación de metales, vitaminas, aminoácidos, reacciones catalíticas, etc. (Yoshida H. et al., 1985; Gomes C. P. et al., 2001; Moreira M. J. et al., 2005; Favre-Réguillon $A$. et al., 2007). Además, la naturaleza altamente hidrofóbica de la matriz polimérica (poliestireno-divinilbenceno) de estas resinas afecta a la selectividad, siendo más selectivas con aminoácidos con cadenas laterales más hidrófobas, aunque su capacidad máxima de separación no se ve modificada debido a que el proceso de separación es por intercambio iónico resultando despreciable la adsorción (Cheng S. et al., 2006).

Uno de los inconvenientes que presenta esta técnica es la dificultad de acceso de los ligandos al interior de los poros, pudiendo no estar completamente saturada la superficie de la resina, favoreciendo que se dé una adsorción no selectiva, con el consiguiente ensuciamiento de la misma.

Estudios recientes investigan la síntesis de nuevos tipos de resinas de intercambio catiónico de naturaleza magnética para conseguir mayores selectividades, estas resinas se catalogan principalmente en dos tipos:

- Resinas consistentes en pequeñas partículas poliméricas con un material magnético dispersado entre su estructura.

- Resinas formadas por un núcleo esférico metálico (ej: acero inoxidable) al que se le hace un recubrimiento con una fina capa de material polimérico adsorbente (ej: estireno-divinilbenceno). En estos casos la superficie se puede considerar heterogénea pudiéndose dar dos tipos de adsorción. Entre sus aplicaciones se encuentran la separación de aminoácidos (Martín C. et al., 2004).

B) Resinas modificadas quelatantes. En los últimos años se ha comenzado el estudio de nuevas resinas consistentes en una matriz a la que se le une un ligando quelatante, lo cuál hace que estas resinas sean más selectivas que las resinas de intercambio iónico (Abd El-Moniem N. M. et al., 2005). Son ampliamente utilizadas para la separación y concentración de metales (Gloe K. et 
al., 2003). Las matrices donde se adsorbe el ligando pueden ser resinas macroporosas tipo XAD (Filik H. et al., 2003; Guo Y. et al., 2004; Prabhakaran D. et al., 2004) o bien con adsorbentes de naturaleza inorgánica como sílica, alúmina o celulosa (Gomez-Salazar S. et al., 2003; Gurnani V. et al., 2003; Hoshi H. et al., 2004; Venkatesh G. et al., 2004).

C) Resinas Levextrel y microcápsulas. Las resinas Levextrel son resinas poliméricas comerciales donde el extractante se agrega en el proceso de polimerización, en la mezcla de monómeros. Suelen englobarse dentro de las resinas de intercambio iónico o quelantes. (Chen J. $H$ et al., 2003). Los extractantes más utilizados son compuestos organofosforados (TBP, DEHPA, DTMPPA, etc...), debido a que generalmente las aminas de elevado peso molecular y las sales de amonio producen la inhibición del proceso de polimerización. (Cortina J.L. et al., 1994). Recientemente, se ha hecho estudios con microcápsulas, la diferencia principal de las resinas Levextrel y las microcápsulas es que estas últimas contienen mezclas de extractante y diluyente, en este caso se pueden utilizar extractantes más selectivos y que producen mejores extracciones sin efectos de inhibición. (Nishihama S. et al., 2004). Uno de los procedimientos de encapsulación más recientes, por su sencillez y bajo coste, consiste en la utilización de alginato como polímero granular, el cuál encapsula pequeñas microgotas de extractante dispersas por su matriz (Outokesh $M$. et al., 2006). Entre sus aplicaciones principales para ambos tipos de resinas están la recuperación de metales.

D) Resinas impregnadas de extractante (RIE). Son resinas poliméricas modificadas donde el extractante penetra por contacto físico en los poros de la resina. La impregnación se suele realizar por contacto directo de la resina con un disolvente formado por un extractante y un diluyente volátil que se elimina posteriormente por evaporación. Para evitar posibles pérdidas de extractante impregnado en los poros de la resina se puede operar de dos formas: estabilización de la RIE con un fino recubrimiento por ejemplo de polivinilalcohol, (Trochimczuk A.W. et al., 2004; Trochimczuk A.W. et al., 2005) o bien operando a concentraciones de extractante un $10 \%$ por debajo de la capacidad máxima de adsorción de la resina. (Ruiz M. O. et al., 2002). Las resinas que suelen emplearse para este fin son las resinas macroporosas del tipo Amberlita XAD, que están formadas por una matriz polimérica aromática o alifática y sin grupos funcionales iónicos, cuyas características se han detallado en el apartado 4.1.5. Además, el extractante utilizado para la impregnación de las resinas, suele presentar gran afinidad por estas matrices poliméricas y se comporta como en el estado líquido (Shiau C. Y. et al, 2005; Babić K. et al., 2006; Babić K. et al., 2007).

\subsubsection{Impregnación de la resina}

La obtención de soportes poliméricos impregnados consiste en la oclusión del extractante en el soporte sólido por contacto directo del adsorbente con el disolvente, generalmente, compuesto por el extractante y un diluyente altamente volátil. Se emplean adsorbentes de elevada superficie específica, hidrofóbicos y altamente porosos, características que reúnen las resinas Amberlita XAD. Este tipo de materiales son apropiados como soportes de extractantes líquidos ya que presentan gran afinidad por el extractante, es decir, 
pueden retener cantidades elevadas del mismo y además con la particularidad de que el extractante no está químicamente enlazado a la matriz polimérica, sino en estado líquido, rellenando gradualmente los poros del sólido. Así, como se ha detallado anteriormente, se puede considerar que el extractante presenta el mismo comportamiento de extracción que cuando está libre o disuelto en un disolvente orgánico (extracción reactiva líquidolíquido) (Cortina J.L. et al., 1994; Juang R.S. et al., 1995 C; Juang R.S. et al., 1996; Warshawsky A., 1981; Ruiz M.O. et al., 2002).

En concreto, en nuestros laboratorios se ha estudiado el proceso de impregnación de Amberlita XAD-4 con Tomac. Cantidades conocidas de Amberlita XAD-4 se pusieron en contacto con disoluciones Tomac $+n$-hexano y se estudió el efecto de variables de proceso tales como presión y velocidad de agitación para producir la impregnación (Santidrián E., 2001; Santidrián E.et al., 2002).

Al objeto de visualizar las posibles diferencias entre la resina impregnada con Tomac y sin impregnar se realizó un estudio microscópico con un microscopio óptico marca ZEISS Axioplan, modelo 308579, con lámpara HB050 dotado de un ocular de 10 aumentos y lentes de 2,5 y 5 aumentos.

No se apreciaron cambios significativos de tamaño, presentando la resina con y sin Tomac geometría esférica. En la Figura 7 se muestra la similitud de tamaño entre la resina impregnada con Tomac (b) y sin impregnar (a).
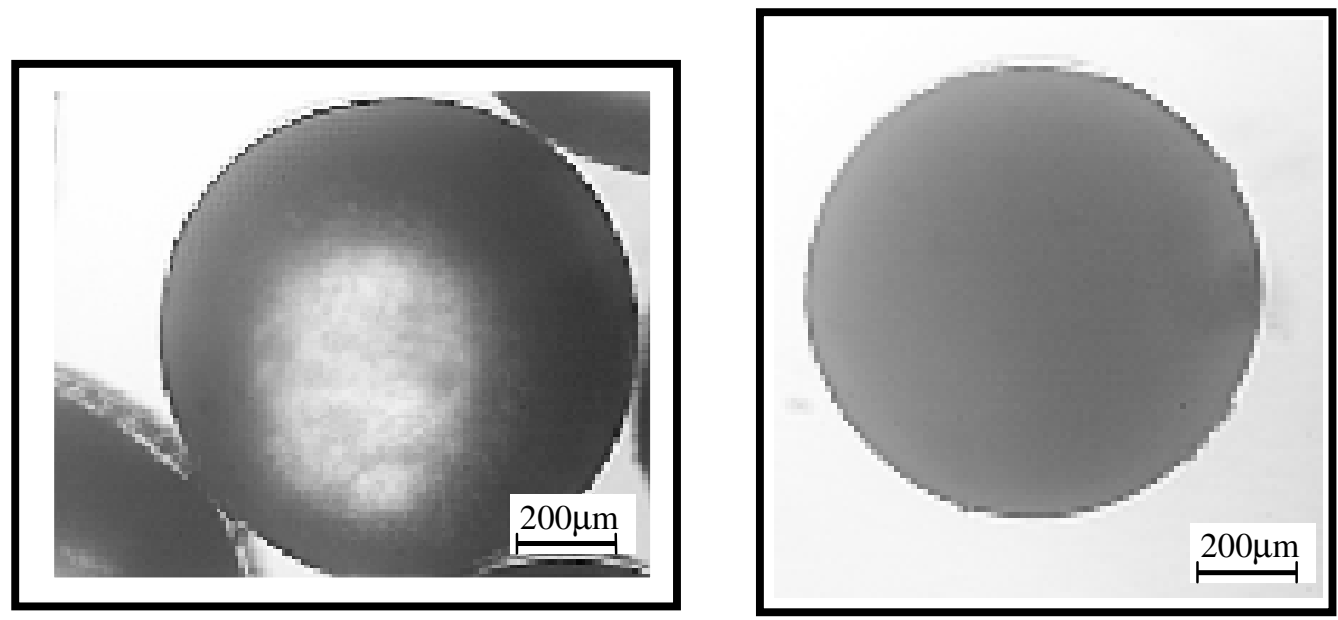

Figura 7: $\quad$ Resina Amberlita XAD-4 (a) sin Tomac, (b) impregnada con Tomac.

Con el objetivo de disminuir el tiempo del proceso de impregnación, facilitando la etapa de volatilización del diluyente, y producir un contacto más íntimo y homogéneo entre la resina y el disolvente, el contacto entre fases se realizó en un rotavapor (Heidolph, modelo WB2000) provisto de agitador rotatorio, baño termostático de agua y sistema de vacio. Se realizaron experimentos con distinta velocidad de agitación y presión. Los resultados mostraron que la concentración de Tomac en la resina y el tiempo de impregnación no se vieron afectados por la presión.

Además, no es adecuado el uso de agitación continua en el proceso de impregnación, ya que se produce la rotura de las partículas de resina al colisionar unas con otras y con las 
paredes del recipiente que las contiene, incluso a velocidades de agitación reducidas de 30 rpm, como puede observarse en la Figura 8 que muestra la resina XAD-4 impregnada con Tomac a vacío (presión=37 kPa) con una velocidad de agitación reducida de $30 \mathrm{rpm}$ y a temperatura constante de $25^{\circ} \mathrm{C}$. Este resultado puede deberse a que el extractante rellena los poros del material adsorbente produciendo tensiones que aumentan su fragilidad y consecuentemente producen la rotura de las partículas. (Cortina J.L. et al., 1994; Rovira M. et al., 1998; Strikovsky A.G. et al., 1998).
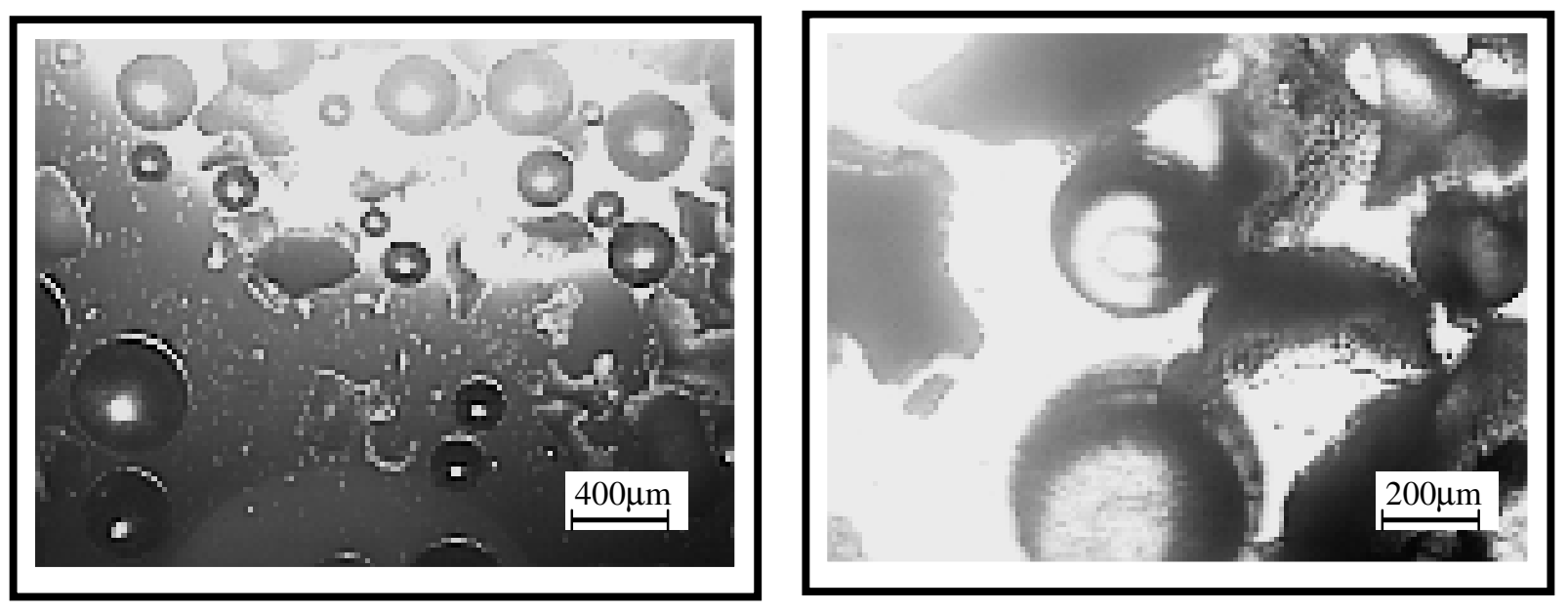

Figura 8: Resina Amberlita XAD-4 impregnada con Tomac a vacío (Presión $=37 \mathrm{kPa}$ ) con una velocidad de agitación de $30 \mathrm{rpm}$ y a $25^{\circ} \mathrm{C}$.

Con estos resultados, la impregnación de las resinas Amberlita XAD se realizó poniendo en contacto cantidades conocidas de resina, lavada y seca, con diferentes disoluciones de impregnación compuestas por Tomac disuelto en n-hexano a distinta concentración, hasta que toda la fase orgánica es completamente adsorbida por la resina. Este paso fue realizado en un horno a $60 \stackrel{\circ}{ } \mathrm{C}$ durante 48 horas hasta completa evaporación del diluyente y con agitación manual cada 4 horas durante el día. (Akita S. et al., 1992; Juang R. S. et al., 1995 a; Juang R. S. et al., 1995 c). Para evitar pérdidas de extractante durante el proceso de extracción, se debe operar un $10 \%$ por debajo de la concentración máxima de extractante que admite la resina; en el caso de la resina Amberlita XAD-4 impregnada con Tomac fue de $1110 \mathrm{~mol} / \mathrm{m}^{3}$ de resina sin impregnar (RSI), por encima de esa concentración la resina tiene un aspecto húmedo y pegajoso. (Ruiz M. O. et al., 2002; Ruiz M. O. et al., 2004). 


\section{RECUPERACIÓN DE AMINOÁCIDOS}





\subsection{PARTE EXPERIMENTAL}

El desarrollo del proyecto de tesis tiene como punto de partida los resultados alcanzados en nuestro laboratorio con la tecnología de extracción reactiva líquido-líquido (Ruiz M. O. et al., 2002) y con la tecnología de extracción con Resinas Impregnadas de Extractante, RIE, (Ruiz M. O. et al., 2001) aplicados a la separación y concentración del aminoácido afenilglicina.

Debido al carácter anfotérico de los aminoácidos, es posible aplicar técnicas de extracción reactiva que conllevan reacciones de intercambio iónico y que requieren trabajar bajo condiciones rigurosas de control de $\mathrm{pH}$. En el caso del aminoácido $\alpha-$ fenilglicina, se calcularon experimentalmente los valores de las constantes de acidez a la temperatura de $30 \stackrel{\circ}{\circ}$ y se seleccionó como agente de extracción TOMAC. Se han estudiado las reacciones de competencia que intervienen en el equilibrio de extracción y se ha formulado un modelo matemático de equilibrio, que permite estimar el grado de extracción alcanzado bajo ciertas condiciones de operación. Se trata de un modelo mecanicista de utilidad en la optimización y control del proceso. Algunos de los resultados obtenidos fueron (Ruiz M.O., 2002; Burgos L. et al., 2001; Santridián E. et al., 2002):

- Los estudios de impregnación de la resina indicaron que la concentración de Tomac en la fase resina crece al aumentar la concentración de Tomac en la disolución de impregnación (Tomac+n-hexano) hasta alcanzar un valor constante de saturación de 3,84 mol Tomac/kg resina sin impregnar para las resinas Amberlita XAD-16 y XAD-1180 y un valor de 2,10 mol Tomac/kg resina sin impregnar para la resina Amberlita XAD-4. Por encima de esta concentración, la resina no admite más extractante, presentando un aspecto húmedo y pegajoso después del proceso de impregnación. Este resultado indica que la carga máxima de Tomac inmovilizada en cada partícula de resina está directamente relacionada con el volumen del poro, resultando menor al disminuir este parámetro (Ruiz M.O. et al., 2007).

- Los estudios de los equilibrios de extracción de $\alpha$-fenilglicina con las resinas impregnadas XAD-4, XAD-16 y XAD-1180 a pH=11 y la misma concentración de Tomac, demostraron que la resina XAD-4 impregnada con Tomac proporciona mejores resultados de extracción.

- Los estudios microscópicos confirmaron que no hay cambios significativos de tamaño (diámetro medio) entre la resina XAD-4 impregnada con Tomac y sin impregnar.

- Se demostró experimentalmente que la carga de Tomac en la RIE debe ser un $10 \%$ inferior a la concentración máxima admitida por la resina para no apreciar efectos de desimpregnación del extractante. 
- La adsorción física de aniones de $\alpha$-fenilglicina e hidroxilo por la resina XAD-4 sin impregnar fue despreciable. Este hecho prueba que la extracción de los iones cuando se utiliza RIE se debe exclusivamente al Tomac impregnado en dicha resina.

- A pH>11 la extracción de a-fenilglicina y la coextracción de iones hidroxilo se produce simultáneamente mediante un mecanismo de intercambio iónico con el extractante TOMAC.

- En el estudio de extracción de $\alpha$-fenilglicina, la concentración de aminoácido en fase orgánica o en la resina aumentó al aumentar su concentración en fase acuosa y fue siempre mayor a $\mathrm{pH}=11$. La coextracción de iones hidroxilo en fase orgánica es mayor a $\mathrm{pH}=12$ que a $\mathrm{pH}=11$.

Partiendo de estos resultados, en este trabajo de investigación para los aminoácidos en estudio se eligió como soporte polimérico Amberlita XAD-4 y como agente extractante TOMAC con una concentración un $25 \%$ inferior a la concentración máxima admitida por la resina (790 $\pm 10 \mathrm{~mol}$ Tomac $/ \mathrm{m}^{3}$ resina sin impregnar). La temperatura de operación seleccionada en este trabajo fue de $30^{\circ} \mathrm{C}$, ya que a esa temperatura, para las condiciones anteriormente señaladas, se conoce el modelo matemático de equilibrio. Además, se demuestra la necesidad de realizar un estudio fundamental del efecto del pH en la separación y concentración de los aminoácidos debido a su carácter anfotérico y para conseguir que se produzca selectivamente la reacción de intercambio iónico con el extractante Tomac inmovilizado en la resina.

\subsubsection{Productos utilizados}

En todos los ensayos se utilizó agua ultrapura Milli-Q, los productos fueron de grado reactivo y se emplearon sin purificación previa. Las características de los productos utilizados, así como su procedencia, se detallan a continuación:

- $D L$ - $\alpha$-Fenilglicina o ácido $\alpha$-amino-fenilacético es un aminoácido, suministrado por Sigma y Fluka con una pureza superior al 99,8\%. A temperatura ambiente es un sólido blanco, altamente inmiscible en agua y soluble en álcalis. Sus propiedades físicas y químicas se detallan en el apartado 2.1.6.

- $D L$ - Ácido Aspartico o ácido aminosuccínico es un aminoácido, suministrado por Fluka con una pureza superior al 99\%. A temperatura ambiente es un sólido 
blanco, soluble en agua, ácidos y álcalis e insoluble en alcoholes. Sus propiedades físicas y químicas se detallan en el apartado 2.1.7.

- $\quad$ - Prolina 0 ácido 2-pirrolidincarboxílico es un aminoácido de fórmula molecular $\mathrm{C}_{5} \mathrm{H}_{9} \mathrm{NO}_{2}$ con una masa molecular de $115,13 \mathrm{~g} / \mathrm{mol}$, fue suministrado por Fluka con una pureza mayor del 99\%. A temperatura ambiente es un sólido blanco, que presenta una gran solubilidad en agua, y es insoluble en eter, butanol e isopropanol. Se empleó como patrón interno en el método de análisis de mezclas de ácido aspártico y $\alpha$-fenilglicina.

- Amberlita XAD-4 es una resina polimérica macroporosa hidrofóbica, de estructura altamente aromática, formada por un copolímero de estireno divinilbenceno, suministrada por Merck y Fluka. Es un sólido, con forma de grano tipo bolas, de color amarillo pálido, con una superficie específica de $750-780$ $\mathrm{m}^{2} / \mathrm{g}$, una porosidad de 0,51 , un volumen medio de poro de $0,98 \mathrm{ml} / \mathrm{g}$, un diámetro medio de poro de $5 \mathrm{~nm}$, una densidad de partícula de $0,529 \mathrm{~g} / \mathrm{cm}^{3}$ (seca) y una densidad de la fase sólida de $1,08 \mathrm{~g} / \mathrm{cm}^{3}$ (densidad aparente). El diámetro de partícula seca es de $0,778 \mathrm{~mm}$. Presenta estabilidad térmica de 1 a $120 \stackrel{\circ}{ } \mathrm{C}$ y una estabilidad al pH comprendida entre 1 y 14. Antes de su utilización, para eliminar las impurezas de fabricación, se lavó sucesivamente con metanol, acetona y nhexano y se secó a vacío a $50^{\circ} \mathrm{C}$. (Komiyama $H$. et al., 1974; Juang R.S. et al., 1995 a; Juang R.S. et al., 1995 b; Mijangos F. et al., 1998).

- Tomac o cloruro de trialquilmetilamonio es una sal de amonio cuaternaria, mezcla de cloruros de trioctil y tridecilmetilamonio, con cloruro de trioctilmetilamonio dominante, con un peso molecular de $404 \mathrm{~g} / \mathrm{mol}$, suministrada por Fluka con una pureza mayor del $90 \%$. Es un líquido de color amarillo pálido, con una densidad de $880 \mathrm{~kg} / \mathrm{m}^{3}$ a $20{ }^{\circ} \mathrm{C}$ y con una viscosidad a $40{ }^{\circ} \mathrm{C}$ de $14,510^{-1}$ Pa s (Chan C. C. et al., 1993; Escalante H. et al., 1998; Galan B. et al., 1994; Molinari R. et al., 1992; Yang S. T. et al., 1991).

- $\boldsymbol{n}$-Hexano, empleado para la eliminación de impurezas de la resina o como diluyente en la etapa de impregnación de la resina. De fórmula molecular $\mathrm{CH}_{3}$ $\left(\mathrm{CH}_{2}\right)_{4}-\mathrm{CH}_{3}$, con una masa molecular de $86,18 \mathrm{~g} / \mathrm{mol}$, fue suministrado por Merck con una pureza $>99 \%$. Es un líquido incoloro, presenta una densidad de 659,33 $\mathrm{kg} / \mathrm{m}^{3}$ a $20 \stackrel{\circ}{ } \mathrm{C}$, un punto de ebullición de $69{ }^{\circ} \mathrm{C}$, una viscosidad $0,3126 \mathrm{cp}$ a $20{ }^{\circ} \mathrm{C}$ y un índice de refracción de 1,37486 a $20^{\circ} \mathrm{C}$. Posee una solubilidad en agua de 0,00123 a $25 \stackrel{\circ}{\circ}$ y una solubilidad de agua en $n$-hexano de 0,0111 a $20 \stackrel{\circ}{ } \mathrm{C}$ (Riddick J. A., 1986; Weast R. C., 1994-1995).

- Acetona, utilizada en el lavado de la resina y suministrada por la casa comercial Fluka. De fórmula molecular $\mathrm{CH}_{3}-\mathrm{CO}-\mathrm{CH}_{3}$, con una masa molecular de 58,08 $\mathrm{g} / \mathrm{mol}$. Presenta una densidad de $0,79 \mathrm{~kg} / \mathrm{dm}^{3}$ a temperatura ambiente, un punto de ebullición de $56,5^{\circ} \mathrm{C}$, un punto de fusión de $-94^{\circ} \mathrm{C}$ y un índice de refracción de 1,3591 a $20 \stackrel{\circ}{C}$.

- Metanol, empleado en el lavado de resina. De fórmula molecular $\mathrm{CH}_{3}-\mathrm{OH}$ con una masa molecular de $32,04 \mathrm{~g} / \mathrm{mol}$, fue suministrado por Lab-Scan con una pureza del $99,9 \%$. Presenta una densidad de $791 \mathrm{~kg} / \mathrm{m}^{3}$ a $20 \stackrel{\circ}{\circ} \mathrm{C}$, un punto de fusión de $97,8^{\circ} \mathrm{C}$ y un punto de ebullición de $64,5^{\circ} \mathrm{C}$.

- Hidróxido de sodio, sosa cáustica, de fórmula molecular $\mathrm{NaOH}$ y con peso molecular 40,01 g/mol. Está formada por un 2,52 \% de hidrógeno, un 57,48 \% de sodio y un $40 \%$ de oxígeno. Es un sólido de color blanco, que presenta una 
densidad a $25 \stackrel{\circ}{\circ}$ de $2130 \mathrm{~kg} / \mathrm{m}^{3}$ y un punto de fusión de $328 \stackrel{\circ}{\circ}$. El hidróxido de sodio utilizado fue suministrado por Panreac (PACS-ISO) con una pureza del 97 $\%$.

- Ácido clorhídrico, es un líquido incoloro de fórmula $\mathrm{HCl}$, suministrado por Panreac con una riqueza del $37 \%$ (RFE, BP, Ph. Eur.)PRS-CODEX. Presenta una densidad a $15{ }^{\circ} \mathrm{C}$ mayor de $1190 \mathrm{~kg} / \mathrm{m}^{3}$.

- Ácido fosfórico. Ácido ortofosfórico, de fórmula molecular $\mathrm{H}_{3} \mathrm{PO}_{4}$, fue suministrado por Aldrich con una pureza del $85 \%$ (A.C.S. Reagent). Es un sólido cristalino delicuescente, pero generalmente se le encuentra en disoluciones concentradas (hasta un $90 \%$ ) con aspecto líquido. Tiene un peso molecular de 98 $\mathrm{g} / \mathrm{mol}$. Está formado por un 3,09 \% de hidrógeno, un $65,31 \%$ de oxígeno y un $31,61 \%$ de fósforo. Presenta una densidad a $25{ }^{\circ} \mathrm{C}$ de $1685 \mathrm{~kg} / \mathrm{m}^{3}$.

\subsubsection{Dispositivos experimentales}

\subsubsection{Ensayos de equilibrio}

Los datos de equilibrio se determinaron poniendo en contacto la fase acuosa y la fase resina en erlenmeyers de $100 \mathrm{~cm}^{3}$ de capacidad. Las fases se agitaron durante 24 horas en un agitador orbital (New Brunswick Scientific. modelo G25) con agitación suave de 150 rpm, para evitar la rotura de las partículas de resina por fuerzas mecánicas y a una temperatura de $30^{\circ} \mathrm{C}$. El agitador orbital dispone de un sistema de termostatización con aire, que permite mantener constante la temperatura durante el proceso de extracción con una precisión de $\pm 0,1^{\circ} \mathrm{C}$.

Una vez alcanzado el equilibrio, las fases se separan por filtración. Las muestras líquidas se tomaron utilizando jeringuillas con filtros de celulosa regenerada con $0,45 \mu \mathrm{m}$ de diámetro de poro.

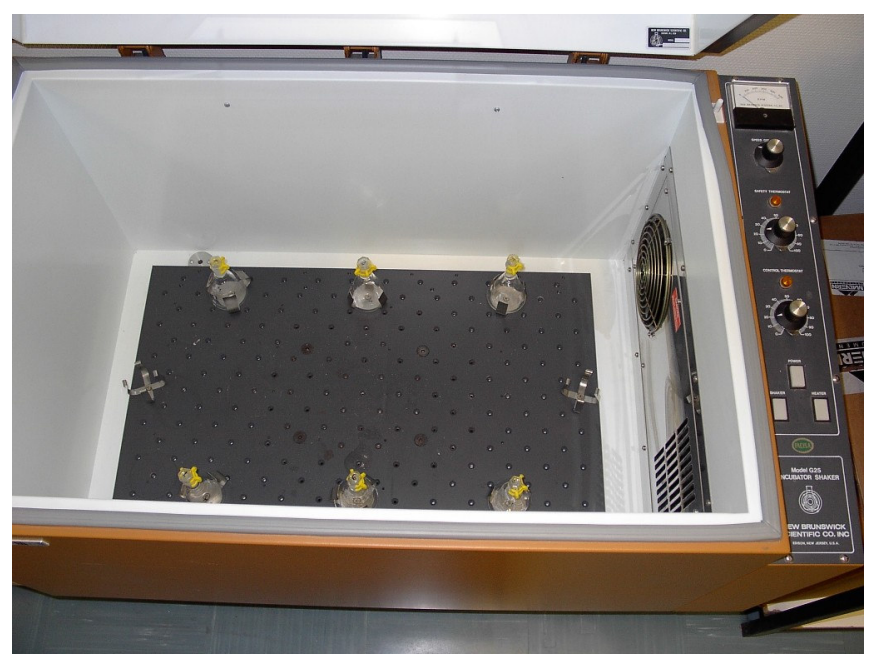

Figura 9: Agitador orbital New Brunswick Scientific. Modelo G25 


\subsubsection{Ensayos cinéticos en tanques agitados}

Los experimentos cinéticos se realizaron en tanques agitados de 0,5 litros de capacidad en cuyo interior se pusieron en contacto la fase acuosa y resina, y cuyo esquema se representa en la Figura 10.

Para mantener la temperatura constante durante el proceso cinético, el tanque va provisto de un encamisado exterior por el que circula agua procedente de un termostato. El tanque está cerrado al exterior con una tapa de base esmerilada. La tapa está provista de varios orificios por los que se introdujeron un termómetro, un agitador de hélice y una sonda de $\mathrm{pH}$, con el objeto de controlar las variables del proceso.

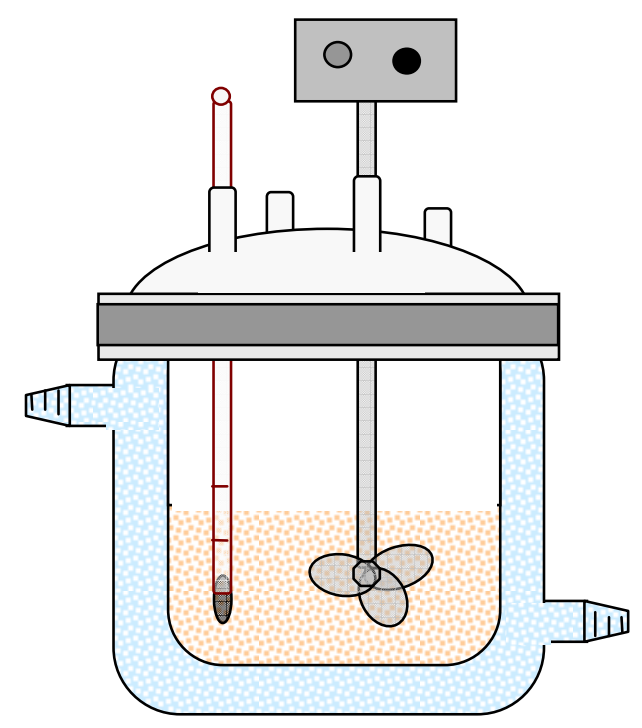

Figura 10: Esquema del tanque utilizado en los estudios cinéticos.

La agitación de las fases se realizó con un agitador de hélice unido a un motor (modelo ALC quit-S Conelec HD-250) a 220 rpm. A esta velocidad se evita la rotura de las bolas de resina y la desimpregnación de la RIE.

La temperatura del proceso fue constante de $30^{\circ} \mathrm{C}$ y se controló mediante un termómetro introducido en el tanque, con una precisión de $\pm 0,1^{\circ} \mathrm{C}$.

El pH de la disolución acuosa a lo largo del ensayo se determinó con un pH-metro Crisol GLP 21 dotado de sonda de temperatura, con una precisión de $\pm 0,01$.

\subsubsection{Ensayos en columnas de lecho fijo con RIE}

En las Figuras 11 y 12 se muestra el esquema del dispositivo experimental utilizado en los ensayos de extracción-reextracción de aminoácidos con una columna de lecho fijo y con dos columnas de lecho fijo dispuestas en serie, respectivamente. 


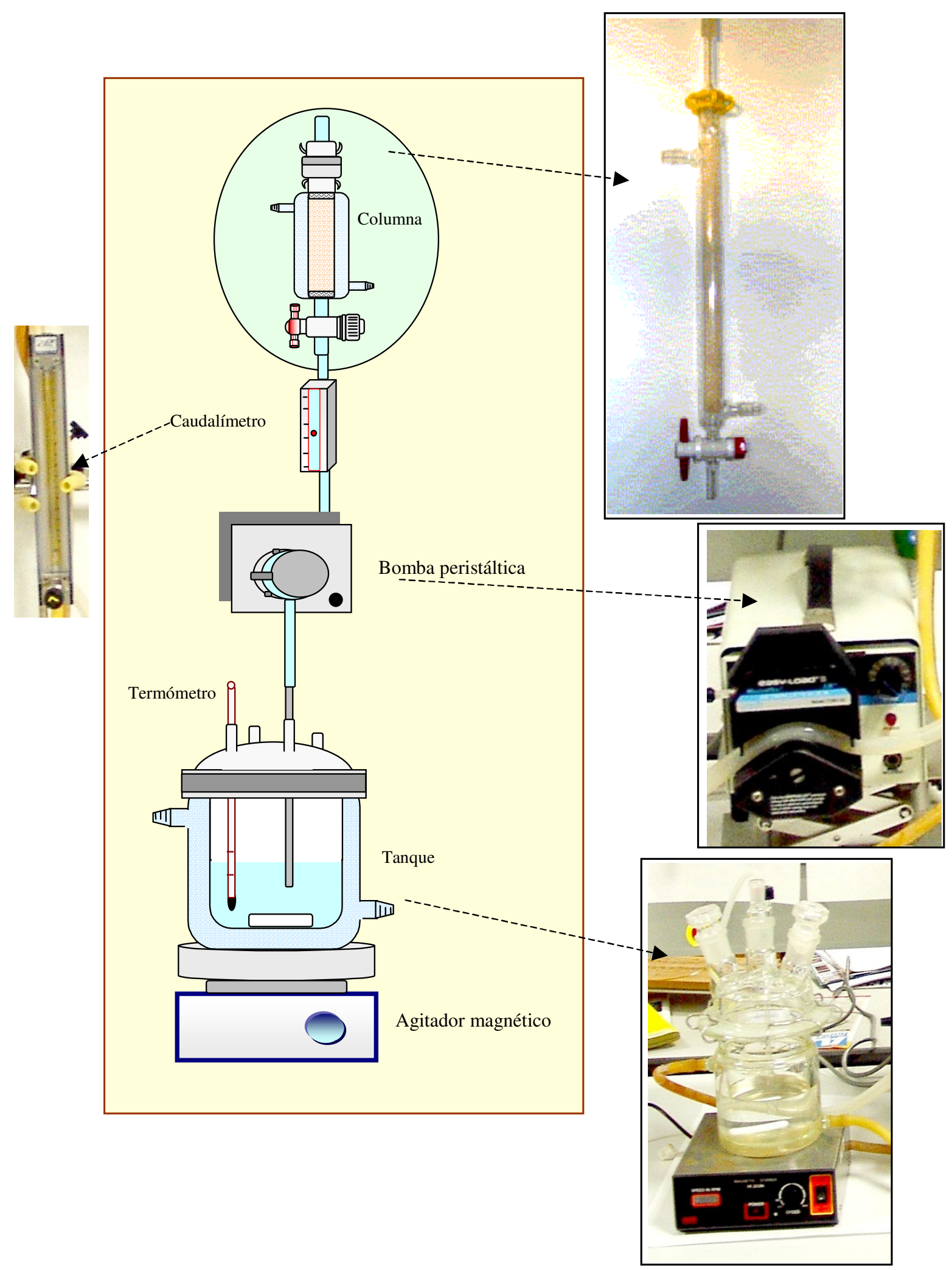

Figura 11: Esquema del dispositivo experimental utilizado en los estudios de extracciónreextracción de aminoácidos en lecho fijo con una sola columna. 


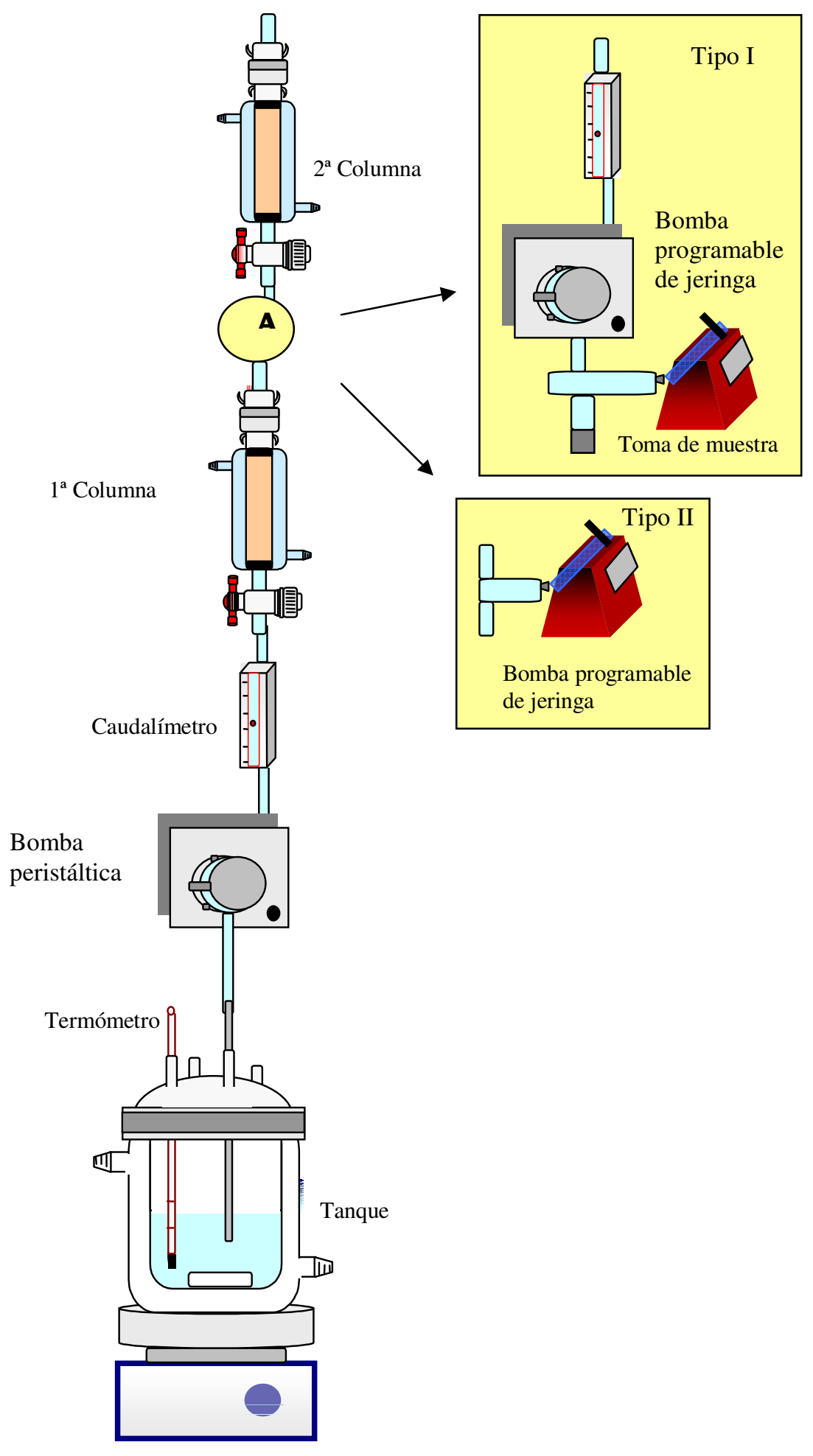

Figura 12: Esquema del dispositivo experimental utilizado en los estudios de extracciónreextracción de aminoácidos en lecho fijo con dos columnas. 
Se utilizaron columnas consistentes en un tubo de vidrio de 9,9 y de $8,4 \mathrm{~mm}$ de diámetro interno, $195 \mathrm{~mm}$ de altura y con una capacidad de 15 y $9,9 \mathrm{~cm}^{3}$, respectivamente. Estas columnas están provistas de un encamisado exterior por el que circula agua procedente de un termostato, para mantener la temperatura constante durante el proceso. Las columnas poseen una llave de teflón en su base inferior, tienen una placa porosa soldada en la parte inferior del tubo interno y están cerradas superiormente con un tapón de vidrio hueco. El tapón también posee una placa porosa soldada en su base, con el objeto de evitar pérdidas de sólido por la parte superior de la columna, y además, con el mismo fin, se utilizó lana de vidrio que recubre esa zona de la columna.

El caudalímetro es de área variable, Cole Parmer $150 \mathrm{~mm}$, modelo 3219-21. El caudalímetro se calibró con agua, en las mismas condiciones de operación que las experimentales, determinando el caudal en cada posición del caudalímetro, con la medida del tiempo de llenado de una probeta graduada. Además, en todas los experimentos en columna se comprobó regularmente, de esta manera, el caudal de circulación de la fase acuosa, con el fin de obtener una mayor exactitud de los datos.

El tanque de alimentación es de 0,5 litros de capacidad y contiene la fase acuosa de aminoácido. Va provisto de un encamisado exterior por el que circula agua procedente de un termostato que permite mantener su temperatura constante a $30^{\circ} \mathrm{C}$.

La fase acuosa es impulsada a través de la columna en sentido ascendente con una bomba peristáltica Masterflex (Cole Parmer) modelo 7521-10, de intervalo 1-100 rpm, de $220 \mathrm{~V}$ y $50 \mathrm{~Hz}$, con un selector de velocidad y posibilidad de cambio de sentido de flujo, adecuada para flujos entre 0,06 y $580 \mathrm{~cm}^{3} / \mathrm{min}$ según cabezal y diámetro de la tubería.

El cabezal peristáltico es del tipo Easy-Load para tubo de alta precisión (Cole Parmer) modelo 77201-62, de oclusión variable, con rotor de acero inoxidable, apto para tubos de diferentes diámetros (tubos de talla 15, 24, 35 y 36) que proporciona un intervalo muy amplio de caudales.

La tubería empleada en el proceso es del tipo tubo Masterflex silicona (flexible) de talla 36 y $9,7 \mathrm{~mm}$ de diámetro interno, que resulta ser de resistencia adecuada a las características de las disoluciones que circulan por ellas.

En la Figura 12 que muestra el esquema del dispositivo experimental utilizado en los ensayos de extracción-reextracción de aminoácidos con dos columnas de lecho fijo. Se observa que a la salida de la primera columna (punto A de la Figura 12) y para regular el $\mathrm{pH}$ a la entrada de segunda columna se conecta una bomba programable de jeringa NE1000 (Multi-Phaser Programable Syringe Pumps) con capacidad para proporcionar flujos que van de $0,76 \mu \mathrm{l} / \mathrm{hr}$ (con jeringas de $1 \mathrm{~cm}^{3}$ ) hasta $2120 \mathrm{ml} / \mathrm{hr}$ (con jeringas de $6 \mathrm{~cm}^{3}$ ). Se realizaron dos tipos de ensayos:

- Ensayos Tipo l. Se dispone de una toma de muestras, lo cuál produce un pequeño desfase a la entrada de la segunda columna, y por tanto se necesita una segunda bomba peristáltica y un caudalímetro adicionales para impulsar la fase acuosa, (del mismo modelo y marca que los anteriores).

- Ensayos Tipo II. El flujo de la fase acuosa a la salida de la primera columna es impulsada directamente a la segunda columna, en este caso en el punto A de la Figura 12 tan sólo se dispone de la bomba programable de jeringa que modifica y regula el pH a la entrada de la segunda columna. 


\subsubsection{Procedimiento experimental}

\subsubsection{Determinación de la concentración de $\alpha$-fenilglicina}

La concentración de a-fenilglicina en fase acuosa, se determinó utilizando cromatografía líquida de alta resolución, con un HPLC Beckman, modelo System Gold, con detector UVVIS. Se empleó una columna C-18 de fase reversa, Ultraesphere ODS marca Beckman, con partículas esféricas de sílice de $5 \mu \mathrm{m}$ y tamaño de poro de $80 \AA$, con un diámetro interno de 4,6 $\mathrm{mm}$ y longitud de $250 \mathrm{~mm}$. Se seleccionó el detector de UV a la longitud de onda de $254 \mathrm{~nm}$ y una fase móvil consistente en una disolución $0,1 \%$ en volumen de ácido fosfórico en agua Milli-Q con un flujo de $1 \mathrm{ml} / \mathrm{min}$.

La limpieza de la columna se realizó periódicamente con disoluciones de acetonitrilo:agua en proporción 65:35.

La concentración de aminoácido en fase resina se determinó por balance de materia. Todas las muestras se analizaron por triplicado, bajo condiciones idénticas. La precisión en la estimación de la composición en $\mathrm{mol} / \mathrm{m}^{3}$ fue de $\pm 0,001$.

\subsubsection{Determinación de la concentración de ácido aspártico}

La concentración de ácido aspártico en fase acuosa, se determinó utilizando cromatografía líquida de alta resolución con el HPLC descrito en el apartado 5.1.3.1. Se empleó una columna C-18 de fase reversa, Inertsil ODS-3V marca GL Sciences Inc, con partículas esféricas de sílice de $5 \mu \mathrm{m}$ y tamaño de poro de $101 \AA$, con un diámetro interno de 4,6 mm y longitud de $250 \mathrm{~mm}$. Se seleccionó el detector de UV a la longitud de onda de $225 \mathrm{~nm}$ y una fase móvil consistente en una disolución $0,1 \%$ en volumen de ácido fosfórico en agua Milli-Q con un flujo de $1 \mathrm{ml} / \mathrm{min}$.

La limpieza de la columna, la concentración de aminoácido en fase resina, los análisis de las muestras y la precisión se realizó o se determinó según el procedimiento detallado anteriormente en el apartado 5.1.3.1.

\subsubsection{Determinación de la concentración de $\alpha$-fenilglicina y ácido aspártico en sus mezclas binarias}

La concentración de $\alpha$-fenilglicina y ácido aspártico de sus mezclas binarias en fase acuosa, se determinó utilizando cromatografía líquida de alta resolución con el HPLC descrito en el apartado 5.1.3.1. Se empleó la misma columna y las mismas condiciones de análisis descritas anteriormente en el apartado 5.1.3.2. Para aumentar la precisión del método se utilizó como patrón interno una disolución de $347,43 \mathrm{~mol} / \mathrm{m}^{3}$ de L-prolina en proporción muestra:prolina, 4:1.

La limpieza de la columna, la concentración de aminoácido en fase resina, los análisis de las muestras y la precisión se realizó o se determinó según el procedimiento detallado anteriormente en el apartado 5.1.3.1. 


\subsubsection{Determinación del pH}

La medida del $\mathrm{pH}$ de las fases acuosas iniciales se realizó utilizando un $\mathrm{pH}$-metro Crison GLP 21 de sobremesa con sonda de temperatura.

Se utilizaron, según su aplicación, tres tipos de electrodo de $\mathrm{pH}$ : el electrodo 52-02 se utiliza para medios acuosos en general, con medidas de $\mathrm{pH}$ entre 0 y 12 , el electrodo 5203 se utiliza para medios acuosos en general, con amplio margen de $\mathrm{pH}$ entre 0 y 14 , y el electrodo 52-08 para medir micromuestras a partir de $100 \mu \mathrm{l}$ para medidas de $\mathrm{pH}$ entre 0 y 14. Los tres electrodos tienen temperaturas de operación entre 0 y $80^{\circ} \mathrm{C}$. El sistema de referencia empleado por el electrodo es alambre de $\mathrm{Ag} / \mathrm{AgCl}$ y el electrolito: Crisolyt-A $(\mathrm{KCl} 3 \mathrm{M}+\mathrm{AgCl})$. Algunas especificaciones técnicas del pH-metro son:

- Error de medida: $\leq 0,02 \mathrm{pH} ; \leq 1 \mathrm{mV} ; \leq 0,3^{\circ} \mathrm{C}$ ( \pm 1 dígito)

- Reproducibilidad: $\pm 0,01 \mathrm{pH} ; \pm 1 \mathrm{mV} ; \pm 0,1^{\circ} \mathrm{C}$

- Compensación automática de temperatura con sonda de temperatura

- Condiciones ambientales: Taㅡ de 5 a $40^{\circ} \mathrm{C}$, humedad relativa máxima: $95 \%$ no condensada.

\subsubsection{Lavado e impregnación de la resina}

Antes de proceder al proceso de impregnación, se realiza una primera etapa de acondicionamiento de la resina para eliminar sus impurezas de fabricación y restos de monómeros de estireno no polimerizados, consistente en un lavado sucesivo con metanol, agua Milli-Q, acetona y n-hexano. El secado de la resina se realiza a vacío a una temperatura de $5^{\circ} \mathrm{C}$ en un rotavapor Heidolph modelo WB2000 (Juang R. S. et al., 1995; Mijangos F. et al., 1998).

Posteriormente, cantidades conocidas de Amberlita XAD-4 lavada y seca se pone en contacto con diferentes disoluciones de Tomac, disuelto en n-hexano, hasta que toda la fase orgánica fue completamente adsorbida por la resina. Este paso se realizó en un horno a $60^{\circ} \mathrm{C}$ durante aproximadamente 48 horas y con agitación manual periódica, hasta conseguir la completa evaporación del diluyente (método de impregnación descrito en el apartado 4.2.3).

Un estudio microscópico previo ha mostrado que la RSI y la RIE tienen el mismo radio medio de 0,389 mm, como se ha comentado en el apartado 4.2.3.

\subsubsection{Datos de equilibrio}

Los datos de equilibrio de extracción de ácido aspártico y a-fenilglicina se obtuvieron poniendo en contacto $0,5 \mathrm{~g}$ de Amberlita XAD-4 impregnada con Tomac (RIE) o sin impregnar (RSI) con $0,05 \mathrm{dm}^{3}$ de fase acuosa a distintos pHs, con concentración variable en ambos aminoácidos. La concentración de Tomac en la resina fue de 791,56 \pm 6,99 $\mathrm{mol} / \mathrm{m}^{3}$ de $\mathrm{RSI}$ (resina sin impregnar) en todos los experimentos realizados con RIE. El $\mathrm{pH}$ de las fases acuosas se modificó por adición de disoluciones de $\mathrm{NaOH}$ ó $\mathrm{HCl}$. 
La proporción masa de resina / volumen de disolución, expresada en kg/m³ , es de 10/1.

Los datos experimentales de los equilibrios de extracción individual de $\alpha$-fenilglicina y ácido aspártico se determinaron bajo las condiciones iniciales reflejadas en las Tablas 2 y 3 , respectivamente.

Tabla 2. Condiciones iniciales para la obtención de las isotermas de equilibrio de extracción de afenilglicina con RIE a $30^{\circ} \mathrm{C}$. Los experimentos IV y V fueron determinados en estudios previos (Ruiz M. O. et al., 2002).

\begin{tabular}{ccc}
\hline Experimento & $\mathrm{pH}_{\mathrm{i}}$ & $\overline{\mathrm{Q}^{+} \mathrm{Cl}^{-}}{ }_{\mathrm{i}}\left(\mathrm{mol} / \mathrm{m}^{3} \mathrm{RSI}\right)$ \\
\hline I-a & $5,01 \pm 0,10$ & $0,00 \pm 0,00$ \\
I-b & $9,16 \pm 0,04$ & $0,00 \pm 0,00$ \\
I-c & $11,13 \pm 0,05$ & $0,00 \pm 0,00$ \\
I-d & $12,03 \pm 0,02$ & $0,00 \pm 0,00$ \\
II & $5,06 \pm 0,05$ & $791,56 \pm 6,99$ \\
III & $9,12 \pm 0,02$ & $791,56 \pm 6,99$ \\
IV & $11,13 \pm 0,05$ & $791,56 \pm 6,99$ \\
V & $12,03 \pm 0,02$ & $791,56 \pm 6,99$ \\
\hline
\end{tabular}

Tabla 3. Condiciones iniciales para la obtención de las isotermas de equilibrio de extracción de ácido aspártico con RIE a $30^{\circ} \mathrm{C}$.

\begin{tabular}{ccc}
\hline Experimento & $\mathrm{pH}_{\mathrm{i}}$ & {$\left[\overline{\mathrm{Q}^{+} \mathrm{Cl}^{-}}\right]_{\mathrm{i}}\left(\mathrm{mol} / \mathrm{m}^{3} \mathrm{RSI}\right)$} \\
\hline I-a & $5,04 \pm 0,04$ & $0,00 \pm 0,00$ \\
I-b & $9,05 \pm 0,04$ & $0,00 \pm 0,00$ \\
I-c & $11,01 \pm 0,02$ & $0,00 \pm 0,00$ \\
I-d & $12,06 \pm 0,05$ & $0,00 \pm 0,00$ \\
II & $5,07 \pm 0,05$ & $791,56 \pm 6,99$ \\
III & $9,05 \pm 0,04$ & $791,56 \pm 6,99$ \\
IV & $11,02 \pm 0,04$ & $791,56 \pm 6,99$ \\
V & $12,06 \pm 0,05$ & $791,56 \pm 6,99$ \\
\hline
\end{tabular}


Los datos de equilibrio de extracción de ácido aspártico y a-fenilglicina de sus mezclas binarias se obtuvieron también a distintas proporciones de cada aminoácido $\left(C_{A(\text { asp })} / C_{A(p g l y)}=1 / 1,1 / 2,1 / 3,2 / 1,3 / 1\right)$. Las isotermas de equilibrio se obtuvieron bajo las condiciones iniciales reflejadas en las Tabla 4.

Tabla 4. Condiciones iniciales para la obtención de las isotermas de equilibrio de extracción de mezclas binarias de ácido aspártico y a-fenilglicina con $\mathrm{RIE}$ a $30^{\circ} \mathrm{C} . \quad\left[\overline{\mathrm{Q}^{+} \mathrm{Cl}^{-}}\right]_{\mathrm{i}}=$ $791,56 \pm 6,99 \mathrm{~mol} / \mathrm{m}^{3} \mathrm{RSI}$.

\begin{tabular}{|c|c|c|c|c|}
\hline \multirow{2}{*}{ Experimento } & \multirow{2}{*}{$\mathrm{pH}_{\mathrm{i}}$} & $\underline{\mathrm{C}_{\mathrm{A}(\text { asp }) \mathrm{i}}}$ & $\left\lfloor\mathrm{A}_{\text {asp }}^{-}\right\rfloor_{\mathrm{i}}$ & $\left\lfloor\mathrm{A}_{\text {asp }}^{2-}\right\rfloor_{\mathrm{i}}$ \\
\hline & & $\overline{\mathrm{C}_{\mathrm{A}(\mathrm{pgly}) \mathrm{i}}}$ & {$\left[\mathrm{A}_{\mathrm{pgly}}^{-}\right]_{\mathrm{i}}$} & $\overline{\left.\mathrm{A}_{\mathrm{pgly}}^{-}\right]_{\mathrm{i}}}$ \\
\hline \multirow[t]{5}{*}{ I } & $5,03 \pm 0,06$ & $1 / 1$ & $1 / 1$ & $0 / 1$ \\
\hline & & $1 / 2$ & $1 / 2$ & $0 / 2$ \\
\hline & & $1 / 3$ & $1 / 3$ & $0 / 3$ \\
\hline & & $2 / 1$ & $2 / 1$ & $0 / 1$ \\
\hline & & $3 / 1$ & $3 / 1$ & $0 / 1$ \\
\hline \multirow[t]{5}{*}{ II } & $11,06 \pm 0,04$ & $1 / 1$ & $0 / 1$ & $1 / 1$ \\
\hline & & $1 / 2$ & $0 / 2$ & $1 / 2$ \\
\hline & & $1 / 3$ & $0 / 3$ & $1 / 3$ \\
\hline & & $2 / 1$ & $0,1 / 1$ & $1,9 / 1$ \\
\hline & & $3 / 1$ & $0,2 / 1$ & $2,8 / 1$ \\
\hline \multirow[t]{5}{*}{ III } & $12,02 \pm 0,06$ & $1 / 1$ & $0 / 1$ & $1 / 1$ \\
\hline & & $1 / 2$ & $0 / 2$ & $1 / 2$ \\
\hline & & $1 / 3$ & $0 / 3$ & $1 / 3$ \\
\hline & & $2 / 1$ & $0 / 1$ & $2 / 1$ \\
\hline & & $3 / 1$ & $0 / 1$ & $3 / 1$ \\
\hline
\end{tabular}

La agitación de las fases se realizó durante 24 horas con el agitador orbital mostrado en la Figura 9 a una velocidad de $150 \mathrm{rpm}$ y a una temperatura constante de $30,0 \pm 0,1 \stackrel{\circ}{ } \mathrm{C}$. Una vez alcanzado el equilibrio las fases se separan por filtración y se determina el pH y la concentración de cada aminoácido en el equilibrio.

La concentración de a-fenilglicina y ácido aspártico en fase acuosa se determinó con el método descrito en los apartados 5.1.3.1-5.1.3.3; y en fase resina se calculó por balance de materia.

\subsubsection{Datos cinéticos en baños agitados}

Los datos cinéticos de extracción individual de ácido aspártico y de las mezclas binarias de $\alpha$-fenilglicina y ácido aspártico con resina Amberlita XAD-4 impregnada con Tomac, se 
obtuvieron a $30 \pm 0,1^{\circ} \mathrm{C}$, utilizando el dispositivo experimental mostrado en la Figura 10. Se seleccionó como velocidad de agitación constante $220 \mathrm{rpm}$, ya que esta velocidad proporcionaba una dispersión homogénea de la RIE en la fase acuosa. Se comprobó experimentalmente que la pérdida de Tomac de la RIE a esta velocidad de agitación es despreciable. Sin embargo, con velocidades superiores a $350 \mathrm{rpm}$ se observó la rotura de las partículas de RIE.

Los experimentos cinéticos comienzan al agregar $5 \mathrm{~g}$ de RIE en $0,5 \mathrm{dm}^{3}$ de disolución acuosa y finaliza cuando el sistema alcanza el equilibrio. Se tomaron muestras de fase acuosa a intervalos de tiempo adecuados durante todo el proceso cinético, analizándose las concentraciones de aminoácido y el $\mathrm{pH}$.

A continuación, en las Tablas 5 y 6 se muestran las condiciones iniciales de los ensayos cinéticos de extracción de ácido aspártico y de las mezclas binarias de ácido aspártico y $\alpha$-fenilglicina. Los datos experimentales de las cinéticas de extracción individual de $\alpha$ fenilglicina se determinaron en un trabajo previo bajo las mismas condiciones del proceso. (Ruiz M. O. et. al., 2002).

La concentración de aminoácido en la fase acuosa inicial y en cada muestra del proceso cinético, se analizó por el procedimiento descrito en los apartados 5.1.3.2 y 5.1.3.3 para los experimentos de la Tablas 5 y 6 , respectivamente.

Tabla 5. Condiciones iniciales de los experimentos cinéticos de extracción de ácido aspártico con $\mathrm{RIE}$ a $30^{\circ} \mathrm{C} .\left[\overline{\mathrm{Q}^{+} \mathrm{Cl}^{-}}\right]_{\mathrm{i}}=782,93 \pm 19,04 \mathrm{~mol} / \mathrm{m}^{3} \mathrm{RSI}$.

\begin{tabular}{ccc}
\hline \multirow{2}{*}{ Experimento } & $\mathrm{pH}_{\mathrm{i}}$ & $\mathrm{C}_{\mathrm{A}(\mathrm{asp}) \mathrm{i}}\left(\mathrm{mol} / \mathrm{m}^{3}\right)$ \\
\hline $\mathrm{I}$ & $5,06 \pm 0,07$ & 7,37 \\
& & 11,11 \\
& & 14,64 \\
& & 21,86 \\
\hline II & $8,96 \pm 0,02$ & 15,29 \\
\hline III & $11,04 \pm 0,06$ & 7,45 \\
& & 11,46 \\
& & 18,94 \\
& & 29,33 \\
\hline IV & 9,58 \\
& $12,02 \pm 0,07$ & 11,19 \\
& & 14,64 \\
& & 24,69
\end{tabular}


Tabla 6. Condiciones iniciales de los experimentos cinéticos de extracción de mezclas de ácido aspártico y $\alpha$-fenilglicina con $\mathrm{RIE}$ a $30 \stackrel{\circ}{\circ} \mathrm{C} .\left[\overline{\mathrm{Q}^{+} \mathrm{Cl}^{-}}\right]_{\mathrm{i}}=765,07 \pm 10,24 \mathrm{~mol} / \mathrm{m}^{3} \mathrm{RSI}$.

\begin{tabular}{ccccc}
\hline Experimento & $\mathrm{pH}_{\mathrm{i}}$ & $\mathrm{C}_{\mathrm{A}(\text { asp }) \mathrm{C}} / \mathrm{C}_{\mathrm{A}(\mathrm{pgly}) \mathrm{i}}$ & $\mathrm{C}_{\mathrm{A}(\mathrm{asp}) \mathrm{i}}\left(\mathrm{mol} / \mathrm{m}^{3}\right)$ & $\mathrm{C}_{\mathrm{A}(\mathrm{pgly}) \mathrm{i}}\left(\mathrm{mol} / \mathrm{m}^{3}\right)$ \\
\hline $\mathrm{I}$ & $11,04 \pm 0,05$ & $1 / 1$ & 6,52 & 6,68 \\
& & $2 / 1$ & 13,11 & 6,74 \\
& & $3 / 1$ & 19,58 & 6,83 \\
& & $1 / 2$ & 6,31 & 12,38 \\
\hline II & $12,02 \pm 0,02$ & $1 / 1$ & 7,65 & 8,10
\end{tabular}

Los experimentos se realizaron sólo con RIE ya que previamente se comprobó que bajo idénticas condiciones de $\mathrm{pH}$ y temperatura, la adsorción de ácido aspártico y de $\alpha$ fenilglicina con la resina Amberlita XAD-4 sin impregnar es despreciable.

\subsubsection{Determinación de las curvas de ruptura: selección de condiciones}

Los datos cinéticos de extracción de ácido aspártico solo y mezclado con $\alpha$-fenilglicina para la determinación de los perfiles de las curvas de ruptura se obtuvieron a $30{ }^{\circ} \mathrm{C}$, utilizando el dispositivo experimental mostrado en la Figura 11. La columna se rellenó con masas conocidas de RIE. Los perfiles de las curvas de ruptura de $\alpha$-fenilglicina se determinaron en un trabajo previo bajo las mismas condiciones del proceso. (Ruiz M. O. et. al., 2002).

Todos los experimentos se realizaron con flujo ascendente, impulsando la alimentación desde la base de la columna, empaquetada con RIE, mediante una bomba peristáltica de flujo constante. Se emplearon como alimentación disoluciones de ácido aspártico a $\mathrm{pH}=5$, 11 y 12; y disoluciones de mezclas binarias de $\alpha$-fenilglicina y ácido aspártico a $\mathrm{pH}=12$ y con distintas proporciones de cada aminoácido $\left(C_{A(a s p)} / C_{A(p g l y)}=1 / 1,1 / 2,1 / 3,2 / 1,3 / 1\right)$. El $\mathrm{pH}$ de la alimentación se modificó con la adición de disoluciones de hidróxido de sodio $0,15 \mathrm{~N}$. Las muestras de efluente se recogieron periódicamente a intervalos de tiempo adecuados, analizándose la concentración de aminoácido y el pH en cada muestra según el procedimiento experimental descrito en los apartados 5.1.3.2-5.1.3.4.

El experimento de extracción en columna finaliza cuando se alcanza la saturación del lecho, es decir, cuando la concentración de aminoácido en el efluente de salida coincide con la de la alimentación. La capacidad de saturación del lecho de RIE se determinó a partir de la cantidad total de aminoácido extraído una vez alcanzada la saturación del lecho. 
Las curvas de ruptura se obtuvieron bajo las condiciones iniciales y de operación mostradas en las Tablas 7 y 8.

Tabla 7. Condiciones iniciales y de operación de los experimentos cinéticos de extracción de ácido aspártico utilizando lechos fijos de RIE a $30^{\circ} \mathrm{C}$.

\begin{tabular}{ccccc}
\hline Experimento & $\mathrm{Q}\left(\mathrm{m}^{3} / \mathrm{s}\right)$ & $\mathrm{pH}_{\mathrm{i}}$ & $\mathrm{C}_{\mathrm{A}(\text { asp }) \mathrm{i}}\left(\mathrm{mol} / \mathrm{m}^{3}\right)$ & $\begin{array}{c}\overline{\mathrm{Q}^{+} \mathrm{Cl}^{-}} \mathrm{i} \\
\left(\mathrm{mol} / \mathrm{m}^{3} \mathrm{RSI}\right)\end{array}$ \\
\hline I & $0,022 \times 10^{-6}$ & $5,05 \pm 0,02$ & 7,40 & $773,72 \pm 3,78$ \\
II & $0,022 \times 10^{-6}$ & $10,99 \pm 0,02$ & 7,55 & $773,72 \pm 3,78$ \\
III & $0,017 \times 10^{-6}$ & $11,24 \pm 0,02$ & 7,29 & $773,72 \pm 3,78$ \\
IV & $0,023 \times 10^{-6}$ & $12,05 \pm 0,02$ & 7,57 & $773,72 \pm 3,78$ \\
V & $0,025 \times 10^{-6}$ & $12,03 \pm 0,02$ & 14,55 & $773,72 \pm 3,78$ \\
VI & $0,022 \times 10^{-6}$ & $12,08 \pm 0,02$ & 15,00 & $618,00 \pm 0,39$ \\
VII & $0,063 \times 10^{-6}$ & $12,03 \pm 0,02$ & 15,72 & $618,00 \pm 0,39$ \\
\hline
\end{tabular}

Tabla 8. Condiciones iniciales y de operación de los experimentos cinéticos de extracción de mezclas de ácido aspártico y $\alpha$-fenilglicina utilizando lechos fijos de RIE a $30 \stackrel{\circ}{\circ}$. $\mathrm{pH}=12,01 \pm 0,07 ; \mathrm{Q}=0,018 \pm 0,001 \times 10^{-6} \mathrm{~m}^{3} / \mathrm{s}$.

\begin{tabular}{ccccc}
\hline Experimento & $\mathrm{C}_{\mathrm{A}(\text { asp })} / \mathrm{C}_{\mathrm{A}(\mathrm{pgly}) \mathrm{i}}$ & $\mathrm{C}_{\mathrm{A}(\text { asp }) \mathrm{i}}\left(\mathrm{mol} / \mathrm{m}^{3}\right)$ & $\mathrm{C}_{\mathrm{A}(\mathrm{pgly}) \mathrm{i}}\left(\mathrm{mol} / \mathrm{m}^{3}\right)$ & $\begin{array}{c}\overline{\mathrm{Q}^{+} \mathrm{Cl}^{-}} \\
\left(\mathrm{mol}^{3} / \mathrm{m}^{3} \mathrm{RSI}\right)\end{array}$ \\
\hline I & $1 / 1$ & 7,96 & 7,98 & $787,62 \pm 4,03$ \\
II & $1 / 2$ & 7,87 & 14,50 & $787,62 \pm 4,03$ \\
III & $1 / 3$ & 7,63 & 20,37 & $787,62 \pm 4,03$ \\
IV & $2 / 1$ & 15,52 & 7,73 & $787,62 \pm 4,03$ \\
V & $3 / 1$ & 22,60 & 7,65 & $787,62 \pm 4,03$ \\
VI & $1 / 1$ & 7,72 & 8,01 & 491,30 \\
\hline
\end{tabular}


La regeneración del lecho de RIE consistió en ciclos sucesivos de reextracción del aminoácido contenido en la RIE y lavado del lecho (Ruiz M. O. et al., 2002; Santridián E., 2003).

La reextracción de ácido aspártico del lecho de RIE se realizó a $30 \pm 0,01 \stackrel{\circ}{\circ}$, empleando como agente de reextracción disoluciones de $\mathrm{HCl}$ de concentración 0,2 N. Los experimentos de reextracción se realizaron también con flujo ascendente.

Las muestras de efluente se recogieron a intervalos de tiempo adecuados, midiéndose la concentración de aminoácido y el pH en cada muestra. La concentración de ácido aspártico en la fase acuosa inicial y en cada muestra de efluente se analizó mediante HPLC empleando el método descrito en el apartado 5.1.3.2.

Después del proceso de reextracción, para el lavado del lecho de RIE se emplearon disoluciones de $\mathrm{NaCl} 0,02 \mathrm{~N}$ a pH=9 y $\mathrm{pH}=11$, al objeto de eliminar las trazas de aminoácido no reextraído en la etapa anterior. Finalmente, la columna de RIE se lavó con una disolución de $\mathrm{HCl} 0,2 \mathrm{~N}$ para neutralizar el medio y con $\mathrm{H}_{2} \mathrm{O}$ milli-Q para aclarar y acondicionar el lecho.

Una vez finalizado el lavado del lecho de RIE, se vació el líquido de la columna antes de iniciar un $2^{\circ}$ o $3^{\text {er }}$ ciclo de extracción.

En la Tabla 9 se presentan las condiciones iniciales de operación de los experimentos de extracción-reextracción de ácido aspártico a $30^{\circ} \mathrm{C}$.

Tabla 9. Condiciones iniciales y de operación de los experimentos cinéticos de extracciónreextracción de ácido aspártico utilizando lechos fijos de RIE a $30 \stackrel{\circ}{\circ} \mathrm{C} .\left[\overline{\mathrm{Q}^{+} \mathrm{Cl}^{-}}\right]_{\mathrm{i}}=771,75$ $\mathrm{mol} / \mathrm{m}^{3} \mathrm{RSI} ; \mathrm{Q}=0,023 \times 10^{-6} \pm 0,001 \mathrm{~m}^{3} / \mathrm{s}$.

\begin{tabular}{|c|c|c|c|c|}
\hline & & \multicolumn{2}{|c|}{ EXTRACCIÓN } & REEXTRACCIÓN \\
\hline \multirow{2}{*}{\multicolumn{2}{|c|}{ Experimentos }} & \multicolumn{2}{|c|}{ Alimentación } & Disolución de reextracción \\
\hline & & & $\mathrm{C}_{\mathrm{A}(\mathrm{asp}) \mathrm{i}}\left(\mathrm{mol} / \mathrm{m}^{3}\right)$ & $\mathrm{C}_{\mathrm{HCl}}(\mathrm{N})$ \\
\hline I- $\mathrm{a}$ & $1^{\mathrm{er}}$ ciclo & 12,03 & 14,55 & 0,20 \\
\hline$I-b$ & $2^{\circ}$ ciclo & 11,97 & 15,24 & 0,20 \\
\hline I- C & $3^{\mathrm{er}}$ ciclo & 12,03 & 15,08 & --- \\
\hline
\end{tabular}




\subsubsection{Proceso integrado de extracción-reextracción utilizando dos lechos fijos de RIE dispuestos en serie}

Estos ensayos se realizaron a $30^{\circ} \mathrm{C}$, utilizando el dispositivo experimental mostrado en la Figura 12 (apartado 5.1.2.3). Las dos columnas se rellenaron con masas conocidas de $\mathrm{RIE}$ con una concentración de Tomac $\left[\overline{\mathrm{Q}^{+} \mathrm{Cl}^{-}}\right]_{\mathrm{i}}=780,10 \mathrm{~mol} / \mathrm{m}^{3} \mathrm{RSI}$. La alimentación es impulsada con flujo ascendente con una bomba peristáltica de flujo constante.

Se utilizó como alimentación una disolución de $\alpha$-fenilglicina y ácido aspártico en proporción $1 / 1\left(\mathrm{C}_{\mathrm{A}(\text { asp }) i}=\mathrm{C}_{\mathrm{A}(\mathrm{pg} \mid \mathrm{y})}=8,14 \pm 0,17 \mathrm{~mol} / \mathrm{m}^{3}\right)$ y a $\mathrm{pH}_{\mathrm{i}}=5,17 \pm 0,07$. El $\mathrm{pH}$ del efluente que abandona la primera columna se modificó con la adición de microflujos de disoluciones de hidróxido de sodio $2 \mathrm{~N}$, empleando una bomba programable de jeringa. A la entrada de la $2^{\text {a }}$ columna, dicho efluente tiene un valor de $\mathrm{pH}=12$. El caudal de circulación en el sistema durante los experimentos fue constante, $Q=0,021 \times 10^{-6} \pm 0,002 \times$ $10^{-6} \mathrm{~m}^{3} / \mathrm{s}$. Como se ha detallado en el apartado 5.1.2.3, se han realizado dos tipos de experimentos:

- Ensayos Tipo I. Se colocó una toma de muestras a la salida de la primera columna. Las muestras de efluente se recogieron a intervalos de tiempo adecuados, analizándose la concentración de aminoácido según el procedimiento detallado en el apartado 5.1.3.3, y se determinó el perfil de la curva de ruptura en el primer lecho. En este caso, existe un desfase entre la primera columna y la segunda, y es necesario colocar una bomba peristáltica adicional que impulse el efluente desde la toma de muestra en sentido ascendente a la base de la segunda columna.

- Ensayos Tipo II. El efluente que sale de la primera columna pasa directamente a la segunda, modificándose únicamente su $\mathrm{pH}$ antes de entrar en la segunda columna. El efluente de salida de la segunda columna se recoge en varias fracciones analizándose la concentración de cada aminoácido y su pH.

La reextracción de los aminoácidos en cada una de las columnas de RIE se realizó utilizando como agente de reextracción disoluciones de $\mathrm{HCl}$ de concentración $1 \mathrm{~N}$ y $0,1 \mathrm{~N}$ y con flujo ascendente. Se recogieron varias fracciones midiéndose la concentración de cada aminoácido y su pH durante el proceso. Para el lavado del lecho de RIE, se procede de igual forma que en el apartado 5.1.3.8.

La concentración de cada aminoácido en fase acuosa se analizó mediante HPLC según el procedimiento detallado en el apartado 5.1.3.3. 


\subsection{RESULTADOS Y DISCUSIÓN: EQUILIBRIOS DE EXTRACCIÓN}

\subsubsection{Impregnación de Amberlita XAD-4 con TOMAC}

La impregnación de la resina Amberlita XAD-4 con Tomac disuelto en n-hexano se realizó mediante el procedimiento que se detalla en el apartado 5.1.3.5.

La concentración de Tomac en la resina después del proceso de impregnación, $\left[\overline{\mathrm{Q}^{+} \mathrm{Cl}^{-}}\right]$, se determinó experimentalmente por pesada de la resina antes y después de someterla al proceso de impregnación, calculándose en unidades de mol de Tomac $/ \mathrm{m}^{3} \mathrm{RSI}$ con la Ec. (5.1):

$$
\left[\overline{\mathrm{Q}^{+} \mathrm{Cl}^{-}}\right]=\frac{\left(\mathrm{m}_{\mathrm{RIE}}-\mathrm{m}_{\mathrm{RSI}}\right) \rho_{\mathrm{RSI}}}{\mathrm{M}_{\mathrm{Tomac}} \mathrm{m}_{\mathrm{RSI}}}=\frac{\overline{\mathrm{Q}^{+} \mathrm{Cl}^{-}} \rho_{\mathrm{RSI}}}{\mathrm{m}_{\mathrm{RSI}}}
$$

donde $m_{\mathrm{RSI}}$ es la masa de resina antes de someterla al proceso de impregnación, $\mathrm{m}_{\mathrm{RIE}}$ es la masa de resina impregnada, $\overline{\mathrm{Q}^{+} \mathrm{Cl}^{-}}$son los moles de Tomac impregnados en la resina, $M_{\text {Tomac }}$ es el peso molecular del extractante y $\rho_{\mathrm{RSI}}$ es la densidad de la resina sin impregnar.

Al objeto de evaluar el rendimiento total del proceso de impregnación, se determinó con la Ec. (5.2) la fracción de Tomac de la disolución de impregnación retenida en la resina:

$$
\% \text { Tomac impregnado }=100 \frac{\overline{\mathrm{Q}^{+} \mathrm{Cl}^{-}}}{\mathrm{Q}^{+} \mathrm{Cl}_{(\mathrm{I})}^{-}}
$$

donde $\mathrm{Q}^{+} \mathrm{Cl}_{(\mathrm{I})}^{-}$son los moles de Tomac en la disolución de impregnación.

Algunos autores justifican que el extractante no está químicamente enlazado a la matriz polimérica, sino que únicamente está inmovilizado por interacciones físicas rellenando gradualmente el volumen del poro del polímero adsorbente, empezando por los más pequeños y finalizando por los más grandes, dependiendo de la concentración de extractante de la disolución de impregnación (Cortina J.L. et al., 1994; Rovira M. et al., 1998; Strikovsky A.G. et al., 1998).

Bajo estas consideraciones, el proceso de impregnación o inmovilización del extractante estará afectado ante todo por las dimensiones del poro de la resina (volumen y diámetro de poro), y dependerá también de la superficie específica de la partícula y de la concentración de extractante en la disolución de impregnación.

La Figura 13 representa la concentración de Tomac en la $\left.\mathrm{RIE}, \overline{\mathrm{Q}^{+} \mathrm{Cl}^{-}}\right]$, frente a la concentración de Tomac en la disolución de impregnación. En dicha Figura se muestra que la concentración de Tomac en fase resina crece al aumentar la concentración de Tomac en la disolución de impregnación y permanece constante a partir de disoluciones de impregnación con una concentración de Tomac del $41 \%$ para la resina XAD-4. Por 
encima de esta concentración, la resina no admite más extractante, y adquiere un aspecto húmedo y pegajoso después del proceso de impregnación.

Estos resultados mostrados en la Figura 13 y en la Tabla $A 1$ del Apéndice $A$, indican que la capacidad máxima de impregnación de la resina XAD-4 con Tomac es $1110 \mathrm{~mol}$ de Tomac $/ \mathrm{m}^{3} \mathrm{RSI}$. En base a estudios previos realizados en nuestro laboratorio y para eliminar los efectos de desimpregnación de la resina, todos los ensayos con RIE, fueron realizados con concentraciones de Tomac inferiores al $25 \%$ de la concentración máxima admitida por la resina.

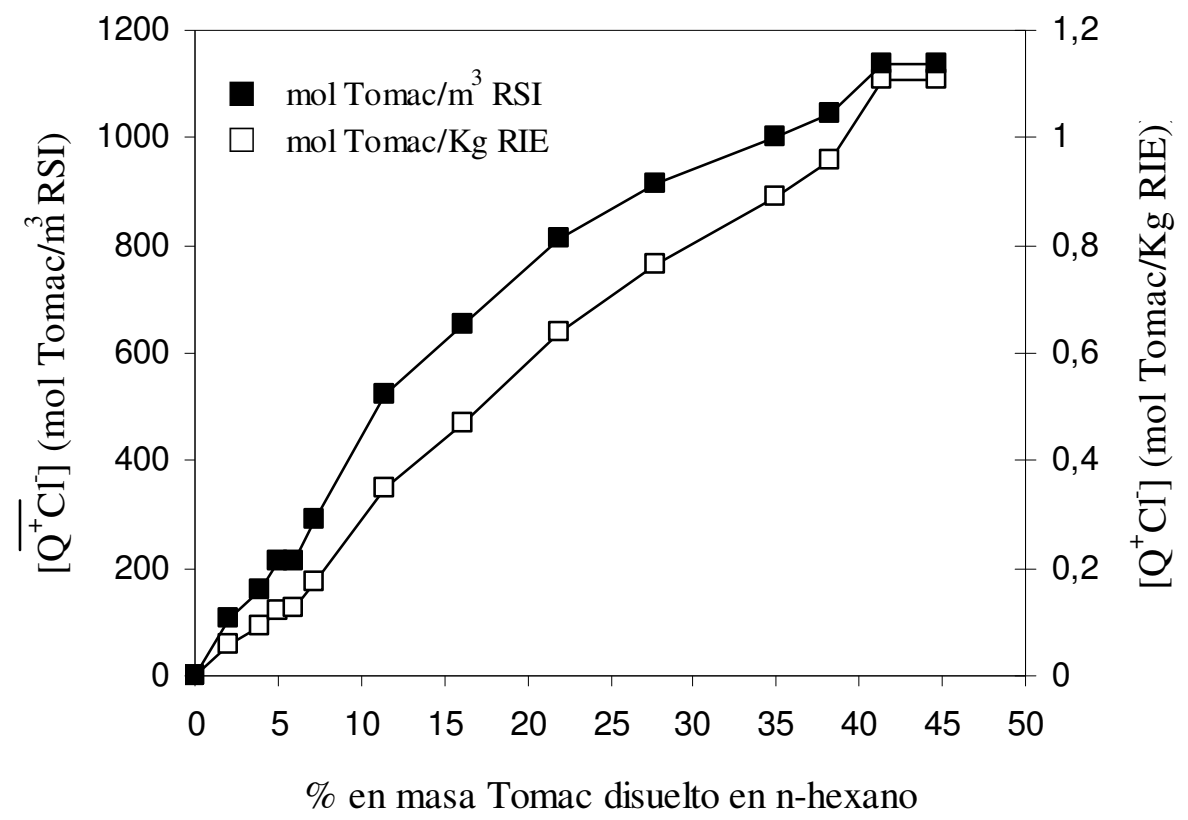

Figura 13. Impregnación de la resina Amberlita XAD-4 con Tomac. Efecto de la concentración de Tomac en la resina en función de la concentración de Tomac en la disolución de impregnación (Tomac disuelto en n-hexano).

Este estudio demuestra que el rendimiento del proceso de impregnación evaluado con la Ec. (5.2) fue superior al $92 \%$ en todos los experimentos realizados.

\section{Se puede concluir:}

- La capacidad máxima de impregnación de la resina XAD-4 con Tomac es 1110 mol de Tomac / $\mathrm{m}^{3}$ RSI. Para evitar efectos de desimpregnación todos los ensayos con RIE fueron realizados con concentraciones de Tomac inferiores al $25 \%$ de la concentración máxima admitida por la resina. 


\subsubsection{Ensayos con a-fenilglicina}

Las condiciones experimentales de las isotermas de equilibrio para la extracción de $\alpha$ fenilglicina con Amberlita XAD-4 impregnada con Tomac se han detallado en la Tabla 2 del apartado 5.1.3.6. Asimismo, se determinaron las isotermas de equilibrio de $\alpha$ fenilglicina con Amberlita XAD-4 sin impregnar bajo las mismas condiciones experimentales.

La concentración total de $\alpha$-fenilglicina en la fase resina, $\overline{\mathrm{C}}_{\mathrm{A}}$, expresada en $\mathrm{mol} / \mathrm{m}^{3}$ resina sin impregnar, se puede calcular con el siguiente balance de materia:

$$
\overline{\mathrm{C}}_{\mathrm{A}}=\left(\mathrm{C}_{\mathrm{Ai}}-\mathrm{C}_{\mathrm{A}}\right) \frac{\mathrm{V}}{\overline{\mathrm{V}}}
$$

donde $C_{A}$ es la concentración total o analítica de aminoácido calculada por el método detallado en el apartado 5.1.3.1, $\mathrm{V}$ es el volumen de las fases. El subíndice i hace referencia a condición inicial y la línea (superrayado) - hace referencia a la fase resina.

La concentración de las especies iónicas de $\alpha$-fenilglicina presentes en la mezcla acuosa se determinó teniendo en cuenta las constantes de disociación del aminoácido en la fase acuosa $\left(\mathrm{K}_{\mathrm{a} 1}, \mathrm{~K}_{\mathrm{a} 2}\right)$, la concentración analítica total del aminoácido, $\mathrm{C}_{\mathrm{A}(\mathrm{pg} \text { ly) }}$ y el $\mathrm{pH}$, con las siguientes ecuaciones:

$$
\begin{aligned}
& {\left[\mathrm{A}_{\mathrm{pgly}}^{+}\right]=\frac{\mathrm{C}_{\mathrm{A}(\mathrm{pgly})}\left[\mathrm{H}^{+}\right]^{2}}{\left[\mathrm{H}^{+}\right]^{2}+\mathrm{K}_{\mathrm{a} 1}\left[\mathrm{H}^{+}\right]+\mathrm{K}_{\mathrm{a} 1} \mathrm{~K}_{\mathrm{a} 2}}} \\
& {\left[\mathrm{~A}_{\mathrm{pgly}}^{+/-}\right]=\frac{\mathrm{C}_{\mathrm{A}(\mathrm{pgly})}\left[\mathrm{H}^{+}\right] \mathrm{K}_{\mathrm{a} 1}}{\left[\mathrm{H}^{+}\right]^{2}+\mathrm{K}_{\mathrm{a} 1}\left[\mathrm{H}^{+}\right]+\mathrm{K}_{\mathrm{a} 1} \mathrm{~K}_{\mathrm{a} 2}}} \\
& {\left[\mathrm{~A}_{\mathrm{pgly}}^{-}\right]=\frac{\mathrm{C}_{\mathrm{A}(\mathrm{pgly})} \mathrm{K}_{\mathrm{a} 1} \mathrm{~K}_{\mathrm{a} 2}}{\left[\mathrm{H}^{+}\right]^{2}+\mathrm{K}_{\mathrm{a} 1}\left[\mathrm{H}^{+}\right]+\mathrm{K}_{\mathrm{a} 1} \mathrm{~K}_{\mathrm{a} 2}}}
\end{aligned}
$$

Los datos de equilibrio obtenidos de las isotermas en los experimentos II y III se muestran en las Tablas B1 y B2 del apéndice $\mathrm{A}$. Los experimentos $\mathrm{VI}$ y $\mathrm{V}$ fueron determinados en estudios previos (Ruiz M. O. et al., 2002).

En la Figura 14 se representa la concentración de $\alpha$-fenilglicina en la fase resina frente a la concentración total de aminoácido en la fase acuosa en el equilibrio para los experimentos de la Tabla 2. 


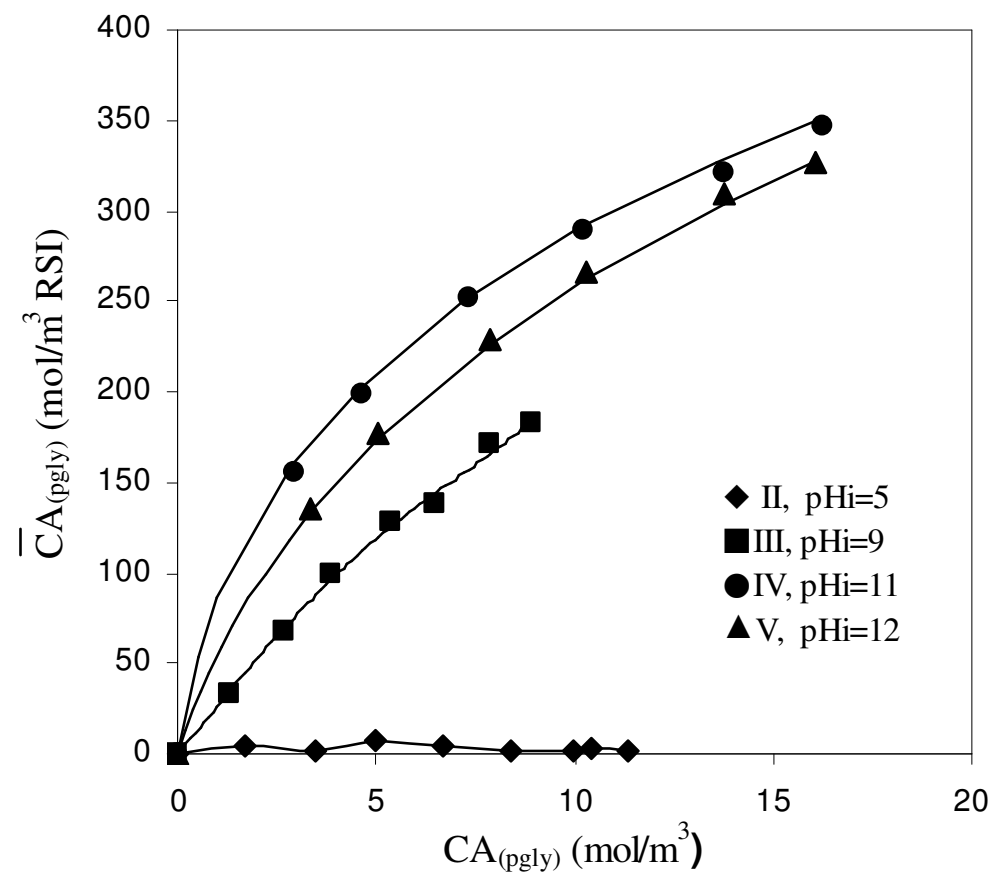

Figura 14. Isotermas de equilibrio de extracción de a-fenilglicina a $30^{\circ} \mathrm{C}$ con RIE para los experimentos II, III, IV y V de la Tabla 2. Concentración de RIE: $\left[\overline{\mathrm{Q}^{+} \mathrm{Cl}^{-}}\right]_{\mathrm{i}}=791,56 \pm 6,99$ $\mathrm{mol} / \mathrm{m}^{3} \mathrm{RSI}$. Experimentos IV y V (Ruiz M. O. et al., 2002).

Los experimentos de equilibrio de adsorción de $\alpha$-fenilglicina con $\mathrm{RSI}$ realizados a $\mathrm{pH}_{\mathrm{i}}=5$, 9, 11 y 12, correspondientes a los experimentos la-ld de la Tabla 2, presentan una adsorción despreciable del aminoácido, en el intervalo de concentraciones ensayado (no mostrados). Así, se puede considerar que no hay interacción entre la cadena orgánica del aminoácido y la matriz sólida de la resina, lo cuál puede deberse a efectos de repulsión de tipo electrostático.

La Figura 14 muestra que a $\mathrm{pH}_{\mathrm{i}}=5$ con RIE la extracción de $\alpha$-fenilglicina es despreciable, esto se debe a que a este $\mathrm{pH}$ la concentración de la forma aniónica extraíble, $\mathrm{A}^{\prime}$, que puede intercambiarse con los iones cloruro del extractante Tomac, es despreciable. Además, se observa que a $\mathrm{pH}=9,11$ y 12 la concentración de a-fenilglicina en la fase resina aumenta al aumentar la concentración de aminoácido en la fase acuosa y es mayor la extracción a $\mathrm{pH}=11$ que a pH=9 y 12 .

La diferencia existente entre las isotermas de equilibrio de $\alpha$-fenilglicina a $\mathrm{pH}=9,11$ y 12 se debe a la presencia, a $\mathrm{pH}=9$, de la forma anfótera $\mathrm{A}^{+/-}$(no extraíble por el extractante) en una proporción considerable junto a la especie aniónica extraíble del aminoácido $A$; mientras que a $\mathrm{pH}=11$ y 12 la forma aniónica es la especie predominante, lo cuál, hace que haya mayor extracción. La menor extracción a $\mathrm{pH}=12$ que a $\mathrm{pH}=11$ se debe al efecto de coextracción de iones hidroxilo, puesto que al trabajar a valores altos de $\mathrm{pH}$, los iones hidroxilo en la disolución compiten efectivamente con los aniones de aminoácido (Ruiz M. O. et al., 2002). El efecto de coextracción de iones hidroxilo resultó despreciable a pH=9. 


\subsubsection{Modelo para la estimación de las isotermas de equilibrio de $\alpha$-fenilglicina}

Con lo expuesto anteriormente se puede suponer:

1) La extracción de a-fenilglicina resultó despreciable a $\mathrm{pH}_{\mathrm{i}}=5\left(<\mathrm{pK}_{\mathrm{a} 2}=9,00\right)$, debido a que no existe especie aniónica extraíble, $\mathrm{A}^{\mathrm{A}}$, que pueda intercambiarse con los iones cloruro del extractante Tomac.

2) La resina Amberlita XAD-4 sin impregnar produce adsorciones despreciables de $\alpha$-fenilglicina incluso a $\mathrm{pH}=5$, por tanto se puede suponer que la adsorción física de los aminoácidos debida a la matriz polimérica es despreciable frente a la extracción reactiva con el extractante.

Con estas consideraciones, el proceso de extracción de a-fenilglicina y coextracción de iones hidroxilo con RIE se puede describir como un mecanismo de extracción reactiva debida únicamente al extractante Tomac impregnado en los poros de la resina mediante las siguientes ecuaciones químicas:

i) Disociación de $\alpha$-fenilglicina en la disolución acuosa con $\mathrm{pH}>\mathrm{pK}_{\mathrm{a} 2(\mathrm{pg} / \mathrm{y})}=9$ :

$$
\begin{aligned}
& \mathrm{A}_{\text {ply }}^{+}+\mathrm{H}_{2} \mathrm{O} \leftrightarrow \mathrm{A}_{\mathrm{pgly}}^{+/-}+\mathrm{H}_{3} \mathrm{O}^{+} \\
& \mathrm{K}_{\mathrm{a} 1 \text { (pgly) }}=\frac{\left[\mathrm{A}_{\mathrm{pgly}}^{+-}\right]\left[\mathrm{H}^{+}\right]}{\left[\mathrm{A}_{\mathrm{pgly}}^{+}\right]} \\
& \mathrm{A}_{\mathrm{ply}}^{+/-}+\mathrm{H}_{2} \mathrm{O} \leftrightarrow \mathrm{A}_{\mathrm{pgly}}^{-}+\mathrm{H}_{3} \mathrm{O}^{+} \\
& \mathrm{K}_{\mathrm{a} 2(\mathrm{pgly})}=\frac{\left[\mathrm{A}_{\mathrm{pgly}}^{-}\right]\left[\mathrm{H}^{+}\right]}{\left[\mathrm{A}_{\mathrm{pgly}}^{+--}\right]}
\end{aligned}
$$

ii) Reacción de intercambio iónico de $\alpha$-fenilglicina con el Tomac impregnado en la resina:

$$
\mathrm{A}_{\text {ply }}^{-}+\overline{\mathrm{Q}^{+} \mathrm{Cl}^{-}} \leftrightarrow \overline{\mathrm{Q}^{+} \mathrm{A}_{\mathrm{pgly}}^{-}}+\mathrm{Cl}^{-} \quad \mathrm{K}_{\mathrm{pl}(\mathrm{pgly})}=\frac{\left.\overline{\mathrm{Q}^{+} \mathrm{A}_{\mathrm{pgly}}^{-}}\right]\left[\mathrm{Cl}^{-}\right]}{\left.\overline{\mathrm{Q}^{+} \mathrm{Cl}^{-}}\right]\left[\mathrm{A}_{\mathrm{pgly}}^{-}\right]}
$$

iii) Coextracción de iones hidroxilo con el Tomac impregnado en la resina:

$\mathrm{OH}^{-}+\overline{\mathrm{Q}^{+} \mathrm{Cl}^{-}} \leftrightarrow \overline{\mathrm{Q}^{+} \mathrm{OH}^{-}}+\mathrm{Cl}^{-}$

$$
\mathrm{K}_{\mathrm{h}}=\frac{\left.\overline{\mathrm{Q}^{+} \mathrm{OH}^{-}}\right]\left[\mathrm{Cl}^{-}\right]}{\left[\overline{\mathrm{Q}^{+} \mathrm{Cl}^{-}}\right]\left[\mathrm{OH}^{-}\right]}
$$

donde $\mathrm{K}_{\mathrm{p} 1(\mathrm{pg} / \mathrm{y})}$ y $\mathrm{K}_{\mathrm{h}}$ son las constantes de equilibrio que rigen el proceso de intercambio iónico, el subíndice pgly hace referencia al aminoácido fenilglicina y el superrayado hace referencia a la fase resina.

Considerando que no hay agregación de las especies extraídas en fase resina y considerando que la solubilidad del Tomac en fase acuosa es despreciable, los balances de materia aplicados al Tomac y a los iones cloruro pueden expresarse mediante las siguientes ecuaciones:

$$
\begin{array}{r}
{\left[\overline{\mathrm{Q}^{+} \mathrm{Cl}^{-}}\right]_{\mathrm{i}}=\left[\overline{\mathrm{Q}^{+} \mathrm{Cl}^{-}}\right]+\left[\overline{\mathrm{Q}^{+} \mathrm{A}_{\mathrm{pgly}}^{-}}\right]+\left[\overline{\mathrm{Q}^{+} \mathrm{OH}^{-}}\right]} \\
{\left[\mathrm{Cl}^{-}\right]=\frac{\overline{\mathrm{V}}}{\mathrm{V}}\left\{\left[\overline{\mathrm{Q}^{+} \mathrm{A}_{\mathrm{pgly}}^{-}}\right]+\left[\overline{\mathrm{Q}^{+} \mathrm{OH}^{-}}\right]\right\}}
\end{array}
$$


donde, $\left.\left.\overline{\mathrm{Q}^{+} \mathrm{Cl}^{-}}\right], \overline{\mathrm{Q}^{+} \mathrm{A}_{\text {pgly }}^{-}}\right\rfloor$y $\left.\overline{\mathrm{Q}^{+} \mathrm{OH}^{-}}\right]$, son las concentraciones en el equilibrio en fase resina del extractante Tomac, del complejo a-fenilglicina-Tomac y del complejo iones hidroxilo-Tomac, respectivamente. Además, como muestra el balance de materia, Ec. (5.12), el proceso de intercambio es bimolecular, es decir, los iones $\mathrm{Cl}^{-}$son intercambiados estequiométricamente por los iones aminoácido y los iones hidroxilo.

La concentración de equilibrio de las especies $A^{+}, A^{+-}, A^{-}$del aminoácido en fase acuosa se calculó mediante las Ecs. (5.4) - (5.6) y se muestran, para los experimentos II y III, en las Tablas B1 y B2 del apéndice A. Los experimentos IV y $\mathrm{V}$ fueron determinados en estudios previos (Ruiz M. O. et al., 2002).

Teniendo en cuenta que únicamente la especie, $A^{\prime}$, de $\alpha$-fenilglicina es la que interviene en el proceso de extracción reactiva con Tomac, se demuestra que a $\mathrm{pH}=5$ no hay extracción al no existir esta especie.

Sólo se observó efecto de coextracción de iones hidroxilo en los experimentos IV y $\mathrm{V}$ de la Tabla 2 realizados a $\mathrm{pH}=11$ y 12 (Ruiz M. O. et al., 2002). Un análisis crítico de los resultados mostró que existe un comportamiento lineal entre extracción y coextracción, disminuyendo la coextracción al aumentar la concentración de aminoácido extraído, pudiéndose expresar mediante la siguiente expresión:

$$
\left.\left[\overline{\mathrm{Q}^{+} \mathrm{OH}^{-}}\right\rfloor=(\mathrm{f}-1) \overline{\mathrm{Q}^{+} \mathrm{A}_{\text {pgly }}^{-}}\right\rfloor+\mathrm{g}
$$

Los parámetros de ajuste $f$ y $g$ y sus regresiones se presentan en la Tabla 10. La pendiente de la línea recta (f) es un parámetro relacionado con la selectividad y definido como la relación entre la concentración de $\alpha$-fenilglicina y de iones hidroxilo extraídos, en el equilibrio. Tanto extracción como coextracción tienen lugar simultáneamente por reacciones de intercambio iónico con el Tomac inmovilizado en la resina, y ambas dependen por tanto de la concentración de aminoácido, para sistemas con igual concentración de extractante y mismo $\mathrm{pH}$ inicial.

Los valores de la constante de equilibrio $K_{p 1(p g l y),}$ definida en la $E c$ (5.9), se obtiene del ajuste de los datos de equilibrio de los experimentos III, IV y V de la Tabla 2 a una línea recta, mostrada en la Figura 15. Los valores obtenidos de $\mathrm{K}_{\mathrm{p} 1 \text { (pgly) }}$ se recogen en la Tabla 10.

Tabla 10. Constantes de equilibrio $\left(K_{p 1(p g l y)}\right)$ y parámetros de ajuste ( $f$ y $g$ ) del modelo de equilibrio de los experimentos de extracción de $\alpha$-fenilglicina con RIE a $30^{\circ} \mathrm{C}$ de la Tabla 2, r= regresión lineal.

\begin{tabular}{cccccc}
\hline \multirow{2}{*}{ Experimento } & $\mathrm{K}_{\mathrm{p} 1(\mathrm{pg} / \mathrm{y})}$ & $\mathrm{r}$ & $\mathrm{f}$ & $\mathrm{g}$ & $\mathrm{r}$ \\
& Ec.(5.9) & Ec (5.9) & Ec. (5.13) & Ec. (5.13) & Ec. (5.13) \\
\hline III & 0,211 & 0,995 & 1,00 & 0 & 0,999 \\
IV & 0,314 & 0,999 & 0,85 & 92 & 0,998 \\
V & 0,314 & 0,999 & 0,62 & 198 & 0,998 \\
\hline
\end{tabular}


Los resultados tabulados en la Tabla 10 indican que el efecto de coextracción es despreciable a $\mathrm{pH}=9$. Además, el valor de la constante de equilibrio, $\mathrm{K}_{\mathrm{p} 1(\mathrm{pg} / \mathrm{ly}) \text {, es similar en }}$ los tres casos.

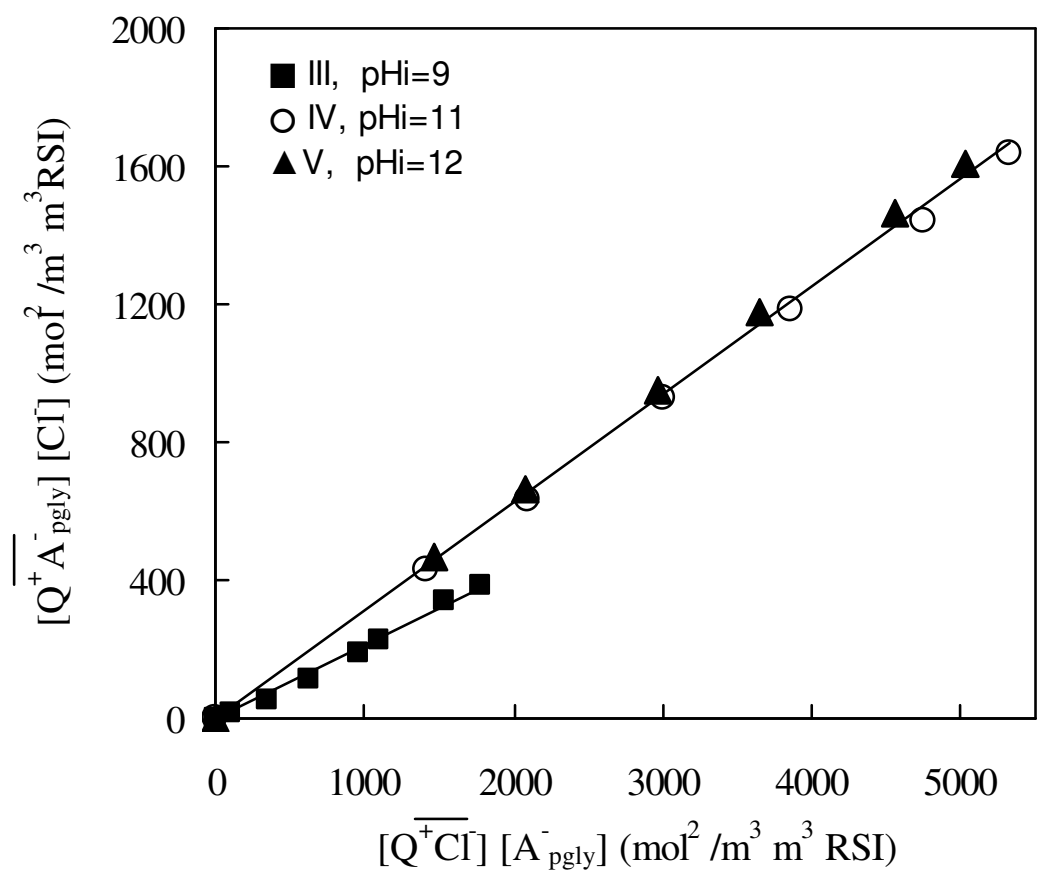

Figura 15. Determinación de la constante de equilibrio de $\alpha$-fenilglicina $K_{p 1(p g l y)}$ para los experimentos III, IV y V de la Tabla 2. Experimentos IV y V (Ruiz M. O. et al., 2002). Símbolos: datos experimentales.

Con la combinación de las Ecs. (5.9), (5.11)-(5.13) se obtiene el siguiente modelo de equilibrio que permite estimar la concentración total de $\alpha$-fenilglicina extraída por la RIE a cualquier valor de $\mathrm{pH}>9$ :

$\left[\overline{\mathrm{Q}^{+} \mathrm{A}_{\text {pgly }}^{-}}\right]=\sqrt{\left.\left(\frac{\mathrm{fVK}_{\text {plpgly }}\left[\mathrm{A}_{\text {ply }}^{-}\right]+\mathrm{g} \overline{\mathrm{V}}}{2 \mathrm{f} \overline{\mathrm{V}}}\right)^{2}+\frac{\mathrm{VK}_{\mathrm{pl}}\left[\mathrm{A}_{\mathrm{pgly}}^{-}\right]}{\mathrm{f} \overline{\mathrm{V}}}\left(\overline{\mathrm{Q}^{+} \mathrm{Cl}}\right]_{\mathrm{i}}-\mathrm{g}\right)}-\frac{\mathrm{fVK}_{\mathrm{pl}}\left[\mathrm{A}_{\mathrm{pgly}}^{-}\right]+\mathrm{g} \overline{\mathrm{V}}}{2 \mathrm{f} \overline{\mathrm{V}}}$

El error medio entre los valores experimentales y los calculados con la Ec. (5.14) para los sistemas en estudio se evaluaron con la siguiente ecuación:

$\%$ error promediado $=\frac{100}{\mathrm{j}} \sum_{1}^{\mathrm{j}} \frac{\left(\left(\overline{\mathrm{C}}_{\mathrm{A}}{ }_{\mathrm{Cal}}-\overline{\mathrm{C}}_{\mathrm{Axp}}\right)^{2}\right)^{1 / 2}}{\overline{\mathrm{C}}_{\mathrm{A}} \operatorname{Exp}}$ 
En la Figura 16 se comparan los resultados experimentales (símbolos) con los estimados mediante la Ec. (5.14) (líneas) para los experimentos III, IV y V de la Tabla 2, observándose una buena concordancia entre los datos experimentales y los calculados. El error medio calculado con la Ec. (5.15) fue inferior al 3\% en todos los experimentos.

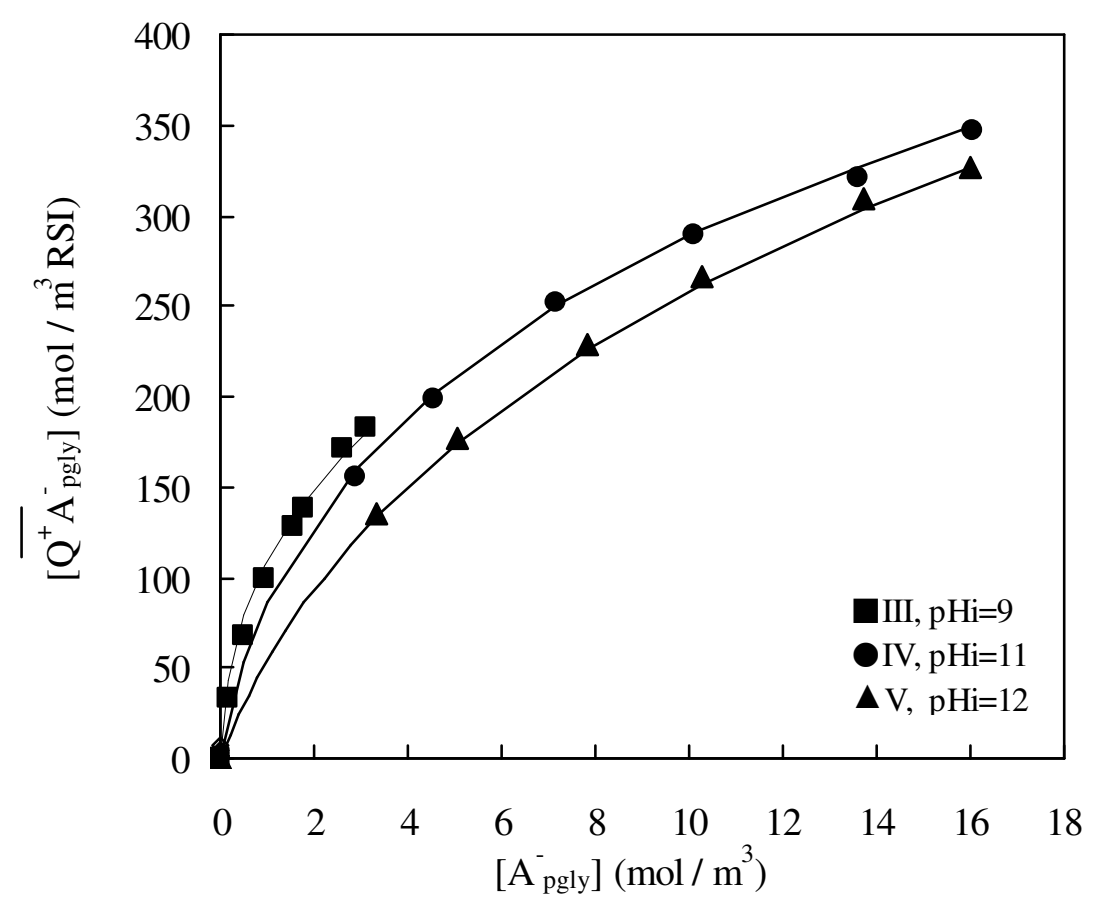

Figura 16. Isotermas de equilibrio de extracción individual de a-fenilglicina con RIE a $30^{\circ} \mathrm{C}$ para los experimentos III, IV y V de la Tabla 2. Experimentos IV y V (Ruiz M. O. et al., 2002). Símbolos: datos experimentales. Línea sólida: datos estimados con la Ec. (5.14).

En la Figura 16 se observa que a $\mathrm{pH}=9$ la extracción es ligeramente superior que a $\mathrm{pH}=11$ y 12 para la misma cantidad de especie $\mathrm{A}^{-}$, esto se debe a que no existe efecto de coextracción de iones hidroxilo a este pH. Esta extracción ligeramente superior es sólo aparente, puesto que al considerar la concentración total de aminoácido como suma de todas las especies presentes, como muestra la Figura 14, a pH=9 la extracción es menor debido a la presencia de especie $\mathrm{A}^{+/-}$no extraíble por el extractante, mientras que a $\mathrm{pH}=11$ y 12 , predomina la especie $\mathrm{A}^{-}$siendo, por tanto, su extracción mayor.

En base a los resultados alcanzados en este apartado, se puede concluir:

- La adsorción física de a-fenilglicina debida a la matriz polimérica de la resina fue despreciable en todos los casos.

- Solo se produce extracción del aminoácido cuando está presente la especie aniónica, es decir a $\mathrm{pH}>\mathrm{pK}_{\mathrm{a} 2}(=9)$. 
- La extracción de $\alpha$-fenilglicina con RIE-Tomac se produce por un mecanismo de intercambio iónico, mediante la formación del complejo $\mathrm{Q}^{+} \mathrm{A}^{-}$y la coextracción competitiva del complejo $\mathrm{Q}^{+} \mathrm{OH}^{-}$, debido a la presencia de iones hidroxilo en el medio.

- El modelo de equilibrio propuesto en la Ec. (5.14) ajustó satisfactoriamente los resultados experimentales y representa un modelo mecanicista de extracción reactiva del aminoácido y de coextracción de iones hidroxilo por efecto del Tomac inmovilizado en los poros de la resina. El modelo es aplicable a disoluciones acuosas a $\mathrm{pH}>9$.

\subsubsection{Ensayos con ácido aspártico}

Las condiciones experimentales de las isotermas de equilibrio para la extracción de ácido aspártico con Amberlita XAD-4 impregnada con Tomac se detallaron en la Tabla 3 del apartado 5.1.3.6.

La concentración total de aminoácido en fase acuosa fue calculada analíticamente por el método detallado en el apartado 5.1.3.2 y en fase resina, expresada en $\mathrm{mol} / \mathrm{m}^{3}$ resina sin impregnar, con el balance de materia expresado en la Ec. (5.3).

La concentración de las especies iónicas de ácido aspártico presentes en la mezcla acuosa se determinó teniendo en cuenta las constantes de disociación del aminoácido en la fase acuosa $\left(\mathrm{K}_{\mathrm{a} 1}, \mathrm{~K}_{\mathrm{a} 2}, \mathrm{~K}_{\mathrm{a} 3}\right)$, la concentración total del aminoácido y el $\mathrm{pH}$, con las siguientes ecuaciones:

$$
\begin{aligned}
& {\left[\mathrm{A}_{\mathrm{asp}}^{+}\right]=\frac{\mathrm{C}_{\mathrm{A}(\mathrm{asp})}\left[\mathrm{H}^{+}\right]^{3}}{\left[\mathrm{H}^{+}\right]^{3}+\mathrm{K}_{\mathrm{a} 1}\left[\mathrm{H}^{+}\right]^{2}+\mathrm{K}_{\mathrm{a} 1} \mathrm{~K}_{\mathrm{a} 2}\left[\mathrm{H}^{+}\right]+\mathrm{K}_{\mathrm{a} 1} \mathrm{Ka}_{2} \mathrm{~K}_{\mathrm{a} 3}}} \\
& {\left[\mathrm{~A}_{\mathrm{asp}}^{+/-}\right]=\frac{\mathrm{C}_{\mathrm{A}(\text { asp })}\left[\mathrm{H}^{+}\right]^{2} \mathrm{~K}_{\mathrm{a} 1}}{\left[\mathrm{H}^{+}\right]^{3}+\mathrm{K}_{\mathrm{a} 1}\left[\mathrm{H}^{+}\right]^{2}+\mathrm{K}_{\mathrm{a} 1} \mathrm{~K}_{\mathrm{a} 2}\left[\mathrm{H}^{+}\right]+\mathrm{K}_{\mathrm{a} 1} \mathrm{Ka}_{2} \mathrm{~K}_{\mathrm{a} 3}}} \\
& {\left[\mathrm{~A}_{\mathrm{asp}}^{-}\right]=\frac{\mathrm{C}_{\mathrm{A}(\text { asp })}\left[\mathrm{H}^{+}\right] \mathrm{K}_{\mathrm{a} 1} \mathrm{~K}_{\mathrm{a} 2}}{\left[\mathrm{H}^{+}\right]^{3}+\mathrm{K}_{\mathrm{a} 1}\left[\mathrm{H}^{+}\right]^{2}+\mathrm{K}_{\mathrm{a} 1} \mathrm{~K}_{\mathrm{a} 2}\left[\mathrm{H}^{+}\right]+\mathrm{K}_{\mathrm{a} 1} \mathrm{Ka}_{2} \mathrm{~K}_{\mathrm{a} 3}}} \\
& {\left[\mathrm{~A}_{\mathrm{asp}}^{2-}\right]=\frac{\mathrm{C}_{\mathrm{A}(\text { asp })} \mathrm{K}_{\mathrm{a} 1} \mathrm{~K}_{\mathrm{a} 2} \mathrm{~K}_{\mathrm{a} 3}}{\left[\mathrm{H}^{+}\right]^{3}+\mathrm{K}_{\mathrm{a} 1}\left[\mathrm{H}^{+}\right]^{2}+\mathrm{K}_{\mathrm{a} 1} \mathrm{~K}_{\mathrm{a} 2}\left[\mathrm{H}^{+}\right]+\mathrm{K}_{\mathrm{a} 1} \mathrm{Ka}_{2} \mathrm{~K}_{\mathrm{a} 3}}}
\end{aligned}
$$

Los datos de equilibrio de extracción de ácido aspártico, se muestran en las Tablas C1C5 del apéndice A. Asimismo, se determinaron las isotermas de equilibrio de ácido 
aspártico con Amberlita XAD-4 sin impregnar bajo las mismas condiciones experimentales, obteniéndose que a $\mathrm{pH}=9,11$ y 12 la adsorción de aminoácido y de iones hidroxilo es despreciable (no mostrado). Tan sólo en el experimento a $\mathrm{pH}=5$ se observó una ligera adsorción del aminoácido como se muestra en la Figura 17, donde se representa la concentración de ácido aspártico en la fase resina frente a la concentración total de aminoácido en la fase acuosa en el equilibrio para los experimentos de la Tabla 3.

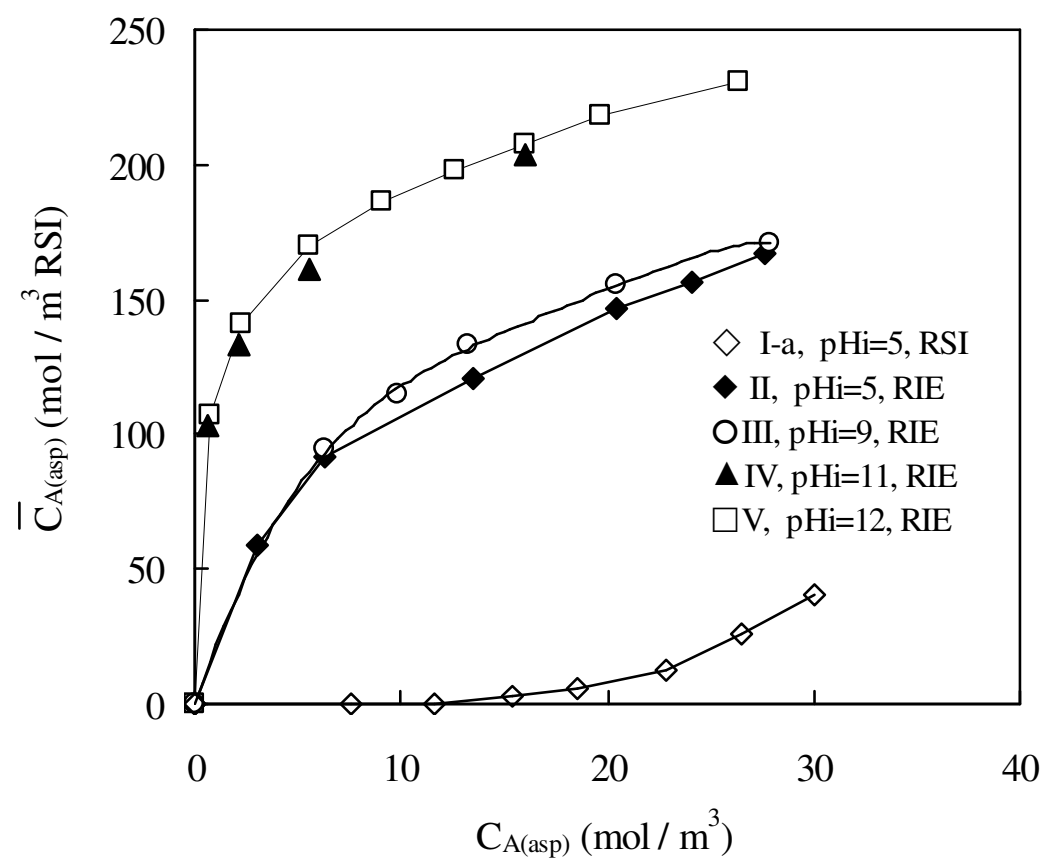

Figura 17. Isotermas de equilibrio de extracción de ácido aspártico a $30^{\circ} \mathrm{C}$ para los experimentos de la Tabla 3. $\left|\overline{\mathrm{Q}}^{+} \mathrm{Cl}^{-}\right|_{\mathrm{i}}=791,56 \pm 6,99 \mathrm{~mol} / \mathrm{m}^{3} \mathrm{RSI}$.

En la Figura 17 se observa que la extracción de aminoácido es mayor al aumentar su concentración en la fase acuosa para todos los valores de pH estudiados, obteniéndose mayor extracción a $\mathrm{pH}=11$ y 12 , donde la especie aniónica extraíble predominante es $\mathrm{A}^{2-}$, frente a $\mathrm{pH}=5$ y $9 \quad\left(\mathrm{pK}_{\mathrm{a} 2}<\mathrm{pH}<\mathrm{pK}_{\mathrm{a} 3}\right)$, donde $\mathrm{A}^{-}$es la especie aniónica extraíble predominante.

5.2.3.1 Modelo para la estimación de las isotermas de equilibrio de ácido aspártico a $\mathrm{pH}_{i}=5$ y 9

Los datos de equilibrio con la resina sin impregnar se pueden ajustar a una isoterma de adsorción de tipo Freundlich:

$$
\overline{\mathrm{C}}_{\mathrm{A}(\mathrm{asp})}=\mathrm{k}\left[\mathrm{A}_{\mathrm{asp}}^{-}\right]^{\mathrm{n}}
$$


donde $\overline{\mathrm{C}}_{\mathrm{A}(\mathrm{asp})}$ es la concentración de ácido aspártico en la fase resina en el equilibrio expresada en $\mathrm{mol} / \mathrm{m}^{3} \mathrm{RSI},\left[\mathrm{A}_{\mathrm{asp}}^{-}\right.$] es la concentración de la forma aniónica del aminoácido en fase acuosa en equilibrio. Los valores de las constantes $\mathrm{k}, \mathrm{n}$ y su regresión lineal se muestran en la Tabla 11, y se obtuvieron ajustando a una línea recta los logaritmos de la concentración de aminoácido en la fase acuosa y en la fase resina en el equilibrio.

En la Figura 18 se representa la concentración de equilibrio de ácido aspártico en fase resina frente a la concentración de equilibrio de aminoácido en su forma aniónica en fase acuosa para el experimento $\mathrm{I}-\mathrm{a}$ de la Tabla 3 realizado $\mathrm{a} \mathrm{pH}_{\mathrm{i}}=5$ con resina sin impregnar y a $30^{\circ} \mathrm{C}$. En esta Figura se comparan los resultados experimentales (símbolos) y los calculados con la Ec. (5.20) (curva sólida), observándose que el modelo propuesto, Ec. (5.20) ajusta satisfactoriamente los resultados experimentales.

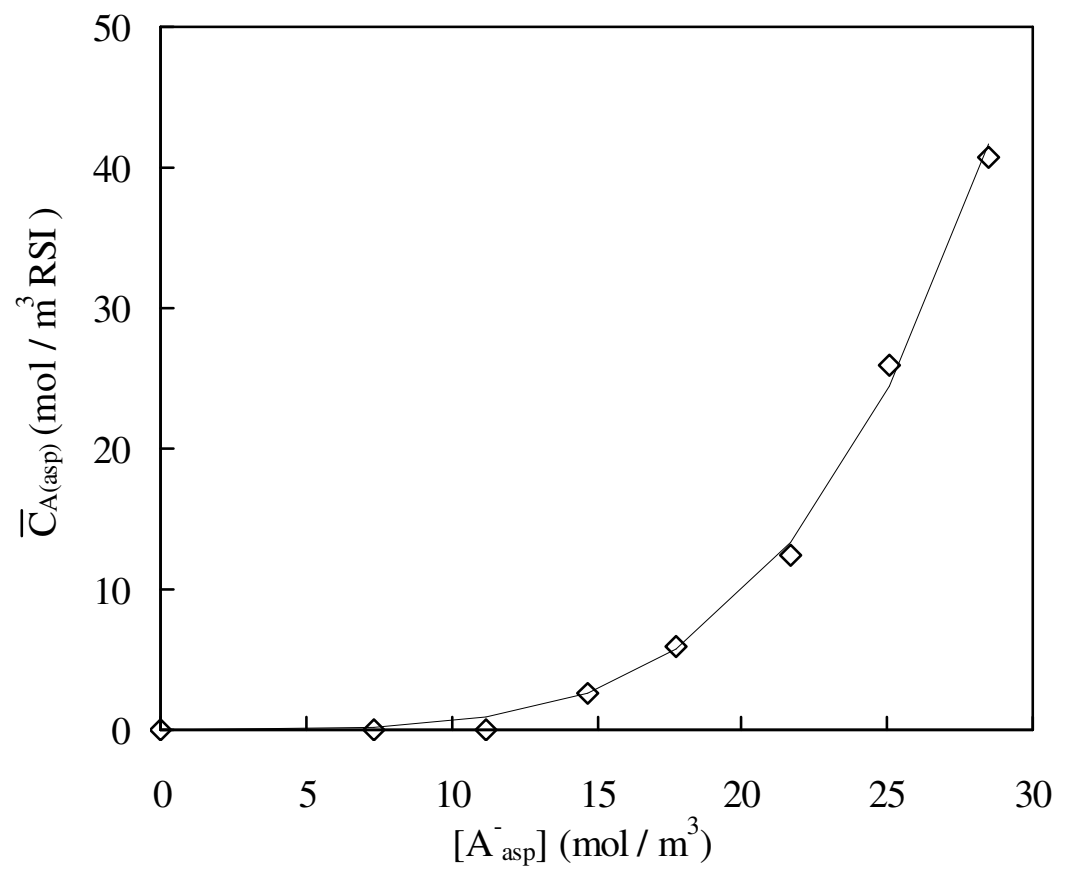

Figura 18. Ajuste de los resultados experimentales de equilibrio de adsorción de ácido aspártico con $\mathrm{RSI}$ a $30^{\circ} \mathrm{C}$ para el experimento $\mathrm{I}-\mathrm{a}\left(\mathrm{pH}_{\mathrm{i}}=5\right)$ de la Tabla 3. Símbolos: datos experimentales. Línea sólida: datos estimados con la Ec. (5.20).

En base a lo expuesto anteriormente, se puede considerar que:

1) La adsorción de iones hidroxilo debida a la matriz polimérica o al efecto de coextracción por intercambio iónico con el extractante resultó despreciable, no observándose disminución en el valor de $\mathrm{pH}$.

2) Aunque a $\mathrm{pH}=5$ hay una ligera adsorción del ácido aspártico por la matriz polimérica de la RSI, se puede considerar que es despreciable frente a la extracción reactiva del aminoácido con el extractante cuando la resina está impregnada. 
Así, el proceso de extracción de ácido aspártico de disoluciones acuosas a $\mathrm{pH}_{\mathrm{i}}=5$ y 9 $\left(\mathrm{pK}_{\mathrm{a} 2}<\mathrm{pH}<\mathrm{pK}_{\mathrm{a} 3}\right)$ con resina impregnada se puede describir como un mecanismo de extracción reactiva debida al extractante, descrito por las siguientes ecuaciones de equilibrio:

i) Disociación de ácido aspártico en la disolución acuosa con $\mathrm{pK}_{\mathrm{a} 2(\mathrm{asp})}=3,9<\mathrm{pH}<\mathrm{pK}_{\mathrm{a} 3(\mathrm{asp})}=9,8$ :

$\mathrm{A}_{\text {asp }}^{+}+\mathrm{H}_{2} \mathrm{O} \leftrightarrow \mathrm{A}_{\text {asp }}^{+/-}+\mathrm{H}_{3} \mathrm{O}^{+}$

$\mathrm{K}_{\mathrm{a}(\text { (asp) }}=\frac{\left[\mathrm{A}_{\text {asp }}^{+/-}\right]\left[\mathrm{H}^{+}\right]}{\left[\mathrm{A}_{\text {asp }}^{+}\right]}$

$\mathrm{A}_{\text {asp }}^{+/-}+\mathrm{H}_{2} \mathrm{O} \leftrightarrow \mathrm{A}_{\text {asp }}^{-}+\mathrm{H}_{3} \mathrm{O}^{+}$

$$
\mathrm{K}_{\mathrm{a} 2 \text { (asp) }}=\frac{\left[\mathrm{A}_{\text {asp }}^{-}\right]\left[\mathrm{H}^{+}\right]}{\left[\mathrm{A}_{\text {asp }}^{+/-}\right]}
$$

ii) Reacción de intercambio iónico del ácido aspártico con el Tomac impregnado en la resina:

$$
\mathrm{A}_{\text {asp }}^{-}+\overline{\mathrm{Q}^{+} \mathrm{Cl}^{-}} \leftrightarrow \overline{\mathrm{Q}^{+} \mathrm{A}_{\text {asp }}^{-}}+\mathrm{Cl}^{-} \quad \mathrm{K}_{\mathrm{pl}(\text { asp })}=\frac{\left.\overline{\mathrm{Q}^{+} \mathrm{A}_{\text {asp }}^{-}}\right]\left[\mathrm{Cl}^{-}\right]}{\left[\overline{\mathrm{Q}^{+} \mathrm{Cl}^{-}}\right]\left[\mathrm{A}_{\text {asp }}^{-}\right]}
$$

donde $\mathrm{K}_{\mathrm{p} 1}$ es la constante de equilibrio que rige el proceso de intercambio iónico del aminoácido con el Tomac inmovilizado en los poros de la resina, el subíndice asp hace referencia al ácido aspártico, y - hace referencia a la fase resina.

Suponiendo que no existe agregación de Tomac en fase resina y considerando que la solubilidad del Tomac en fase acuosa es despreciable, los balances de materia aplicados al Tomac y a los iones cloruro pueden expresarse mediante las siguientes ecuaciones:

$$
\begin{aligned}
& {\left[\overline{\mathrm{Q}^{+} \mathrm{Cl}^{-}}\right]_{\mathrm{i}}=\left[\overline{\mathrm{Q}^{+} \mathrm{Cl}^{-}}\right]+\left[\overline{\mathrm{Q}^{+} \mathrm{A}_{\text {asp }}^{-}}\right]} \\
& \left.\left[\mathrm{Cl}^{-}\right]=\frac{\overline{\mathrm{V}}}{\mathrm{V}}\left\{\overline{\mathrm{Q}^{+} \mathrm{A}_{\text {asp }}^{-}}\right]\right\}
\end{aligned}
$$

donde, $\left.\overline{\mathrm{Q}^{+} \mathrm{Cl}^{-}}\right\rfloor$es la concentración de Tomac en el equilibrio y $\left.\overline{\mathrm{Q}^{+} \mathrm{A}_{\text {asp }}^{-}}\right\rfloor$es la concentración del aminoácido en fase resina en el equilibrio. Las concentraciones de las especies que intervienen en el proceso de extracción para los experimentos II y III de la Tabla 3 se muestran en las Tablas C2 y C3 del apéndice A.

En la Figura 19 se representa el producto $\overline{\mathrm{Q}^{+} \mathrm{A}_{\text {asp }}^{-}} \mid\left[\mathrm{Cl}^{-}\right]$frente al producto $\left[\overline{\mathrm{Q}^{+} \mathrm{Cl}^{-}}\right]\left[\mathrm{A}_{\text {asp }}^{-}\right]$para los experimentos II y III de la Tabla 3. Mediante el ajuste de los resultados experimentales a una línea recta se obtiene el valor de la pendiente que es la constante de equilibrio $K_{\mathrm{p} 1(\mathrm{asp})}$, y cuyos valores se muestran en la Tabla 11, junto a su regresión lineal. 


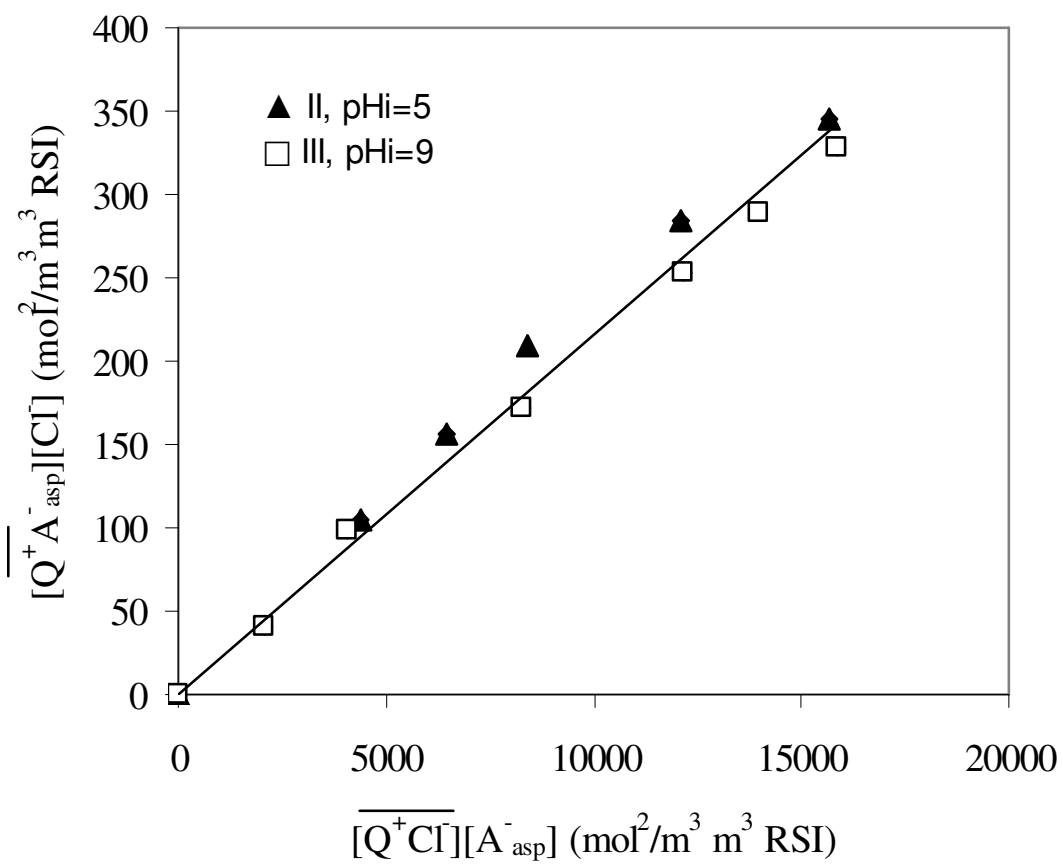

Figura 19. Determinación de la constante de equilibrio de ácido aspártico $\mathrm{K}_{\mathrm{p} 1 \text { (asp) }}$ definida en la Ec. (5.23) para los experimentos II y III de la Tabla 3. Símbolos: datos experimentales.

Combinando las Ecs. (5.23), (5.24) y (5.25) se obtiene el modelo de equilibrio siguiente:

$$
\left[\overline{\mathrm{Q}^{+} \mathrm{A}_{\mathrm{asp}}^{-}}\right]=\sqrt{\left.\left(\frac{\mathrm{VK}_{\mathrm{p} 1}\left[\mathrm{~A}_{\text {asp }}^{-}\right]}{2 \overline{\mathrm{V}}}\right)^{2}+\frac{\mathrm{VK}_{\mathrm{p} 1}\left[\mathrm{~A}_{\text {asp }}^{-}\right]\left[\overline{\mathrm{Q}^{+} \mathrm{Cl}}\right]}{\overline{\mathrm{V}}}\right] \mathrm{i}}-\frac{\mathrm{VK}_{\mathrm{p} 1}\left[\mathrm{~A}_{\text {asp }}^{-}\right]}{2 \overline{\mathrm{V}}}
$$

La Ec. (5.26) es una simplificación de la Ec. (5.14), expresión correspondiente al modelo de equilibrio calculado para la extracción de a-fenilglicina donde se han sustituido los parámetros $\mathrm{f}=1$ y $\mathrm{g}=0$ al no haber efecto de coextracción de iones hidroxilo.

Tabla 11. Constantes de equilibrio y parámetros de ajuste del modelo de equilibrio de los experimentos de adsorción y extracción de ácido aspártico I-a, II y III a $\mathrm{pH}_{\mathrm{i}}=5$ y 9 con $\mathrm{RSI}$ y RIE a $30^{\circ} \mathrm{C}$ mostrados en la Tabla 3 , regresión lineal.

\begin{tabular}{cccccc}
\hline \multirow{2}{*}{ Experimento } & $\mathrm{K}$ & $\mathrm{n}$ & $\mathrm{r}$ & $\mathrm{K}_{\mathrm{p} \text { (asp) }}$ & $\mathrm{r}$ \\
& Ec. (5.20) & Ec (5.20) & Ec. (5.20) & Ec. (5.23) & Ec. (5.23) \\
\hline I-a & $3,61 \times 10^{-5}$ & 4,166 & 0,999 & - & - \\
II & - & - & - & 0,022 & 0,993 \\
III & - & - & - & 0,022 & 0,993 \\
\hline
\end{tabular}


En la Figura 20 se observa una buena concordancia entre los datos experimentales (símbolos) y los calculados mediante la Ec. (5.26) para los experimentos II y III de la Tabla 3. El error medio calculado con la Ec. (5.15) fue inferior al 3\%.

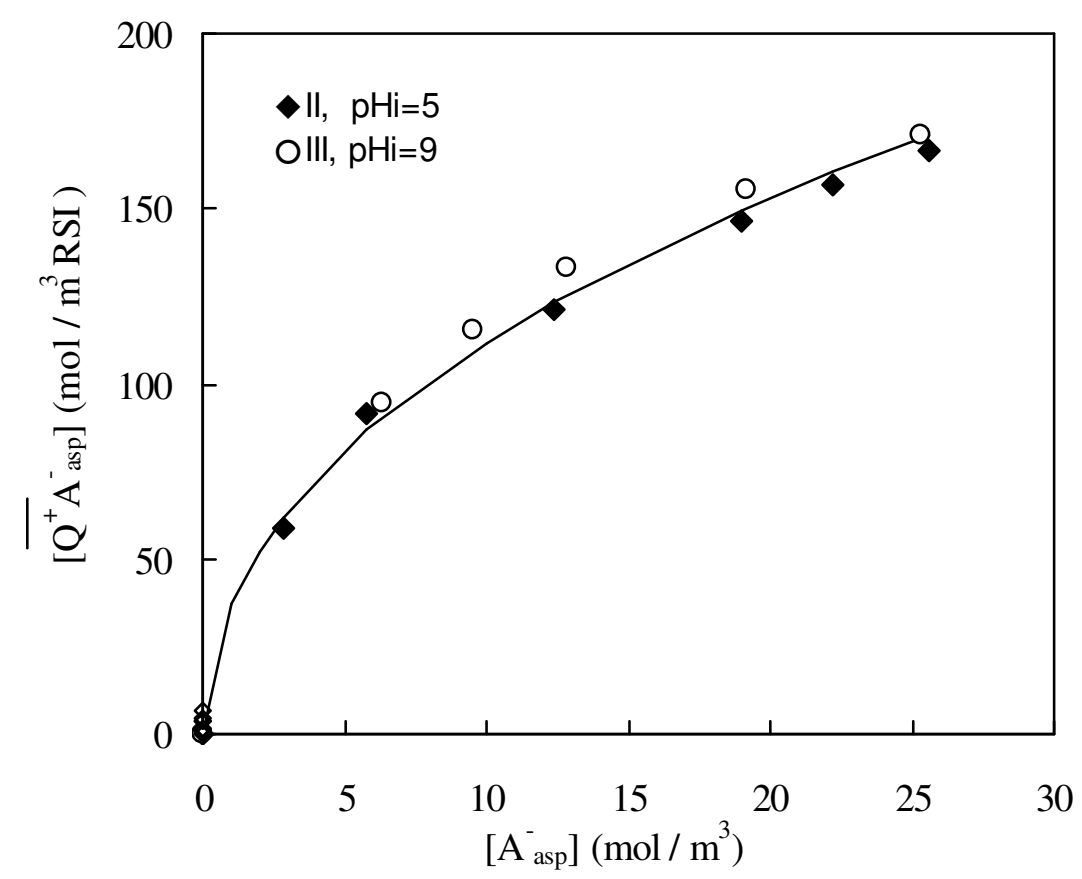

Figura 20. Isotermas de equilibrio de extracción individual de ácido aspártico con RIE a $30^{\circ} \mathrm{C}$ para los experimentos II y III de la Tabla 3. Símbolos: datos experimentales. Línea: datos estimados con la Ec. (5.26).

5.2.3.2 Modelo para la estimación de las isotermas de equilibrio de ácido aspártico a $\mathrm{pH}_{i=11}$ y 12

Al igual que en el apartado anterior, se puede suponer que no hay efecto de adsorción ni de extracción de iones hidroxilo, y que es despreciable el proceso de adsorción del aminoácido debido a la matriz polimérica de la RIE. Por tanto, el proceso de extracción de ácido aspártico con RIE a $\mathrm{pH}_{\mathrm{i}}=11$ y 12 , puede describirse como un mecanismo de extracción reactiva debida únicamente al Tomac impregnado en los poros de la resina, a través de las siguientes ecuaciones de equilibrio: 
i) Disociación de ácido aspártico en la disolución acuosa con $\mathrm{pH}>\mathrm{pK}_{\mathrm{a} 3(\mathrm{asp})}=9,8$ :

$$
\begin{array}{ll}
\mathrm{A}_{\text {asp }}^{+}+\mathrm{H}_{2} \mathrm{O} \leftrightarrow \mathrm{A}_{\text {asp }}^{+/-}+\mathrm{H}_{3} \mathrm{O}^{+} & \mathrm{K}_{\text {a1(asp) }}=\frac{\left[\mathrm{A}_{\text {asp }}^{+/-}\right]\left[\mathrm{H}^{+}\right]}{\left[\mathrm{A}_{\text {asp }}^{+}\right]} \\
\mathrm{A}_{\text {asp }}^{+/-}+\mathrm{H}_{2} \mathrm{O} \leftrightarrow \mathrm{A}_{\text {asp }}^{-}+\mathrm{H}_{3} \mathrm{O}^{+} & \mathrm{K}_{\text {a2(asp) }}=\frac{\left[\mathrm{A}_{\text {asp }}^{-}\right]\left[\mathrm{H}^{+}\right]}{\left[\mathrm{A}_{\text {asp }}^{+/-}\right]} \\
\mathrm{A}_{\text {asp }}^{-}+\mathrm{H}_{2} \mathrm{O} \leftrightarrow \mathrm{A}_{\text {asp }}^{2-}+\mathrm{H}_{3} \mathrm{O}^{+} & \mathrm{K}_{\text {a3(asp) }}=\frac{\left[\mathrm{A}_{\text {asp }}^{2-}\right]\left[\mathrm{H}^{+}\right]}{\left[\mathrm{A}_{\text {asp }}^{-}\right]}
\end{array}
$$

ii) Reacción de intercambio iónico del ácido aspártico con el Tomac impregnado en la resina:

$$
\mathrm{A}_{\text {asp }}^{2-}+2 \overline{\mathrm{Q}^{+} \mathrm{Cl}^{-}} \leftrightarrow \overline{\mathrm{Q}_{2}^{+} \mathrm{A}_{\text {asp }}^{2-}}+2 \mathrm{Cl}^{-} \quad \mathrm{K}_{\mathrm{p} 2 \text { (asp) }}=\frac{\left[\overline{\mathrm{Q}_{2}^{+} \mathrm{A}_{\text {asp }}^{2-}}\right]\left[\mathrm{Cl}^{-}\right]^{2}}{\left[\overline{\mathrm{Q}^{+} \mathrm{Cl}^{-}}{ }^{2}\left[\mathrm{~A}_{\text {asp }}^{2-}\right]\right.}
$$

donde $\mathrm{K}_{\mathrm{p} 2(\mathrm{asp})}$ es la constante de equilibrio que rige el proceso de intercambio iónico a $\mathrm{pH}=11$ y 12, el subíndice asp hace referencia al ácido aspártico, y - hace referencia a la fase resina.

Considerando que la solubilidad del Tomac en fase acuosa es despreciable, que no hay agregación de las especies extraídas en fase resina, y debido a que predomina la especie, $A^{2-}$, en fase acuosa, se puede considerar que la única especie en fase resina es $\left[\overline{\mathrm{Q}_{2}^{+} \mathrm{A}_{\text {asp }}^{2-}}\right]$. Así, los balances de materia aplicados al Tomac y a los iones cloruro, pueden expresarse mediante las siguientes ecuaciones:

$$
\begin{aligned}
& {\left[\overline{\mathrm{Q}^{+} \mathrm{Cl}^{-}}\right]_{\mathrm{i}}=\left[\overline{\mathrm{Q}^{+} \mathrm{Cl}^{-}}\right]+2\left[\overline{\mathrm{Q}_{2}^{+} \mathrm{A}_{\text {asp }}^{2-}}\right]} \\
& {\left[\mathrm{Cl}^{-}\right]=\frac{\overline{\mathrm{V}}}{\mathrm{V}} 2\left[\overline{\mathrm{Q}_{2}^{+} \mathrm{A}_{\text {asp }}^{2-}}\right]}
\end{aligned}
$$

donde, $\left.\left.\overline{\mathrm{Q}^{+} \mathrm{Cl}^{-}}\right], \overline{\mathrm{Q}_{2}^{+} \mathrm{A}_{\text {asp }}^{2-}}\right\rfloor$ son las concentraciones de Tomac y del complejo ácido aspártico-Tomac en fase resina, respectivamente.

Las concentraciones de las especies que intervienen en el proceso de extracción para el experimento IV y $\mathrm{V}$ de la Tabla 3 se muestran en la Tablas C4 y C5 del apéndice A.

La constante de equilibrio $\mathrm{K}_{\mathrm{p} 2(\text { asp })}$ se determinó con la representación lineal de los datos de equilibrio de los experimentos IV y V mostrados en la Figura 21. El valor de la pendiente es la constante de equilibrio $\mathrm{K}_{\mathrm{p} 2(\mathrm{asp})}=0,0019$ con una regresión lineal de 0,996. 


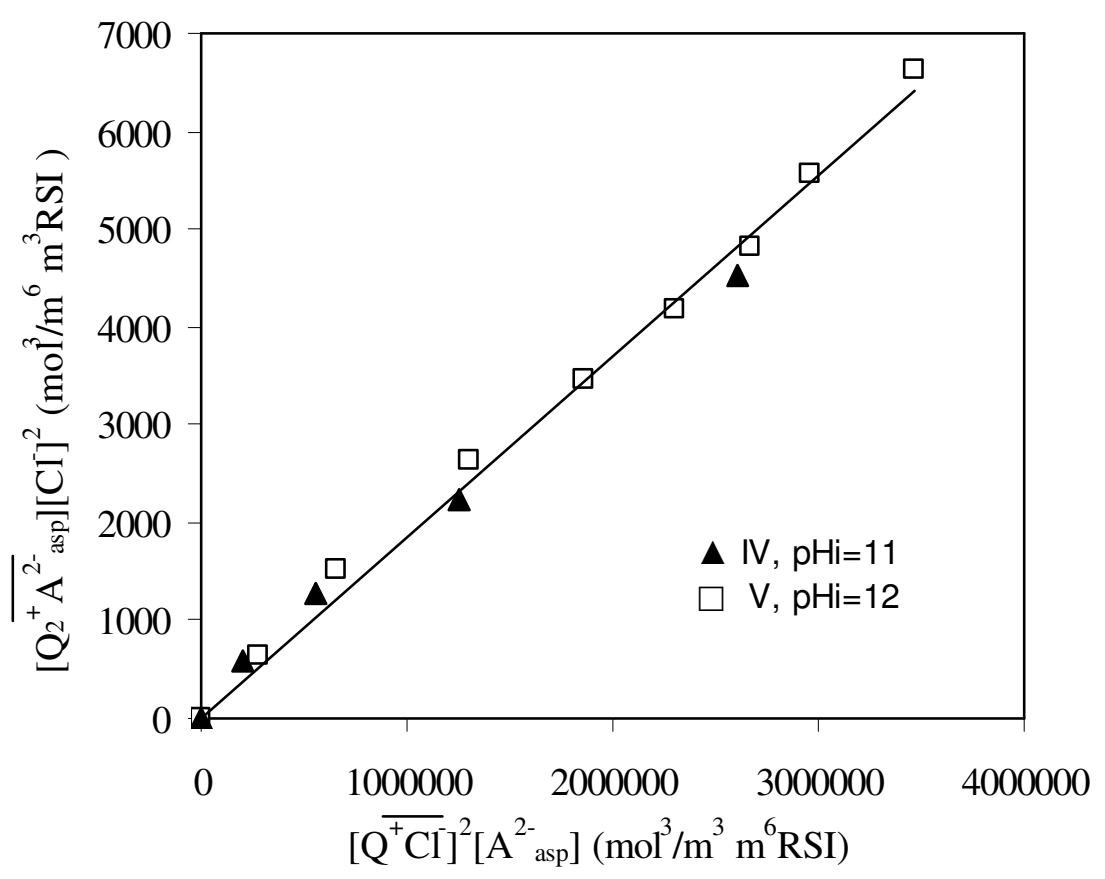

Figura 21. Determinación de la constante de equilibrio de ácido aspártico $\mathrm{K}_{\mathrm{p} 2 \text { (asp) }}$ definida en la Ec. (5.30) para los experimentos IV y V de la Tabla 3. Símbolos: datos experimentales.

El modelo de equilibrio propuesto para estimar la concentración de ácido aspártico en la fase resina, Ec. (5.33), se obtiene combinando las Ecs. (5.30), (5.31) y (5.32).

$$
\left.\left[\overline{\mathrm{Q}_{2}^{+} \mathrm{A}_{\text {asp }}^{2-}}\right]^{3}-\frac{\mathrm{V}^{2}}{\overline{\mathrm{V}}^{2}} \mathrm{~K}_{\text {p2(asp) }}\left[\mathrm{A}_{\text {asp }}^{2-}\right\}\left\{\left[\overline{\mathrm{Q}_{2}^{+} \mathrm{A}_{\text {asp }}^{2-}}\right]^{2}-\left[\overline{\mathrm{Q}^{+} \mathrm{Cl}^{-}}\right]_{\mathrm{i}}\left[\overline{\mathrm{Q}_{2}^{+} \mathrm{A}_{\text {asp }}^{2-}}\right]+\frac{\overline{\mathrm{Q}^{+} \mathrm{Cl}^{-}}}{4}\right]_{\mathrm{i}}^{2}\right\}=0
$$

La solución analítica de la Ec. (5.33) se muestra en las Ecs. (5.34) y (5.35). Este modelo de equilibrio permite estimar la concentración de ácido aspártico en la RIE para cualquier valor de $\mathrm{pH}>\mathrm{pK}_{\mathrm{a} 3}=9,8$ :

$$
\begin{aligned}
& {\left[\overline{\mathrm{Q}_{2}^{+} \mathrm{A}_{\text {asp }}^{2-}}\right]=\frac{\mathrm{j}}{3}+\frac{1}{6}\left\{-36 \mathrm{j}^{2}\left[\mathrm{Q}^{+} \mathrm{Cl}{ }^{-}\right]_{\mathrm{i}}+27 \mathrm{j}\left[\mathrm{Q}^{+} \mathrm{Cl}^{-}\right]_{\mathrm{i}}^{2}+8 \mathrm{j}^{3}+12 \sqrt{3} \sqrt{\frac{27 \mathrm{j}^{2}\left[\mathrm{Q}^{+} \mathrm{Cl}^{-}\right]_{\mathrm{i}}^{4}}{16}-\frac{\mathrm{j}^{3}\left[\mathrm{Q}^{+} \mathrm{Cl}^{-}\right]_{\mathrm{i}}^{3}}{2}}\right\}^{1 / 3}-} \\
& -\frac{2}{3}\left\{\frac{3 \mathrm{j}\left[\mathrm{Q}^{+} \mathrm{Cl}^{-}\right]_{\mathrm{i}}-\mathrm{j}^{2}}{\left(-36 \mathrm{j}^{2}\left[\mathrm{Q}^{+} \mathrm{Cl}^{-}\right]_{\mathrm{i}}+27 \mathrm{j}\left[\mathrm{Q}^{+} \mathrm{Cl}^{-}\right]_{\mathrm{i}}^{2}+8 \mathrm{j}^{3}+12 \sqrt{3} \sqrt{\frac{27 \mathrm{j}^{2}\left[\mathrm{Q}^{+} \mathrm{Cl}^{-}\right]_{\mathrm{i}}^{4}}{16}-\frac{\mathrm{j}^{3}\left[\mathrm{Q}^{+} \mathrm{Cl}^{-}\right]_{\mathrm{i}}^{3}}{2}}\right)^{1 / 3}}\right\}
\end{aligned}
$$




$$
\mathrm{j}=\frac{\mathrm{V}^{2}}{\overline{\mathrm{V}}^{2}} \mathrm{~K}_{\mathrm{p} 2 \text { (asp) }}\left[\mathrm{A}_{\text {asp2- }}^{2-}\right]
$$

En la Figura 22 se muestra la buena concordancia entre los datos de las isotermas de equilibrio experimentales (símbolos) y los estimados mediante el modelo propuesto en las Ecs. (5.33)-(5.35) (líneas sólidas). El error medio evaluado con la Ec. (5.15) fue menor del $3,2 \%$ para los experimentos IV y $\mathrm{V}$ de la Tabla 3.

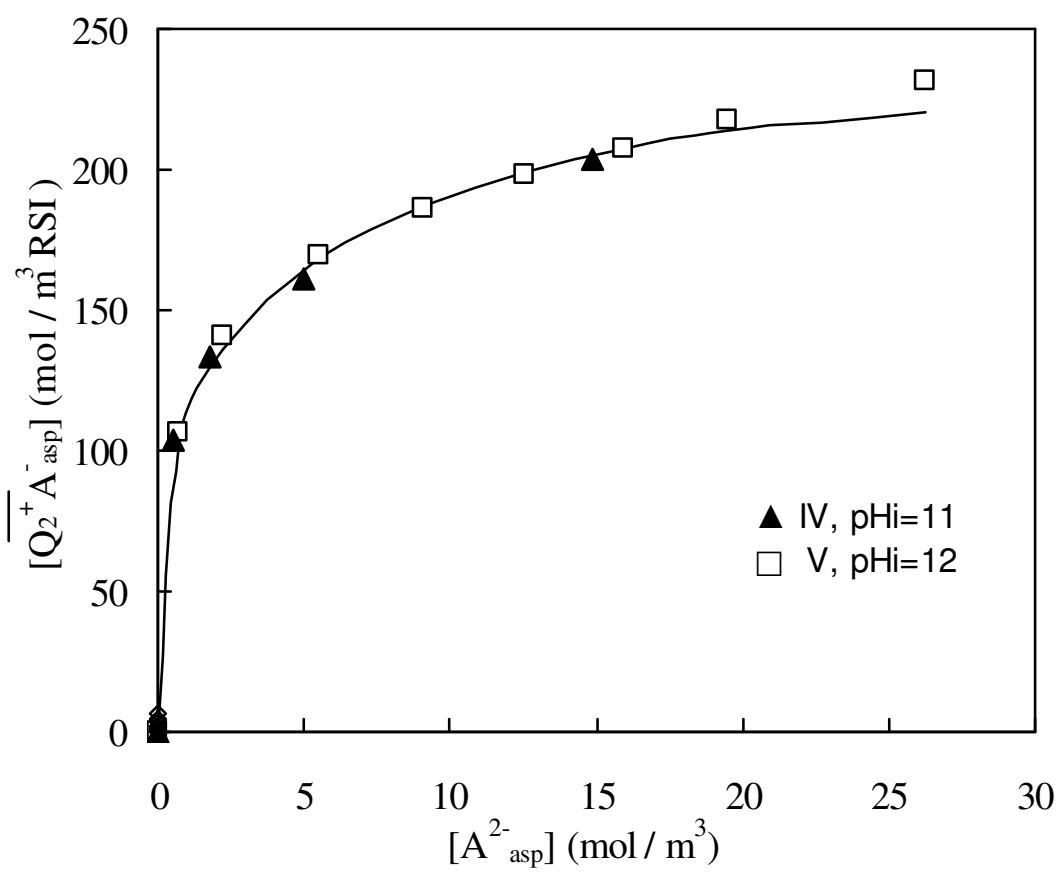

Figura 22. Isotermas de equilibrio de extracción de ácido aspártico con RIE a 30C para los experimentos IV y $\mathrm{V}$ de la Tabla 3. Símbolos: datos experimentales. Línea: datos estimados con las Ecs. (5.34) y (5.35).

Las conclusiones más relevantes de este apartado son:

- La adsorción física de ácido aspártico debida a la matriz polimérica de la resina y la coextracción de iones hidroxilo debida al Tomac inmovilizado en los poros de la resina fue despreciable en todos los experimentos realizados, a excepción del experimento a $\mathrm{pH}=5$ realizado con $\mathrm{RSI}$ donde se observó una pequeña adsorción, ajustándose los datos experimentales a una isoterma de adsorción de tipo Freundlich.

- El grado de extracción de ácido aspártico con resina XAD-4 impregnada con Tomac aumenta con la concentración del aminoácido en fase acuosa y al aumentar el pH, siendo la extracción igual para $\mathrm{pH}=11$ y 12 . Además, la igualdad entre las isotermas de extracción $\mathrm{a} \mathrm{pH}=5$ y 9 demuestra que la adsorción física es despreciable en comparación con la extracción debida al Tomac incluso a pH = 5 . 
- En disolución acuosa el ácido aspártico, como todos los aminoácidos, sufre una disociación dependiente del $\mathrm{pH}$. Para disoluciones acuosas con $\mathrm{pH}$ comprendido entre el $\mathrm{pK}_{\mathrm{a} 2}$ y el $\mathrm{pK}_{\mathrm{a} 3}(\mathrm{pH}=5)$ predomina la forma aniónica del aminoácido $A^{\text {; }}$, mientras que a $\mathrm{pH}$ superior al $\mathrm{pK}_{\mathrm{a} 3}(\mathrm{pH}=11$ y 12) predomina la forma aniónica del aminoácido $A^{2-}$. Así, la extracción de ácido aspártico con RIE tiene lugar por reacciones de intercambio iónico con el Tomac formando distintos complejos ácido aspártico - Tomac $\left(\mathrm{Q}^{+} \mathrm{A}^{-}, \mathrm{Q}_{2}^{+} \mathrm{A}^{2-}\right)$ dependiendo del $\mathrm{pH}$ del medio.

- La separación de ácido aspártico con Amberlita XAD-4 impregnada con Tomac puede describirse adecuadamente mediante un modelo de equilibrio, dependiente del valor del $\mathrm{pH}$, que considera la extracción reactiva de las especies iónicas del aminoácido. Los modelos matemáticos propuestos representados por las Ecs. (5.26) y (5.34) ajustan satisfactoriamente los resultados experimentales.

\subsubsection{Ensayos con mezclas binarias de ácido aspártico y a- fenilglicina}

La concentración total de cada aminoácido (ácido aspártico y $\alpha$-fenilglicina) en fase acuosa fue calculada por el método detallado en el apartado 5.1.3.3 y en la fase resina, con el balance de materia expresado en la Ec. (5.3).

La concentración de las especies iónicas del ácido aspártico se calculó con las Ecs. (5.16)-(5.19) recogidas en el apartado 5.2.3; y las de $\alpha$-fenilglicina con las Ecs. (5.4)-(5.6) mostradas en el apartado 5.2.2.

Las isotermas de equilibrio, determinadas bajo las condiciones experimentales mencionadas en el apartado 5.1.3.6 y en la Tabla $4\left(\mid \overline{\mathrm{Q}^{+} \mathrm{Cl}^{-}}\right)_{\mathrm{i}}=791,56 \pm 6,99 \mathrm{~mol} / \mathrm{m}^{3} \mathrm{RSI}$; temperatura constante de $30^{\circ} \mathrm{C} ; \mathrm{pH}_{\mathrm{i}}=5,11$ y $\left.12 ; \mathrm{C}_{\mathrm{A}(\text { asp })} / \mathrm{C}_{\mathrm{A}(\mathrm{pgly})}=1 / 1,1 / 2,1 / 3,2 / 1,3 / 1\right)$, se muestran en las Tablas D1-D15 del apéndice A y en las Figuras 23-27.

Asimismo, se determinaron las isotermas de equilibrio de reparto de ambos aminoácidos con RSI, bajo las mismas condiciones experimentales. Los resultados experimentales mostraron que la RSI no adsorbe aminoácido ni iones hidroxilo, debido principalmente a efectos de repulsión entre la matriz polimérica y los radicales que presentan carga.

En los experimentos de extracción conjunta de ambos aminoácidos con $\mathrm{RIE}$ a $\mathrm{pH}_{\mathrm{i}}=5$, la extracción de fenilglicina resultó despreciable, al no existir especie aniónica extraíble, $A^{-}$, que pueda intercambiarse con los iones cloruro del extractante Tomac, y únicamente se observa extracción de ácido aspártico a este pH. Además, en la Figura 23 se observa que a $\mathrm{pH}_{\mathrm{i}}=5$ las isotermas de extracción de ácido aspártico de las mezclas binarias (experimento I de la Tabla 4), presentan todas el mismo grado de extracción de ácido aspártico y consecuentemente, su extracción no depende de la presencia de $\alpha$ fenilglicina. 
En las Figuras 24 y 25 se representan las isotermas de equilibrio con $\mathrm{RIE}$ a $\mathrm{pH}_{\mathrm{i}}=11$ para la extracción conjunta de ácido aspártico y fenilglicina respectivamente, correspondiente al experimento II de la Tabla 4. En dichas figuras se observa que la extracción de cada aminoácido depende de su proporción en la mezcla, y más concretamente, al aumentar su proporción en la mezcla se consigue aumentar su grado de extracción.

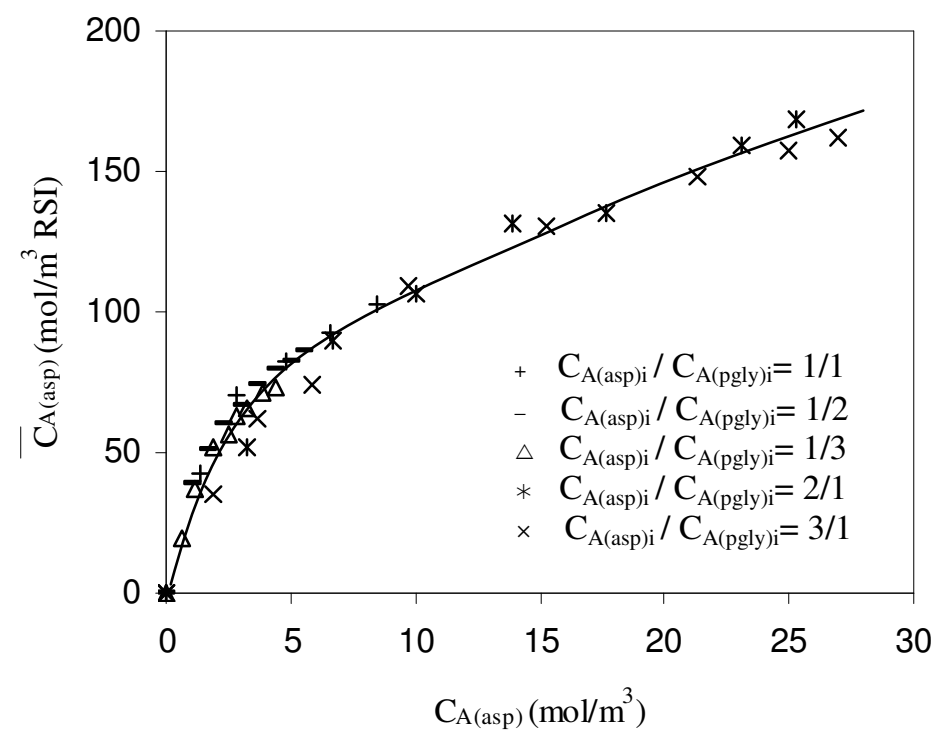

Figura 23. Isotermas de equilibrio de extracción de ácido aspártico de mezclas de ácido aspártico y a-fenilglicina con RIE a $30^{\circ} \mathrm{C}$ para el experimento I $\left(\mathrm{pH}_{\mathrm{i}}=5,03 \pm 0,06\right)$ de la Tabla 4. $\left[\overline{\mathrm{Q}^{+} \mathrm{Cl}^{-}}\right]_{\mathrm{i}}=791,56 \pm 6,99 \mathrm{~mol} / \mathrm{m}^{3} \mathrm{RSI}$.

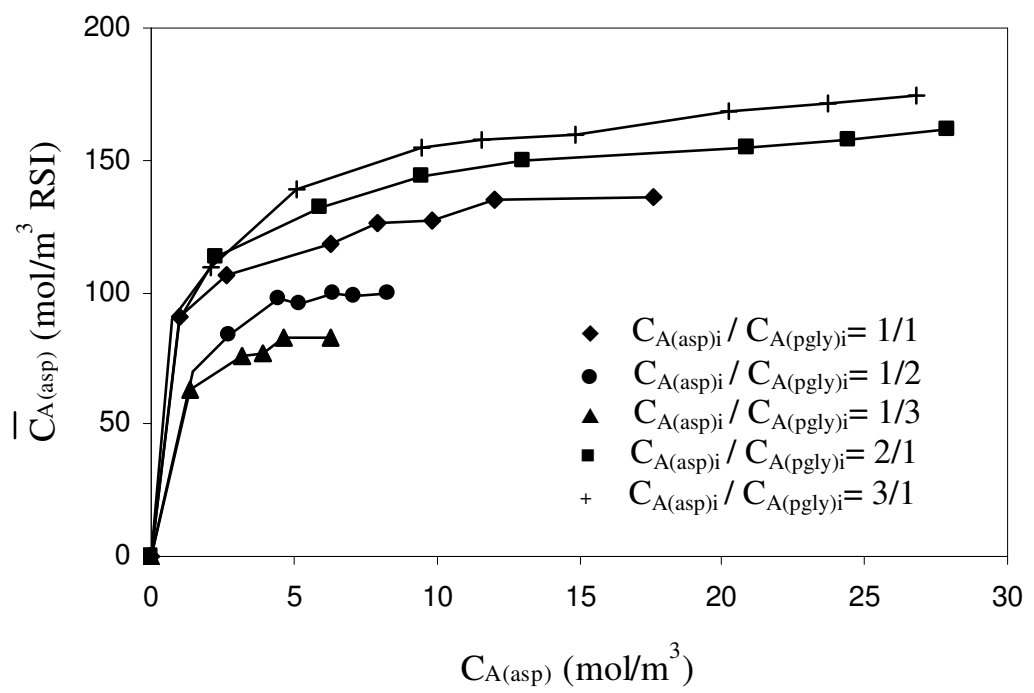

Figura 24. Isotermas de equilibrio de extracción de ácido aspártico de mezclas de ácido aspártico y a-fenilglicina con RIE a $30^{\circ} \mathrm{C}$ para el experimento II $\left(\mathrm{pH}_{\mathrm{i}}=11,06 \pm 0,04\right)$ de la Tabla 4. $\left.\overline{\mathrm{Q}^{+} \mathrm{Cl}^{-}}\right]_{\mathrm{i}}=791,56 \pm 6,99 \mathrm{~mol} / \mathrm{m}^{3} \mathrm{RSI}$. 


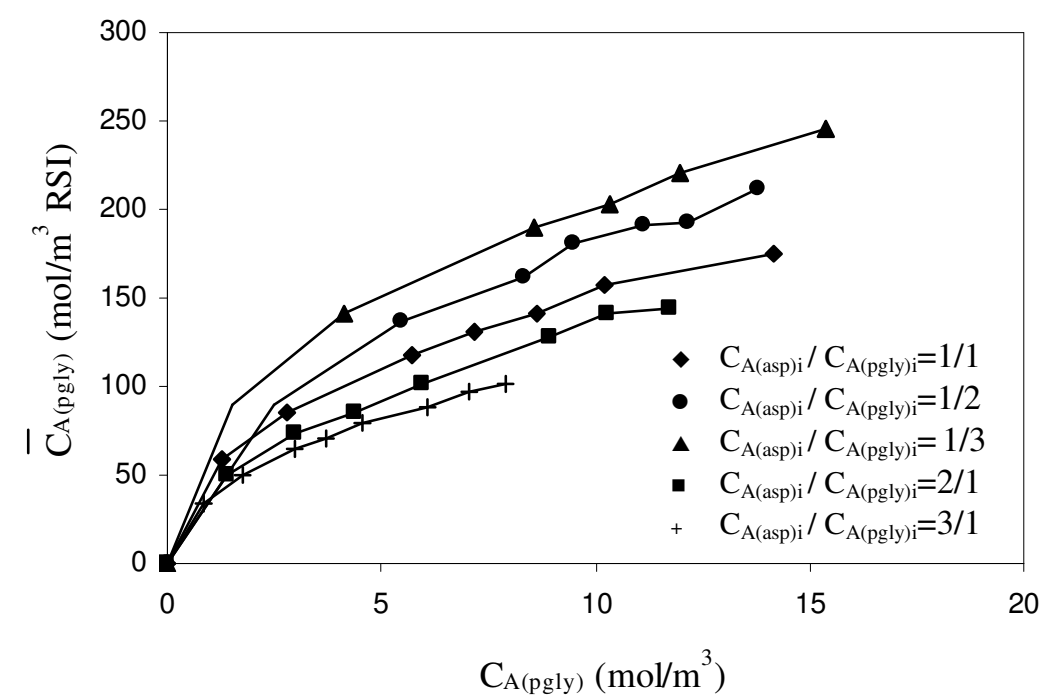

Figura 25. Isotermas de equilibrio de extracción de a-fenilglicina de mezclas de ácido aspártico y a-fenilglicina con RIE a $30^{\circ} \mathrm{C}$ para el experimento II $\left(\mathrm{pH}_{\mathrm{i}}=11,06 \pm 0,04\right)$ de la Tabla 4.; $\left[\mathrm{Q}^{+} \mathrm{Cl}^{-}{ }_{\mathrm{i}}=791,56 \pm 6,99 \mathrm{~mol} / \mathrm{m}^{3} \mathrm{RSI}\right.$.

Al igual que a $\mathrm{pH}_{\mathrm{i}}=11$, a $\mathrm{pH}_{\mathrm{i}}=12$ se obtiene que la extracción de cada aminoácido depende de su proporción en la mezcla como puede observarse en las Figuras 26 y 27. En dichas Figuras se muestran las isotermas de equilibrio a $\mathrm{pH}_{\mathrm{i}}=12$ para la extracción conjunta de ácido aspártico y $\alpha$-fenilglicina respectivamente, del experimento III de la Tabla 4. Además, los resultados experimentales muestran que a $\mathrm{pH}_{\mathrm{i}}=11$ y 12 no existen grandes diferencias en la extracción de ambos aminoácidos.

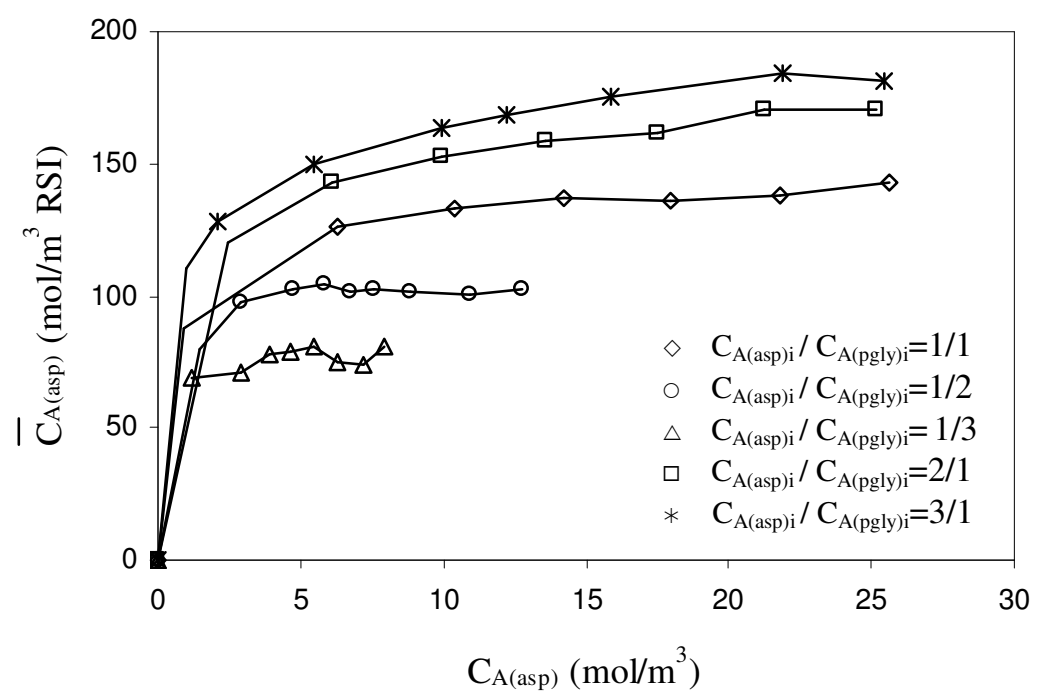

Figura 26. Isotermas de equilibrio de extracción de ácido aspártico de mezclas de ácido aspártico y a-fenilglicina con RIE a $30^{\circ} \mathrm{C}$ para el experimento III $\left(\mathrm{pH}_{\mathrm{i}}=12,02 \pm 0,06\right)$ de la Tabla 4.; $\left[\overline{\mathrm{Q}^{+} \mathrm{Cl}^{-}}\right]_{\mathrm{i}}=791,56 \pm 6,99 \mathrm{~mol} / \mathrm{m}^{3} \mathrm{RSI}$. 


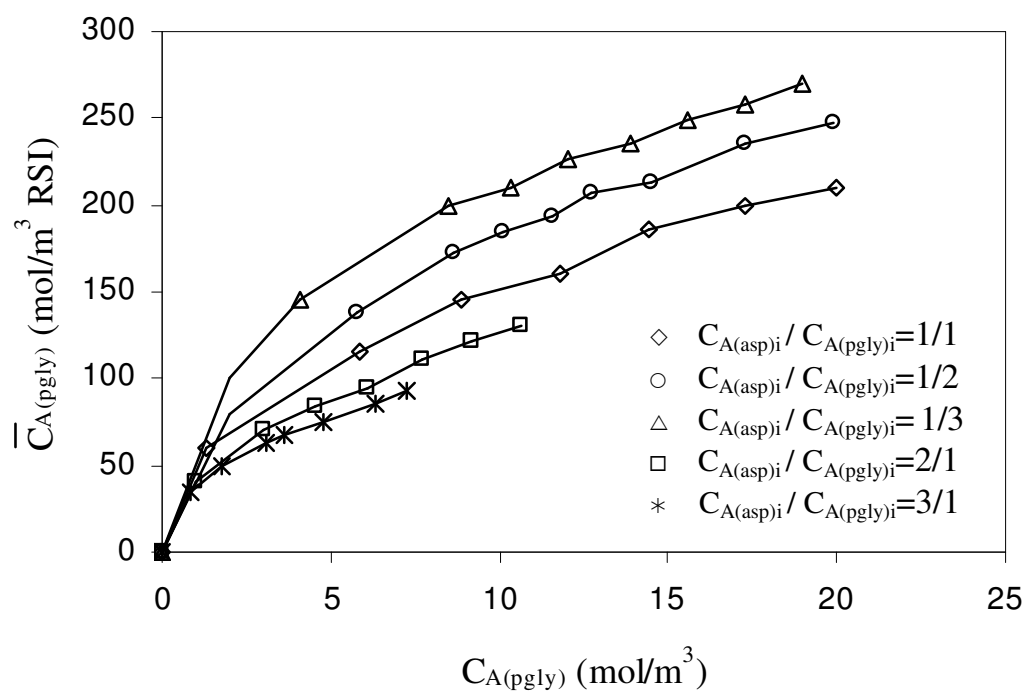

Figura 27. Isotermas de equilibrio de extracción $\alpha$-fenilglicina de mezclas de ácido aspártico y $\alpha$ fenilglicina con RIE a $30^{\circ} \mathrm{C}$ para el experimento III $\left(\mathrm{pH}_{\mathrm{i}}=12,02 \pm 0,06\right)$ de la Tabla 4.; $\left.\overline{\mathrm{Q}^{+} \mathrm{Cl}^{-}}\right|_{\mathrm{i}}=791,56 \pm 6,99 \mathrm{~mol} / \mathrm{m}^{3} \mathrm{RSI}$.

Una comparación de los resultados (Figuras 23-27), demuestra que el grado de extracción de los aminoácidos es mayor a $\mathrm{pH} \geq 11$, seleccionándose $\mathrm{pH}_{\mathrm{i}}=11$ y 12 para posteriores experimentos.

En la Figura 28 se representa la concentración total de aminoácido en la resina frente a la concentración total de aminoácido en la fase acuosa en el equilibrio, para los experimentos II y III de la Tabla 4. En esta figura se observa que a $\mathrm{pH}_{\mathrm{i}}=11$ y $12 \mathrm{la}$ extracción total aminoácido es similar y crece al aumentar proporcionalmente la concentración de $\alpha$-fenilglicina en la mezcla y al disminuir proporcionalmente la de ácido aspártico.

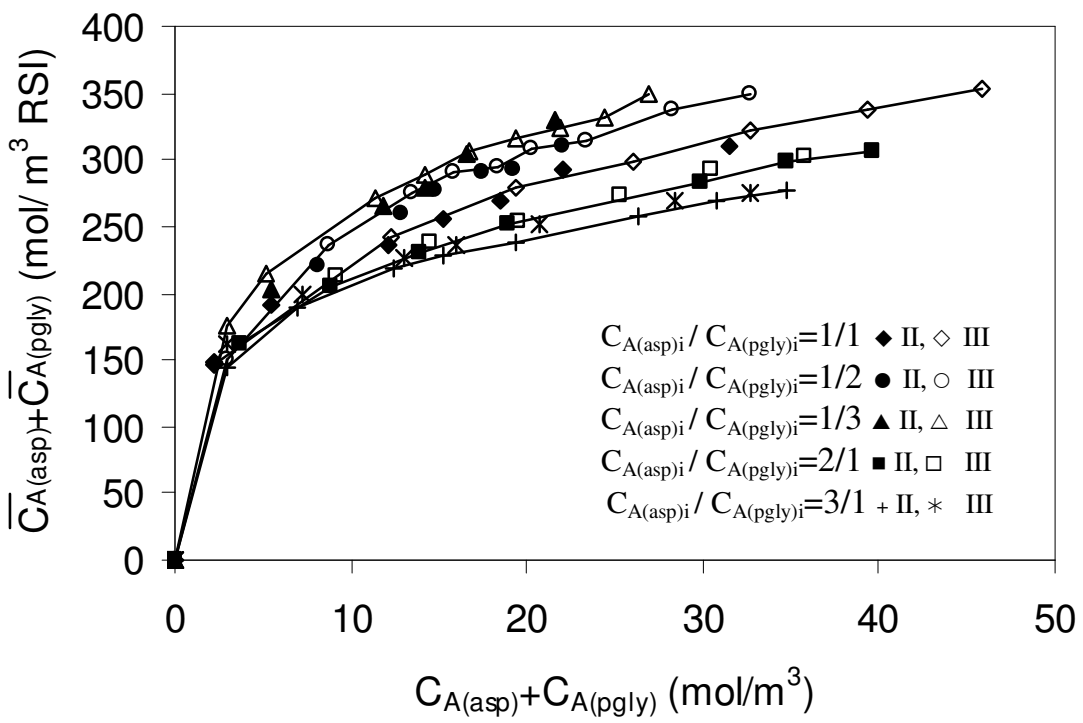

Figura 28. Isotermas de equilibrio de extracción total de aminoácido con RIE a $30^{\circ} \mathrm{C}$ para los experimentos II $\left(\mathrm{pH}_{\mathrm{i}}=11,06 \pm 0,04\right)$ y III $\left(\mathrm{pH}_{\mathrm{i}}=12,02 \pm 0,06\right)$ de la Tabla 4. 
5.2.4.1 Modelo para la estimación de las isotermas de equilibrio de mezclas binarias de ácido aspártico y $\alpha$-fenilglicina a $\mathrm{pH}_{i}=5$

Como se ha comentado anteriormente se puede considerar que:

1) La adsorción y la extracción de a-fenilglicina resultó despreciable $\left(\mathrm{pH}_{\mathrm{i}}=5<\mathrm{pK}_{\mathrm{a} 2}=9,00\right)$, al no existir especie aniónica extraíble, $\mathrm{A}$, que pueda intercambiarse con los iones cloruro del extractante Tomac.

2) Aunque la resina Amberlita XAD-4 sin impregnar produce una ligera adsorción física del ácido aspártico debida a la matriz polimérica, se puede suponer que esta es despreciable frente a la extracción reactiva con el extractante.

3) La adsorción y la coextracción de iones hidroxilo es despreciable a pH $=5$.

Bajo estas consideraciones, la extracción del ácido aspártico en presencia de fenilglicina con RIE, puede describirse como un mecanismo de extracción reactiva debida únicamente al Tomac impregnado en los poros de la resina y coincide con el modelo expuesto en el apartado 5.2.3.1 de la extracción individual de ácido aspártico obtenido de la combinación de las Ecs. (5.23), (5.24) y (5.25):

$$
\left[\overline{\mathrm{Q}^{+} \mathrm{A}_{\text {asp }}^{-}}\right]=\sqrt{\left(\frac{\mathrm{VK}_{\mathrm{p} 1}\left[\mathrm{~A}_{\text {asp }}^{-}\right]}{2 \overline{\mathrm{V}}}\right)^{2}+\frac{\mathrm{VK}_{\mathrm{p} 1}\left[\mathrm{~A}_{\text {asp }}^{-}\right]\left[\overline{\mathrm{Q}^{+} \mathrm{Cl}}\right]_{\mathrm{i}}}{\overline{\mathrm{V}}}}-\frac{\mathrm{VK}_{\mathrm{p} 1}\left[\mathrm{~A}_{\text {asp }}^{-}\right]}{2 \overline{\mathrm{V}}}
$$

donde $K_{p 1}$ es la constante de equilibrio que rige el proceso de intercambio iónico del aminoácido con el Tomac inmovilizado en los poros de la resina, el subíndice asp hace referencia al ácido aspártico, y el superrayado - hace referencia a la fase resina.

De forma análoga al apartado 5.2.3.1 se han determinado las concentraciones de las especies que intervienen en el proceso de extracción para el experimento I de la Tabla 4 que se muestran en las Tablas D1-D5 del apéndice A.

En la Figura 29 se representa el producto $\left.\overline{\left[\mathrm{Q}^{+} \mathrm{A}_{\text {asp }}^{-}\right.}\right]\left[\mathrm{Cl}^{-}\right]$frente al producto $\left[\mathrm{Q}^{+} \mathrm{Cl}^{-}\right]\left[\mathrm{A}_{\text {asp }}^{-}\right]$para el experimento I de la Tabla 4. La constante de equilibrio obtenida de la pendiente de la recta tiene un valor de $\mathrm{K}_{\mathrm{p} 1(\mathrm{asp})}=0,022 \pm 0,003$ con una regresión lineal de 0,993 . Como era de esperar, el valor de $K_{\mathrm{p} 1 \text { (asp) }}$ obtenido es idéntico al mostrado en la Tabla 11 para el experimento II de la Tabla 3, es decir el valor de la constante de equilibrio no se ve afectada por la presencia de $\alpha$-fenilglicina. 


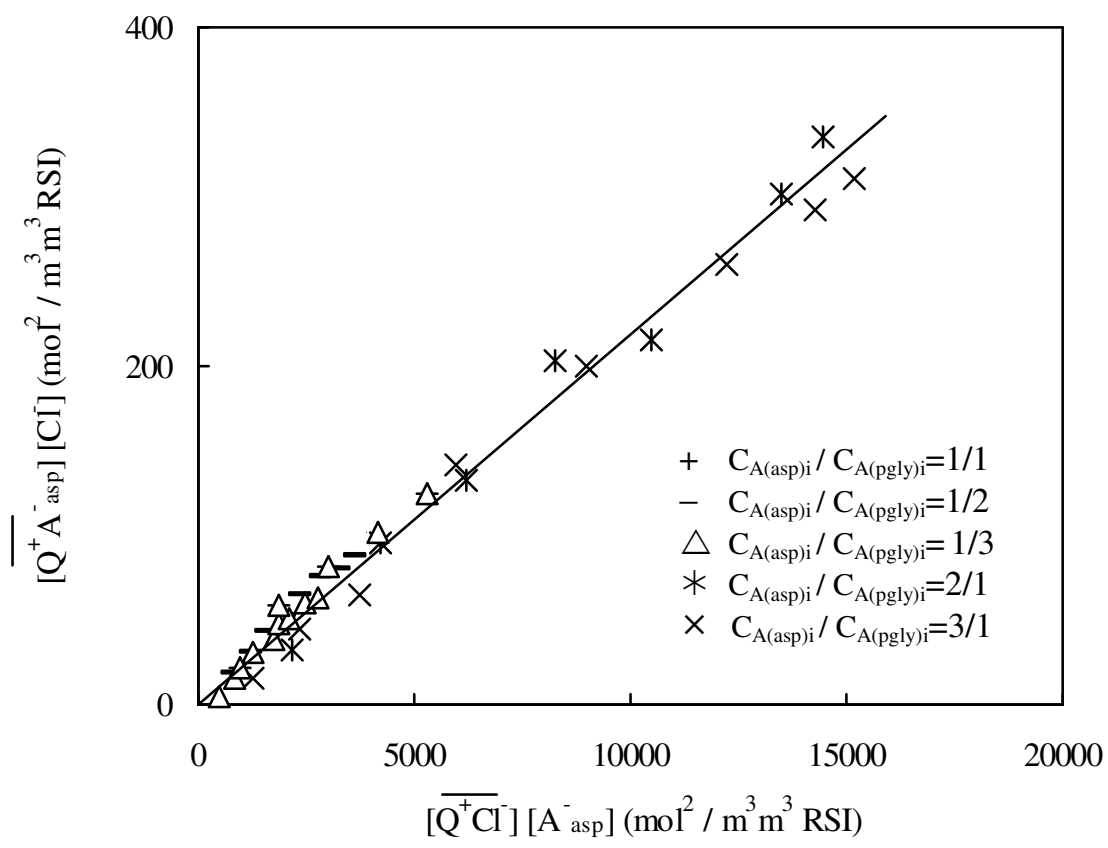

Figura 29. Determinación de la constante de equilibrio $\mathrm{K}_{\mathrm{p} 1 \text { (asp) }}$ para el experimento $\mathrm{I}\left(\mathrm{pH}_{\mathrm{i}}=\right.$ $5,03 \pm 0,06)$ de la Tabla 4. Símbolos: datos experimentales.

En la Figura 30 se muestra la buena concordancia existente entre los datos experimentales (símbolos), y los estimados con el modelo de equilibrio estimado mediante la Ec. (5.26) (curva sólida) para el experimento I de la Tabla 4. El error medio entre los datos experimentales y predichos calculado mediante la Ec. (5.15) fue inferior al $3 \%$ en todos los sistemas del experimento I.

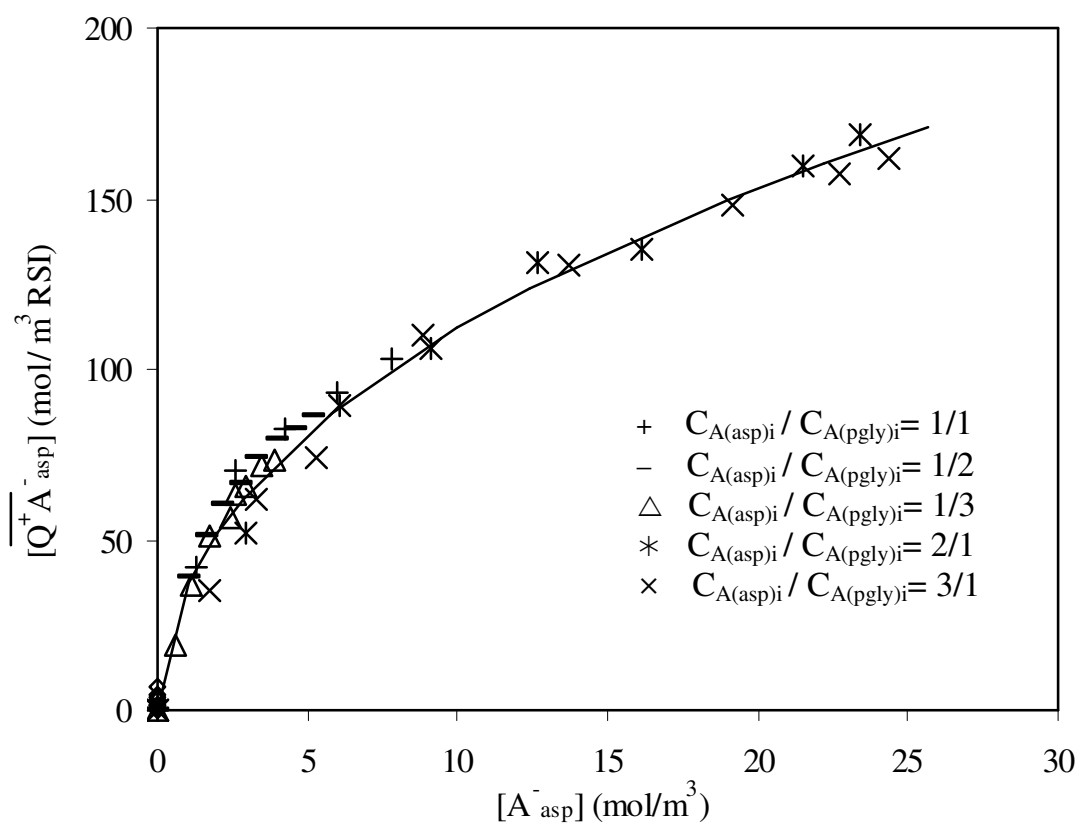

Figura 30. Isotermas de equilibrio de extracción de ácido aspártico de mezclas de ácido aspártico y a-fenilglicina con RIE a $30^{\circ} \mathrm{C}$ para el experimento I $\left(\mathrm{pH}_{\mathrm{i}}=5,03 \pm 0,06\right)$ de la Tabla 4 . $\left[\overline{\mathrm{Q}^{+} \mathrm{Cl}^{-}}\right]_{\mathrm{i}}=791,56 \pm 6,99 \mathrm{~mol} / \mathrm{m}^{3} \mathrm{RSI}$. Símbolos: datos experimentales. Línea sólida: datos estimados con la Ec. (5.26). 
5.2.4.2 Modelo para la estimación de las isotermas de equilibrio de mezclas binarias de ácido aspártico y $\alpha$-fenilglicina a $\mathrm{pH}_{i=11}$ y 12

Se ha comprobado experimentalmente, que la adsorción de los aminoácidos debida a la matriz polimérica es despreciable a todos los $\mathrm{pH}$ ensayados y que no hay disminución del pH durante el proceso de extracción, es decir, la adsorción de los iones hidroxilo debida a la matriz polimérica y la coextracción de los mismos debida a la reacción de intercambio iónico con el extractante Tomac es despreciable. Bajo estas consideraciones y como en casos anteriores, la extracción simultánea de ácido aspártico y a-fenilglicina de sus mezclas binarias con RIE, puede describirse como un mecanismo de extracción reactiva debida únicamente al Tomac impregnado en los poros de la resina. Las ecuaciones de equilibrio que describen este mecanismo de extracción son:

i) Disociación de $\alpha$-fenilglicina en la disolución acuosa con $\mathrm{pH}>\mathrm{pK}_{\mathrm{a} 2(\mathrm{pg} \mid \mathrm{y})}=9$ :

$$
\begin{array}{ll}
\mathrm{A}_{\mathrm{pgly}}^{+}+\mathrm{H}_{2} \mathrm{O} \leftrightarrow \mathrm{A}_{\mathrm{pgly}}^{+/-}+\mathrm{H}_{3} \mathrm{O}^{+} & \mathrm{K}_{\mathrm{a} 1 \text { (pgly) }}=\frac{\left[\mathrm{A}_{\mathrm{pgly}}^{+/-}\right]\left[\mathrm{H}^{+}\right]}{\left[\mathrm{A}_{\mathrm{pgly}}^{+}\right]} \\
\mathrm{A}_{\mathrm{pgly}}^{+/-}+\mathrm{H}_{2} \mathrm{O} \leftrightarrow \mathrm{A}_{\mathrm{pgly}}^{-}+\mathrm{H}_{3} \mathrm{O}^{+} & \mathrm{K}_{\mathrm{a} 2 \text { (pgly) }}=\frac{\left[\mathrm{A}_{\mathrm{pgly}}^{-}\right]\left[\mathrm{H}^{+}\right]}{\left[\mathrm{A}_{\mathrm{pgly}}^{+/-}\right]}
\end{array}
$$

ii) Disociación de ácido aspártico en la disolución acuosa con $\mathrm{pH}>\mathrm{pK}_{\mathrm{a} 3(\mathrm{asp})}=9,8$ :

$\mathrm{A}_{\text {asp }}^{+}+\mathrm{H}_{2} \mathrm{O} \leftrightarrow \mathrm{A}_{\text {asp }}^{+/-}+\mathrm{H}_{3} \mathrm{O}^{+}$

$$
\begin{aligned}
& \mathrm{K}_{\mathrm{a} 1 \text { (asp) }}=\frac{\left.\left\lfloor\mathrm{A}_{\text {asp }}^{+/-}\right\rfloor \mid \mathrm{H}^{+}\right\rfloor}{\left[\mathrm{A}_{\text {asp }}^{+}\right]} \\
& \mathrm{K}_{\mathrm{a} 2 \text { (asp) }}=\frac{\left.\left\lfloor\mathrm{A}_{\text {asp }}^{-}\right\rfloor \mid \mathrm{H}^{+}\right\rfloor}{\left[\mathrm{A}_{\text {asp }}^{+/-}\right]}
\end{aligned}
$$

$\mathrm{A}_{\text {asp }}^{+/-}+\mathrm{H}_{2} \mathrm{O} \leftrightarrow \mathrm{A}_{\text {asp }}^{-}+\mathrm{H}_{3} \mathrm{O}^{+}$

$\mathrm{A}_{\text {asp }}^{-}+\mathrm{H}_{2} \mathrm{O} \leftrightarrow \mathrm{A}_{\text {asp }}^{2-}+\mathrm{H}_{3} \mathrm{O}^{+}$

$$
\mathrm{K}_{\mathrm{a} 3(\mathrm{asp})}=\frac{\left[\mathrm{A}_{\mathrm{asp}}^{2-}\right]\left[\mathrm{H}^{+}\right]}{\left[\mathrm{A}_{\mathrm{asp}}^{-}\right]}
$$

iii) Reacción de intercambio iónico de $\alpha$-fenilglicina y ácido aspártico con el Tomac impregnado en la resina:

$$
\mathrm{A}_{\text {pgly }}^{-}+\overline{\mathrm{Q}^{+} \mathrm{Cl}^{-}} \leftrightarrow \overline{\mathrm{Q}^{+} \mathrm{A}_{\text {pgly }}^{-}}+\mathrm{Cl}^{-}
$$

$$
\mathrm{K}_{\mathrm{p} 1(\mathrm{pgly})}=\frac{\left.\overline{\mathrm{Q}^{+} \mathrm{A}_{\mathrm{pgly}}^{-}}\right]\left[\mathrm{Cl}^{-}\right]}{\left[\overline{\mathrm{Q}^{+} \mathrm{Cl}^{-}}\right]\left[\mathrm{A}_{\mathrm{pgly}}^{-}\right]}
$$


$\mathrm{A}_{\text {asp }}^{2-}+2 \overline{\mathrm{Q}^{+} \mathrm{Cl}^{-}} \leftrightarrow \overline{\mathrm{Q}_{2}^{+} \mathrm{A}_{\text {asp }}^{2-}}+2 \mathrm{Cl}^{-}$

$$
\mathrm{K}_{\mathrm{p} 2 \text { (asp) }}=\frac{\left[\overline{\mathrm{Q}_{2}^{+} \mathrm{A}_{\text {asp }}^{2-}}\right]\left[\mathrm{Cl}^{-}\right]^{2}}{\left[\overline{\mathrm{Q}^{+} \mathrm{Cl}^{-}}\right]^{2}\left[\mathrm{~A}_{\text {asp }}^{2-}\right]}
$$

donde $\mathrm{K}_{\mathrm{p} 1 \text { (pgly) }}$ y $\mathrm{K}_{\mathrm{p} 2(\mathrm{asp})}$ son las constantes de equilibrio que rigen el proceso de intercambio iónico, los subíndices asp y pgly hacen referencia al aminoácido fenilglicina y al ácido aspártico, respectivamente y - hace referencia a la fase resina.

Asumiendo que no hay agregación de las especies extraídas en fase resina y considerando que la solubilidad del Tomac en fase acuosa es despreciable, los balances de materia aplicados al Tomac y a los iones cloruro pueden expresarse mediante las siguientes ecuaciones:

$$
\begin{aligned}
& {\left[\overline{\mathrm{Q}^{+} \mathrm{Cl}^{-}}\right]_{\mathrm{i}}=\left[\overline{\mathrm{Q}^{+} \mathrm{Cl}^{-}}\right]+2\left[\overline{\mathrm{Q}_{2}^{+} \mathrm{A}_{\text {asp }}^{2-}}\right]+\left[\overline{\mathrm{Q}^{+} \mathrm{A}_{\text {pgly }}^{-}}\right]} \\
& {\left[\mathrm{Cl}^{-}\right]=\frac{\overline{\mathrm{V}}}{\mathrm{V}}\left\{\left[\overline{\mathrm{Q}^{+} \mathrm{A}_{\text {pgly }}^{-}}\right]+2\left[\overline{\mathrm{Q}_{2}^{+} \mathrm{A}_{\text {asp }}^{2-}}\right]\right\}}
\end{aligned}
$$

donde, $\left.\left.\left.\overline{\mathrm{Q}^{+} \mathrm{Cl}^{-}}\right], \overline{\mathrm{Q}_{2}^{+} \mathrm{A}_{\mathrm{asp}}^{2-}}\right\rfloor, \overline{\mathrm{Q}^{+} \mathrm{A}_{\mathrm{pgly}}^{-}}\right\rfloor$son las concentraciones de Tomac, del complejo ácido aspártico-Tomac y del complejo a-fenilglicina-Tomac en fase resina, respectivamente.

Las concentraciones de las especies que intervienen en el proceso de extracción para el experimento II y III de la Tabla 4 se muestran en la Tablas D6-D15 del apéndice A.

Las constantes de equilibrio $\mathrm{K}_{\mathrm{p} 1(\mathrm{pgly})}$ y $\mathrm{K}_{\mathrm{p} 2(\text { asp })}$ se determinaron con la representación lineal de los datos de equilibrio de los experimentos II y III mostradas en las Figuras 31 y 32. Los valores de $\mathrm{K}_{\mathrm{p} 1 \text { (pgly) }}$ y $\mathrm{K}_{\mathrm{p} 2 \text { (asp) }}$ se muestran en la Tabla 12. Los valores obtenidos, como era de esperar, son coincidentes con los obtenidos previamente en los ensayos de extracción con el mismo aminoácido.

Tabla 12. Constantes de equilibrio y regresiones lineales de los experimentos de equilibrio de ácido aspártico y a-fenilglicina en mezclas binarias con RIE a $30^{\circ} \mathrm{C}$, mostrados en la Tabla 4, $r$ = regresión lineal.

\begin{tabular}{ccccccc}
\hline \multirow{2}{*}{ Experimento } & $\begin{array}{c}\mathrm{K}_{\mathrm{p} 1 \text { (asp) }} \\
\mathrm{Ec}(5.23)\end{array}$ & $\begin{array}{c}\mathrm{r} \\
\mathrm{Ec} .(5.23)\end{array}$ & $\begin{array}{c}\mathrm{K}_{\mathrm{p} 1 \mathrm{pgly})} \\
\mathrm{Ec} .(5.9)\end{array}$ & $\mathrm{r}$ Ec.(5.9) & $\begin{array}{c}\mathrm{K}_{\mathrm{p} 2 \text { (asp) }} \text { Ec. (5.30) } \\
\left(\mathrm{m}^{3} \mathrm{RSI} / \mathrm{m}^{3}\right)\end{array}$ & $\begin{array}{c}\mathrm{r} \\
\mathrm{Ec} .(5.30)\end{array}$ \\
\hline I & $0,022 \pm 0,003$ & 0,993 & --- & --- & --- & --- \\
II & --- & --- & $0,196 \pm 0,016$ & 0,982 & $0,0019 \pm 0,0001$ & 0,990 \\
III & --- & --- & $0,196 \pm 0,016$ & 0,982 & $0,0019 \pm 0,0001$ & 0,990 \\
\hline
\end{tabular}




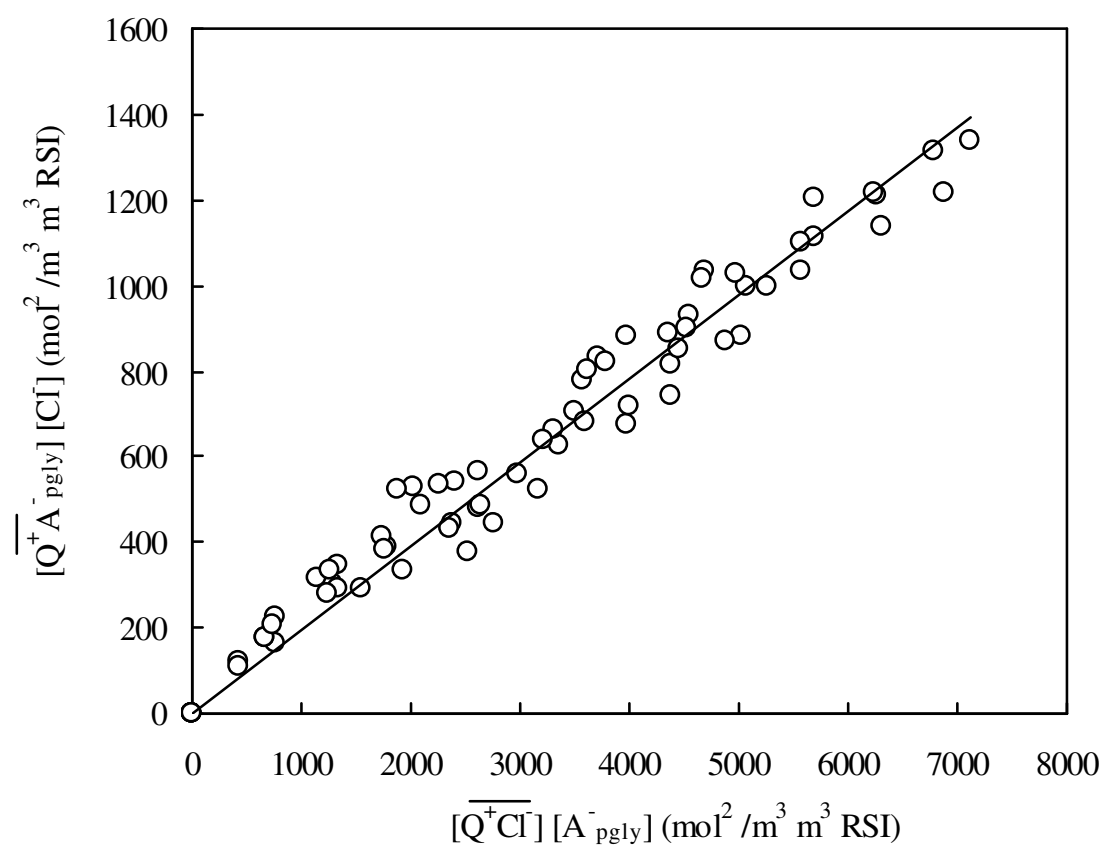

Figura 31. Determinación de la constante de equilibrio $\mathrm{K}_{\mathrm{p} 1 \text { (pgly) }}$ para los experimentos II $\left(\mathrm{pH}_{\mathrm{i}}=\right.$ $11,06 \pm 0,04)$ y III $\left(\mathrm{pH}_{\mathrm{i}}=12,02 \pm 0,06\right)$ de la Tabla $4 .\left[\mathrm{Q}^{+} \mathrm{Cl}^{-}\right]_{\mathrm{i}}=791,56 \pm 6,99 \mathrm{~mol} / \mathrm{m}^{3} \mathrm{RSI}$. Símbolos: datos experimentales; línea: datos estimados con la Ec. (5.9).

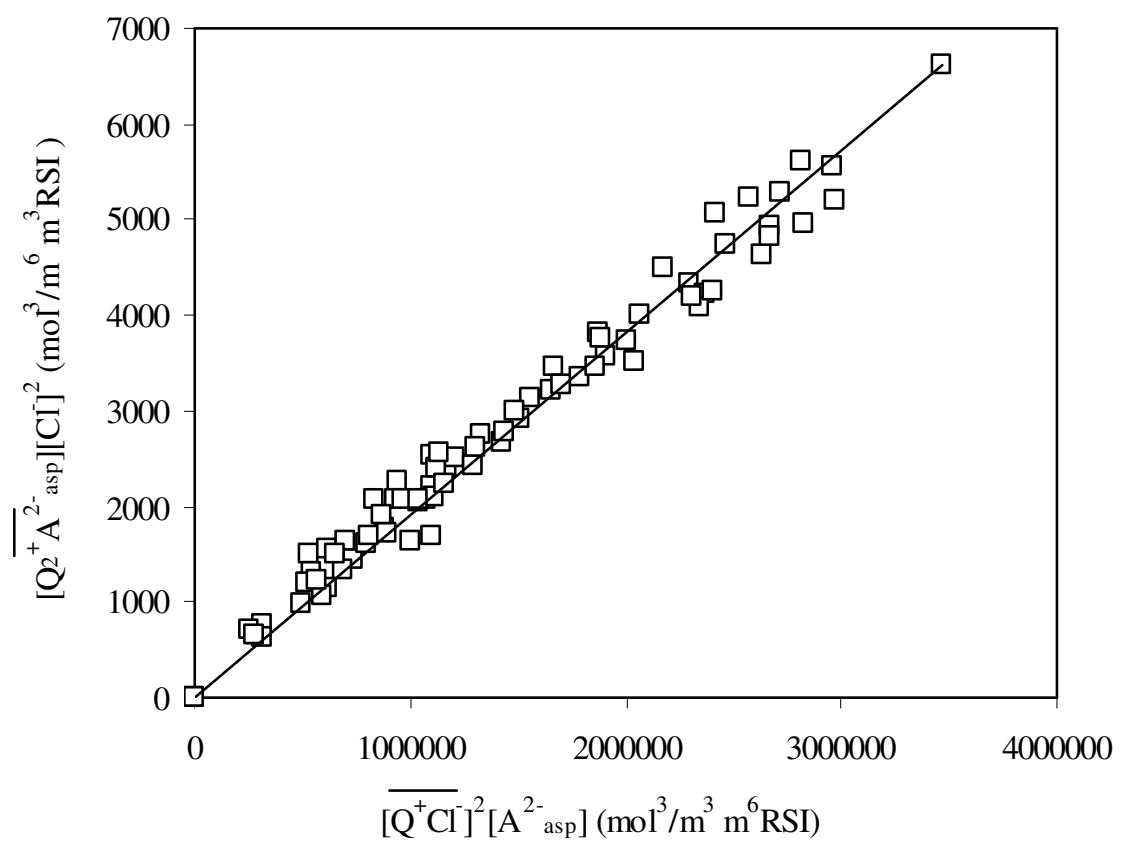

Figura 32. Determinación de la constante de equilibrio $\mathrm{K}_{\mathrm{p} 2(\mathrm{asp})}$ para los experimentos $\|\left(\mathrm{pH}_{\mathrm{i}}=\right.$ $11,06 \pm 0,04)$ y III $\left(\mathrm{pH}_{\mathrm{i}}=12,02 \pm 0,06\right)$ de la Tabla $4 .\left[\overline{\mathrm{Q}^{+} \mathrm{Cl}^{-}}\right]_{\mathrm{i}}=791,56 \pm 6,99 \mathrm{~mol} / \mathrm{m}^{3} \mathrm{RSI}$. Símbolos: datos experimentales; línea: datos estimados con la Ec. (5.30). 
Combinando las Ecs. (5.9), (5.30), (5.36) y (5.37) se obtiene el siguiente modelo de equilibrio para estimar la concentración total en fase resina de cada uno de los aminoácidos presentes en la mezcla:

$$
\begin{aligned}
& {\left[\overline{Q_{2}^{+} A_{\text {asp }}^{2-}}\right]=G \frac{V}{2 \bar{V}}\left\{\frac{1}{6} i^{1 / 3}-\frac{2}{3} \frac{h-\left(\frac{V}{\bar{V}}\right)^{2}-h^{2}\left(\frac{\bar{V}}{V}\right)^{2}}{i^{1 / 3}}-\frac{1}{3}\left(\frac{V}{\bar{V}}+\frac{\bar{V}}{V} h\right)\right\}^{2}} \\
& {\left[\overline{Q^{+} A_{\text {pgly }}^{-}}\right]=h G\left\{\frac{1}{6} i^{1 / 3}-\frac{2}{3} \frac{h-\left(\frac{V}{\bar{V}}\right)^{2}-h^{2}\left(\frac{\bar{V}}{V}\right)^{2}}{i^{1 / 3}}-\frac{1}{3}\left(\frac{V}{\bar{V}}+\frac{\bar{V}}{V} h\right)\right\}}
\end{aligned}
$$

donde los parámetros $\mathrm{G}, \mathrm{h}$, i se definen con las siguientes ecuaciones:

$$
\mathrm{G}=2 \mathrm{~K}_{\mathrm{p} 2(\mathrm{asp})}\left[\mathrm{A}_{\mathrm{asp}}^{2-}\right] \frac{\overline{\mathrm{V}}}{\mathrm{V}}
$$

$h=\frac{K_{p 1(p g l y)}\left[A_{p g l y}^{-}\right]}{G}$

$$
\begin{aligned}
& \mathrm{i}=\frac{12 \mathrm{~h}\left(\mathrm{~h}^{2}+\mathrm{V}^{2}\right)}{\mathrm{V} \overline{\mathrm{V}}}+\frac{108\left[\mathrm{Q}^{+} \mathrm{Cl}^{-}\right]_{\mathrm{i}}}{\mathrm{G}}-\frac{8\left(\overline{\mathrm{V}}^{6} \mathrm{~h}^{3}+\mathrm{V}^{6}\right)}{(\mathrm{v} \overline{\mathrm{V}})^{3}}+ \\
& +12 \sqrt{3} \sqrt{4 \mathrm{~h}^{3}-\frac{\mathrm{h}^{2}\left(\overline{\mathrm{V}}^{2} \mathrm{~h}+\mathrm{V}^{2}\right)^{2}}{(\mathrm{v} \overline{\mathrm{V}})^{2}}+\frac{\left[\mathrm{Q}^{+} \mathrm{Cl}^{-}\right]_{\mathrm{i}}}{\mathrm{G}}\left[\frac{27\left[\mathrm{Q}^{+} \mathrm{Cl}^{-}\right]_{\mathrm{i}}}{\mathrm{G}}+\frac{18 \mathrm{~h}\left(\overline{\mathrm{V}}^{2} \mathrm{~h}+\mathrm{V}^{2}\right)}{\mathrm{V} \overline{\mathrm{V}}}-\frac{4\left(\overline{\mathrm{V}}^{2} \mathrm{~h}+\mathrm{V}^{2}\right)^{3}}{(\mathrm{v} \overline{\mathrm{V}})^{3}}\right]}
\end{aligned}
$$

En la Figura 33 para el ácido aspártico y en la Figura 34 para $\alpha$-fenilglicina se muestra la buena concordancia entre los datos de equilibrio experimentales (símbolos) y los estimados con el modelo de equilibrio, Ecs. (5.38)-(5.42), (líneas sólidas). El error medio calculado con la Ec. (5.15) fue inferior al 3,4\% para todos los sistemas de los experimentos II y III de la Tabla 4.

Por otra parte, las pequeñas diferencias de extracción de ambos aminoácidos en las proporciones $\mathrm{C}_{\mathrm{A}(\text { asp) })} / \mathrm{C}_{\mathrm{A}(\mathrm{pgly}) \mathrm{i}}=2 / 1$ y $3 / 1$ son debidas a que a estos valores de $\mathrm{pH}$ las proporciones de especies extraíbles de aminoácido $\left(\left[A_{\text {asp }}^{2-}\right]_{i} /\left[A_{p g l y}^{-}\right]_{i}\right)$ son distintas, 
resultando $\left[\mathrm{A}_{\text {asp }}^{2-}\right]_{\mathrm{i}} /\left[\mathrm{A}_{\text {pgly }}^{-}\right]_{\mathrm{i}}=1,9 / 1,2,8 / 1$ para $\mathrm{pH}=11, \mathrm{y}\left[\mathrm{A}_{\text {asp }}^{2-}\right]_{\mathrm{i}} /\left[\mathrm{A}_{\text {pgly }}^{-}\right]_{\mathrm{i}}=2 / 1,3 / 1$ para $\mathrm{pH}=12$.

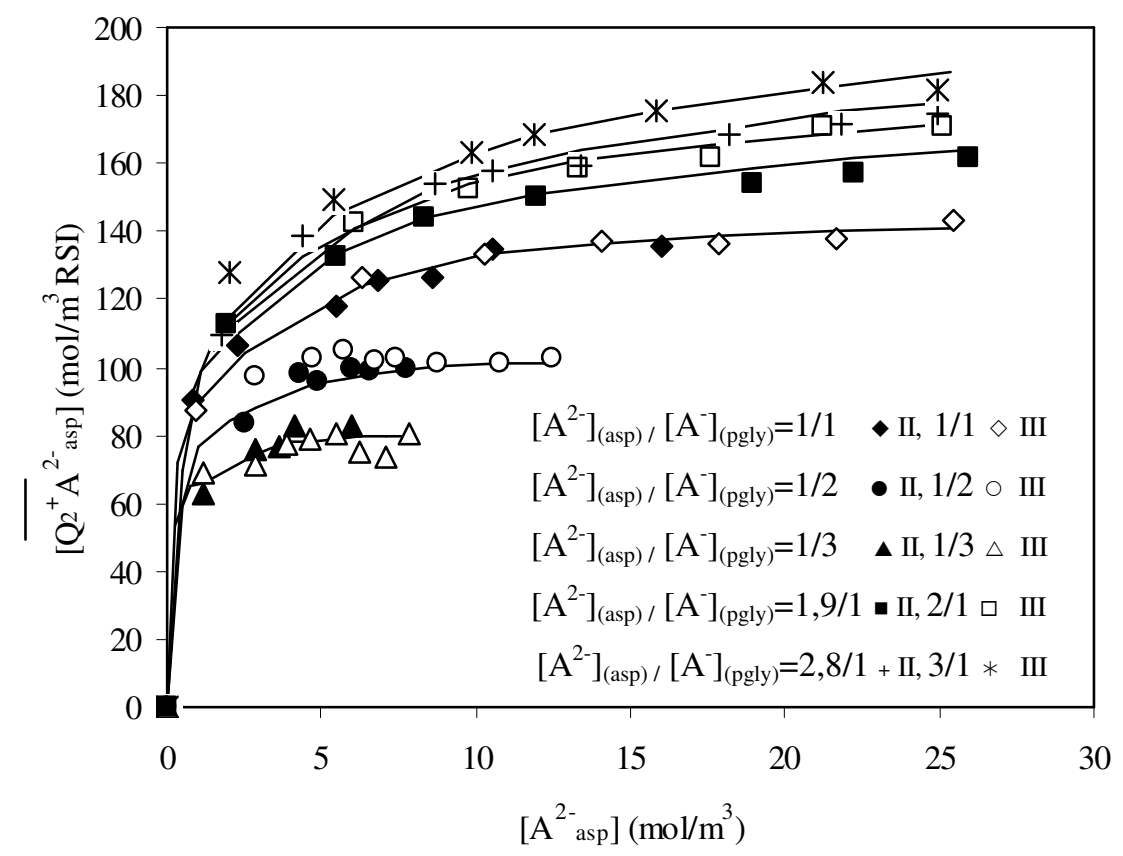

Figura 33. Ajuste de los datos experimentales (símbolos) con las Ecs. (5.38), (5.40)-(5.42) (líneas) para los experimentos II $\left(\mathrm{pH}_{\mathrm{i}}=11,06 \pm 0,04\right)$ y III $\left(\mathrm{pH}_{\mathrm{i}}=12,02 \pm 0,06\right)$ de la Tabla 4 . $\left[\overline{\mathrm{Q}^{+} \mathrm{Cl}^{-}}\right]_{\mathrm{i}}=791,56 \pm 6,99 \mathrm{~mol} / \mathrm{m}^{3} \mathrm{RSI}$.

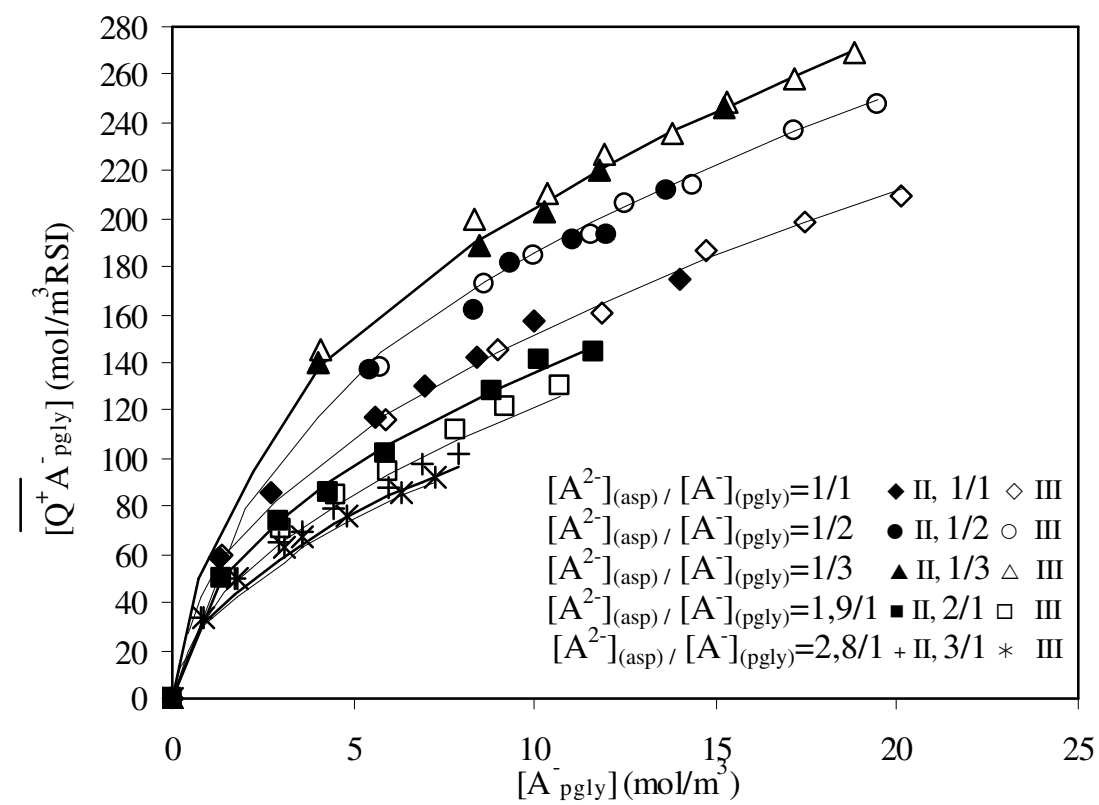

Figura 34. Ajuste de los datos experimentales (símbolos) con las Ecs. (5.39), (5.40)-(5.42) (líneas) para los experimentos II $\left(\mathrm{pH}_{\mathrm{i}}=11,06 \pm 0,04\right)$ y III $\left(\mathrm{pH}_{\mathrm{i}}=12,02 \pm 0,06\right)$ de la Tabla 4.

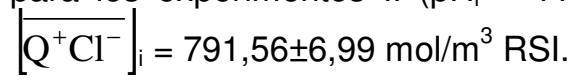


Con lo expuesto en este apartado, se puede concluir que:

- La adsorción física de ácido aspártico y a-fenilglicina debida a la matriz polimérica de la resina y la coextracción de iones hidroxilo debida al Tomac inmovilizado en los poros de la resina fue despreciable en los experimentos de extracción conjunta de ambos aminoácidos.

- El grado de extracción de ácido aspártico y a-fenilglicina con Amberlita XAD-4 impregnada con Tomac fue superior a $\mathrm{pH} \geq 11$, y aumenta al aumentar la concentración de cada aminoácido en fase acuosa y su proporción en la mezcla.

- La extracción de $\alpha$-fenilglicina a $\mathrm{pH}=5$ es despreciable. El grado de extracción de ácido aspártico en mezclas es igual para todas las proporciones realizadas, y por tanto, su extracción no depende de la presencia de a-fenilglicina

- Los resultados obtenidos en la extracción conjunta de ácido aspártico y afenilglicina con RIE presentan tendencias análogas a los de la extracción individual, lo que induce a presuponer un mecanismo de extracción por reacciones de intercambio iónico de las especies aniónicas de los dos aminoácidos con los iones cloruro del Tomac inmovilizado en los poros de la resina.

- La separación de ácido aspártico y a-fenilglicina de sus mezclas binarias, con Amberlita XAD-4 impregnada con Tomac puede describirse adecuadamente mediante un modelo de equilibrio diferente para cada valor del $\mathrm{pH}$ y que considera la extracción reactiva de cada aminoácido con el Tomac inmovilizado en los poros de la resina. Los modelos propuestos ajustan satisfactoriamente los resultados experimentales, obteniéndose igual valor para la constante de equilibrio en la extracción individual y conjunta.

\subsubsection{Comparación de los equilibrios de extracción individual y conjunta de ácido aspártico y a-fenilglicina}

En la Figura 35 se representan las isotermas de equilibrio para la extracción de ácido aspártico, solo o de las mezclas, con $\mathrm{RIE} \mathrm{a} \mathrm{pH}_{\mathrm{i}}=5$ y a $30^{\circ} \mathrm{C}$. En esta figura se observa que la extracción de ácido aspártico es igual solo o mezclado con $\alpha$-fenilglicina, debido a que no hay extracción de $\alpha$-fenilglicina a este $\mathrm{pH}$, y consecuentemente, en la estimación de los datos de equilibrio se puede aplicar el mismo modelo comentado en los apartado 5.2.3.1 y 5.2.4.1. 


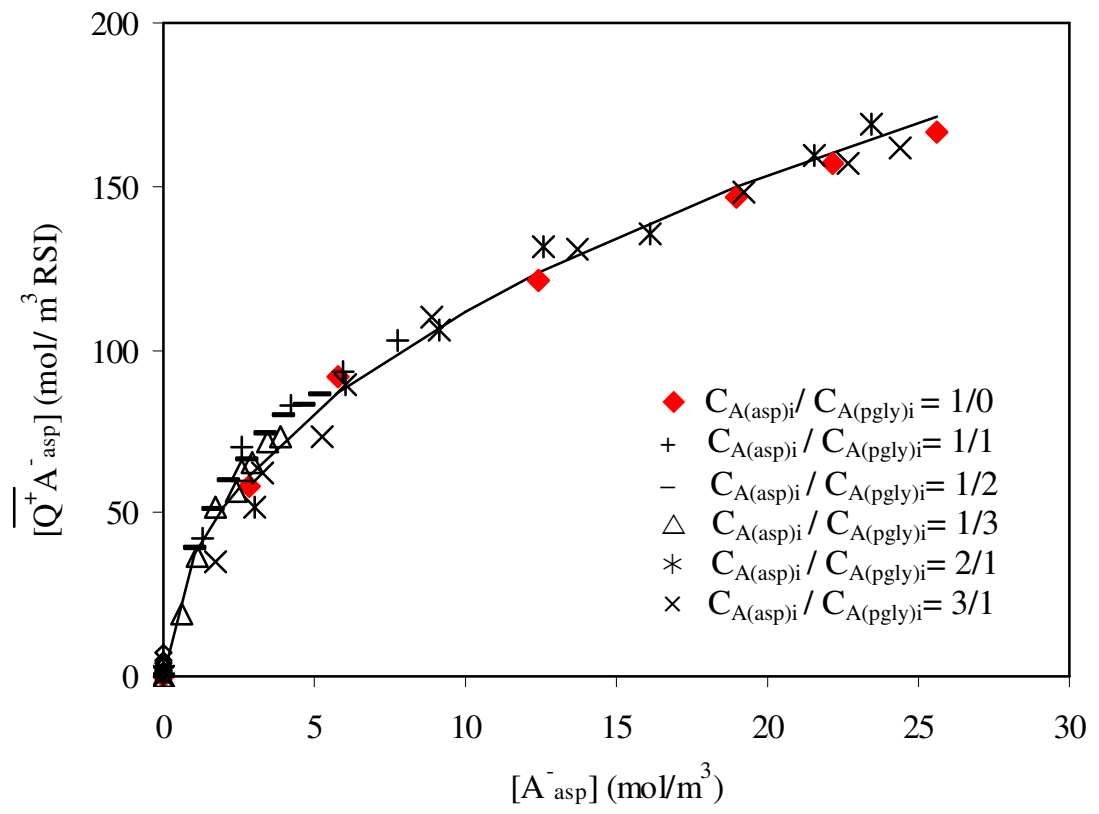

Figura 35. Comparación de las isotermas de extracción de ácido aspártico solo (rojo) (experimento II de la Tabla 3) y mezclado con a-fenilglicina (experimento I de la Tabla 4) con RIE a $30 \stackrel{\circ}{ } \mathrm{C}$. Símbolos: datos experimentales. Línea: datos estimados con modelo, Ec. (5.26).

Las isotermas de equilibrio de extracción individual y conjunta de ácido aspártico y $\alpha$ fenilglicina a $\mathrm{pH}_{\mathrm{i}}=12$ con $\mathrm{RIE}$ y a $30^{\circ} \mathrm{C}$ se representan en las Figuras 36 y 37 , respectivamente. En la Figura 36 se muestra que el grado de extracción de ácido aspártico se ve afectado por la presencia de $\alpha$-fenilglicina y más concretamente, disminuye al aumentar la concentración relativa de $\alpha$-fenilglicina en la mezcla. Este mismo efecto se observa en la Figura 37 que muestra que el grado de extracción de $\alpha$ fenilglicina es menor al encontrarse mezclado con el ácido aspártico y depende de la proporción relativa de ambos aminoácidos en la mezcla. Estos mismos resultados se obtuvieron al representar las isotermas de extracción individual y conjunta de ambos aminoácidos a $\mathrm{pH}_{\mathrm{i}}=11$ (no mostrado).

Un análisis más detallado de estos resultados con los obtenidos en el apartado 5.2.4.2, correspondiente a los modelos de equilibrio, indican que a $\mathrm{pH}_{\mathrm{i}}=11$ y 12 existe una reacción simultánea de extracción de cada aminoácido con el Tomac impregnado en la resina y se puede concluir que estas reacciones de intercambio iónico son competitivas debido a que el grado de extracción de cada aminoácido resultó distinto solo o mezclado es decir, al variar sus proporciones relativas.

Es importante destacar que los modelos de equilibrio de extracción con RIE planteados en este trabajo conllevan las mismas etapas que las que describen un proceso de extracción líquido - líquido, lo que induce a suponer que el extractante está en fase líquida y por tanto se encuentra simplemente ocluido en el interior de los poros de la resina. Esta hipótesis, mantenida por varios autores, se refuerza por estudios anteriores realizados en nuestro laboratorio, basados en el resultado de ensayos de impregnación de diferentes resinas porosas y en la adecuación de modelos heterogéneos cinéticos que contemplan la inmovilización del extractante en los poros de la resina. 


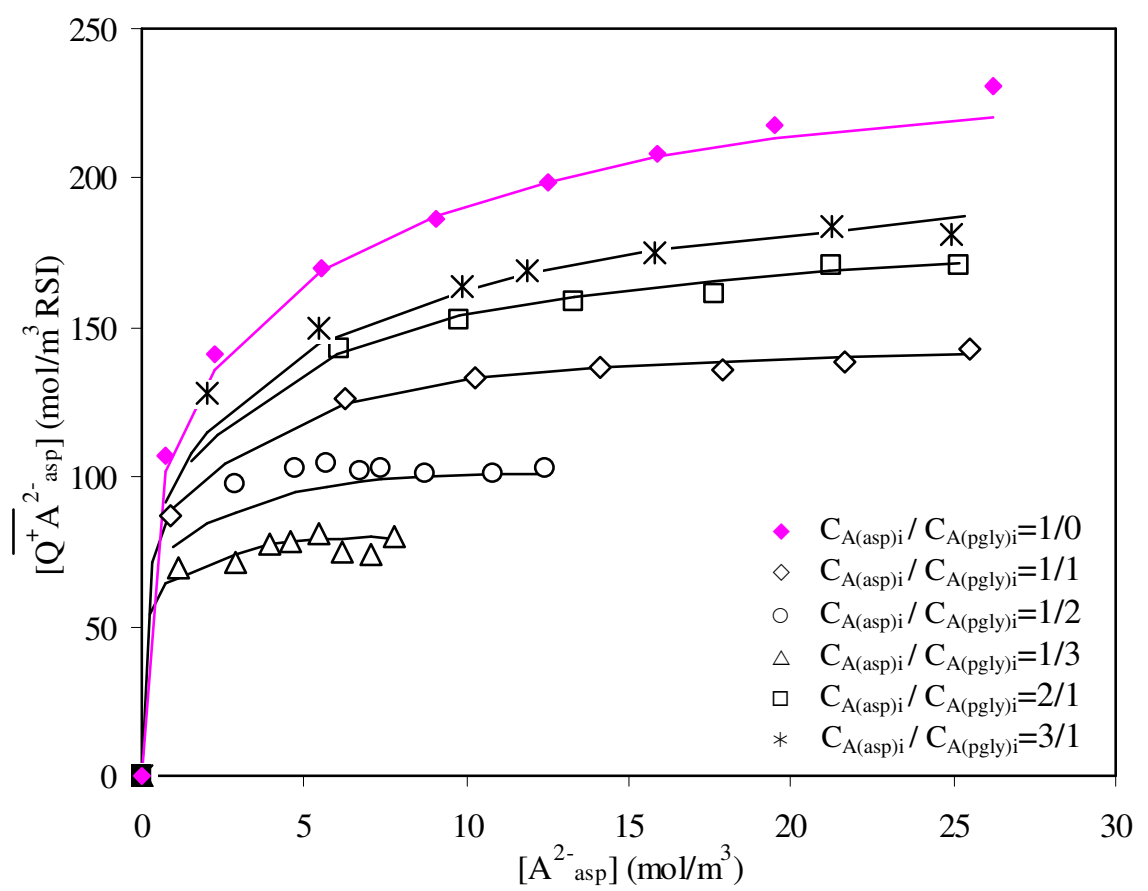

Figura 36. Comparación de las isotermas de equilibrio de extracción de ácido aspártico, solo (experimento $\mathrm{V}$ de la Tabla 3 ) y mezclado con $\alpha$-fenilglicina, con $\mathrm{RIE}$ a $\mathrm{pH}_{\mathrm{i}}=12$ y $30^{\circ} \mathrm{C}$ (experimento III de la Tabla 4).

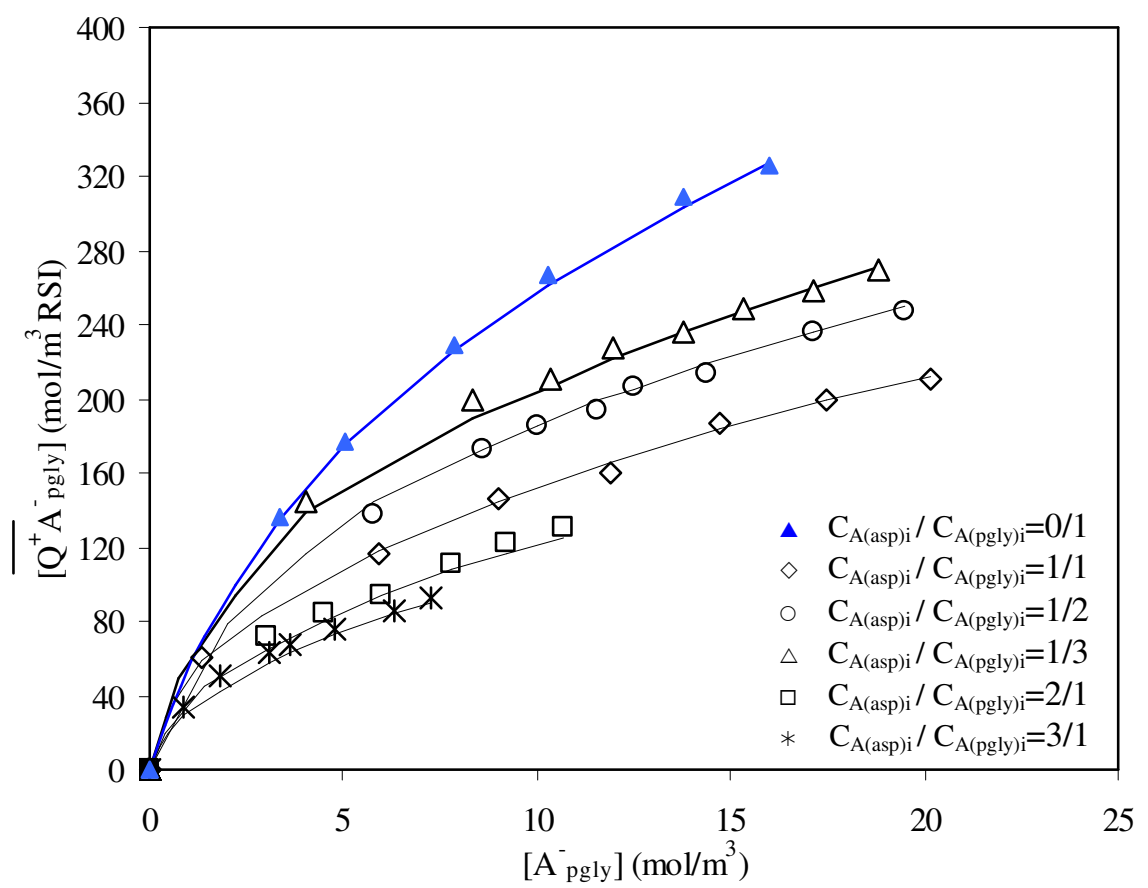

Figura 37. Comparación de las isotermas de equilibrio de extracción de a-fenilglicina, solo (experimento $\mathrm{V}$ de la Tabla 2) y mezclado con ácido aspártico, con $\mathrm{RIE}$ a $\mathrm{pH}_{\mathrm{i}}=12$ y $30^{\circ} \mathrm{C}$ (experimento III de la Tabla 4). 


\subsection{RESULTADOS Y DISCUSIÓN: CINÉTICAS DE EXTRACCIÓN EN BAÑOS AGITADOS}

\subsubsection{Ensayos con ácido aspártico}

Los estudios cinéticos de extracción de ácido aspártico con RIE a $30^{\circ} \mathrm{C}$ se determinaron empleando el dispositivo mostrado en el apartado 5.1.2.2 y con el procedimiento experimental detallado en el apartado 5.1.3.7 de esta memoria. Las condiciones iniciales de estos experimentos se muestran en la Tabla 5 del apartado 5.1.3.7 La carga de Tomac en la RIE fue la misma que se utilizó en los experimentos de equilibrio $\left(\overline{\mathrm{Q}^{+} \mathrm{Cl}^{-}}\right]_{\mathrm{i}}=$ $\left.782,93 \pm 19,04 \mathrm{~mol} / \mathrm{m}^{3} \mathrm{RSI}\right)$.

La evolución de las especies aniónicas de ácido aspártico en fase acuosa en el tiempo se puede calcular utilizando las siguientes ecuaciones:

$$
\begin{aligned}
& {\left[\mathrm{A}_{\mathrm{asp}}^{-}\right](\mathrm{t})=\frac{\mathrm{C}_{\mathrm{A}(\text { asp })}(\mathrm{t})\left[\mathrm{H}^{+}\right](\mathrm{t}) \mathrm{K}_{\mathrm{a} 1} \mathrm{~K}_{\mathrm{a} 2}}{\left[\mathrm{H}^{+}\right]^{3}(\mathrm{t})+\mathrm{K}_{\mathrm{a} 1}\left[\mathrm{H}^{+}\right]^{2}(\mathrm{t})+\mathrm{K}_{\mathrm{a} 1} \mathrm{~K}_{\mathrm{a} 2}\left[\mathrm{H}^{+}\right](\mathrm{t})+\mathrm{K}_{\mathrm{a} 1} \mathrm{~K}_{\mathrm{a} 2} \mathrm{~K}_{\mathrm{a} 3}}} \\
& {\left[\mathrm{~A}_{\mathrm{asp}}^{2-}\right](\mathrm{t})=\frac{\mathrm{C}_{\mathrm{A} \text { (asp) }}(\mathrm{t}) \mathrm{K}_{\mathrm{a} 1} \mathrm{~K}_{\mathrm{a} 2} \mathrm{~K}_{\mathrm{a} 3}}{\left[\mathrm{H}^{+}\right]^{3}(\mathrm{t})+\mathrm{K}_{\mathrm{a} 1}\left[\mathrm{H}^{+}\right]^{2}(\mathrm{t})+\mathrm{K}_{\mathrm{a} 1} \mathrm{~K}_{\mathrm{a} 2}\left[\mathrm{H}^{+}\right](\mathrm{t})+\mathrm{K}_{\mathrm{a} 1} \mathrm{~K}_{\mathrm{a} 2} \mathrm{~K}_{\mathrm{a} 3}}}
\end{aligned}
$$

donde $\left.\mathrm{C}_{\mathrm{A}(\text { asp })}(\mathrm{t}), \mathrm{A}_{\text {asp }}^{-}\right](\mathrm{t})$ y $\left[\mathrm{A}^{2-}{ }_{\text {asp }}\right](\mathrm{t})$ representan la concentración total del aminoácido, la de la forma aniónica del aminoácido con una carga negativa y la de la forma aniónica del aminoácido con dos cargas negativas en función del tiempo, respectivamente, expresadas en $\mathrm{mol} / \mathrm{m}^{3}$, cuyo $\mathrm{pH}$ también es función del tiempo.

No se apreciaron cambios significativos en el valor de $\mathrm{pH}$ a lo largo del tiempo. Este resultado confirma que el efecto de coextracción es despreciable en los procesos de extracción de ácido aspártico con RIE. Por otra parte, los estudios de equilibrio de extracción individual de ácido aspártico a distintos pHs demostraron que a $\mathrm{pH}=5$ y 9 $\left(\mathrm{pK}_{\mathrm{a} 2(\text { asp })}=3,9<\mathrm{pH}_{<}<\mathrm{pK}_{\mathrm{a} 3(\mathrm{asp})}=9,8\right)$ la única especie de aminoácido en fase resina es $\left\langle\mathrm{Q}^{+} \mathrm{A}^{-}{ }_{\text {asp })}\right.$; mientras que a $\mathrm{pH}=11$ y $12\left(\mathrm{pH} \geq \mathrm{pK}_{\mathrm{a} 3(\text { asp })}=9,8\right)$ es $\left.\overline{\mathrm{Q}_{2}^{+} \mathrm{A}^{2-}}\right|_{\text {asp })}$. Bajo estas consideraciones, la concentración de ácido aspártico en la fase resina en el tiempo se puede estimar con los balances de materia mostrados en la Ec. (5.45) para $\mathrm{pH}=5$ y 9 y en la Ec. (5.46) para $\mathrm{pH}=11$ y 12.

$$
\overline{\mathrm{C}}_{\mathrm{A}(\text { asp })}(\mathrm{t})=\left[\overline{\mathrm{Q}^{+} \mathrm{A}^{-}}\right]_{(\text {(asp) }}(\mathrm{t})=\left(\mathrm{C}_{\mathrm{A}(\text { asp }) \mathrm{i}}-\mathrm{C}_{\mathrm{A}(\text { asp })}(\mathrm{t})\right) \frac{\mathrm{V}}{\overline{\mathrm{V}}}
$$




$$
\overline{\mathrm{C}}_{\mathrm{A}(\text { asp })}(\mathrm{t})=\left[\overline{\mathrm{Q}_{2}^{+} \mathrm{A}^{2-}}\right]_{(\text {asp })}(\mathrm{t})=\left(\mathrm{C}_{\mathrm{A}(\text { asp }) \mathrm{i}}-\mathrm{C}_{\mathrm{A}(\text { asp })}(\mathrm{t})\right) \frac{\mathrm{V}}{\overline{\mathrm{V}}}
$$

donde el superrayado - representa la fase resina, el subíndice $\mathrm{i}$ hace referencia a la condición inicial, $\mathrm{C}_{\mathrm{A}(\mathrm{asp})}$ concentración total de aminoácido en fase acuosa, $\mathrm{V}$ y $\overline{\mathrm{V}}$ son el volumen de la fase acuosa y el volumen de la fase resina, respectivamente. $\left[\left.\mathrm{Q}^{+} \mathrm{A}^{-}\right|_{\text {asp }}(\mathrm{t})\right.$ y $\left.\overline{\mathrm{Q}_{2}^{+} \mathrm{A}^{2-}}\right|_{\text {asp }}(\mathrm{t})$ son las concentraciones molares de ácido aspártico en fase resina, dependientes del tiempo t y expresadas en $\mathrm{mol} / \mathrm{m}^{3} \mathrm{RSI}$.

Los resultados experimentales de las cinéticas de extracción de ácido aspártico con RIE a $\mathrm{pH}=5,9,11$ y 12 (experimentos de la Tabla 5) se recogen en las Tablas A1-A13 del apéndice $B$.

En las Figuras 38 - 41 se representa la evolución de la concentración total de ácido aspártico $\left(\mathrm{C}_{\mathrm{A}(\text { asp })}(\mathrm{t}) / \mathrm{C}_{\mathrm{A}(\text { aspli) }}\right)$ frente al tiempo, para los experimentos de la Tabla 5.

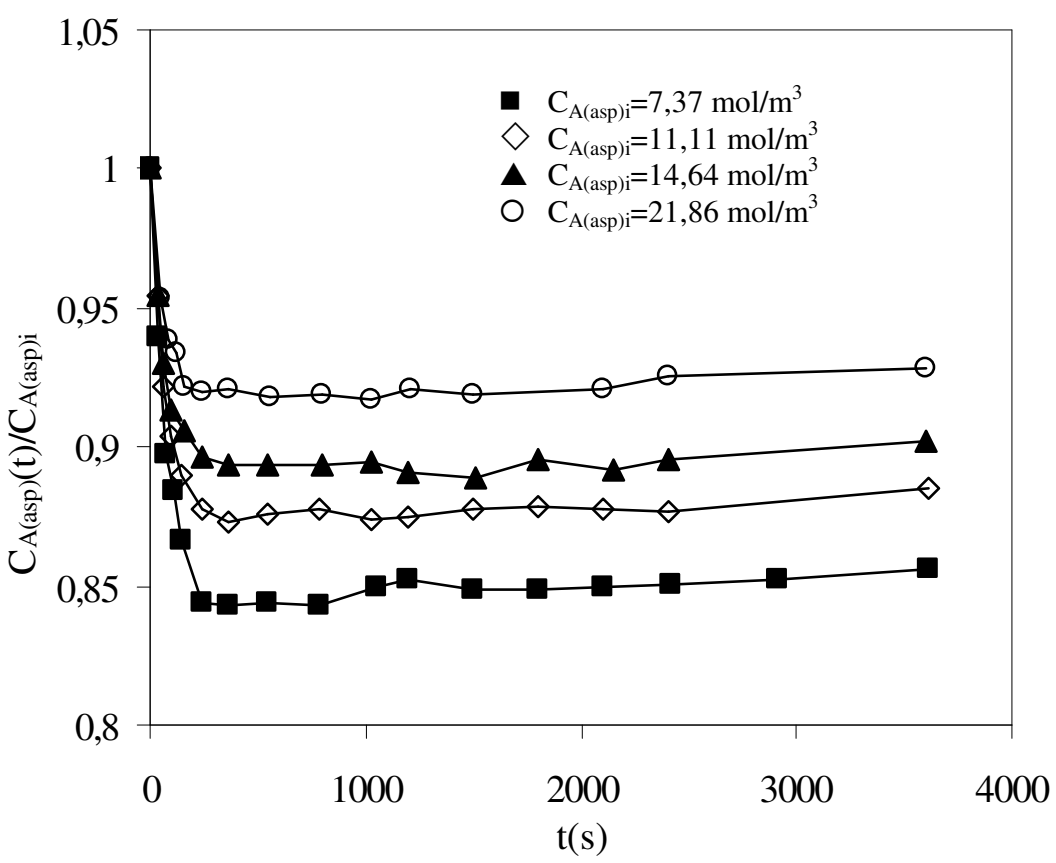

Figura 38. Evolución de la concentración de ácido aspártico en la fase acuosa con el tiempo para el experimento I $\left(\mathrm{pH}_{\mathrm{i}}=5,06 \pm 0,07 ; \mathrm{T}=30^{\circ} \mathrm{C}\right)$ de la Tabla 5. 


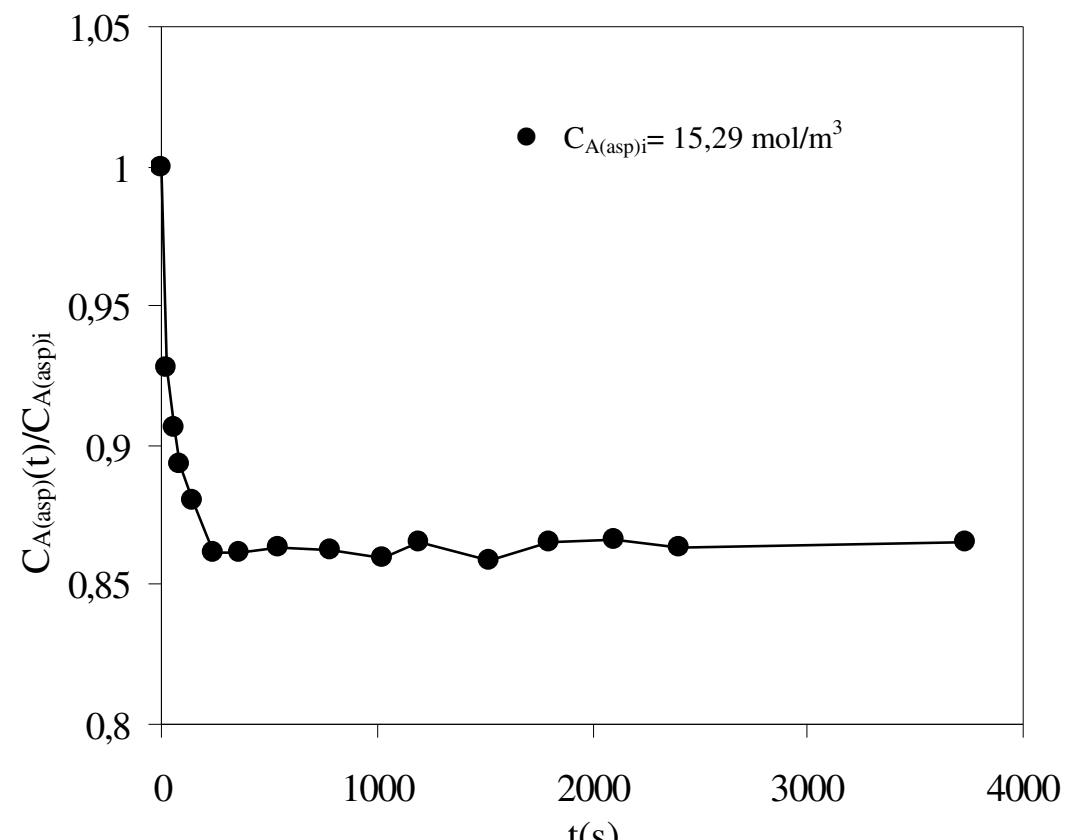

Figura 39. Evolución de la concentración de ácido aspártico en la fase acuosa con el tiempo para el experimento II $\left(\mathrm{pH}_{\mathrm{i}}=8,96 \pm 0,07 ; \mathrm{T}=30^{\circ} \mathrm{C}\right)$ de la Tabla 5.

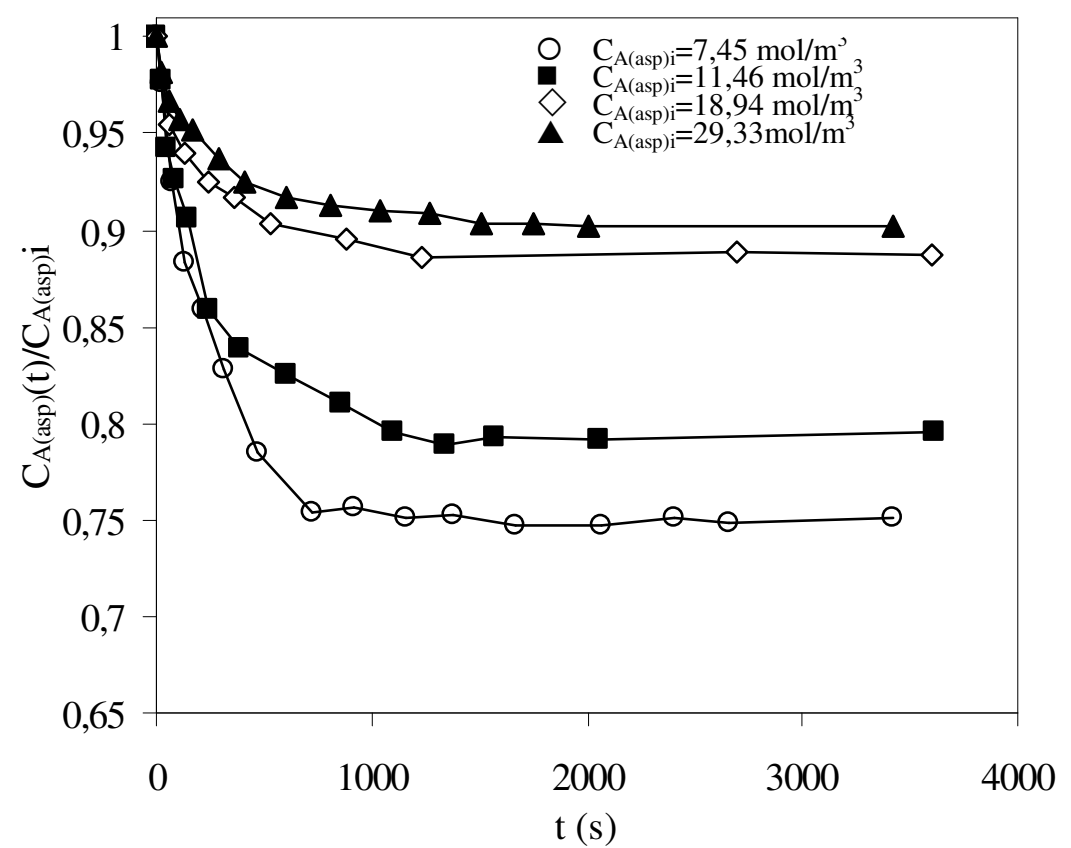

Figura 40. Evolución de la concentración de ácido aspártico en la fase acuosa con el tiempo para el experimento III $\left(\mathrm{pH}_{\mathrm{i}}=11,04 \pm 0,06 ; \mathrm{T}=30^{\circ} \mathrm{C}\right)$ de la Tabla 5. 


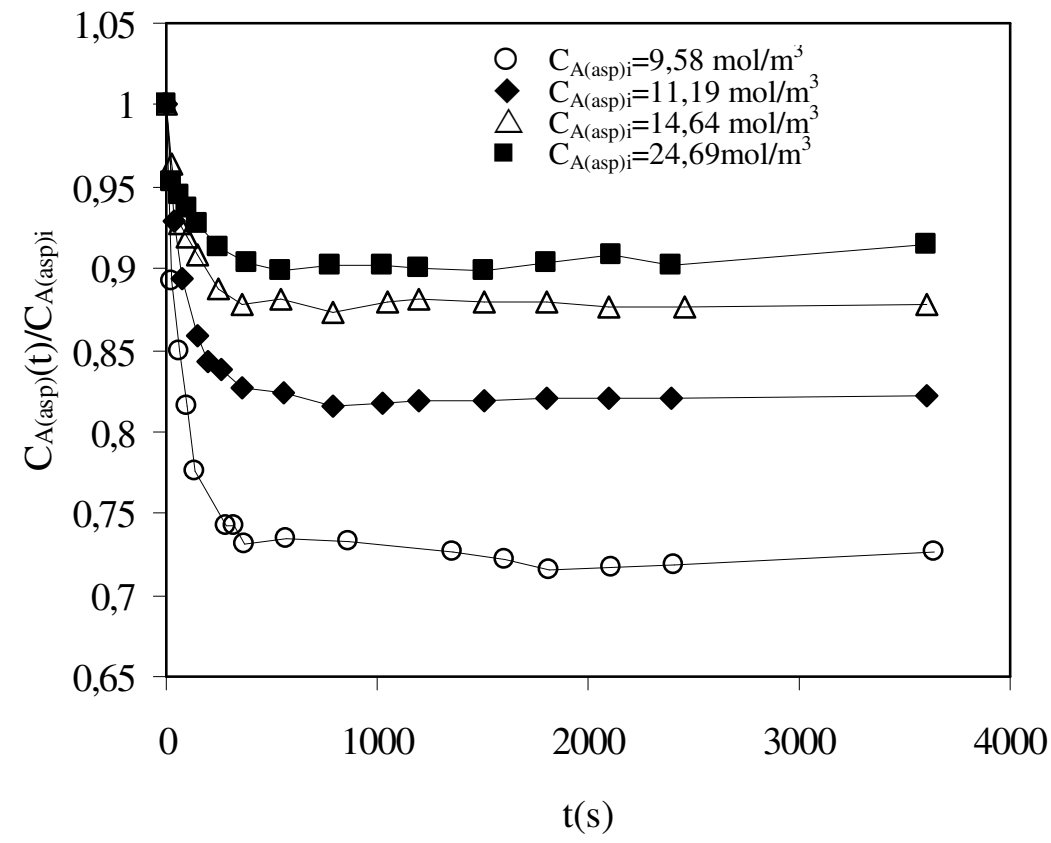

Figura 41. Evolución de la concentración de ácido aspártico en la fase acuosa con el tiempo el experimento IV $\left(\mathrm{pH}_{\mathrm{i}}=12,02 \pm 0,07 ; \mathrm{T}=30 \stackrel{\circ}{\circ} \mathrm{C}\right)$ de la Tabla 5.

En estas figuras se observa que los procesos cinéticos de extracción de ácido aspártico son rápidos y se alcanza el equilibrio a tiempos reducidos inferiores a 20 minutos para los experimentos a $\mathrm{pH}=5$ y 9 e inferiores a 40 minutos para $\mathrm{pH}=11$ y 12 . En cualquier caso, las curvas presentan una tendencia y forma similar, lo cual induce a pensar que el proceso cinético posee las mismas características y etapas controlantes en todos los sistemas estudiados.

Es necesaria una evaluación detallada de los resultados cinéticos para determinar si la velocidad del proceso de intercambio iónico está controlada por la difusión del aminoácido en la película líquida externa, por la reacción química en la superficie con el Tomac impregnado en la resina, o por la difusión intrapartícula del complejo Tomacaminoácido, o bien, por una combinación de dos o más de estas etapas limitantes del proceso cinético de extracción.

\subsubsection{Determinación de la etapa controlante del proceso cinético}

El modelo cinético propuesto por Bhandari et al. (Bhandari V.M. et al., 1992) es un modelo aproximado para correlacionar la dinámica de difusión intrapartícula en procesos de adsorción de ácidos orgánicos o inorgánicos con resinas básicas débiles de 
intercambio iónico, en medios agitados finitos y que considera la reversibilidad de los procesos de adsorción. Los autores Juang y Lin (Juang R.S. et al., 1995 b; Juang R S. et al., 1995 c) extendieron este modelo a cinéticas de adsorción donde la etapa controlante del proceso no es únicamente la difusión intrapartícula, sino también la difusión en la película líquida externa o incluso la reacción química. Este modelo se aplicó con éxito a procesos cinéticos de extracción de a-fenilglicna de disoluciones acuosas con resina macroporosa Amberlita XAD-4 impregnada con Tomac en tanques finitos (Ruiz M. O. et al., 2002 b) y en la separación de amino-alcoholes mediante resinas impregnadas de extractante (Babić K. et al., 2007).

Aunque es necesario un modelo más riguroso de correlación de los resultados cinéticos basado en las leyes de Fick o de Nerst-Planck, el modelo de Bhandari permite estimar de manera aproximada las resistencias implicadas en el transporte de materia, y por tanto es útil como primer paso en el tratamiento de los datos cinéticos.

La evolución de la concentración de ácido aspártico extraída por la RIE expresada en fracción molar en función del tiempo durante el proceso de extracción, X, teniendo en cuenta la estequiometria de la reacción química, se define como:

$$
\mathrm{X}=\frac{\mathrm{b} \overline{\mathrm{C}}_{\mathrm{A}(\text { asp })}(\mathrm{t})}{\left[\overline{\mathrm{Q}^{+} \mathrm{Cl}^{-}}\right]_{\mathrm{i}}}
$$

donde $\left[\overline{\mathrm{Q}^{+} \mathrm{Cl}^{-}}\right]_{\mathrm{i}}$ es la concentración de Tomac impregnado en la resina expresada en $\mathrm{mol} / \mathrm{m}^{3} \mathrm{RSI}$; b es la carga de la forma aniónica del aminoácido y por tanto es el coeficiente estequimétrico de las reacciones de intercambio iónico del aminoácido con el Tomac impregnado en la resina mostradas en las Ecs. (5.23) y (5.30), siendo $b=1$ en los experimentos a $\mathrm{pH}=5$ y 9, y $\mathrm{b}=2$ en los experimentos a $\mathrm{pH}=11$ y12; $\overline{\mathrm{C}}_{\mathrm{A} \text { (asp) }}$ (t) es la concentración de ácido aspártico en fase resina definida en la Ec. (5.45) en los experimentos a $\mathrm{pH}=5$ y 9 y mediante la Ec. (5.46) en los experimentos a $\mathrm{pH}=11$ y 12 .

Para evaluar la evolución de la concentración del aminoácido extraído por la RIE en el tiempo, se emplearon las Ecs. (5.48)-(5.50) que fueron determinadas considerando que el proceso de extracción está controlado independientemente por difusión en la película líquida, en la partícula o por reacción química:

1- Control por difusión en la película líquida externa:

$$
\left.\mathrm{X}=\frac{3 \mathrm{bD}_{\mathrm{f}}}{\mathrm{a} \delta\left[\overline{\mathrm{Q}^{+} \mathrm{Cl}^{-}}\right.}\right]_{\mathrm{i}}^{\mathrm{t}}\left[\mathrm{A}_{\mathrm{asp}}^{\mathrm{b}-}\right](\mathrm{t}) \mathrm{dt}
$$

2- Control por difusión intrapartícula:

$$
\mathrm{Y}=\frac{\mathrm{X}_{\mathrm{e}}}{\mathrm{K}}\left[1-3\left(1-\frac{\mathrm{X}}{\mathrm{Xe}}\right)^{\frac{2}{3}}+2\left(1-\frac{\mathrm{X}}{\mathrm{Xe}}\right)\right]=\frac{6 \mathrm{~b} \mathrm{D}_{\mathrm{e}}}{\mathrm{a}^{2}\left[\overline{\mathrm{Q}^{+} \mathrm{Cl}^{-}}\right]_{i}} \int_{0}^{\mathrm{t}}\left[\mathrm{A}_{\text {asp }}^{\mathrm{b}-}\right](\mathrm{t}) \mathrm{dt}
$$


3- Control por reacción química:

$$
\mathrm{Z}=\frac{1}{\mathrm{~K}}\left[1-\left(1-\frac{\mathrm{X}}{\mathrm{Xe}}\right)^{\frac{1}{3}}\right]=\frac{\mathrm{b} \mathrm{K}_{\mathrm{C}}}{\mathrm{a}} \int_{0}^{\mathrm{t}}\left[\mathrm{A}_{\text {asp }}^{\mathrm{b}-}\right](\mathrm{t}) \mathrm{dt}
$$

donde $\delta$ es el espesor de la película líquida estancada, $D_{f}$ y $D_{e}$ son las difusividades en la película líquida externa y en la fase resina, respectivamente; $\mathrm{K}_{c}$ es la constante de velocidad aparente de reacción química; $X_{e}$ es la concentración instantánea de ácido aspártico extraída en la superficie externa de la RIE en función del tiempo, expresada en fracción molar; a es el radio de la partícula, siendo para la resina Amberlita-XAD4, $\mathrm{a}=0,000389 \mathrm{~m}$; b es el coeficiente estequimétrico; $\left[\mathrm{A}^{\mathrm{b}-}\right.$ asp $]$ es la forma aniónica del ácido aspártico y $\mathrm{K}$ es el coeficiente de distribución de la forma aniónica $\left[\mathrm{A}^{\mathrm{b}-}{ }_{\text {asp }}\right]$ del aminoácido en el equilibrio expresada como:

$$
\mathrm{K}=\frac{\overline{\mathrm{C}}_{\mathrm{A}(\text { asp })_{(\mathrm{r}=\mathrm{a})}}}{\left[\mathrm{A}_{\text {asp }}^{\mathrm{b}-}\right]}
$$

donde $\overline{\mathrm{C}}_{\mathrm{A}(\operatorname{asp})_{(\mathrm{r}=\mathrm{a})}}$ es la concentración de aminoácido en la superficie de la RIE en el equilibrio expresada en $\mathrm{mol} / \mathrm{m}^{3} \mathrm{RSI}$ y $\left[\mathrm{A}_{\text {asp }}^{\mathrm{b}-}\right]$ es la concentración de la forma aniónica del aminoácido en la fase acuosa en el equilibrio expresada en $\mathrm{mol} / \mathrm{m}^{3}$.

Considerando que toda la superficie de la RIE está en equilibrio con la disolución acuosa extra-partícula y utilizando la Ec. (5.51) se puede definir $\mathrm{X}_{\mathrm{e}}$ con la siguiente relación:

$$
\mathrm{X}_{\mathrm{e}}=\frac{\mathrm{bK}\left[\mathrm{A}_{\text {asp }}^{\mathrm{b}-}\right](\mathrm{t})}{\left[\overline{\mathrm{Q}^{+} \mathrm{Cl}^{-}}\right]_{\mathrm{i}}}
$$

Los valores obtenidos de $X, Y, Z$ y $\int_{0}^{t}\left[A_{\text {asp }}^{b-}\right](t) d t$, se muestran en la Tabla A14 del apéndice $B$ para todos los experimentos de la Tabla 5.

Un análisis del modelo propuesto en las Ecs. (5.48)-(5.50) demuestra que para que el proceso esté controlado por difusión en la película líquida externa, difusión intrapartícula y/o reacción química, al representar $X, Y, Z$ frente a $\int_{0}^{t}\left[A_{\text {asp }}^{b-}\right](t) d t$ se deben obtener líneas rectas con ordenada en el origen cero y de cuya pendiente se puede evaluar $K_{f}, D_{e}$ y $\mathrm{K}_{\mathrm{C}}$, respectivamente.

En la Figura 42 se representa $X, Y, Z$ frente a $\int_{0}^{t}\left[A_{\text {asp }}^{b-}\right](t) d t$ para el experimento $I,\left(C_{A i}=\right.$ $14,64 \mathrm{~mol} / \mathrm{m}^{3} ; \mathrm{pH}_{\mathrm{i}}=5,06 \pm 0,07 ; \mathrm{T}=30 \stackrel{\circ}{\circ}$ ) de la Tabla 5 . En esta figura se observa que los 
datos experimentales de $\mathrm{X}, \mathrm{Z}$ frente a $\int_{0}^{\mathrm{t}}\left[\mathrm{A}_{\text {asp }}^{\mathrm{b}-}\right](\mathrm{t}) \mathrm{dt}$ no tienen tendencia lineal, así se puede suponer que la difusión en la película líquida externa y la reacción química no son etapas limitantes de la velocidad de los procesos cinéticos de extracción de ácido aspártico. Sin embargo, la Ec. (5.49) proporciona un buen ajuste lineal de los datos experimentales, indicando que el proceso está controlado por difusión intrapartícula.

Resultados similares se obtuvieron para todos los experimentos de la Tabla 5 del apartado 5.1.3.7 (no mostrados). Así, se puede concluir que el proceso cinético de extracción de ácido aspártico está controlado por la difusión intrapartícula a todos los pHs ensayados.

Los valores de la difusividad efectiva, $D_{e(a s p)}$, estimados con la Ec. (5.49) se muestran en la Tabla 13 a), junto con sus regresiones lineales. En estudios anteriores realizados en nuestro laboratorio (Ruiz M. O. et al., 2002 b), se obtuvieron de forma análoga, los valores de la difusividad efectiva de a-fenilglicina, $D_{e(p g l y)}$, bajo las mismas condiciones de proceso, mostrados en la Tabla $13 \mathrm{~b}$ ).

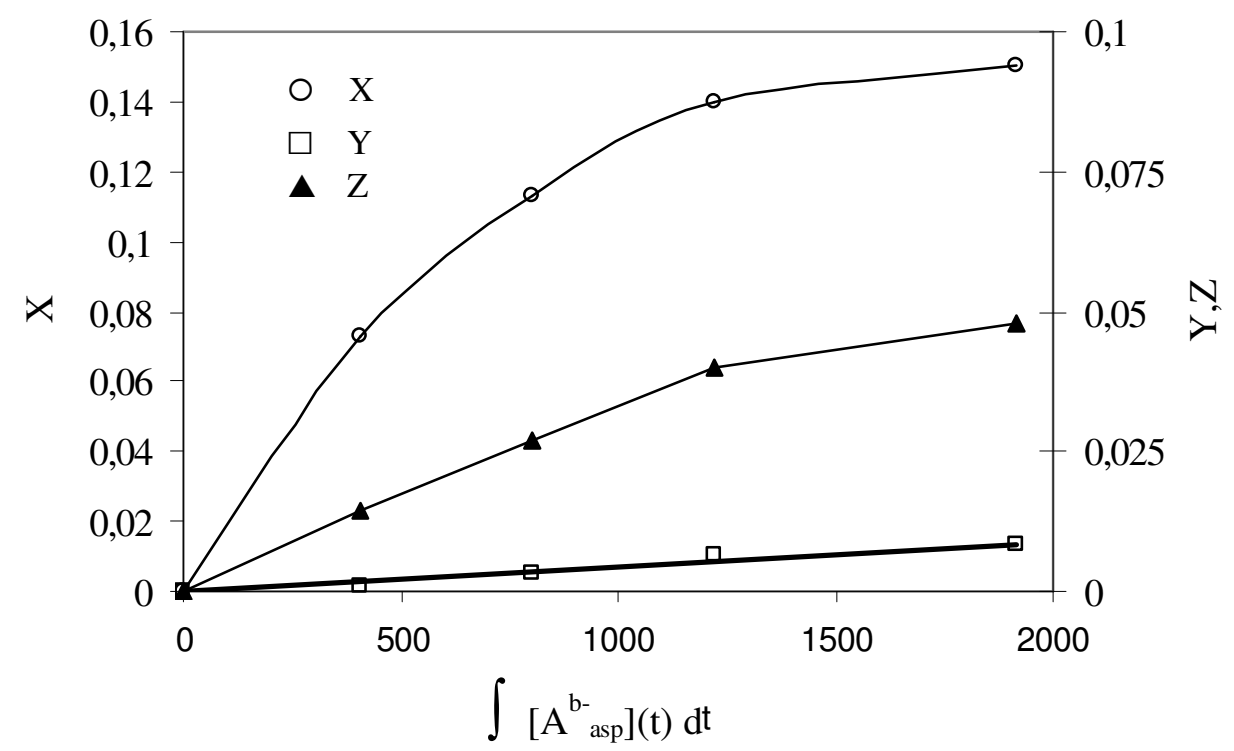

Figura 42. Determinación de las etapas controlantes de la velocidad de extracción de ácido aspártico con resina impregnada con Tomac para el experimento I $\left(C_{A i}=14,64 \mathrm{~mol} / \mathrm{m}^{3}\right.$; $\mathrm{pH}_{\mathrm{i}}=5,06 \pm 0,07 ; \mathrm{T}=30^{\circ} \mathrm{C}$ ) de la Tabla 5. 
Tabla 13. Valores de difusividad efectiva, $D_{e}$, evaluados con la Ec. (5.49), $r=$ regresión lineal.

a) Ácido aspártico

\begin{tabular}{|c|c|c|c|c|}
\hline Experimento & $\mathrm{pH}_{\mathrm{i}}$ & $\mathrm{C}_{\mathrm{A}(\mathrm{asp}) \mathrm{i}}\left(\mathrm{mol} / \mathrm{m}^{3}\right)$ & $\begin{array}{c}\mathrm{D}_{\mathrm{e}(\text { (asp })} \mathrm{X} 10^{11}\left(\mathrm{~m}^{2} / \mathrm{s}\right) \\
\operatorname{Ec}(5.49)\end{array}$ & $\mathrm{r}$ \\
\hline \multirow[t]{4}{*}{ I } & $5,06 \pm 0,07$ & 7,37 & 7,96 & 0,991 \\
\hline & & 11,11 & 7,96 & 0,984 \\
\hline & & 14,64 & 7,96 & 0,986 \\
\hline & & 21,86 & 9,95 & 0,995 \\
\hline II & $8,96 \pm 0,02$ & 15,29 & 13,78 & 0,994 \\
\hline \multirow[t]{4}{*}{ III } & $11,04 \pm 0,06$ & 7,45 & 1,38 & 0,986 \\
\hline & & 11,46 & 1,39 & 0,988 \\
\hline & & 18,94 & 1,76 & 0,991 \\
\hline & & 29,33 & 1,80 & 0,998 \\
\hline \multirow[t]{4}{*}{ IV } & $12,02 \pm 0,07$ & 9,58 & 4,52 & 0,992 \\
\hline & & 11,19 & 4,97 & 0,993 \\
\hline & & 14,64 & 4,97 & 0,986 \\
\hline & & 24,69 & 4,95 & 0,994 \\
\hline
\end{tabular}

b) a-Fenilglicina (Ruiz M. O. et al., 2002 b)

\begin{tabular}{cccc}
\hline $\mathrm{pHi}$ & $\mathrm{C}_{\mathrm{A}(\mathrm{pgly}) \mathrm{i}}\left(\mathrm{mol} / \mathrm{m}^{3}\right)$ & $\begin{array}{c}\mathrm{D}_{\mathrm{e}(\mathrm{pgly})} \times 10^{12}\left(\mathrm{~m}^{2} / \mathrm{s}\right) \\
\mathrm{Ec} .(5.49)\end{array}$ & $\mathrm{r}$ \\
\hline 11,07 & 7,26 & 7,25 & 0,996 \\
11,09 & 13,23 & 9,49 & 0,994 \\
12,06 & 7,26 & 5,84 & 0,996 \\
\hline
\end{tabular}

La comparación de los valores de la difusividad efectiva de $\alpha$-fenilglicina y ácido aspártico muestra que la velocidad de extracción de ambos aminoácidos crece ligeramente al aumentar su concentración inicial, produciendo comparativamente procesos de extracción más rápidos. Además, en todos los casos, la difusividad efectiva del ácido aspártico es un orden de magnitud mayor que la de $\alpha$-fenilglicina, y por tanto, la velocidad del proceso de extracción del ácido aspártico es más rápida que la velocidad de extracción de la a-fenilglicina. Este efecto puede deberse a que la a-fenilglicina es un aminoácido de mayor tamaño con un grupo fenilo en su cadena radical, mientras que el ácido aspártico presenta una cadena radical alifática. 


\subsubsection{Modelo cinético basado en la ley de Fick}

Los procesos de intercambio iónico se describen de forma rigurosa mediante las ecuaciones de Nerst-Planck que consideran los procesos de contra-difusión de iones de diferente movilidad causada por gradientes de concentración y de potencial electrostático (Helfferich F. Et al., 1958). El modelo más sencillo de difusión de partícula (intrapartícula) es el descrito por la segunda ley de Fick, y debido a su simplicidad y rigor es el que se adopta en el estudio de los datos cinéticos experimentales.

El modelo considera una reacción de intercambio iónico heterogénea entre las partículas esféricas de la RIE y la disolución acuosa agitada de volumen finito en la cual están inmersas. La resistencia a la difusión en la película líquida externa se puede considerar despreciable, por efecto de la agitación. En la interfase líquido-sólido se mantiene un equilibrio instantáneo y $\mathrm{K}$ es el coeficiente de distribución de la especie que difunde entre ambas fases, definido en la Ec. (5.51). Posteriormente, la especie extraída en la superficie de la RIE difunde lentamente al interior de la fase resina. Además, el modelo considera que la concentración de aniones de aminoácido en el seno de la fase acuosa varía con el tiempo y asume que la difusividad en la fase resina es constante.

Bajo estas condiciones, el balance de materia en coordenadas esféricas, aplicado a la especie aniónica del aminoácido $A^{b-}$ en fase resina, puede ser expresado por la siguiente ecuación:

$$
\frac{\partial \overline{\mathrm{C}}_{\mathrm{A}(\mathrm{asp})}(\mathrm{r}, \mathrm{t})}{\partial \mathrm{t}}=\mathrm{D}_{\mathrm{e}} \frac{1}{\mathrm{r}^{2}} \frac{\partial}{\partial \mathrm{r}}\left(\mathrm{r}^{2} \frac{\partial \overline{\mathrm{C}}_{\mathrm{A}(\mathrm{asp})}(\mathrm{r}, \mathrm{t})}{\partial \mathrm{r}}\right) ; \quad 0 \leq \mathrm{r} \leq \mathrm{a} ; \mathrm{t}>0
$$

con las condiciones límite e iniciales que se citan a continuación:

$$
\begin{array}{lll}
\overline{\mathrm{C}}_{\mathrm{A}(\text { asp })}(\mathrm{r}, \mathrm{t})=\mathrm{K}\left[\mathrm{A}^{\mathrm{b}-}\right](\mathrm{t}) & \mathrm{r}=\mathrm{a} & \mathrm{t}>0 \\
\overline{\mathrm{C}}_{\mathrm{A}(\text { asp })}(\mathrm{r}, \mathrm{t})=0 & 0 \leq \mathrm{r} \leq \mathrm{a} & \mathrm{t}=0 \\
\overline{\mathrm{C}}_{\mathrm{A} \text { (asp) }}(\mathrm{r}, \mathrm{t})=\text { finito } & \mathrm{r}=0 & \mathrm{t} \geq 0
\end{array}
$$

La cantidad de aminoácido extraído en la RIE en función del tiempo expresado en unidades de mol, $M(t)$, se puede determinar conociendo la cantidad de aminoácido transferida de la disolución acuosa, utilizando la siguiente igualdad:

$$
\mathrm{M}(\mathrm{t})=\mathrm{V}\left(\mathrm{C}_{\mathrm{A}(\text { asp }) \mathrm{i}}-\mathrm{C}_{\mathrm{A}(\text { asp })}(\mathrm{t})\right)=4 \pi \mathrm{N} \int_{0}^{\mathrm{a}} \mathrm{r}^{2} \overline{\mathrm{C}}_{\mathrm{A}(\text { asp })}(\mathrm{r}, \mathrm{t}) \mathrm{dr}
$$

donde a es el radio de la partícula de resina y $\mathrm{N}$ es el número de partículas de resina en la suspensión.

La fracción final de aminoácido extraído en la RIE en un volumen de disolución finito se expresa en términos del parámetro $\alpha$ con la siguiente ecuación: 


$$
\mathrm{M}(\infty)=\frac{\mathrm{V}\left[\mathrm{A}^{\mathrm{b}-}\right\rfloor_{(\text {asp }) \mathrm{i}}}{1+\alpha}
$$

La solución del modelo propuesto, Ec. (5.59) representa la fracción de aminoácido extraída por la RIE en función del tiempo (Crank J., 1975; Juang R.S. et al., 1995 a; Ruiz M.O., 2002).

$$
\frac{M(t)}{M(\infty)}=1-\sum_{n=1}^{\infty} \frac{6 \alpha(1+\alpha) \exp \left(-g_{n}{ }^{2} \frac{D_{e t}}{a^{2}}\right)}{9+9 \alpha+\alpha^{2} g_{n}^{2}}
$$

donde $g_{n}$ son las raíces distintas de cero de la ecuación (5.60) y $\alpha$ es un número adimensional definido en la Ec. (5.61).

$$
\begin{aligned}
& \frac{g_{n}}{\tan g_{n}}=1+\frac{\alpha g_{n}^{2}}{3} \\
& \alpha=\frac{3 V}{4 \pi a^{3} N K}=\frac{V}{\bar{V} K}
\end{aligned}
$$

La Ec. (5.59) muestra que $\mathrm{M}(\mathrm{t}) / \mathrm{M}(\infty)$ es función del coeficiente de difusión intrapartícula, $\mathrm{D}_{\mathrm{e}} \mathrm{y}$ de $\alpha$ cuyo valor depende del $\mathrm{pH}$ inicial, de la concentración inicial de aminoácido en la fase acuosa y de la concentración de Tomac en la RIE, tal como se muestra en la Ec. (5.58).

La fracción de aminoácido extraída por la RIE, $M(t) / M(\infty)$, y los valores $D_{e}$ se estimaron de dos formas distintas, una empleando en la determinación de a (Ec. (5.61)) el valor del coeficiente de distribución del aminoácido entre las fases acuosa y resina determinado experimentalmente ( $\left.\mathrm{K}_{\text {experimental }}\right)$ o calculado con el modelo de equilibrio expuesto en los apartados 5.2.3.1 y 5.2.3.2 ( $\mathrm{K}_{\text {calculada }}$. En este segundo caso, se emplearon las siguientes ecuaciones para el cálculo de K:

a) $\mathrm{pH}_{\mathrm{i}}=5$ y 9 :

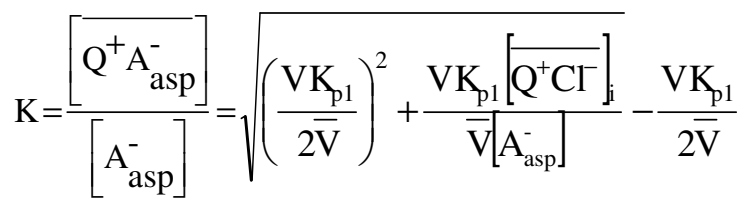

donde $\overline{\mathrm{Q}^{+} \mathrm{A}_{\text {asp }}^{-}} \mid$se sustituye por la Ec. (5.26) del apartado 5.2.3.1.

b) $\mathrm{pH}_{\mathrm{i}}=11$ y 12 :

$$
K=\frac{\left[\overline{\mathrm{Q}_{2}^{+} \mathrm{A}_{\text {asp }}^{2-}}\right]}{\left[\begin{array}{c}
\mathrm{A}_{\text {asp }}^{2-} \\
\text { as }
\end{array}\right]}
$$

donde $\left.\overline{\mathrm{Q}_{2}^{+} \mathrm{A}_{\text {asp }}^{2-}}\right\rfloor$ calculada, se obtiene resolviendo la ecuación de tercer orden (5.33) y cuya solución viene expresada por las Ecs. (5.34) y (5.35) del apartado 5.2.3.2. 


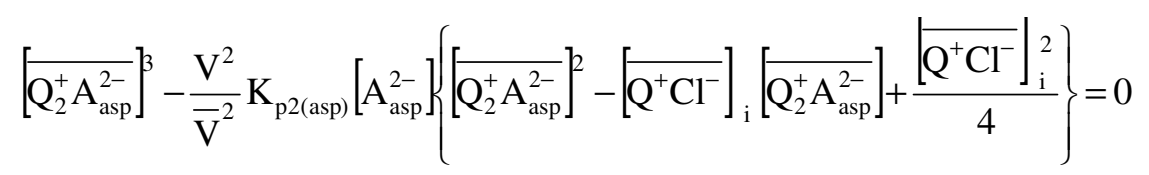

El porcentaje de error se estimó con la Ec. (5.64), donde $\sigma$ es la desviación estándar del coeficiente de difusividad intrapartícula efectivo calculado con los valores de $\mathrm{K}_{\text {experimental }} \mathrm{Y}$ $\mathrm{K}_{\text {calculado }} \mathrm{y} \mathrm{D}_{\mathrm{e}}$ es el coeficiente de difusividad intrapartícula efectivo calculado con el valor de $\mathrm{K}_{\text {experimental: }}$

$$
\% \text { Error }=\frac{\sigma \times 100}{D_{\mathrm{e}}}
$$

En las Figuras 43 y 44 se representan $\log (1-\mathrm{M}(\mathrm{t}) / \mathrm{M}(\infty))$ frente al tiempo. El valor de la difusividad efectiva, $D_{e}$, se obtiene de la resolución conjunta de las Ecs. (5.59)-(5.61) y la Ec. (5.51). En la Tabla 14 se presentan los valores de $D_{e}$ evaluados con el valor de $K$ experimental y de $\mathrm{K}$ calculada con las Ecs. (5.62) o (5.63) y (5.33)-(5.35) para los experimentos de ácido aspártico de la Tabla 5. Además, se recogen los resultados de los experimentos de a-fenilglicina realizados bajo las mismas condiciones del proceso (Ruiz M. O. et al., 2002 b).

En las Figuras 43 y 44 se observa la buena concordancia existente entre las velocidades medidas experimentalmente empleando el valor de $\mathrm{K}_{\text {experimental }}$ (símbolos) y las calculadas con las Ecs. (5.59)-(5.61) (líneas).

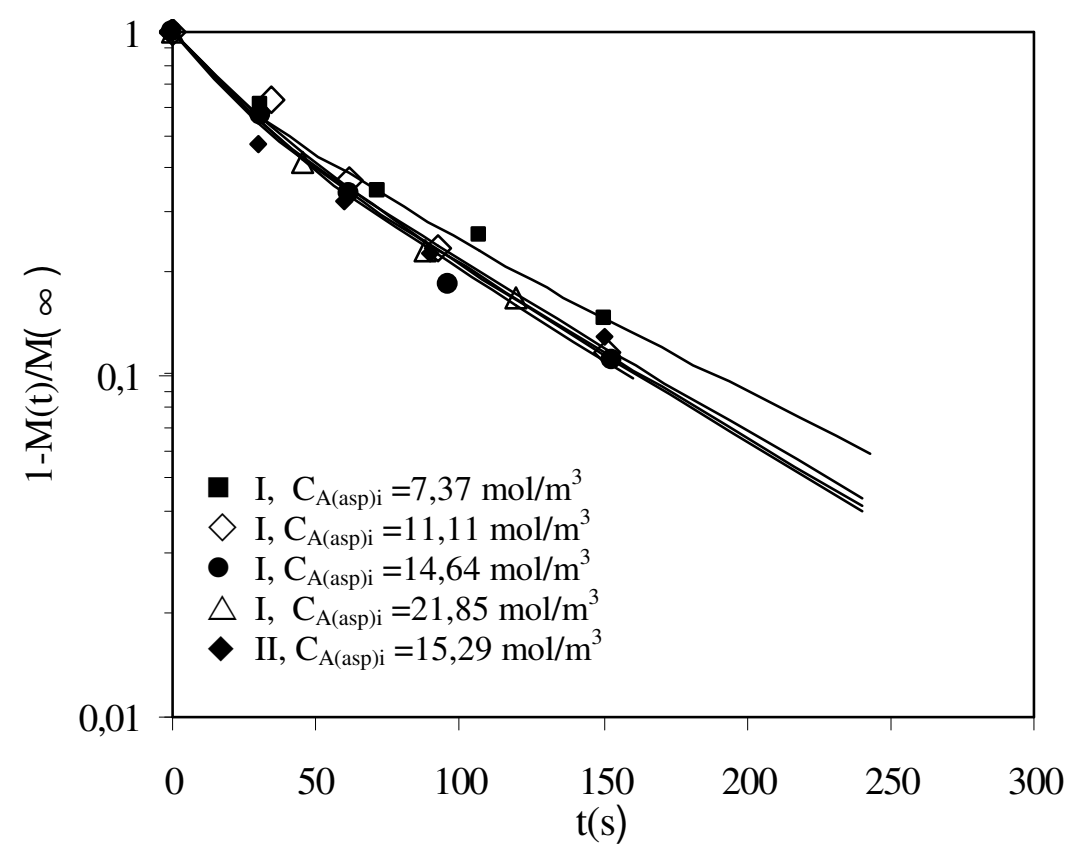

Figura 43. Efecto de la concentración inicial de ácido aspártico en la fase acuosa sobre la velocidad de extracción de ácido aspártico a $30 \stackrel{\circ}{\circ}$ para los experimentos I $(\mathrm{pH}=5,06 \pm 0,07)$ y II $(\mathrm{pH}=8,96 \pm 0,02)$, de la Tabla 5 . Símbolos: datos experimentales y con el valor de $\mathrm{K}_{\text {experimental. }}$ Líneas: datos calculados con las Ecs. (5.59)-(5.61). 


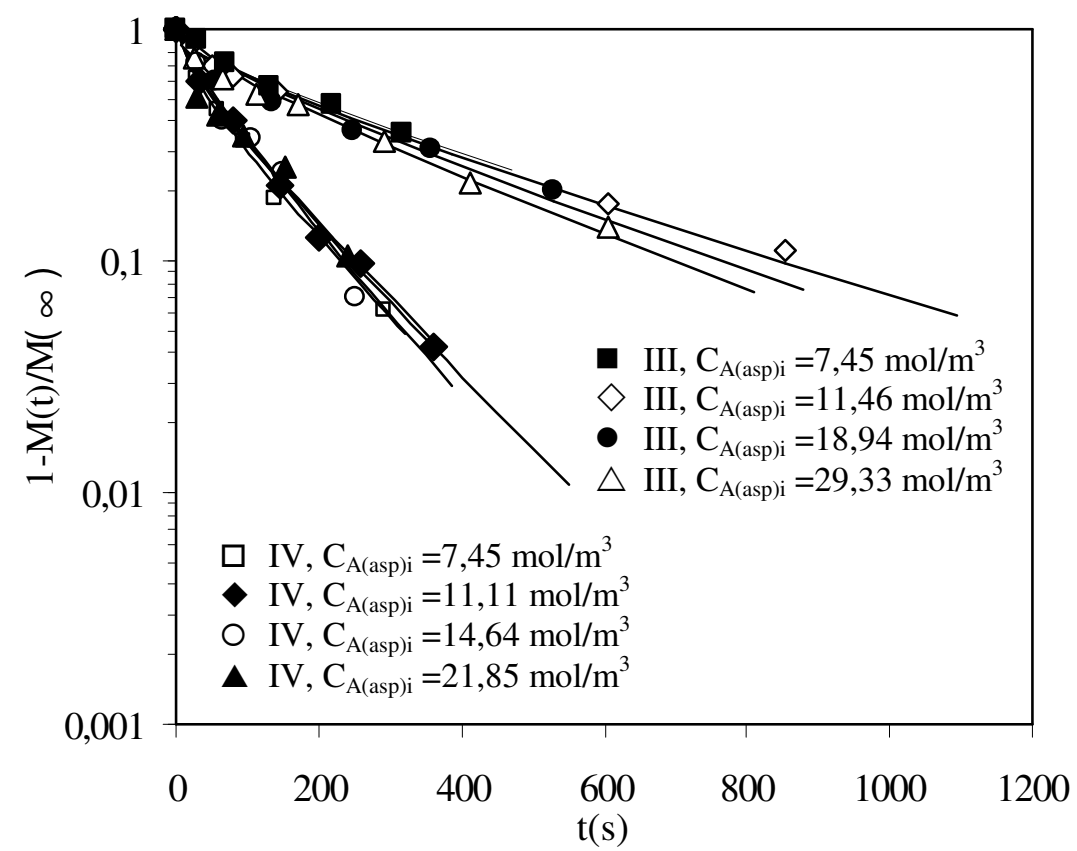

Figura 44. Efecto de la concentración inicial de ácido aspártico en la fase acuosa sobre la velocidad de extracción de ácido aspártico a $30{ }^{\circ} \mathrm{C}$ para los experimentos III $\left(\mathrm{pH}_{\mathrm{i}}=11,04 \pm 0,06\right)$ y IV $\left(\mathrm{pH}_{\mathrm{i}}=12,02 \pm 0,07\right)$ de la Tabla 5. Símbolos: datos experimentales

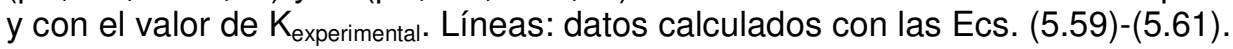

Tabla 14. Parámetros cinéticos evaluados con la segunda ley de Fick para los experimentos de ácido aspártico de la Tabla 5 y para los experimentos de $\alpha$-fenilglicina.

a) ácido aspártico

\begin{tabular}{|c|c|c|c|c|c|}
\hline Experimento & $\mathrm{pH}_{\mathrm{i}}$ & $\begin{array}{c}\mathrm{C}_{\mathrm{A}(\mathrm{asp}) \mathrm{i}} \\
\left(\mathrm{mol} / \mathrm{m}^{3}\right)\end{array}$ & $\begin{array}{c}\mathrm{D}_{\text {e(asp })} \times 10^{11}\left(\mathrm{~m}^{2} / \mathrm{s}\right) \\
\operatorname{Ec}(5.59) \\
\left(\mathrm{K}_{\text {experimental }}\right)\end{array}$ & $\begin{array}{c}\mathrm{D}_{\text {e(asp) }} \times 10^{11}\left(\mathrm{~m}^{2} / \mathrm{s}\right) \\
\mathrm{Ec}(5.59) \\
\left(\mathrm{K}_{\text {calculada }}\right)\end{array}$ & $\begin{array}{l}\% \text { Error } \\
\text { Ec(5.64) }\end{array}$ \\
\hline \multirow[t]{4}{*}{ I } & $5,06 \pm 0,07$ & 7,37 & 43,00 & 43,20 & 0,66 \\
\hline & & 11,11 & 50,00 & 50,20 & 0,28 \\
\hline & & 14,64 & 52,00 & 52,10 & 0,14 \\
\hline & & 21,86 & 54,00 & 54,00 & 0,00 \\
\hline II & $8,96 \pm 0,02$ & 15,29 & 52,00 & 52,50 & 0,68 \\
\hline \multirow[t]{4}{*}{ III } & $11,04 \pm 0,06$ & 7,45 & 8,50 & 8,70 & 1,66 \\
\hline & & 11,46 & 9,20 & 9,67 & 3,61 \\
\hline & & 18,94 & 11,00 & 10,50 & 3,21 \\
\hline & & 29,33 & 12,00 & 12,10 & 0,59 \\
\hline \multirow[t]{4}{*}{ IV } & $12,02 \pm 0,07$ & 9,58 & 32,60 & 33,80 & 2,60 \\
\hline & & 11,19 & 32,40 & 32,30 & 0,22 \\
\hline & & 14,64 & 33,00 & 32,30 & 1,61 \\
\hline & & 24,69 & 37,20 & 36,20 & 1,90 \\
\hline
\end{tabular}


Tabla 14. (Continuación)

b) a-fenilglicina (Ruiz M. O. et al., 2002 b)

\begin{tabular}{ccc}
\hline $\mathrm{pH}_{\mathrm{i}}$ & $\mathrm{C}_{\mathrm{A}(\mathrm{pgly}) \mathrm{i}}\left(\mathrm{mol} / \mathrm{m}^{3}\right)$ & $\begin{array}{c}\mathrm{D}_{\mathrm{e}(\mathrm{pgly})} \times 10^{11}\left(\mathrm{~m}^{2} / \mathrm{s}\right) \\
\mathrm{Ec}(5.59) \\
(\mathrm{K} \text { experimental })\end{array}$ \\
\hline 11,07 & 7,26 & 1,47 \\
11,09 & 13,23 & 1,85 \\
12,06 & 7,26 & 1,13 \\
\hline
\end{tabular}

Los valores de $D_{e}$ fueron similares al estimarlos empleando el valor de $\mathrm{K}$ determinado experimentalmente o calculado con los modelos de equilibrio, con errores inferiores al 3,6 $\%$. Este resultado indica que el modelo de equilibrio describe perfectamente a los sistemas de extracción de los aminoácidos con RIE a $30^{\circ} \mathrm{C}$.

El valor de $D_{e}$ en función de la concentración de ácido aspártico en la fase acuosa para distintos valores de $\mathrm{pH}$ inicial, mostrados en la Tabla 14, se representan en las Figuras 45 y 46.

En la Figura 45 se observa que los valores de $D_{e}$ aumentan ligeramente al aumentar la concentración de ácido aspártico en la fase acuosa a todos los valores de $\mathrm{pH}$ ensayados y también varían con el $\mathrm{pH}$, resultando mayores a $\mathrm{pH}=5$ y 9 . Este resultado puede deberse a que a $\mathrm{pH}=5$ y 9 la única especie de aminoácido que difunde por los poros de la resina es $\mathrm{Q}^{+} \mathrm{A}_{\text {asp }}^{-}$, la cuál es más pequeña que la especie $\mathrm{Q}_{2}^{+} \mathrm{A}_{\text {asp }}^{2-}$ que es la que difunde a $\mathrm{pH}=12$. Además, se observa que el proceso de extracción de ácido aspártico es comparativamente más rápido a $\mathrm{pH}=12$ que a $\mathrm{pH}=11$ debido, a que a $\mathrm{pH}=11$ existen pequeñas cantidades de especie $\mathrm{A}_{\text {asp }}^{-}$, que reducen la fuerza impulsora del proceso cinético.

La Figura 46 muestra que comparativamente los valores de las difusividades efectivas del ácido aspártico son siempre mayores que las de $\alpha$-fenilglicina, indicando por tanto, que la velocidad del proceso de extracción del ácido aspártico es más rápida que la velocidad de extracción de $\alpha$-fenilglicina. Este efecto puede deberse a que el aminoácido $\alpha$ fenilglicina es un aminoácido de mayor tamaño, con un grupo fenilo en su cadena radical, mientras que el ácido aspártico presenta una cadena radical alifática.

Además, la velocidad de extracción de ambos aminoácidos, $\alpha$-fenilglicina y ácido aspártico, crece ligeramente al aumentar su concentración inicial, produciendo comparativamente procesos de extracción más rápidos, como se observa en la Figura 46.

Los valores de la difusividad efectiva obtenidos con la segunda ley de Fick (Ecs. (5.59)(5.61)) son mayores que los obtenidos con el modelo cinético propuesto por Bhandari (Ec. 5.49). Estos resultados pueden ser debidos a que este modelo considera el llenado parcial de los huecos reactivos de la RIE, y consecuentemente, predice un camino de difusión más corto que el modelo de Fick, el cual al considerar que el camino de difusión es el espesor total de la partícula, el camino de difusión es más largo y ajusta los datos experimentales de la velocidad de extracción con un valor más grande de la difusividad. 
En cualquier caso, ambos modelos proporcionan una tendencia ascendente de $D_{e}$ con la concentración inicial de ácido aspártico.

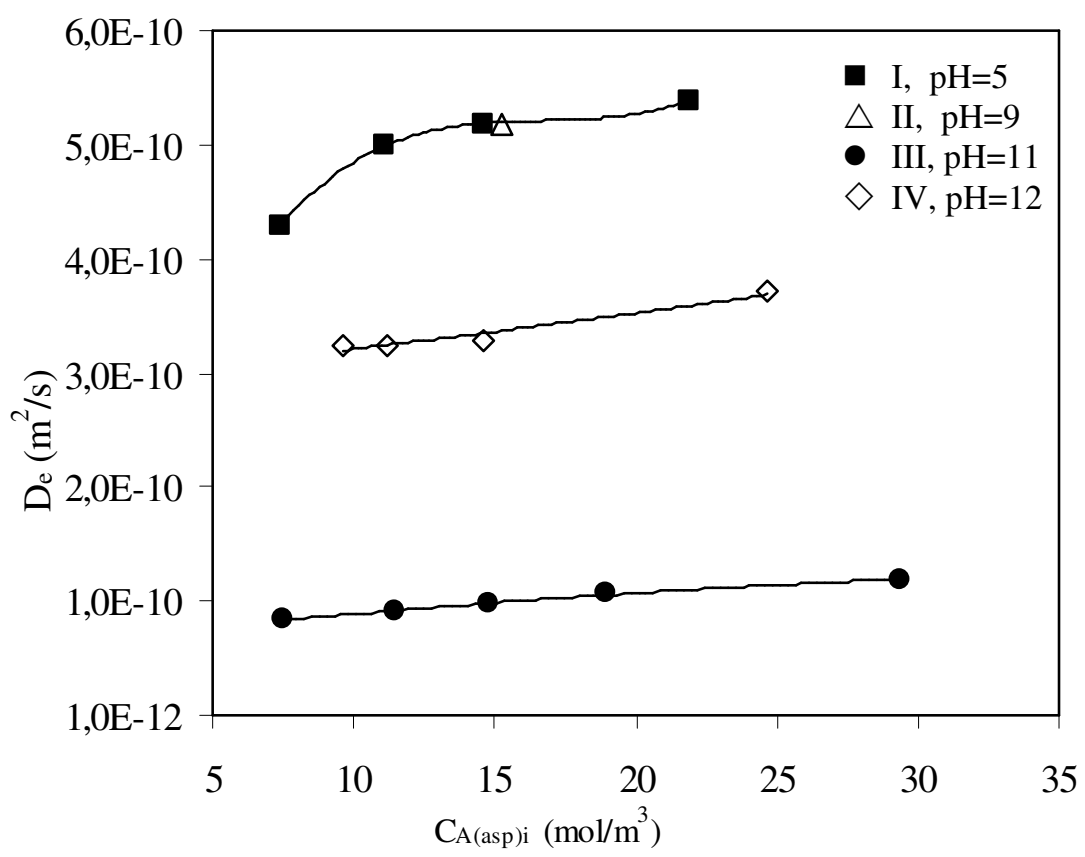

Figura 45. Efecto de la concentración inicial de ácido aspártico y del pH sobre el valor de la difusividad efectiva evaluada con las Ecs. (5.59)-(5.61) para los experimentos de la Tabla 5.

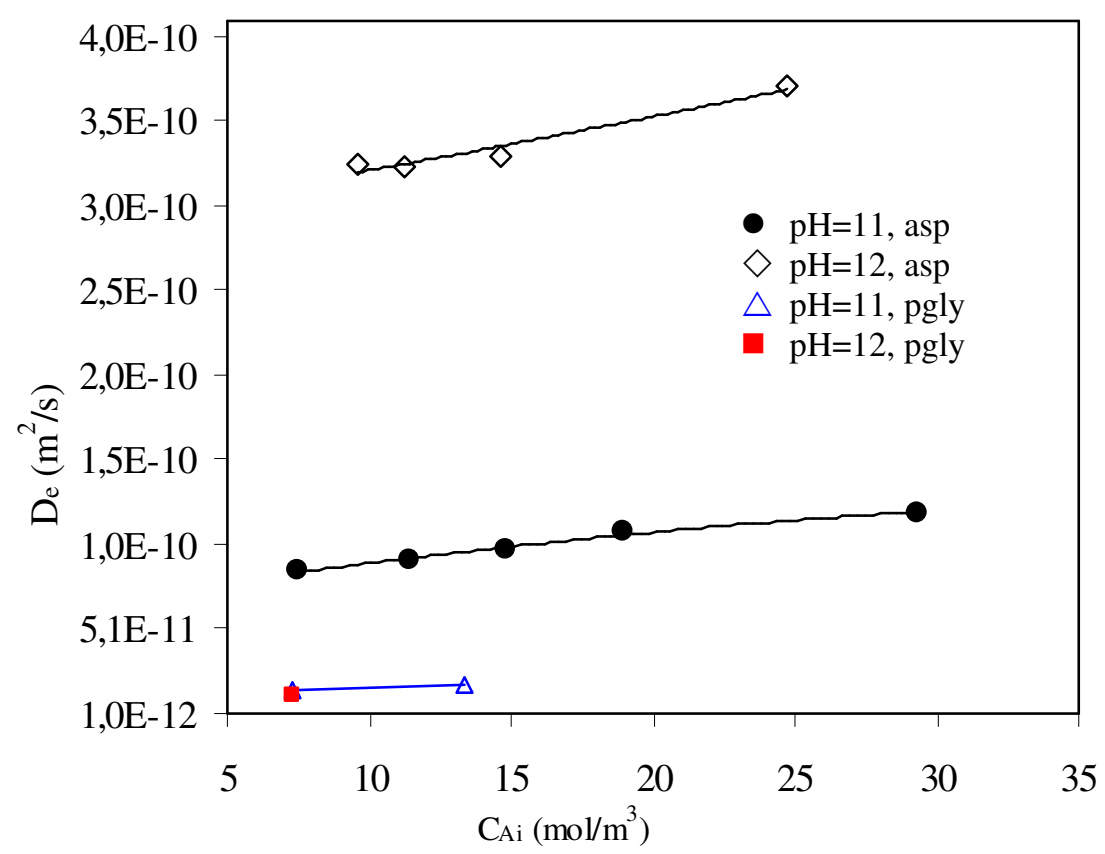

Figura 46. Valores de la difusividad efectiva para la extracción individual de $\alpha$-fenilglicina y ácido aspártico, evaluada con las Ecs. (5.59)-(5.61) para los experimentos III $(\mathrm{pH}=11)$ y IV $(\mathrm{pH}=12)$ de la Tabla 5 y los experimentos de fenilglicina mostrados en Tabla 14-b (Ruiz M. O. et al., 2002 b). 
A partir de los valores del cociente $M(t) / M(\infty)$ obtenidas con el modelo cinético (Ecs. (5.59)-(5.61)) representados en las Figuras 43 y 44 como líneas, y considerando la definición de $\mathrm{M}(\mathrm{t})$ mostrada en la Ec. (5.57), se pueden obtener los valores calculados de la concentración de ácido aspártico en la fase acuosa a lo largo del tiempo, $\mathrm{C}_{\mathrm{A}(\mathrm{asp})}(\mathrm{t})_{\text {cal }}$.

En las Figuras 47-50 se observa la buena concordancia existente entre los datos cinéticos de la concentración temporal de ácido aspártico experimentales (símbolos) y los calculados (líneas). El error estimado con la Ec. (5.15) fue inferior al 7,78 \% para todos los experimentos de la Tabla 5.

$\%$ error promediado $=\frac{100}{\mathrm{j}} \sum_{1}^{\mathrm{j}} \frac{\left(\left(\mathrm{C}_{\mathrm{A}(\text { asp })}(\mathrm{t})_{\mathrm{Cal}}-\mathrm{C}_{\mathrm{A}(\text { asp })}(\mathrm{t})_{\operatorname{Exp}}\right)^{2}\right)^{1 / 2}}{\mathrm{C}_{\mathrm{A}(\text { asp })}(\mathrm{t})_{\operatorname{Exp}}}$

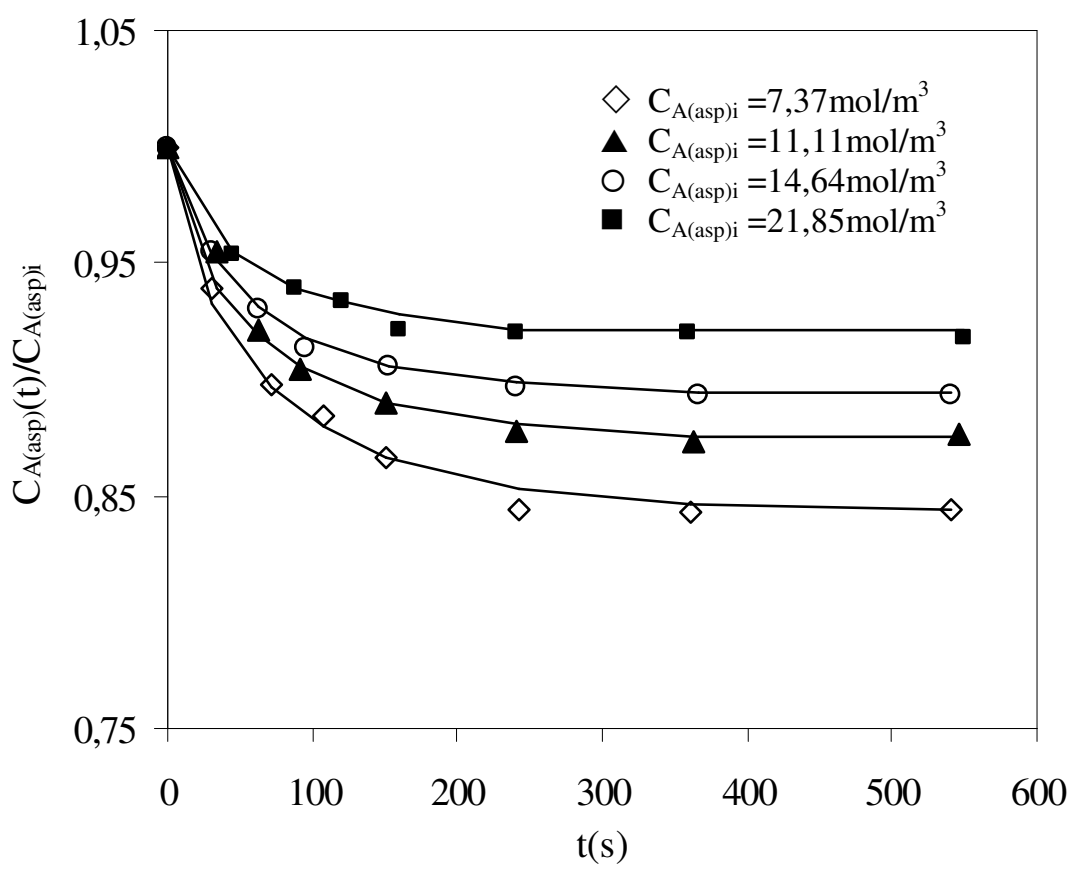

Figura 47. Evolución de la concentración de ácido aspártico con el tiempo experimental (símbolos) y calculados a partir del modelo cinético y con la definición de M(t), Ec. (5.57) (líneas) para el experimento I $\left(\mathrm{pH}_{\mathrm{i}}=5,06 \pm 0,07 ; \mathrm{T}=30 \stackrel{\circ}{\circ}\right)$ de la Tabla 5. 


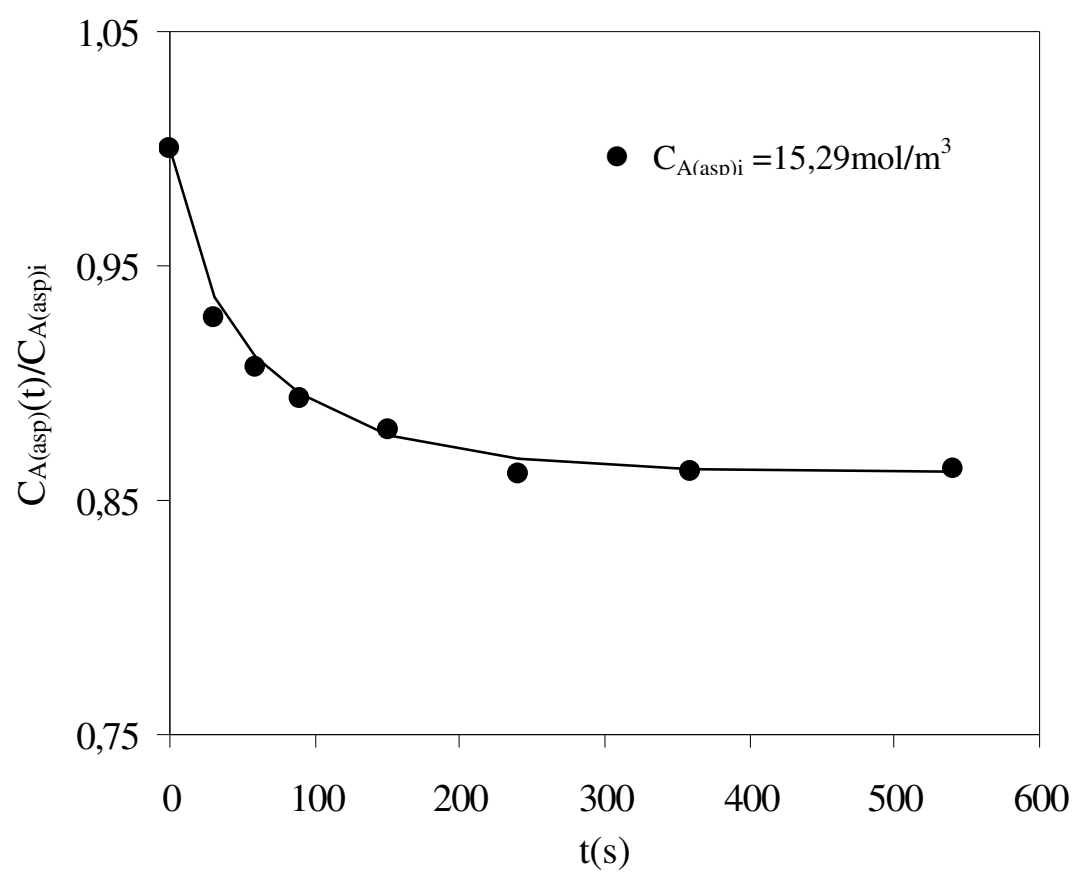

Figura 48. Evolución de la concentración de ácido aspártico con el tiempo experimental (símbolos) y calculados a partir del modelo cinético y con la definición de $M(t)$, Ec. (5.57) (líneas) para el experimento II $\left(\mathrm{pH}_{\mathrm{i}}=8,96 \pm 0,07 ; \mathrm{T}=30 \stackrel{\circ}{\circ} \mathrm{C}\right)$ de la Tabla 5.

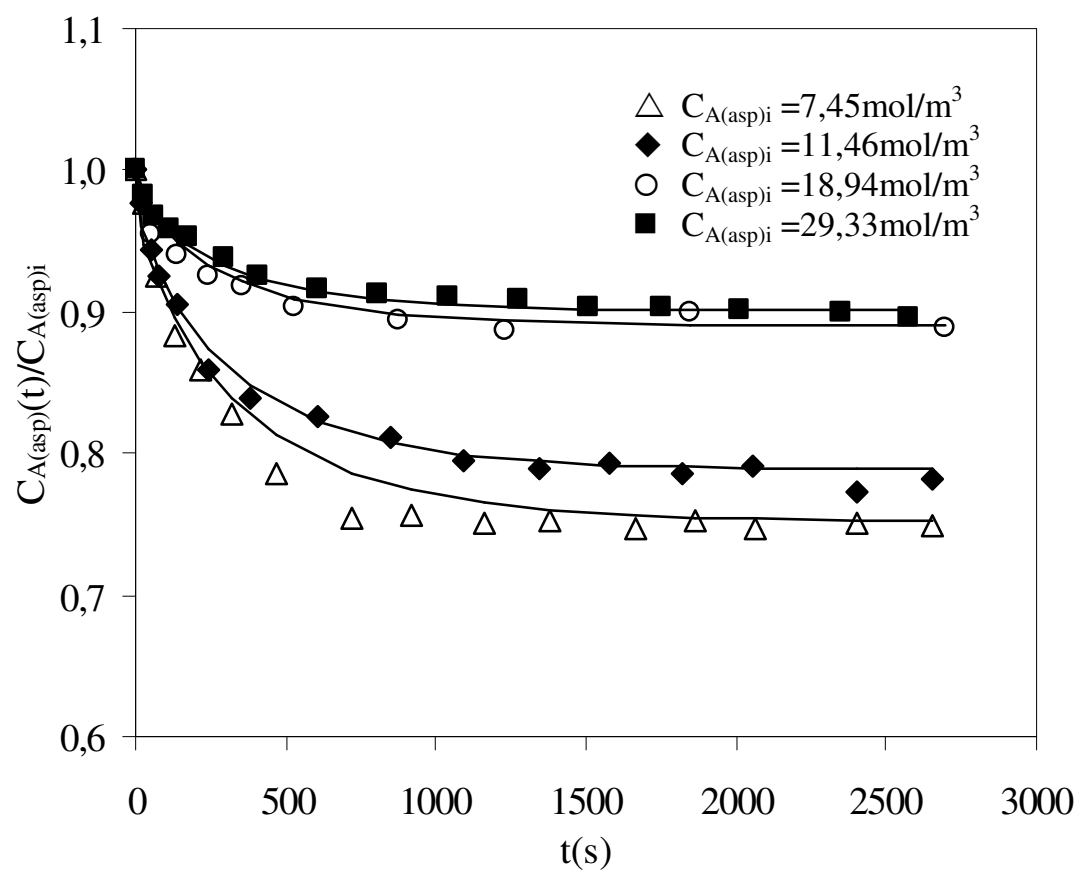

Figura 49. Evolución de la concentración de ácido aspártico con el tiempo experimental (símbolos) y calculados a partir del modelo cinético y con la definición de $M(t)$, Ec. (5.57) (líneas) para el experimento III $\left(\mathrm{pH}_{\mathrm{i}}=11,04 \pm 0,06 ; \mathrm{T}=30 \stackrel{\circ}{\mathrm{C}}\right)$ de la Tabla 5 . 


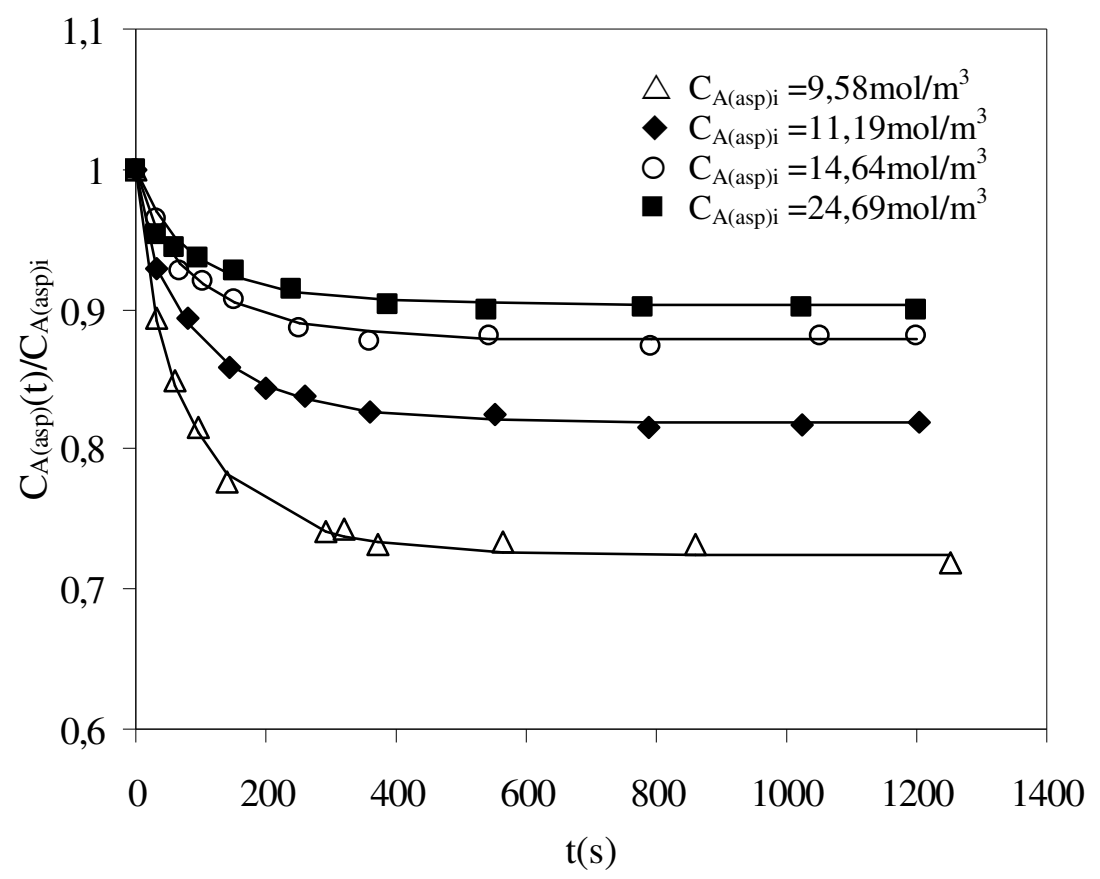

Figura 50. Evolución de la concentración de ácido aspártico con el tiempo experimental (símbolos) y calculados a partir del modelo cinético y con la definición de $\mathrm{M}(\mathrm{t})$, Ec. (5.57) (líneas) para el experimento IV $\left(\mathrm{pH}_{\mathrm{i}}=12,02 \pm 0,07 ; \mathrm{T}=30^{\circ} \mathrm{O}\right)$ de la Tabla 5.

En base a lo expuesto, se puede concluir:

- Los procesos cinéticos de separación de ácido aspártico de disoluciones acuosas diluidas son rápidos y se alcanza el equilibrio a tiempos reducidos, inferiores a 40 minutos. Además, varían con el pH y con la concentración de aminoácido en la fase acuosa.

- La forma y evolución de las curvas cinéticas es similar en todos los experimentos realizados a diferentes valores de pH y concentración inicial de ácido aspártico, por tanto el proceso cinético debe poseer las mismas características y estar controlado por los mismos mecanismos de transferencia de materia.

- Los resultados de las cinéticas de separación de ácido aspártico en tanques agitados se correlacionaron adecuadamente mediante un modelo cinético basado en la segunda ley de Fick, considerando que el proceso de transferencia de materia está controlado por la difusión intrapartícula del complejo ácido aspárticoTomac y que existe un equilibrio instantáneo en la interfase sólido-líquido.

- Los valores de las difusividades efectivas se estimaron a partir del modelo y resultaron del orden de $D_{e}=10^{-10} \mathrm{~m}^{2} / \mathrm{s}$ para el ácido aspártico. El análisis comparado de los valores de $D_{e}$ del ácido aspártico $\left(10^{-10} \mathrm{~m}^{2} / \mathrm{s}\right)$ con $D_{e}$ de $\alpha$ fenilglicina $\left(10^{-11} \mathrm{~m}^{2} / \mathrm{s}\right)$ ratifica los resultados experimentales que ponen de 
manifiesto que la velocidad de extracción del ácido aspártico es más rápida que la de a-fenilglicina, probablemente como consecuencia de su mayor tamaño, ya que contiene un grupo fenilo en su cadena radical.

- La difusividad para el ácido aspártico individual crece ligeramente, y consecuentemente, la velocidad del proceso de transferencia de materia es más rápida, al aumentar la concentración de aminoácido, y a $\mathrm{pH}=5$ y 9.

\subsubsection{Ensayos con mezclas binarias de ácido aspártico y a- fenilglicina}

Los estudios cinéticos de extracción de mezclas de ácido aspártico y a-fenilglicina a $\mathrm{pH}_{\mathrm{i}}=11$ y 12 se determinaron a la temperatura de $30 \stackrel{\circ}{\circ}$, bajo las condiciones experimentales indicadas en la Tabla 6 del apartado 5.1.3.7. La carga de Tomac en la RIE fue la misma que se utilizó en los experimentos de equilibrio.

En base a lo expuesto anteriormente, se puede suponer que a $\mathrm{pH} \geq 11$ la especie predominante del ácido aspártico es $\mathrm{A}_{\text {asp }}^{2-}$, y de la a-fenilglicina es $\mathrm{A}_{\mathrm{pgly}}^{-}$.

La evolución de la concentración de ácido aspártico y a-fenilglicina con el tiempo, en sus formas aniónicas en fase acuosa, a $\mathrm{pH}=11$ y 12 se puede calcular utilizando las siguientes ecuaciones:

$$
\begin{aligned}
& {\left[\mathrm{A}_{\text {asp }}^{2-}\right](\mathrm{t})=\frac{\mathrm{C}_{\mathrm{A}(\text { asp })}(\mathrm{t}) \mathrm{K}_{\mathrm{a} 1} \mathrm{~K}_{\mathrm{a} 2} \mathrm{~K}_{\mathrm{a} 3}}{\left[\mathrm{H}^{+}\right]^{3}(\mathrm{t})+\mathrm{K}_{\mathrm{a} 1}\left[\mathrm{H}^{+}\right]^{2}(\mathrm{t})+\mathrm{K}_{\mathrm{a} 1} \mathrm{~K}_{\mathrm{a} 2}\left[\mathrm{H}^{+}\right](\mathrm{t})+\mathrm{K}_{\mathrm{a} 1} \mathrm{Ka}_{2} \mathrm{~K}_{\mathrm{a} 3}}} \\
& {\left[\mathrm{~A}_{\mathrm{pgly}}^{-}\right](\mathrm{t})=\frac{\mathrm{C}_{\mathrm{A}(\mathrm{pgly})}(\mathrm{t}) \mathrm{K}_{\mathrm{a} 1} \mathrm{~K}_{\mathrm{a} 2}}{\left[\mathrm{H}^{+}\right]^{2}(\mathrm{t})+\mathrm{K}_{\mathrm{a} 1}\left[\mathrm{H}^{+}\right](\mathrm{t})+\mathrm{K}_{\mathrm{a} 1} \mathrm{Ka}_{2}}}
\end{aligned}
$$

donde $\mathrm{C}_{\mathrm{A}}(\mathrm{t})$, representa la concentración total del aminoácido con el tiempo, $\left[\mathrm{A}_{\text {asp }}^{2-}\right](\mathrm{t})$ y $\left[\mathrm{A}_{\mathrm{pgly}}^{-}\right](\mathrm{t})$ son las concentraciones de las formas aniónicas en función del tiempo del ácido aspártico y a-fenilglicina, respectivamente, expresadas en $\mathrm{mol} / \mathrm{m}^{3}$, cuyo $\mathrm{pH}$ también es función del tiempo. Los subíndices pgly y asp representan al aminoácido fenilglicina y ácido aspártico, respectivamente.

Se midió experimentalmente la evolución del pH en estos experimentos cinéticos, ratificando que el efecto de la coextracción de $\mathrm{OH}^{-}$es despreciable. La concentración de 
ácido aspártico y a-fenilglicina en fase resina en el tiempo se obtuvieron a partir de los siguientes balances de materia:

$$
\begin{aligned}
& \overline{\mathrm{C}}_{\mathrm{A}(\text { asp })}(\mathrm{t})=\left[\overline{\mathrm{Q}_{2}^{+} \mathrm{A}^{2-}}\right]_{(\text {asp })}(\mathrm{t})=\left(\mathrm{C}_{\mathrm{A}(\text { asp }) i}-\mathrm{C}_{\mathrm{A}(\text { asp })}(\mathrm{t})\right) \frac{\mathrm{V}}{\overline{\mathrm{V}}} \\
& \overline{\mathrm{C}}_{\mathrm{A}(\text { pgly })}(\mathrm{t})=\left[\overline{\mathrm{Q}^{+} \mathrm{A}^{-}}\right]_{(\text {pgly })}(\mathrm{t})=\left(\mathrm{C}_{\mathrm{A}_{\text {(pgly }) i}}-\mathrm{C}_{\mathrm{A}_{(\text {pgly })}}(\mathrm{t})\right) \frac{\mathrm{V}}{\overline{\mathrm{V}}}
\end{aligned}
$$

donde el superrayado - representa la fase resina, el subíndice i hace referencia a la condición inicial, $\mathrm{V}$ y $\overline{\mathrm{V}}$ son el volumen de la fase acuosa y de la fase resina, respectivamente, y $\left.\overline{\mathrm{Q}_{2}^{+} \mathrm{A}^{2-}}\right\rfloor_{\text {asp })}(\mathrm{t})$ y $\left.\overline{\mathrm{Q}^{+} \mathrm{A}^{-}}\right|_{\text {pgly }}(\mathrm{t})$ son las especies de ácido aspártico y $\alpha$ fenilglicina presentes en la fase resina.

Los resultados obtenidos en las cinéticas de extracción de ácido aspártico y a-fenilglicina de sus mezclas binarias a $\mathrm{pH} \geq 11$ con RIE se muestran en las Tablas B1-B5 del apéndice B y en las Figuras 51 y 52.

En las Figuras 51 y 52 se muestra la evolución temporal de la concentración total de ácido aspártico y de a-fenilglicina de sus mezclas binarias, respectivamente, para los experimentos de la Tabla 6 . Los procesos de extracción de ácido aspártico son rápidos, alcanzándose el equilibrio a tiempos reducidos inferiores a $20 \mathrm{~min}$, mientras que la extracción de a-fenilglicina es más lenta, aunque a pesar de todo, el equilibrio se alcanza a tiempos reducidos inferiores a 45 min para los experimentos de mezclas realizados a $\mathrm{pH}=11$ y 12 .

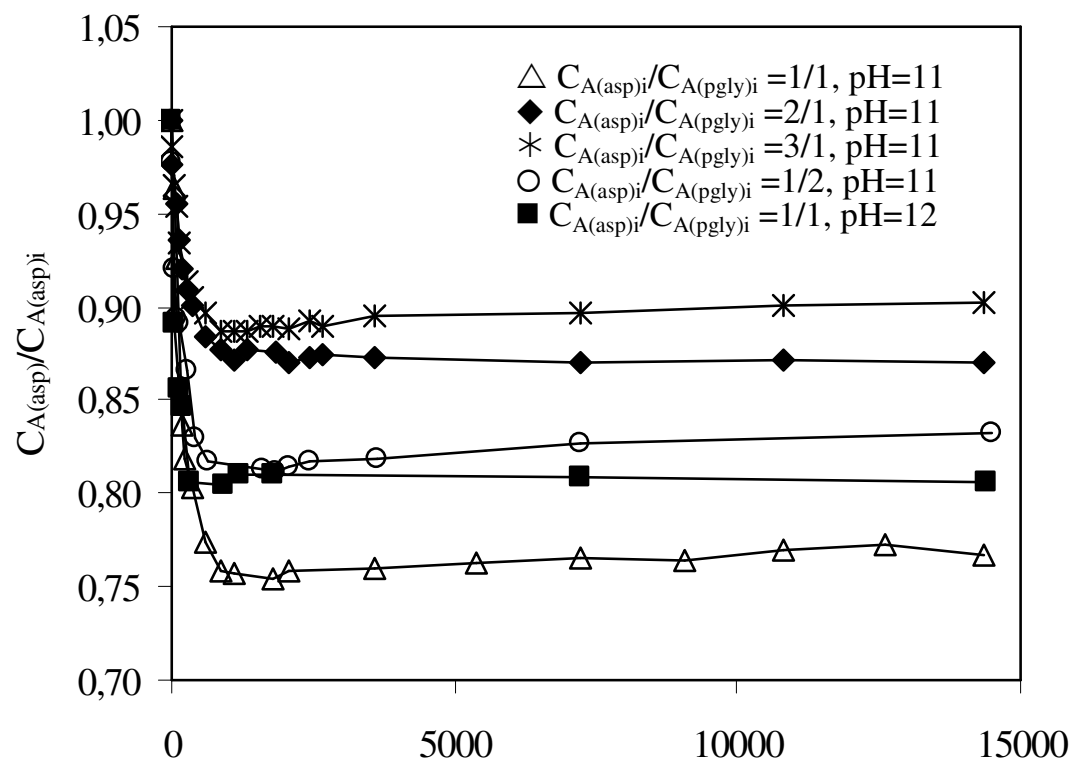

$\mathrm{t}(\mathrm{s})$

Figura 51. Evolución de la concentración de ácido aspártico en la fase acuosa con el tiempo para los experimentos cinéticos I $\left(\mathrm{pH}_{\mathrm{i}}=11,04 \pm 0,05\right)$ y II $\left(\mathrm{pH}_{\mathrm{i}}=12,02 \pm 0,02\right)$ de la Tabla 6 . 


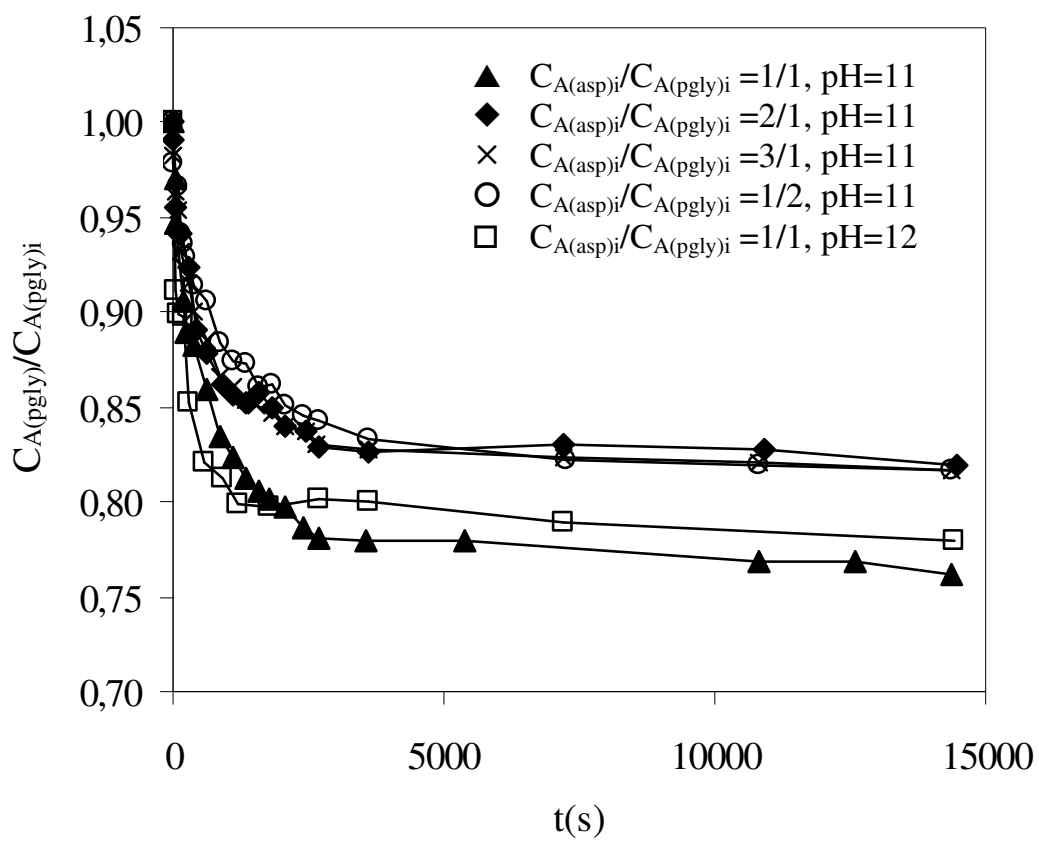

Figura 52. Evolución de la concentración de $\alpha$-fenilglicina en la fase acuosa con el tiempo para los experimentos cinéticos I $\left(\mathrm{pH}_{\mathrm{i}}=11,04 \pm 0,05\right)$ y II $\left(\mathrm{pH}_{\mathrm{i}}=12,02 \pm 0,02\right)$ de la Tabla 6 .

En todos los experimentos cinéticos tanto de extracción individual como de extracción conjunta de ambos aminoácidos, se obtienen curvas que presentan una forma y evolución similar, lo cual induce a pensar que el proceso cinético posee las mismas características y etapas controlantes en todos los sistemas estudiados.

Con los resultados obtenidos de los experimentos de equilibrio y cinéticas, se puede suponer que el proceso se basa en la reacción de intercambio iónico de los aminoácidos con el Tomac retenido en la resina. La velocidad del proceso de intercambio iónico puede estar controlada por la difusión de cada aminoácido en la película líquida externa, por la reacción química en la superficie con el Tomac impregnado en la resina o por la difusión intrapartícula del complejo Tomac-aminoácido, o bien por una combinación de dos o más de estas etapas limitantes del proceso.

\subsubsection{Determinación de la etapa controlante del proceso}

La estimación de la etapa controlante del proceso se realizó utilizando el modelo cinético de Bhandari expuesto en el apartado 5.3.1.1.

La evolución de la concentración de ácido aspártico y a-fenilglicina extraída por la RIE a $\mathrm{pH}=11$ y 12 expresadas en fracción molar, en función del tiempo durante el proceso de extracción, $X$, teniendo en cuenta la estequiometria de la reacción química se definen como: 


$$
\begin{aligned}
& \mathrm{X}_{(\text {asp })}=\frac{2 \overline{\mathrm{C}}_{\mathrm{A} \text { (asp) }}(\mathrm{t})}{\left[\overline{\mathrm{Q}^{+} \mathrm{Cl}^{-}}\right]_{\mathrm{i}}} \\
& \mathrm{X}_{(\mathrm{pgly})}=\frac{\overline{\mathrm{C}}_{\mathrm{A}(\mathrm{pgly})}(\mathrm{t})}{\left[\overline{\mathrm{Q}^{+} \mathrm{Cl}^{-}}\right]_{\mathrm{i}}}
\end{aligned}
$$

donde $\left[\overline{\mathrm{Q}^{+} \mathrm{Cl}^{-}}\right]_{\mathrm{i}}$ es la concentración de Tomac impregnado en la resina expresada en $\mathrm{mol} / \mathrm{m}^{3} \mathrm{RSI} ; \overline{\mathrm{C}}_{\mathrm{A}(\mathrm{asp})}(\mathrm{t})$ es la concentración de ácido aspártico en fase resina definida en la Ec. (5.46); y $\overline{\mathrm{C}}_{\mathrm{A}(\mathrm{pgly})}(\mathrm{t})$ es la concentración de a-fenilglicina en fase resina definida en la Ec. (5.66).

Para estimar la evolución de las concentraciones de ácido aspártico y a-fenilglicina extraídas por la RIE en función del tiempo, este modelo propone las Ecs. (5.69)-(5.74). Estas ecuaciones fueron determinadas considerando que el proceso de extracción está controlado independientemente por difusión en la película líquida, en la partícula o por reacción química:

1- Control por difusión en la película líquida externa:

$$
\begin{aligned}
& \mathrm{X}_{\text {(asp) }}=\frac{3 b \mathrm{D}_{\mathrm{f}(\text { asp })}}{\mathrm{a} \delta\left[\overline{\mathrm{Q}^{+} \mathrm{Cl}^{-}}\right]_{\mathrm{i}}^{\mathrm{t}}} \int_{0}^{\mathrm{t}}\left[\mathrm{A}_{\text {asp }}^{2-}\right](\mathrm{t}) \mathrm{dt} \\
& \mathrm{X}_{(\mathrm{pgly})}=\frac{3 \mathrm{bD} \mathrm{f}_{\mathrm{f}(\mathrm{pgly})}}{\mathrm{a} \delta\left[\overline{\mathrm{Q}^{+} \mathrm{Cl}^{-}}\right]_{1}^{\mathrm{t}}}\left[\mathrm{A}_{\mathrm{pgly}}^{-}\right](\mathrm{t}) \mathrm{dt}
\end{aligned}
$$

2- Control por difusión intrapartícula:

$$
\begin{aligned}
& \mathrm{Y}_{\text {(asp) }}=\frac{\mathrm{X}_{\mathrm{e} \text { (asp) }}}{\mathrm{K}_{\text {(asp) }}}\left[1-3\left(1-\frac{\mathrm{X}_{\text {(asp) }}}{\mathrm{Xe}_{\text {(asp) }}}\right)^{\frac{2}{3}}+2\left(1-\frac{\mathrm{X}_{\text {(asp) }}}{\mathrm{Xe}_{\text {(asp) }}}\right)\right]=\frac{6 \mathrm{bD}_{\mathrm{e}(\text { asp) }}}{\mathrm{a}^{2}\left[\mathrm{Q}^{+} \mathrm{Cl}^{-}\right.} \int_{0}^{\mathrm{t}}\left[\mathrm{A}_{\text {asp }}^{2-}\right](\mathrm{t}) \mathrm{dt} \\
& \left.\mathrm{Y}_{(\mathrm{pgly})}=\frac{\mathrm{X}_{\mathrm{e}(\mathrm{pgly})}}{\mathrm{K}_{(\mathrm{pgly})}}\left[1-3\left(1-\frac{\mathrm{X}_{(\mathrm{pgly})}}{\mathrm{Xe}_{(\mathrm{pgly})}}\right)^{\frac{2}{3}}+2\left(1-\frac{\mathrm{X}_{(\mathrm{pgly})}}{\mathrm{Xe}_{(\mathrm{pgly})}}\right)\right]=\frac{6 \mathrm{bD}_{\mathrm{e}(\mathrm{pgly})}}{\mathrm{a}^{2}\left[\mathrm{Q}^{+} \mathrm{Cl}^{-}\right.}\right]_{0}^{\mathrm{t}}\left[\mathrm{A}_{\mathrm{pgly}}^{-}\right](\mathrm{t}) \mathrm{dt}
\end{aligned}
$$

3- Control por reacción química:

$$
\mathrm{Z}_{\text {(asp) }}=\frac{1}{\mathrm{~K}_{\text {(asp) }}}\left[1-\left(1-\frac{\mathrm{X}_{\text {(asp) }}}{\mathrm{Xe}_{\text {(asp) }}}\right)^{\frac{1}{3}}\right]=\frac{\mathrm{bK}_{\mathrm{C}(\text { asp })}}{\mathrm{a}} \int_{\mathrm{o}}^{\mathrm{t}}\left[\mathrm{A}_{\text {asp }}^{2-}\right](\mathrm{t}) \mathrm{dt}
$$




$$
\mathrm{Z}_{(\mathrm{pgly})}=\frac{1}{\mathrm{~K}_{(\mathrm{pgly})}}\left[1-\left(1-\frac{\mathrm{X}_{(\mathrm{pgly})}}{\mathrm{Xe}_{(\mathrm{pgly})}}\right)^{\frac{1}{3}}\right]=\frac{\mathrm{bK}_{\mathrm{C}(\mathrm{pgly})}}{\mathrm{a}} \int_{0}^{\mathrm{t}}\left[\mathrm{A}_{\text {pgly }}^{-}\right](\mathrm{t}) \mathrm{dt}
$$

donde $\delta$ es el espesor de la película líquida estancada, $D_{f}$ y $D_{e}$ son las difusividades en la película líquida externa y en la fase resina, respectivamente; $K_{c}$ es la constante de velocidad aparente de reacción química; $X_{e}$ es la concentración instantánea de aminoácido extraída en la superficie externa de la RIE en función del tiempo, expresada en fracción molar; a es el radio de la partícula, b es el coeficiente estequimétrico de las reacciones de intercambio iónico del aminoácido con el Tomac impregnado en la resina (a $\mathrm{pH}=11$ y 12: $\mathrm{b}=1$ para $\alpha$-fenilglicina y $\mathrm{b}=2$ para ácido aspártico); $\left[\mathrm{A}_{\text {asp }}^{2-}\right]$ y $\left[\mathrm{A}_{\mathrm{pgly}}^{-}\right]$son las formas aniónicas predominantes del ácido aspártico y $\alpha$-fenilglicina a $\mathrm{pH}=11$ y 12 ; y $\mathrm{K}$ es el coeficiente de distribución de las formas aniónicas predominantes de cada uno de los aminoácidos en el equilibrio expresadas como:

$$
\begin{gathered}
\mathrm{K}_{\text {(asp) }}=\frac{\overline{\mathrm{C}}_{\mathrm{A}(\mathrm{asp})_{(\mathrm{r}=\mathrm{a})}}}{\left[\mathrm{A}_{\text {asp }}^{2-}\right]} \\
\mathrm{K}_{(\mathrm{pgly})}=\frac{\overline{\mathrm{C}}_{\mathrm{A}(\mathrm{pgly})_{(\mathrm{r}=\mathrm{a})}}}{\left[\mathrm{A}_{\mathrm{pgly}}^{-}\right]}
\end{gathered}
$$

donde $\overline{\mathrm{C}}_{\mathrm{A}_{(\mathrm{r}=\mathrm{a})}}$ es la concentración de equilibrio de aminoácido en la superficie de la RIE expresada en $\mathrm{mol} / \mathrm{m}^{3} \mathrm{RSI}$ y $\left[\mathrm{A}_{\text {asp }}^{2-}\right]$ y $\left[\mathrm{A}_{\mathrm{pgly}}^{-}\right]$son las concentraciones de equilibrio de las formas aniónicas predominantes de los aminoácidos en la fase acuosa a $\mathrm{pH}=11$ y 12 expresada en $\mathrm{mol} / \mathrm{m}^{3}$.

Considerando que todos los puntos de la superficie de la RIE están en equilibrio con la disolución acuosa extra-partícula, se puede definir $\mathrm{X}_{\mathrm{e}}$ para cada uno de los aminoácidos utilizando las Ecs. (5.75) y (5.76) como las siguientes relaciones:

$$
\begin{aligned}
& \mathrm{X}_{\mathrm{e}(\mathrm{asp})}=\frac{2 \mathrm{~K}\left[\mathrm{~A}_{\mathrm{asp}}^{2-}\right](\mathrm{t})}{\left.\overline{\mathrm{Q}^{+} \mathrm{Cl}^{-}}\right]_{\mathrm{i}}} \\
& \mathrm{X}_{\mathrm{e}(\mathrm{pgly})}=\frac{\mathrm{K}\left[\mathrm{A}_{\mathrm{pgly}}^{-}\right](\mathrm{t})}{\left.\overline{\mathrm{Q}^{+} \mathrm{Cl}^{-}}\right]_{\mathrm{i}}}
\end{aligned}
$$

Los valores obtenidos de $\mathrm{X}, \mathrm{Y}, \mathrm{Z}, \int_{0}^{\mathrm{t}}\left[\mathrm{A}_{\mathrm{asp}}^{2-}\right](\mathrm{t}) \mathrm{dt} \mathrm{y} \int_{0}^{\mathrm{t}}\left[\mathrm{A}_{\mathrm{pgly}}^{-}\right](\mathrm{t}) \mathrm{dt}$ para los experimentos de la Tabla 6, que se muestran en la Tabla B6 del apéndice B. 
El sistema estará controlado por difusión en la película líquida externa, difusión intrapartícula y/o reacción química, si al representar $X, Y, Z$ frente a $\int_{0}^{t}\left[A_{\text {asp }}^{2-}\right](t) d t \quad o$ $\int_{0}^{t}\left[A_{\text {pgly }}^{-}\right](t) d t$ se obtienen líneas rectas con ordenada en el origen cero y de cuya pendiente se podrán evaluar los parámetros cinéticos $\mathrm{K}_{\mathrm{f}}, \mathrm{D}_{\mathrm{e}} \mathrm{y} \mathrm{K}_{\mathrm{C}}$, respectivamente.

En las Figuras 53 y 54 se representa $X, Y, Z$ frente a $\int_{0}^{t}\left[A_{\text {asp }}^{2-}\right](t) d t$ y $\int_{0}^{t}\left[A_{\text {pgly }}^{-}\right](t) d t$, respectivamente, para el experimento I de la Tabla $6 .\left(\mathrm{C}_{A(\text { asp })}=6,52 \mathrm{~mol} / \mathrm{m}^{3} ; \mathrm{C}_{\mathrm{A}(\mathrm{pgly}) \mathrm{i}}=6,68\right.$ $\left.\mathrm{mol} / \mathrm{m}^{3} \mathrm{pH}_{\mathrm{i}}=11,04 \pm 0,05 ; \mathrm{T}=30^{\circ} \mathrm{C}\right)$.

Las Figuras 53 y 54 muestran que las Ecs (5.69), (5.70), (5.73) y (5.74) no ajustan los datos cinéticos experimentales, así se puede suponer que la difusión en la película líquida externa y la reacción química no son etapas controlantes de la velocidad de los procesos cinéticos de extracción de ácido aspártico y a-fenilglicina de sus mezclas. Sin embargo, las Ecs. (5.71) y (5.72) proporcionan un buen ajuste de los datos cinéticos experimentales indicando que el proceso está controlado por difusión intrapartícula.

Resultados similares se obtuvieron para todos los experimentos cinéticos de la Tabla 6 (no mostrados). Esto indica que el proceso de extracción del ácido aspartico y afenilglicina de sus mezclas, a los pH ensayados, se puede suponer que está únicamente controlado por la difusión intrapartícula.

Los valores de las difusividades efectivas, $D_{e(a s p)}$ y $D_{e(p g l y)}$, evaluados mediante las pendientes de $Y$ frente a $\int_{0}^{t}\left[A_{\text {asp }}^{2-}\right](t) d t y \int_{0}^{t}\left[A_{\text {pgly }}^{-}\right](t) d t$, respectivamente, se muestran en la Tabla 15 , junto con sus regresiones lineales para los experimentos de la Tabla 6.

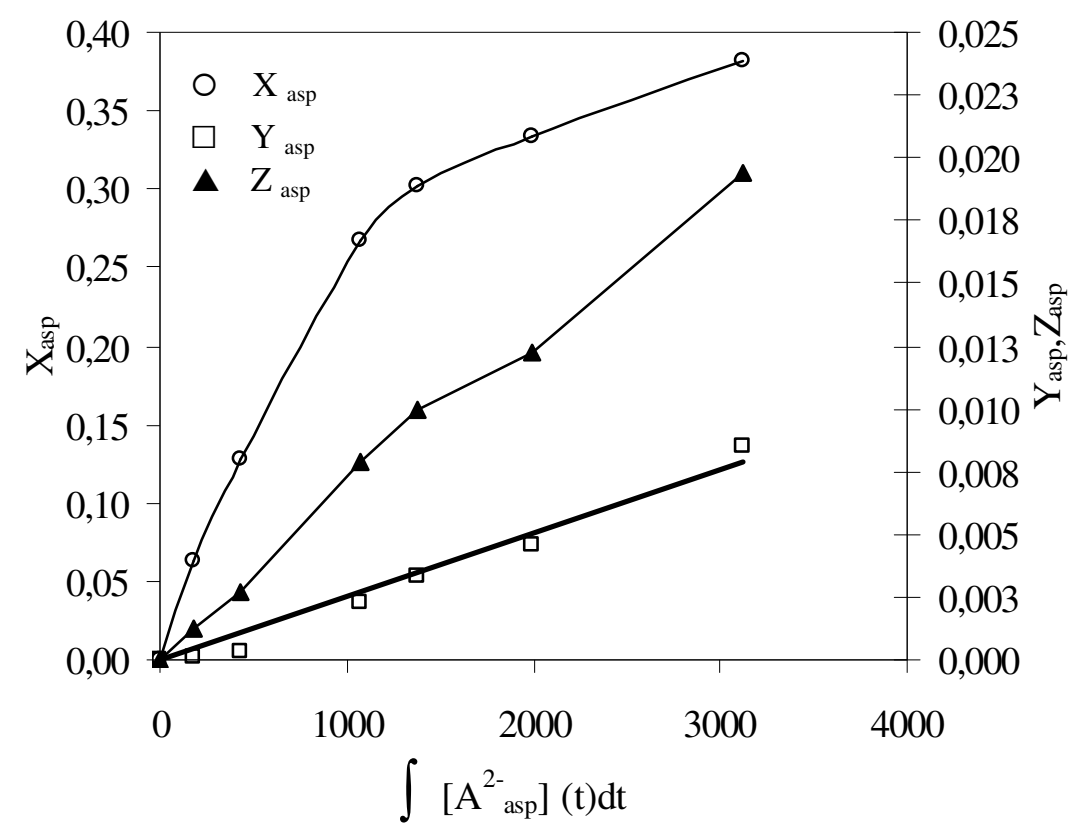

Figura 53. Determinación de la etapa controlante de la velocidad de extracción de ácido aspártico de sus mezclas binarias de ácido aspártico y a-fenilglicina con RIE correspondiente al experimento I $\left(\mathrm{C}_{\mathrm{A}(\text { asp })} / \mathrm{C}_{\mathrm{A}(\text { pgly)i }}=1 / 1\right)$ de la Tabla 6. 


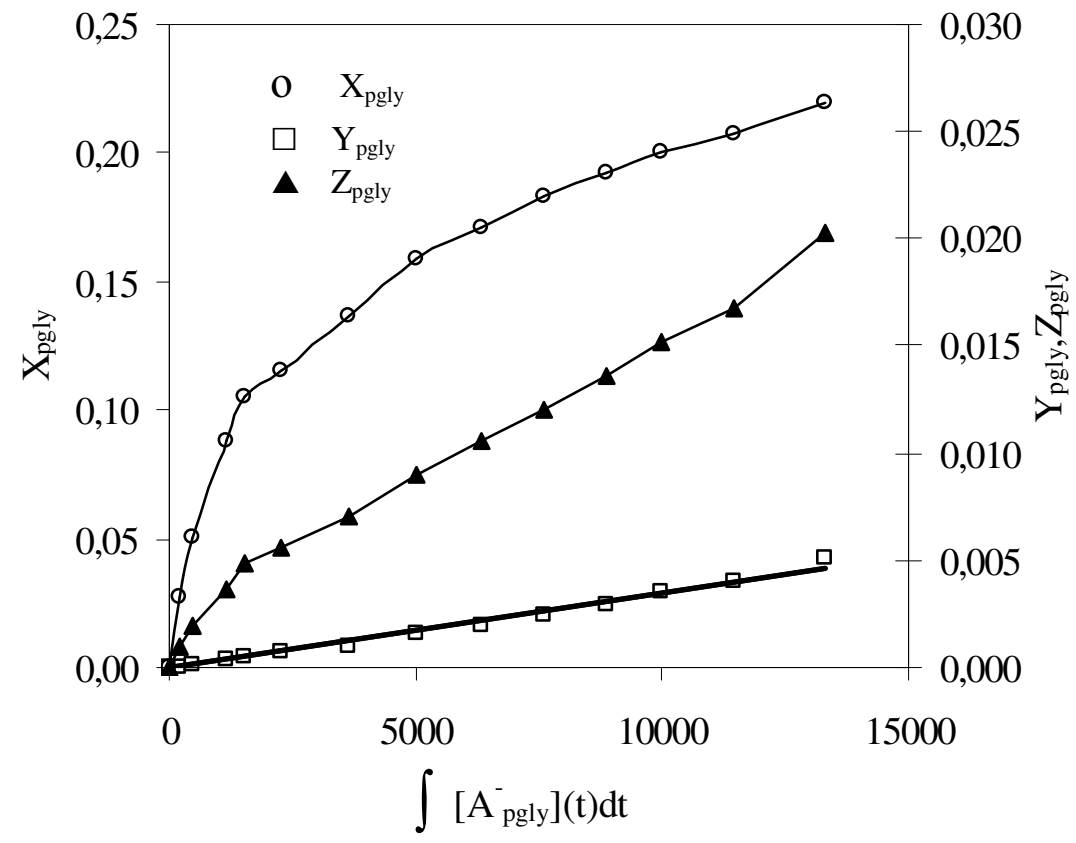

Figura 54. Determinación de la etapa controlante de la velocidad de extracción de $\boldsymbol{\alpha}$-fenilglicina de sus mezclas binarias de ácido aspártico a-fenilglicina con RIE correspondiente al experimento I $\left(\mathrm{C}_{\mathrm{A}(\text { asp })} / \mathrm{C}_{\mathrm{A}(\mathrm{pg} \text { ly) }}=1 / 1\right)$ de la Tabla 6 .

Tabla 15. Valores de difusividades efectivas, $D_{e}$, evaluados con las Ecs. (5.71) y (5.72), $r=$ regresión lineal.

a) Ácido aspártico

\begin{tabular}{cccccc}
\hline Experimento & $\mathrm{pH}_{\mathrm{i}}$ & $\mathrm{C}_{\mathrm{A}(\text { (asp) } \mathrm{i}}\left(\mathrm{mol} / \mathrm{m}^{3}\right)$ & $\mathrm{C}_{\mathrm{A}(\mathrm{pgly)})}\left(\mathrm{mol} / \mathrm{m}^{3}\right)$ & $\begin{array}{c}\mathrm{D}_{\mathrm{e}(\mathrm{sasp})} \mathrm{x} 10^{11} \\
\left(\mathrm{~m}^{2} / \mathrm{s}\right) \operatorname{Ec}(5.71)\end{array}$ & $\mathrm{r} \mathrm{Ec(5.71)}$ \\
\hline $\mathrm{I}$ & $11,04 \pm 0,05$ & 6,52 & 6,68 & 2,87 & 0,987 \\
& & 13,11 & 6,74 & 1,92 & 0,998 \\
& & 19,58 & 6,83 & 3,83 & 0,995 \\
$\mathrm{II}$ & $12,02 \pm 0,02$ & 6,31 & 12,38 & 2,87 & 0,997 \\
& & 7,65 & 8,10 & 4,92 & 0,990 \\
\hline
\end{tabular}

b) a-Fenilglicina

\begin{tabular}{|c|c|c|c|c|c|}
\hline Experimento & $\mathrm{pH}_{\mathrm{i}}$ & $\mathrm{C}_{\mathrm{A} \text { (asp)i }}\left(\mathrm{mol} / \mathrm{m}^{3}\right)$ & $\mathrm{C}_{\mathrm{A}(\mathrm{pgly}) \mathrm{i}}\left(\mathrm{mol} / \mathrm{m}^{3}\right)$ & $\begin{array}{c}\mathrm{D}_{\mathrm{e}(\mathrm{pgly})} \mathrm{x} 10^{12} \\
\left(\mathrm{~m}^{2} / \mathrm{s}\right) \operatorname{Ec}(5.72)\end{array}$ & $\mathrm{r} \operatorname{Ec}(5.72)$ \\
\hline \multirow[t]{4}{*}{ I } & $11,04 \pm 0,05$ & 6,52 & 6,68 & 5,75 & 0,993 \\
\hline & & 13,11 & 6,74 & 7,68 & 0,987 \\
\hline & & 19,58 & 6,83 & 9,58 & 0,999 \\
\hline & & 6,31 & 12,38 & 11,50 & 0,991 \\
\hline II & $12,02 \pm 0,02$ & 7,65 & 8,10 & 19,68 & 0,998 \\
\hline
\end{tabular}




\subsubsection{Modelo cinético basado en la ley de Fick}

Al igual que en los procesos cinéticos de extracción individual de ácido aspártico, como el proceso cinético está controlado, únicamente, por difusión intrapartícula, se puede aplicar para el ajuste de los datos experimentales un modelo basado en la segunda ley de Fick para cada uno de los aminoácidos que intervienen en la mezcla.

El modelo considera una reacción de intercambio iónico heterogénea entre las partículas esféricas de la RIE y los aminoácidos de la disolución acuosa agitada de volumen finito en la cual están inmersas. La resistencia a la difusión en la película líquida externa se puede considerar despreciable, por efecto de la agitación. En la interfase líquido-sólido se mantiene un equilibrio instantáneo y $\mathrm{K}$ es el coeficiente de distribución de las especies que difunden entre ambas fases, definido en la Ec. (5.75) para el ácido aspártico y en la Ec. (5.76) para $\alpha$-fenilglicina. Posteriormente, las especies extraídas en la superficie $\left(Q_{2}{ }^{+} A^{2-}\right.$ asp, $\left.Q^{+} A_{\text {pgly }}^{-}\right)$de la RIE difunden lentamente al interior de la fase resina. Además, se asume que la concentración de aniones de aminoácido en el seno de la fase acuosa varía con el tiempo y que la difusividad en la fase resina es constante.

Bajo estas condiciones los balances de materia en coordenadas esféricas, de cada uno de los aminoácidos presentes en la mezcla en fase resina pueden ser expresados por las siguientes ecuaciones:

$$
\begin{aligned}
& \frac{\partial \overline{\mathrm{C}}_{\mathrm{A}(\text { asp })}(\mathrm{r}, \mathrm{t})}{\partial \mathrm{t}}=\mathrm{D}_{\mathrm{e}(\text { asp })} \frac{1}{\mathrm{r}^{2}} \frac{\partial}{\partial \mathrm{r}}\left(\mathrm{r}^{2} \frac{\partial \overline{\mathrm{C}}_{\mathrm{A}(\text { asp })}(\mathrm{r}, \mathrm{t})}{\partial \mathrm{r}}\right) ; 0 \leq \mathrm{r} \leq \mathrm{a} ; \mathrm{t}>0 \\
& \frac{\partial \overline{\mathrm{C}}_{\mathrm{A}(\mathrm{pgly})}(\mathrm{r}, \mathrm{t})}{\partial \mathrm{t}}=\mathrm{D}_{\mathrm{e}(\mathrm{pgly})} \frac{1}{\mathrm{r}^{2}} \frac{\partial}{\partial \mathrm{r}}\left(\mathrm{r}^{2} \frac{\partial \overline{\mathrm{C}}_{\mathrm{A}(\mathrm{pgly})}(\mathrm{r}, \mathrm{t})}{\partial \mathrm{r}}\right) ; 0 \leq \mathrm{r} \leq \mathrm{a} ; \mathrm{t}>0
\end{aligned}
$$

con las condiciones límite e iniciales que se citan a continuación:

$$
\begin{array}{lll}
\overline{\mathrm{C}}_{\mathrm{A}(\mathrm{asp})}(\mathrm{r}, \mathrm{t})=\mathrm{K}_{(\text {asp })}\left[\mathrm{A}_{\text {asp }}^{2-}\right](\mathrm{t}) & \mathrm{r}=\mathrm{a} & \mathrm{t}>0 \\
\overline{\mathrm{C}}_{\mathrm{A}(\mathrm{pgly})}(\mathrm{r}, \mathrm{t})=\mathrm{K}_{(\mathrm{pgly})}\left[\mathrm{A}_{\text {pgly }}^{-}\right](\mathrm{t}) & \mathrm{r}=\mathrm{a} \quad \mathrm{t}>0 \\
\overline{\mathrm{C}}_{\mathrm{A}(\text { asp })}(\mathrm{r}, \mathrm{t})=0, \overline{\mathrm{C}}_{\mathrm{A}(\mathrm{pgly})}(\mathrm{r}, \mathrm{t})=0 & 0 \leq \mathrm{r} \leq \mathrm{a} \quad \mathrm{t}=0 \\
\overline{\mathrm{C}}_{\mathrm{A}(\text { asp })}(\mathrm{r}, \mathrm{t})=\text { finito }, \overline{\mathrm{C}}_{\mathrm{A}(\mathrm{pgly})}(\mathrm{r}, \mathrm{t})=\text { finito } & \mathrm{r}=0 \quad \mathrm{t} \geq 0
\end{array}
$$

La cantidad de ácido aspártico y a-fenilglicina extraídos en la RIE en función del tiempo expresado en unidades de mol, $\mathrm{M}(\mathrm{t})$, se puede determinar conociendo la cantidad de cada uno de los aminoácidos transferida de la disolución acuosa utilizando los balances de materia de las Ecs. (5.46) y (5.66); así se obtienen las siguientes igualdades: 
$\mathrm{M}(\mathrm{t})_{(\text {asp })}=\mathrm{V}\left(\mathrm{C}_{\mathrm{A}(\text { asp }) \mathrm{i}}-\mathrm{C}_{\mathrm{A}(\text { asp })}(\mathrm{t})\right)=4 \pi \mathrm{N} \int_{0}^{\mathrm{a}} \mathrm{r}^{2} \overline{\mathrm{C}}_{\mathrm{A}(\text { asp })}(\mathrm{r}, \mathrm{t}) \mathrm{dr}$

$\mathrm{M}(\mathrm{t})_{(\mathrm{pgly})}=\mathrm{V}\left(\mathrm{C}_{\mathrm{A}(\mathrm{pgly}) \mathrm{i}}-\mathrm{C}_{\mathrm{A}(\mathrm{pgly})}(\mathrm{t})\right)=4 \pi \mathrm{N} \int_{0}^{\mathrm{a}} \mathrm{r}^{2} \overline{\mathrm{C}}_{\mathrm{A}(\mathrm{pgly})}(\mathrm{r}, \mathrm{t}) \mathrm{dr}$

donde a es el radio de la partícula de resina y $\mathrm{N}$ es el número de partículas de resina en la suspensión.

La fracción final de cada aminoácido extraído en la RIE en un volumen de disolución finito se expresa en términos del parámetro $\alpha$ con las siguientes ecuaciones:

$$
\begin{aligned}
& \mathrm{M}(\infty)_{(\text {asp })}=\frac{\mathrm{V}\left[\mathrm{A}_{\text {asp }}^{2-}\right]_{\mathrm{i}}}{1+\alpha_{(\text {asp })}} \\
& \mathrm{M}(\infty)_{(\mathrm{pgly})}=\frac{\mathrm{V}\left[\mathrm{A}_{\mathrm{pgly}}^{-}\right]_{\mathrm{i}}}{1+\alpha_{(\mathrm{pgly})}}
\end{aligned}
$$

Las soluciones del modelo propuesto, Ecs. (5.89) y (5.90) representan la fracción de cada uno de los aminoácidos extraídos por la RIE en función del tiempo (Crank J., 1975; Ruiz M.O., 2002).

$$
\begin{aligned}
& \frac{\mathrm{M}(\mathrm{t})_{(\text {asp })}}{\mathrm{M}(\infty)_{(\text {asp })}}=1-\sum_{\mathrm{n}=1}^{\infty} \frac{6 \alpha_{(\text {asp })}\left(1+\alpha_{(\text {asp })}\right) \exp \left(-\mathrm{g}_{\mathrm{n}(\text { asp })}^{2} \frac{\mathrm{D}_{\mathrm{e}(\text { asp })}}{\mathrm{a}^{2}}\right)}{9+9 \alpha_{\text {(asp) }}+\alpha_{(\text {asp })}^{2} \mathrm{~g}_{\mathrm{n} \text { (asp) }}^{2}} \\
& \frac{\mathrm{M}(\mathrm{t})_{(\mathrm{pgly})}}{\mathrm{M}(\infty)_{(\mathrm{pgly})}}=1-\sum_{\mathrm{n}=1}^{\infty} \frac{6 \alpha_{(\mathrm{pgly})}\left(1+\alpha_{(\mathrm{pgly})}\right) \exp \left(-\mathrm{g}_{\mathrm{n}(\mathrm{pgly})}^{2} \frac{D_{\mathrm{e}(\mathrm{pgly}) \mathrm{t}}}{\mathrm{a}^{2}}\right)}{9+9 \alpha_{(\mathrm{pgly})}+\alpha_{(\mathrm{pgly})}^{2} \mathrm{~g}_{\mathrm{n}(\mathrm{pgly})}^{2}}
\end{aligned}
$$

donde $\mathrm{g}_{\mathrm{n}}$ son las raíces distintas de cero de cada aminoácido definidas en las ecuaciones (5.91) y (5.92); $\alpha$ es un número adimensional definido en las Ecs. (5.93) y (5.94) y $\mathrm{D}_{\mathrm{e}}$ son los coeficientes de difusión efectivos intrapartícula de cada uno de los aminoácidos.

$$
\begin{aligned}
& \frac{\mathrm{g}_{\mathrm{n} \text { (asp) }}}{\tan \mathrm{g}_{\mathrm{n} \text { (asp) }}}=1+\frac{\alpha_{(\text {asp) }} \mathrm{g}_{\mathrm{n} \text { (asp) }}^{2}}{3} \\
& \frac{g_{n(p g l y)}}{\tan g_{n(p g l y)}}=1+\frac{\alpha_{(\text {pgly })} g_{n(p g l y)}^{2}}{3} \\
& \alpha_{\text {(asp) }}=\frac{3 \mathrm{~V}}{4 \pi \mathrm{a}^{3} \mathrm{NK}_{\text {(asp) }}}=\frac{\mathrm{V}}{\overline{\mathrm{V}} \mathrm{K}_{\text {(asp) }}} \\
& \alpha_{(\mathrm{pgly})}=\frac{3 \mathrm{~V}}{4 \pi \mathrm{a}^{3} \mathrm{NK}_{(\mathrm{pgly})}}=\frac{\mathrm{V}}{\overline{\mathrm{V}} \mathrm{K}_{(\mathrm{pgly})}}
\end{aligned}
$$

En las Figuras 55 y 56 se representa $\log (1-\mathrm{M}(\mathrm{t}) / \mathrm{M}(\infty))$ frente al tiempo para los experimentos de la Tabla 6 . Los valores de las difusividades efectivas de cada aminoácido, $\mathrm{D}_{\mathrm{e}}$, se obtienen de la resolución conjunta de las Ecs. (5.89), (5.91) y (5.93) para ácido aspártico y de las Ecs. (5.90), (5.92) y (5.94) para la a-fenilglicina con el 
coeficiente de distribución determinado experimentalmente $\left(\mathrm{K}_{\text {experimental }}\right)$ o calculado con el modelo de equilibrio anteriormente desarrollado en el apartado 5.2.4.1 ( $\mathrm{K}_{\text {calculado }}$ ). En este segundo caso los valores de $\mathrm{K}_{\text {calculado }}$ para los dos aminoácidos de la mezcla se estimaron con las siguientes ecuaciones:

$$
\begin{gathered}
\mathrm{K}_{\text {(asp) }}=\frac{\left.\overline{\mathrm{Q}_{2}^{+} \mathrm{A}_{\text {asp }}^{2-}}\right]}{\left[\mathrm{A}_{\text {asp }}^{2-}\right]}=\mathrm{K}_{\mathrm{p} 2 \text { (asp) }} \frac{\left[\overline{\mathrm{Q}^{+} \mathrm{Cl}^{-}}\right]^{2}}{\left[\mathrm{Cl}^{-}\right]^{2}} \\
\mathrm{~K}_{\text {(pgly) }}=\frac{\left.\overline{\mathrm{Q}^{+} \mathrm{A}_{\text {pgly }}^{-}}\right]}{\left[\mathrm{A}_{\text {pgly }}^{-}\right]}=\mathrm{K}_{\mathrm{p} 1 \text { (pgly) }} \frac{\left[\overline{\mathrm{Q}^{+} \mathrm{Cl}^{-}}\right]}{\left[\mathrm{Cl}^{-}\right]}
\end{gathered}
$$

donde la relación $\overline{\mathrm{Q}^{+} \mathrm{Cl}^{-}} \mid /\left[\mathrm{Cl}^{-}\right]$se obtiene resolviendo la siguiente ecuación de tercer orden:

$$
\begin{aligned}
& 2 \mathrm{~K}_{\mathrm{p} 2 \text { (asp) }}\left[\mathrm{A}_{\text {asp }}^{2-}\right]\left(\frac{\left[\overline{\mathrm{Q}^{+} \mathrm{Cl}^{-}}\right]}{\left[\mathrm{Cl}^{-}\right]}\right)^{3}+\left(\mathrm{K}_{\mathrm{p} 1(\mathrm{pgly})}\left[\mathrm{A}_{\mathrm{pgly}}^{-}\right]+2 \frac{\mathrm{V}}{\overline{\mathrm{V}}} \mathrm{K}_{\mathrm{p} 2 \text { (asp) }}\left[\mathrm{A}_{\text {asp }}^{2-}\right]\right)\left(\frac{\left[\overline{\mathrm{Q}^{+} \mathrm{Cl}^{-}}\right.}{\left[\mathrm{Cl}^{-}\right]}\right)^{2}+ \\
& \left.+\frac{\mathrm{V}}{\overline{\mathrm{V}}} \mathrm{K}_{\mathrm{p} 1 \text { (pgly) }}\left[\mathrm{A}_{\mathrm{pgly}}^{-}\right]\left(\frac{\overline{\mathrm{Q}^{+} \mathrm{Cl}^{-}}}{\left[\mathrm{Cl}^{-}\right]}\right)-\frac{\mathrm{V}}{\overline{\mathrm{V}}} \overline{\mathrm{Q}^{+} \mathrm{Cl}^{-}}\right]_{\mathrm{i}}=0
\end{aligned}
$$

En la Tabla 16 se presentan los resultados obtenidos de $D_{e}$ para mezclas de ácido aspártico y $\alpha$-fenilglicina a $\mathrm{pH}_{\mathrm{i}}=11$ y 12 de los experimentos de la Tabla 6.

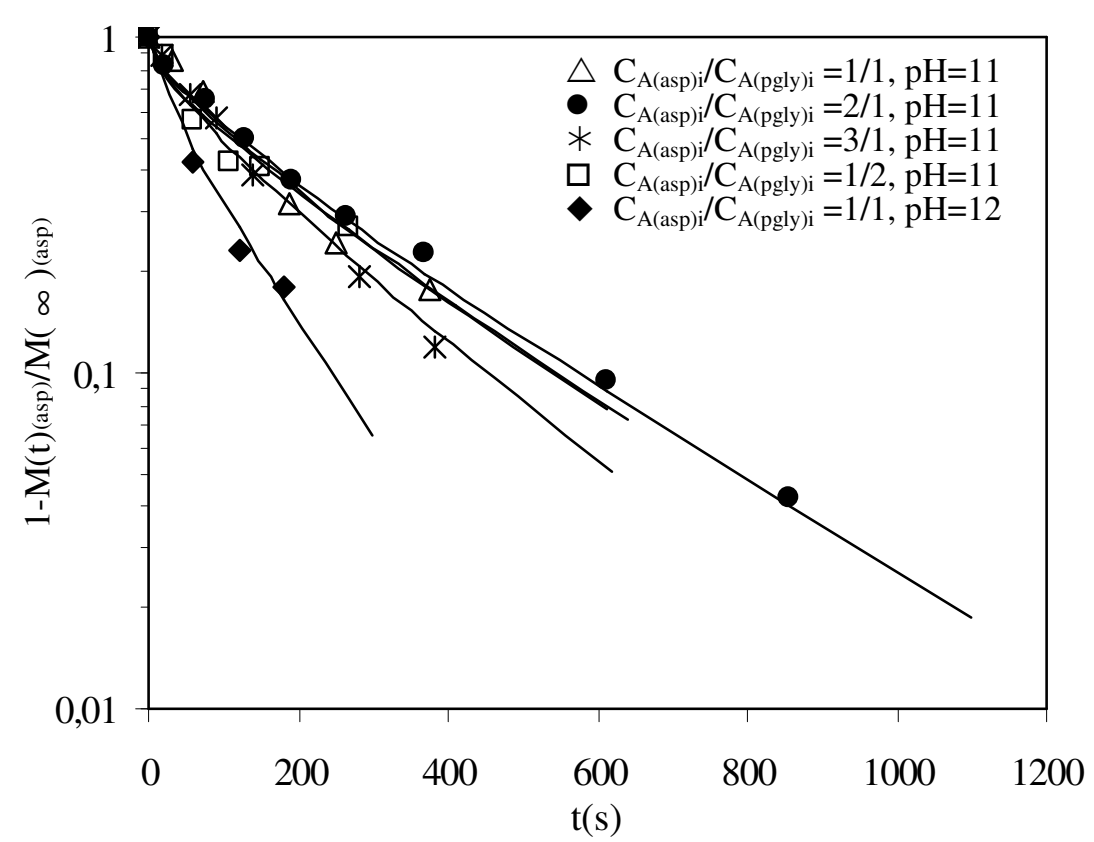

Figura 55. Velocidad de extracción de ácido aspártico a $30 \stackrel{\circ}{\circ}$ para los experimentos I $\left(\mathrm{pH}_{\mathrm{i}}=11,04 \pm 0,05\right)$ y II $\left(\mathrm{pH}_{\mathrm{i}}=12,02 \pm 0,02\right)$, de la Tabla 6. Símbolos: datos experimentales. Líneas: datos calculados con el valor de $\mathrm{K}_{\text {experimental }} \mathrm{y}$ con las Ecs. (5.89), (5.91) y (5.93). 


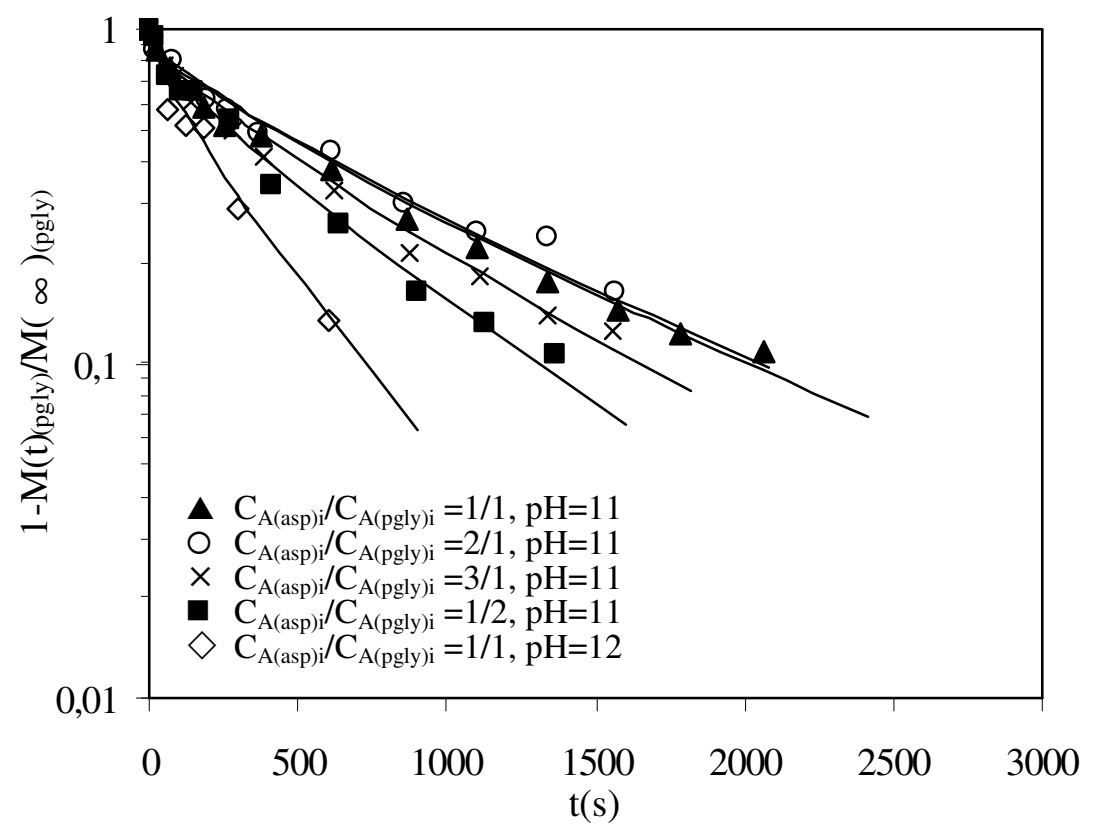

Figura 56. Velocidad de extracción de a-fenilglicina a $30 \stackrel{\circ}{\circ}$ para los experimentos I $\left(\mathrm{pH}_{\mathrm{i}}=11,04 \pm 0,05\right)$ y II $\left(\mathrm{pH}_{\mathrm{i}}=12,02 \pm 0,02\right)$, de la Tabla 6 . Símbolos: datos experimentales. Líneas: datos calculados con el valor de Kexperimental y con las Ecs. (5.90), (5.92) y (5.94).

En las Figuras 55 y 56 se observa la buena concordancia existente entre las velocidades de extracción de ambos aminoácidos medidas experimentalmente (símbolos) y las calculadas (líneas).

Tabla 16. Valores de difusividad efectiva, $D_{e}$, calculadas con las Ecs. (5.89)-(5.94) para los experimentos cinéticos de la Tabla 6.

a) Ácido aspártico

\begin{tabular}{|c|c|c|c|c|c|c|c|}
\hline Experimento & $\mathrm{pH}_{\mathrm{i}}$ & $\begin{array}{c}\mathrm{C}_{\mathrm{A}(\text { asp }) \mathrm{i}} \\
/ \mathrm{C}_{\mathrm{A}(\mathrm{pgly}) \mathrm{i}}\end{array}$ & $\begin{array}{c}\mathrm{C}_{\mathrm{A}(\mathrm{asp}) \mathrm{i}} \\
\left(\mathrm{mol} / \mathrm{m}^{3}\right)\end{array}$ & $\begin{array}{l}\mathrm{C}_{\mathrm{A}(\mathrm{pgly}) \mathrm{i}} \\
\left(\mathrm{mol} / \mathrm{m}^{3}\right.\end{array}$ & $\begin{array}{c}\mathrm{D}_{\mathrm{e}(\mathrm{asp})} \mathrm{X} 10^{11} \\
\left(\mathrm{~m}^{2} / \mathrm{s}\right) \operatorname{Ec}(5.89) \\
\left(\mathrm{K}_{\text {experimental }}\right)\end{array}$ & $\begin{array}{c}\mathrm{D}_{\mathrm{e}(\text { asp })} \times 10^{11} \\
\left(\mathrm{~m}^{2} / \mathrm{s}\right) \operatorname{Ec}(5.89) \\
\left(\mathrm{K}_{\text {calculada }} \text { con }\right. \\
\text { Ec. } 5.95)\end{array}$ & $\begin{array}{l}\% \text { Error } \\
\operatorname{Ec}(5.15)\end{array}$ \\
\hline \multirow[t]{4}{*}{ I } & $11,04 \pm 0,05$ & $1 / 1$ & 6,52 & 6,68 & 13,80 & 14,40 & 2,95 \\
\hline & & $2 / 1$ & 13,11 & 6,74 & 13,90 & 14,32 & 2,07 \\
\hline & & $3 / 1$ & 19,58 & 6,83 & 18,00 & 18,50 & 1,91 \\
\hline & & $1 / 2$ & 6,31 & 12,38 & 14,20 & 14,90 & 3,32 \\
\hline II & $12,02 \pm 0,02$ & $1 / 1$ & 7,65 & 8,10 & 32,60 & 32,60 & 0,00 \\
\hline
\end{tabular}


Tabla 16. (Continuación)

b) $\alpha$-Fenilglicina

\begin{tabular}{|c|c|c|c|c|c|c|c|}
\hline Experimento & $\mathrm{pH}_{\mathrm{i}}$ & $\begin{array}{c}\mathrm{C}_{\mathrm{A}(\text { asp }) \mathrm{i}} \\
/ \mathrm{C}_{\mathrm{A}(\mathrm{pgly}) \mathrm{i}}\end{array}$ & $\begin{array}{c}\mathrm{C}_{\mathrm{A}(\mathrm{asp}) \mathrm{i}} \\
\left(\mathrm{mol} / \mathrm{m}^{3}\right)\end{array}$ & $\begin{array}{l}\mathrm{C}_{\mathrm{A}(\mathrm{pgly}) \mathrm{i}} \\
\left(\mathrm{mol} / \mathrm{m}^{3}\right.\end{array}$ & $\begin{array}{c}\mathrm{D}_{\mathrm{e}(\mathrm{pgly})} \mathrm{x} 10^{11} \\
\left(\mathrm{~m}^{2} / \mathrm{s}\right) \operatorname{Ec}(5.90) \\
\left(\mathrm{K}_{\text {experimental }}\right)\end{array}$ & $\begin{array}{c}\mathrm{D}_{\mathrm{e}(\mathrm{pgly})} \mathrm{x} 10^{11} \\
\left(\mathrm{~m}^{2} / \mathrm{s}\right) \mathrm{Ec}(5.90) \\
\left(\mathrm{K}_{\text {calculada }} \text { con }\right. \\
\text { Ec.5.96) }\end{array}$ & $\begin{array}{l}\% \text { Error } \\
\operatorname{Ec}(5.15)\end{array}$ \\
\hline \multirow[t]{4}{*}{ I } & $11,04 \pm 0,05$ & $1 / 1$ & 6,52 & 6,68 & 3,70 & 3,77 & 1,34 \\
\hline & & $2 / 1$ & 13,11 & 6,74 & 3,80 & 3,95 & 2,79 \\
\hline & & $3 / 1$ & 19,58 & 6,83 & 4,70 & 4,99 & 4,36 \\
\hline & & $1 / 2$ & 6,31 & 12,38 & 6,00 & 6,15 & 1,77 \\
\hline II & $12,02 \pm 0,02$ & $1 / 1$ & 7,65 & 8,10 & 11,00 & 10,79 & 1,35 \\
\hline
\end{tabular}

El \% de error que se muestra en la Tabla 16, definido en la Ec. (5.15), se estimó a partir de la desviación estándar de $\mathrm{D}_{\mathrm{e}}$ calculada con el valor de $\mathrm{K}_{\text {experimental }} \mathrm{y}$ de $\mathrm{K}_{\text {calculada }}$ con la Ec. (5.95) para el ácido aspártico y con la Ec. (5.96) para la a-fenilglicina. Los valores de $D_{e}$ fueron similares para ambos aminoácidos al estimarlos empleando el valor de $\mathrm{K}_{\text {experimental }}$ o $\mathrm{K}_{\text {calculada }}$ con los modelos de equilibrio, con errores inferiores al 4,36 \%. Este resultado indica que el modelo de equilibrio describe perfectamente a los sistemas de extracción conjunta de los aminoácidos con RIE a $30^{\circ} \mathrm{C}$.

En la Tabla 16 y en las Figuras 57 y 58 se muestran los resultados de las $D_{e}$ para distintas concentraciones iniciales de ácido aspártico y a-fenilglicina en las mezclas, respectivamente. Los resultados indican que los valores de las difusividades efectivas aumentan ligeramente al aumentar la concentración de aminoácido en la fase acuosa, produciendo comparativamente procesos de extracción más rápidos.

Los valores de las difusividades efectivas de ácido aspártico y a-fenilglicina obtenidos con las Ecs. (5.89)-(5.94) son mayores que los obtenidos con el modelo cinético propuesto por Bhandari con las Ecs. (5.71) y (5.72). Estos resultados pueden ser debidos a que este modelo considera el llenado parcial de los huecos reactivos de la RIE y consecuentemente predice un camino de difusión más corto que el modelo de Fick, el cual, al considerar que el camino de difusión es el espesor total de la partícula, el camino de difusión es más largo y ajusta los datos para un mismo valor de velocidad de extracción con un valor más grande de la difusividad. En cualquier caso, ambos modelos proporcionan una tendencia ascendente de $D_{e}$ con la concentración inicial de aminoácido.

En las Figuras 57 y 58 se observa que las difusividades efectivas son mayores a $\mathrm{pH}=12$ que a $\mathrm{pH}=11$, tanto para ácido aspártico como para fenilglicina, proporcionando comparativamente procesos cinéticos de extracción más rápidos. Además, en la Figura 57 se observa que la presencia de a-fenilglicina no afecta a los valores de difusividad efectiva de ácido aspártico, sin embargo, la presencia de ácido aspártico afecta y provoca que la difusividad efectiva de la $\alpha$-fenilglicina aumente ligeramente su valor, indicando que comparativamente los procesos cinéticos de extracción son más rápidos, como se observa en la Figura 58. 


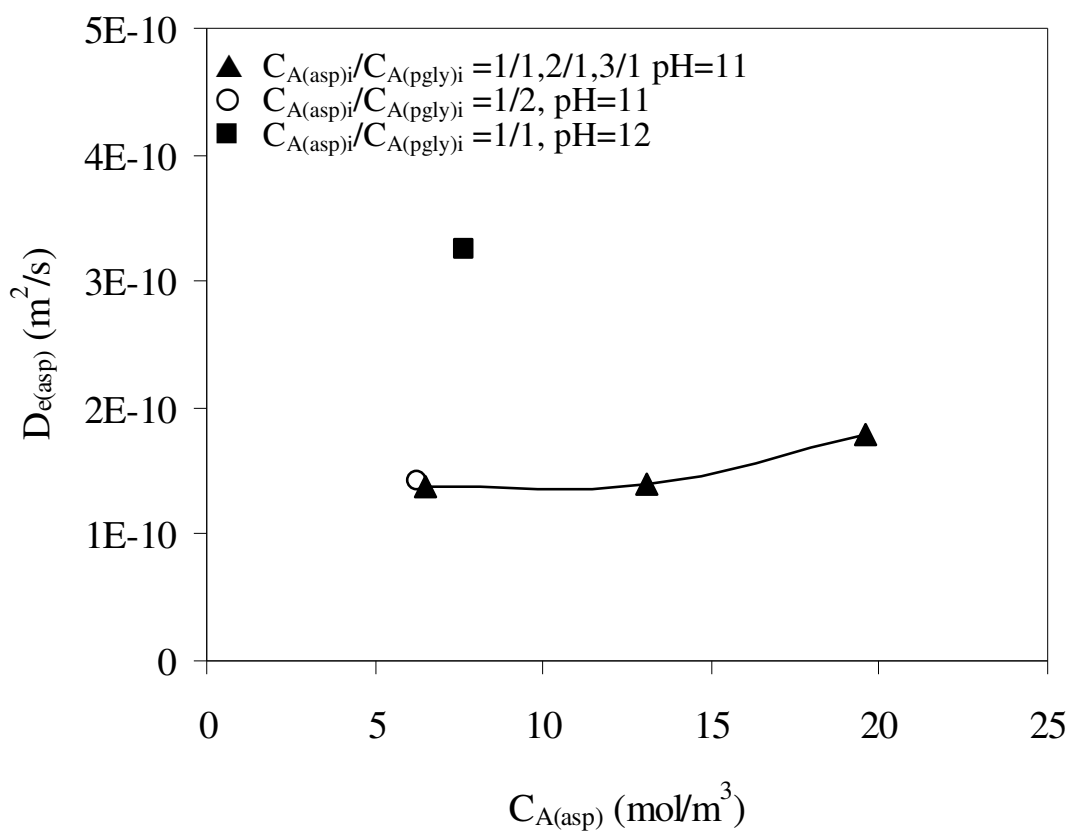

Figura 57. Efecto de la concentración inicial de ácido aspártico, de la proporción de fenilglicina, y del $\mathrm{pH}$ sobre la difusividad efectiva de ácido aspártico evaluada con las Ecs. (5.89), (5.91) y (5.93) para los experimentos de la Tabla 6.

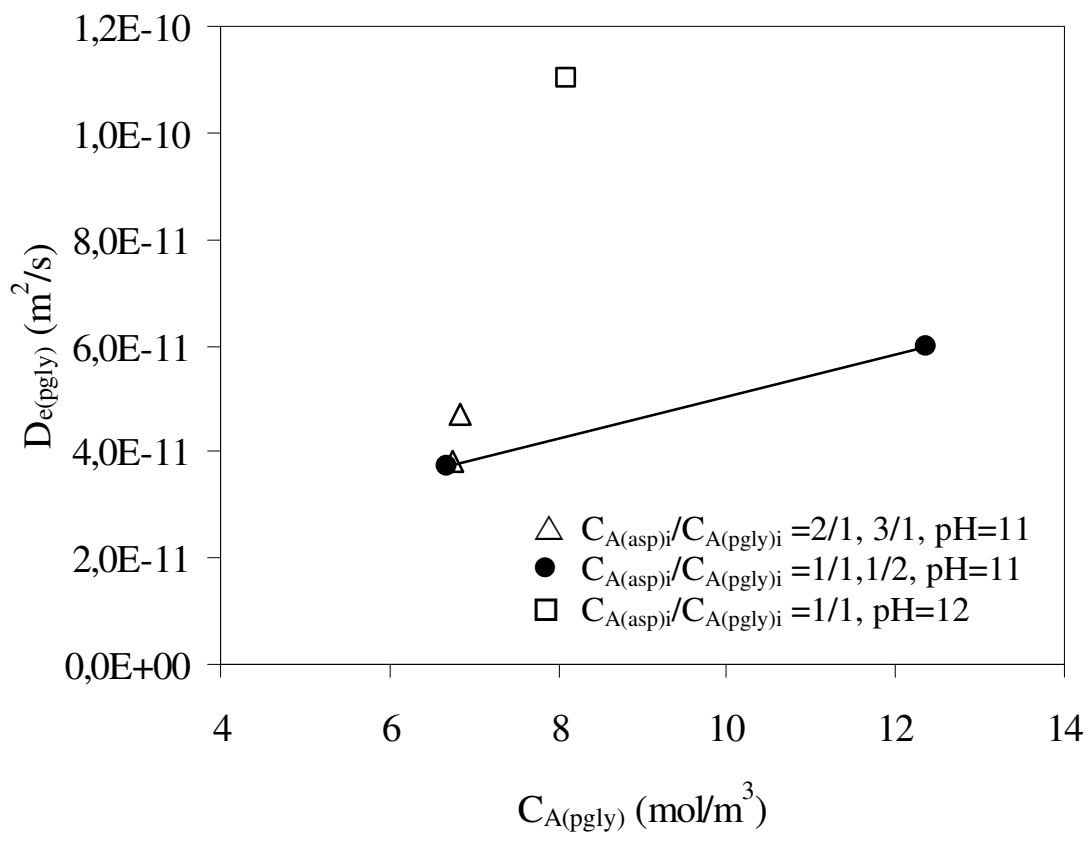

Figura 58. Efecto de la concentración inicial de a-fenilglicina, de la proporción de ácido aspártico, y del $\mathrm{pH}$ sobre la difusividad efectiva de a-fenilglicina evaluada con las Ecs. (5.90), (5.92) y (5.94) para los experimentos de la Tabla 6. 
En la Tabla 16 y comparando las Figuras 57 y 58 se observa que los valores de las difusividades efectivas del ácido aspártico son siempre mayores que las de $\alpha$-fenilglicina. Este resultado corrobora el hecho experimental de que la velocidad del proceso de extracción del ácido aspártico es más rápida que la velocidad de extracción de $\alpha$ fenilglicina. Este efecto también se observó en los procesos cinéticos de extracción individual de ácido aspártico y $\alpha$-fenilglicina y puede deberse, como ya se ha comentado, a que el aminoácido $\alpha$-fenilglicina es un aminoácido de mayor tamaño, con un grupo fenilo en su cadena radical, mientras que el ácido aspártico es más pequeño y presenta una cadena radical alifática.

En las Figuras 59 y 60 se representa el ajuste de los resultados experimentales cinéticos de mezclas de ácido aspártico y $\alpha$-fenilglicina al modelo cinético mostrado en las Ecs. (5.89)-(5.94). En estas figuras se observa que existe una buena concordancia entre los datos experimentales (símbolos) y los calculados con el modelo (líneas). El error estimado con la Ec. (5.15) para cada uno de los aminoácidos fue inferior a 3,25\% para todos los experimentos de la Tabla 6.

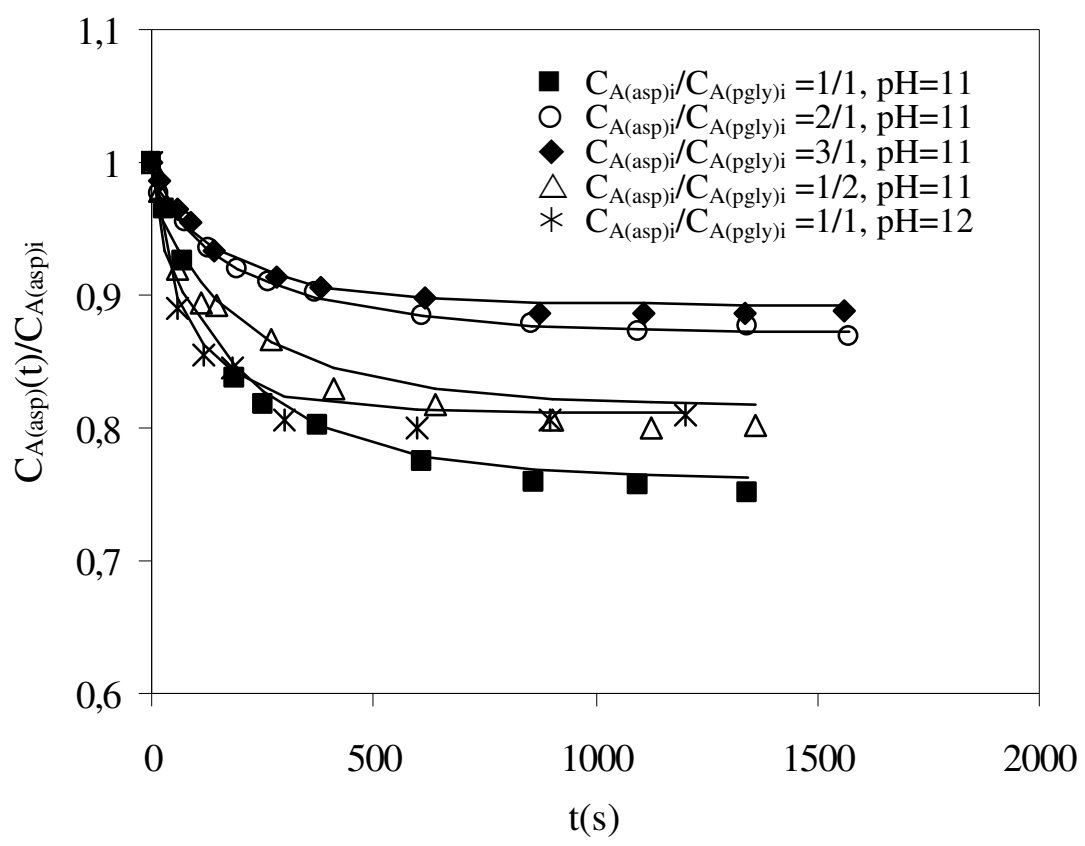

Figura 59. Evolución de la concentración de ácido aspártico con el tiempo experimental (símbolos) y calculados (líneas) a partir del modelo cinético y con la definición de $\mathrm{M}(\mathrm{t})$ (Ec. (5.85)) para los experimentos de mezclas binarias I $\left(\mathrm{pH}_{\mathrm{i}}=11,04 \pm 0,05\right)$ y II $\left(\mathrm{pH}_{\mathrm{i}}=12,02 \pm 0,02\right)$ de la Tabla 6 . 


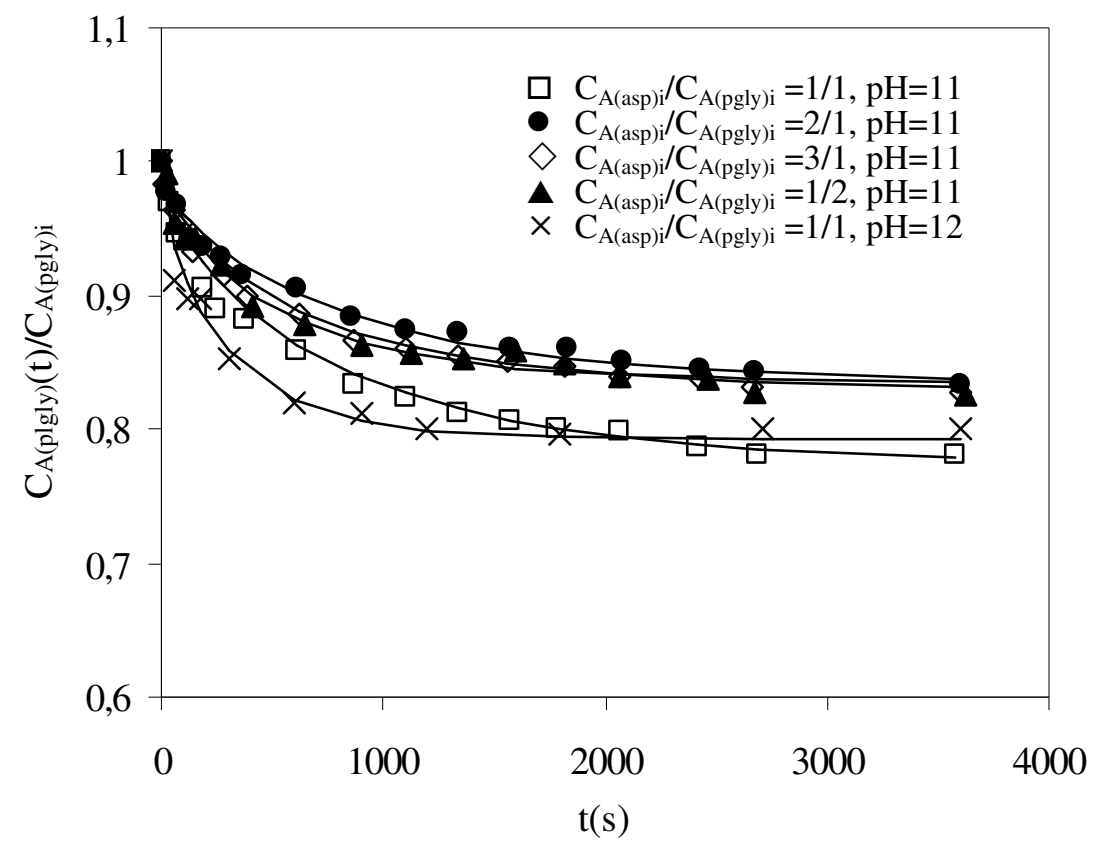

Figura 60. Evolución de la concentración de a-fenilglicina con el tiempo experimental (símbolos) y calculados (líneas) a partir del modelo cinético y con la definición de $\mathrm{M}(\mathrm{t})$ (Ec. (5.86)) para los experimentos de mezclas binarias I $\left(\mathrm{pH}_{\mathrm{i}}=11,04 \pm 0,05\right)$ y II $\left(\mathrm{pH}_{\mathrm{i}}=12,02 \pm 0,02\right)$ de la Tabla 6.

Las conclusiones alcanzadas en este apartado referente a los ensayos cinéticos de extracción conjunta de ácido aspártico y a-fenilglicina se señalan a continuación:

- La forma y evolución de las curvas cinéticas es similar en todos los experimentos realizados, por tanto el proceso cinético debe poseer las mismas características y estar controlado por los mismos mecanismos de transferencia de materia.

- No hay cambios significativos en las cinéticas de extracción individual y conjunta del ácido aspártico a $\mathrm{pH}=5$, este resultado puede ser debido a que el aminoácido $\alpha$-fenilglicina no se extrae a este $\mathrm{pH}$.

- Los procesos cinéticos de fraccionamiento de mezclas de $\alpha$-fenilglicina y ácido aspártico a pH =11 y 12 son rápidos, y se alcanza el equilibrio a tiempos reducidos, resultando comparativamente más rápida la extracción del ácido aspártico. Estos resultados son análogos a los obtenidos en las cinéticas de extracción de cada aminoácido por separado.

- La velocidad de separación de los aminoácidos desde la mezcla binaria depende de la concentración relativa en la que se encuentran presentes.

- Los resultados de las cinéticas de separación de mezclas binarias de ácido aspártico y a-fenilglicina en tanques agitados se correlacionaron adecuadamente 
mediante un modelo cinético basado en la segunda ley de Fick, considerando que el proceso de transferencia de materia está controlado por la difusión intrapartícula del complejo ácido aspártico-Tomac y fenilglicina-Tomac y que existe un equilibrio instantáneo en la interfase sólido-líquido.

- Los valores de las difusividades efectivas, $D_{e}$, fueron del orden de $10^{-10} \mathrm{~m}^{2} / \mathrm{s}$ para el ácido aspártico y de $10^{-11} \mathrm{~m}^{2} / \mathrm{s}$ para $\alpha$-fenilglicina. Este resultado confirma que la velocidad de extracción del ácido aspártico es más rápida que la de afenilglicina como consecuencia de su mayor tamaño, ya que contiene un grupo fenilo en su cadena radical.

- La difusividad efectiva intrapartícula para ambos aminoácidos en las mezclas binarias crece ligeramente, al aumentar su concentración relativa en la mezcla y a $\mathrm{pH}=12$.

\subsubsection{Comparación de las cinéticas de la extracción individual y conjunta de ácido aspártico y a-fenilglicina}

Al objeto de comparar la velocidad de la extracción individual de ácido aspártico y afenilglicina y de sus mezclas binarias, en las Figuras 61 y 62 se representa los valores de las difusividades estimadas con la segunda ley de Fick para la extracción individual y conjunta de ácido aspártico y a-fenilglicina, respectivamente.

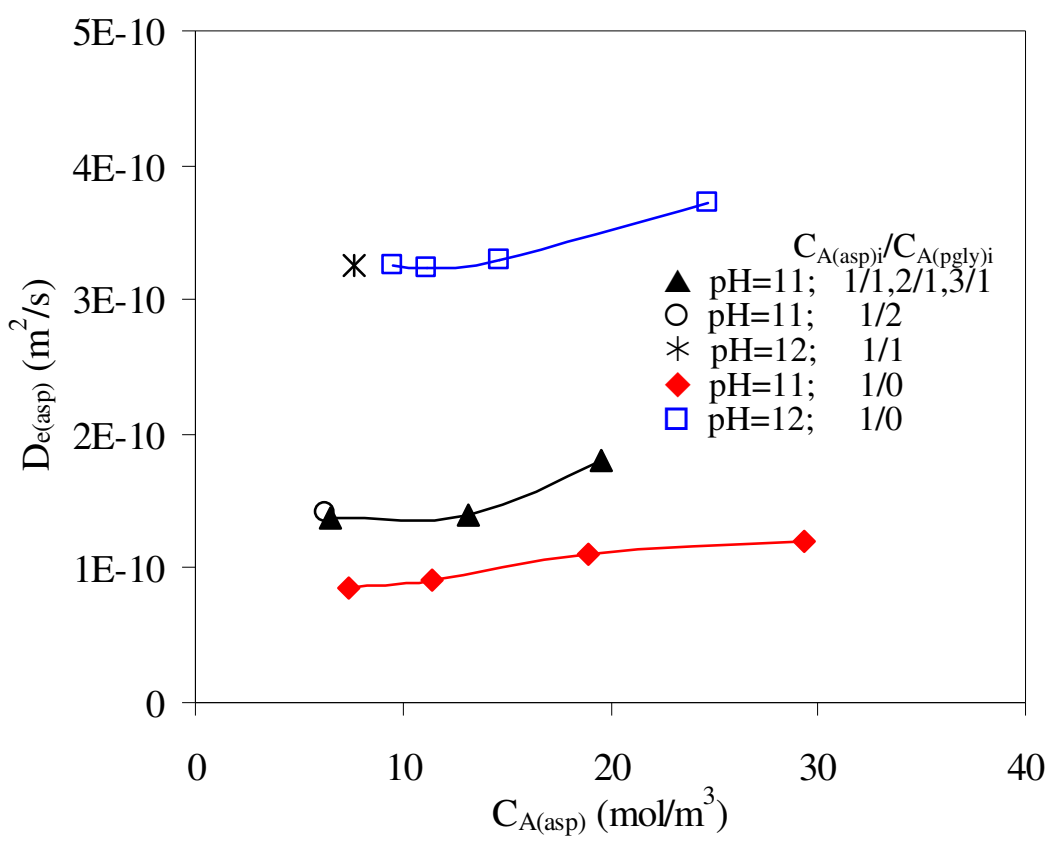

Figura 61.Comparación de los valores de $D_{e}$ estimados con la segunda ley de Fick para la extracción de ácido aspártico sólo y mezclado con a-fenilglicina. 
En la Figura 61 se observa que la difusividad efectiva del ácido aspártico aumenta ligeramente al aumentar la concentración de aminoácido, y por tanto proporciona procesos de extracción más rápidos. Por otra parte, la difusividad efectiva del ácido aspártico en todos los casos es mayor a $\mathrm{pH}=12$ que a $\mathrm{pH}=11$, esto puede deberse a que a $\mathrm{pH}=11$ todavía existe una pequeña cantidad de especie $A^{-}$que dificulta 0 inhibe la extracción de la especie $A^{2-}$.

Además, se puede suponer que a $\mathrm{pH}=12$, la presencia de $\alpha$-fenilglicina no influye en el proceso cinético de extracción de ácido aspártico debido a que se obtiene el mismo valor de $D_{e}$ sólo que mezclado, como puede observarse en la Figura 61. Sin embargo, a $p H=11$ el valor de la difusividad efectiva es ligeramente superior en las mezclas binarias que en el proceso individual.

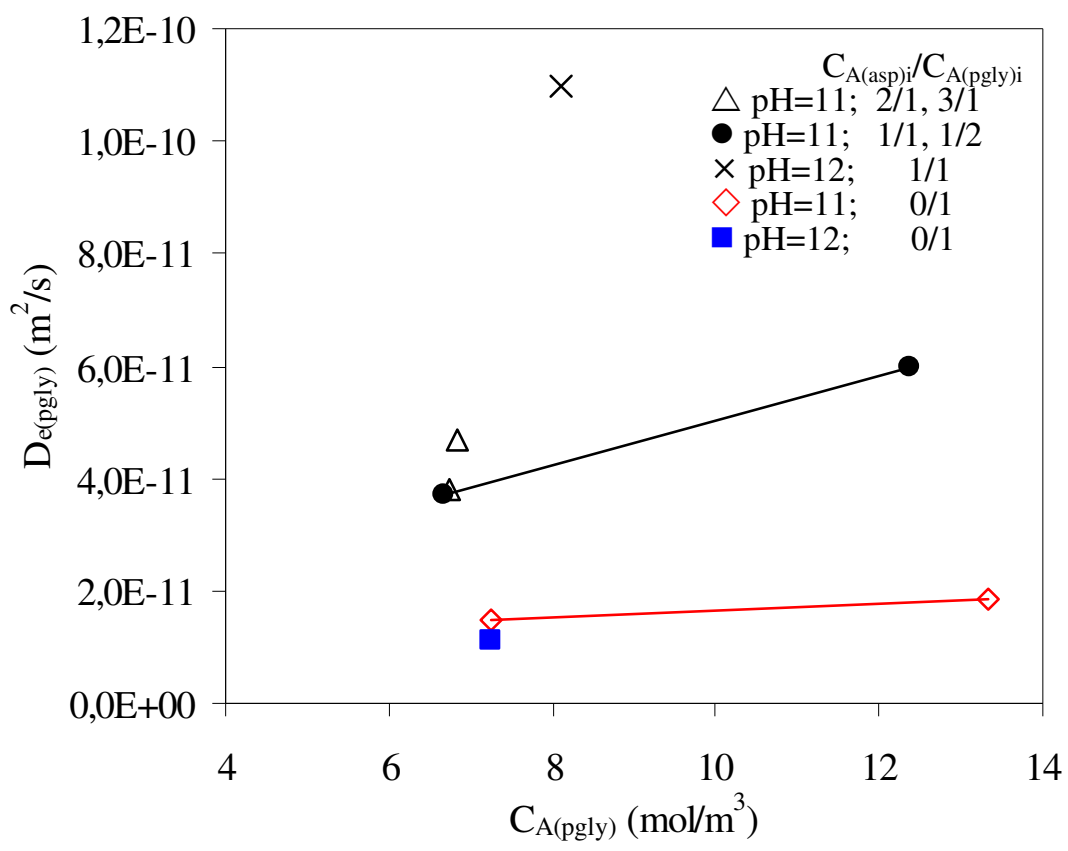

Figura 62. Comparación de los valores de $D_{e}$ estimados con la segunda ley de Fick para la extracción de a-fenilglicina sola y mezclada con ácido aspártico.

En la Figura 62 se observa que la difusividad efectiva de a-fenilglicina aumenta al aumentar la concentración de aminoácido en la disolución acuosa, provocando comparativamente procesos cinéticos de extracción más rápidos. Además, se observa que a $\mathrm{pH}=11$ y 12 el comportamiento cinético en la extracción de $\alpha$ - fenilglicina varía al estar sólo o mezclado con ácido aspártico, obteniéndose valores de $D_{e}$ menores cuando está sólo que mezclado. Por otro lado, apenas hay diferencia del valor de $D_{e} a p H=11$ y 12 cuando está la $\alpha$-fenilglicina sola, mientras que cuando está mezclada con ácido aspártico $D_{e}$ es mayor a $\mathrm{pH}=12$ que a 11. Esta diferencia en el comportamiento cinético puede estar relacionada con el efecto de coextracción de los iones hidroxilo presentes en el medio básico y que sólo es significativa en los procesos de extracción individual de $\alpha$ fenilglicina. La extracción significativa de iones hidroxilo produce una disminución del pH y por consiguiente, la transformación de parte de las especies aniónicas del aminoácido en especies no extraíbles bajo las condiciones de proceso. 
Por otra parte, tanto en los procesos de extracción individual de ácido aspártico y afenilglicina como de sus mezclas, se obtuvieron valores de la difusividad efectiva mayores para el ácido aspártico que para la a-fenilglicina, siendo por tanto el proceso de extracción del ácido aspártico más rápido que el de a-fenilglicina. Este efecto puede deberse a que el aminoácido $\alpha$-fenilglicina es un aminoácido de mayor tamaño que el ácido aspártico.

\section{Se puede concluir:}

- Los valores de $D_{e}$ son mayores para el ácido aspártico que para a-fenilglicina tanto en su extracción individual como conjunta, indicando que el proceso de extracción del ácido aspártico es más rápido que el de a-fenilglicina. Esta diferencia se debe a la diferencia de tamaño que presentan ambos aminoácidos. 


\subsection{RESULTADOS Y DISCUSIÓN: EXTRACCIÓN EN COLUMNAS DE LECHO FIJO}

\subsubsection{Ensayos con ácido aspártico}

Las curvas de ruptura de ácido aspártico con RIE a $30^{\circ} \mathrm{C}$ se determinaron empleando el dispositivo mostrado en el apartado 5.1.2.3 y con el procedimiento experimental detallado en el apartado 5.1.3.8 de esta memoria. Las condiciones iniciales de estos experimentos se muestran en la Tabla 7 del apartado 5.1.3.8. Los resultados obtenidos se recogen en las Tablas A1-A7 del apéndice $\mathrm{C}$ y se representan en las Figuras 63-70.

Las curvas de ruptura de a-fenilglicina fueron estudiadas en trabajos previos (Ruiz M. O. et al., 2000).

Los volúmenes de lecho $(\mathrm{VL})$ son números adimensionales y representan el número de veces que la alimentación circula por el lecho de RIE, y se define como la relación entre el volumen de efluente y el volumen del lecho:

$$
\begin{array}{r}
\mathrm{VL}=\frac{\mathrm{Qt}}{\mathrm{V}_{\mathrm{L}}\left(1-\varepsilon_{\mathrm{L}}\right)} \\
\varepsilon_{\mathrm{L}}=\frac{\mathrm{m}_{\text {Hue cos }} / \rho}{\mathrm{V}_{\mathrm{L}}}
\end{array}
$$

donde $Q$ es el caudal de circulación expresado en $\mathrm{m}^{3} / \mathrm{s}$; $t$ es el tiempo; $V_{L}$ es el volumen de la columna cuyo valor numérico es $15 \circ 9,9 \mathrm{~cm}^{3}$ según la columna utilizada; $\varepsilon_{\mathrm{L}}$ es la porosidad del lecho, calculada experimentalmente con Ec. (5.99); m $\mathrm{m}_{\text {Huecos }}$ es la masa de disolución que queda entre los huecos de las partículas de RIE calculada experimentalmente por pesada y $\rho$ es la densidad de la disolución que circula por la columna expresada en $\mathrm{kg} / \mathrm{m}^{3}$.

En la Figura 63 se muestran las curvas de ruptura de extracción de ácido aspártico a $30^{\circ} \mathrm{C}$ en función de los volúmenes de lecho (VL), para los experimentos VI y VII de la Tabla 7, correspondientes al estudio del efecto de la velocidad de flujo de la alimentación. Estos experimentos se realizaron utilizando la misma concentración de ácido aspártico en la alimentación, $\mathrm{pH}_{\mathrm{i}}=12$ y la misma carga de Tomac en la resina.

Se observa que las curvas de ruptura de extracción de ácido aspártico están afectadas por la velocidad de flujo de la alimentación. Un aumento de la velocidad de flujo produce un desplazamiento del punto de ruptura hacia volúmenes de lecho más bajos. Este hecho puede deberse a que al aumentar la velocidad del flujo, se reduce el tiempo de residencia y disminuye el tiempo de contacto entre la RIE y la alimentación, obteniéndose efluentes con cantidad apreciable de aminoácido a tiempos reducidos. Este efecto es debido a que 
el proceso cinético de extracción de ácido aspártico con RIE presenta una elevada resistencia de difusión intrapartícula, y por tanto una lenta velocidad de transferencia de materia.

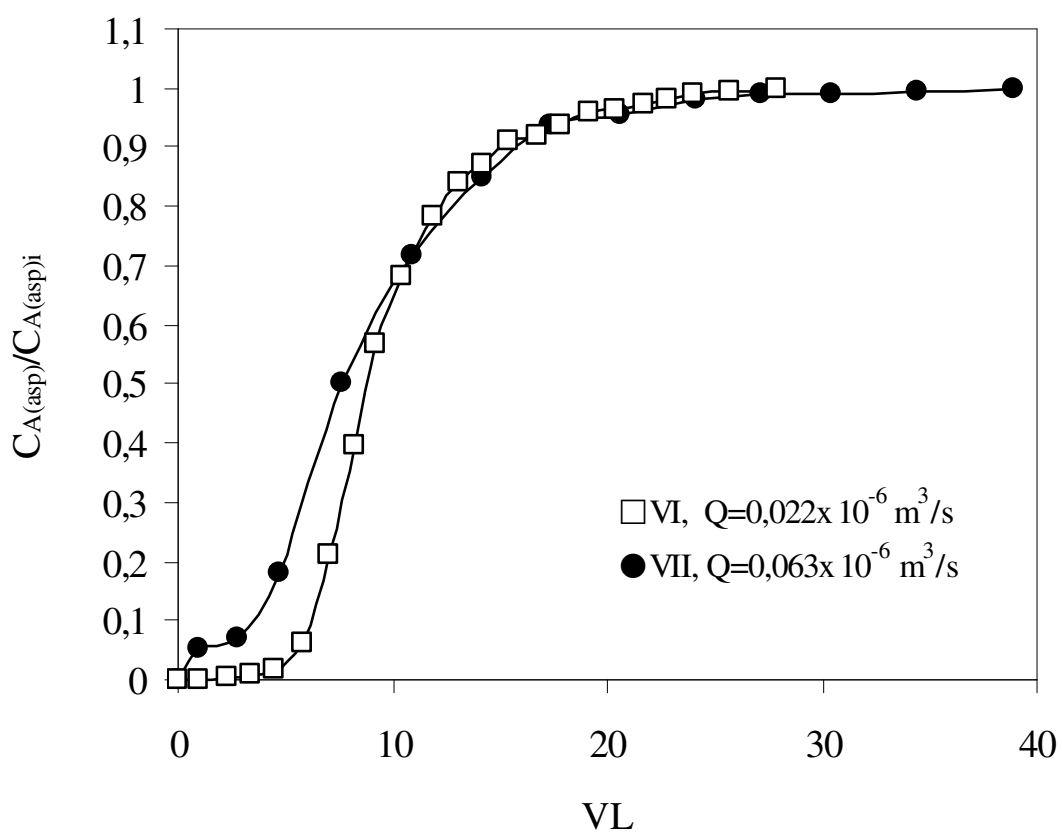

Figura 63. Efecto del caudal de la alimentación en las curvas de ruptura de extracción de ácido aspártico a $30^{\circ} \mathrm{C}$ con RIE para los experimentos $\mathrm{VI}$ y VII de la Tabla 7. ( $\mathrm{C}_{\mathrm{A}(\text { asp })}=$ $\left.15,36 \pm 0,51 \mathrm{~mol} / \mathrm{m}^{3} ; \mathrm{pH}_{\mathrm{i}}=12,05 \pm 0,03 ;\left[\overline{\mathrm{Q}^{+} \mathrm{Cl}^{-}}\right]_{\mathrm{i}}=618,00 \pm 0,39 \mathrm{~mol} / \mathrm{m}^{3} \mathrm{RSI}\right)$.

En las Figuras 64 y 65 se representa el efecto de la concentración de Tomac en la RIE (experimentos $\mathrm{V}$ y $\mathrm{VI}$ de la Tabla 7) y de la concentración de ácido aspártico en la alimentación (experimentos IV y $\vee$ de la Tabla 7), respectivamente, utilizándose la misma velocidad de flujo de alimentación y a $\mathrm{pH}_{\mathrm{i}}=12$.

En estas Figuras se observa que al aumentar la concentración de Tomac en la RIE o al disminuir la concentración de ácido aspártico, tanto el punto de ruptura como el punto de saturación se desplazan a volúmenes de lecho superiores, prolongando el tiempo de operación de la columna. 


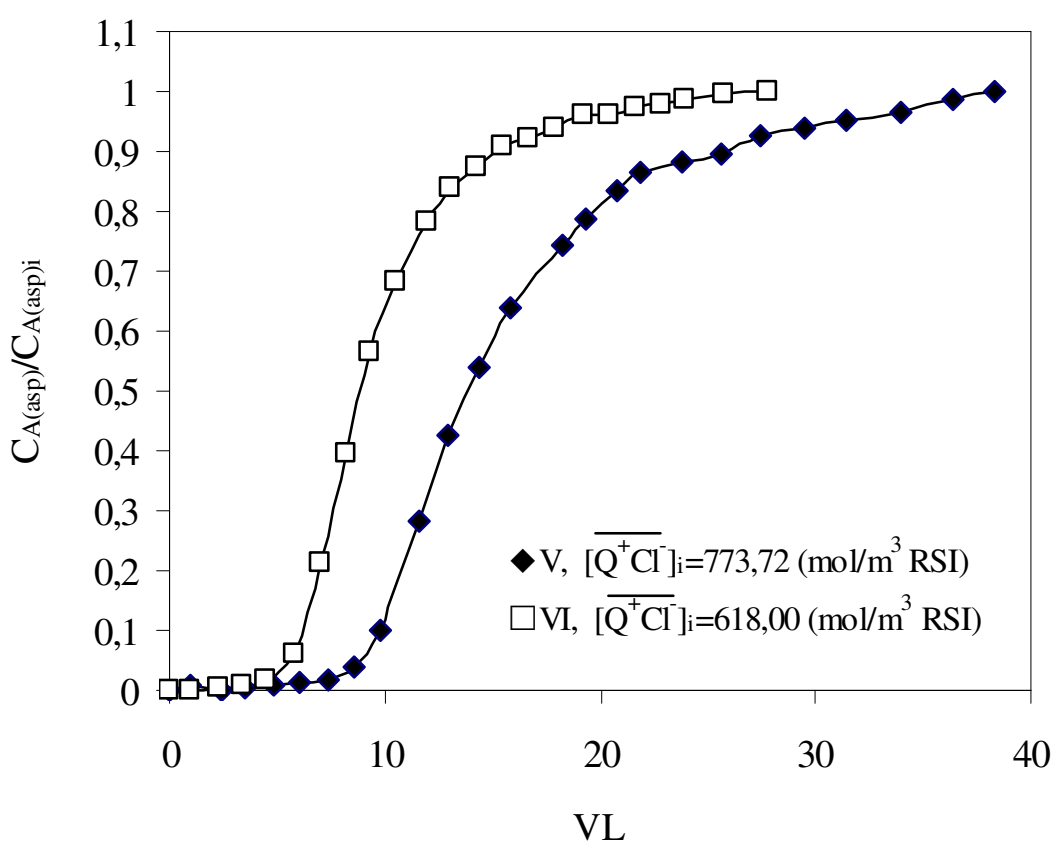

Figura 64. Efecto de la concentración de Tomac en la RIE en las curvas de ruptura de extracción de ácido aspártico a $30^{\circ} \mathrm{C}$ con RIE para los experimentos $\mathrm{V}$ y $\mathrm{VI}$ de la Tabla 7. $\left(\mathrm{C}_{\mathrm{A}(\mathrm{ass}))}=\right.$ $\left.14,77 \pm 0,32 \mathrm{~mol} / \mathrm{m}^{3} ; \mathrm{pH}_{\mathrm{i}}=12,05 \pm 0,03 ; \mathrm{Q}=0,023 \times 10^{-6} \mathrm{~m}^{3} / \mathrm{s}\right)$.

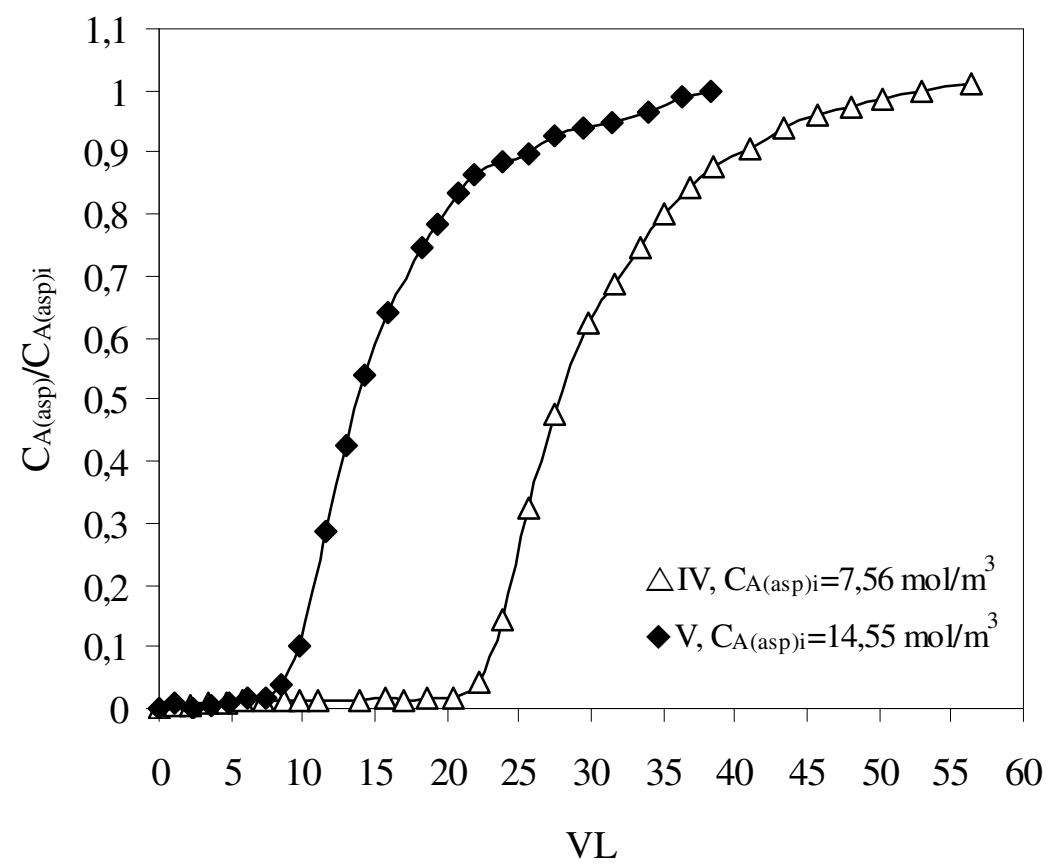

Figura 65. Efecto de la concentración de ácido aspártico en la alimentación en las curvas de ruptura de extracción de ácido aspártico a $30^{\circ} \mathrm{C}$ con RIE para los experimentos IV y V de la Tabla 7. $\left(\mathrm{pH}_{\mathrm{i}}=12,05 \pm 0,03 ; \mid \overline{\mathrm{Q}^{+} \mathrm{Cl}^{-}}\right]=773,72 \pm 3,78 \mathrm{~mol} / \mathrm{m}^{3} \mathrm{RSI} ; \mathrm{Q}=0,024 \times 10^{-6}$ $\left.\mathrm{m}^{3} / \mathrm{s}\right)$. 
Las Figuras 66 y 67 muestran las curvas de ruptura de extracción de ácido aspártico para los experimentos I-IV de la Tabla 7 correspondientes al estudio del efecto del $\mathrm{pH}$, utilizándose la misma concentración de aminoácido, concentración de Tomac en la RIE e igual velocidad de flujo en la alimentación. En estas figuras, se observa que a $\mathrm{pH}_{\mathrm{i}}=5$ (experimento I), el punto de ruptura no aparece y el punto de saturación se alcanza antes que a pH básico (experimentos II-IV). Esta diferencia en el perfil de las curvas de ruptura se debe a que se extrae distinta especie iónica a $\mathrm{pH}_{\mathrm{i}}=5,\left(\mathrm{~A}_{\text {asp }}^{-}\right)$, que a $\mathrm{pH}_{\mathrm{i}} \geq 11,\left(\mathrm{~A}^{2-}\right.$ asp $)$.

Por otra parte, se observa que a pH básico (experimentos II-IV de la Figura 67), el punto de saturación se alcanza a unos 55-58 volúmenes de lecho, sin embargo, el punto de ruptura varía alcanzándose antes a $\mathrm{pH}_{\mathrm{i}}=11$ (experimento II). Este efecto negativo puede deberse a la coextracción de iones hidroxilo, que si existe, es más rápida que la del aminoácido y tiene lugar en los primeros volúmenes de lecho, ocasionando una disminución del $\mathrm{pH}$. Si el $\mathrm{pH}$ de la disolución que recorre la columna es inferior al $\mathrm{pK}_{\mathrm{a} 3(\mathrm{asp})}=9,8$ del aminoácido, se produce la conversión del ácido aspártico de su forma iónica, $A^{2-}$ asp a sus formas $A_{\text {asp }}^{-}$y $A^{+-}$asp, ocasionando una disminución en la extracción del aminoácido y la pérdida del mismo por la cabeza del lecho.

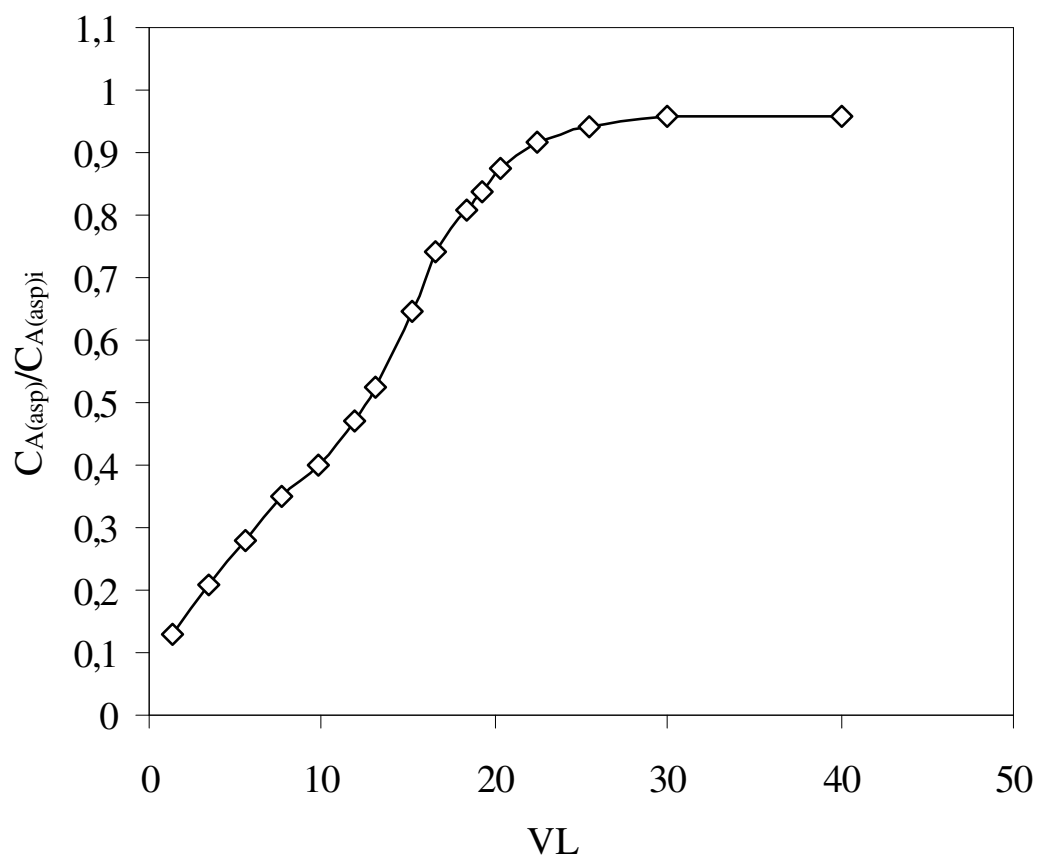

Figura 66. Curva de ruptura de extracción de ácido aspártico a $30^{\circ} \mathrm{C}$ con RIE para el experimento I de la Tabla 7. $\left(\mathrm{C}_{\mathrm{A}(\text { asp }) i}=7,40 \mathrm{~mol} / \mathrm{m}^{3} ; \mathrm{pH}_{\mathrm{i}}=5,05 \pm 0,02 ;\left[\overline{\mathrm{Q}^{+} \mathrm{Cl}^{-}}\right]_{\mathrm{i}}=773,72 \pm 3,78 \mathrm{~mol} / \mathrm{m}^{3}\right.$ $\left.\mathrm{RSI} ; \mathrm{Q}=0,022 \times 10^{-6} \mathrm{~m}^{3} / \mathrm{s}\right)$. 


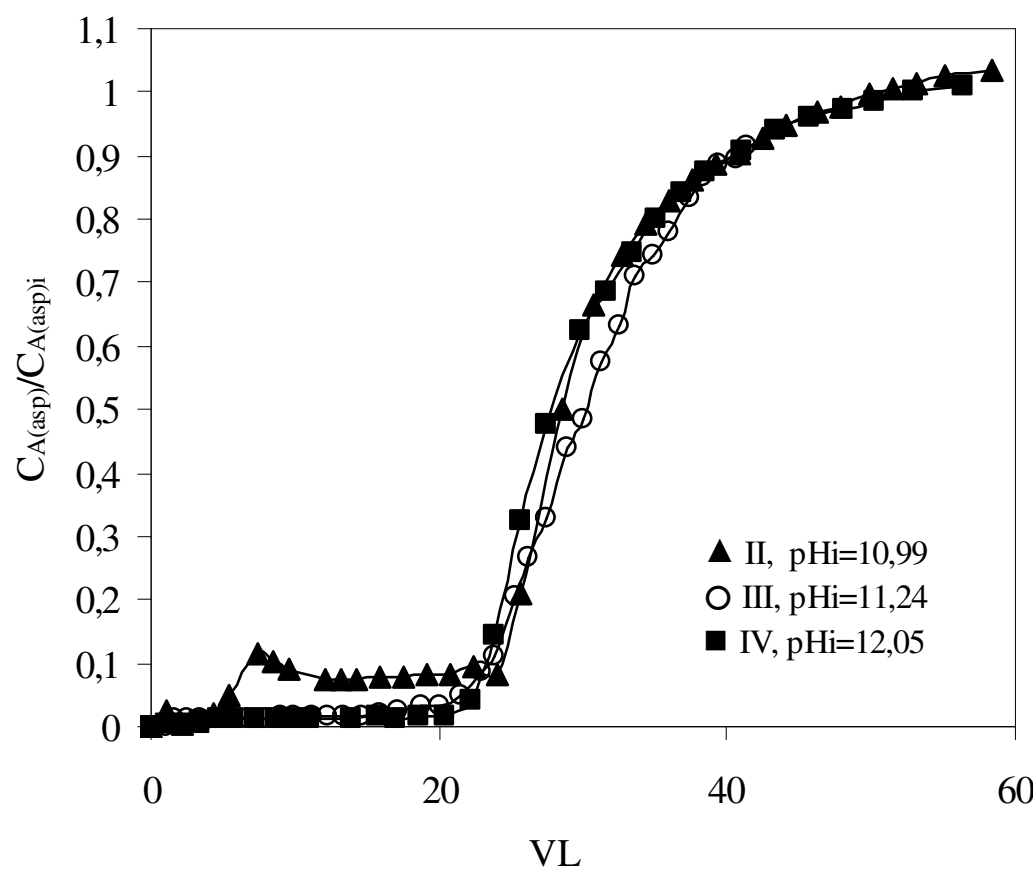

Figura 67. Efecto del pH en las curvas de ruptura de extracción de ácido aspártico a $30^{\circ} \mathrm{C}$ con RIE

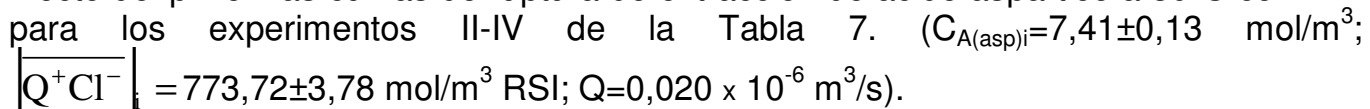

En las Figuras 68-70 se comparan las curvas de ruptura de extracción de ácido aspártico expresadas en concentración total $\left(\mathrm{C}_{\mathrm{A}(\text { asp })} / \mathrm{C}_{\mathrm{A}(\text { asp }) \mathrm{i}}\right)$, en concentración de la especie iónica extraible $\left[\mathrm{A}^{2-}{ }_{\text {asp }}\right] /\left[\mathrm{A}^{2-}{ }_{\text {asp }}\right]_{i}$ y las curvas de ruptura de coextración de los iones hidroxilo $\left(\mathrm{pH} / \mathrm{pH}_{\mathrm{i}}\right)$ para los experimentos II-IV de la Tabla 7. Estos resultados muestran que a $\mathrm{pH}$ básico la coextracción es pequeña y más rápida al aumentar el pH de la alimentación, alcanzándose la saturación en tiempos reducidos.

En las Figuras 69 y 70 se observa que a $\mathrm{pH}_{i} \geq 11,3$ (experimentos III y IV) las dos curvas de ruptura del aminoácido total y de la especie iónica, $A^{2-}$ asp, coinciden en todo el intervalo de operación debido a que la coextración de los iones hidroxilo provoca una disminución pequeña del $\mathrm{pH}$ a lo largo del lecho, resultando en todo momento el $\mathrm{pH}$ superior al $\mathrm{pK}_{\mathrm{a} 3}$ del aminoácido. Sin embargo, tal como se refleja en la Figura 68, a $\mathrm{pH}_{\mathrm{i}}=11$ (experimento II), las curvas de ruptura del aminoácido total y de la especie $A^{2-}$ asp no coinciden en la etapa inicial del proceso. Este resultado se debe a la disminución brusca de pH al inicio del proceso, por debajo del valor del $\mathrm{pK}_{\mathrm{a} 3}$, en esta situación se inhibe la extracción del aminoácido alcanzándose el punto de ruptura antes, en torno a $5 \mathrm{VL}$. Es decir, para alcanzar las condiciones óptimas de operación de la columna el pH de la alimentación debe ser mayor de 11,3. 


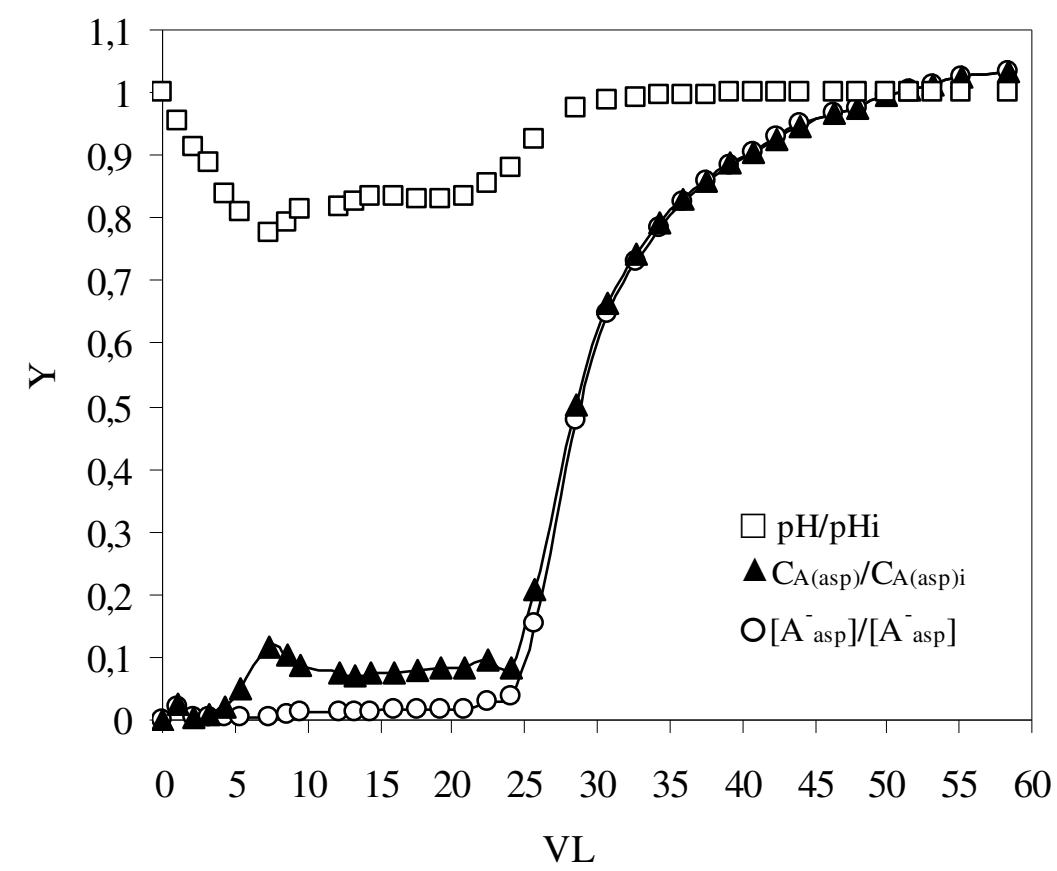

Figura 68. Curvas de ruptura correspondientes al experimento II de la Tabla $7\left(\mathrm{pH}_{\mathrm{i}}=10,99\right)$.

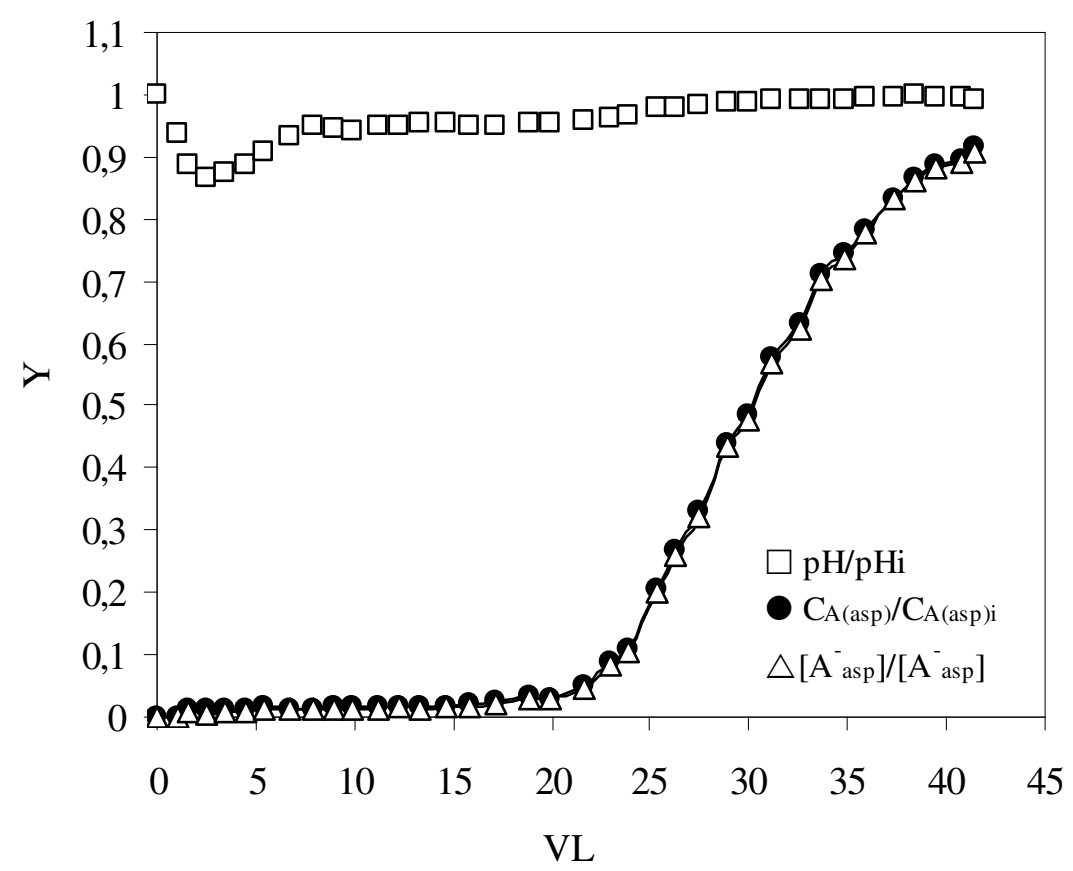

Figura 69. Curvas de ruptura correspondientes al experimento III de la Tabla $7\left(\mathrm{pH}_{\mathrm{i}}=11,24\right)$. 


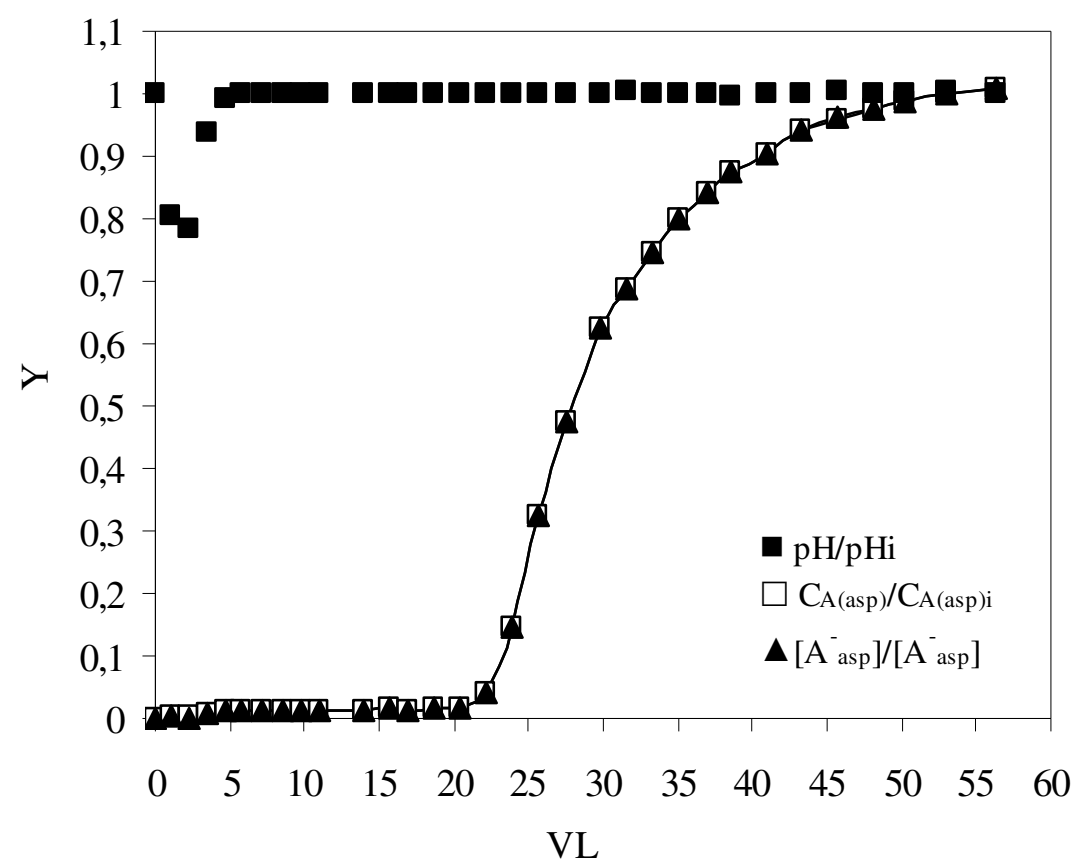

Figura 70. Curvas de ruptura correspondientes al experimento IV de la Tabla $7\left(\mathrm{pH}_{\mathrm{i}}=12,05\right)$.

\subsubsection{Reextracción y ciclos sucesivos de extracción de ácido aspártico}

La regeneración del lecho de RIE y los ciclos sucesivos de extracción se realizaron empleando el procedimiento experimental detallado en el apartado 5.1.2.3. Las condiciones iniciales y de operación mostradas en el apartado 5.1.3.8 y en la Tabla 9.

Los resultados experimentales de las curvas de ruptura obtenidas para el experimento I de la Tabla 9 se muestran en las Tablas B1-3 del apéndice C, correspondientes al $1^{\text {er }}$, $2^{\circ}$ y $3^{\text {er }}$ ciclo de extracción. En las Tablas B4 y B5 del apéndice $C$ se recogen los resultados experimentales del $1^{\text {er }}$ y $2^{\circ}$ ciclo de reextracción, respectivamente.

En la Figura 71 se representan el $1^{\text {er }}$ y $2^{\circ}$ ciclo de reextracción de ácido aspártico para los experimentos I-a y I-b de la Tabla 9. No se apreciaron cambios significativos en estos dos ciclos sucesivos de reextracción de ácido aspártico. Además, el proceso de reextracción de ácido aspártico es rápido, recuperándose más del $92 \%$ del aminoácido presente en la RIE. 


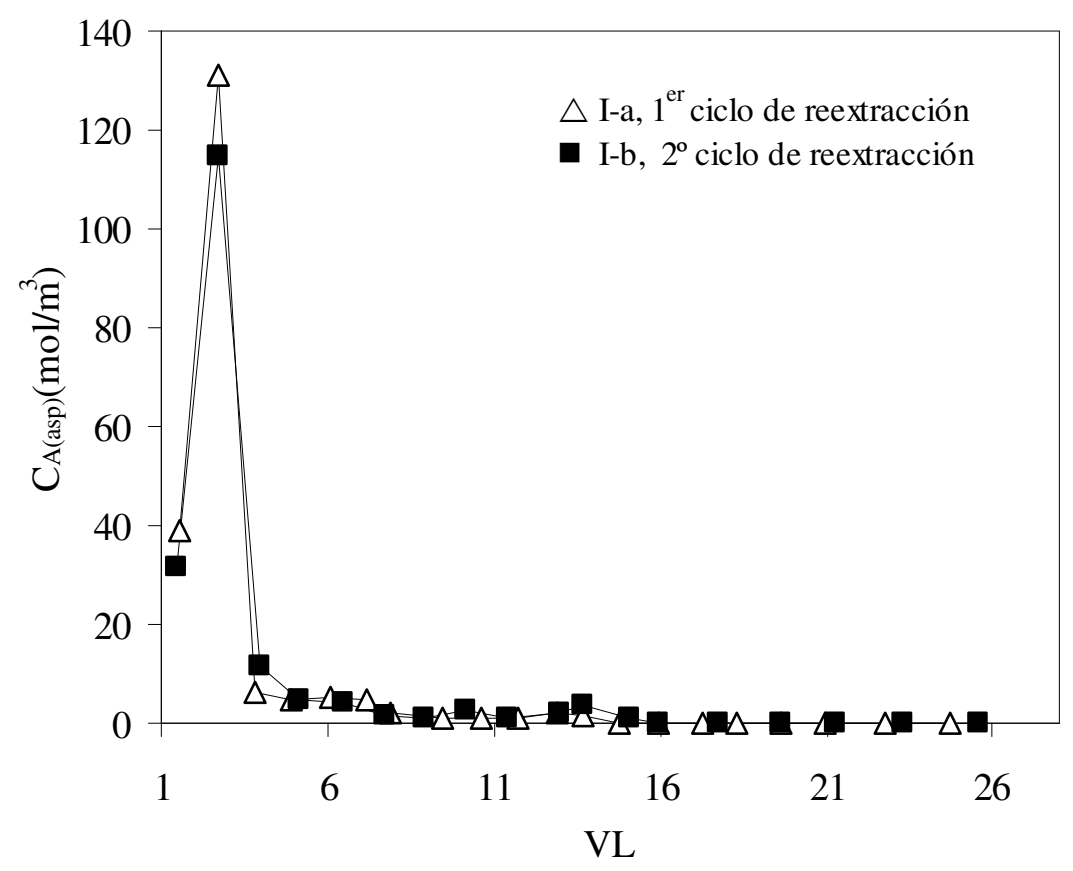

Figura 71. Curvas de ciclos sucesivos de reextracción para los experimentos I-a y I-b de la Tabla 9 $\left(\mathrm{C}_{\mathrm{HCl}}=0,2 \mathrm{M}\right)$.

En la Figura 72 se muestran las curvas de ruptura correspondientes al $1^{\text {er }}$, $2^{\circ}$ y $3^{\text {er }}$ ciclo de extracción de ácido aspártico para los experimentos I a-c de la Tabla 9. En dicha Figura, los tres ciclos de extracción presentan puntos de ruptura y de saturación similares, indicando que es despreciable la pérdida de capacidad de saturación del lecho.

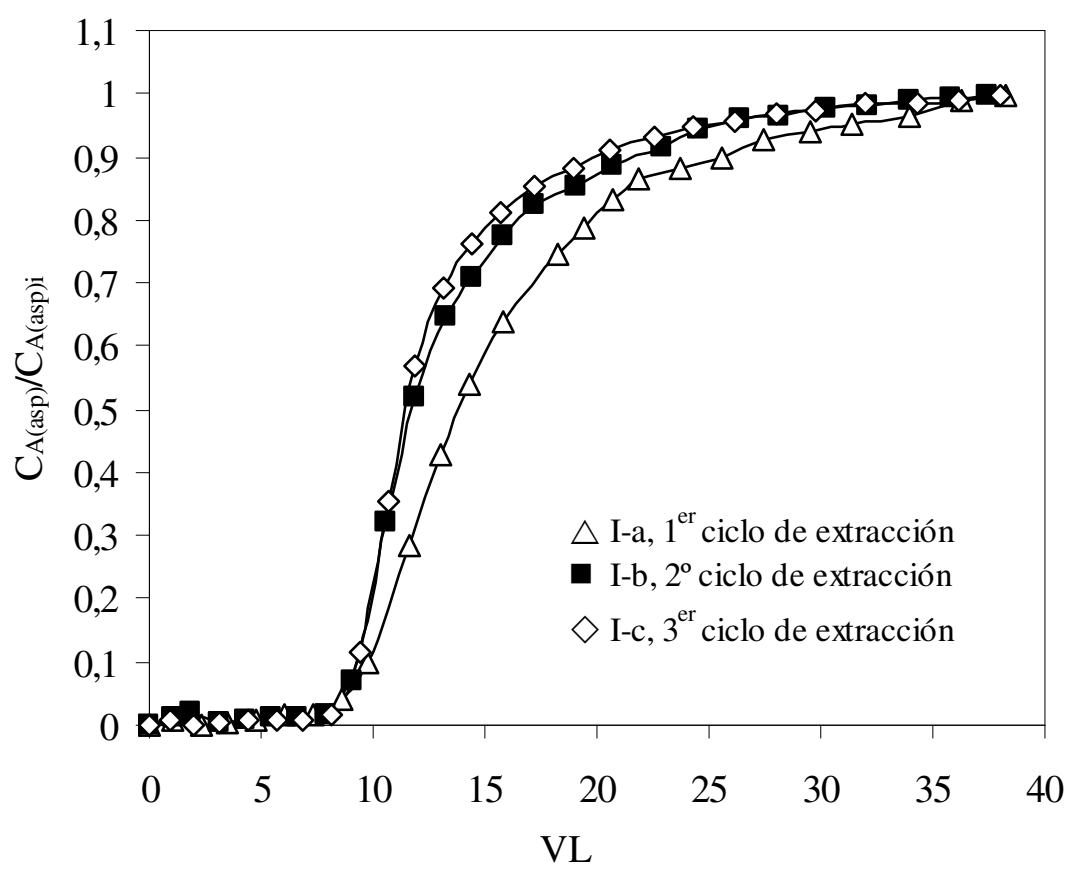

Figura 72. Curvas de ruptura de tres ciclos sucesivos de extracción de ácido aspártico correspondiente al experimento $\mathrm{I}$ a-c de la Tabla 9. $\left(\mathrm{pH}_{\mathrm{i}}=12,01 \pm 0,03\right.$; $\left.\left.C_{A(\text { asp }) i}=14,96 \pm 0,36 ; Q=0,024 \times 10^{-6} \mathrm{~m}^{3} / \mathrm{s}, \overline{\mathrm{Q}^{+} \mathrm{Cl}^{-}}\right]_{\mathrm{i}}=771,75 \mathrm{~mol} / \mathrm{m}^{3} \mathrm{RSI}\right)$. 
La capacidad de saturación del lecho se puede calcular realizando un balance de materia al ácido aspártico en la columna, desde el inicio del proceso $(t=0)$, hasta que el efluente alcanzó la concentración de la alimentación $\left(t_{s}\right)$, es decir, hasta el punto de saturación de la columna. Los moles de ácido aspártico que se acumulan entre los huecos del lecho y dentro de las partículas, se evaluan como la diferencia entre los moles de aminoácido que entran y los que salen de la columna durante todo el proceso dinámico con la siguiente expresión:

$$
\begin{aligned}
& \text { moles de aminoácido } \\
& \text { acumulados en el lecho de RIE }
\end{aligned}=\mathrm{Q}\left[\mathrm{C}_{\mathrm{A}(\text { asp }) \mathrm{i}} \int_{\mathrm{o}}^{\mathrm{t}_{\mathrm{s}}} \mathrm{dt}-\int_{\mathrm{o}}^{\mathrm{t}_{\mathrm{s}}} \mathrm{C}_{\mathrm{A}(\text { asp })}(\mathrm{t}) \mathrm{dt}\right]
$$

donde $Q$ es el caudal de circulación expresado en $\mathrm{m}^{3} / \mathrm{s}, \mathrm{C}_{\mathrm{A}(\text { asp)i }}$ es la concentración de ácido aspártico en la alimentación expresada en $\mathrm{mol} / \mathrm{m}^{3}, \mathrm{C}_{\mathrm{A}(\text { asp })}(\mathrm{t})$ es la concentración de ácido aspártico en el efluente, expresada en $\mathrm{mol} / \mathrm{m}^{3}$ y $\mathrm{t}_{\mathrm{s}}$ es el tiempo en que el efluente alcanza el valor de la concentración de la alimentación.

La acumulación de ácido aspártico retenida en los huecos del lecho de RIE se puede calcular con el siguiente balance de materia, donde se supone un lecho ideal sin extracción:

$$
\varepsilon_{\mathrm{L}} \mathrm{V}_{\mathrm{L}} \frac{\mathrm{dC}_{\mathrm{A}(\text { asp })}^{*}}{\mathrm{dt}}=\mathrm{Q}\left(\mathrm{C}_{\mathrm{A}(\text { asp }) \mathrm{i}}-\mathrm{C}_{\mathrm{A}(\text { asp })}^{*}\right)
$$

donde $\mathrm{C}^{*}{ }_{\mathrm{A}(\mathrm{asp})}$ es la concentración de ácido aspártico que tendría el efluente suponiendo que no hay extracción bajo las condiciones del proceso, $V_{L}$ es el volumen del lecho de RIE $\left(15 \mathrm{~cm}^{3}\right)$ y $\varepsilon_{\mathrm{L}}$ es la porosidad del lecho evaluada con la Ec. (5.99).

El valor de $\mathrm{C}^{*}{ }_{\mathrm{A}(\mathrm{asp})}$ se determina con la Ec. (5.102), obtenida de la integración de la Ec. (5.101).

$$
\mathrm{C}_{\mathrm{A}(\text { asp })}^{*}(\mathrm{t})=\mathrm{C}_{\mathrm{A}(\text { asp }) \mathrm{i}}\left(1-\mathrm{e}^{\frac{-\mathrm{Qt}}{\varepsilon_{\mathrm{L}} \mathrm{V}_{\mathrm{L}}}}\right)
$$

El cálculo de $\mathrm{C}^{\star}{ }_{\mathrm{A}(\mathrm{asp})}(\mathrm{t})$ demuestra que la acumulación de ácido aspártico en los huecos del lecho es despreciable frente a su extracción con el Tomac de la RIE para todos los experimentos realizados.

En base a lo expuesto, la capacidad de saturación se puede determinar con la siguiente ecuación:

$$
\mathrm{Q}_{\mathrm{s}}=\frac{\mathrm{Q}\left[\mathrm{C}_{\mathrm{A}(\text { asp }) \mathrm{i}} \int_{\mathrm{o}}^{\mathrm{t}_{\mathrm{s}}} \mathrm{dt}-\int_{\mathrm{o}}^{\mathrm{t}_{\mathrm{s}}} \mathrm{C}_{\mathrm{A}(\text { asp })}(\mathrm{t}) \mathrm{dt}\right]}{\mathrm{V}_{\mathrm{RSI}}}
$$

donde $\mathrm{V}_{\mathrm{RSI}}$ es el volumen de $\mathrm{RSI}$ del lecho expresado en $\mathrm{m}^{3}$ de resina sin impregnar y determinado experimentalmente a partir de la masa de RIE por pesada.

La capacidad de saturación calculada con la Ec. (5.103) se muestra en la Tabla 17-a para los experimentos I a-c. Estos resultados demostraron que la pérdida de capacidad entre 
el $1^{\text {er }}$ y $2^{\circ}$ ciclo es inferior al $8 \%$ y fue despreciable entre el $2^{\circ}$ y $3^{\text {er }}$ ciclo. Estos resultados pueden deberse, más que a una pérdida de capacidad por efecto de desimpregnación a que en el $1^{\text {er }}$ ciclo la concentración de ácido aspártico fue ligeramente inferior a la de los ciclos posteriores.

Tabla 17-a. Valores de capacidad de saturación, $Q_{s}$, calculada con la Ec. (5.103), para los experimentos cinéticos de la Tabla 9.

\begin{tabular}{ccc}
\hline Experimento & $\mathrm{C}_{\mathrm{A}(\text { asp }) \mathrm{i}}\left(\mathrm{mol} / \mathrm{m}^{3}\right)$ & $\mathrm{Q}_{\mathrm{s}}\left(\mathrm{mol} / \mathrm{m}^{3} \mathrm{RSI}\right)$ \\
\hline I-a $1^{\text {er }}$ ciclo & 14,55 & 281,44 \\
I-b $2^{\text {o ciclo }}$ & 15,24 & 259,42 \\
I-c $3^{\text {er }}$ ciclo & 15,08 & 253,05 \\
\hline
\end{tabular}

Las conclusiones más relevantes de este apartado son:

- Las curvas de ruptura de extracción de ácido aspártico se ven afectadas por el caudal, concentración y pH de la alimentación, y por la carga de Tomac en la RIE.

- Se necesita un $\mathrm{pH} \geq 11,3$ para alcanzar las condiciones óptimas de extracción de ácido aspártico con un lecho fijo de RIE.

- Para llevar a cabo la reextracción de los aminoácidos del lecho de RIE se sugiere un proceso químico de intercambio iónico que emplea como agente de reextracción disoluciones de ácido clorhídrico que producen en una misma etapa la reextracción del aminoácido y la regeneración del extractante presente en la RIE.

- No se observaron pérdidas de capacidad del lecho durante tres ciclos sucesivos. 


\subsubsection{Ensayos con mezclas binarias de ácido aspártico y a- fenilglicina}

Las curvas de ruptura de ácido aspártico y a-fenilglicina de sus mezclas binarias con RIE a $\mathrm{pH}_{\mathrm{i}}=12$ y a $30^{\circ} \mathrm{C}$ se determinaron empleando el dispositivo mostrado en el apartado 5.1.2.3. El procedimiento experimental y las condiciones iniciales de estos experimentos, recogidas en la Tabla 8, se detallan en el apartado 5.1.3.8. Los resultados obtenidos se recogen en las Tablas $\mathrm{C} 1-\mathrm{C} 6$ del apéndice $\mathrm{C}$. Los volúmenes de lecho (VL) y la porosidad del lecho $\left(\varepsilon_{\mathrm{L}}\right)$ se calcularon mediante las Ecs. (5.98) y (5.99), respectivamente.

En las Figuras 73-77 se muestran las curvas de ruptura de extracción conjunta de ácido aspártico y $\alpha$-fenilglicna de sus mezclas binarias a $\mathrm{pH}_{\mathrm{i}}=12$ y a $30^{\circ} \mathrm{C}$, correspondientes a los experimentos I-V de la Tabla 8. Estos experimentos se realizaron utilizando la misma velocidad de flujo en la alimentación $\left(\mathrm{Q}=0,018 \times 10^{-6} \mathrm{~m}^{3} / \mathrm{s}\right)$, igual carga de Tomac en la resina $\left.\left(\widehat{\mathrm{Q}^{+} \mathrm{Cl}^{-}}\right]_{\mathrm{i}}=787,62 \mathrm{~mol} / \mathrm{m}^{3} \mathrm{RSI}\right)$ y con distinta proporción de los aminoácidos en la mezcla $\left(\mathrm{C}_{\mathrm{A}(\mathrm{asp})} / \mathrm{C}_{\mathrm{A}(\mathrm{pgly})}=1 / 1,1 / 2,1 / 3,2 / 1,3 / 1\right)$.

En estas figuras se observa que el perfil de las curvas de ruptura de extracción de ácido aspártico presenta una pendiente mucho más acusada y el punto de saturación se desplaza a tiempos o volúmenes de lecho inferiores que las curvas de ruptura de afenilglicina, aunque en todos los casos, presentan puntos de ruptura similares. Estos resultados están relacionados con los obtenidos en los experimentos de equilibrio y cinéticos (apartados 5.2.4 y 5.3.2) que demostraron un grado de extracción menor y una velocidad de transferencia de materia mayor para el ácido aspártico que para la $\alpha$ fenilglicna.

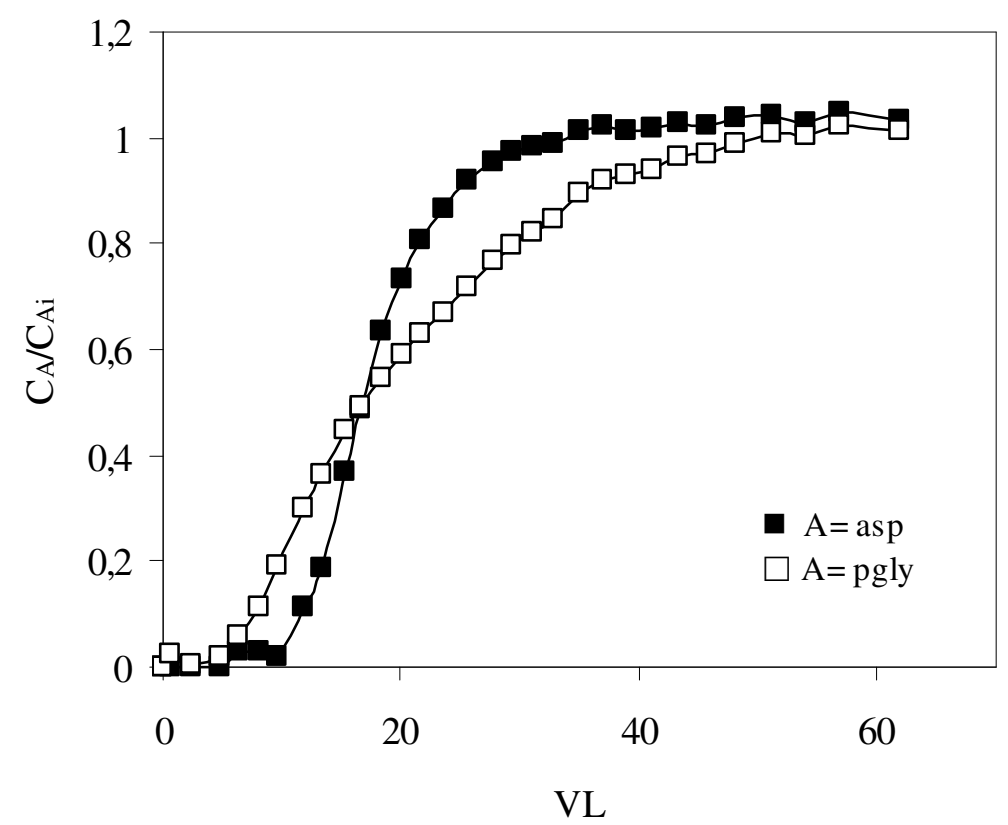

Figura 73. Curvas de ruptura de extracción de ácido aspártico y a-fenilglicina con RIE para el experimento I de la Tabla 8. Proporción de los aminoácidos en la mezcla: $\mathbf{C}_{\mathrm{A}(\text { asp })} / \mathbf{C}_{\mathrm{A}(\mathrm{pgly})}=\mathbf{1} / \mathbf{1}\left(\mathrm{pH}_{\mathrm{i}}=12,01 \pm 0,03 ; \mathrm{Q}=0,018 \times 10^{-6} \mathrm{~m}^{3} / \mathrm{s},\left[\overline{\mathrm{Q}}^{+} \mathrm{Cl}^{-}\right]_{\mathrm{i}}=787,62 \mathrm{~mol} / \mathrm{m}^{3} \mathrm{RSI}\right)$. 


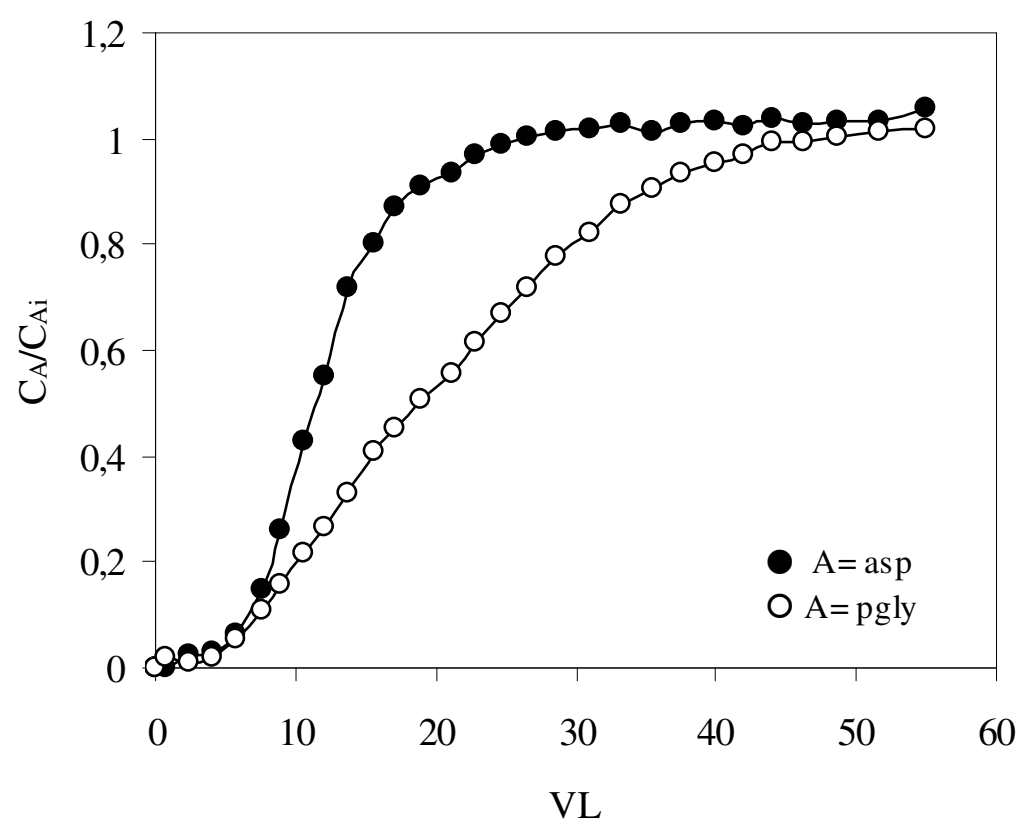

Figura 74. Curvas de ruptura de extracción de ácido aspártico y a-fenilglicina con RIE para el experimento II de la Tabla 8. Proporción de los aminoácidos en la mezcla: $\mathrm{C}_{\mathrm{A}(\text { asp })} / \mathbf{C}_{\mathrm{A}(\text { pgly })}=2 / \mathbf{1}\left(\mathrm{pH}_{\mathrm{i}}=12,01 \pm 0,03 ; \mathrm{Q}=0,018 \times 10^{-6} \mathrm{~m}^{3} / \mathrm{s},\left|\overline{\mathrm{Q}^{+} \mathrm{Cl}^{-}}\right|_{\mathrm{i}}=787,62 \mathrm{~mol} / \mathrm{m}^{3} \mathrm{RSI}\right)$.

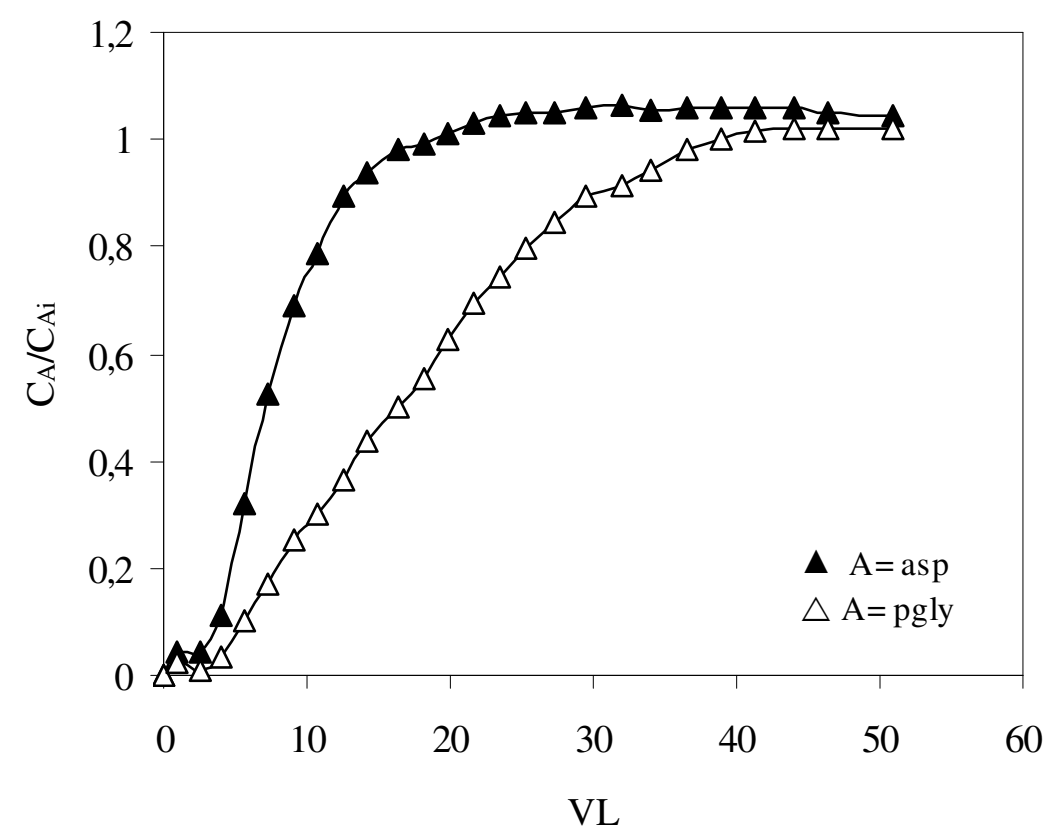

Figura 75. Curvas de ruptura de extracción de ácido aspártico y a-fenilglicina con RIE para el experimento III de la Tabla 8. Proporción de los aminoácidos en la mezcla: $\left.\mathbf{C}_{\mathrm{A}(\text { asp })} / \mathbf{C}_{\mathrm{A}(\text { pgly })}=3 / \mathbf{1}\left(\mathrm{pH}_{\mathrm{i}}=12,01 \pm 0,03 ; \mathrm{Q}=0,018 \times 10^{-6} \mathrm{~m}^{3} / \mathrm{s}, \overline{\mathrm{Q}^{+} \mathrm{Cl}^{-}}\right]_{\mathrm{i}}=787,62 \mathrm{~mol} / \mathrm{m}^{3} \mathrm{RSI}\right)$. 


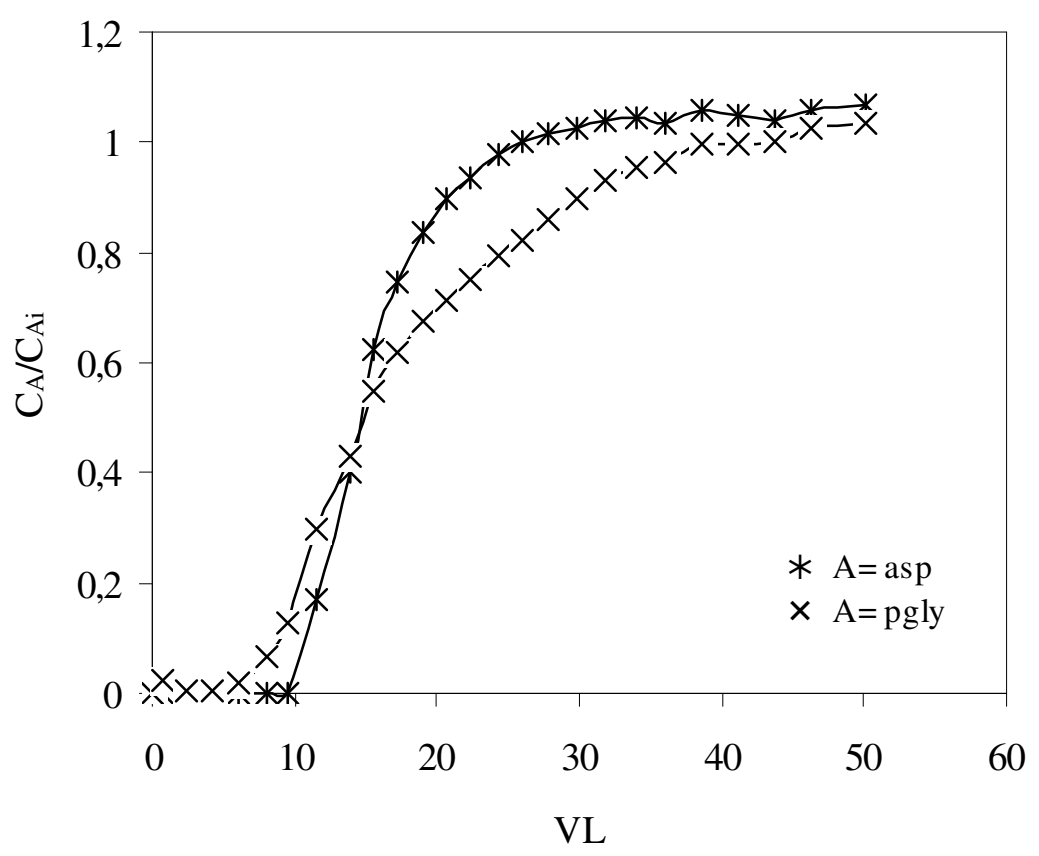

Figura 76. Curvas de ruptura de extracción de ácido aspártico y a-fenilglicina con RIE para el experimento IV de la Tabla 8. Proporción de los aminoácidos en la mezcla: $\left.\mathbf{C}_{A(\text { asp })} / \mathbf{C}_{A(p g l y)}=1 / 2\left(\mathrm{pH}_{\mathrm{i}}=12,01 \pm 0,03 ; \mathrm{Q}=0,018 \times 10^{-6} \mathrm{~m}^{3} / \mathrm{s}, \mid \overline{\mathrm{Q}^{+} \mathrm{Cl}^{-}}\right]_{\mathrm{i}}=787,62 \mathrm{~mol} / \mathrm{m}^{3} \mathrm{RSI}\right)$.

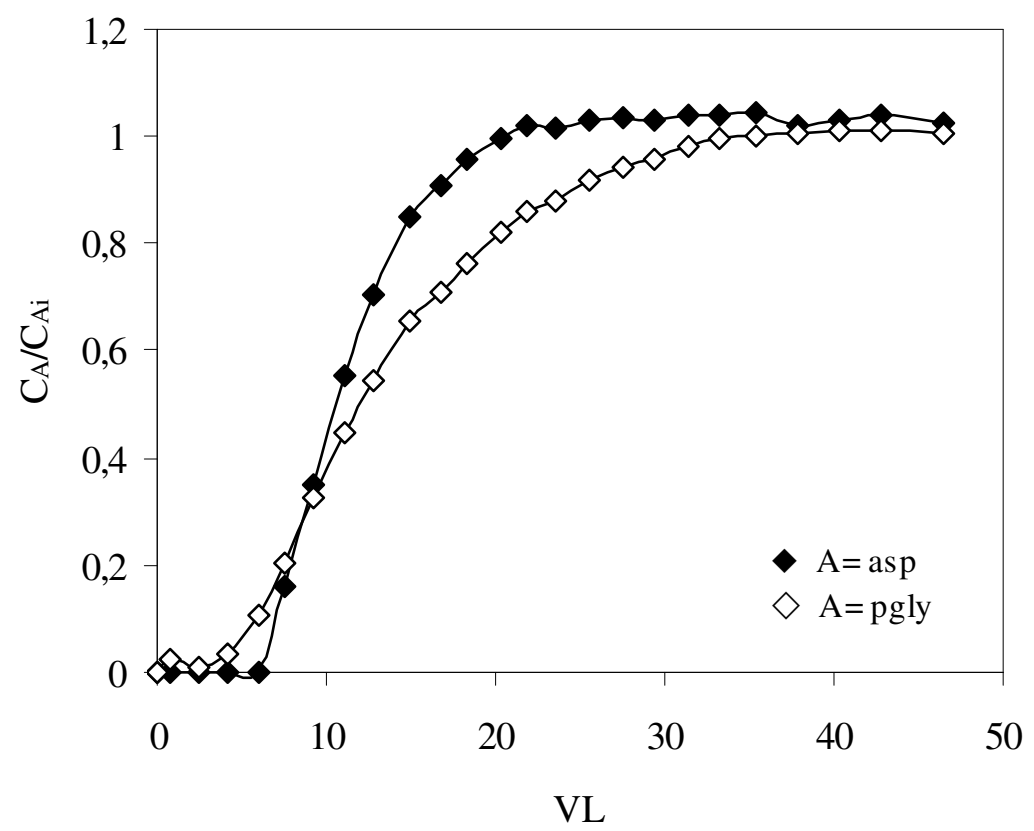

Figura 77. Curvas de ruptura de extracción de ácido aspártico y a-fenilglicina con RIE para el experimento $\mathrm{V}$ de la Tabla 8. Proporción de los aminoácidos en la mezcla: $\left.\mathbf{C}_{A(\text { asp })} / \mathbf{C}_{\mathrm{A}(\mathrm{pgly})}=\mathbf{1 / 3}\left(\mathrm{pH}_{\mathrm{i}}=12,01 \pm 0,03 ; \mathrm{Q}=0,018 \times 10^{-6} \mathrm{~m}^{3} / \mathrm{s}, \mid \mathrm{Q}^{+} \mathrm{Cl}^{-}\right]_{\mathrm{i}}=787,62 \mathrm{~mol} / \mathrm{m}^{3} \mathrm{RSI}\right)$. 
Por otra parte, en las Figuras 73-77 se comprueba que la separación entre las curvas de ruptura de extracción de ácido aspártico y de $\alpha$-fenilglicina varía con su proporción en la mezcla, resultando mayor al aumentar la concentración de ácido aspártico en la mezcla.

En las Figuras 78 y 79 se representan las curvas de ruptura de extracción conjunta de ácido aspártico y de a-fenilglicina, respectivamente, correspondientes a los experimentos I-V de la Tabla 8. Estas figuras muestran el efecto que produce en las curvas de ruptura la distinta proporción de ácido aspártico y de a-fenilglicina en la mezcla.

Los resultados indican que las curvas de ruptura de extracción de ácido aspártico (Figura 78) varian desplazando su punto de ruptura y de saturación hacia volúmenes de lecho o tiempos inferiores al aumentar la concentración de ácido aspártico o de a-fenilglicina en la mezcla. Sin embargo, las curvas de ruptura de extracción de a-fenilglicina (Figura 79) son independientes de la concentración de ácido aspártico en la mezcla y están ligeramente afectadas por la concentración de a-fenilglicina.

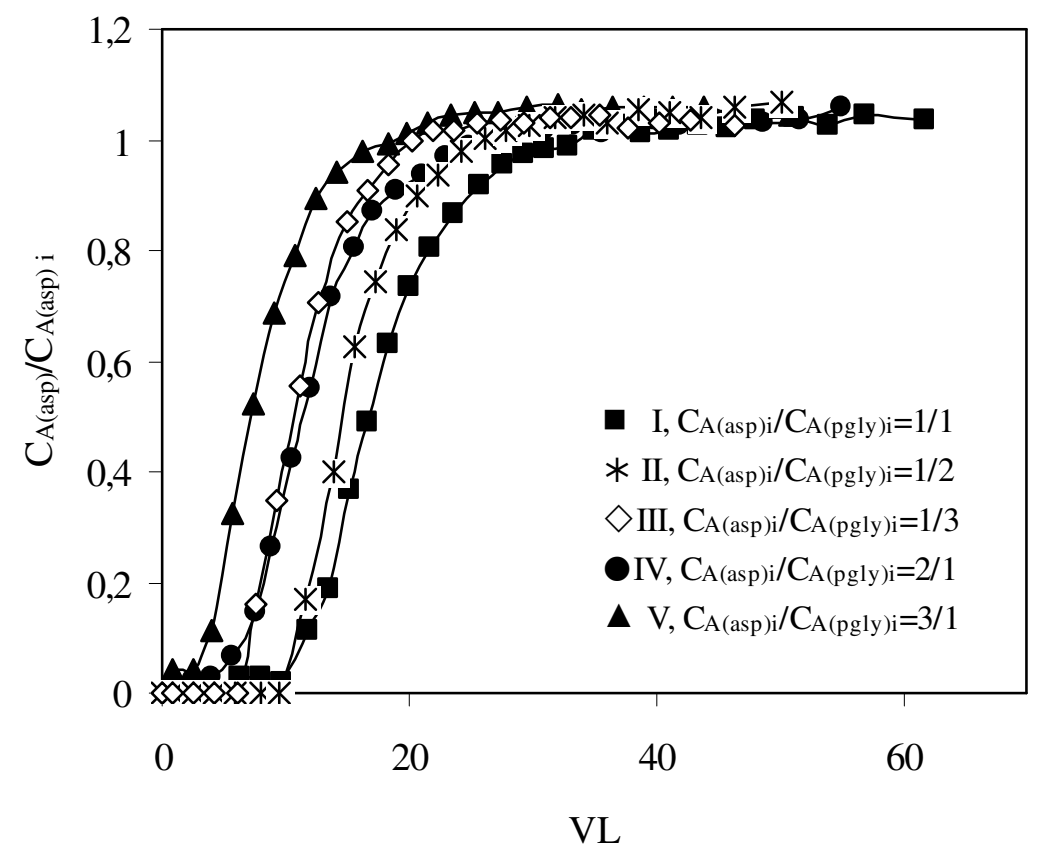

Figura 78. Comparación de las curvas de ruptura de extracción de ácido aspártico con RIE de mezclas binarias con distintas proporciones de ácido aspártico y $\alpha$-fenilglicina, experimentos I-V de la Tabla 8. $\left(\mathrm{pH}_{\mathrm{i}}=12,01 \pm 0,03 ; \mathrm{Q}=0,018 \times 10^{-6} \mathrm{~m}^{3} / \mathrm{s}, \quad\left[\overline{\mathrm{Q}^{+} \mathrm{Cl}^{-}}\right]_{\mathrm{i}}=\right.$ $\left.787,62 \mathrm{~mol} / \mathrm{m}^{3} \mathrm{RSI}\right)$. 


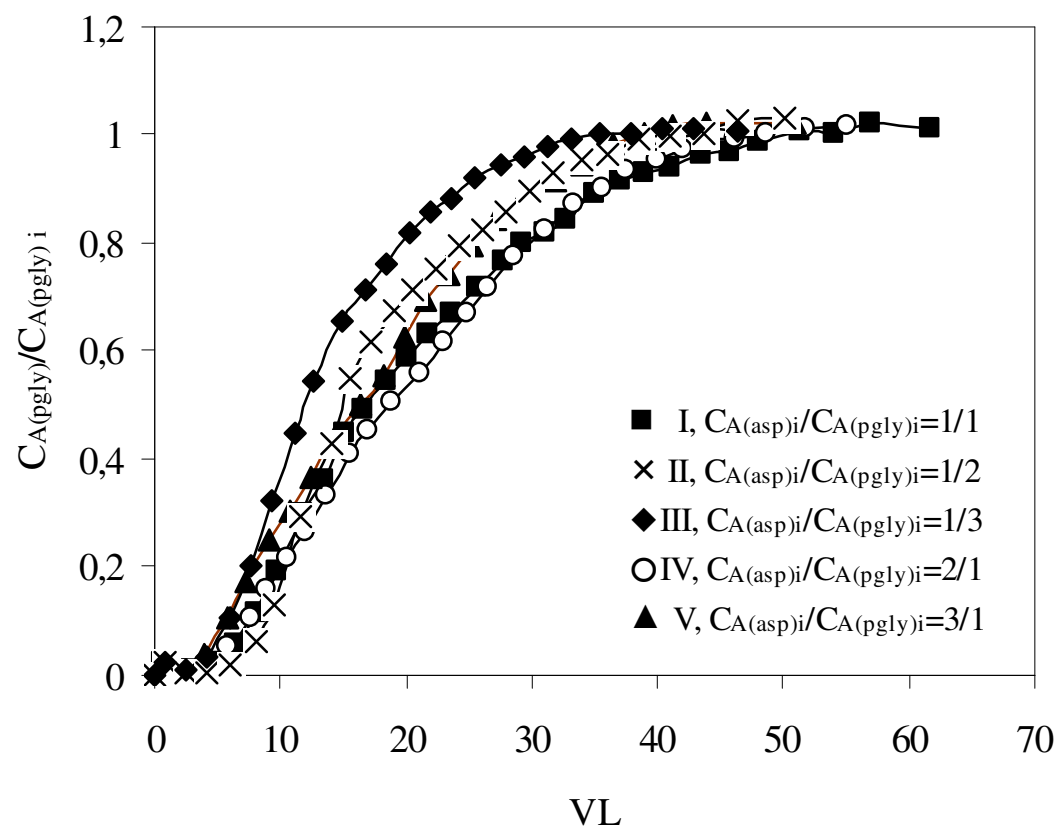

Figura 79. Comparación de las curvas de ruptura de extracción de a-fenilglicina con RIE de mezclas binarias con distintas proporciones de ácido aspártico y a-fenilglicina, experimentos I-V de la Tabla 8. $\left(\mathrm{pH}_{\mathrm{i}}=12,01 \pm 0,03 ; \mathrm{Q}=0,018 \times 10^{-6} \mathrm{~m}^{3} / \mathrm{s}, \overline{\mathrm{Q}^{+} \mathrm{Cl}^{-}}\right]_{\mathrm{i}}=$ $\left.787,62 \mathrm{~mol} / \mathrm{m}^{3} \mathrm{RSI}\right)$.

Las curvas de ruptura de extracción conjunta de ácido aspártico y de a-fenilglicina con RIE con distinta carga de Tomac (experimento I y VI de la Tabla 8) se representan en las Figuras 80 y 81 , respectivamente.

La capacidad de saturación del lecho calculada con la Ec. (5.103) para cada uno de los aminoácidos y la capacidad total obtenida como suma de ambos se tabulan para ambos experimentos en la Tabla 17-b. Los resultados indican que la capacidad total es mayor al aumentar la carga de Tomac en la RIE.

Tabla 17-b. Valores de capacidad de saturación, $\mathrm{Q}_{\mathrm{s}}$, calculada con la Ec. (5.103), para los experimentos cinéticos I y VI de la Tabla 8.

\begin{tabular}{cccc}
\hline Experimento & $\begin{array}{c}\mathrm{Q}_{\mathrm{S}(\text { asp })} \\
\left(\mathrm{mol} / \mathrm{m}^{3} \mathrm{RSI}\right)\end{array}$ & $\begin{array}{c}\mathrm{Q}_{\mathrm{S}(\mathrm{pg} / \mathrm{y})} \\
\left(\mathrm{mol} / \mathrm{m}^{3} \mathrm{RSI}\right)\end{array}$ & $\begin{array}{c}\mathrm{Q}_{\mathrm{s} \text { TOTAL }} \\
\left(\mathrm{mol} / \mathrm{m}^{3} \mathrm{RSI}\right)\end{array}$ \\
\hline $\mathrm{I}$ & 171,58 & 193,58 & 365,15 \\
$\mathrm{VI}$ & 107,53 & 180,05 & 287,58 \\
\hline
\end{tabular}




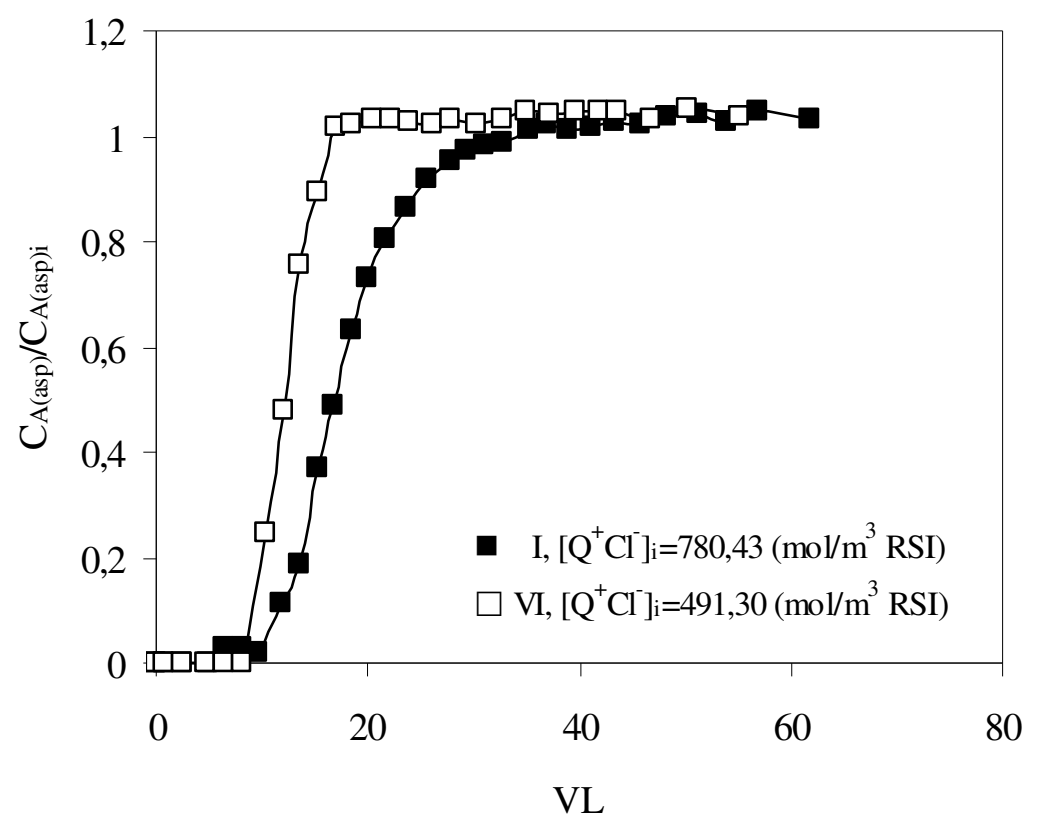

Figura 80. Efecto de la distinta concentración de Tomac en la RIE sobre las curvas de ruptura de extracción de ácido aspártico de mezclas binarias con a-fenilglicina, para los experimentos I y VI de la Tabla 8. $\left(\mathrm{pH}_{\mathrm{i}}=12,01 \pm 0,03 ; \mathrm{Q}=0,018 \times 10^{-6} \mathrm{~m}^{3} / \mathrm{s}\right.$, $\left.\mathrm{C}_{\mathrm{A}(\mathrm{asp}) \mathrm{i}}=\mathrm{C}_{\mathrm{A}(\mathrm{pg} \mid \mathrm{y}) \mathrm{i}}=7,86 \pm 0,2 \mathrm{~mol} / \mathrm{m}^{3}\right)$.

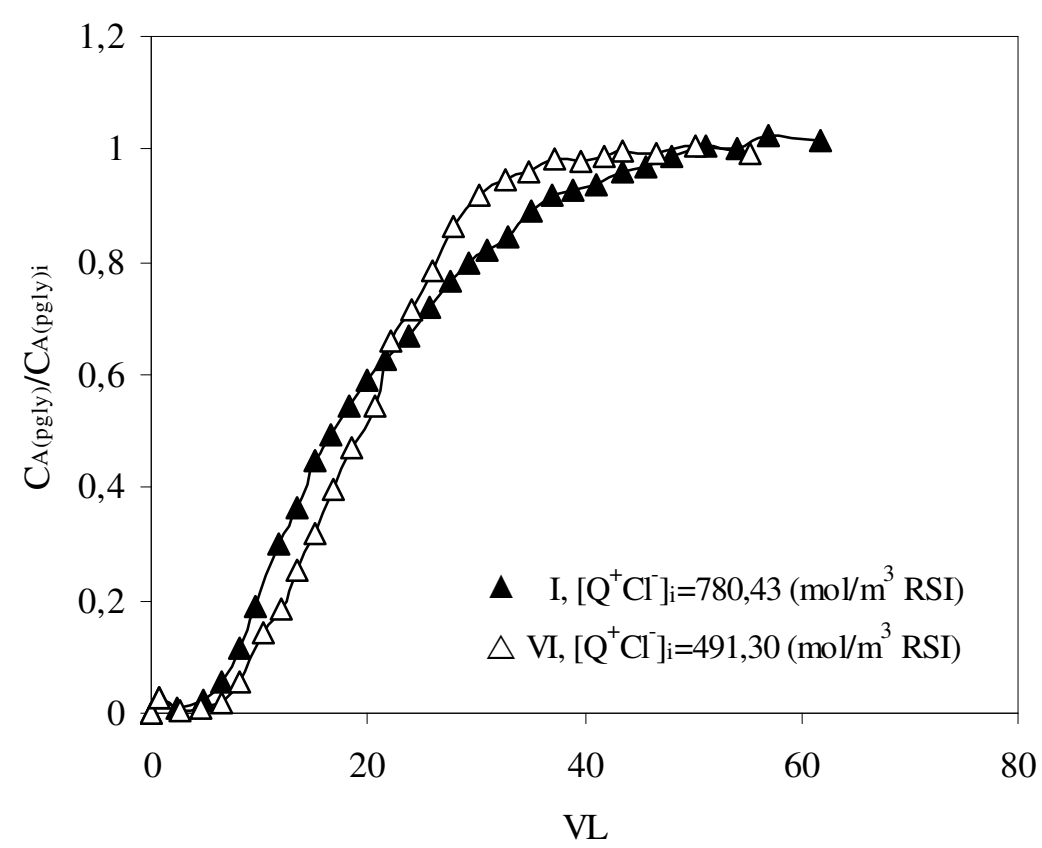

Figura 81. Efecto de la distinta concentración de Tomac en la RIE sobre las curvas de ruptura de extracción de a-fenilglicina de mezclas binarias con ácido aspártico, para los experimentos I y VI de la Tabla 8. $\left(\mathrm{pH}_{\mathrm{i}}=12,01 \pm 0,03 ; \mathrm{Q}=0,018 \times 10^{-6} \mathrm{~m}^{3} / \mathrm{s}\right.$, $\left.\mathrm{C}_{\mathrm{A}(\mathrm{asp}) \mathrm{i}}=\mathrm{C}_{\mathrm{A}(\mathrm{pg} \mid \mathrm{l}) \mathrm{i}}=7,86 \pm 0,2 \mathrm{~mol} / \mathrm{m}^{3}\right)$. 
En base a lo expuesto se puede concluir:

- Las curvas de ruptura de extracción conjunta de ácido aspártico y de $\alpha$-fenilglicina de sus mezclas binarias presentan perfiles diferenciados y la separación entre ambas varía al modificarse la proporción relativa de los aminoácidos en la mezcla, resultando mayor al aumentar la concentración de ácido aspártico en la mezcla.

- Las curvas de ruptura de extracción de ácido aspártico varían al modificarse la concentración relativa de ambos aminoácidos en la mezcla. Sin embargo, las de a-fenilglicina son independientes de la concentración de ácido aspártico en la mezcla y están ligeramente afectadas por la concentración de a-fenilglicina.

\subsubsection{Modelo dinámico para la estimación de las curvas de ruptura}

La velocidad del proceso de extracción de ácido aspártico y de a-fenilglicina en un lecho fijo de RIE, puede estar controlado por las siguientes etapas: 1) transporte de los aminoácidos de la disolución acuosa a la superficie del relleno; 2) adsorción y reacción química en la superficie y en el interior de los poros de las partículas; 3) difusión superficial del aminoácido adsorbido y difusión del complejo aminoácido-Tomac en fase orgánica dentro de los poros de las partículas impregnadas.

En los estudios cinéticos en baños agitados del apartado 5.3 se demostró que la reacción química es instantánea y que la difusión intrapartícula es la etapa controlante del proceso (etapa 3). Sin embargo, en las cinéticas en lecho fijo la resistencia de la película líquida externa debe considerarse también como etapa controlante del proceso (Rosen J. B., 1954; Coulson J. M. et al., 1993; Ruthvens D.M. 1984).

Como ya se expuso en el apartado 4.1.8 en un proceso de extracción isotérmico en un lecho fijo y uniforme de resina, con una porosidad $\varepsilon_{\mathrm{L}}$, el balance de materia diferencial al aminoácido se puede determinar mediante la Ec. (4.20), y suponiendo despreciable el término de dispersión axial se simplifica en la siguiente expresión:

$$
\mathrm{u} \frac{\partial \mathrm{C}_{\mathrm{A}}(\mathrm{z}, \mathrm{t})}{\partial \mathrm{z}}+\frac{\partial \mathrm{C}_{\mathrm{A}}(\mathrm{z}, \mathrm{t})}{\partial \mathrm{t}}+\frac{1-\varepsilon_{\mathrm{L}}}{\varepsilon_{\mathrm{L}}} \frac{\partial \overline{\mathrm{C}}_{\mathrm{A}}(\mathrm{z}, \mathrm{t})}{\partial \mathrm{t}}=0
$$

con las condiciones límite e iniciales:

$$
\begin{aligned}
& \mathrm{C}_{\mathrm{A}}(\mathrm{z}, \mathrm{t})=\mathrm{C}_{\mathrm{Ai}} \quad \mathrm{z}=0 \quad \mathrm{t} \geq 0 \\
& \mathrm{C}_{\mathrm{A}}(\mathrm{z}, \mathrm{t})=\overline{\mathrm{C}}_{\mathrm{A}}(\mathrm{z}, \mathrm{t})=0 \quad 0 \leq \mathrm{z} \leq \mathrm{L} \quad \mathrm{t}=0
\end{aligned}
$$


donde $\overline{\mathrm{C}}_{\mathrm{A}}$ es la concentración total de aminoácido en fase resina expresada en $\mathrm{mol} / \mathrm{m}^{3}$ $\mathrm{RSI}, \mathrm{C}_{\mathrm{A}}$ es la concentración de aminoácido en fase acuosa expresada en $\mathrm{mol} / \mathrm{m}^{3}$, $\varepsilon_{\mathrm{L}}$ es la porosidad del lecho, $u$ es la velocidad intersticial del fluido en el lecho expresada en $\mathrm{m} / \mathrm{s}$ (constante durante todo el proceso), z es la altura del lecho expresada en $\mathrm{m}$, y t el tiempo expresado en segundos.

Considerando que las partículas de RIE son esféricas y homogéneas $\left(a=0,38910^{-3} \mathrm{~m}\right)$, la concentración de aminoácido en la partícula de resina, $\overline{\mathrm{C}}_{\mathrm{A}}$, se define como:

$$
\overline{\mathrm{C}}_{\mathrm{A}}(\mathrm{z}, \mathrm{t})=\frac{3}{\mathrm{a}^{3}} \int_{0}^{\mathrm{a}} \mathrm{r}^{2} \overline{\mathrm{C}}_{\mathrm{A}}(\mathrm{r}, \mathrm{t}) \mathrm{dr}
$$

donde r es la distancia radial desde el centro de la partícula.

Teniendo en cuenta los resultados obtenidos de los datos cinéticos en baño, la evolución de la concentración de aminoácido en las partículas de RIE, se puede describir mediante un modelo de difusión homogéneo, basado en la segunda ley de Fick:

$$
\frac{\partial \overline{\mathrm{C}}_{\mathrm{A}}(\mathrm{r}, \mathrm{t})}{\partial \mathrm{t}}=\mathrm{D}_{\mathrm{e}} \frac{1}{\mathrm{r}^{2}} \frac{\partial}{\partial \mathrm{r}}\left(\mathrm{r}^{2} \frac{\partial \overline{\mathrm{C}}_{\mathrm{A}}(\mathrm{r}, \mathrm{t})}{\partial \mathrm{r}}\right) ; \quad 0 \leq \mathrm{r} \leq \mathrm{a} ; \mathrm{t}>0
$$

con las condiciones límite e iniciales:

$$
\begin{aligned}
& D_{e} \frac{\partial \bar{C}_{A}(r, t)}{\partial r}=\frac{3 k_{f}}{a}\left(C_{A}(z, t)-\frac{\bar{C}_{A}(r, t)}{K}\right) ; r=a ; t>0 \\
& \frac{\partial \bar{C}_{A}(r, t)}{\partial r}=0 ; \quad r=0 ; \quad t>0
\end{aligned}
$$

donde $k_{f}$ es el coeficiente de transferencia de materia en la película líquida externa expresada en $\mathrm{m} / \mathrm{s}$ y $D_{e}$ es la difusividad efectiva intrapartícula expresada en $\mathrm{m}^{2} / \mathrm{s}$. Los valores de $D_{e}$, que se recogen en las Tablas 14 y 16 , fueron calculados previamente en los ensayos cinéticos en baños agitados mostrados en los apartados 5.3.1.2 y 5.3.2.2.

Suponiendo que en la interfase sólido-líquido se mantiene un equilibrio instantáneo, se define el coeficiente de distribución, K, por la siguiente relación de concentraciones:

$$
\mathrm{K}=\frac{\overline{\mathrm{C}}_{\mathrm{A}}{ }_{(\mathrm{r}=\mathrm{a})}}{\left[\mathrm{A}^{\mathrm{b}-}\right]}
$$

siendo $\bar{C}_{A}$ la concentración de aminoácido en la fase resina en el equilibrio y $\left[\mathrm{A}^{\mathrm{b}}{ }^{-}\right]$la concentración de la especie iónica extraíble de aminoácido en la fase acuosa en el equilibrio.

La solución analítica de la Ec. (5.104) resuelta conjuntamente con las Ecs. (5.105)(5.110) fue dada por Rosen (Rosen J. B., 1952; Rosen J. B., 1954) mediante la siguiente expresión: 


$$
\frac{\mathrm{C}_{\mathrm{A}}}{\mathrm{C}_{\mathrm{Ai}}}=\frac{1}{2}\left[1+\operatorname{erf}\left(\frac{\frac{3 \tau}{2 \lambda}-1}{2 \sqrt{\frac{1+5 \psi}{5 \lambda}}}\right)\right]
$$

donde erf es la función de error (Crank J., 1975), y los números adimensionales $\lambda, \tau$, y $\psi$ se definen como:

$$
\begin{aligned}
& \lambda=3 \frac{D_{\mathrm{e}}}{\mathrm{a}^{2}} \frac{\mathrm{K} \mathrm{z}}{\mathrm{u}} \frac{\left(1-\varepsilon_{\mathrm{L}}\right)}{\varepsilon_{\mathrm{L}}} \\
& \tau=2 \frac{\mathrm{D}_{\mathrm{e}}}{\mathrm{a}^{2}}\left(\mathrm{t}-\frac{\mathrm{L}}{\mathrm{u}}\right) \\
& \psi=3 \frac{\mathrm{D}_{\mathrm{e}}}{\mathrm{a}} \frac{\mathrm{K}}{\mathrm{k}_{\mathrm{f}}}
\end{aligned}
$$

donde $\lambda$, es el parámetro de la longitud, $\tau$, es el parámetro del tiempo y $\psi$ es el parámetro de las resistencias.

La porosidad del lecho de resina, se estimó experimentalmente aplicando la Ec. (5.99). Se obtuvo un valor de porosidad de lecho, $\varepsilon_{\mathrm{L}}=0,30 \pm 0,05$ para todos los experimentos realizados.

Los valores del coeficiente de distribución $(K)$ se calcularon por los dos métodos que a continuación se describen, dando valores similares en ambos casos: 1) La Ec. (5.103) correspondiente al cálculo de la capacidad de saturación del lecho y que representa la concentración de aminoácido acumulada en el lecho de RIE en equilibrio con la alimentación; y 2) Los modelos de equilibrio previamente calculados en los apartados 5.2.3.1, 5.2.3.2 y 5.2.4.1 que se relacionan de nuevo a continuación:

a) Extracción de ácido aspártico a $\mathrm{pH}_{\mathrm{i}}=5$ (apartado 5.2.3.1):

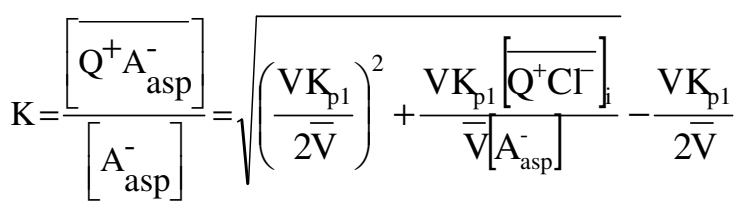

b) Extracción de ácido aspártico a $\mathrm{pH}_{\mathrm{i}}=11$ y 12 (apartado 5.2.3.2):

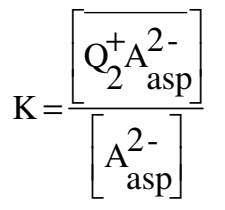

donde la especie, $\left[\overline{\mathrm{Q}_{2}^{+} \mathrm{A}_{\text {asp }}^{2-}}\right]$, se obtiene resolviendo la siguiente ecuación: 


$$
\left.\left[\overline{\mathrm{Q}_{2}^{+} \mathrm{A}_{\text {asp }}^{2-}}\right]^{3}-\frac{\mathrm{V}^{2}}{\overline{\mathrm{V}}^{2}} \mathrm{~K}_{\mathrm{p} 2 \text { (asp) }}\left[\mathrm{A}_{\text {asp }}^{2-}\right]\left\{\left[\overline{\mathrm{Q}_{2}^{+} \mathrm{A}_{\text {asp }}^{2-}}\right]^{2}-\left[\overline{\mathrm{Q}^{+} \mathrm{Cl}^{-}}\right]_{\mathrm{i}}\left[\overline{\mathrm{Q}_{2}^{+} \mathrm{A}_{\text {asp }}^{2-}}\right]+\frac{\overline{\mathrm{Q}^{+} \mathrm{Cl}^{-}}}{4}\right]_{\mathrm{i}}^{2}\right\}=0
$$

c) Extracción de mezclas binarias de ácido aspártico y a-fenilglicina a $\mathrm{pH}_{\mathrm{i}}=11$ y 12 (apartado 5.2.4.1):

$$
\begin{aligned}
& \mathrm{K}_{\text {(asp) }}=\frac{\left.\overline{\mathrm{Q}_{2}^{+} \mathrm{A}_{\text {asp }}^{2-}}\right\rfloor}{\left[\mathrm{A}_{\text {asp }}^{2-}\right]}=\mathrm{K}_{\mathrm{p} 2 \text { (asp) }} \frac{\left[\overline{\mathrm{Q}^{+} \mathrm{Cl}^{-}}\right]^{2}}{\left[\mathrm{Cl}^{-}\right]^{2}} \\
& \mathrm{~K}_{\text {(pgly) }}=\frac{\left.\overline{\mathrm{Q}^{+} \mathrm{A}_{\text {pgly }}^{-}}\right]}{\left[\mathrm{A}_{\text {pgly }}^{-}\right]}=\mathrm{K}_{\mathrm{pl}(\text { pgly })} \frac{\left[\overline{\mathrm{Q}^{+} \mathrm{Cl}^{-}}\right]}{\left[\mathrm{Cl}^{-}\right]}
\end{aligned}
$$

donde la proporción $\left.\overline{\mathrm{Q}^{+} \mathrm{Cl}^{-}}\right] /\left[\mathrm{Cl}^{-}\right]$se obtiene resolviendo la siguiente ecuación de tercer orden:

$$
\begin{aligned}
& 2 \mathrm{~K}_{\mathrm{p} 2 \text { (asp) }}\left[\mathrm{A}_{\text {asp }}^{2-}\right]\left(\frac{\left[\overline{\mathrm{Q}^{+} \mathrm{Cl}^{-}}\right)^{3}}{\left[\mathrm{Cl}^{-}\right]}\right)^{3}+\left(\mathrm{K}_{\mathrm{p} 1(\mathrm{pgly})}\left[\mathrm{A}_{\mathrm{pgly}}^{-}\right]+2 \frac{\mathrm{V}}{\overline{\mathrm{V}}} \mathrm{K}_{\mathrm{p} 2 \text { (asp) }}\left[\mathrm{A}_{\text {asp }}^{2-}\right]\right)\left(\frac{\left[\overline{\mathrm{Q}^{+} \mathrm{Cl}^{-}}\right]}{\left[\mathrm{Cl}^{-}\right]}\right)^{2}+ \\
& +\frac{\mathrm{V}}{\overline{\mathrm{V}}} \mathrm{K}_{\mathrm{p} 1(\mathrm{pgly})}\left[\mathrm{A}_{\mathrm{pgly}}^{-}\right]\left(\frac{\overline{\mathrm{Q}^{+} \mathrm{Cl}^{-}}}{\left[\mathrm{Cl}^{-}\right]}\right)-\frac{\mathrm{V}}{\overline{\mathrm{V}}}\left[\overline{\mathrm{Q}^{+} \mathrm{Cl}^{-}}\right]=0
\end{aligned}
$$

En las Tablas 18 y 19 se muestran los valores del coeficiente de distribución para los experimentos I, IV y V de la Tabla 7 y I-V de la Tabla 8 . Se observa que K disminuye al aumentar la concentración de aminoácido en la alimentación y a $\mathrm{pH}_{\mathrm{i}}=5$, resultado análogo al obtenido en los ensayos de equilibrio expuestos en el apartado 5.2, debido a la no linealidad de las isotermas de extracción (Figura 3) y a su dependencia con el pH.

Como se ha comentado anteriormente, la difusividad intrapartícula efectiva, $D_{e}$, fue determinada previamente en los ensayos cinéticos en baños agitados (apartados 5.3.1.2 y 5.3.2.2), excepto para los experimentos II-V de la Tabla 8 donde se consideró constante e igual a la del experimento I, debido a que se puede asumir despreciable su variación en el intervalo de concentraciones del aminoácido.

El coeficiente de transferencia de materia en la película líquida externa, $\mathrm{k}_{\mathrm{f}}$, se obtuvo del ajuste de los datos experimentales a las Ecs. (5.112)-(5.115). El valor de los parámetros cinéticos $D_{e}$ y $k_{f}$ se presentan en las Tablas 18 y 19 junto con las condiciones iniciales de los experimentos de extracción en columna.

Con el valor de $\mathrm{k}_{\mathrm{f}} \mathrm{y}$ la ecuación de Wilson-Geankoplis se estimó la difusividad en la película líquida externa, $\mathrm{D}_{\mathrm{L}}$, (Ruthvens D.M. 1984; M. O. Ruiz et al., 2006): 


$$
\frac{\mathrm{k}_{\mathrm{f}} \mathrm{a}}{\mathrm{D}_{\mathrm{L}}}=\frac{1,09}{\varepsilon_{\mathrm{L}}}\left(\frac{\mu}{\rho \mathrm{D}_{\mathrm{L}}}\right)^{0,33}\left(\frac{2 \mathrm{au}_{\mathrm{s}} \rho}{\mu}\right)^{0,33}
$$

donde $u_{s}$ es la velocidad superficial, $\mu$ y $\rho$ son la viscosidad y la densidad de la fase acuosa, respectivamente.

Tabla 18. Coeficiente de distribución y parámetros cinéticos de los experimentos I, IV y V de la Tabla 7, correspondientes a la extracción en columna de ácido aspártico $\left(\left[\mathrm{Q}^{+} \mathrm{Cl}^{-}\right)_{\mathrm{i}}=\right.$ $773,72 \pm 3,78 \mathrm{~mol} / \mathrm{m}^{3} \mathrm{RSI}$ y $\mathrm{Q}=0,023 \times 10^{-6} \pm 0,001 \mathrm{~m}^{3} / \mathrm{s}$ ).

\begin{tabular}{|c|c|c|c|c|c|c|}
\hline Experimento & $\mathrm{pH}_{\mathrm{i}}$ & $\underset{\left(\mathrm{mol} / \mathrm{m}^{3}\right)}{\mathrm{C}_{\mathrm{A}(\text { asp })}}$ & $\begin{array}{c}\mathrm{K}\left(\mathrm{m}^{3} / \mathrm{m}^{3}\right. \\
\mathrm{RSI}) \\
\text { Ec }(5.111)\end{array}$ & $\begin{array}{c}\mathrm{D}_{\text {e(asp }} \times 10^{11} \\
\left(\mathrm{~m}^{2} / \mathrm{s}\right) \\
\text { Ec. }(5.59)\end{array}$ & $\begin{array}{c}\mathrm{k}_{\mathrm{f}(\text { asp })} \times 10^{5} \\
(\mathrm{~m} / \mathrm{s}) \\
\text { Ec. }(5.112)\end{array}$ & $\begin{array}{l}\mathrm{D}_{\mathrm{L}(\text { asp }} \times 10^{11} \\
\left(\mathrm{~m}^{2} / \mathrm{s}\right) \\
\text { Ec. }(5.116)\end{array}$ \\
\hline I & $5,05 \pm 0,02$ & 7,40 & $12,8 \pm 3,6$ & 43,00 & 0,60 & 3,00 \\
\hline IV & $12,03 \pm 0,02$ & 7,57 & $27,6 \pm 5,1$ & 32,60 & 4,00 & 6,05 \\
\hline V & $12,08 \pm 0,02$ & 14,55 & $15,1 \pm 3,3$ & 33,00 & 2,00 & 21,49 \\
\hline
\end{tabular}

Tabla 19. Coeficiente de distribución y parámetros cinéticos de los experimentos I-V de la Tabla 8, correspondientes a la extracción en columna de ácido aspártico y a-fenilglicina de sus mezclas binarias. $\left(\mathrm{pH}_{\mathrm{i}}=12,01 \pm 0,07 ; \mid \overline{\mathrm{Q}^{+} \mathrm{Cl}^{-}}\right]_{\mathrm{i}}=787,62 \pm 4,03 \mathrm{~mol} / \mathrm{m}^{3} \mathrm{RSI}$ y $\mathrm{Q}=0,018 \times 10^{-6} \pm 0,001 \mathrm{~m}^{3} / \mathrm{s}$ )

a) Ácido aspártico

\begin{tabular}{|c|c|c|c|c|c|}
\hline Experimento & $\begin{array}{l}\mathrm{C}_{\mathrm{A}(\text { asp }) i} / \\
\mathrm{C}_{\mathrm{A}(\text { pgly) }}\end{array}$ & $\begin{array}{c}\mathrm{K}_{(\mathrm{asp})}\left(\mathrm{m}^{3} / \mathrm{m}^{3}\right. \\
\mathrm{RSI}) \\
\text { Ec }(5.111)\end{array}$ & $\begin{array}{c}\mathrm{D}_{\mathrm{e}(\text { asp }} \times 10^{11} \\
\left(\mathrm{~m}^{2} / \mathrm{s}\right) \\
\text { Ec. }(5.89)\end{array}$ & $\begin{array}{l}\mathrm{k}_{\mathrm{f}(\mathrm{asp})} \times 10^{5} \\
(\mathrm{~m} / \mathrm{s}) \\
\text { Ec. }(5.112)\end{array}$ & $\begin{array}{l}\mathrm{D}_{\mathrm{L}(\text { asp })} \times 10^{11} \\
\left(\mathrm{~m}^{2} / \mathrm{s}\right) \\
\text { Ec. }(5.116)\end{array}$ \\
\hline I & $1 / 1$ & $17,3 \pm 1,9$ & 32,60 & 3,00 & 37,41 \\
\hline II & $1 / 2$ & $14,0 \pm 3,6$ & 32,60 & 2,00 & 20,43 \\
\hline III & $1 / 3$ & $9,7 \pm 2,6$ & 32,60 & 2,00 & 20,43 \\
\hline IV & $2 / 1$ & $10,7 \pm 2,9$ & 32,60 & 1,50 & 13,30 \\
\hline V & $3 / 1$ & $6,8 \pm 0,1$ & 32,60 & 1,00 & 7,29 \\
\hline
\end{tabular}


Tabla 19. (continuación)

b) $\alpha$-Fenilglicina

\begin{tabular}{|c|c|c|c|c|c|}
\hline Experimento & $\begin{array}{l}\mathrm{C}_{\mathrm{A}(\text { asp }) i} / \\
\mathrm{C}_{\mathrm{A}(\text { pgly)i }}\end{array}$ & $\begin{array}{c}\mathrm{K}_{\text {(pgly) }}\left(\mathrm{m}^{3} / \mathrm{m}^{3}\right. \\
\mathrm{RSI}) \\
\text { Ec }(5.111)\end{array}$ & $\begin{array}{c}\mathrm{D}_{\mathrm{e}(\mathrm{pg} \mid \mathrm{y}) \mathrm{x}} \mathrm{x} 10^{11} \\
\quad\left(\mathrm{~m}^{2} / \mathrm{s}\right) \\
\text { Ec. }(5.90)\end{array}$ & $\begin{array}{c}\mathrm{k}_{\mathrm{f}(\mathrm{pgly}) \times 1} 10^{5} \\
(\mathrm{~m} / \mathrm{s}) \\
\text { Ec. }(5.112)\end{array}$ & $\begin{array}{l}\mathrm{D}_{\mathrm{L}(\mathrm{pg} \mid \mathrm{y}) \mathrm{X}} \times 10^{11} \\
\left(\mathrm{~m}^{2} / \mathrm{s}\right) \\
\text { Ec. }(5.116)\end{array}$ \\
\hline I & $1 / 1$ & $20,4 \pm 4,7$ & 11,00 & 0,60 & 3,38 \\
\hline II & $1 / 2$ & $16,1 \pm 3,0$ & 11,00 & 0,70 & 4,26 \\
\hline III & $1 / 3$ & $13,9 \pm 1,8$ & 11,00 & 0,90 & 6,20 \\
\hline IV & $2 / 1$ & $18,4 \pm 7,3$ & 11,00 & 0,70 & 4,26 \\
\hline V & $3 / 1$ & $15,4 \pm 5,3$ & 11,00 & 0,80 & 5,20 \\
\hline
\end{tabular}

Los parámetros $D_{e}$ y $D_{L}$ son del mismo orden de magnitud, como se observa en las Tablas 18 y 19, indicando que el proceso de extracción de ácido aspártico y a-fenilglicina en lechos fijos de RIE está principalmente controlado por la difusión intrapartícula y por la difusión en la película líquida externa. En estudios anteriores de extracción de afenilglicina en lechos fijos de RIE, se obtuvieron similares resultados (Ruiz M. O., 2000).

Los experimentos relacionados en las Tablas 18 y 19 se muestran en las Figuras 82 y 83 donde se observa una buena concordancia entre los datos experimentales (símbolos) y el modelo cinético mostrado en las Ecs. (5.111)-(5.115) (líneas). El error fue inferior al 5\% en todos los casos.

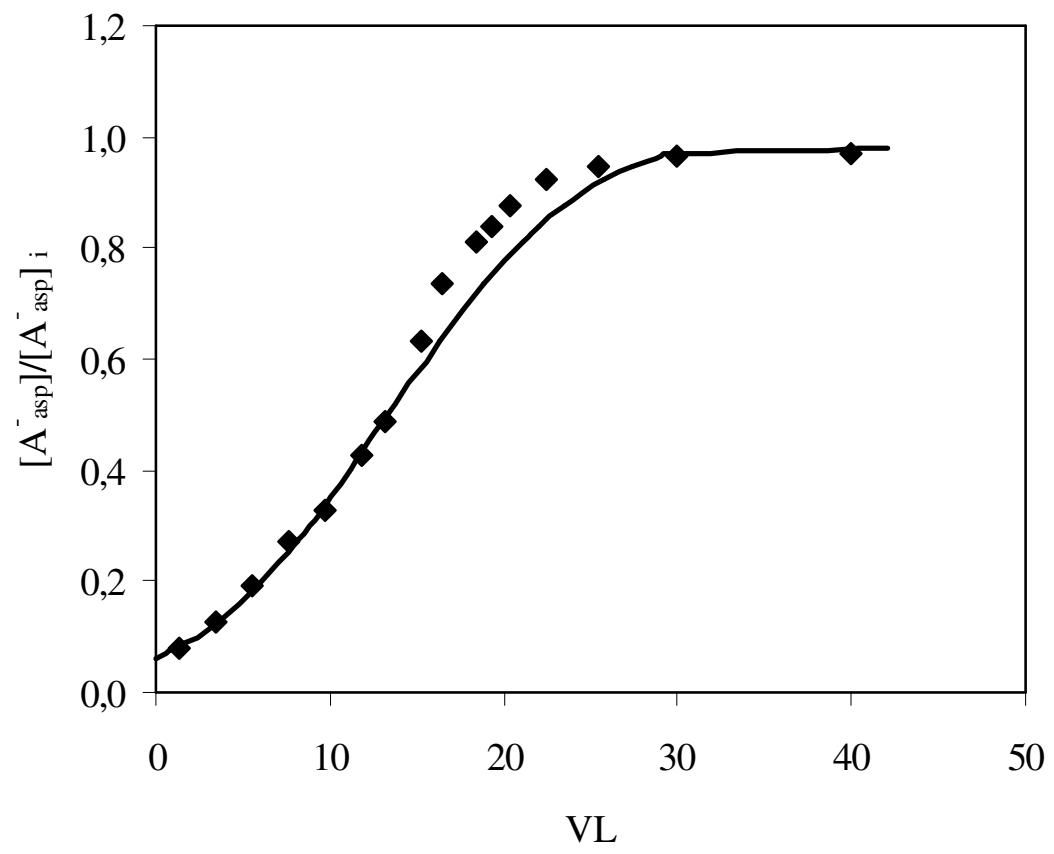

Figura 82. Curvas de ruptura de extracción de ácido aspártico individual a $\mathrm{pH}_{\mathrm{i}}=5,05 \pm 0,02$ con RIE, para el experimento I de la Tabla $18\left(Q=0,022 \times 10^{-6} \mathrm{~m}^{3} / \mathrm{s}, C_{A(\text { asp })}=7,40 \mathrm{~mol} / \mathrm{m}^{3}\right.$, $\left.\left[\overline{\mathrm{Q}^{+} \mathrm{Cl}^{-}}\right]_{\mathrm{i}}=773,72 \pm 3,78 \mathrm{~mol} / \mathrm{m}^{3} \mathrm{RSI}\right)$ Símbolos: datos experimentales. Líneas: datos calculados con las Ecs. (5.112)-(5.115). 


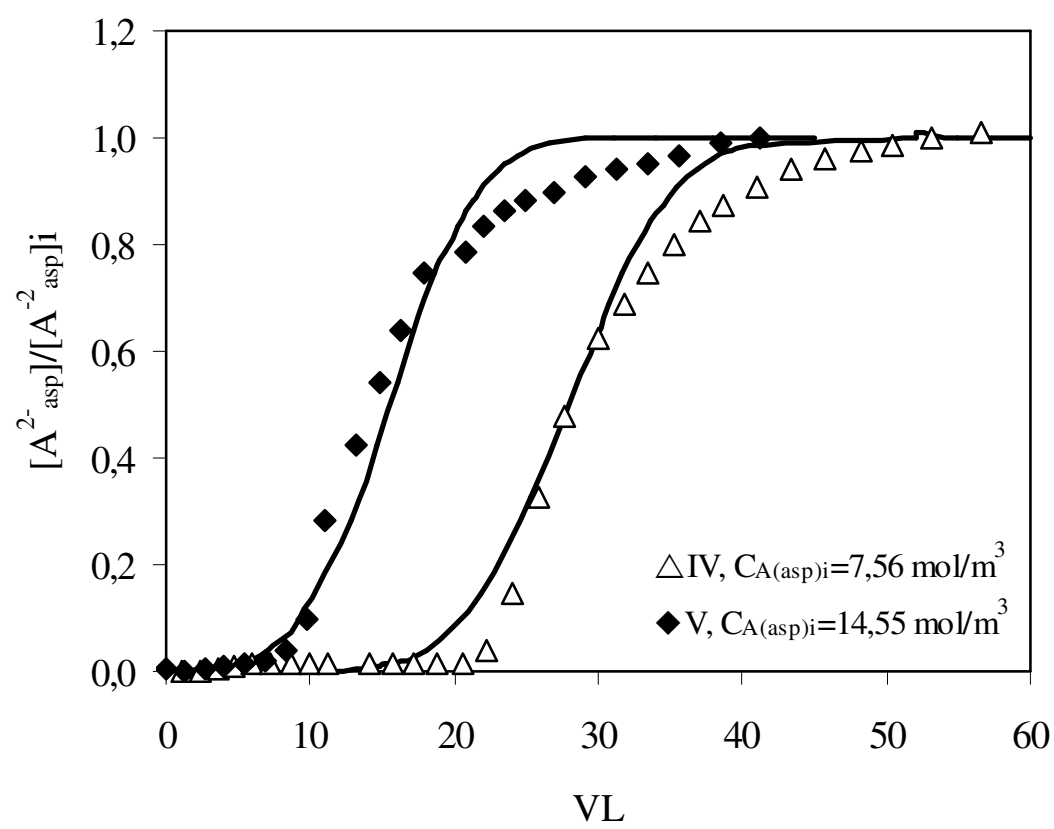

Figura 83. Curvas de ruptura de extracción de ácido aspártico a $\mathrm{pH}_{\mathrm{i}}=12,05 \pm 0,02$ con $\mathrm{RIE}$ para los experimentos IV y $V$ de la Tabla $18\left(\mathrm{Q}=0,024 \times 10^{-6} \mathrm{~m}^{3} / \mathrm{s}, \quad \overline{\mathrm{Q}}^{+} \mathrm{Cl}^{-}\right]_{\mathrm{i}}=773,72 \pm 3,78$ $\left.\mathrm{mol} / \mathrm{m}^{3} \mathrm{RSI}\right)$. Símbolos: datos experimentales. Líneas: datos calculados con las Ecs. (5.112)-(5.115).

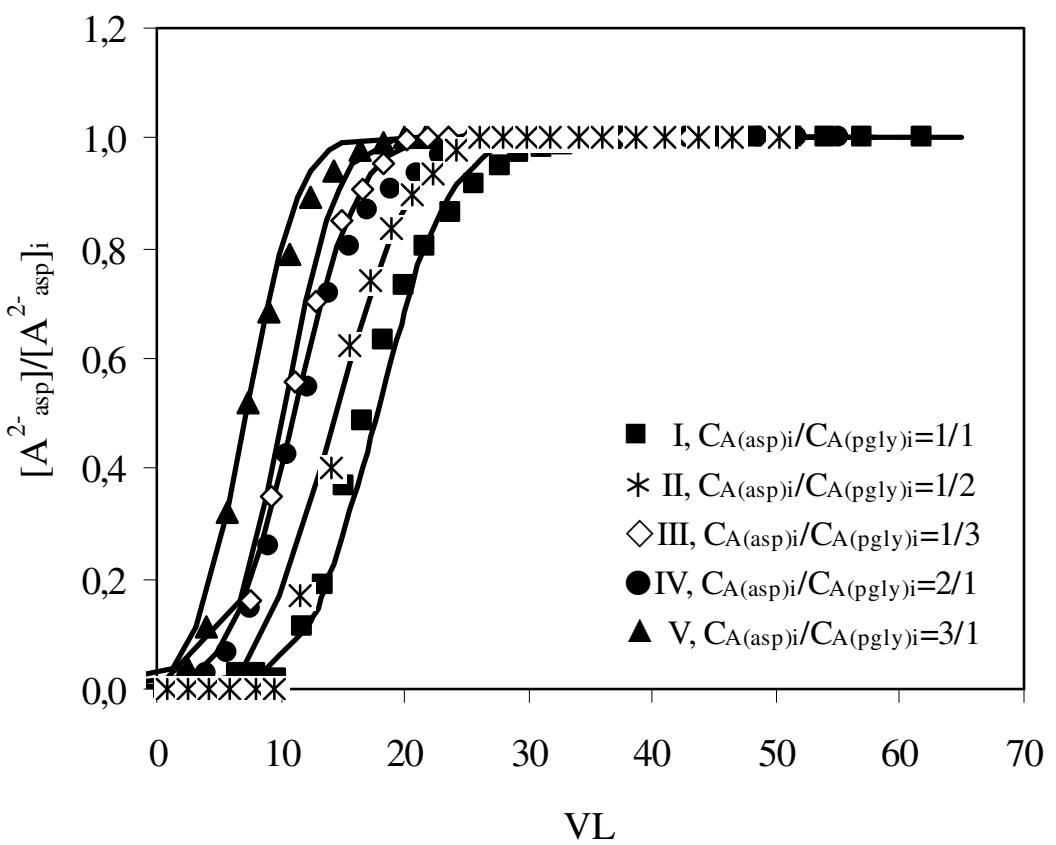

Figura 84. Curvas de ruptura de extracción de ácido aspártico de sus mezclas binarias con $\alpha$ fenilglicina para los experimentos I-V de la Tabla $19\left(\mathrm{pH}_{\mathrm{i}}=12,01 \pm 0,02 ; \mathrm{Q}=0,018 \times 10^{-6}\right.$ $\left.\mathrm{m}^{3} / \mathrm{s}, \overline{\mathrm{Q}^{+} \mathrm{Cl}^{-}}{ }_{\mathrm{i}}=787,62 \pm 4,03 \mathrm{~mol} / \mathrm{m}^{3} \mathrm{RSI}\right)$. Símbolos: datos experimentales. Líneas: datos calculados con las Ecs. (5.112)-(5.115). 


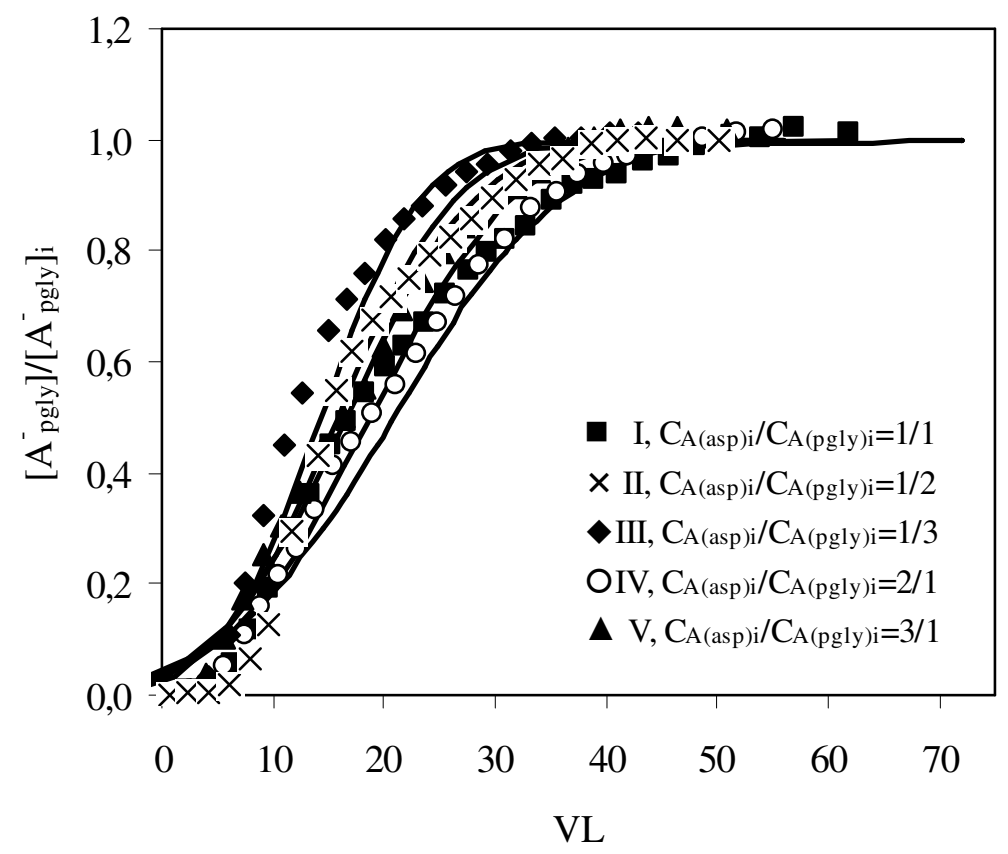

Figura 85. Curvas de ruptura de extracción de a-fenilglicina de sus mezclas binarias con ácido aspártico para los experimentos I-V de la Tabla $19\left(\mathrm{pH}_{\mathrm{i}}=12,01 \pm 0,02 ; \mathrm{Q}=0,018 \times 10^{-6}\right.$ $\left.\left.\mathrm{m}^{3} / \mathrm{s}, \overline{\mathrm{Q}}^{+} \mathrm{Cl}^{-}\right]_{\mathrm{i}}=787,62 \pm 4,03 \mathrm{~mol} / \mathrm{m}^{3} \mathrm{RSI}\right)$. Símbolos: datos experimentales. Líneas: datos calculados con las Ecs. (5.112)-(5.115).

Con estos resultados se alcanzan las siguientes conclusiones:

- El modelo cinético propuesto por Rosen ajusta adecuadamente los resultados de experimentales de extracción individual y conjunta de ácido aspártico y $\alpha$ fenilglicina en columnas fijas de resina impregnada y proporciona el valor del coeficiente de transferencia de materia en la película líquida externa, $\mathrm{k}_{\mathrm{f}}$.

- Los valores de la difusividad intrapartícula efectiva $\left(\mathrm{D}_{\mathrm{e}}=10^{-11}\right)$ y la difusividad en la película líquida externa $\left(D_{\mathrm{L}}=10^{-10}-10^{-11}\right)$ son del mismo orden de magnitud indicando que bajo las condiciones experimentales estudiadas, el proceso de extracción de ácido aspártico y a-fenilglicina en lechos fijos de RIE está controlado por ambas resistencias a la transferencia de materia: la difusión intrapartícula y la difusión en la película líquida externa. 


\subsubsection{Extracción-reextracción en un sistema con dos columnas de RIE en serie}

A partir de los resultados obtenidos en los apartados anteriores, se estudió el proceso de extracción-reextracción empleando dos columnas de lecho fijo en serie para evaluar la separación y posterior recuperación de ácido aspártico y a-fenilglicina de sus mezclas binarias.

Se trabajó con el dispositivo experimental mostrado en la Figura 12 del apartado 5.1.2.3 y el procedimiento experimental detallado en el apartado 5.1.3.9. Como alimentación se utilizó una disolución acuosa con la misma proporción de ácido aspártico y a-fenilglicina de concentración: $\mathrm{C}_{\mathrm{A}(\text { asp }) \mathrm{i}} \mathrm{C}_{\mathrm{A}(\mathrm{pg} \mid \mathrm{y}) \mathrm{i}}=8,14 \mathrm{~mol} / \mathrm{m}^{3}$, termostatizada a $30^{\circ} \mathrm{C}$ con caudal constante $Q=0,02110^{-6} \mathrm{~m}^{3} / \mathrm{s}$, y la concentración de Tomac en la RIE fue de 780,10 mol Tomac $/ \mathrm{m}^{3} \mathrm{RSI}$.

Los ensayos se han realizado siguiendo el diagrama de flujo que se muestra a continuación:

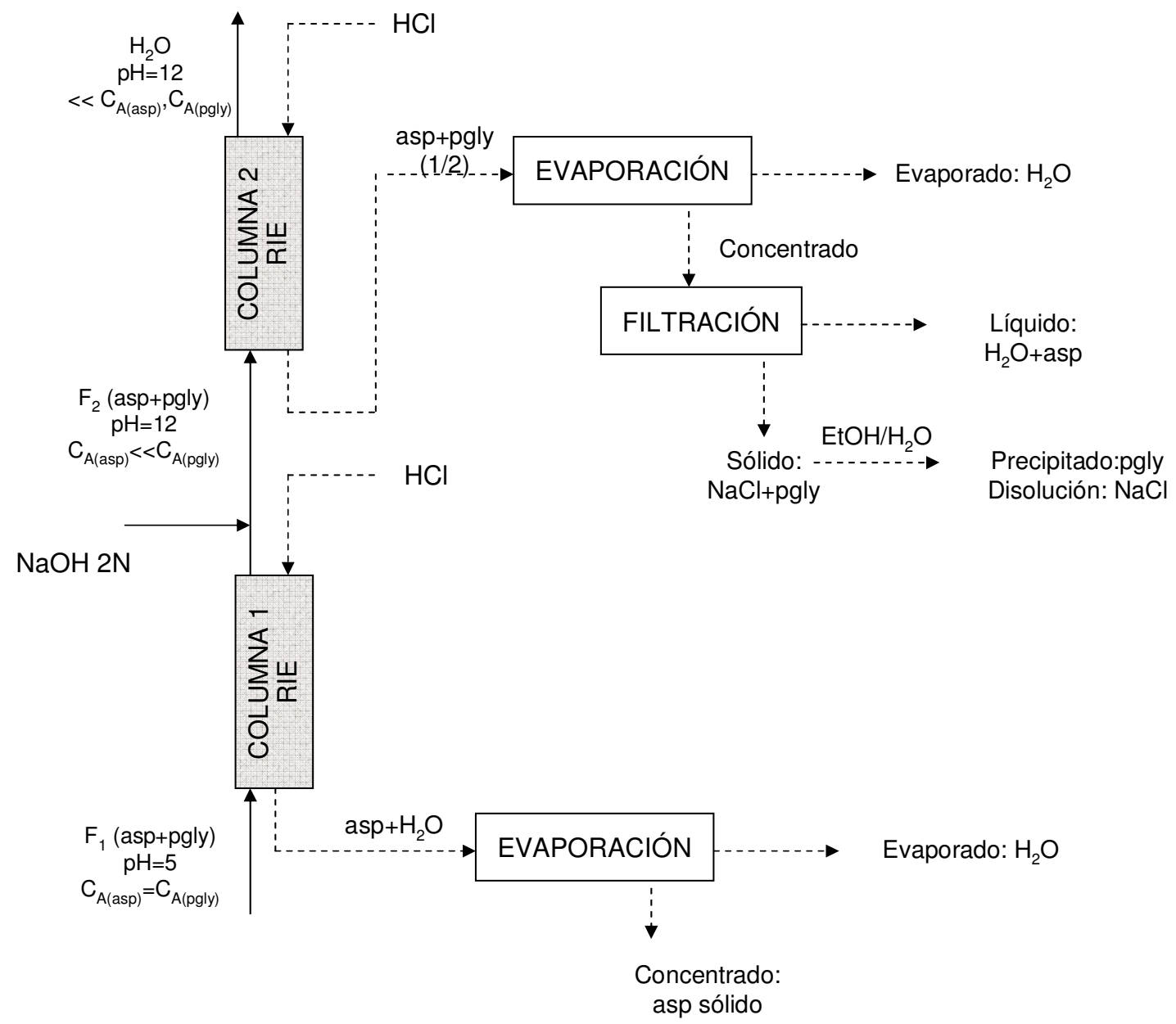

Figura 86. Diagrama de Flujo del proceso integrado con dos columnas:

- proceso de extracción de ácido aspártico (asp) y a-fenilglicina (pgly).

---- proceso de reextracción de aminoácidos 
Como se ha comentado anteriormente en el apartado 5.1.3.9 se realizaron dos tipos de ensayo. En el ensayo Tipo I se colocó una toma de muestra a la salida de cada columna y se determinó experimentalmente la evolución de la concentración de ácido aspártico y fenilglicina en los efluentes recogidos a la salida de ambas columnas. En el ensayo Tipo II, se elimina la toma de muestra de la primera columna, y por tanto el efluente que abandona la primera columna pasa directamente a la segunda. En ambos casos, el efluente que entra en la segunda columna es basificado hasta $\mathrm{pH}=12$ con adición de microflujos de hidróxido de sodio $0,2 \mathrm{~N}$.

\subsubsection{Ensayos Tipo I}

La evolución de la concentración de ácido aspártico y a-fenilglicina en los efluentes recogidos a la salida de la primera y segunda columna se representan en las Figuras 87 y 88, respectivamente. Como es de esperar, en la primera columna con RIE sólo hay extracción de ácido aspártico, debido a que a $\mathrm{pH}_{\mathrm{i}}=5$ no hay especie extraíble de $\alpha$ fenilglicina, y por tanto, se obtiene la misma extracción de ácido aspártico sólo o mezclado con $\alpha$-fenilglicina, como se observa en la Figura 87. Este resultado es análogo a los alcanzados en los experimentos de equilibrio de los apartados 5.2.3 y 5.2.4.

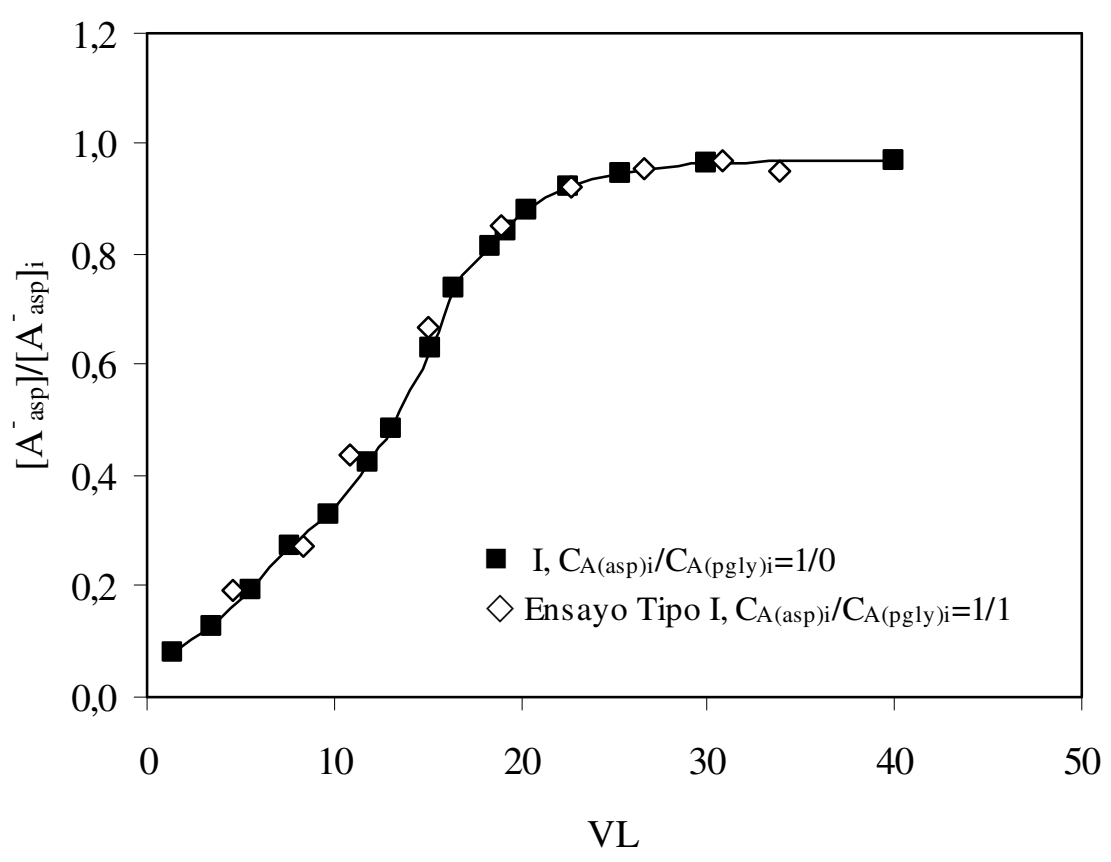

Figura 87. Comparación de curvas de ruptura de extracción de ácido aspártico con $\mathrm{RIE}$ a $\mathrm{pH}_{\mathrm{i}}=5$ correspondiente al experimento I de la Tabla 7 y al ensayo Tipo I, utilizando mezclas de ácido aspártico y a-fenilglicna en proporción 1/1. 
Así, el efluente que sale de la primera columna está compuesto mayoritariamente por afenilglicina y del ácido aspártico no retenido en la primera columna.

En la Figura 88 se observa que el punto de ruptura de la a-fenilglicina se produce a valores de tiempo inferiores que el punto de ruptura del ácido aspártico, resultado ya obtenido en las curvas de ruptura de mezclas binarias de aminoácidos cuando la proporción de $\alpha$-fenilglicina es mayor que la de ácido aspártico y a $\mathrm{pH}=12$. Con los resultados representados en la Figura 88, se seleccionó para el ensayo Tipo II el tiempo óptimo del proceso de extracción en la $2^{2}$ columna en unos $9000 \mathrm{~s}$, aproximadamente, al objeto de lograr que el efluente a la salida de la segunda columna no tenga prácticamente ácido aspártico ni a-fenilglicina.

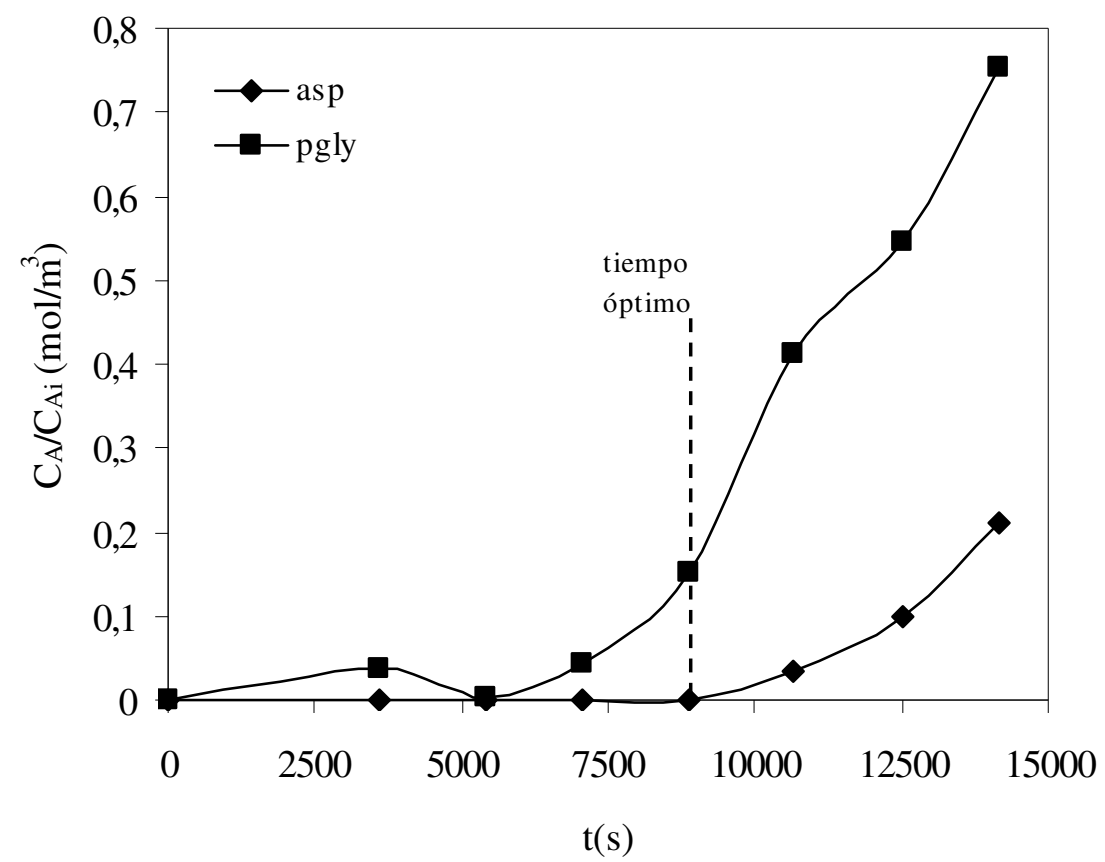

Figura 88. Curvas de ruptura de extracción de ácido aspártico y a-fenilglicna con RIE en la segunda columna a $\mathrm{pH}_{\mathrm{i}}=12$ en el ensayo tipo I.

En cuanto a la etapa de reextracción de ácido aspártico en la primera columna se realizó utilizando como agente de reextracción $\mathrm{HCl} 1 \mathrm{~N}$. En la Figura 89 se representan los resultados de la curva de reextracción de ácido aspártico en la $1^{\text {a }}$ columna de RIE, observándose que en 25 minutos se ha reextraído el $98 \%$ del ácido aspártico, seleccionándose este como tiempo óptimo del proceso de reextracción en la $1^{1 \stackrel{a}{ }}$ columna de RIE.

La reextracción de los dos aminoácidos en la segunda columna se realizó utilizando como agente de reextracción disoluciones de $\mathrm{HCl} 1 \mathrm{~N}$ y $0,1 \mathrm{~N}$. Se comprobó que con $\mathrm{HCl}$ 
$0,1 \mathrm{~N}$ la reextracción es más lenta y no se mejora la selectividad. Con estos resultados se seleccionó para el ensayo tipo II como agente de reextracción $\mathrm{HCl} 1 \mathrm{~N}$ y un tiempo de proceso de unos 45 minutos para producir la reextracción completa de los aminoácidos (no mostrado).

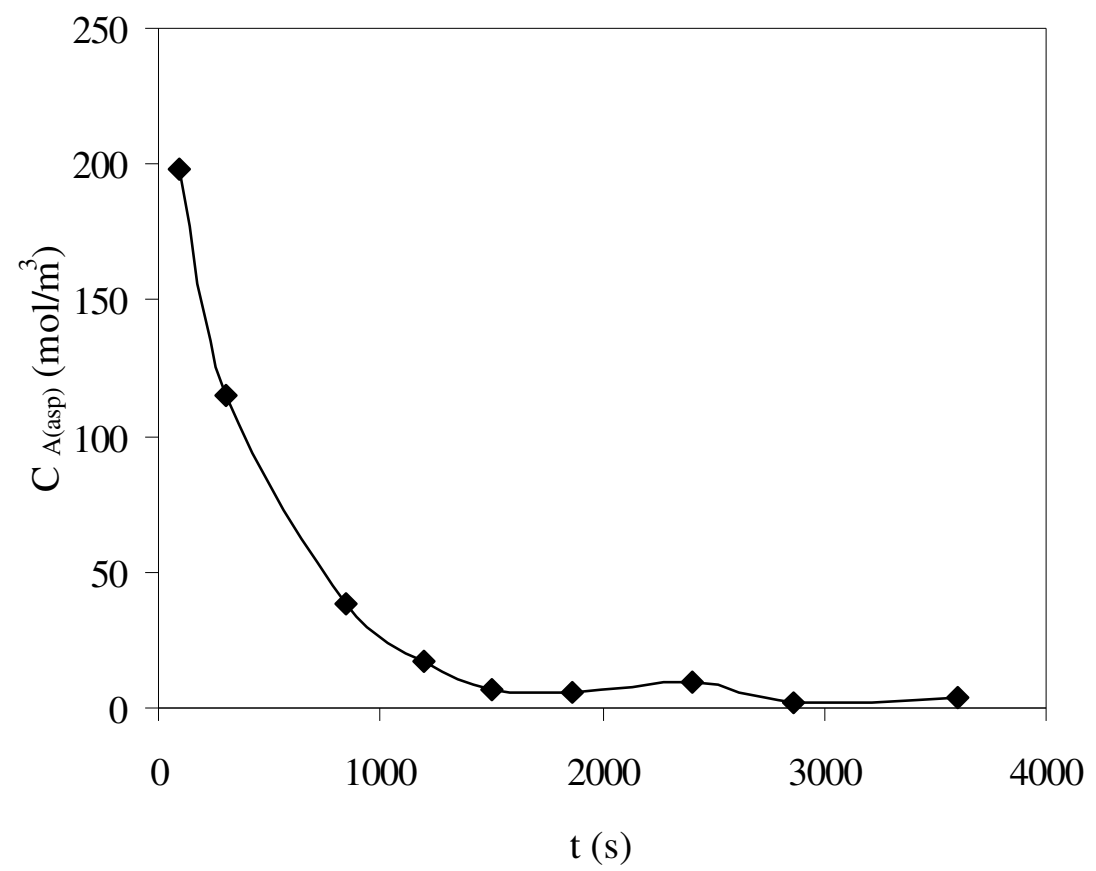

Figura 89. Curvas de ruptura de reextracción de ácido aspártico con $\mathrm{HCl} 1 \mathrm{~N}$, en la primera columna de RIE para el ensayo Tipo I.

\subsubsection{Ensayos Tipo II}

En este experimento se estudia la separación ácido aspártico y a-fenilglicina de sus mezclas binarias, utilizando un proceso de extracción con dos lechos fijos rellenos de RIE en serie y la etapa posterior de reextracción en cada una de las columnas. Los resultados alcanzados se relacionan a continuación, separados por las tres etapas que componen el proceso:

- ETAPA DE EXTRACCIÓN. El tiempo total del proceso de extracción fue de 3 horas (10800 s) y se trató un volumen de alimentación, $V_{i}$, de $174 \mathrm{~cm}^{3}$. La concentración de $\alpha$-fenilglicina y de ácido aspártico en el efluente que abandona la $2^{\underline{a}}$ columna de RIE es inferior al $3 \%$ de la concentración inicial de cada aminoácido, es decir, en este tiempo de proceso está prácticamente exento de aminoácidos.

El porcentaje de extracción total, \%E, se calculó con la Ec. (5.117) que representa la relación entre la masa del aminoácido acumulada en las dos columnas de RIE (masa acumulada: $0,18 \mathrm{~g}$ de ácido aspártico y $0,21 \mathrm{~g}$ de $\alpha$-fenilglicina) y la que entra 
en el sistema. Los resultados alcanzados demuestran que la extracción total de los aminoácidos en el proceso global fue superior al $98 \%\left(\% \mathrm{E}_{\mathrm{asp}}=98,1 ; \% \mathrm{E}_{\mathrm{pgly}}=98,3\right)$.

$$
\% \mathrm{E}=\frac{\left.\mathrm{M}_{\mathrm{A}} \mathrm{Q} \mid \mathrm{C}_{\mathrm{Ai}} \int_{0}^{\mathrm{t}=10800 \mathrm{~s}} \mathrm{dt}-\int_{0}^{\mathrm{t}=10800 \mathrm{~s}} \mathrm{C}_{\mathrm{A}}(\mathrm{t}) \mathrm{dt}\right]}{\mathrm{M}_{\mathrm{A}} \mathrm{QC}_{\mathrm{Ai}} \int_{0}^{\mathrm{t}=10800 \mathrm{~s}} \mathrm{dt}} 100=\left(1-\frac{\mathrm{C}_{\mathrm{A}}(\mathrm{t}=10800 \mathrm{~s})}{\mathrm{C}_{\mathrm{Ai}}}\right) 100
$$

donde $\mathrm{M}$ es el peso molecular del aminoácido, $\mathrm{C}$ es la concentración de aminoácido expresada en $\mathrm{mol} / \mathrm{m}^{3}, Q$ es el caudal, $t$ es el tiempo y los subíndices i y $A$ representan a la alimentación y al aminoácido (ácido aspártico o $\alpha$-fenilglicina), respectivamente.

- ETAPA DE REEXTRACCIÓN EN LA 1a COLUMNA DE RIE. El tiempo total del proceso de reextracción en la primera columna de RIE fue de 26 minutos, utilizando como agente de reextracción $30 \mathrm{~cm}^{3}$ de $\mathrm{HCl} 1 \mathrm{~N}$. La concentración de ácido aspártico en la disolución de reextracción $\left(C_{A(a s p) R}=24,1 \mathrm{~mol} / \mathrm{m}^{3}\right)$ fue tres veces superior a la de la alimentación tratada. El porcentaje de recuperación, \%R, evaluado con la Ec. (5.118) fue del 52,4\% (porcentaje de reextracción > 95\%). Finalmente, esta fase de reextracción se somete a evaporación para la obtención una disolución concentrada o su precipitación para obtener el aminoácido libre de eluyente.

$$
\% \mathrm{R}=\frac{\mathrm{V}_{\mathrm{R}} \mathrm{C}_{\mathrm{A}(\text { asp }) \mathrm{R}}}{\mathrm{V}_{\mathrm{i}} \mathrm{C}_{\mathrm{A}(\text { asp }) \mathrm{i}}} 100
$$

donde los subíndices i y $\mathrm{R}$ representan a la fase alimentación y a la de reextracción.

- ETAPA DE REEXTRACCIÓN EN LA 2 $2^{a}$ COLUMNA DE RIE. El tiempo total del proceso de reextracción en la $2^{-2}$ columna de RIE fue de 45 minutos, utilizando como agente de reextracción $49,5 \mathrm{~cm}^{3}$ de $\mathrm{HCl} 1 \mathrm{~N}$. El porcentaje de recuperación de cada uno de los aminoácidos evaluado con la Ec. (5.118) fue del $29 \%$ para el ácido aspártico y del $52 \%$ para la $\alpha$-fenilglicina. Es necesario una etapa posterior de regeneración del lecho de RIE con $\mathrm{HCl} 2 \mathrm{M}$ para eliminar las trazas de aminoácidos para posteriores ciclos.

Finalmente, se estudió el método de separación de a-fenilglicina y ácido aspártico de esta fase acuosa de reextracción. Se sometió a evaporación en un rotavapor a vació y a $55^{\circ} \mathrm{C}$ sin cambio de $\mathrm{pH}$, de esta manera se produce la evaporación de agua pero sin alcanzar la sequedad, al objeto de aprovechar para su separación la distinta solubilidad que presentan en agua ambos aminoácidos. Se obtienen dos fases, que se separan por filtración, un sólido y un líquido con un volumen de 2 $\mathrm{cm}^{3}$ que contiene tan sólo el ácido aspártico. El análisis del sólido demuestra que no precipitó nada de ácido aspártico y que contiene únicamente de $\alpha$-fenilglicina. 


\section{Se puede concluir que:}

- Se ha demostrado la viabilidad técnica del proceso de recuperación y fraccionamiento de ácido aspártico y fenilglicina de sus mezclas binarias diluidas empleando dos lechos fijos rellenos con RIE con una carga de Tomac de $780 \mathrm{~mol}$ de Tomac $/ \mathrm{m}^{3} \mathrm{RSI}$. El procedimiento combina una etapa de extracción a $30^{\circ} \mathrm{C}$ con control del $\mathrm{pH}$ de la alimentación, siendo los óptimos $\mathrm{pH}_{\mathrm{i}}=5$ en la primera columna y $\mathrm{pH}_{\mathrm{i}}=12$ en la segunda, y una etapa de reextracción a temperatura ambiente con ácido clorhídrico $1 \mathrm{~N}$. 



\section{RECUPERACIÓN DE BETAÍNA}





\subsection{PARTE EXPERIMENTAL}

\subsubsection{Productos utilizados}

El agua empleada fue agua ultrapura Milli-Q de Millipore. Las características de los productos utilizados, así como su procedencia, se detallan a continuación:

- Betaína, o sal de (carboximetil)trimetilamonio, es un aminoácido de fórmula molecular $\left(\mathrm{CH}_{3}\right)_{3} \mathrm{~N}^{+} \mathrm{CH}_{2} \mathrm{COO}^{-}$suministrado por Fluka con una pureza superior al $98 \%$, con un contenido en agua $\leq 1 \%$, con una masa molar $117,15 \mathrm{~g} / \mathrm{mol}$. A temperatura ambiente es un sólido blanco, tiene una solubilidad en metanol de 0,1 $\mathrm{g} / \mathrm{ml}$. Sus propiedades y características se detallaron en mayor profundidad en el apartado 2.2.

- $\boldsymbol{D ( + )}$ Sacarosa también llamado azúcar, a temperatura ambiente es un sólido blanco con fórmula molecular $\mathrm{C}_{12} \mathrm{H}_{22} \mathrm{O}_{11}$, fue suministrado por Fluka con una pureza superior al $99 \%$ (HPLC), con una masa molar $342,30 \mathrm{~g} / \mathrm{mol}$ y una solubilidad en agua de $0,1 \mathrm{~g} / \mathrm{ml}$.

- D(-) Fructosa, también llamada levulosa, monosacárido utilizado como patrón interno en el método de análisis de HPLC para la cuantificación de sacarosa. A temperatura ambiente es un sólido blanco con fórmula molecular $\mathrm{C}_{6} \mathrm{H}_{12} \mathrm{O}_{6}$, fue suministrado por Fluka con una pureza superior al 99\% (HPLC), con una masa molar $180,16 \mathrm{~g} / \mathrm{mol}$ y una solubilidad en agua $0,1 \mathrm{M}$ a $20^{\circ} \mathrm{C}$.

- Amberlyst 15 (forma $\boldsymbol{H}^{+}$), es una resina macroreticular de intercambio iónico, fuertemente catiónica o ácida, caracterizada por su alta porosidad y superficie de área. Fue suministrada por Fluka, es un sólido granulado de color gris, su matriz está formada por estireno - divinilbenceno macroreticular, con grupo funcional: $\mathrm{SO}_{3}{ }^{-} \mathrm{H}^{+}$, tamaño de partícula: $20-50$ mesh (malla), porosidad: $32 \%$, área: 45 $\mathrm{m}^{2} / \mathrm{gm}$, humedad: $5 \%$ aproximadamente. Su capacidad de intercambio iónico viene dada por: volumen de lecho húmedo: $1,8 \mathrm{meq} / \mathrm{ml}$ y peso seco: $4,7 \mathrm{meq} / \mathrm{g}$. Temperatura máxima de operación: $120^{\circ} \mathrm{C}$ y estabilidad a $\mathrm{pH}=0-14$. Cambio de volumen al pasar de seco a húmedo (swelling): hexano $10-15 \%$, agua: $60-70 \%$, tolueno $10-15 \%$. Para eliminar impurezas se lavó varias veces con agua ultrapura (algunos autores también lavan con etanol) y se secó a vacío a 90 (Bo-Lun Yang.et al., 2000; Abella L.C. et al., 1999).

- Amberlite 200 C (forma $\mathrm{Na+}$ ), es una resina macroreticular de intercambio iónico fuertemente catiónica ó ácida con grupo funcional ácido sulfónico. Fue suministrada por Fluka, es un sólido granulado de color marrón, su matriz está formada por estireno - divinilbenceno macroreticular, con grupo funcional: $\mathrm{SO}_{3}{ }^{-} \mathrm{H}^{+}$, un tamaño de partícula: $32-35$ mesh (malla), humedad: $49 \%$, tamaño efectivo: $0,56 \mathrm{~mm}$, peso húmedo: $800 \mathrm{~g} / \mathrm{l}$, densidad de lecho húmedo: $1,26 \mathrm{~g} / \mathrm{ml}$. Su capacidad de intercambio iónico viene dada por: volumen de lecho húmedo: 1,8 $\mathrm{meq} / \mathrm{ml}$. La temperatura máxima de operación: $150^{\circ} \mathrm{C}$ y estabilidad en rango de $\mathrm{pH}:$ 0-14. Cambio de volumen al pasar de seco a húmedo al pasar de $\mathrm{H}^{+} \rightarrow \mathrm{Na}^{+}$ (swelling): $3-5 \%$. Para la eliminación de impurezas se lava la resina sucesivamente en una disolución metanol-agua $50 \%$ que contiene ácido 
clorhídrico $4 \mathrm{M}$, y a continuación en agua destilada o bien con hidróxido de sodio para reestablecer las condiciones iniciales de intercambio iónico secando a vacío a 70드 (Vaughan T. et. al., 2000; Amara M. et. al., 2003; Chen J. et. al., 2002).

- Lewatit TP 260 (forma di-Na+), es una resina quelatante de intercambio iónico débilmente catiónica o ácida, su matriz porosa está formada por estirenodivinilbenceno, la cuál contiene el ácido (aminometil)fosfónico como grupo activo. Fue suministrada por Fluka, es un sólido granulado de color amarillo, con una densidad 1,2 g/ml, un tamaño de partícula 400-1250 $\mu \mathrm{m}$ o 20-50 mesh (malla), una humedad $60 \%$, pérdidas al secar $45-55 \%$ a $110^{\circ} \mathrm{C}$. La temperatura máxima de operación: $85^{\circ} \mathrm{C}$ y estabilidad en rango de $\mathrm{pH}: 0-14$. Su capacidad de intercambio iónico es mayor de $2,3 \mathrm{meq} / \mathrm{ml}\left(\mathrm{H}^{+}\right)$. Cambio de volumen al pasar de seco a húmedo al pasar de $\mathrm{Na}^{+} \rightarrow \mathrm{H}^{+}$(swelling): $25 \%$. Para la eliminación de impurezas se lava la resina sucesivamente con una disolución de ácido clorhídrico 7,5\%, agua, e hidróxido de sodio y se seca a vacío a $70^{\circ} \mathrm{C}$.

- Lewatit OC 1026 (forma ester ácido), es una resina quelatante de intercambio iónico, su matriz porosa está formada por estireno-divinilbenceno, la cuál contiene di-2-etilhexilfosfato (DEHPA) adsorbido. Fue suministrada por Fluka, es un sólido granulado de color blanco, con una densidad 0,97 $\mathrm{g} / \mathrm{ml}$, un tamaño de partícula 0,3-1,25 mm, pérdidas al secar 30-40\%. La temperatura máxima de operación: $30-40^{\circ} \mathrm{C}$ y estabilidad en rango de $\mathrm{pH}: 0-7$. Cambio de volumen al pasar de seco a húmedo (swelling): $+3 \%$. Para la eliminación de impurezas se lava la resina en una columna sucesivamente con una disolución de ácido clorhídrico $7 \%$, agua, se filtra a vacío, se seca a temperatura ambiente durante una semana (Simpson $C$. et. al., 1998; Cortina J. L. et. al., 1993).

- Amberlita XAD-4, es una resina polimérica macroporosa hidrofóbica, de estructura altamente y aromática, formada por un copolímero de estireno divinilbenceno, suministrada por Merck y Fluka. Sus características y propiedades físico-químicas se detallan en el apartado 5.1.1.

- DNNSA ácido dinonilnaftalensulfónico disolución al $50 \%$ en peso en heptano, fórmula molecular $\left(\mathrm{C}_{6} \mathrm{H}_{19}\right)_{2} \mathrm{C}_{10} \mathrm{H}_{5} \mathrm{SO}_{3} \mathrm{H}$, fue suministrado por Aldrich con una masa molar de $460,71 \mathrm{~g} / \mathrm{mol}$, un punto de ebullición $94-99^{\circ} \mathrm{C}$, una densidad $0,852 \mathrm{~g} / \mathrm{ml}$ a $25^{\circ} \mathrm{C}$. Es un líquido marrón, insoluble en agua y soluble en: alcoholes, ésteres, cetonas, hidrocarburos aromáticos y alifáticos.

- DEHPA ó Di(2-etilhexil)-fosfato ó Hidrogenofosfato de bis(2-etilhexilo) ó ácido bis(2-etilhexil)ortofosfórico $\mathrm{C}_{16} \mathrm{H}_{35} \mathrm{O}_{4} \mathrm{P}$, suministrado por Merk con una masa molar de $322,48 \mathrm{~g} / \mathrm{mol}$, densidad $0,968-0,973 \mathrm{Kg} / \mathrm{m}^{3}$ a $20^{\circ} \mathrm{C}-4^{\circ} \mathrm{C}$, es un líquido incoloro con baja solubilidad en agua.

- $\quad \boldsymbol{n}$-Heptano, empleado como diluyente en la impregnación de la resina. Fórmula molecular $\mathrm{CH}_{3}-\left(\mathrm{CH}_{2}\right)_{5}-\mathrm{CH}_{3}$ fue suministrado por Merck con una pureza superior al $99 \%$. Es un líquido incoloro, presenta una densidad de $694 \mathrm{Kg} / \mathrm{m}^{3}$ a $15{ }^{\circ} \mathrm{C}$, un punto de ebullición de $95{ }^{\circ} \mathrm{C}$, una viscosidad $3,810^{-4}$ Pas $40^{\circ} \mathrm{C}$. Contiene un porcentaje en volumen de aromáticos menor del $0,1 \%$ y una solubilidad en agua inferior a 5 ppm (Riddick J.A., 1986; Weast R.C., 1994-1995).

- $\boldsymbol{n}$-Hexano, empleado para la eliminación de impurezas de la resina o como diluyente en la etapa de impregnación de la resina. De fórmula molecular $\mathrm{CH}_{3}$ - 
$\left(\mathrm{CH}_{2}\right)_{4}-\mathrm{CH}_{3}$, con una masa molecular de $86,18 \mathrm{~g} / \mathrm{mol}$, fue suministrado por Merck con una pureza $>99 \%$. Es un líquido incoloro, presenta una densidad de 659,33 $\mathrm{kg} / \mathrm{m}^{3}$ a $20{ }^{\circ} \mathrm{C}$, un punto de ebullición de $69 \stackrel{\circ}{ } \mathrm{C}$, una viscosidad $0,3126 \mathrm{cp}$ a $20{ }^{\circ} \mathrm{C}$ y un índice de refracción de 1,37486 a $20^{\circ} \mathrm{C}$. Posee una solubilidad en agua de 0,00123 a $25 \stackrel{\circ}{ } \mathrm{C}$ y una solubilidad de agua en $\mathrm{n}$-hexano de 0,0111 a $20{ }^{\circ} \mathrm{C}$ (Riddick J. A., 1986; Weast R. C., 1994-1995).

- Acetona, utilizada en el lavado de la resina y suministrada por la casa comercial Fluka de fórmula molecular $\mathrm{CH}_{3}-\mathrm{CO}-\mathrm{CH}_{3}$, con una masa molecular de 58,08 $\mathrm{g} / \mathrm{mol}$. Presenta una densidad de $0,79 \mathrm{~kg} / \mathrm{dm}^{3}$ a temperatura ambiente, un punto de ebullición de $56,5^{\circ} \mathrm{C}$, un punto de fusión de $-94^{\circ} \mathrm{C}$ y un índice de refracción de 1,3591 a $20 \stackrel{\circ}{C}$.

- Metanol, empleado en el lavado de resina. De fórmula molecular $\mathrm{CH}_{3}-\mathrm{OH}$ con una masa molecular de $32,04 \mathrm{~g} / \mathrm{mol}$, fue suministrado por Lab-Scan con una pureza del $99,9 \%$. Presenta una densidad de $791 \mathrm{~kg} / \mathrm{m}^{3}$ a $20 \stackrel{\circ}{\circ} \mathrm{C}$, un punto de fusión de $97,8 \stackrel{\circ}{\mathrm{C}}$ y un punto de ebullición de $64,5 \stackrel{\circ}{ } \mathrm{C}$.

- Ácido clorhídrico, es un líquido incoloro de fórmula $\mathrm{HCl}$, suministrado por Panreac con una riqueza del $37 \%$ (RFE, BP, Ph. Eur.)PRS-CODEX. Presenta una densidad a $15^{\circ} \mathrm{C}$ mayor de $1190 \mathrm{~kg} / \mathrm{m}^{3}$.

- Ácido fosfórico, Ácido ortofosfórico, de fórmula molecular $\mathrm{H}_{3} \mathrm{PO}_{4}$ fue suministrado por Aldrich con una pureza del $85 \%$ (A.C.S. Reagent). Es un sólido cristalino delicuescente, pero generalmente se le encuentra en disoluciones concentradas (hasta un $90 \%$ ) con aspecto líquido. Tiene un peso molecular de 98 $\mathrm{g} / \mathrm{mol}$. Está formado por un $3,09 \%$ de hidrógeno, un $65,31 \%$ de oxígeno y un $31,61 \%$ de fósforo. Presenta una densidad a $25{ }^{\circ} \mathrm{C}$ de $1685 \mathrm{~kg} / \mathrm{m}^{3}$.

\subsubsection{Dispositivos experimentales}

\subsubsection{Ensayos con resinas}

En los experimentos para obtener los datos de equilibrio sólido-líquido se utilizó el dispositivo experimental descrito en el apartado 5.1.2.1, en las cinéticas en tanques agitados el dispositivo descrito en el apartado 5.1.2.2, y en las cinéticas en columna de lecho fijo el detallado en el partado 5.1.2.3 y en la Figura 11.

\subsubsection{Ensayos líquido-líquido para la selección del extractante}

Los datos de equilibrio líquido-líquido se determinaron empleando celdas de decantación de $50 \mathrm{~cm}^{3}$ de capacidad para poner en contacto las fases acuosa y orgánica. Estas celdas disponen de tapón esmerilado, llave de teflón y van provistos de un encamisado 
exterior por el que puede circular agua procedente de un termostato para mantener la temperatura constante durante todo el proceso.

La agitación de las fases se realizó manualmente y se dejó decantar en la celda durante 20-48 horas, tiempo superior al necesario para alcanzar el equilibrio.

\subsubsection{Procedimiento experimental}

\subsubsection{Determinación de la concentración de Betaína y Sacarosa}

La concentración de betaína y sacarosa en fase acuosa, se determinó utilizando cromatografía líquida de alta resolución, con un HPLC Beckman, modelo System Gold, con detector UV-VIS.

En la Tabla 20 se muestran las condiciones de operación del análisis para la determinación de la concentración de betaína y sacarosa en fase acuosa.

Tabla 20. Condiciones del método analítico por HPLC para la determinación de la concentración de betaína y sacarosa en fase acuosa.

\begin{tabular}{|c|c|c|c|c|c|}
\hline \multirow{2}{*}{ Soluto } & \multirow{2}{*}{$\begin{array}{c}\text { Columna } \\
\text { HPLC }\end{array}$} & \multicolumn{2}{|c|}{ Fase móviil } & \multirow{2}{*}{$\begin{array}{l}\text { Patrón } \\
\text { interno }\end{array}$} & \multirow{2}{*}{ Detector } \\
\hline & & Tipo & $\begin{array}{l}\text { Velocidad } \\
\text { (ml/min) }\end{array}$ & & \\
\hline Betaína & $\begin{array}{l}\text { Ultraesphere } \\
\text { ODS }\end{array}$ & $\mathrm{H}_{3} \mathrm{PO}_{4} 0,1 \%$ & 1 & No & UV-VIS \\
\hline Sacarosa & $\begin{array}{l}\text { Supelcosil } \\
\text { LC-NH2 }\end{array}$ & $\begin{array}{c}\text { Acetonitrilo-agua } \\
(75-25 \%)\end{array}$ & 1 & $\begin{array}{c}\text { Fructosa } \\
(\mathrm{M}: \mathrm{Pl}=2: 1)^{*}\end{array}$ & $\begin{array}{l}\text { Índice de } \\
\text { refracción }\end{array}$ \\
\hline $\begin{array}{c}\text { Mezclas binarias } \\
\text { de betaína y } \\
\text { sacarosa }\end{array}$ & $\begin{array}{l}\text { Supelcosil } \\
\text { LC-NH2 }\end{array}$ & $\begin{array}{c}\text { Acetonitrilo-agua } \\
(75-25 \%)\end{array}$ & 1 & $\begin{array}{c}\text { Fructosa } \\
(\mathrm{M}: \mathrm{Pl}=2: 1) \text { * }\end{array}$ & $\begin{array}{l}\text { UV-VIS e } \\
\text { Îndice de } \\
\text { refracción }\end{array}$ \\
\hline
\end{tabular}

* M=muestra; P:I=Patrón interno

La limpieza de la columna se realizó periódicamente con disoluciones de acetonitrilo: agua en proporción 65:35.

La concentración de betaína en fase resina se determinó por balance de materia. Todas las muestras se analizaron por triplicado, bajo condiciones idénticas. La precisión en la estimación de la composición en $\mathrm{mol} / \mathrm{m}^{3}$ fue de $\pm 0,001$. 


\subsubsection{Determinación del pH}

Se empleó el mismo pH-metro y proceso descrito en el apartado 5.1.3.4.

\subsubsection{Lavado de resinas de intercambio iónico}

Las resinas de intercambio iónico, RI, se deben lavar y acondicionar antes de su utilización, con el fin de eliminar sus impurezas de fabricación.

- Amberlyst 15: se realizaron ciclos sucesivos de lavado con agua y en algunos casos con etanol. Se secó a vacío a una temperatura de $80^{\circ} \mathrm{C}$ en un rotavapor Heidolph modelo WB2000.

- Amberlite 200C: se lavó sucesivamente con una disolución al 50\% de metanolagua que contiene ácido clorhídrico $4 \mathrm{M}$, posteriormente con agua destilada o con $\mathrm{NaOH}$ al 4\% para reestablecer las condiciones iniciales de intercambio iónico. Finalmente, se seca a vacío a $70^{\circ} \mathrm{C}$ en el rotavapor.

- Lewatit OC-1026: se realizaron ciclos sucesivos de lavado con una disolución al $7 \%$ de ácido clorhídrico y con agua. Previo filtrado a vacío, se secó a temperatura ambiente.

- Lewatit TP 260: se realizaron lavados sucesivos con ácido clorhídrico al 7,5\%, agua, y en algunos casos con $\mathrm{NaOH}$ al $4 \%$, y posterior secado a vacío a $70^{\circ} \mathrm{C}$ con el rotavapor anteriormente descrito.

\subsubsection{Ensayos con RI: selección de condiciones}

Todas las resinas empleadas en estos experimentos (Amberlyst 15, Amberlite 200C, Lewatit TP260 y Lewatit OC1026) son de intercambio catiónico.

Los datos de equilibrio de extracción de betaína y sacarosa se obtuvieron poniendo en contacto cantidades conocidas de Rl con $25 \mathrm{~g}$ de fase acuosa. El pH de las fases acuosas se modificó por adición de disoluciones de $\mathrm{NaOH}$ ó $\mathrm{HCl}$ para estudiar su efecto en la extracción.

La agitación de las fases se realizó a una velocidad de 150 rpm durante 24 horas empleando el agitador orbital mostrado en la Figura 9 del apartado 5.1.2.1. Dicho agitador posee un sistema de termostatización de aire que permitió operar a una temperatura constante de $28,0 \pm 0,1 \stackrel{\circ}{ } \mathrm{C}$. Una vez alcanzado el equilibrio, las fases se separaron por filtración y se determinó el $\mathrm{pH}$ y la concentración de betaína y de sacarosa en la fase acuosa en el equilibrio mediante el método descrito en los apartados 6.1.3.1 y 6.1.3.2. 
Las condiciones iniciales de los experimentos de equilibrio para la selección de la resina, condiciones de lavado y selección de pH se muestran en las Tablas 21 y 22.

Tabla 21. Condiciones iniciales de los equilibrios de extracción de betaína a $28^{\circ} \mathrm{C}$. $\left(\mathrm{C}_{\mathrm{Bi}}=450\right.$ $\mathrm{mol} / \mathrm{m}^{3}$; masa de fase acuosa $\left.=25,01 \pm 0,02 \mathrm{~g} ; \mathrm{pH}_{\mathrm{i}}=2,22 \pm 0,02\right)$ : selección del tipo de $\mathrm{Rl}$ y de sus condiciones de lavado.

\begin{tabular}{cccc}
\hline Experimento & Tipo de resina & Condiciones de lavado & $\begin{array}{c}\text { Masa de resina } \\
(\mathrm{g})\end{array}$ \\
\hline I-a & Amberlyst 15 & Agua & 0,5 \\
I-b & Amberlyst 15 & Agua/etanol & 0,5 \\
I-c & Amberlite 200C & Metanol-agua/NaOH & 0,5 \\
I-d & Amberlite 200C & Metanol-agua/agua & 0,5 \\
I-e & Lewatit TP 260 & HCl/NaOH & 0,5 \\
I-f & Lewatit TP 260 & HCl/Agua & 0,5 \\
I-g & Lewatit OC1026 & HCl/Agua & 0,5 \\
II-a & Amberlyst 15 & Agua & 2,0 \\
II-b & Amberlite 200C & Metanol-agua/agua & 2,0 \\
II-c & Lewatit TP 260 & HCl/NaOH & 2,0 \\
II-d & Lewatit TP 260 & HCl/agua & 2,0 \\
II-e & Lewatit OC1026 & HCl/agua & 2,0 \\
\hline III-a & Amberlyst 15 & Agua & 4,0 \\
III-b & Amberlyst 15 & Agua & 8,0 \\
III-c & Amberlite 200C & Agua & 4,0 \\
III-d & Amberlite 200C & Agua & 8,0 \\
\hline
\end{tabular}

Tabla 22. Condiciones iniciales de los equilibrios de extracción de betaína con $\mathrm{RI}$ a $28^{\circ} \mathrm{C}\left(\mathrm{C}_{\mathrm{B} i}=450\right.$ $\mathrm{mol} / \mathrm{m}^{3}$ ): efecto de $\mathrm{pH}$.

\begin{tabular}{cccc}
\hline Experimento & Tipo de resina & $\mathrm{pH}$ & $\begin{array}{c}\text { Masa de RI (g)/ masa de } \\
\text { disolución }(\mathrm{g})\end{array}$ \\
\hline I & Amberlyst 15 & $2,16 \pm 0,02$ & $10 / 25$ \\
II & Amberlyst 15 & $6,50 \pm 0,27$ & $10 / 25$ \\
III & Amberlyst 15 & $12,20 \pm 0,02$ & $10 / 25$ \\
IV & Amberlite 200C & $2,16 \pm 0,02$ & $10 / 25$ \\
V & Amberlite 200C & $6,50 \pm 0,27$ & $10 / 25$ \\
VI & Amberlite 200C & $12,20 \pm 0,02$ & $10 / 25$ \\
VII & Lewatit OC1026 & $6,50 \pm 0,27$ & $10 / 25$ \\
VIII & Lewatit OC1026 & $12,20 \pm 0,02$ & $10 / 25$ \\
IX & Lewatit TP 260 & $6,50 \pm 0,27$ & $0,50 / 25$ \\
X & Lewatit TP 260 & $12,20 \pm 0,02$ & $0,50 / 25$ \\
\hline
\end{tabular}


Posteriormente se estudió el efecto en los datos de equilibrio de la distinta proporción entre la resina y la disolución acuosa. En estos experimentos se emplearon distintas cantidades de Amberlyst 15 y $25 \mathrm{~g}$ de disolución acuosa a pH natural $(6,50 \pm 0,27)$ con una concentración de betaína inicial de $\mathrm{C}_{\mathrm{Bi}}=450 \mathrm{~mol} / \mathrm{m}^{3}$.

Finalmente, bajo las condiciones de operación óptimas se han determinado las isotermas de equilibrio de extracción de betaína sola o mezclada con sacarosa con Amberlyst 15. Los datos de equilibrio se obtuvieron poniendo en contacto $6 \mathrm{~g}$ de resina con $25 \mathrm{~g}$ de fase acuosa con concentración variable de betaína y sacarosa a pH natural y a $28^{\circ} \mathrm{C}$.

\subsubsection{Ensayos de equilibrio líquido-líquido: selección del extractante}

Se pusieron en contacto $15 \mathrm{~g}$ de disolución acuosa de betaína con una concentración inicial de $\mathrm{C}_{\mathrm{B} i}=450 \mathrm{~mol} / \mathrm{m}^{3}$ con $15 \mathrm{~g}$ de disolución orgánica compuesta por el ácido dinonilnaftalensulfónico (DNNSA) disuelto en heptano o di(2-etilhexil)-fosfato (DEHPA) disuelto en hexano a distintos valores de $\mathrm{pH}$. Las condiciones iniciales de los experimentos se muestran en la Tabla 23.

El tiempo de agitación manual de las fases fue de 5 minutos. Las fases permanecieron en contacto entre 20 y 48 horas, para asegurar que se alcanzara el equilibrio. La concentración de betaína en la fase acuosa se determinó por el método descrito en el apartado 6.1.3.1.

Tabla 23. Condiciones iniciales de los ensayos de extracción líquido-líquido de betaína a $25^{\circ} \mathrm{C}\left(\mathrm{C}_{\mathrm{Bi}}=450 \mathrm{~mol} / \mathrm{m}^{3}\right)$.

\begin{tabular}{cccc}
\hline Experimento & Extractante-diluyente & $\mathrm{pH}$ & $\begin{array}{c}\% \text { peso } \\
\text { extractante-diluyente }\end{array}$ \\
\hline I & DNNSA-heptano & $6,50 \pm 0,27$ & $25-75 \%$ \\
II & DNNSA-heptano & $2,25 \pm 0,02$ & $12,5-87,5 \%$ \\
III & DEHPA-hexano & $6,50 \pm 0,27$ & $25-75 \%$ \\
IV & DEHPA-hexano & $2,25 \pm 0,02$ & $12,5-87,5 \%$ \\
\hline
\end{tabular}

\subsubsection{Impregnación de RIE con DNNSA}

Antes de proceder al proceso de impregnación, se realiza una primera etapa de lavado y acondicionamiento de la resina Amberlita XAD-4, siguiendo el procedimiento experimental mostrado en el apartado 5.1.3.5 de esta memoria.

Posteriormente, cantidades conocidas de Amberlita XAD-4 lavada y seca se pone en contacto con diferentes disoluciones de DNNSA 50\%-heptano, disueltas en n-hexano, hasta que toda la fase orgánica fue completamente adsorbida por la resina. Este paso se 
realizó en un horno a $60^{\circ} \mathrm{C}$ durante 48 horas y con agitación manual periódica, hasta conseguir la completa evaporación del diluyente (método descrito en el apartado 4.2.3).

\subsubsection{Ensayos de equilibrio con RIE: selección de condiciones}

Se realizaron distintos experimentos variando la proporción masa de resina / volumen de disolución y el $\mathrm{pH}$. Se pusieron en contacto distintas cantidades de RIE con una concentración $500,14 \pm 1,21 \mathrm{~mol} \mathrm{DNNSA} / \mathrm{m}^{3} \mathrm{RSI}$, con $0,025 \mathrm{dm}^{3}$ de fase acuosa con una concentración de betaína de $450,5 \mathrm{~mol} / \mathrm{m}^{3}$ (5\% peso) a $\mathrm{pH}$ natural $(\mathrm{pH}=6,50 \pm 0,27)$ y $\mathrm{pH}=2,01$. Se utilizó el dispositivo experimental descrito en el apartado 5.1.2.1, realizando con agitación orbital a $150 \mathrm{rpm}$ durante 72 horas y a $28^{\circ} \mathrm{C}$ empleando el agitador mostrado en la Figura 9.

Se determinó experimentalmente el tiempo de equilibrio. En todos los casos, los tiempos de equilibrio resultaron inferiores a 24 horas, seleccionándose este tiempo como tiempo suficiente para alcanzar el equilibrio de betaína con RIE

Finalmente, bajo las condiciones del proceso seleccionadas, se determinaron los datos de equilibrio de extracción individual o conjunta de betaína y sacarosa poniendo en contacto $6 \mathrm{~g}$ de Amberlita XAD-4 impregnada con DNNSA (RIE) o sin impregnar (RSI) con $0,025 \mathrm{dm}^{3}$ de fase acuosa a pH natural $(\mathrm{pH}=6,50 \pm 0,27)$ y a $28^{\circ} \mathrm{C}$, con concentración variable de betaína y sacarosa. La concentración de DNNSA en la resina fue de $500,14 \pm 1,21 \mathrm{~mol} / \mathrm{m}^{3} \mathrm{RSI}$ y la proporción masa de RIE / volumen de disolución, expresada en $\mathrm{kg} / \mathrm{m}^{3}$, fue de $240 / 1$.

La agitación de las fases se realizó durante 24 horas con el agitador orbital mostrado en la Figura 9 a $150 \mathrm{rpm}$ y a temperatura constante de $28{ }^{\circ} \mathrm{C}$. Una vez alcanzado el equilibrio, las fases se separan por filtración y se determinó el pH y la concentración de cada componente en el equilibrio.

En todos estos experimentos la concentración de betaína y sacarosa en fase acuosa se determinó con el método descrito en el apartado 6.1.3.1 y en fase resina se calculó por balance de materia.

\subsubsection{Datos cinéticos en baños agitados con RIE}

Los datos cinéticos de extracción de betaína con resina Amberlita XAD-4 impregnada con DNNSA, se obtuvieron a $28 \stackrel{\circ}{\circ}$ y a $\mathrm{pH}$ natural $(\mathrm{pH}=6,50 \pm 0,27)$, utilizando el dispositivo experimental mostrado en la Figura 10 del apartado 5.1.2.2.

Este experimento comienza con la adición de $5 \mathrm{~g}$ de RIE $\left(500,14 \pm 1,21 \mathrm{~mol} \mathrm{DNNSA} / \mathrm{m}^{3}\right.$ $\mathrm{RSI}$ ) en $0,5 \mathrm{dm}^{3}$ de una disolución acuosa de $45,37 \mathrm{~mol} / \mathrm{m}^{3}$ de betaína ( $0,5 \%$ en peso); y finaliza cuando el sistema alcanza el equilibrio. Se tomaron muestras de fase acuosa a intervalos de tiempo adecuados durante todo el proceso cinético, analizándose la concentración de betaína mediante el procedimiento descrito en el apartado 6.1.3.1 y la evolución del pH. 


\subsubsection{Datos cinéticos en columna de lecho fijo con RIE}

Los datos cinéticos de extracción de betaína para la determinación de los perfiles de las curvas de ruptura se obtuvieron a $28^{\circ} \mathrm{C}$, utilizando el dispositivo experimental mostrado en la Figura 11 del apartado 5.1.2.3. La columna tiene un volumen de $15 \mathrm{~cm}^{3}$ y se rellenó con masas conocidas de RIE.

Todos los experimentos se realizaron con flujo ascendente, impulsando la alimentación desde la base de la columna, empaquetada con RIE, mediante una bomba peristáltica de flujo constante. Se empleó como alimentación disoluciones de betaína con distintas concentraciones y pH como se indica en la Tabla 24. El pH de la alimentación se modificó con adición de $\mathrm{HCl} 1 \mathrm{~N}$. Las muestras de efluente se recogieron periódicamente a intervalos de tiempo adecuados, analizándose la concentración de betaína y el pH en cada muestra según el procedimiento experimental descrito en el apartado 6.1.3.1.

El experimento de extracción en columna finaliza cuando se alcanza la saturación del lecho, es decir, cuando la concentración de betaína en el efluente de salida coincide con la de la alimentación.

Tabla 24. Condiciones iniciales y de operación de los experimentos en columna de extracción de betaína con RIE a $28^{\circ} \mathrm{C}$. Concentración de DNNSA en la resina: $\left[\overline{\operatorname{RSO}_{3}^{-} \mathrm{H}^{+}}=500,14 \pm 1,21 \mathrm{~mol} / \mathrm{m}^{3}\right.$ de RSI.

\begin{tabular}{cccc}
\hline Experimento & $\mathrm{C}_{\mathrm{Bi}}\left(\mathrm{mol} / \mathrm{m}^{3}\right)$ & $\mathrm{pH}$ & $\mathrm{Q}\left(\mathrm{m}^{3 / \mathrm{s}}\right)$ \\
\hline I & 41,01 & $6,50 \pm 0,27$ & $0,018 \times 10^{-6}$ \\
II & 41,14 & 2,13 & $0,018 \times 10^{-6}$ \\
III & 82,65 & $6,50 \pm 0,27$ & $0,017 \times 10^{-6}$ \\
IV & 19,85 & $6,50 \pm 0,27$ & $0,018 \times 10^{-6}$ \\
V & 38,09 & $6,50 \pm 0,27$ & $0,032 \times 10^{-6}$ \\
\hline
\end{tabular}

\subsubsection{Ensayos de reextracción}

Se realizaron ensayos para seleccionar el agente de reextracción más adecuado para la recuperación selectiva de betaína. Se ensayaron como agente de reextracción: hidróxido de sodio $0,5 \mathrm{~N}$; cloruro de sodio $0,5 \mathrm{~N}$; cloruro de amonio $0,36 \mathrm{~N}$; cloruro de amonio $0,36 \mathrm{~N}$ con hidróxido de sodio $0,34 \mathrm{~N}$; y cloruro de sodio $0,37 \mathrm{~N}$ con ácido clorhídrico $0,37 \mathrm{~N}$.

En estos experimentos se partió de una RIE cargada de betaína obtenida de una etapa previa de extracción utilizando $0,1 \mathrm{dm}^{3}$ de una disolución de betaína al $1 \%$ en peso con $10 \mathrm{~g}$ de RIE con agitación orbital a $150 \mathrm{rpm}$ durante 24 horas. Seguidamente las fases se separan por filtración, y la RIE cargada de betaína se seca en una estufa a 60C. Fracciones de RIE de $2 \mathrm{~g}$, cargadas de betaína, se ponen en contacto con $0,01 \mathrm{dm}^{3} \mathrm{de}$ cada una de las disoluciones de reextracción, la agitación de las fases se realizó durante 24 horas con agitador orbital mostrado en la Figura 9 a 150 rpm. Tras la separación de 
las fases por filtración se analizó la concentración de betaína en el equilibrio con el procedimiento descrito en el apartado 6.1.3.1.

\subsubsection{Ciclos sucesivos de extracción -reextracción en lecho fijo de RIE}

La reextracción de betaína de RIE se realizó empleando como agente de reextracción $\mathrm{NaOH} 0,5 \mathrm{~N}$. Estos experimentos se realizaron con flujo ascendente con las condiciones iniciales y de operación indicadas en la Tabla 25.

Las muestras de efluente se recogieron a intervalos de tiempo adecuados, midiéndose la concentración de betaína en la fase acuosa mediante el procedimiento descrito en el apartado 6.1.3.1.

Después del proceso de reextracción, la regeneración del lecho para su posterior uso en ciclos sucesivos, consistió en el lavado del lecho de RIE con disoluciones de $\mathrm{HCl}$ al $0,074 \%$ en volumen, con el objeto de eliminar posibles trazas de betaína no reextraída en la etapa anterior, y seguido de un aclarado con agua para acondicionar el lecho.

Una vez finalizado el lavado del lecho de RIE, se vació el líquido de la columna antes de iniciar un $2^{\circ} \circ 3^{\text {er }}$ ciclo de extracción.

Tabla 25. Condiciones iniciales y de operación de los experimentos en columna de extracciónreextracción de betaína con $\mathrm{RIE}$ a $28 \stackrel{\circ}{\circ} \mathrm{C},\left[\overline{\mathrm{RSO}_{3}^{-} \mathrm{H}^{+}}\right]=500,14 \pm 1,21 \mathrm{~mol} / \mathrm{m}^{3} \mathrm{de} \mathrm{RSI}$.

\section{EXTRACCIÓN}

Alimentación

REEXTRACCIÓN

\begin{tabular}{ccccccc}
\hline \multicolumn{2}{c}{ Experimentos } & \multicolumn{3}{c}{ Alimentación } & \multicolumn{2}{c}{ Disolución de reextracción } \\
\hline & & $\mathrm{pH}_{\mathrm{i}}$ & $\mathrm{C}_{\mathrm{Bi}}\left(\mathrm{mol} / \mathrm{m}^{3}\right)$ & $\mathrm{Q}\left(\mathrm{m}^{3} / \mathrm{s}\right)$ & $\begin{array}{c}\mathrm{C}_{\mathrm{NaOH}} \\
(\mathrm{N})\end{array}$ & $\mathrm{Q}\left(\mathrm{m}^{3} / \mathrm{s}\right)$ \\
\hline I- a & $1^{\text {er }}$ ciclo & $6,50 \pm 0,27$ & 38,096 & $0,032 \times 10^{-6}$ & 0,50 & $0,018 \times 10^{-6}$ \\
I- $\mathrm{b}$ & $2^{\mathrm{o}}$ ciclo & $6,50 \pm 0,27$ & 48,163 & $0,037 \times 10^{-6}$ & 0,50 & $0,021 \times 10^{-6}$ \\
I- $\mathrm{C}$ & $3^{\text {er }}$ ciclo & $6,50 \pm 0,27$ & 47,732 & $0,035 \times 10^{-6}$ & --- & --- \\
\hline
\end{tabular}




\subsection{RESULTADOS Y DISCUSIÓN: ENSAYOS CON RI}

\subsubsection{Selección de condiciones}

En la selección del tipo de resina de intercamio iónico comercial $(\mathrm{RI})$ para la extracción de betaína de disoluciones acuosas, así como su procedimiento de lavado, se realizaron los experimentos de equilibrio recogidos en la Tabla 21 del apartado 6.1.3.4.

Los resultados obtenidos se expresan en función del porcentaje de extracción, \% E, definido como:

$$
\% \mathrm{E}=\frac{\overline{\mathrm{C}}_{\mathrm{B}} \mathrm{m}_{\mathrm{RI}}}{\mathrm{C}_{\mathrm{Bi}} \mathrm{m}_{\mathrm{i}}} 100
$$

donde $\overline{\mathrm{C}}_{\mathrm{B}}$ es la concentración de betaína en fase resina en el equilibrio expresada en $\mathrm{mol} / \mathrm{kg} \mathrm{RI}, \mathrm{C}_{\mathrm{Bi}}$ es la concentración de betaína en fase acuosa inicial expresada en mol $/ \mathrm{kg}$ de fase acuosa, $m_{R l}$ es la masa de $R I$ y $m_{i}$ es la masa de fase acuosa inicial.

En las Figuras 90 y 91 se muestra el grado de extracción de betaína con las distintas resinas $\mathrm{RI}$ utilizadas junto con sus agentes de lavado, para los experimentos I y II de la Tabla 21.

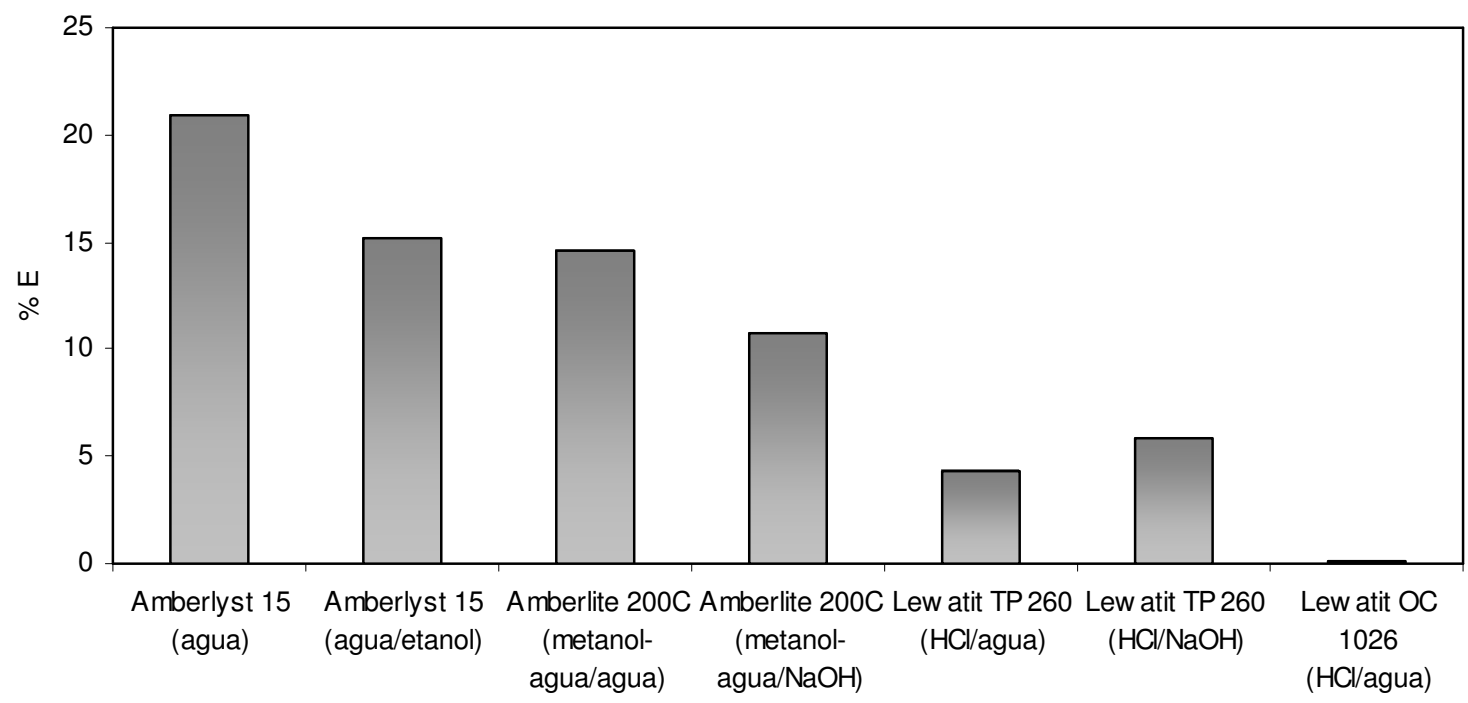

Figura 90. Efecto del tipo de resina de intercambio iónico $(\mathrm{RI})$ y del agente de lavado en el grado de extracción de betaína a $28 \stackrel{\circ}{\circ}$ para el experimento I de la Tabla 21. (masa de RI/ masa de fase acuosa $=0,5 / 25 ; \mathrm{C}_{\mathrm{Bi}}=450 \mathrm{~mol} / \mathrm{m}^{3}, \mathrm{pH}_{\mathrm{i}}=2,22$ )

En la Figura 90 se observa que las resinas Amberlyst 15 y Amberlite 200C son las que proporcionan mayor grado de extracción, aunque, en cualquier caso, es bajo al ser inferior al $22 \%$. Además, se observa que realizando un lavado final con agua se mejoran las características de extracción de betaína de ambas resinas.

En la Figura 91 se observa la misma tendencia en la extracción de betaína con las RI que en la Figura 90, proporcionando de nuevo un mayor porcentaje de extracción la resina Amberlyst 15 y la Amberlite $200 \mathrm{C}$, indicando que las resinas con grupo funcional ácido 
sulfónico $\mathrm{R}-\mathrm{SO}_{3} \mathrm{H}$ producen mejores extracciones que las que poseen grupos funcionales organofosforados como son las resinas Lewatit.

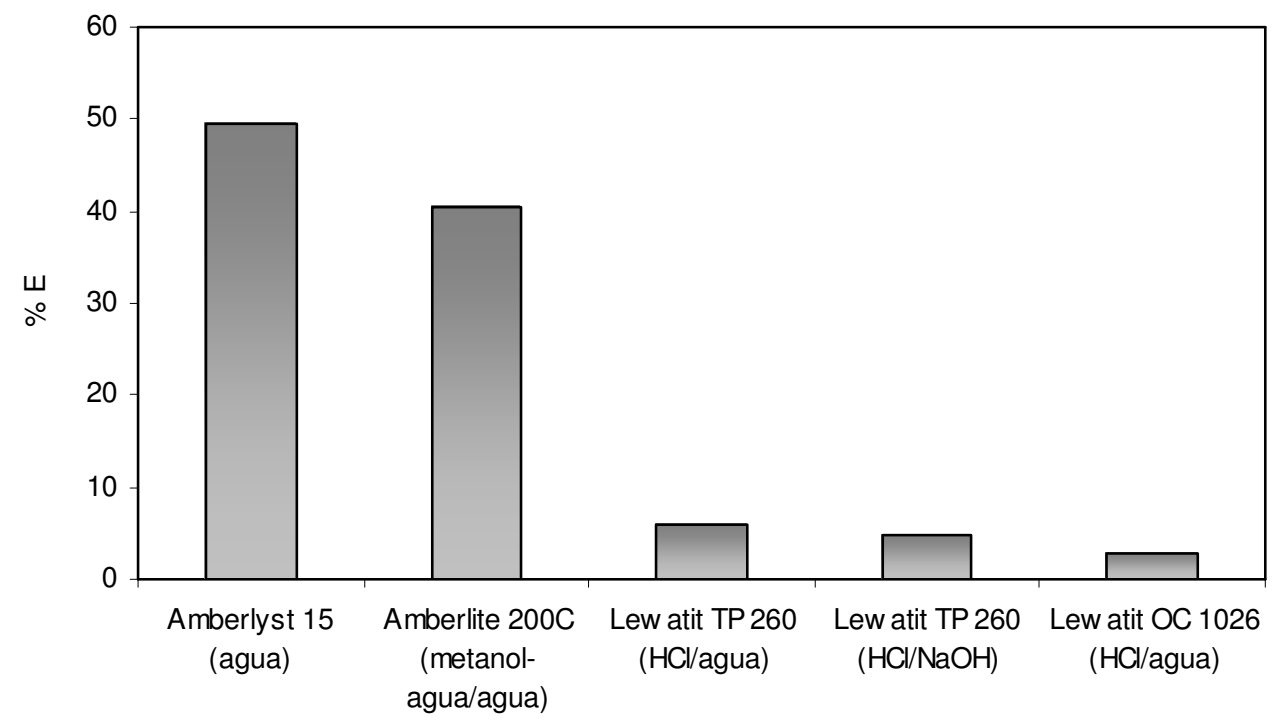

Figura 91. Efecto del tipo de resina $\mathrm{RI}$ en la extracción de betaína a $28{ }^{\circ} \mathrm{C}$ para el experimento II de la Tabla 21. (masa de Rl/ masa de disolución:2 / 25; $\mathrm{C}_{\mathrm{Bi}}=450 \mathrm{~mol} / \mathrm{m}^{3}, \mathrm{pH}_{\mathrm{i}}=2,22$ )

En la Figura 92 se muestra el porcentaje de extracción de betaína con distintas masas de las resinas Amberlyst 15 y Amberlita 200C (experimentos I-a, I-d, II-a, II-b y III-(a-d) de la Tabla 21 y experimentos I y IV de la Tabla 22), resultando ligeramente superior la extracción con Amberlyst 15 que con Amberlita 200C, alcanzando incluso valores superiores al $93 \%$ en el caso de utilizar $10 \mathrm{~g}$ de resina.

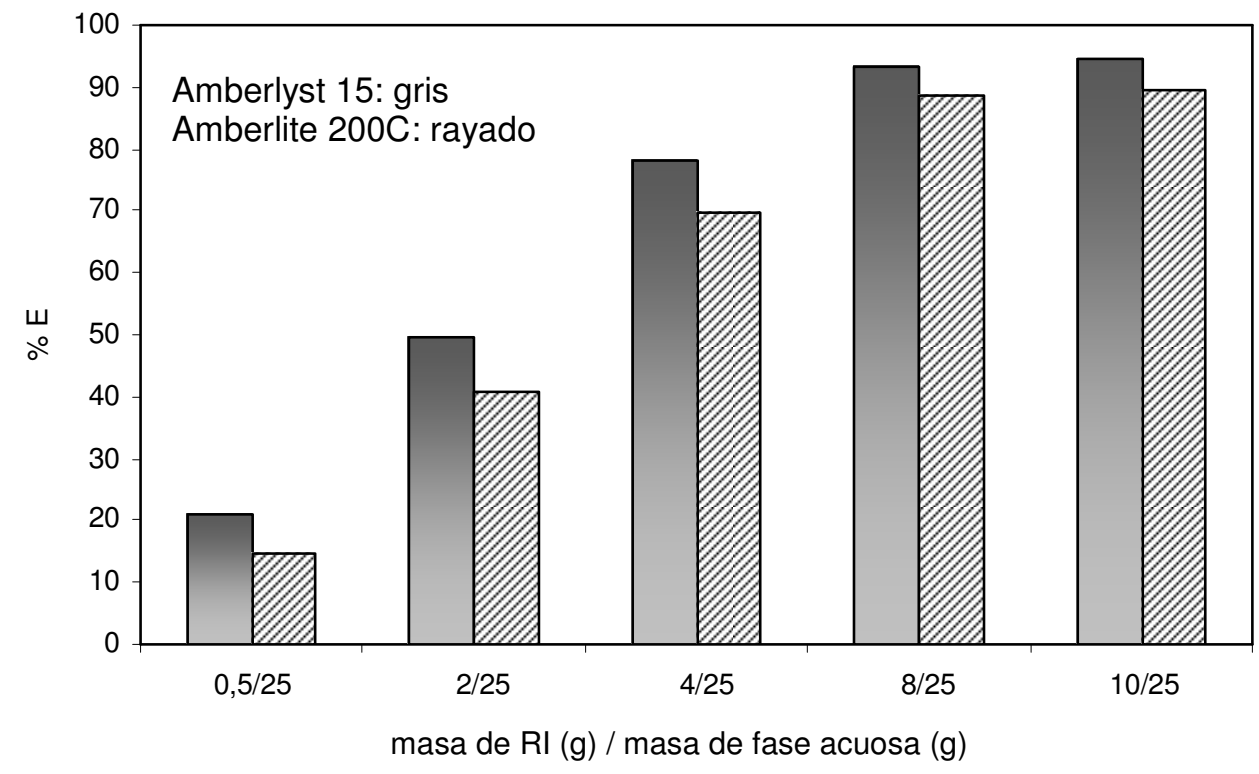

Figura 92. Porcentaje de extracción de betaína a $\mathrm{pH}_{\mathrm{i}}=2,22$ con distintas masas de Amberlyst 15 y Amberlite $200 \mathrm{C}$ (experimentos I-a, I-d, II-a, II-b y III de la Tabla 21 y I y IV de la Tabla 22). (Fase acuosa $=25 \mathrm{~g}$ y $_{\mathrm{Bi}}=450 \mathrm{~mol} / \mathrm{m}^{3}$ ) 
En la selección del pH óptimo se realizaron los experimentos detallados en el apartado 6.1.3.4 y recogidos en la Tabla 22. En la Figura 93 se representa el porcentaje de extracción de betaína con Amberlyst 15 y Amberlite 200C a distintos valores de pH (masa de RI/ masa de disolución=10/25).

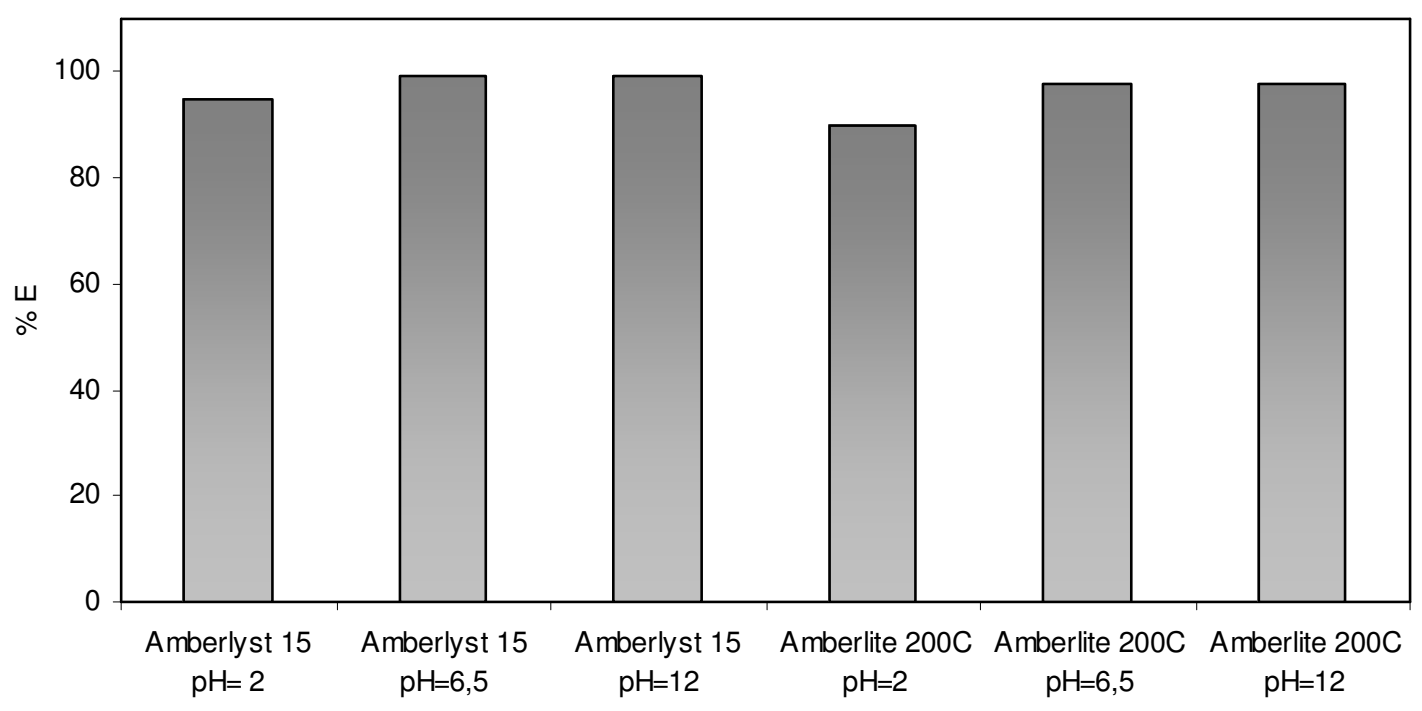

Figura 93. Efecto del pH en la extracción de betaína a $28 \stackrel{\circ}{\circ} \mathrm{C}$ con Amberlite $200 \mathrm{C}$ y Amberlyst 15. Experimentos I-VI de la Tabla 22. (masa de RI/ masa de disolución: 10/25; $\mathrm{C}_{\mathrm{Bi}}=450$ $\mathrm{mol} / \mathrm{m}^{3}$ )

La Figura 93 muestra que el porcentaje de extracción de betaína no varía mucho con el $\mathrm{pH}$, siendo ligeramente inferior a $\mathrm{pH}$ ácido, tanto para Amberlyst 15 y Amberlite 200C; obteniendo extracciones superiores al $97 \%$ a pH natural o básico.

Similares experimentos fueron realizados para las resinas Lewatit OC1026 y Lewatit TP260 en las condiciones mostradas en la Tabla 22, siendo el porcentaje de extracción inferior al $4 \%$ en todos los casos (no mostradas).

En base a estos resultados, se seleccionó la resina Amberlyst $15 \mathrm{a} \mathrm{pH}$ natural para posteriores experimentos y se estudió experimentalmente la cantidad óptima de resina empleada en la extracción de betaína a $28^{\circ} \mathrm{C}$ y $25 \mathrm{~g}$ de fase acuosa con una concentración inicial de $450 \mathrm{~mol} / \mathrm{m}^{3}$ de betaína. Estos experimentos se realizaron a $\mathrm{pH}$ natural, siguiendo el procedimiento experimental del apartado 6.1.3.4 y se representan en la Figura 94.

En la Figura 94 se observa que $6 \mathrm{~g}$ de Amberlyst 15 es la cantidad óptima necesaria para producir extracciones de betaína superiores al 95\%. Seleccionándose dicho valor para posteriores ensayos. 


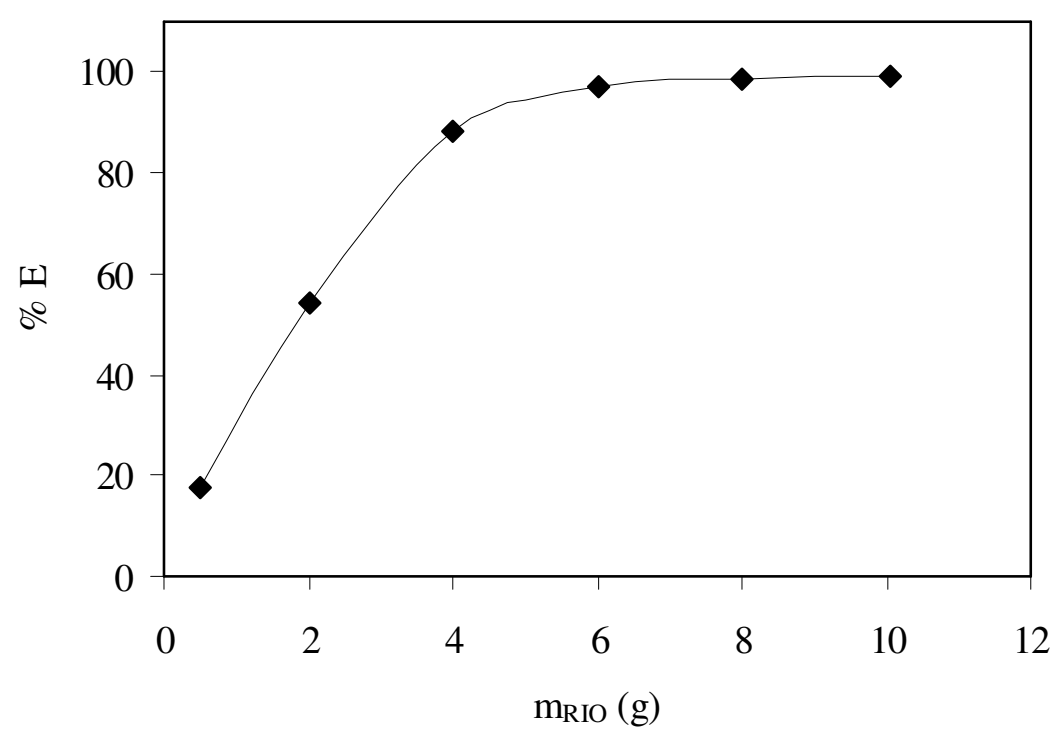

Figura 94. Porcentaje de extracción de betaína a $\mathrm{pH}$ natural $(\mathrm{pH}=6,50)$ con distintas masas de Amberlyst 15 y a $28{ }^{\circ} \mathrm{C}$ (masa de fase acuosa $\left.=25 \mathrm{~g} ; \mathrm{C}_{\mathrm{Bi}}=450 \mathrm{~mol} / \mathrm{m}^{3}\right)$.

Posteriormente, se determinó el valor de la humedad o de la adsorción de agua que se produce en la resina Amberlyst 15 que fue constante tanto en disoluciones compuestas por betaína o únicamente agua, siendo el valor experimental de 1,25 $\pm 0,04 \mathrm{~g}$ agua adsorbida/g resina seca.

En este apartado se han alcanzado las siguientes conclusiones:

- El mayor grado de extracción de betaína se obtuvo con las resinas de intercambio iónico que contienen el grupo funcional $\mathrm{RSO}_{3}{ }^{-} \mathrm{H}$ (Amberlyst 15 y Amberlite $200 \mathrm{C}$ ) frente a las que tienen como grupo funcional compuestos organofosforados (Lewatit TP260 y Lewatit OC1026).

- No se observaron diferencias significativas en el grado de extracción de betaína con Amberlyst 15 al operar con distintos valores de $\mathrm{pH}=2,6,5$ (natural, sin modificación) y 12.

- La proporción masa RI/ masa de disolución= 6/25 produce más de un $95 \%$ de extracción de betaína, en todos los ensayos realizados. 


\subsubsection{Equilibrios de extracción de betaina con Amberlyst 15}

Los datos de equilibrio de extracción de betaína con Amberlyst 15, se determinaron a pH natural y $28^{\circ} \mathrm{C}$, siguiendo el procedimiento experimental detallado en el apartado 6.1.3.4 y se recogen en la Tabla A1 del apéndice $D$.

La concentración total de betaína en fase resina, expresada en mol/kg Rl, se calculó con el siguiente balance de materia:

$$
\overline{\mathrm{C}}_{\mathrm{B}}=\left(\mathrm{C}_{\mathrm{Bi}}-\mathrm{C}_{\mathrm{B}}\right) \frac{\mathrm{V}}{\mathrm{m}_{\mathrm{RI}}}
$$

donde $C_{B}$ es la concentración analítica total de betaína en fase acuosa, $V$ es el volumen de la fase acuosa, $m_{R I}$ es la masa de la resina de intercambio iónico. El subíndice i hace referencia a condición inicial y - hace referencia a la fase resina.

La concentración de las especies iónicas de betaína presentes en la fase acuosa se determinan con la constante de disociación en disolución acuosa ( $\mathrm{pK}_{\mathrm{a} 1}=1,81$ ), su concentración analítica total y el pH, utilizando las siguientes ecuaciones:

$$
\begin{gathered}
{\left[\mathrm{B}^{+}\right]=\frac{\mathrm{C}_{\mathrm{B}}\left[\mathrm{H}^{+}\right]}{\left[\mathrm{H}^{+}\right]+\mathrm{K}_{\mathrm{a} 1}}} \\
{\left[\mathrm{~B}^{+/-}\right]=\frac{\mathrm{C}_{\mathrm{B}} \mathrm{K}_{\mathrm{a} 1}}{\left[\mathrm{H}^{+}\right]+\mathrm{K}_{\mathrm{a} 1}}}
\end{gathered}
$$

En la Figura 95 se representa la isoterma de extracción de betaína con Amberlyst 15 a $28^{\circ} \mathrm{C}$ y $\mathrm{pH}$ natural. En esta Figura se observa la buena concordancia entre los datos experimentales (símbolos) y los calculados (líneas) con el modelo de equilibrio tipo Langmuir mostrado en la Ec. (6.5):

$$
\overline{\mathrm{C}}_{\mathrm{B}}=\mathrm{Q}_{\mathrm{s}} \frac{\mathrm{KC}_{\mathrm{B}}}{1+\mathrm{KC}_{\mathrm{B}}}
$$

Del ajuste de los resultados experimentales al modelo, Ec. (6.5), se obtuvieron los valores de los parámetros del modelo de Langmuir, la capacidad máxima de adsorción de la resina $Q_{s}=2,754 \mathrm{~mol} / \mathrm{m}^{3} \mathrm{RSI}$ y la constante de adsorción $\mathrm{K}=0,175 \mathrm{~mol} / \mathrm{m}^{3}$, con un coeficiente de regresión lineal de $r=0,998$.

En base a lo expuesto se puede concluir:

- Los resultados obtenidos de los equilibrios de adsorción de betaína con Amberlyst 15 se ajustaron satisfactoriamente a una isoterma de tipo Langmuir. 


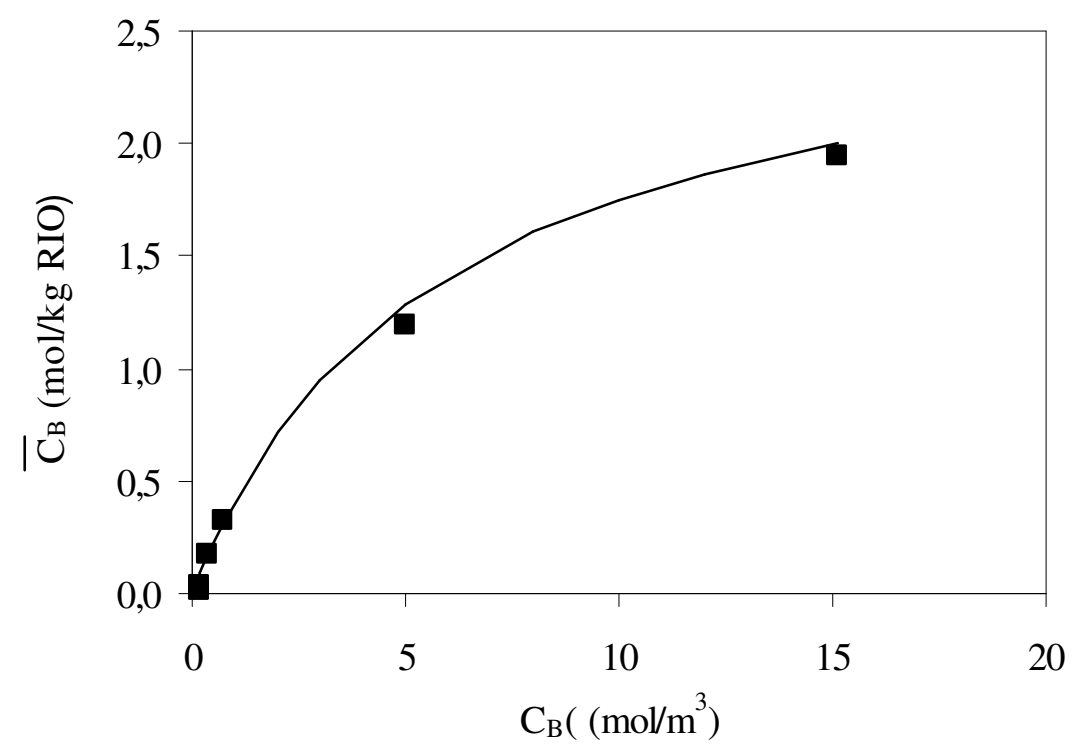

Figura 95. Isoterma de equilibrio de extracción de betaína con resina Amberlyst 15 a $\mathrm{pH}_{\mathrm{i}}=6,50 \pm 0,27$ y $28 \stackrel{\circ}{\circ}$. Símbolos: datos experimentales. Línea sólida: datos estimados con la Ec. (6.5).

\subsubsection{Equilibrios de extracción de mezclas binarias de betaina y sacarosa con Amberlyst 15}

Los datos de equilibrio de extracción de mezclas binarias de betaína y sacarosa con Amberlyst 15 , se realizaron a pH natural y $28^{\circ} \mathrm{C}$, siguiendo el procedimiento experimental detallado en el apartado 6.1.3.4 y se muestran en la Tabla A2 del Apéndice D. La concentración total en fase resina de betaína y de sacarosa, se calculó por los balances de materia mostrados en las Ecs. (6.2) y (6.6), respectivamente. La extracción de sacarosa fue despreciable en todos los experimentos realizados.

$$
\overline{\mathrm{C}}_{\mathrm{S}}=\left(\mathrm{C}_{\mathrm{Si}}-\mathrm{C}_{\mathrm{S}}\right) \frac{\mathrm{V}}{\mathrm{m}_{\mathrm{RIO}}}
$$

donde $\mathrm{C}_{\mathrm{S}}$ es la concentración total de sacarosa en fase acuosa calculada por el método analítico detallado en el apartado 6.1.3.1.

En la Figura 96 se representan los datos de equilibrio que muestran el efecto de la presencia de sacarosa en la extracción de betaína a $\mathrm{pH}$ natural $(\mathrm{pH}=6,50 \pm 0,27)$ y $28^{\circ} \mathrm{C}$ con Amberlyst 15. 


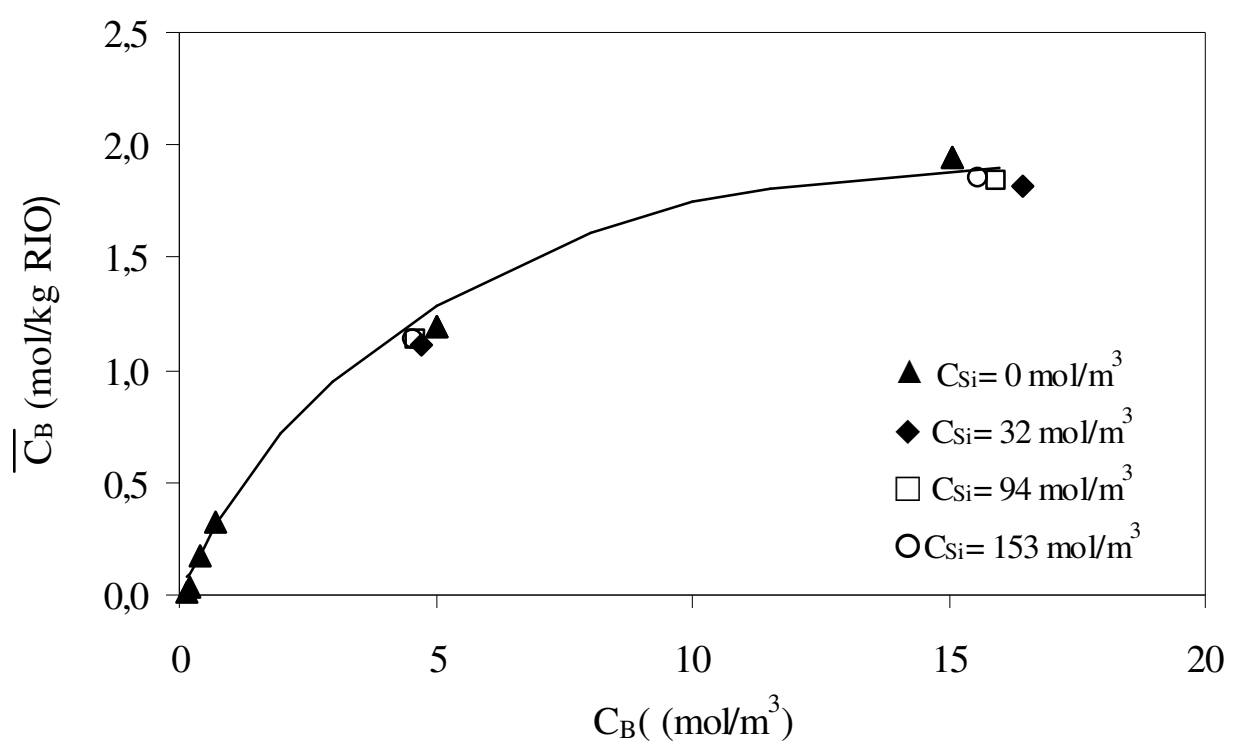

Figura 96. Efecto de la presencia de sacarosa en la extracción de betaína a pH natural $(\mathrm{pH}=6,50 \pm 0,27)$ y a $28^{\circ} \mathrm{C}$ con Amberlyst 15 en mezclas binarias con sacarosa.

La Figura 96 muestra que la extracción de betaína con Amberlyst 15 es similar e independiente de la presencia de sacarosa en el sistema, resultando por tanto selectiva a la betaína.

Se ha comprobado experimentalmente que la resina Amberlyst 15 aunque proporciona un elevado grado de extracción de betaína presenta algunos inconvenientes de operación como que se rompe fácilmente en los ciclos de lavado y durante la experimentación a pesar de utilizar agitación orbital suave (=150 rpm). Además, produce una reacción exotérmica, calentando las fases y tiñe las disoluciones acuosas de color marrón debido al desprendimiento de sulfitos en el medio acuoso. Por otra parte, la resina Amberlyst 15 al ser hidrófila adsorbe agua (se hincha) y cambia su volumen al contactar con las disoluciones acuosas.

En este apartado se puede concluir:

- La extracción de sacarosa con Amberlyst 15 fue despreciable. Este hecho justifica que la extracción de betaína con Amberlyst 15 no se modifique en presencia de sacarosa. 


\subsection{RESULTADOS Y DISCUSIÓN: ENSAYOS CON RIE:}

\subsubsection{Ensayos de equilibrio de extracción liquido-liquido: selección del extractante}

Con el objeto de seleccionar un extractante selectivo a la betaína para su recuperación de disoluciones acuosas, se realizaron los ensayos de extracción líquido-líquido, descritos en el apartado 6.1.3.5 y en la Tabla 23 y utilizando los extractantes catiónicos Di(2-etilhexil)fosfato (DEHPA) y el ácido dinonilnaftalensulfónico (DNNSA), disueltos en hexano y en heptano, respectivamente.

En la Figura 97 se muestran los resultados obtenidos expresados en función del porcentaje de extracción, \%E, definido en la Ec. (6.7) y que indican que la extracción mayoritaria de betaína se consigue con el extractante catiónico sulfonado DNNSA, resultando similar a los dos valores de $\mathrm{pH}$ ensayados.

$$
\% \mathrm{E}=\frac{\mathrm{C}_{\mathrm{Bi}}-\mathrm{C}_{\mathrm{B}}}{\mathrm{C}_{\mathrm{Bi}}} 100
$$

A la vista de estos resultados, se seleccionó el extractante DNNSA para la impregnación de la resina Amberlita XAD-4.

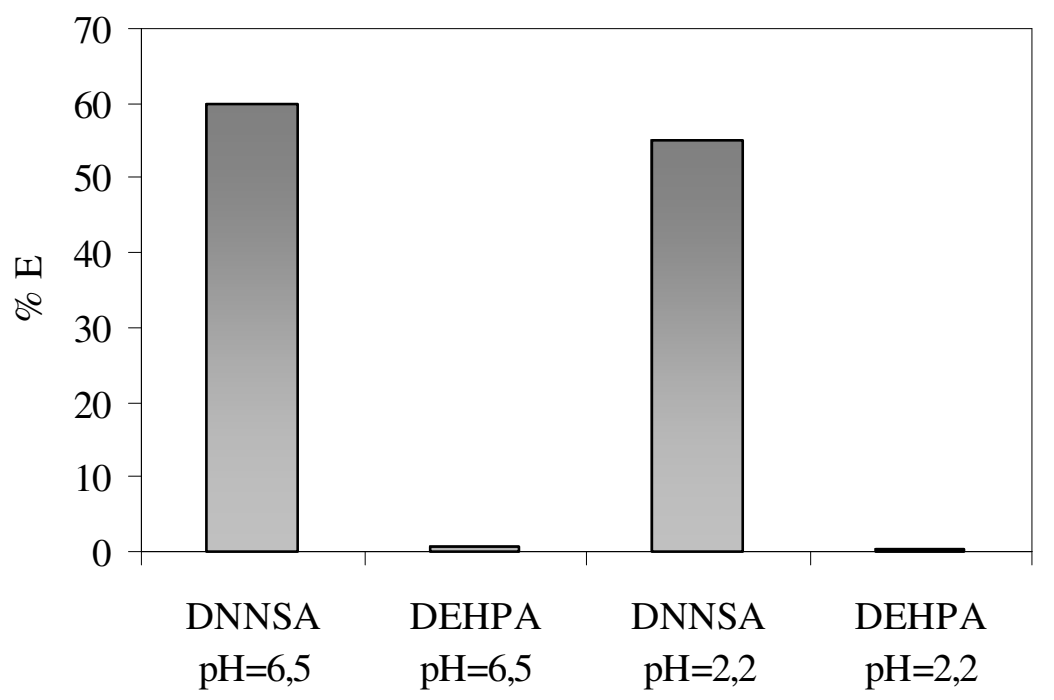

Figura 97. Porcentaje de extracción de betaína de disoluciones acuosas a $25^{\circ} \mathrm{C}$, utilizando como disolvente orgánico DNNSA disuelto en heptano y DEHPA disuelto en hexano. Experimentos de la Tabla $23\left(\mathrm{C}_{\mathrm{Bi}}=450 \mathrm{~mol} / \mathrm{m}^{3}\right)$. 
Con estos resultados se concluye que:

- El grado de extracción de betaína en el proceso de extracción líquido-líquido con el extractante catiónico sulfonado DNNSA es mayor al obtenido con el extractante organofosforado DEHPA. Resultado similar, en ambos casos, al trabajar a $\mathrm{pH}=2,2$ o 6,5.

\subsubsection{Lavado e impregnación de RIE}

Los resultados experimentales de impregnación de la resina Amberlita XAD-4 con DNNSA (50\%-heptano) disuelto en n-hexano, obtenidos por el procedimiento 6.1.3.6, se recogen en la Tabla $B 1$ del apéndice $D$.

La concentración de DNNSA en la resina después del proceso de impregnación, $\left[\overline{\mathrm{RSO}_{3}^{-} \mathrm{H}^{+}}\right]$, se determinó experimentalmente por pesada de la resina antes y después del proceso de impregnación, calculándose en unidades de mol DNNSA / $\mathrm{m}^{3} \mathrm{RSI}$ con la Ec.(6.8):

$$
\left[\overline{\mathrm{RSO}_{3}^{-} \mathrm{H}^{+}}\right]=\frac{\left(\mathrm{m}_{\mathrm{RIE}}-\mathrm{m}_{\mathrm{RSI}}\right) \rho_{\mathrm{RSI}}}{\mathrm{M}_{\mathrm{DNNSA}} \mathrm{m}_{\mathrm{RSI}}}=\frac{\overline{\mathrm{RSO}_{3}^{-} \mathrm{H}^{+}} \rho_{\mathrm{RSI}}}{\mathrm{m}_{\mathrm{RSI}}}
$$

donde $m_{R S I}$ es la masa de resina antes del proceso de impregnación, $m_{\text {RIE }}$ es la masa de resina impregnada, $\overline{\mathrm{RSO}_{3}^{-} \mathrm{H}^{+}}$son los moles de DNNSA impregnados en la resina, $\mathrm{M}_{\mathrm{DNNSA}}$ es el peso molecular del extractante y $\rho_{\mathrm{RSI}}$ es la densidad de la resina sin impregnar.

En la Figura 98 se representa la concentración de DNNSA en la RIE, $\left[\overline{\mathrm{RSO}_{3}^{-} \mathrm{H}^{+}}\right\rfloor$, frente a la concentración de DNNSA en la disolución de impregnación. Se observa que la concentración de DNNSA en fase resina crece al aumentar la concentración de DNNSA en la disolución de impregnación y permanece constante a partir de disoluciones de impregnación con una concentración del $20 \%$ en peso de DNNSA, proporcionando una capacidad máxima de impregnación de $540 \mathrm{~mol}$ DNNSA / $\mathrm{m}^{3} \mathrm{RSI}$. Por encima de esta concentración, la resina XAD-4 no admite más extractante, y adquiere un aspecto húmedo y pegajoso después del proceso de impregnación. 


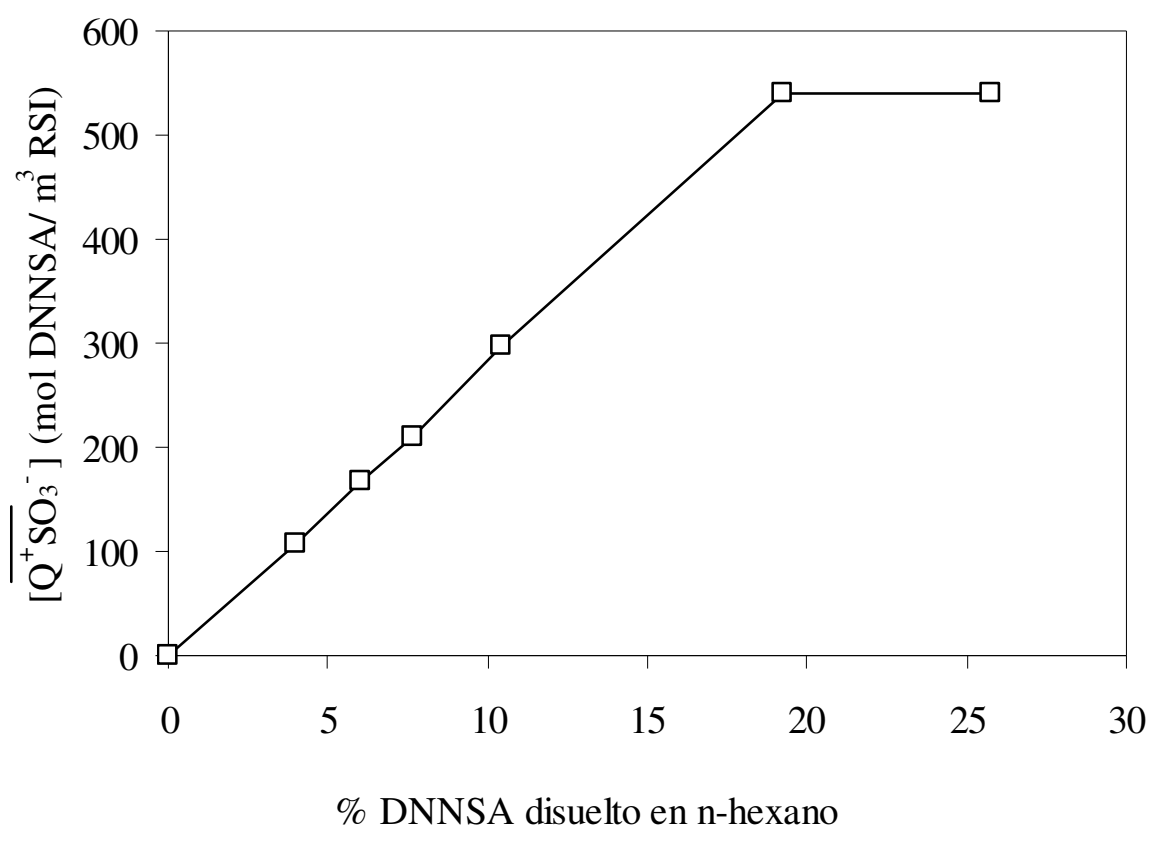

Figura 98. Concentración de DNNSA en la RIE en función de su concentración en la disolución de impregnación (DNNSA + n-hexano).

Resultados similares se obtuvieron utilizando n-heptano como diluyente en la disolución de impregnación, recogidos en la Tabla B2 del apéndice D. Sin embargo, el hexano es más volátil y se seleccionó como diluyente del DNNSA ya que se reduce el tiempo del proceso de impregnación de la resina XAD-4.

Un estudio microscópico ha demostrado que la resina XAD-4 impregnada y sin impregnar tienen el mismo radio de $0,389 \mathrm{~mm}$.

Por tanto, se puede concluir:

- La capacidad máxima de impregnación de la resina XAD-4 con DNNSA es 540 mol DNNSA / $\mathrm{m}^{3} \mathrm{RSI}$, por encima de esta concentración, la resina no admite más extractante y adquiere un aspecto húmedo y pegajoso. Para evitar efectos de desimpregnación todos los ensayos con RIE fueron realizados con concentración constante de DNNSA de 500,14 $\pm 1,21 \mathrm{~mol}$ DNNSA / $\mathrm{m}^{3} \mathrm{RSI}$. 


\subsubsection{Selección de condiciones}

Se determinaron los datos de equilibrio de extracción de betaína a $28^{\circ} \mathrm{C}$ empleando distintas proporciones de RIE con el procedimiento y las condiciones experimentales descritas en el apartado 6.1.3.7. En la Figura 99 se muestran los resultados obtenidos expresados en función del porcentaje de extracción, definido en la Ec. (6.7).

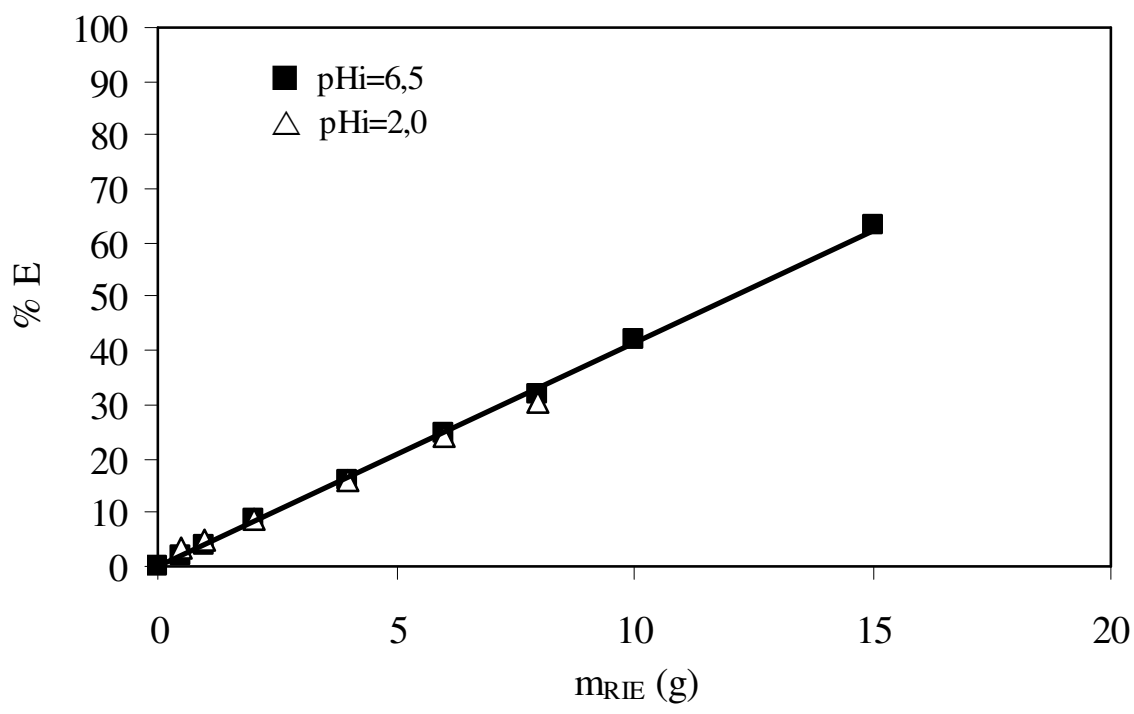

Figura 99. Selección de proporción de RIE y pH. Datos de equilibrio de extracción de betaína a 28ㄷ. $\left[\mathrm{RSO}_{3}^{-} \mathrm{H}^{+}\right]=500,14 \mathrm{~mol}$ DNNSA $/ \mathrm{m}^{3} \mathrm{RSI}, \mathrm{V}=0,025 \mathrm{dm}^{3}, \mathrm{C}_{\mathrm{Bi}}=450 \mathrm{~mol} / \mathrm{m}^{3}$.

En la Figura 99 se observa que el porcentaje de extracción de betaína es directamente proporcional a la masa de RIE utilizada y que la extracción de nuevo resulta similar a $\mathrm{pH}=2$ y 6 . Con el ajuste lineal se obtiene la Ec. (6.9), que relaciona la masa de resina y el grado de extracción de betaína.

$$
\text { \% Extracción }=4,152 \mathrm{~m}_{\mathrm{RIE}} \quad(\mathrm{r}=0,998)
$$

En base a los resultados alcanzados, se seleccionó para posteriores experimentos con RIE $\mathrm{pH}$ natural y la relación masa de resina / volumen de disolución $=240 / 1$ que corresponde a una masa de RIE de $6 \mathrm{~g}$.

Asimismo, se realizaron experimentos con resina Amberlita XAD-4 sin impregnar bajo las mismas condiciones experimentales (no mostrados). En estos experimentos se observa que la adsorción de betaína es en todos los casos despreciable, por tanto, se puede considerar que no hay interacción entre la matriz polimérica de la resina y la cadena orgánica de la betaína, fenómeno que ya se observó con los aminoácidos estudiados. 
Con los resultados obtenidos se concluye que:

- El grado de extracción de betaína es directamente proporcional a la masa de RIE empleada y resultó similar a pH=2,2 ó 6,5.

- La adsorción física de betaína con Amberlita XAD-4 sin impregnar es despreciable, por tanto, se puede considerar que no hay interacción entre la matriz polimérica de la resina y la cadena orgánica de la betaína.

\subsubsection{Equilibrios de extracción de betaina con RIE}

La isoterma de equilibrio para la extracción de betaína con Amberlita XAD-4 impregnada de DNNSA, a pH natural y $28^{\circ} \mathrm{C}$ (condiciones seleccionadas en los apartados anteriores), se realizó siguiendo el procedimiento experimental detallado en el apartado 6.1.3.7.

La concentración total de betaína en fase resina, expresada en $\mathrm{mol} / \mathrm{m}^{3} \mathrm{RSI}$, se calculó con el siguiente balance de materia:

$$
\overline{\mathrm{C}}_{\mathrm{B}}=\left(\mathrm{C}_{\mathrm{Bi}}-\mathrm{C}_{\mathrm{B}}\right) \frac{\mathrm{V}}{\overline{\mathrm{V}}}
$$

donde $C_{B}$ es la concentración total de betaína en fase acuosa calculada por el método detallado en el apartado 6.1.3.1, $\mathrm{V}$ es el volumen de las fases. El subíndice i hace referencia a condición inicial y - hace referencia a la fase resina.

La concentración de las especies iónicas de betaína presentes en la fase acuosa se determinó utilizando las ecuaciones (6.3) y (6.4). Los datos de equilibrio de la isoterma se recogen en la Tabla B3 del apéndice $D$.

En la Figura 100 se representa la isoterma de extracción individual de betaína a $28^{\circ} \mathrm{C}$ y a $\mathrm{pH}$ natural. 


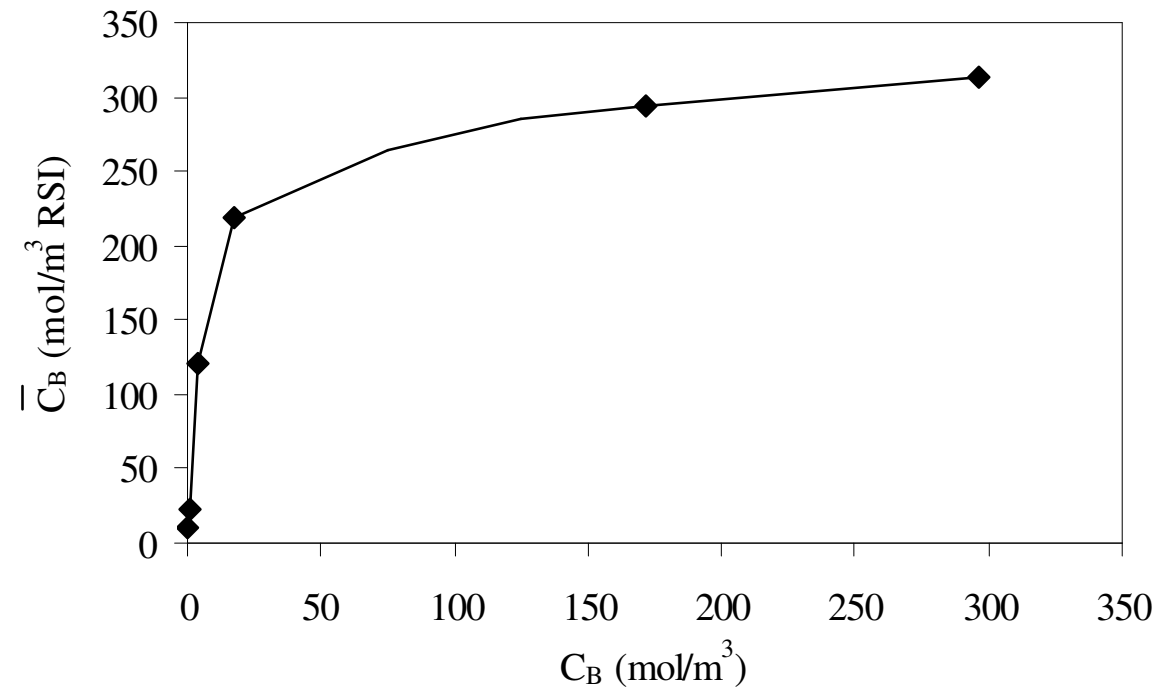

Figura 100. Isoterma de equilibrio de extracción de betaína individual con RIE a $28^{\circ} \mathrm{C}$. $\left.\left(\mathrm{pH}_{\mathrm{i}}=6,50 \pm 0,27 ; \overline{\mathrm{RSO}_{3}^{-} \mathrm{H}^{+}}\right]=500,14 \mathrm{~mol} \mathrm{DNNSA} / \mathrm{m}^{3} \mathrm{RSI}\right)$.

\subsubsection{Modelo para la estimación de isotermas de equilibrio de betaína}

Como se ha comentado anteriormente, la resina Amberlita XAD-4 sin impregnar no produce adsorción de betaína, por tanto se puede suponer que la adsorción física de la betaína debida a la matriz polimérica es despreciable frente a la extracción reactiva con el extractante. En este caso, el proceso de extracción de betaína con Amberlita XAD-4 impregnada de DNNSA se puede describir como un mecanismo de extracción reactiva debida únicamente al extractante mediante las siguientes ecuaciones de equilibrio:

i) Disociación de la betaína en la disolución acuosa:

$$
\mathrm{B}^{+}+\mathrm{H}_{2} \mathrm{O} \leftrightarrow \mathrm{B}^{+/-}+\mathrm{H}_{3} \mathrm{O}^{+} \quad \mathrm{K}_{\mathrm{a} 1}=\frac{\left[\mathrm{B}^{+/-}\right]\left[\mathrm{H}^{+}\right]}{\left[\mathrm{B}^{+}\right]}
$$

ii) Reacción de intercambio iónico de betaína con el DNNSA impregnado en la resina:

$$
\mathrm{B}^{+}+\overline{\mathrm{RSO}_{3}^{-} \mathrm{H}^{+}} \leftrightarrow \overline{\mathrm{RSO}_{3}^{-} \mathrm{B}^{+}}+\mathrm{H}^{+} \quad \mathrm{K}_{\mathrm{p} 1}=\frac{\left.\overline{\mathrm{RSO}_{3}^{-} \mathrm{B}^{+}}\right]\left[\mathrm{H}^{+}\right]}{\left[\mathrm{B}^{+}\right]\left[\overline{\mathrm{RSO}_{3}^{-} \mathrm{H}^{+}}\right]}
$$

donde $\mathrm{K}_{\mathrm{p} 1}$ es la constante de equilibrio que rige el proceso de intercambio iónico.

Considerando que no hay agregación de las especies extraídas en fase resina y considerando que la solubilidad del DNNSA en fase acuosa es despreciable, el balance de materia aplicado al DNNSA puede expresarse como: 


$$
\left.\left[\overline{\mathrm{RSO}_{3}^{-} \mathrm{H}^{+}}\right\rfloor_{\mathrm{i}}=\overline{\mathrm{RSO}_{3}^{-} \mathrm{H}^{+}}\right]+\overline{\mathrm{RSO}_{3}^{-} \mathrm{B}^{+}}
$$

donde $\left[\overline{\mathrm{RSO}_{3}^{-} \mathrm{B}^{+}}\right]$y $\left[\overline{\mathrm{RSO}_{3}^{-} \mathrm{H}^{+}}\right]$son las concentraciones de betaína y de DNNSA en el equilibrio en fase resina, respectivamente. La concentración de las especies $\mathrm{B}^{+}$y $\mathrm{B}^{+/-}$de la betaína en el equilibrio se calculan mediante las Ecs. (6.3) y (6.4) y se muestran en la Tabla B3 del apéndice D.

Asumiendo que la reacción de intercambio iónico de betaína con el DNNSA es mol a mol, los protones procedentes de dicha reacción de intercambio iónico se pueden calcular mediante la siguiente expresión:

$$
\left[\mathrm{H}^{+}\right]=\frac{\overline{\mathrm{V}}}{\mathrm{V}}\left[\overline{\mathrm{RSO}_{3}^{-} \mathrm{B}^{+}}\right]
$$

En la Figura 101 se representa el producto $\left.\overline{\mathrm{RSO}_{3}^{-} \mathrm{B}^{+}}\right]\left[\mathrm{H}^{+}\right]$frente al producto $\left[\overline{\mathrm{RSO}_{3}^{-} \mathrm{H}^{+}}\right]\left[\mathrm{B}^{+}\right]$. Del ajuste de los datos experimentales a una línea recta se obtiene el valor de la pendiente que es la constante de equilibrio de la betaína definida en la Ec. (6.12), presentando un valor de $\mathrm{K}_{\mathrm{p} 1}=15,393$ con una regresión lineal de 0,998 bajo las condiciones experimentales estudiadas.

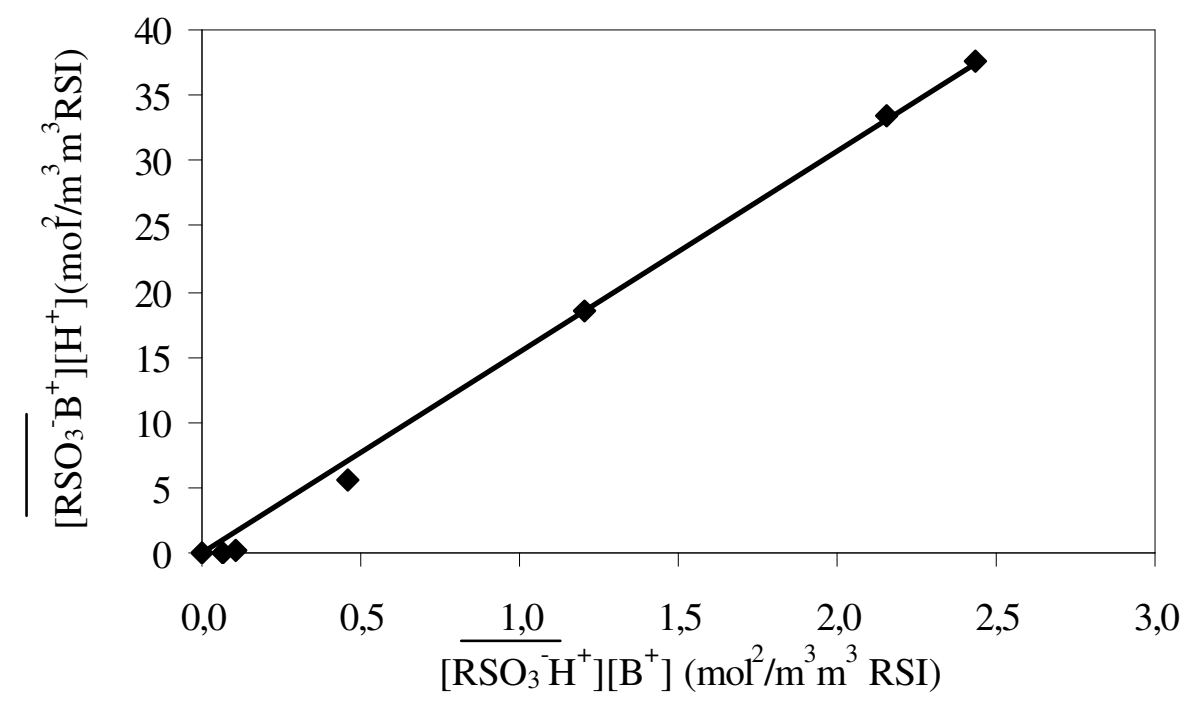

Figura 101. Determinación de la constante de equilibrio de betaína con $\mathrm{RIE}$ a $28^{\circ} \mathrm{C}$ y $\mathrm{pH}=6,50$. Símbolos: datos experimentales; línea sólida: datos estimados con la Ec. (6.12).

Combinando las Ecs. (6.12), (6.13) y (6.14) se obtiene el siguiente modelo de equilibrio para estimar la concentración total de betaína extraída por la RIE: 
$\left[\mathrm{RSO}_{3}^{-} \mathrm{B}^{+}\right]=\sqrt{\left(\frac{\mathrm{VK}_{\mathrm{p} 1}\left[\mathrm{~B}^{+}\right]}{2 \overline{\mathrm{V}}}\right)^{2}+\frac{\mathrm{VK}_{\mathrm{pl}}\left[\mathrm{B}^{+}\right]\left[\overline{\left.\mathrm{RSO}_{3}^{-} \mathrm{H}^{+}\right]}\right.}{\overline{\mathrm{V}}}}-\frac{\mathrm{VK}_{\mathrm{p} 1}\left[\mathrm{~B}^{+}\right]}{2 \overline{\mathrm{V}}}$

El porcentaje de error medio entre los valores experimentales y los calculados con la Ec. (6.15) se evaluó con la siguiente expresión:

$\%$ error promediado $=\frac{100}{\mathrm{j}} \sum_{1}^{\mathrm{j}} \frac{\left.\left(\left(\overline{\mathrm{C}}_{\mathrm{B}}{ }_{\text {Cal }}-\overline{\mathrm{C}}_{\mathrm{B}}\right)_{\text {Exp }}\right)^{2}\right)^{1 / 2}}{\overline{\mathrm{C}}_{\mathrm{B}}}$

En la Figura 102 se observa una buena concordancia entre los resultados experimentales (símbolos) y los estimados con la Ec. (6.15) (curva sólida). El error medio, Ec. (6.16), fue inferior al $3 \%$.

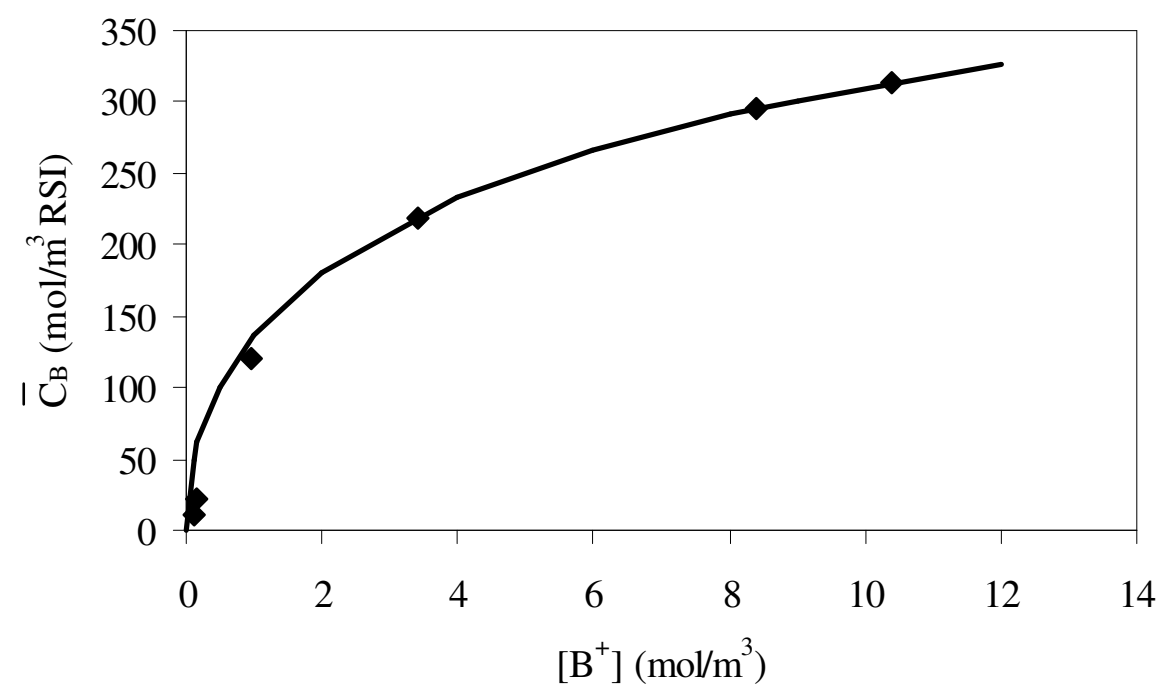

Figura 102. Isoterma de equilibrio de extracción de betaína con RIE a $28^{\circ} \mathrm{C}$ y pH natural. Datos experimentales (símbolos). Datos estimados con la Ec. (6.15) (líneas). 
Las conclusiones más relevantes se relacionan a continuación:

- El grado de extracción de betaína con la resina Amberlita XAD-4 impregnada con DNNSA aumenta al aumentar la concentración de betaína en fase acuosa.

- La separación de betaína con Amberlita XAD-4 impregnada con DNNSA puede describirse adecuadamente mediante un modelo de equilibrio donde la extracción de betaína con RIE tiene lugar por reacciones de intercambio iónico con el DNNSA inmovilizado en los poros de la resina, formando complejos betaínaDNNSA $\left(\mathrm{RSO}_{3}{ }^{-} \mathrm{B}^{+}\right)$. El modelo propuesto ajusta satisfactoriamente los resultados experimentales.

\subsubsection{Equilibrios de extracción de mezclas binarias de betaina $y$ sacarosa con RIE}

Se realizaron experimentos de equilibrio de extracción de sacarosa con resina impregnada y sin impregnar siguiendo el procedimiento experimental detallado en el apartado 6.1.3.7. En dichos experimentos (no mostrados), se observó que tanto la adsorción como la extracción de la sacarosa son despreciables, en todos los casos estudiados.

Los datos de equilibrio de extracción de distintas mezclas de betaína y sacarosa con RIE a $\mathrm{pH}$ natural y $28^{\circ} \mathrm{C}$, se realizaron siguiendo el procedimiento experimental detallado en el apartado 6.1.3.7.

La concentración total de betaína y sacarosa en fase resina, expresadas en $\mathrm{mol} / \mathrm{m}^{3} \mathrm{RSI}$, se calculó mediante los siguientes balances de materia:

$$
\begin{gathered}
\overline{\mathrm{C}}_{\mathrm{B}}=\left(\mathrm{C}_{\mathrm{Bi}}-\mathrm{C}_{\mathrm{B}}\right) \frac{\mathrm{V}}{\overline{\mathrm{V}}} \\
\overline{\mathrm{C}}_{\mathrm{S}}=\left(\mathrm{C}_{\mathrm{Si}}-\mathrm{C}_{\mathrm{S}}\right) \frac{\mathrm{V}}{\overline{\mathrm{V}}}
\end{gathered}
$$

donde $\mathrm{C}_{\mathrm{B}}$ y $\mathrm{C}_{\mathrm{S}}$ son la concentración total de betaína y sacarosa en fase acuosa calculada por el método detallado en el apartado 6.1.3.1, $\mathrm{V}$ es el volumen de las fases. El subíndice i hace referencia a condición inicial y - hace referencia a la fase resina.

La concentración de las especies iónicas de betaína presentes en la fase acuosa se determinó utilizando las ecuaciones (6.3) y (6.4). Los datos obtenidos en las mezclas 
binarias se muestran en la Tabla B4 del apéndice D. Estos resultados demuestran que la extracción de sacarosa es despreciable frente a la extracción de betaína en todos los experimentos realizados.

En la Figura 103 se representa la concentración de betaína en la fase resina frente a la concentración total de betaína en fase acuosa en el equilibrio para distintas mezclas de betaína y sacarosa a $28^{\circ} \mathrm{C}$ y $\mathrm{pH}=6,50 \pm 0,27$.

La extracción de betaína con la RIE no se ve afectada por la presencia de sacarosa. Por tanto, como se observa en la Figura 103 es selectiva.

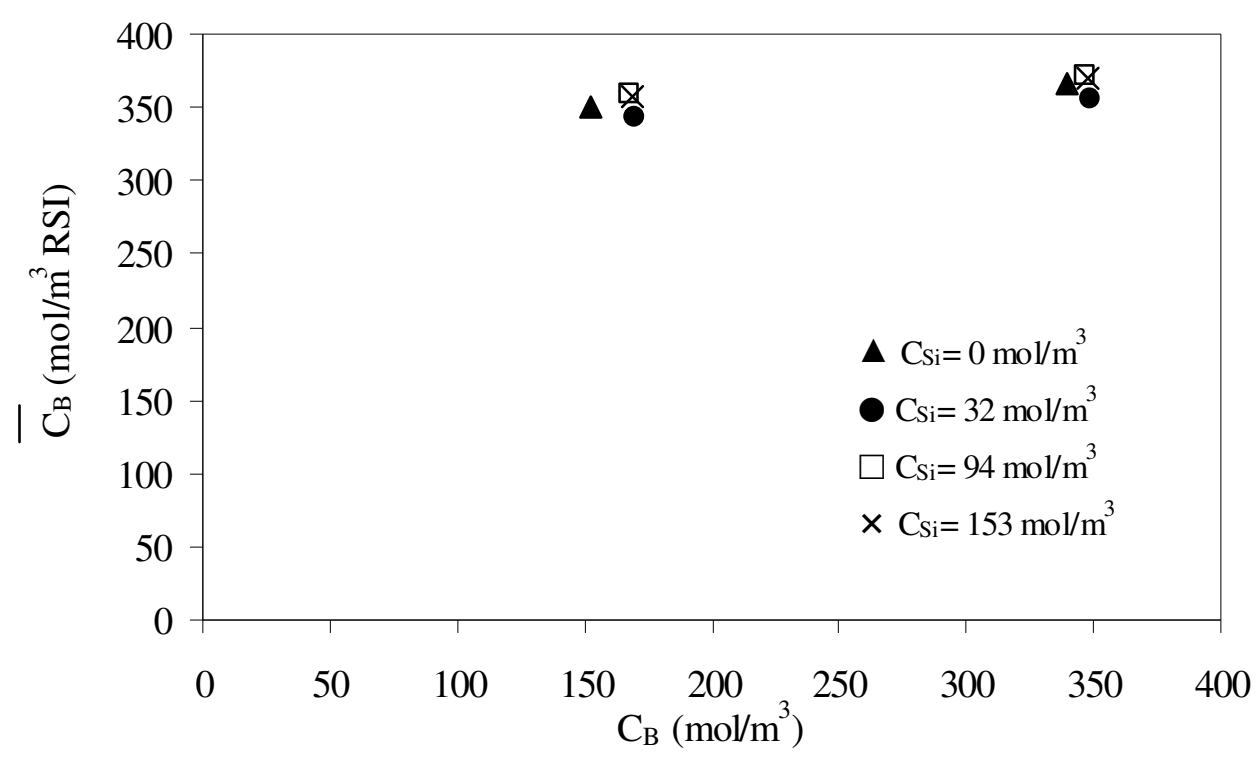

Figura 103. Efecto de la presencia de sacarosa en la extracción de betaína a $\mathrm{pH}_{\mathrm{i}}=6,50 \pm 0,27$ y 28 oC con RIE en mezclas binarias con sacarosa.

En este apartado se concluye que:

- No hay extracción de sacarosa con RIE ni adsorción con RSI. Por tanto, el DNNSA es un extractante selectivo para la betaína en presencia de sacarosa. 


\subsubsection{Cinéticas de extracción de betaina en baños agitados}

El estudio cinético de extracción de betaína con $\mathrm{RIE}$ a $28^{\circ} \mathrm{C}$ y $\mathrm{pH}_{\mathrm{i}}=6,50 \pm 0,27$ ( $\mathrm{pH}$ natural), se realizó empleando el procedimiento y las condiciones experimentales detallados en el apartado 6.1.3.8. La concentración de DNNSA en la RIE fue la misma que se utilizó en los experimentos de equilibrio.

La concentración de betaína en fase resina en el tiempo se obtiene del siguiente balance de materia:

$$
\overline{\mathrm{C}}_{\mathrm{B}}(\mathrm{t})=\left[\overline{\mathrm{RSO}_{3}^{-} \mathrm{B}^{+}}\right](\mathrm{t})=\left(\mathrm{C}_{\mathrm{Bi}}-\mathrm{C}_{\mathrm{B}}(\mathrm{t})\right) \frac{\mathrm{V}}{\overline{\mathrm{V}}}
$$

donde - representa la fase resina, el subíndice $i$ hace referencia a la condición inicial, $C_{B}$ es la concentración total de betaína en fase acuosa, $V$ y $\overline{\mathrm{V}}$ son el volumen de la fase acuosa y de la fase resina, respectivamente, y $\overline{\mathrm{RSO}_{3}^{-} \mathrm{B}^{+}} \mid(\mathrm{t})$ es la concentración de betaína en fase resina dependiente del tiempo t y expresada en $\mathrm{mol} / \mathrm{m}^{3} \mathrm{RSI}$.

Los resultados obtenidos de la evolución de la concentración de betaína en el experimento con RIE a pH natural y $28^{\circ} \mathrm{C}$ se muestran en la Tabla $\mathrm{C} 1$ del Apéndice $\mathrm{D}$ y en la Figura 104.

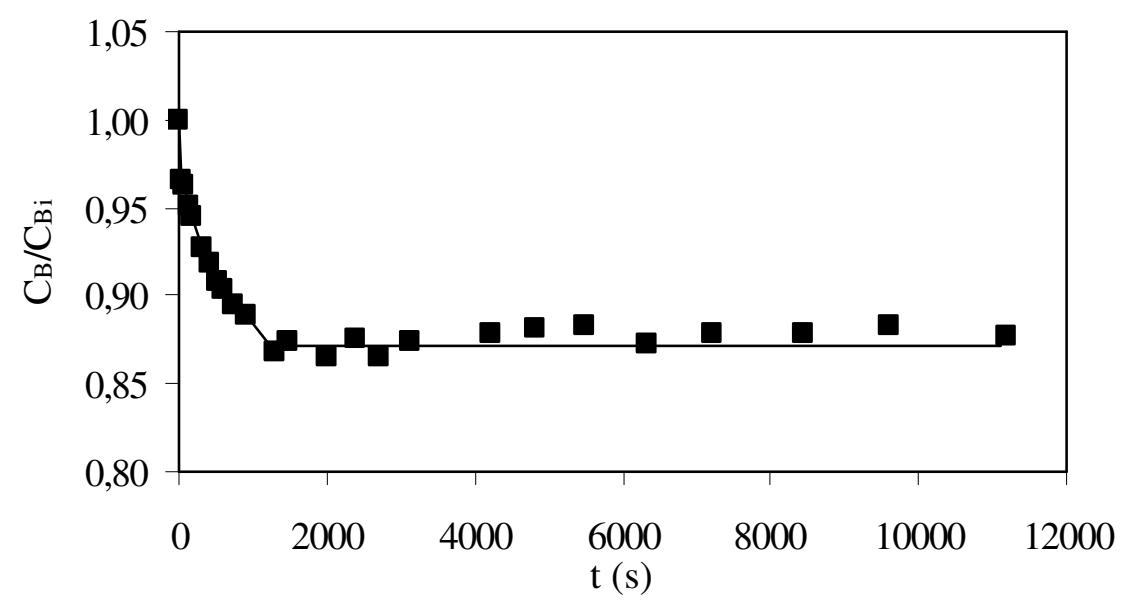

Figura 104. Evolución de la concentración de betaína en la fase acuosa con el tiempo para el experimento cinético con RIE a $\mathrm{pH}_{\mathrm{i}}=6,50 \pm 0,27$ y $28^{\circ} \mathrm{C}$. $\quad\left(\mathrm{C}_{\mathrm{Bi}}=45,37 \mathrm{~mol} / \mathrm{m}^{3}\right.$; $\left.\left[\overline{\mathrm{RSO}_{3}{ }^{-} \mathrm{H}^{+}}\right] \mathrm{i}=500,14 \mathrm{~mol} / \mathrm{m}^{3} \mathrm{RSI}\right)$.

En la Figura 104 se observa que el proceso de extracción de la betaína es rápido, alcanzándose el equilibrio en un tiempo reducido inferior a 40 min. Según los resultados obtenidos de los experimentos de equilibrio, se puede suponer que el proceso se basa en la reacción de intercambio iónico de la betaína con el DNNSA impregnado en los poros de la resina. Por tanto, la velocidad del proceso de intercambio iónico puede estar controlada por la difusión de la betaína en la película líquida externa, por la reacción química en la superficie con el DNNSA retenido en la resina, por la difusión intrapartícula del complejo DNNSA-betaína, o bien por una combinación de dos o más etapas limitantes del proceso cinético de extracción. 


\subsubsection{Determinación de la etapa controlante del proceso cinético}

La etapa controlante del proceso se estimó mediante el modelo cinético desarrollado en el apartado 5.3.1.1, donde la evolución de la concentración de betaína extraída por la $\mathrm{RIE}$, expresada en fracción molar en función del tiempo durante el proceso de extracción, $X$, teniendo en cuenta la estequiometría de la reacción química, se define como:

$$
\mathrm{X}=\frac{\overline{\mathrm{C}}_{\mathrm{B}}(\mathrm{t})}{\left[\overline{\mathrm{RSO}_{3}^{-} \mathrm{H}^{+}}\right]_{\mathrm{i}}}
$$

donde $\left[\overline{\mathrm{RSO}_{3}^{-} \mathrm{H}^{+}}\right]_{\mathrm{i}}$ es la concentración de DNNSA impregnado en la resina expresada en $\mathrm{mol} / \mathrm{m}^{3} \mathrm{RSI} ; \overline{\mathrm{C}}_{\mathrm{B}}(\mathrm{t})$ es la concentración de betaína en fase resina definida en la $\mathrm{Ec}(6.18)$.

El modelo propone las Ecs. (6.20)-(6.22) para evaluar la evolución de la concentración de betaína extraída por la RIE en el tiempo, considerando que el proceso de extracción está controlado independientemente por difusión en la película líquida, en la partícula o por reacción química:

1- Control por difusión en la película líquida externa:

$$
\mathrm{X}=\frac{3 \mathrm{bD}_{\mathrm{f}}}{\mathrm{a} \delta\left[\overline{\mathrm{RSO}_{3}^{-} \mathrm{H}^{+}}\right]_{\mathrm{i}}} \int_{\mathrm{o}}^{\mathrm{t}} \mathrm{C}_{\mathrm{B}}(\mathrm{t}) \mathrm{dt}
$$

2- Control por difusión intrapartícula:

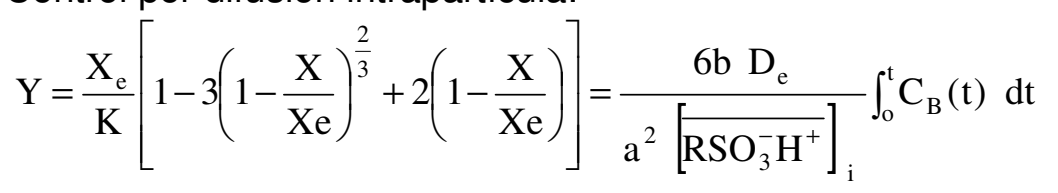

3- Control por reacción química:

$$
\mathrm{Z}=\frac{1}{\mathrm{~K}}\left[1-\left(1-\frac{\mathrm{X}}{\mathrm{Xe}}\right)^{\frac{1}{3}}\right]=\frac{\mathrm{bK}_{\mathrm{C}}}{\mathrm{a}} \int_{\mathrm{o}}^{\mathrm{t}} \mathrm{C}_{\mathrm{B}}(\mathrm{t}) \mathrm{dt}
$$

donde $\delta$ es el espesor de la película líquida estancada, $D_{f}$ y $D_{e}$ son las difusividades en la película líquida externa y en la fase resina, respectivamente; $\mathrm{K}_{c}$ es la constante de velocidad aparente de reacción química; $X_{e}$ es la concentración instantánea de betaína extraída en la superficie externa de la RIE en función del tiempo, expresada en fracción molar; a es el radio de la partícula, siendo para la resina Amberlita XAD-4 a=0,000389 m; $b$ es el coeficiente estequiométrico siendo $b=1$ para la betaína; $C_{B}$ es la concentración de betaína en fase acuosa y $\mathrm{K}$ es el coeficiente de distribución de la betaína en el equilibrio definido como:

$$
\mathrm{K}=\frac{\overline{\mathrm{C}}_{\mathrm{B}(\mathrm{r}=\mathrm{a})}}{\mathrm{C}_{\mathrm{B}}}
$$

donde $\overline{\mathrm{C}}_{\mathrm{B}_{(\mathrm{r}=\mathrm{a})}}$ es la concentración de betaína en la superficie de la RIE en el equilibrio expresada en $\mathrm{mol} / \mathrm{m}^{3} \mathrm{RSI}$ y $\mathrm{C}_{B}$ es la concentración de la betaína en la fase acuosa en el equilibrio expresada en $\mathrm{mol} / \mathrm{m}^{3}$. 
Considerando que toda la superficie de la RIE está en equilibrio con la disolución acuosa extra-partícula y utilizando la Ec. (6.23) se puede definir $\mathrm{X}_{\mathrm{e}}$ con la siguiente relación:

$$
\mathrm{X}_{\mathrm{e}}=\frac{\mathrm{bKC}_{\mathrm{B}}(\mathrm{t})}{\left[\overline{\mathrm{RSO}_{3}^{-} \mathrm{H}^{+}}\right]_{\mathrm{i}}}
$$

Los valores obtenidos de $\mathrm{X}, \mathrm{Y}, \mathrm{Z}$ y $\int_{0}^{\mathrm{t}} \mathrm{C}_{\mathrm{B}}(\mathrm{t}) \mathrm{dt}$ para el experimento realizado, se muestran en la Tabla C2 del apéndice $D$ y en la Figura 105. Como se comentó en el apartado 5.3.1.1, para que el proceso esté controlado por difusión en la película líquida externa, difusión intrapartícula y/o reacción química, al representar $X, Y, Z$ frente a $\int_{0}^{t} C_{B}(t) d t$ se deben obtener líneas rectas con ordenada en el origen cero y de cuya pendiente se puede evaluar los parámetros $\mathrm{K}_{\mathrm{f}}, \mathrm{D}_{\mathrm{e}}$ y $\mathrm{K}_{\mathrm{C}}$, respectivamente.

En la Figura 105 se observa que las Ecs. (6.20) y (6.21) no ajustan a los datos $X, Z$ frente $a \int_{0}^{t} C_{B}(t) d t$, así se puede concluir que la difusión en la película externa y la reacción química no son etapas limitantes del proceso de transferencia de materia. Sin embargo, la Ec. (6.21) proporciona un buen ajuste de los datos experimentales, lo cuál indica que el proceso está controlado por difusión intrapartícula, resultado análogo al obtenido para la extracción de los aminoácidos ácido aspártico y a-fenilglicina, anteriormente estudiados. El valor de la difusividad efectiva de la betaína, $D_{e}$, calculado con la Ec. (6.21) fue de $D_{e}=$ $1,14 \times 10^{-11}\left(\mathrm{~m}^{2} / \mathrm{s}\right)$, con una regresión lineal, $r$ de 0,993 .

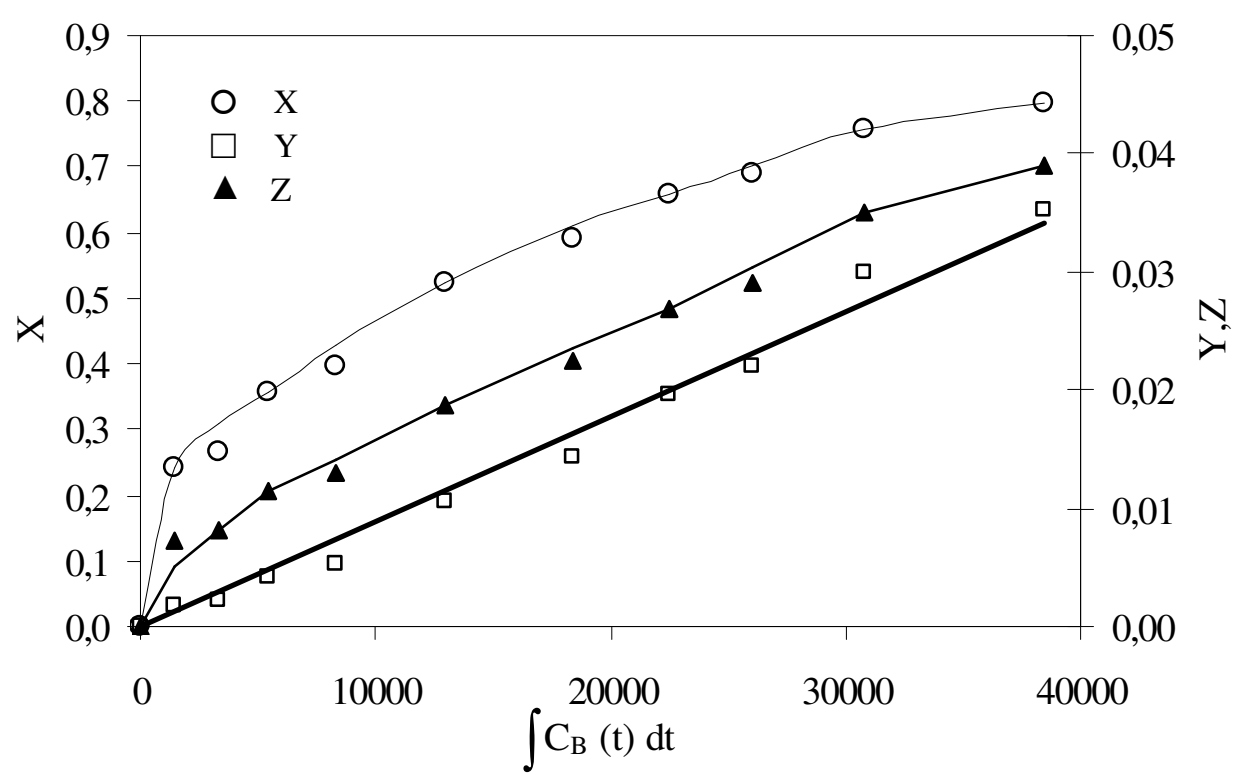

Figura 105. Determinación de la etapa controlante de la velocidad de extracción de betaína con RIE para el experimento cinético realizado a $\mathrm{pH}_{\mathrm{i}}=6,50 \pm 0,02$ y $28^{\circ} \mathrm{C}$. $\left(\mathrm{C}_{\mathrm{Bi}}=45,37\right.$

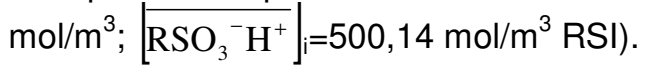




\subsubsection{Modelo cinético basado en la ley de Fick}

El modelo más sencillo de difusión de partícula (intrapartícula) es el descrito por la segunda ley de Fick, y debido a su simplicidad y rigor es el que se adopta en el estudio de los datos cinéticos experimentales al igual que se hizo con los aminoácidos ácido aspártico y a-fenilglicina.

Este modelo considera una reacción de intercambio iónico heterogénea entre las partículas esféricas de la RIE y la disolución acuosa agitada de volumen finito en la cual están inmersas. La resistencia a la difusión en la película líquida externa se puede considerar despreciable, por efecto de la agitación. En la interfase líquido-sólido se mantiene un equilibrio instantáneo y $\mathrm{K}$ es el coeficiente de distribución de la especie que difunde entre ambas fases, definido en la Ec. (6.23). Posteriormente, la especie extraída en la superficie de la RIE difunde lentamente al interior de la fase resina. Además, se asume que la concentración de betaína en el seno de la fase acuosa varía con el tiempo y que la difusividad en la fase resina es constante.

Bajo estas condiciones, el balance de materia en coordenadas esféricas, aplicado a la betaína en fase resina, puede expresarse como:

$$
\frac{\partial \overline{\mathrm{C}}_{\mathrm{B}}(\mathrm{r}, \mathrm{t})}{\partial \mathrm{t}}=\mathrm{D}_{\mathrm{e}} \frac{1}{\mathrm{r}^{2}} \frac{\partial}{\partial \mathrm{r}}\left(\mathrm{r}^{2} \frac{\partial \overline{\mathrm{C}}_{\mathrm{B}}(\mathrm{r}, \mathrm{t})}{\partial \mathrm{r}}\right) ; 0 \leq \mathrm{r} \leq \mathrm{a} ; \mathrm{t}>0
$$

con las condiciones límite e iniciales que se citan a continuación:

$$
\begin{array}{lll}
\overline{\mathrm{C}}_{\mathrm{B}}(\mathrm{r}, \mathrm{t})=\mathrm{KC}_{\mathrm{B}}(\mathrm{t}) & \mathrm{r}=\mathrm{a} & \mathrm{t}>0 \\
\overline{\mathrm{C}}_{\mathrm{B}}(\mathrm{r}, \mathrm{t})=0 & 0 \leq \mathrm{r} \leq \mathrm{a} & \mathrm{t}=0 \\
\overline{\mathrm{C}}_{\mathrm{B}}(\mathrm{r}, \mathrm{t})=\text { finito } & r=0 & \mathrm{t} \geq 0
\end{array}
$$

La cantidad de betaína extraída en la RIE en función del tiempo expresada en unidades de $\mathrm{mol}, \mathrm{M}(\mathrm{t})$, se puede determinar conociendo la cantidad de betaína transferida de la disolución acuosa, utilizando la siguiente igualdad:

$$
M(t)=V\left(C_{B i}-C_{B}(t)\right)=4 \pi N \int_{0}^{a} r^{2} \bar{C}_{B}(r, t) d r
$$

donde a es el radio de la partícula de resina y $\mathrm{N}$ es el número de partículas de resina en la suspensión.

La fracción final de betaína extraída en la RIE en un volumen de disolución finito se expresa en términos del parámetro $\alpha$ con la siguiente ecuación:

$$
\mathrm{M}(\infty)=\frac{\mathrm{V} \mathrm{C}_{\mathrm{B}_{\mathrm{i}}}}{1+\alpha}
$$


Como se comentó en el apartado 5.3.1.2, la solución del modelo propuesto, Ec. (6.31), representa la fracción de betaína extraída por la RIE en función del tiempo (Crank J., 1975; Ruiz M.O., 2002).

$$
\frac{M(t)}{M(\infty)}=1-\sum_{n=1}^{\infty} \frac{6 \alpha(1+\alpha) \exp \left(-g_{n} \frac{D_{e t}}{a^{2}}\right)}{9+9 \alpha+\alpha^{2} g_{n}^{2}}
$$

donde $g_{n}$ son las raíces distintas de cero de la ecuación (6.32) y $\alpha$ es un número adimensional definido en la Ec. (6.33).

$$
\begin{aligned}
& \frac{g_{n}}{\tan g_{n}}=1+\frac{\alpha g_{n}^{2}}{3} \\
& \alpha=\frac{3 V}{4 \pi a^{3} N K}=\frac{V}{\bar{V} K}
\end{aligned}
$$

La Ec. (6.31) muestra que $\mathrm{M}(\mathrm{t}) / \mathrm{M}(\infty)$ es función de la difusividad efectiva, $\mathrm{D}_{\mathrm{e}}$, y de $\alpha$ cuyo valor depende de la concentración inicial de betaína en la fase acuosa y de la concentración de DNNSA en la RIE, tal como se muestra en la Ec. (6.30).

En la Figura 106 se representa el $\log (1-\mathrm{M}(\mathrm{t}) / \mathrm{M}(\infty))$ frente al tiempo, para el experimento cinético realizado. El valor de la difusividad efectiva de la betaína, $D_{e}$, se obtiene de la resolución conjunta de las Ecs. (6.31)-(6.33) con el coeficiente de distribución, K, obtenido experimentalmente ( $\left.\mathrm{K}_{\text {experimental }}\right)$, y calculado con el modelo de equilibrio desarrollado en el apartado 6.3.4.1 ( $\mathrm{K}_{\text {calculado }}$ ). En este segundo caso, se empleó la siguiente ecuación para el cálculo de K:

$$
\mathrm{K}=\frac{\left[\overline{\mathrm{RSO}_{3}^{-} \mathrm{B}^{+}}\right]}{\mathrm{C}_{\mathrm{B}}}=\frac{\sqrt{\left(\frac{\mathrm{VK}_{\mathrm{p} 1}\left[\mathrm{~B}^{+}\right]}{2 \overline{\mathrm{V}}}\right)^{2}+\frac{\mathrm{VK}_{\mathrm{pl}}\left[\mathrm{B}^{+}\right]\left[\overline{\left.\mathrm{RSO}_{3}^{-} \mathrm{H}^{+}\right]}\right.}{\overline{\mathrm{V}}}}-\frac{\mathrm{VK}_{\mathrm{p} 1}\left[\mathrm{~B}^{+}\right]}{2 \overline{\mathrm{V}}}}{\mathrm{C}_{\mathrm{B}}}
$$

donde $\left.\overline{\mathrm{RSO}_{3}^{-} \mathrm{B}^{+}}\right]$se sustituye por la Ec. (6.15) del apartado 6.3.4.1.

El porcentaje de error se estimó con la Ec. (5.64) representa el cociente entre la desviación estándar $(\sigma)$ del coeficiente de difusión intrapartícula efectivo (con el valor de $\mathrm{K}_{\text {experimental }} \mathrm{y}$ de $\mathrm{K}_{\text {calculada }}$ ) y el valor de $\mathrm{D}_{\mathrm{e}}$ estimado con $\mathrm{K}_{\text {experimental }}$ :

$$
\% \text { Error }=\frac{\sigma \times 100}{D_{\mathrm{e}}}
$$


En la Figura 106 se observa una buena concordancia entre las velocidades de medidas experimentalmente (símbolos) y las calculadas con las Ecs. (6.31)-(6.33) (líneas).

El valor de $D_{e}$ estimado para la betaína fue de $D_{e}=7,5 \times 10^{-11} \mathrm{~m}^{2} / \mathrm{s}$, con un error inferior al $0,1 \%$, indicando que el modelo de equilibrio describe adecuadamente la extracción de betaína en el intervalo de concentraciones estudiado con RIE a pH natural y a $28^{\circ} \mathrm{C}$.

Al igual que con los aminoácidos anteriormente estudiados, los valores de difusividad efectiva obtenidos con la segunda ley de Fick, Ecs. (6.31)-(6.33), son mayores que los obtenidos con el modelo obtenido de Bhandari, Ec. (6.21).

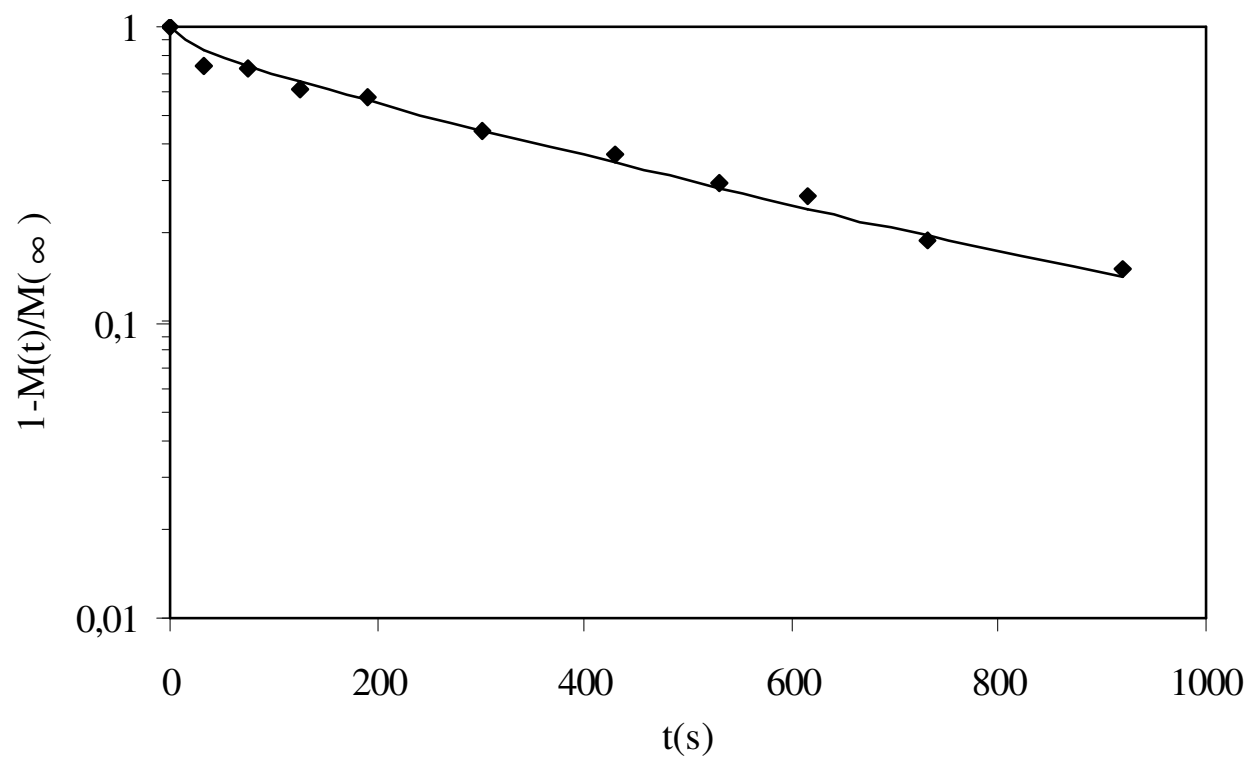

Figura 106. Velocidad de extracción de betaína con RIE para experimento cinético en baño agitado a $\mathrm{pH}_{\mathrm{i}}=6,50 \pm 0,27$ y $28^{\circ} \mathrm{C}$. $\left(\mathrm{C}_{\mathrm{Bi}}=45,37 \mathrm{~mol} / \mathrm{m}^{3} ; \mid \mathrm{RSO}_{3}{ }^{-} \mathrm{H}^{+}{ }_{i}=500,14 \mathrm{~mol} / \mathrm{m}^{3} \mathrm{RSI}\right)$. Símbolos: datos experimentales. Líneas: datos calculados con las Ecs. (6.31)-(6.33) y con el valor de $\mathrm{K}_{\text {experimental. }}$

A partir de los datos cinéticos obtenidos con el modelo, Ecs (6.31)-(6.33), se puede determinar el valor de la concentración de betaína calculada. En la Figura 107 se representa el ajuste entre los datos experimentales (símbolos) y los calculados a partir del modelo cinético (líneas). El error estimado con la Ec. (6.16) fue inferior al 4,65\%.

$\%$ error promediado $=\frac{100}{\mathrm{j}} \sum_{1}^{\mathrm{j}} \frac{\left(\left(\overline{\mathrm{C}}_{\mathrm{B}}{ }_{\mathrm{Cal}}-\overline{\mathrm{C}}_{\mathrm{B}}{ }_{\operatorname{Exp}}\right)^{2}\right)^{1 / 2}}{\overline{\mathrm{C}}_{\mathrm{B}} \operatorname{Exp}}$ 


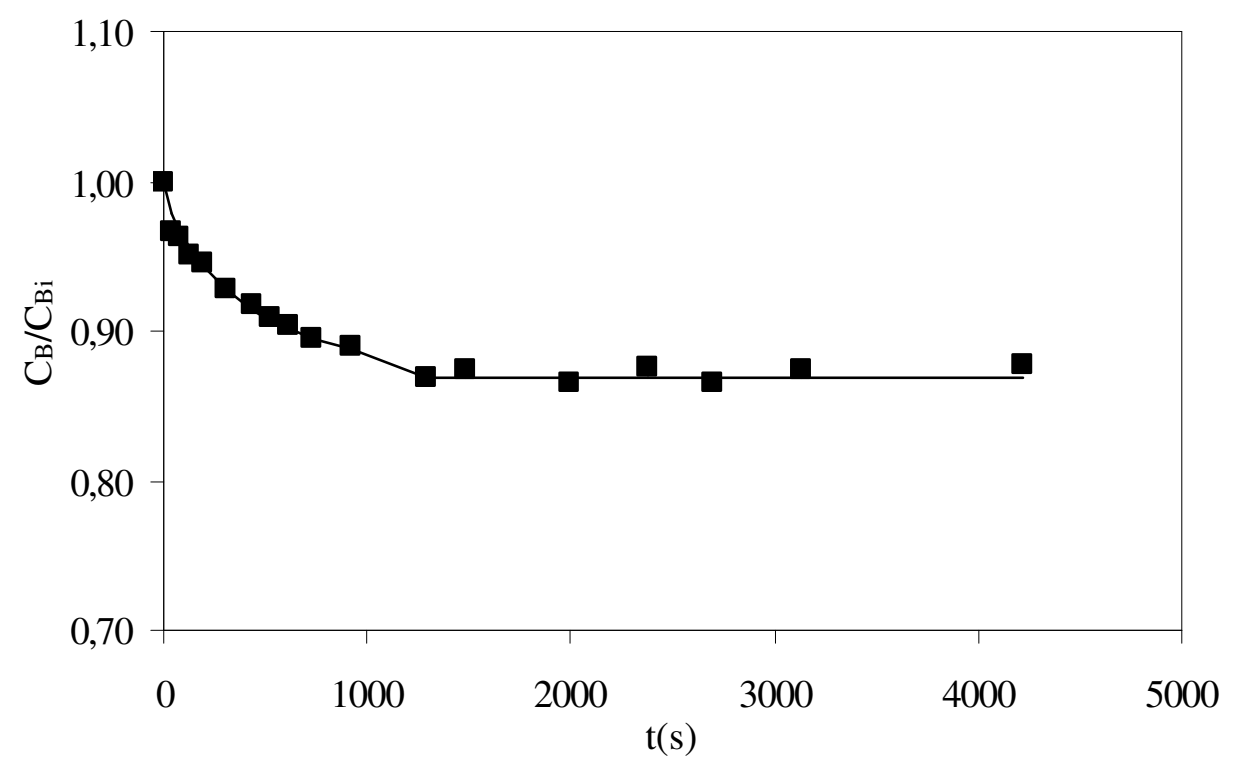

Figura 107. Evolución de la concentración de betaína con el tiempo con $\mathrm{RIE}$ a $\mathrm{pH}_{\mathrm{i}}=6,50 \pm 0,27$ y 28ํㅡ. Símbolos: datos experimentales. Líneas: datos calculados a partir del modelo cinético y con la definición de $\mathrm{M}(\mathrm{t})$ Ec. (6.29). $\left(\mathrm{C}_{\mathrm{Bi}}=45,37 \mathrm{~mol} / \mathrm{m}^{3} ; \quad\left[\mathrm{RSO}_{3}{ }^{-} \mathrm{H}^{+}\right]_{\mathrm{i}}=500,14\right.$ $\left.\mathrm{mol} / \mathrm{m}^{3} \mathrm{RSI}\right)$.

En base a lo expuesto, se puede concluir:

- El proceso cinético de extracción de betaína con RIE de disoluciones acuosas es rápido y se alcanza el equilibrio a tiempos reducidos, inferiores a 40 minutos.

- Un modelo cinético basado en la segunda ley de Fick correlacionó adecuadamente los resultados experimentales de la cinética de extracción de betaína en tanques agitados. Este modelo considera que el proceso de transferencia de materia está controlado por la difusión intrapartícula del complejo betaína-DNNSA y que existe un equilibrio instantáneo en la interfase sólidolíquido. El valor de $D_{e}$ obtenido con el modelo fue de $7,5 \times 10^{-11} \mathrm{~m}^{2} / \mathrm{s}$. 


\subsubsection{Extracción de betaina en columnas de lecho fijo}

Las curvas de ruptura de extracción de betaína con RIE a $28^{\circ} \mathrm{C}$ se determinaron con el procedimiento experimental detallado en el apartado 6.1.3.9. Las condiciones iniciales de los experimentos realizados se muestran en la Tabla 24. Los resultados obtenidos se recogen en las Tablas D1-D5 del apéndice D.

Al igual que se describió en el apartado 5.4.1, los volúmenes de lecho, (VL), se evaluan con la Ec (5.98) y la porosidad del lecho, $\varepsilon_{\mathrm{L}}$, con la Ec. (5.99):

$$
\begin{array}{r}
\mathrm{VL}=\frac{\mathrm{Qt}}{\mathrm{V}_{\mathrm{L}}\left(1-\varepsilon_{\mathrm{L}}\right)} \\
\varepsilon_{\mathrm{L}}=\frac{\mathrm{m}_{\text {Hue cos }} / \rho}{\mathrm{V}_{\mathrm{L}}}
\end{array}
$$

La Figura 108 muestra las curvas de ruptura de extracción de betaína a 28ํㅡ, correspondientes al estudio del efecto del pH, para los experimentos I y II de la Tabla 24, utilizando la misma concentración de betaína, flujo de la alimentación y la misma concentración de DNNSA en la resina. En esta Figura, se observa que no hay punto de ruptura para el experimento a $\mathrm{pH}_{\mathrm{i}}=2,13$, y que el de saturación se alcanza a volumenes de lecho inferiores al obtenido en el experimento I a $\mathrm{pH}=6,50$ y por tanto, demuestra que se debe operar con $\mathrm{pH}$ de 6,50.

En la Figura 109 se representan las curvas de ruptura de extracción de betaína para los experimentos I, III y IV de la Tabla 24. En estas Figuras se estudia el efecto de la concentración de betaína en la alimentación, utilizándose la misma velocidad de flujo, concentración de DNNSA en la RIE y $\mathrm{pH}_{\mathrm{i}}$. Se observa que al aumentar la concentración de betaína, tanto el punto de ruptura como el punto de saturación se desplazan volúmenes de lecho inferiores, disminuyendo el tiempo de operación de la columna. Este resultado también se observó en los experimentos realizados con los aminoácidos ácido aspártico y $\alpha$-fenilglicina. 


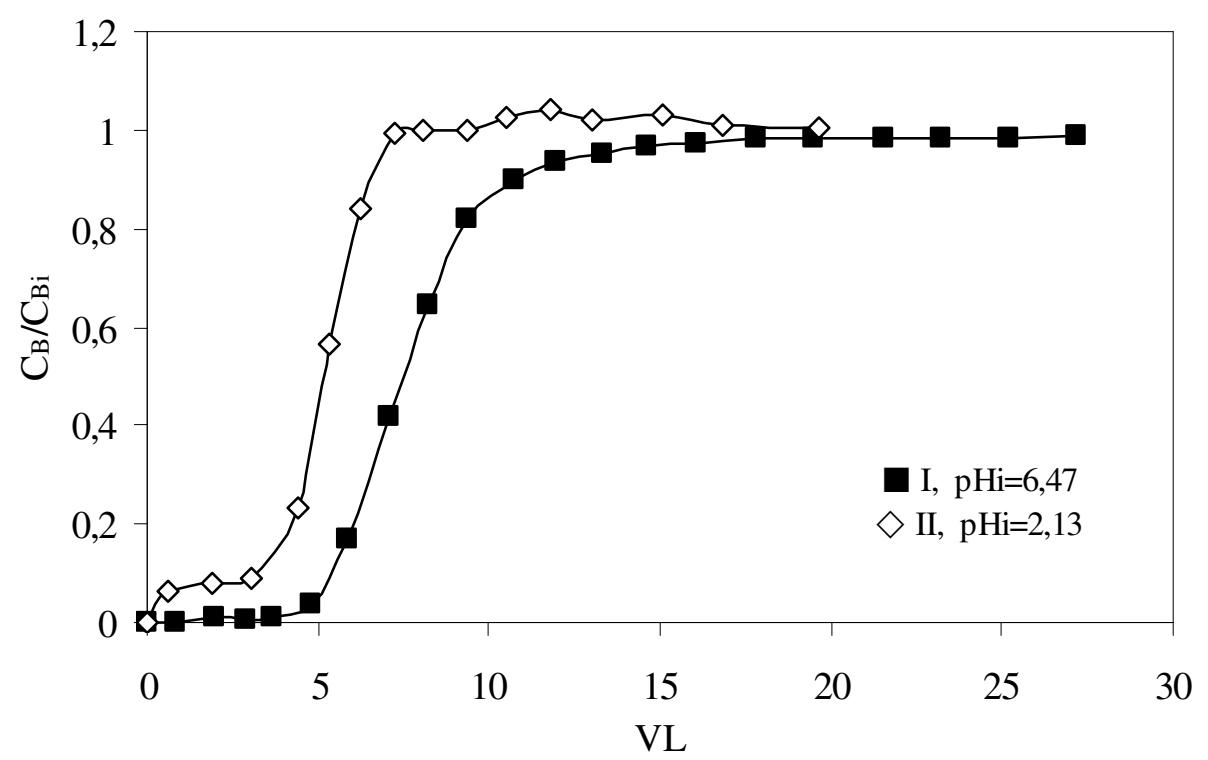

Figura 108. Efecto del $\mathrm{pH}$ en las curvas de ruptura de extracción de betaína a $28^{\circ} \mathrm{C}$ con RIE para los experimentos I y II de la Tabla 24. $\left(\mathrm{C}_{\mathrm{Bi}}=41,07 \mathrm{~mol} / \mathrm{m}^{3} ; \mid \mathrm{RSO}_{3}{ }^{-} \mathrm{H}^{+}{ }_{j}=500,14 \mathrm{~mol} / \mathrm{m}^{3}\right.$ $\mathrm{RSI})$.

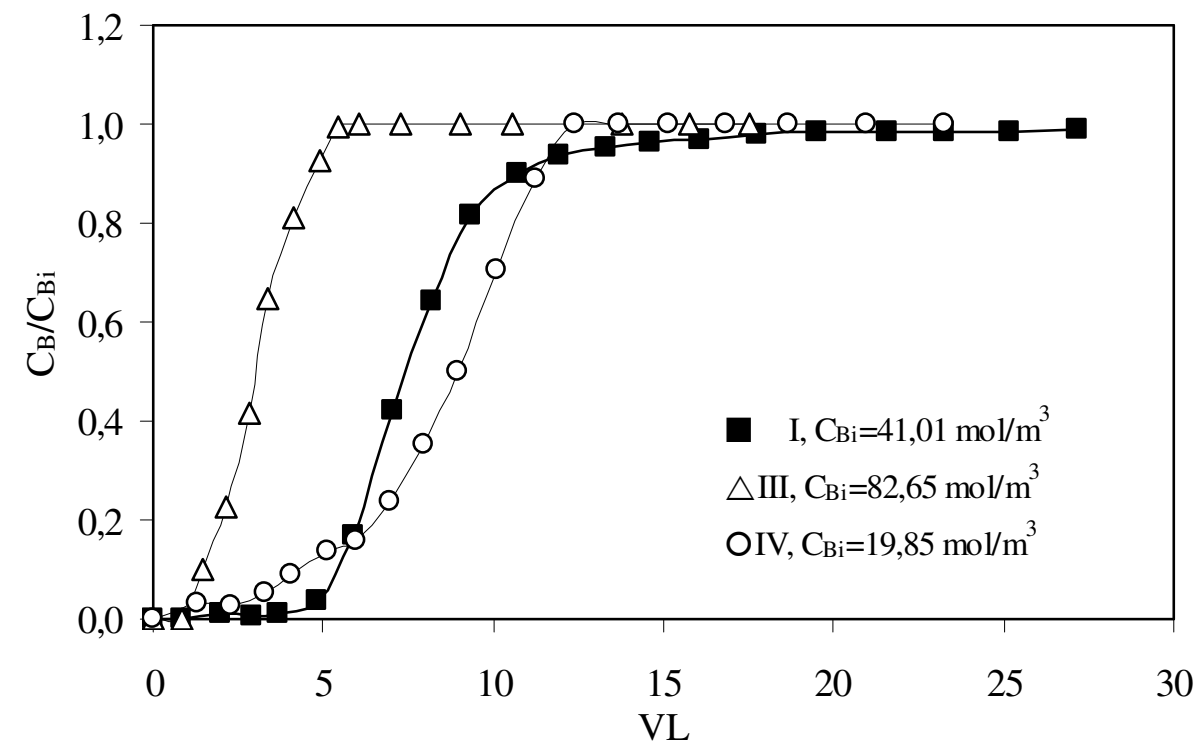

Figura 109. Efecto de la concentración de betaína en la alimentación en las curvas de ruptura de extracción de betaína a ${ }^{2} 8^{\circ} \mathrm{C}$ con RIE para los experimentos I, III y IV de la Tabla 24. $\left.\left(\mathrm{pH}_{\mathrm{i}}=6,50 \pm 0,27 ; \widehat{\mathrm{RSO}_{3}{ }^{-} \mathrm{H}^{+}}\right]_{\mathrm{i}}=500,14 \mathrm{~mol} / \mathrm{m}^{3} \mathrm{RSI}\right)$. 
Las curvas de ruptura de extracción de betaína correspondientes al estudio del efecto de la velocidad de flujo de la alimentación, para los experimentos I y $\mathrm{V}$ de la Tabla 24, se muestran en la Figura 110. En estos experimentos se utilizó la misma concentración de DNNSA en la RIE, $\mathrm{pH}_{\mathrm{i}}$ y la misma concentración de betaína en la alimentación.

Al igual que en los experimentos de ácido aspártico y a-fenilglicina, las curvas de ruptura de extracción de betaína están afectadas por la velocidad de flujo de la alimentación. Un aumento de la velocidad de flujo produce un desplazamiento del punto de ruptura hacia volúmenes de lecho más bajos. Este hecho puede deberse a que al aumentar la velocidad del flujo, se reduce el tiempo de residencia y disminuye el tiempo de contacto entre la RIE y la alimentación, obteniéndose efluentes con cantidad apreciable de betaína desde volúmenes de lecho a tiempos reducidos, este efecto es debido a que el proceso cinético de extracción de betaína con RIE presenta una elevada resistencia de difusión intrapartícula, y por tanto una lenta velocidad de transferencia de materia.

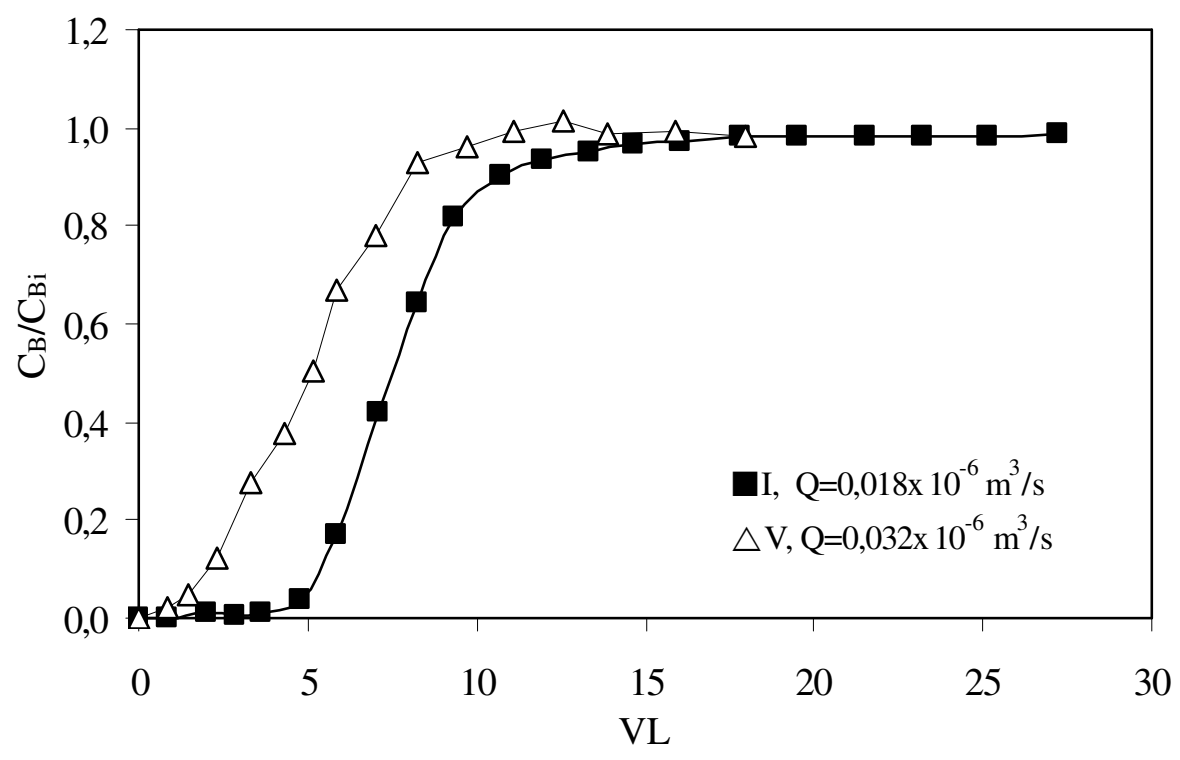

Figura 110. Efecto del caudal de la alimentación en las curvas de ruptura de extracción de betaína a $28^{\circ} \mathrm{C}$ con RIE para los experimentos I y V de la Tabla 24 . $\left(\mathrm{C}_{\mathrm{Bi}}=39,55 \pm 1,5 \mathrm{~mol} / \mathrm{m}^{3}\right.$;

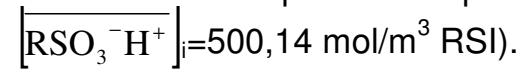

\subsubsection{Selección de agente de reextracción para la betaína}

Con el objeto de seleccionar un agente de reextracción óptimo para la betaína, se realizaron unas pruebas con diferentes disoluciones de reextracción siguiendo el procedimiento descrito en el apartado 6.1.3.10.

Los resultados obtenidos se muestran en la Figura 111, donde se observa que el grado de extracción con hidróxido de sodio $0,5 \mathrm{~N}$ es mayor y por tanto se seleccionó para los posteriores experimentos de extracción-reextracción de betaína. 


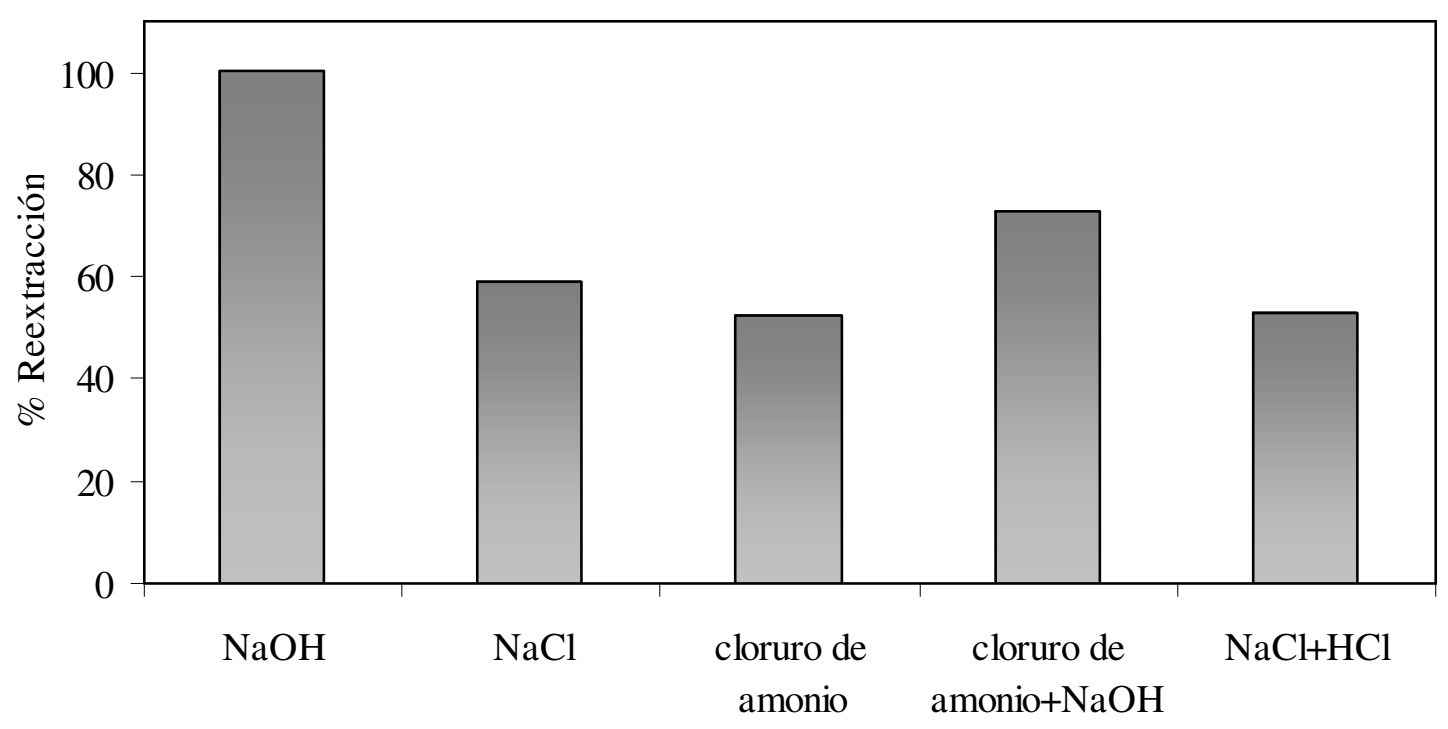

Figura 111. Selección de agente de reextracción para la betaína, \% de reextracción de betaína de RIE con distintos agentes de reextracción.

\subsubsection{Reextracción y ciclos sucesivos de extracción de betaína}

Los experimentos de extracción-reextracción de betaína y la regeneración del lecho de RIE se realizaron siguiendo el procedimiento experimental del apartado 6.1.3.11 y en las condiciones iniciales y de operación mostradas en la Tabla 25.

Los resultados de las curvas de ruptura de los ciclos sucesivos de extracción y de reextracción se recogen en las Tablas E del Apéndice D. En la Figura 112 se representan los ciclos sucesivos de reextracción de betaína de lechos fijos de XAD-4 impregnada de DNNSA, observándose que los cambios no son significativos, y que el proceso de reextracción es rápido con una recuperación mayor del 95\% de betaína presente en la RIE.

En la Figura 113 se representan las curvas de ruptura correspondientes al $1^{\text {er }}, 2^{\circ}$ y $3^{\text {er }}$ ciclo de extracción de betaína para los experimentos I a-c de la Tabla 25. Se puede observar que el $2^{\circ}$ y $3^{\text {er }}$ ciclo de extracción presentan puntos de ruptura y de saturación similares, las diferencias en el punto de ruptura en el primer ciclo pueden ser debidas a que la RIE necesita al menos un ciclo para acondicionarse y así poder estabilizar su capacidad de extracción. 


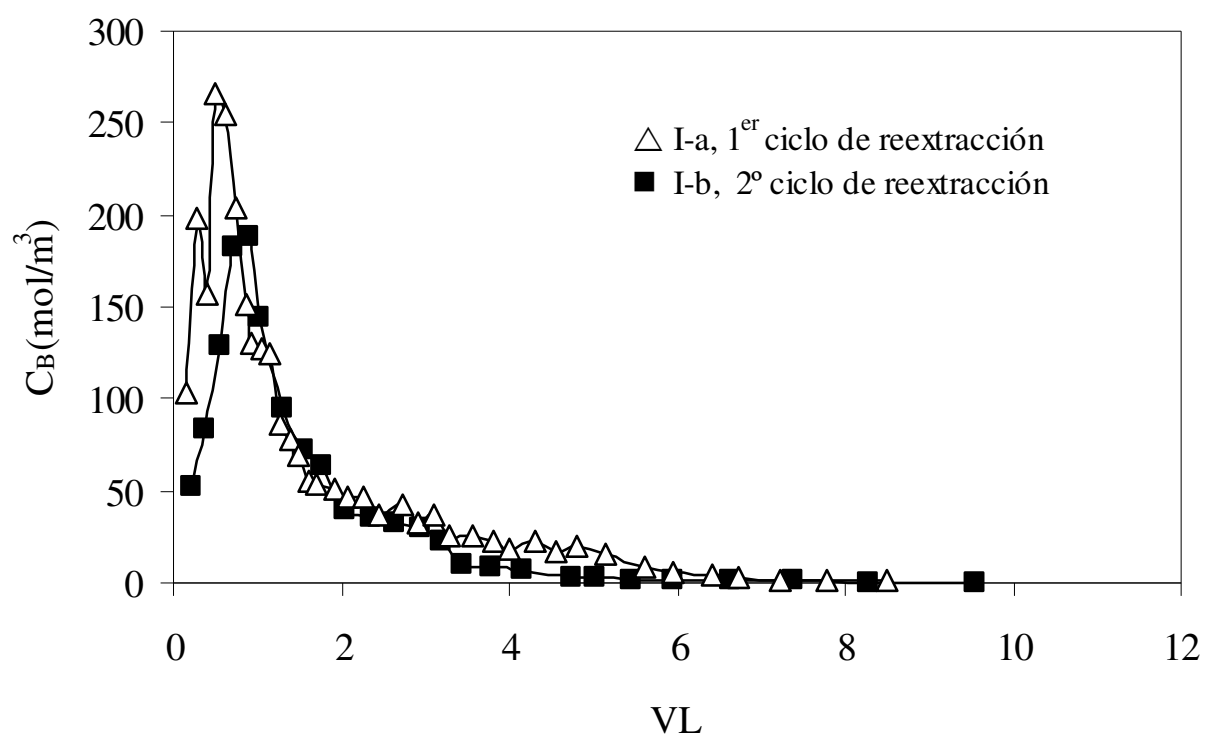

Figura 112. Curvas de ciclos sucesivos de reextracción de betaína para los experimentos I-a y I-b de la Tabla $25\left(\mathrm{C}_{\mathrm{NaOH}}=0,5 \mathrm{~N}\right)$.

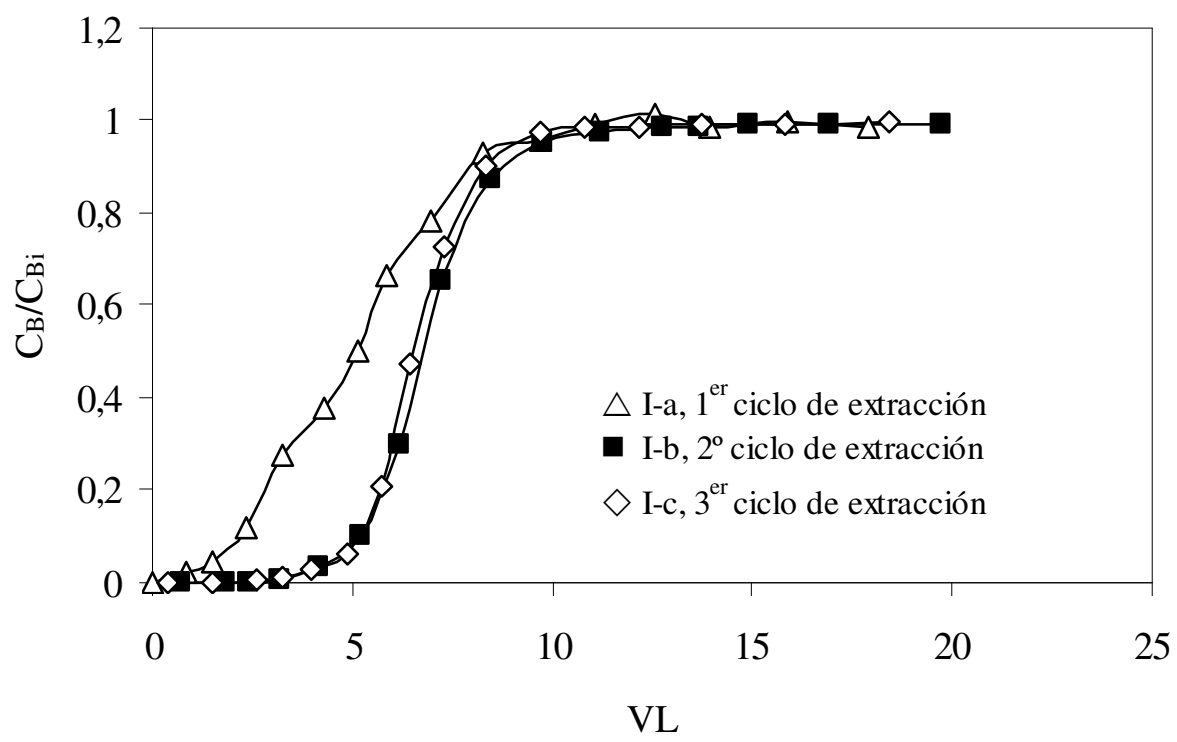

Figura 113. Curvas de ruptura de los ciclos sucesivos de extracción de betaína para los experimentos I a-c de la Tabla 25.

La capacidad de saturación del lecho se calculó, al igual que en los experimentos con los aminoácidos ácido aspártico y a-fenilglicina, realizando un balance de materia a la betaína en la columna, desde el inicio del proceso $(t=0)$, hasta que el efluente alcanzó la concentración de la alimentación $\left(\mathrm{t}_{\mathrm{s}}\right.$ ). Los moles de betaína que se acumulan, entre los huecos del lecho y dentro de la partícula, se calculan con la siguiente expresión: 
$\begin{aligned} & \text { moles de betaína } \\ & \text { acumulados en el lecho }\end{aligned}=\mathrm{Q}\left[\mathrm{C}_{\mathrm{Bi}} \int_{\mathrm{o}}^{\mathrm{t}_{\mathrm{s}}} \mathrm{dt}-\int_{\mathrm{o}}^{\mathrm{t}_{\mathrm{s}}} \mathrm{C}_{\mathrm{B}}(\mathrm{t}) \mathrm{dt}\right]$

donde $Q$ es el caudal de circulación expresado en $\mathrm{m}^{3} / \mathrm{s}, \mathrm{C}_{\mathrm{Bi}}$ es la concentración de betaína en la alimentación expresada en $\mathrm{mol} / \mathrm{m}^{3}, \mathrm{C}_{\mathrm{B}}(\mathrm{t})$ es la concentración de betaína en el efluente, expresada en $\mathrm{mol} / \mathrm{m}^{3}$ y $\mathrm{t}_{\mathrm{s}}$ es el tiempo en que el efluente alcanza el valor de la concentración de la alimentación.

La acumulación de betaína retenida en los huecos del lecho de RIE, se puede calcular con el siguiente balance de materia, donde se supone un lecho ideal sin extracción:

$$
\varepsilon_{\mathrm{L}} \mathrm{V}_{\mathrm{L}} \frac{\mathrm{dC}_{\mathrm{B}}^{*}}{\mathrm{dt}}=\mathrm{Q}\left(\mathrm{C}_{\mathrm{Bi}}-\mathrm{C}^{*}{ }_{\mathrm{B}}\right)
$$

donde $C^{*}{ }_{B}$ es la concentración de betaína que tendría el efluente suponiendo que no hay extracción bajo las condiciones del proceso, VL es el volumen del lecho de RIE $\left(15 \mathrm{~cm}^{3}\right)$ y $\varepsilon_{\mathrm{L}}$ es la porosidad del lecho evaluada con la Ec. (5.99).

El valor de $C^{*}{ }_{B}$ se determina con la Ec. (6.37), obtenida de la integración de la Ec. (6.36).

$$
\mathrm{C}_{\mathrm{B}}^{*}(\mathrm{t})=\mathrm{C}_{\mathrm{Bi}}\left(1-\mathrm{e}^{\frac{-\mathrm{Qt}}{\varepsilon_{\mathrm{L}} \mathrm{V}_{\mathrm{L}}}}\right)
$$

El cálculo de $\mathrm{C}^{*}{ }_{\mathrm{B}}(\mathrm{t})$ demuestra que la acumulación de betaína en los huecos del lecho es despreciable frente a su extracción con el DNNSA de la RIE para todos los experimentos realizados.

Considerando que el término de acumulación es el calculado con la Ec. (6.35) y dividiendo entre el volumen de RSI que compone el lecho, se obtiene la siguiente expresión para el cálculo de la capacidad de saturación:

$$
\mathrm{Q}_{\mathrm{s}}=\frac{\mathrm{Q}\left[\mathrm{C}_{\mathrm{Bi}} \int_{\mathrm{o}}^{\mathrm{t}_{\mathrm{s}}} \mathrm{dt}-\int_{\mathrm{o}}^{\mathrm{t}_{\mathrm{s}}} \mathrm{C}_{\mathrm{B}}(\mathrm{t}) \mathrm{dt}\right]}{\mathrm{V}_{\mathrm{RSI}}}
$$

donde $\mathrm{V}_{\mathrm{RSI}}$ es el volumen del lecho expresado en $\mathrm{m}^{3}$ de resina sin impregnar.

Como muestra la Tabla 26, la pérdida de capacidad de saturación entre el $2^{\circ}$ y $3^{\text {er }}$ ciclo se demostró que es despreciable. La diferencia de capacidad en el $1^{\text {er }}$ ciclo es debida a que la concentración de betaína fue un $20 \%$ inferior a la de los ciclos posteriores.

Tabla 26. Valores de capacidad de saturación, $Q_{s}$, calculada con la Ec. (6.38), para los experimentos cinéticos de la Tabla 25.

\begin{tabular}{ccc}
\hline Experimento & $\mathrm{C}_{\mathrm{Bi}}\left(\mathrm{mol} / \mathrm{m}^{3}\right)$ & $\mathrm{Q}_{\mathrm{s}}\left(\mathrm{mol} / \mathrm{m}^{3} \mathrm{RSI}\right)$ \\
\hline I-a $1^{\text {er }}$ ciclo & 38,10 & 226,11 \\
$\mathrm{I}-\mathrm{b} 2^{\circ}$ ciclo & 48,16 & 377,99 \\
$\mathrm{I}-\mathrm{c} 3^{\text {er }}$ ciclo & 47,73 & 373,01 \\
\hline
\end{tabular}




\subsubsection{Modelo dinámico para la estimación de las curvas de ruptura de betaína}

Para la estimación de las curvas de ruptura de extracción de betaína se aplicó el mismo modelo que se utilizó para la extracción de ácido aspártico y de a-fenilglicina en lechos fijos de RIE, mostrado en el apartado 5.4.3, y cuya solución analítica fue dada por Rosen (Rosen J. B., 1952; Rosen J. B., 1954) mediante la siguiente expresión:

$$
\frac{\mathrm{C}_{\mathrm{B}}}{\mathrm{C}_{\mathrm{Bi}}}=\frac{1}{2}\left[1+\operatorname{erf}\left(\frac{\frac{3 \tau}{2 \lambda}-1}{2 \sqrt{\frac{1+5 \psi}{5 \lambda}}}\right)\right]
$$

donde erf es la función de error (Crank J., 1975), y los números adimensionales $\lambda, \tau$, y $\psi$ se definen como:

$$
\begin{aligned}
& \lambda=3 \frac{D_{\mathrm{e}}}{\mathrm{a}^{2}} \frac{\mathrm{K} \mathrm{z}}{\mathrm{u}} \frac{\left(1-\varepsilon_{\mathrm{L}}\right)}{\varepsilon_{\mathrm{L}}} \\
& \tau=2 \frac{\mathrm{D}_{\mathrm{e}}}{\mathrm{a}^{2}}\left(\mathrm{t}-\frac{\mathrm{L}}{\mathrm{u}}\right) \\
& \psi=3 \frac{\mathrm{D}_{\mathrm{e}}}{\mathrm{a}} \frac{\mathrm{K}}{\mathrm{k}_{\mathrm{f}}}
\end{aligned}
$$

donde $\lambda$, es el parámetro de la longitud, $\tau$, es el parámetro del tiempo, $\psi$ es el parámetro de las resistencias, $k_{f}$ es el coeficiente de transferencia de materia en la película líquida externa expresada en $\mathrm{m} / \mathrm{s}, D_{e}$ es la difusividad efectiva intrapartícula calculada en los ensayos cinéticos en baños agitados (apartado 6.3.6.2) y cuyo valor fue $D_{e}=7,5 \times 10^{-11}$ $\mathrm{m}^{2} / \mathrm{s}$. Además, el coeficiente de distribución, $\mathrm{K}$, queda definido por la relación de concentraciones en el equilibrio:

$$
\mathrm{K}=\frac{\overline{\mathrm{C}}_{\mathrm{B}}}{\mathrm{C}_{\mathrm{B}}}
$$

siendo $\overline{\mathrm{C}}_{B}$ la concentración de betaína en la fase resina en el equilibrio y $\mathrm{C}_{B}$ la concentración de betaína en la fase acuosa en el equilibrio.

La porosidad del lecho de resina, $\varepsilon_{L}=0,30 \pm 0,05$, se estimó experimentalmente aplicando la Ec. (5.99), para todos los experimentos realizados, este valor coincide con el obtenido en el estudio de aminoácidos.

El coeficiente de distribución $\mathrm{K}$, para cada una de las curvas de ruptura de los experimentos de columna de la Tabla 24 se calculó como el valor medio entre $\mathrm{K}_{\text {experimental }}$ calculada con la Ec. (6.43) y $\mathrm{K}_{\text {calculada }}$ con el modelo de equilibrio recogido en la Ec.(6.44): 


$$
\mathrm{K}=\frac{\left[\overline{\mathrm{RSO}_{3}^{-} \mathrm{B}^{+}}\right]}{\mathrm{C}_{\mathrm{B}}}=\frac{\sqrt{\left(\frac{\mathrm{VK}_{\mathrm{p} 1}\left[\mathrm{~B}^{+}\right]}{2 \overline{\mathrm{V}}}\right)^{2}+\frac{\mathrm{VK}_{\mathrm{p} 1}\left[\mathrm{~B}^{+}\right]\left[\overline{\mathrm{RSO}_{3}^{-} \mathrm{H}^{+}}\right]}{\overline{\mathrm{V}}}}-\frac{\mathrm{VK}_{\mathrm{p} 1}\left[\mathrm{~B}^{+}\right]}{2 \overline{\mathrm{V}}}}{\mathrm{C}_{\mathrm{B}}}
$$

donde $\left.\overline{\mathrm{RSO}_{3}^{-} \mathrm{B}^{+}}\right]$se sustituye por la Ec. (6.15) del apartado 6.3.4.1.

Los resultados de los parámetros cinéticos para los experimentos I, III-V de la Tabla 24 a $\mathrm{pH}=6,50$ se muestran en la Tabla 27. Comparando los experimentos I, III y IV se observa que $\mathrm{K}$ disminuye al aumentar la concentración de betaína en la alimentación, resultado que concuerda con el obtenido en los ensayos de equilibrio del apartado 6.3.4 puesto que las isotermas son de tipo favorable al igual que los aminoácidos estudiados. Por otra parte en los experimentos I y IV de la Tabla 27 se observa que al operar con distinto caudal de alimentación se obtiene similares valores del coeficiente de distribución, indicando que la concentración de betaína en la alimentación es el factor limitante de este parámetro de equilibrio.

La difusividad intrapartícula efectiva, $D_{e}$, se determinó experimentalmente en el ensayo cinético en baños agitados (apartado 6.3.6), para el experimento I de la Tabla 27 y se asumió constante e igual para los experimentos III-V de la Tabla 27 debido a que su variación es despreciable en el rango de concentraciones estudiado.

El coeficiente de transferencia de materia en la película líquida externa, $\mathrm{k}_{\mathrm{f}}$, se obtiene del ajuste de los datos experimentales con la solución analítica del modelo de Rosen Ec. (6.39) y Ecs. (6.40)-(6.42), puesto que todos los demás parámetros son conocidos. El valor de la difusividad en la película líquida externa, $D_{L}$, se estimó con la ecuación de Wilson-Geankoplis, Ec. (5.116), mostrada en el apartado 5.4.3. Los resultados obtenidos se muestran en la Tabla 27.

Tabla 27. Parámetros cinéticos para los experimentos en columna I, III, IV y V de betaína con RIE de la Tabla 24. $\left(\left[\overline{\mathrm{RSO}_{3}^{-} \mathrm{H}^{+}}\right]_{i}=500,14 \pm 1,21 \mathrm{~mol} / \mathrm{m}^{3} \mathrm{RSI}\right.$ y $\mathrm{pH}_{\mathrm{i}}=$ $6,50 \pm 0,27$ )

\begin{tabular}{ccccccc}
\hline Experimento & $\begin{array}{c}\mathrm{C}_{\mathrm{Bi}} \\
\left(\mathrm{mol} / \mathrm{m}^{3}\right)\end{array}$ & $\begin{array}{c}\mathrm{Q} \\
\left(\mathrm{m}^{3 / \mathrm{s}}\right)\end{array}$ & $\begin{array}{c}\mathrm{K} \\
\left(\mathrm{m}^{3} / \mathrm{m}^{3} \mathrm{RSI}\right) \\
\mathrm{Ec}(6.43)\end{array}$ & $\begin{array}{c}\mathrm{D}_{\mathrm{e}} \times 10^{11} \\
\left(\mathrm{~m}^{2} / \mathrm{s}\right) \\
\mathrm{Ec}(6.31)\end{array}$ & $\begin{array}{c}\mathrm{k}_{\mathrm{f}} \times 10^{9} \\
(\mathrm{~m} / \mathrm{s}) \\
\mathrm{Ec})(6.39)\end{array}$ & $\begin{array}{c}\mathrm{D}_{\mathrm{L} \times 10^{17}} \\
\left(\mathrm{~m}^{2} / \mathrm{s}\right) \\
\mathrm{Ec} .(5.116)\end{array}$ \\
\hline I & 41,01 & $0,018 \times 10^{-6}$ & $6,62 \pm 1,05$ & 7,5 & 1,00 & 9,23 \\
III & 82,65 & $0,017 \times 10^{-6}$ & $3,17 \pm 1,04$ & 7,5 & 0,60 & 4,31 \\
IV & 19,85 & $0,018 \times 10^{-6}$ & $7,77 \pm 2,26$ & 7,5 & 1,00 & 9,23 \\
V & 38,09 & $0,032 \times 10^{-6}$ & $4,78 \pm 1,77$ & 7,5 & 1,20 & 9,13 \\
\hline
\end{tabular}

En la Tabla 27 se observa que la difusividad en la película líquida externa, $D_{L}$, es 6 ordenes de magnitud inferior que $\mathrm{D}_{\mathrm{e}}$, indicando que el proceso de extracción de betaína, 
bajo las condiciones de flujo ensayadas, está principalmente controlado por la difusión en la película líquida externa y también aunque en menor medida por difusión intrapartícula.

En la Figura 114 se representa el ajuste de las curvas de ruptura de los experimentos I, III, IV y V de la Tabla 24 (símbolos) con el modelo cinético mostrado en las Ecs. (6.39)(6.43), (líneas). Se observa una buena concordancia entre los datos experimentales y el modelo para los sistemas estudiados. El error fue inferior al $5 \%$ en todos los casos.

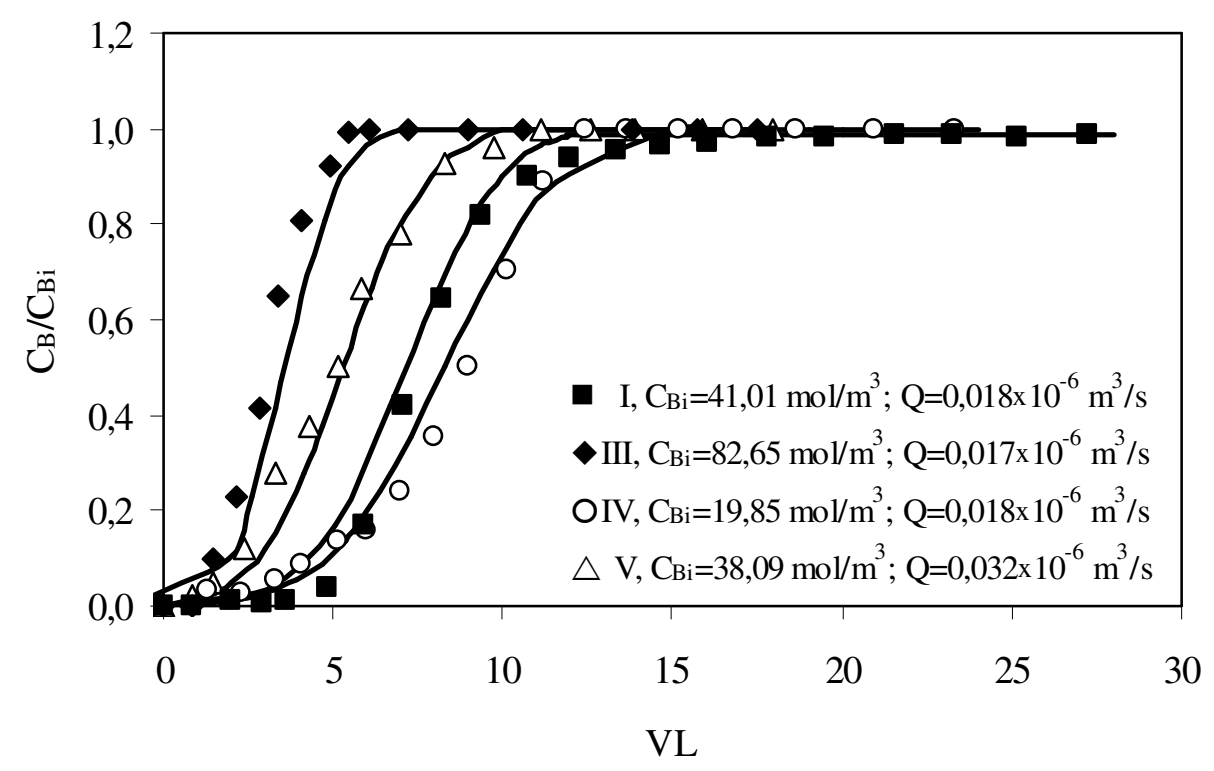

Figura 114. Curvas de ruptura de extracción con RIE de betaína para los experimentos I, III, IV y V de la Tabla 27. $\left(\mathrm{pH}_{\mathrm{i}}=6,50 \pm 0,27 ;\left|\overline{\mathrm{RSO}_{3}{ }^{-} \mathrm{H}^{+}}\right|_{\mathrm{i}}=500,14 \mathrm{~mol} / \mathrm{m}^{3} \mathrm{RSI}\right)$. Símbolos: datos experimentales. Líneas: datos calculados con la Ec. (6.39)-(6.42).

Las conclusiones más relevantes del estudio en columna son:

- Las curvas de ruptura de extracción de betaína se ven afectadas por el caudal, concentración y pH de la alimentación.

- Se utilizó el modelo de Rosen para la estimación de la curvas de ruptura. La difusividad en la película líquida externa, $D_{L}$, es 6 ordenes de magnitud inferior que $D_{e}$, indicando que el proceso de extracción de betaína está principalmente controlado por la difusión en la película líquida externa, y también aunque en menor medida por difusión intrapartícula.

- La reextracción de la betaína del lecho de RIE se puede realizar utilizando como agente de reextracción disoluciones de hidróxido de sodio que producen en una misma etapa la reextracción de la betaína y la regeneración del extractante presente en la RIE mediante un proceso químico de intercambio iónico. 



\section{CONCLUSIONES GENERALES}



Se relacionan a continuación las conclusiones más relevantes alcanzadas en este estudio orientado a la separación de los aminoácidos $\alpha$-fenilglicina, ácido aspártico y betaína de disoluciones acuosas diluidas, utilizando la tecnología de extracción reactiva con resinas impregnadas de extractante (RIE).

- Se ha constatado la adecuación de la resina Amberlita XAD-4 como soporte polimérico para la impregnación de los extractantes seleccionados Tomac y DNNSA, debido a que es un sólido macroporoso, altamente hidrófobo, no iónico y presenta una elevada capacidad de impregnación (1110 mol de Tomac / $\mathrm{m}^{3} \mathrm{RSI}$ y $540 \mathrm{~mol}$ DNNSA / $\mathrm{m}^{3} \mathrm{RSI}$ ). Por encima de estas concentraciones, la resina no admite más extractante y adquiere un aspecto húmedo y pegajoso.

- Para evitar pérdidas de extractante se debe trabajar con un grado de impregnación 10\% o 15\% inferior a la capacidad máxima de impregnación de la RIE.

- La adsorción física de iones y moléculas en la matriz polimérica de resina XAD-4 sin impregnar fue despreciable en todos los casos, con excepción del ácido aspártico a $\mathrm{pH}=5$ donde se observó una pequeña adsorción que se ajustó adecuadamente a una isoterrma de adsorción de tipo Freundlich y que, en cualquier caso, fue despreciable frente a la extracción reactiva por efecto del Tomac inmovilizado en la RIE.

- La extracción individual y conjunta de $\alpha$-fenilglicina y ácido aspártico con RIETomac y de betaína con RIE-DNNSA se puede describir adecuadamente mediante mecanismos de intercambio iónico de las especies iónicas del biocompuesto con los iones cloruro del Tomac o con los protones del DNNSA impregnado en la resina, formando distintos complejos biocompuesto-extractante dependiendo del valor de $\mathrm{pH}$ del medio. Los modelos propuestos consideran también la coextración competitiva de otros iones presentes en el medio acuoso. Esta modelización de los resultados permite cuantificar los valores del coeficiente de distribución necesario en los estudios cinéticos.

- El grado de extracción de ácido aspártico y $\alpha$-fenilglicina con RIE-Tomac fue superior a $\mathrm{pH} \geq 11$, y aumenta al crecer la concentración de cada aminoácido en fase acuosa. A este valor de $\mathrm{pH}$ predomina la forma aniónica $A^{-}$de $\alpha$-fenilglicina $\left(\mathrm{pK}_{\mathrm{a} 2(\mathrm{pgly})}=9\right)$ y la forma aniónica divalente $A^{2-}$ del ácido aspártico $\left(\mathrm{pK}_{\mathrm{a} 3(\mathrm{asp})}=9,8\right)$ Así, su extracción con RIE tiene lugar por reacciones de intercambio iónico con el Tomac formando los complejos aminoácido - Tomac $\mathrm{Q}^{+} \mathrm{A}_{\text {pgly }}^{-}$y $\mathrm{Q}_{2}^{+} \mathrm{A}_{\text {asp }}^{2-}$.

- El grado de extracción de betaína con RIE-DNNSA aumenta al aumentar la concentración de betaína en fase acuosa, no se modifica en presencia de sacarosa y la extracción resultó similar a $\mathrm{pH}=2$ y 6,5 debido a que el mecanismo 
de extracción produce la liberación de $\mathrm{H}^{+}$y por tanto, la acidificación del medio que permite la formación del complejo $\mathrm{RSO}_{3}{ }^{-} \mathrm{B}^{+}$.

- Los procesos cinéticos de separación de $\alpha$-fenilglicina, ácido aspártico y betaína con RIE en baños agitatados son rápidos y se alcanza el equilibrio a tiempos reducidos, inferiores a 2 horas. La forma y evolución de las curvas cinéticas es similar en todos los experimentos realizados a diferentes valores de $\mathrm{pH}$ y con distinta concentración inicial de soluto, por tanto el proceso cinético debe estar controlado por los mismos mecanismos de transferencia de materia.

- Los resultados de las cinéticas de extracción individual y conjunta de los aminoácidos $\alpha$-fenilglicina y ácido aspártico y de betaína con RIE en tanques agitados se correlacionaron adecuadamente mediante un modelo cinético basado en la segunda ley de Fick, considerando que el proceso de transferencia de materia está controlado por la difusión intrapartícula del complejo biocompuestoextractante y que existe un equilibrio instantáneo en la interfase sólido-líquido.

- Los valores de las difusividades intrapartícula efectivas $D_{e}$ estimados a partir del modelo cinético fueron del orden de $10^{-10} \mathrm{~m}^{2} / \mathrm{s}$ para la betaína y de $10^{-10} \mathrm{~m}^{2} / \mathrm{s}$ para el ácido aspártico y de $10^{-11} \mathrm{~m}^{2} / \mathrm{s}$ para $\alpha$-fenilglicina tanto en la extracción individual de cada aminoácido como desde sus mezclas binarias. Este resultado confirma que la velocidad de extracción de $\alpha$-fenilglicina es más lenta que la de ácido aspártico como consecuencia de su mayor tamaño, ya que contiene un grupo fenilo en su cadena radical.

- Las curvas de ruptura del proceso de extracción de ácido aspártico, $\alpha$-fenilglicina y betaína en lechos porosos de RIE se ven afectadas por el caudal, el pH y la concentración de la alimentación y por la carga de extractante en la RIE. El modelo propuesto por Rosen ajusta adecuadamente los resultados experimentales de extracción individual y conjunta de los aminoácidos ácido aspártico y $\alpha$-fenilglicina y del derivado betaína; además de proporcionar el valor del coeficiente de transferencia de materia en la película líquida externa, $\mathrm{k}_{\mathrm{f}}$.

- Los valores de la difusividad intrapartícula efectiva $\left(D_{e}=10^{-11}\right)$ y la difusividad en la película líquida externa $\left(D_{L}=10^{-10}-10^{-11}\right)$ son del mismo orden de magnitud indicando que, bajo las condiciones experimentales estudiadas, el proceso de extracción de ácido aspártico y a-fenilglicina en lechos fijos de RIE está controlado por ambas resistencias a la transferencia de materia: la difusión intrapartícula y la difusión en la película líquida externa. Sin embargo en la extracción de betaína $D_{L}$ es 6 ordenes de magnitud inferior que $D_{e}$ indicando que, en las condiciones de operación ensayadas, el proceso está controlado principalmente por la difusión en la película líquida externa, y también aunque en menor medida por la difusión intrapartícula.

- Para llevar a cabo la reextracción de $\alpha$-fenilglicina, ácido aspártico y betaína del lecho de RIE se sugiere un proceso químico de intercambio iónico que emplea como agente de reextracción disoluciones de ácido clorhídrico para los aminoácidos y disoluciones de hidróxido de sodio para la betaína. 
- Se ha diseñado un proceso continuo para el fraccionamiento de los aminoácidos $\alpha$-fenilglicina y ácido aspártico desde sus mezclas binarias utilizando dos columnas fijas de RIE en serie con control del pH. Las condiciones de operación de la etapa de extracción son las siguientes: $\mathrm{pH}$ de la alimentación de la primera columna $=5, \mathrm{pH}$ de la alimentación de la segunda columna $=12$, tiempo de operación $\leq$ tiempo de saturación de la primera columna. Transcurrido el tiempo de operación de la etapa de extracción comienzan las etapas de reextracción por separado para cada una de las columnas, utilizando disoluciones de ácido clorhídrico $1 \mathrm{~N}$ en ambas columnas. Los efluentes de la reextracción de cada una de las columnas son tratados convenientemente por evaporación controlada y precipitación para la obtención de los aminoácidos puros. Los porcentajes de recuperación de ambos aminoácidos son altos con respecto a la cantidad de aminoácido presente en la fase acuosa de alimentación.

- Un estudio comparativo con resinas de intercambio iónico comerciales demuestra que el grado de extracción de betaína es mayor con resinas catiónicas sulfonadas como Amberlyst 15 y Amberlite $200 \mathrm{C}$ que con resinas con grupos funcionales organofosforados como Lewatit TP260 y Lewatit OC1026. Sin embargo, se ha comprobado experimentalmente que las resinas catiónicas sulfonadas ensayadas presentan algunos inconvenientes de operación como su rotura en los ciclos de lavado y durante la experimentación a pesar de utilizar agitación orbital suave (=150 rpm). Además, producen una reacción exotérmica calentando las fases y tiñen las disoluciones acuosas de color marrón debido al desprendimiento de sulfitos en el medio acuoso. Por otra parte, son resinas hidrófilas es decir adsorben agua y se hinchan. 



\section{BIBLIOGRAFÍA}



Abbasian K., Degener W. and Schügerl K., Chances of Reactive Extraction of Primary and Secondary Metabolites: Ber. Bunsenges. Phys. Chem. 93 (1989) 976 - 980.

Abd El-Moniem N. M., El-Sourougy M. R., Shaaban D.A.F., Heavy metal ions renoval by chelating resin: Pigment \& Resin Technology 34/6 (2005) 332-339.

Abella L. C., Gaspillo P.-A. D., Maeda M. and Goto S., Kinetic study on the dehydration of tert-Butyl alcohol catalyzed by ion exchange resins: Dehydration of tert-butyl alcohol, John Wiley \& Sons, Inc (1999) 854-859.

Akita S. and Takeuchi H., Sorption and Separation of Metals from Aqueous Solutions by a Macroporous Resin Containing Tri-n-octylamine: J. Chem. Eng. Japan 23 (4) (1990) 439 $-443$.

Akita S. and Takeuchi H., Sorption of Divalent Metals by a Macromolecular Resin Containing Organophosporus Acids: J Chem Eng Data, 37 (1992) 303-306.

Akita S. and Takeuchi H., 1993, Column Sorption and Separation of Divalent Metals by a Macroporous Resin Containing Organophosphorus Acids: J Chem Eng Japan, 26 (1993) 442-444.

Akita S., Hirano K. and Ohashi Y., Equilibrium Distribution of Palladium (II) between Hydrochloric Acid Solution and Macromolecular Resin Containing Tri-n-octylamine: Solv. Extr. Ion Exch. 11 (5) (1993 a) 797 - 810.

Amara M., Kerdjoudj $\mathbf{H}$., Modification of the cation exchange resin properties by impregnation in polyethyleneimine solutions. Aplication to the separation of metallic ions: Talanta 60 (2003) 991-1001.

Babić K., Van der Hamm L., de Haan A., Recovery of benzaldehyde from aqueous streams using extractant impregnated resins: Reactive \& Functional Polymers 66 (2006) 1494-1505.

Babić K., Driessen H. H. M., Van der Hamm A. G. J., de Haan A. B., Chiral separation of amino-alcohols using extractant impregnated resins: Journal of Chromatography $A$, 1142 (2007) 84-92.

Baldwin W. H. and Higgins C. E., Liquid-Liquid Distribution, Tributyl Phosphate between Immiscible Solvents: J. Chem. Eng. Data 19 (2) (1974) 152 - 154.

Bhandari V. M., Juvekar V. A. and Patwardhan S. R., Modified Shrinking Core Model for Reversible Sorption on Ion-Exchange Resins: Sep. Sci. Technol. 27 (8-9) (1992) 1043 -1064 .

Barre R. M., Flow into and Through Zeolite Beds and Compacts: Langmuir 3 (1987) 309 315.

Bart H. J., Schöneberger A., Reactive Proceses for Recovery of Heavy Metals in Miniplants: Chem. Eng. Technol. (23) (2000) 653-660.

Bennett A. N., Recovery of betaine and betaine salts from sugar beet wastes. United States Patent Office. 2,375,164. May 1, 1945. 
Belitz H. D. and Grosch W., "Química de los alimentos", $2^{\underline{a}}$ ed., Editorial Acribia, Zaragoza, (1997).

Blanch H. W. And Clark D. S., Product Recovery, en Biochemical Engineering, Marcel Dekker In., New York, 1996.

Bubnik Z., Pour V., Gruberova A., Starhova H., Hinkova A. and Kadlec P., "Application of continuos chromatographic separation in sugar processing": Journal of Food Engineering 61 (2004) 509-513.

Burgos L., Desarrollo de un Proceso de Separación de $\alpha$-fenilglicina Utilizando Contactores de Membranas de Fibras Huecos; Tesis de Licenciatura, directores Ruiz M. O.; Escudero I.; (2001).

Brown C. M., Campell I., Priest F. G., "Introducción a la biotecnología". Editorial Acribia, S.A. Zaragoza, 1989.

Browne T. E. and Cohen Y., Polymer-Grafted Silica: A Screening System for Polymeric Adsorption Resin Development: Ing. Eng. Chem. Res. 32 (1993) 716 - 725.

Calvarin L., Roche B. and Renon H., Anion Exchange and Aggregation of Dicyanocobalamin with Quaternary Ammonium Salts in Apolar Environment: Ind. Eng. Chem. Res. 31 (1992) 1705 - 1709.

Camporro A., Eliminación/Recuperación de Fenol y Derivados de Efluentes Industriales Mediante Procesos de Sorción. Tesis Doctoral, (1991), Universidad de Oviedo.

Cardoso M. M., Mendes C. M., Carrondo M. J. T., Kroner K. H., Deckwer W. D. And Crespo J. P. S. G., Extraction of Amino Acids By lon-Pairing And Reversed Micellar Transport, in Separation for Biotechnology 3, D. L. Pyle. (Ed). SCI, London (1994), 93-99.

Cascaval D., Oniscu C. and, Galaction I., Selective separation of amino acids by reactive extraction: Biochemical Engineering Journal, Vol 7 (3) (2001) 171-176.

Chan C. C. and Wang S. S., Kinetics of the Extraction of Phenylalanine and Glutamic Acid by lon - Exchange Carriers: J. Membrane Sci. 76 (1993) 219 - 232.

Cheftel J.C, CUQ J.L, Lorient D., "Proteinas alimentarias", Editorial Acribia, Zaragoza, 1989.

Chen J. H., Chen W. R., Gau Y. Y. and Lin C. H., The preparation of di(2ethylhexyl)phosphoric acid modified Amberlite 200 and its application in the separation of metal ions from sulfuric acid solution: Reactive \& Functional Polymers (56) (2003) 175188.

Cheng S., Yan H., Zhao C., The synergistic effect between hydrophobic and electrostatic interactions in the uptake of amino acids by strongly acidic cation-exchange resins: Journal of Chromatography A. 1108 (2006) 43-49.

Cheremisinoff P. N. and Morresi A. C., Carbon Adsorption Applications. In Carbon Adsorption Handbook, P. Cheremisinoff and F. Ellerbusch (Eds.), Ann Arbor Science Publishers Inc., Michigan, 1978.

Clark G. A., Gastrone R. C. and Horwitz E. P., The Extraction of Carboxylic Acids by OфD(iB)CMPO: Solv. Ext. Ion Exch. 5 (3) (1987) 471 - 491. 
Cockrem M. C. M., Flatt J. H. and Lightfoot E. N., Solvent Selection for Extraction from Dilute Solution: Sep. Sci. Technol. 24 (11) (1989) 769 - 807.

Cohn E. J. The solubillity of proteins, amino acids and peptides. Eds. Reinhold, New York, 1943, pp.569-585.

Costa C. and Rodrigues A., Intraparticle Diffusion of Phenol in Macroreticular Adsorbents: Modelling and Experimental Study of Barth and CSTR Adsorbers: Chem. Eng. Sci. 40 (6) (1985 a) $983-993$.

Coulson J. M. and Richardson J.F., Chemical Engineering. Particle Technology and Separation Processes. 4를. ed., vol 2, Pergamon Press, Oxford, 1993.

Cortina J. L., Miralles N., Sastre A. M., Aguilar M., Profumo A. and Pesavento M., Solvent Impregnated Resins Containing Di(2,4,4-trimethylpentyl)phosphinic Acid. I. Comparative Study of $\mathrm{Di}(2,4,4$-trimethylpentyl)phosphinic acid adsorbed into Amberlite XAD-2 and Dissolved in Toluene: React Polym, 21 (1993a) 89-101.

Cortina J. L., Miralles N., Sastre A. M., Aguilar M., Profumo A. and Pesavento M., Solvent Impregnated Resins Containing Di(2,4,4-trimethylpentyl)phosphinic Acid. II. Study of the Distribution Equilibria of Zn, Cu and Cd: React Polym, 21 (1993b) 103-116.

Cortina J. L., Miralles N., Aguilar M. and Sastre A. M., Extraction studies of Zn (II), Cu (II) and Cd (II) with impregnated and Levextrel resins containing di(2ethylhexyl)phosphoric acid (Lewatit 1026 Oc): Hydrometallurgy 36 (1994) 131-142.

Cortina J. L., Miralles N., Sastre A. M., Aguilar M., Profumo A. and Pesavento M., Solvent Impregnated Resin Containing Di(2-ethylhexyl)phosphoric Acid. I Preparation and Study of the Retention and Distribution of the Extractant on the Resin: Solvent Extr lon Exch, 12(2) (1994a) 349-369.

Cortina J. L., Miralles N., Aguilar M. and Sastre A. M., Solvent Impregnated Resins Containing Di(2-ethyl-hexyl)phosphoric Acid. II. Study of The Distribution Equilibria of Zinc(II), Cu(II) and Cd(II): Solvent Extr lon Exch, 12(2) (1994b) 371-391.

Crank J., The Mathematics of Diffusion, 2nd edn., Oxford University Press, London, 1975.

Do D. D. and Rice R. G., On the Relative Importance of Pore and Surface Diffusion in Non-Equilibrium Adsorption Rate Processes: Chem. Eng. Sci. 42 (10) (1987) 2269 2284.

Do D. D. and Rice R. G., A Simple Method of Determining Pore and Surface Diffusivities in Adsorption Studies. Chem. Eng. Comm. 107 (1991) 151 - 161.

Doulia D.,Rigas F., Gimouhopoulos C., Removal of amino acids from water by adsorption on polystyrene resins: J. Chem. Technol. Biotechnol (76) (2001) 83-89.

Dzygiel P. and Wieczorek P., Extraction of amino acids with emulsion liquid membranes using industrial surfactants and lecithin as stabilisers, J. Membr. Sci., 172 (2000) 223-232.

Escalante H., Alonso A. I., Ortiz I. and Irabien A., Separation of L-Phenylalanine by nondispersive Extraction and Back extraction. Equilibrium and Kinetics: Sep. Sci. Technol. 33 (1) (1998) $119-139$. 
Esteve-Garcia E. and Mack S., The effect of DL-methionine and betaine on growth performance and carcass characteristics in broilers: Animal Feed Science and Technology 87 (2000) 85-93.

Eyal A. M. and Canari R., pH Dependence of Carboxylic and Mineral Acid Extraction by Amine-Based Extractants: Effects of pKa, Amine Basicity, and Diluent Properties: Ind. Eng. Chem. Res. 34 (5) (1995) 1789 - 1798.

Fernández C., Sánchez-Seiquer P., Sánchez A., Contreras A., de la Fuente J. M., Influence of betaine on milk yield and composition in primiparous lactating dairy goats: Small Rumiant Research 52 (2004) 37-43.

Faver-Réguillon A., Fiaty K., Laurent P., Poriel L., Pellet-Rostaing S. and Lemaire M., Solid/Liquid Extraction of Zirconimum and Hafnium in Hydrochloric Acid Aqueous Solution with Anion Exchange Resin-Kinetic Study and Equilibrium Analyses: Ind. Eng. Chem. Res. 46 (2007) 1286-1291.

Fennema O. R., "Química de los alimentos", 2aㅗ ed., Editorial Acribia, S.A, Zaragoza, 2000.

Filik H., Dogutan M. and Apak R., Speciation analysis of chromium by separation on a 5palmitoyl oxine-functionalysed XAD-2 resin and spectrophotometric determination with diphenylcarbazide: Anal. Bioanal. Chem 376 (2003) 928-933.

Foster P. R., Protein precipitation in engineering process for bioseparations, Ed. Weatherley L. R., The Queen's University of Belfast, Northern Ireland, UK, 1994, pp. 73109.

Galan B., Urtiaga A. M., Alonso A. I., Irabien J. A. and Ortiz M. I., Extraction of Anions with Aliquat 336: Chemical Equilibrium Modeling: Ind. Eng. Chem. Res. 33 (1994) 1765 1770.

García R., Martínez C., "Residuos en la industria farmaceútica", Ingeniería Química, №409, Enero 2004.

Ghazi I., Fernandez-Arrojo L., Gomez de Segura A., Alcalde M., Plou F. J. and Ballesteros A., Beet sugar syrup and molasses as low-cost Feedstock for the enzymatic production of Fructo-oligosaccharides: Journal of Agricultural and Food Chemistry: 54 (2006) 2964-2968.

Gloe K., Stephan H. and Grotjahn M., Where is the Anion Extraction Going? Review: Chemical Engineering\& Technology 26 (2003) 1107-1117.

Golob J., Grilc V. and Zadnik B., Extraction of Acetic Acid from Dilute Aqueous Solutions with Trioctylphosphine Oxide: Ind. Eng. Chem. Process Des. Dev. 20 (1981) $433-435$.

Gomez-Salazar S., Lee J. S., Heydweiller J. C. and Tavlarides L. L., Analysis of Cadmium Adsorption on Novel Organo-Ceramic Adsorbents with a Thiol Functionality: Ind. Eng. Chem. Res. 42 (2003), 3403-3412.

Gomes C. P., Almeida M. F., Loureiro J. M., Gold recovery with ion exchange used resins: Separation and Purification Technology 24 (2001) 35-57. 
González-Muñoz M. J., Luque S., Álvarez J. R., Coca J., Reactive extraction of D,L-aphenylglycine with a quaternary ammonium salt: Effect of hydroxide anions and water coextraction: Separation and Purification Technology 51 (2006) 18-23.

Goto M., Ono T., Nakashio F. and Hatton T.A., Design of surfactants suitable for protein extraction by reversed micelles, Biotechnol. Bioeng., 54(1) (1997) 26-32.

Granö H., Yli-Kauhaluoma J., Suortti T., Käki J. and Nurmi K., Preparation of starch betainate: a novel cationic starch derivate: Carbohydrate Polymers 41 (2000) 277-283.

Grant T. M. and King C. J., Mechanism of Irreversible Adsorption of Phenolic Compounds by Activated Carbons: Ind. Eng. Chem. Res. 29 (1990) $264-271$.

Gurnani V., Singh A. K. and Venkataramani B., Cellulose based macromolecular chelator having pyrocatechol as an anchored ligand: syntesis and applications as metal extractant prior to their determination by flame atomic absorption spectrometry: Talanta 61 (2003) 889-903.

Gurnani V. and Singh A. K., Equilibrium Studies on the Optimazation of Solid-Phase Extraction of Metal lons with Pyrogallol-Anchored Cellulose Synthesized by a New Method and Applications of the Extraction in Metal Enrichment, Removal, and Determination: Ind. Eng. Chem. Res. 43 (2004) 2302-2309.

Guijarro J. I., Gonzalez Pastor J. E., Baleux F. and Millan. J. L. S., Chemical-structure and translation Inhibition studies of the antibiotic microcin C7: Journal of Biological Chemistry, Vol 270 (40) (1995) 23520-23532.

Guo Y., Din B., Liu Y., Chang X., Meng S., Tian M., Preconcentration of trace metals with 2-(methylthio)aniline-functionalized XAD-2 and their determination by flame atomic absorption spectrometry: Analytica Chimica Acta 504 (2004) 319-324.

Guo Y., Din B., Liu Y., Chang X., Meng S., Liu J., Preconcentration and determination of trace metals with 2-aminoacetylthiophenol functionalized Amberlite XAD-2 by inductively coupled plasma-atomic emission spectrometry: Talanta 62 (2004) 209-215.

Gusler G. M., Browne T. E. and Cohen Y., Sorption of Organics from Aqueous Solution onto Polymeric Resins: Ind. Eng. Chem. Res. 32 (1993) 2727 - 2735.

Haensel R., Halwachs W. and Schügerl K., Reactive Extraction of D,L - Phenylalanine with Trioctil - methyl - ammonium Chloride (Tomac) as a Carrier. III. Equilibrium and Mass Transfer Investigations: J. Chem. Eng. Sci. 41 (7) (1986) 1811 - 1815.

Hampe M. J., Selection of Solvents in Liquid - Liquid Extraction According to Physico Chemical Aspects: Ger. Chem. Eng. 9 (1986) 251 - 263.

Hanson C., Basic Principles of Solvent Extraction: Advanced Solvent Extraction Technology, University of Bradford, 1979.

Hartl J. and Marr R., Utilization of Third-Phase Formation in Solvent Extraction Systems Employing Amine Extractant: Solvent Extraction, Elsevier (Eds.), New York, 1990.

Hasanain M. A. and Hines A. L., Application of the Adsorption Potencial Theory to Adsorption of Carboxylic Acids from Aqueous Solutions onto a Macroreticular: Ind. Eng. Chem. Process Des. Dev. 20 (1981) 621 - 625. 
Hawley G. Gessuer, Irvingsax N., Richard J. and Lewis S. R. "Diccionario de química y de productos químicos.", Editorial Omega S. A., Barcelona (1993).

Heikkila H, Goran H., Jarmo K., Method for recovery of betaine from molasses. European Patent Application. 0345511 A2.Date of publication 13.12.89

Heikkila H, Goran H., Jarmo K., Method for recovery of betaine from molasses. United States Patent. 5,127,957. July 7, 1992.

Heikkila H, Goran H., Jarmo K., Method for the fractionation of molasses. United States Patent. 6,093,326. July 25, 2000.

Helfferich F. and Plesset M. S., Ion Exchange Kinetics. A Nonlinear Diffusion Problem: J. Chem. Phys. 28 (1958) $418-424$.

Herrera E., "Elementos de Bioquímica": 1aㅡ Ed., Editorial Interamericana McGrwawHill,México, (1993).

Horta A. I., Santridian E., Ruiz M. O., Cabezas J. L., Escudero I., Equilibrium studies on amino acids separation by macroporous resin impregnated with tri-alkyl-methylammonium chloride. Congress manuscripts C32-006. $7^{\text {th }}$ World Congress of Chemical Engineering, Glasgow- Scotland (2005).

Hoshi H., Wei Y.-Z., Kumagai M., Asakura T., Morita Y., Group separation of trivalent minor actinidides and lanthanides by TODGA extraction chromatography for radioctive waste management. Journal of Alloys and Compounds 374 (2004) 451-455.

Itoh H., Thien M. P., Hatton T. A. and Wang D. I. C., Liquid Emulsion Membrane Process for Separation of Amino Acids: Biotechnol. Bioeng. 35 (1990) 853 - 860.

Jones I. and Carta G., Ion Exchange of Amino Acid and Dipeptides on Cation Resins with Varying Degree of Cross-Linking. 1. Equilibrium: Ind. Eng. Chem. Res. 32 (1993a) $107-117$.

Jones I. and Carta G., Ion Exchange of Amino Acid and Dipeptides on Cation Resins with Varying Degree of Cross-Linking. 2. Intraparticle Transport: Ind. Eng. Chem. Res. 32 (1993b) 117 - 125.

Juang R. S. and Chou T. C., Sorption Kinetics of Citric Acid from Aqueous Solutions by Macroporous Resins Containing a Tertiary Amine: J. Chem. Eng. Japan 29 (1996 a) 146 151.

Juang R. S. and Lee S. H., Column Sorption of Divalent Metals from Sulfate Solutions by Extractant-Impregnated Macroporous Resins: J Chem Tech Biotechnol, 66 (1996b) 153159.

Juang R. S. and Chang H-L., Distribution Equilibrium of Citric Acid between Aqueous Solutions and Tri-n-octylamine-Impregnated Macroporous Resins: Ind. Eng. Chem. Res. (34) (1995) 1294-1301.

Juang R. S. and Lin H. C., Metal Sorption with Extractant-Impregnated Macroporous Resins. 1. Particle Diffusion Kinetics: J Chem Tech Biotecnol, 62 (1995a) 132-140. 
Juang R. S. and Lin H. C., Metal Sorption with Extractant-Impregnated Macroporous Resins. 2. Chemical Reaction and Particle Diffusion Kinetics: J Chem Tech Biotecnol, 62 (1995b) 141-147.

Juang, R. S. and Chang H. L., Column Sorption of Citric Acid from Aqueous Solutions Using Tri-n-octylamine-Impregnated Macroporous Resins: Sep. Sci. Technol. 30 (6) (1995c) 917 - 931.

Juang R. S. and Su J. Y., Sorption of Copper and Zinc from Aqueous Sulfate Solutions with Bis(2-ethylhexyl)phosphoric Acid-Impregnated Macroporous Resin: Ind Eng Chem Res, 31(12) (1992a) 2774-2779.

Juang R. S. and Su J. Y., Separation of Zinc and Copper from Aqueous Sulfate Solutions with Bis(2-ethylhexyl)phosphoric Acid-Impregnated Macroporous Resin: Ind Eng Chem Res, 31(12) (1992b) 2779-2783.

Kabay N., Solak Ö., Arda M., Topal Ü., Yüksel M., Trochimczuk A., Streat M., Packed column study of the sorption of hexavalent chromium by novel solvent impregnated resins containing aliquat 336: Effect of chloride and sulfate ions: Reactive \& Functional Polymers 64 (2005) 75-82.

Kelly N. A., Lukhezo M., Reuben B. G., Dunne L. J. and Verrall S., Reactive Solvent Extraction of Amino Acids with Cationic Extractants: J. Chem. Tecnol. Biotechnol. 72 (1998) $347-355$.

Kende A. S., Liu K., Kaldor I., Dorey-G. and Koch K.., Total synthesis of the macrolide antitumor antibiotic lankacidin-C: Journal of the American Chemical Society, Vol 117 (31) (1995) 8258-8270.

Kertes A. S. and King C. J., Extraction Chemistry of Fermentation Product Carboxylic Acids: Biotechnol. Bioeng. 28 (1986) 269 - 282.

Kikuchi K. I., Gotoh T., Takahashi H., Higashino S. and Dranoff J. S., Separation of amino acids by electrodialysis with lon-exchange membrane, J. Chem. Eng. Japan, 28 (1) (1995) 103-109.

Kim M. G. and Lee S. B., Penicillin Acylase Catalyzed Synthesis of Beta Lactam Antibiotics in Water Methanol Mixtures: Effect of Cosolvent Content and Chemical Nature of Substrate on Reaction Rates and Yields: J. Molecular Catalysis B-enzymatic. 1 (3-6) (1996) 201 - 211.

King C. J., Acetic Acid Extraction, Handbook of Solvent Extraction, John Wiley \& Sons, New York, 1983.

King C. J. and Senetar J. L., Solvent Extraction of Industrial Organic Substances from Aqueous Streams: Solv. Ext. Ion Exch. 10 (1) (1988) 1 - 61.

Kirk-Othmer., "Encyclopedia of Chemical Technology", 4a ed., Vol. 2, pp 504-579 M. Howe-Grant (Ed.) John Wiley \& Sons, New York, (1997).

Kirk-Othmer., "Encyclopedia of Chemical Technology", 4a ed., Vol. 23, pp 1-59 and 602604 M. Howe-Grant (Ed.) John Wiley \& Sons, New York, (1997). 
Koc H., Mar M. H., Ranasinghe A., Swenberg J. A. and Zeisel S. H., Quantification of Choline and its Metabolites in Tissues and Foods by Liquid Chromatography/Electrospray Ionization-Isotope Dilution Mass Spectrometry: Anal. Chem. 74 (2002) 4734-4740.

Komiyama H. and Smith J. M., Surface Diffusion in Liquid-Filled Pores: AlChE J. 20 (6) (1974 b) $1110-1117$.

Komiyama H. and Smith J. M., Intraparticle Mass Transport in Liquid-Filled Pores: AIChE J. 20 (4) (1974 a) 728 - 734.

Lawson-Yuen A. and Levy H. L., The use of betaine in the treatment of elevated homocysteine: Molecular Genetics and Metabolism 88 (2006) 201-207.

Liapis A. L. and Rippin W. T., A General Model for the Simulation of Multi-Component Adsorption from a Finite Bath: Chem. Eng. Sci. 32 (1977) 619 - 627.

Liddell J. M., Introduction to Downstream Processing, en Engineering Processes for Bioseparations, Ed. Weatherley L. R., The Queen's University of Belfast, Northen Ireland, UK, 1994, pp. 5-34.

Lin S. H., Chen C. N., Juang R. S., Extraction equilibria and separation of phenylalanine and aspartic acid from water with di(2-ethylhexyl)phosphoric acid: Journal of Chemical Technology and Biotechnology 81 (2006) 406-412.

Lin S. H., Chen C. N., Simultaneous reactive extraction separation of amino acids from water with D2EHPA in hollow fiber contactors: Journal of Membrane Science 280 (2006) 771-780.

Linden G. and Lorient D., "Bioquímica agroindustrial. Revalorización alimentaria de la producción agrícola.", Editorial Acribia, Zaragoza, (1996).

Liu Z. H., Wang J., Fan C.L. and Zhou R. X., Synthesis and swelling characterizations of alpha, beta-poly-DL-asparamide derivative hidrogel: Acta Polimerica Sinica, (5) (1998) 562-566.

Liu J. S., Chen H., Guo Z. L., Hu Y. C., Selective Separation of In(III), Ga (III), and Zn (II) from dilute solution using Solvent-Impregnated Resin containing Di(2-ethylhexyl) Phosphoric Acid: Journal of Applied Polymer Science, 100, (2006) 253-259.

Lundberg P., Dudman N. P. B., Kuchel P. W., and Wücken D. E.L.; H NMR Determination of Urinary Betaine in Patients with Premature Vascular Disease and Mild Homocysteinemia: CLIN. CHEM. 41/2, (1995) 275-283.

Mäck G., Hoffmann C. M., Organ-specific adaptation to low precipitation in solute concentration of sugar beet: Europ. J. Agronomy 25 (2006) 270-279.

Ma Z., Whitley R. D. and Wang N. H. L., Pore and Surface Diffusion in Multicomponet Adsorption and Liquid Chromatography Systems: AIChE J. 42 (5) (1996) 1244 - 1262.

Mahn K., Hoffmann C. and Märländer B.; Distribution of quality components in different morphological sections of sugar beet (Beta vulgaris L.): European Journal of Agronomy 17 (2002) 29-39. 
Maity N., Payne G. F. and Chipchosky J. L., Adsorptive Separations Bases on the Differences in Solute-Sorbent Hydrogen-Bonding Strengths: Ind. Eng. Chem. Res. 30 (1991) $2456-2463$.

Margreth A., Wegman A., Michiel H. A., Fred V. R. and Roger A. S., Towards Biocatalytic Synthesis of B-Lactam Antibiotics: Review, Adv. Synth. Catal. (2001), 343, 559-576.

Martín C. and Cuellar J., Synthesis of a Novel Magnetic Resin and the Study of Equilibrium in Cation Exchange with Amino Acids: Ind. Eng. Chem. Res. (43) (2004) 475485.

Martín C. and Cuellar J., Synthesis of Poly(styrene-co-divinylbenzene)-stainless Steel Beads through a factorial design of Experiments: Ind. Eng. Chem. Res. (43) (2004) 20932103

McCabe W. L., Smith J. C. and Harriot P., Operaciones Básicas de Ingeniería Química. 4ª ed., McGraw-Hill, Madrid, 1991.

Mijangos F., González C. And Varona F., Envenenamiento Inducido y Regeneración Química con Disolventes de Resinas Adsorbentes Apolares: Afinidad LV 477 (1998) 369 $-376$.

Molinari R., Bartolo D. L. and Drioli E., Coupled Transport of Amino Acid Through a Supported Liquid Membrane. I. Experimental Optimization: J. Membrane Sci. 73 (1992) $203-215$.

Moreira M. J. and Ferreira L. M., Kinetics studies for sorption of amino acids using strong anion-exchange resin. Effect of ionic strength: Journal of Chromatography A, 1092 (2005) 101-106.

Moreira M. J. and Ferreira L. M., Equilibrium studies of phenylalanine and tyrosine on ion-exchange resins: Chemical Engineering Science 60 (2005) 5022-5034.

Mulder M., Basic principles of membrane technology, Kluwer academic publishing, 1991.

Munson C. L. and King C. J., Factors Influencing Solvent Selection for Extraction of Ethanol from Aqueous Solutions: Ind. Eng. Chem. Process Des. Dev. 23 (1) (1984) 115 121.

Nath M., Yadav R., Eng G., and Musingarimi P., Synthesis, Spectral Studies, In Vitro Antimicrobial and In Vivo Multi-infection Antifungal Activities in Mice of New Organotin (IV) Derivatives of Amino Acids: J. Chem. Research (8) (1998) 409.

Nitta H., Ueda I. and Hatanaka M., Enantioselective synthesis of 2-isocephem and 2isooxacephem antibiotics: J. Chem. Soc., Perkin Trans., (1) (1997) 1793-1796.

Nishihama S., Nishimura G., Hirai T. and Komasawa, Separation and Recovery of $\mathrm{Cr}(\mathrm{VI})$ from Simulated Plating Waste Using Microcapsules Containing Quaternary Ammonium Salt Extractant and Phosphoric Acid Extractant: Ind. Eng. Chem. Res. (43) (2004) $751-757$.

Nishiki T., Nakamura K. and Kato D., Forward and backward extraction rates of amino acid in reversed micellar extraction, Biochem. Eng. J., 4 (2000) 189-195. 
Oshima T., Inoue K., Uezu K. and Goto M., Dominant factors affecting extraction behaviour of amino compounds by a calix[6]arene carboxilic acid derivate. Analytica Acta 509 (2004) 137-144.

Outokesh M., Mimura H., Nibori Y. and Tanaka K., Equilibrium and Kinetics of Silver Uptake by Multinuclear Alginate Microcapsules Comprising an Ion Exchanger Matrix and Cianex 302 Organophosphinic Acid Extractant. Ind. Eng. Chem. Res. 45 (2006) 36333643.

Paananen H., Kuisma J., Ravanko V., Nurmi N., Heillila H., Lewandowski J., A multistep process for recovering betaine, erythritol, inositol, sucrose, mannitol, glycerol and amino acids from a process solution using a weakly acid cation exchange resin. European Patent Office. EP 1328664 B1, Date of filling: 28.09.2001.

Paananen H., Pia S., Nurmi N., Method for separating betaine. United States Patent Application Publication. US 2007/0158269 A1, Publication Date: jul. 12, 2007.

Parrish J. R., Macroporous Resins as Supports for a Chelating Liquid ion-exchanger in Extraction Chromatography. Analytical Chemistry 49 (8) (1977) 1189 - 1192.

Perry R. H. and Chilton C. H., Chemical Engineer's Handbook, 6 th ed., McGraw-Hill, Co., New York, 1984.

Prabhakaran D. and Subramaniam M. S., Selective extraction of U(VI), $T h(I V)$, and $\mathrm{La}$ (III) from acidic matrix solutions and environmental samples using chemically modified Amberlite XAD-16 resin: Analytical and Bioanalytical Chemistry (2004).

Qin W., Zhang Y., Li Z. and Dai Y., Extraction Equilibria of Glycolic and Glyoxylic Acids with Tryalkylphosphine Oxide and Trioctylamine as Extractant: J. Chem. Eng. Data, 48 (2003), 430-434.

Rai R. and Taneja V., Production of D-Amino Acids Using Immobilized D-Hydantoinase from Lentil, Lens Esculenta, Seeds, Appl. Microbiol. Biotechnol., 50 (1998) 658-662.

Riddick J. A., Bunger W. B. and Sakano T. K., Techniques of Chemistry, O.S.F.E.A. Wilssberg II. Organic Solvent, 4 th. Arnold Wilssberg, John Wiley and Sons (Eds.), New York, 1986.

Robinson S. M., Arnold W. D. and Byers C. H., Mass-Transfer Mechanisms for Zeolite Ion Exchange in Wastewater Treatment: AIChE J. 40 (12) (1994) 2045 - 2054.

Roche Molecular Biochemicals, Biocatalysis Products for de Synthesis of $\beta$-Lactam Antibiotics, http://www.roche.com. 2000.

Rosen J. B., Kinetics of a Fixed Bed System for Solid diffussion into spherical particle: J. Chem. Phys. 20 (1952) 387-394.

Rosen J. B., General numerical solution for solid diffusion in fixed beds: Ind. Eng. Chen. 46 (1954)1590-1594.

Rovira M., Hurtado L., Cortina J.L., Arnaldos JI, and Sastre A. M., Recovery of palladium (II) form hydrochloric acid solutions using impregnated resins containing Alamine 336: Reactive \& Functional Polymers (38) (1998) 279-287. 
Rovira M., Cortina J. L., Arnaldos J. And Sastre A. M., Impregnated Resins Containing Di-(2ethylhexyl) thiophosphoric acid for the extraction of palladium (II). II. Selective palladium (II) recovery from hydrochloric acid solutions: Solv. Extr. Ion Exch., 17 (1999) 351-366.

Ruiz M. O., Cabezas J. L., Escudero I., Álvarez J. R. And Coca J., Extraction of Valeric Acid from Aqueous Solutions Using Tri-n-butylphosphate, in Separation for Biotechnology 3, D. L. Pyle (Ed), SCl, London, (1994) 447-453.

Ruiz M. O., Estudio de la separación de ácido valérico y $\alpha$-fenilglicina de disoluciones acuosas por extracción reactiva con extractante libre y soportado. Tesis doctoral, 2000.

Ruiz M. O., Cabezas J. L. Escudero I., Alvarez J. R. and Coca J., $\alpha$-Phenylglycine Extraction with Trialkylmethylammonium Chloride free and immobilized in a macroporous resin. 1. Equilibria: Trans IChemE, (80), Part A, (2002) 529-535.

Ruiz M. O., Escudero I., Cabezas J. L. and Coca J., $\alpha$-Phenylglycine Extraction with Trialkylmethylammonium Chloride-Impregnated Macroporous resin. 2. Kinetics: Trans IchemE, (80), Part A, (2002) 537-542.

Ruiz M. O., Cabezas J. L. Escudero I. and Coca J., Valeric Acid Extraction with Tri-Nbutyl Phosphate Impregnated in a Macroporous Resin. I. Equilibrium and Mass Transfer Rates: Separation Science and Technology, 39, No. 1, (2004) 77-95.

Ruiz M. O., Cabezas J. L. Escudero I. and Coca J., Valeric Acid Extraction with Tri-Nbutyl Phosphate Impregnated in a Macroporous Resin. II. Studies in fixed bed columns: Journal of Chemical Technology and Biotechnology, 81, No. 1, (2006) 275-281.

Ruiz M. O., Escudero I., Horta A. I., Extraction equilibria of $\alpha$-fenilglycine and aspartic acid wtih Tomac-impregnated resins. Chemical Engineering Science 62 (2007) 27372749.

Ruthven D. M., Principles of Adsorption and Adsorption Processes. Wiley-Interscience, John Wiley and Sons (Eds.), New York, 1984.

Salazar E., Ortiz M. I., Urtiaga A. M. and Irabien J. A., Equilibrium and Kinetics of Cr (VI) Extraction with Aliquat 336: Ind. Eng. Chem. Res. 31 (6) (1992) 1516 - 1522.

Sanchez P., Recuperación de aminoácidos de corrientes acuosas diluidas empleando contactores de membranas de fibras huecas; Proyecto de investigación para optar al Diploma de Estudios Avanzados. Director: Ruiz M. O. (2006).

Santidrián E., Estudio de la Separación de Aminoácidos con el Extractante Inmovilizado en Resinas Macroporosas. Equilibrios y Cinéticas de Extracción Aplicadas al Ácido Aspártico y $\alpha$-Fenilglicina; Tesis de Licenciatura, directores: Ruiz M. O.; Escudero I., (2001).

Santidrián E., Estudio de un proceso híbrido de adsorción-extracción para la separación de aminoácidos; Proyecto de investigación, directores: Ruiz M. O.; Escudero I., (2003).

Santidrián E., Ruiz M. O., Cabezas J. L., and Escudero I., $\alpha$-phenylglycine Equilibrium Extraction with Tri-alkylmethylammonium Chloride Immobilized in Several Macroporous Resins. "Libro de resúmenes", p2-21, pp 163 (Ed.) Fira del 9º Congreso del Mediterráneo de IQ de Barcelona, (2002). 
Scarpello J. T. and Stuckey D. C., 2000, The Reactive Extraction of Phenylalanine with Aliquat 336: Buffer Co-Extraction Equilibrium and Mass Transfer Kinetics, Biotechnol Bioeng, 69(5): 469-477.

Schügerl K. and Degener W., Recovery of Low - Molecular - Weight Compounds from Complex Aqueous Mixtures by Extraction: Int. Chem. Eng. 32 (1) (1992) 29 - 40.

Shiau C. Y., Lin C. L. and Chang H. S., Adsorption equilibrium of Zinc from aqueous sulfate solution by Solvent-Impregnated Resins containing Cyanex 272: Ind. Eng. Chem. Res. 44 (2005) 4771-4777.

Simpson C., Laurie S. H., lon exchange studies on zinc-rich waste liquors: Hydrometallurgy 51 (1999) 335-344.

Strikovsky A. G., Jerabek K., Cortina A. M., Sastre A. M. and Warshawsky A., Solvent impregnated resin (SIR) containing dialkyl dithiophosphoric acid on Amberlite XAD-2: extraction of copper and comparison to the liquid-liquid extraction: React Funct Polym, 28(2) (1996) 149-158.

Strikovsky A. G., Warshawsky A., Hanková L. and Jerábek K., Morphology of solventimpregnated resins bases on reactive supports: Acta Polym. (49) (1998) 600-605.

Sudge S.S., Bastawde K.B., Gokhale D. V., Kalkote U.R. and Ravindranathan T., Production of D-Hydantoinase by Halophilic Pseudomonas sp. NCIM 5109: Appl. Microbiol. Biotechnol., 49 (1998) 594-599.

Tamada J. A., Kertes A. S. and King C. J., Extraction of Carboxylic Acids with Extractants. 1. Equilibria and Law of Mass Action Modelling: Ind. Eng. Chem. Res. 29 (7) (1990 a) $1319-1326$.

Tamada J. A., Kertes A. S. and King C. J., Extraction of Carboxylic Acids with Extractants. 3. Effect of Temperature, Water Coextraction and Process Considerations: Ind. Eng. Chem. Res. 29 (7) (1990 c) 1333 - 1338.

Tambe A. S., High Performance Liquid Chromatographic of Cyclohexylhydantoin and Cyclohexylidenehydantoin Formed During the Synthesis of Phenyldantoin from Hydantoin and Cyclohexanone: J. Chromatogr. A. 740 (2) (1996) 284 - 288.

Tan B., Luo G. and Wang J., Enantioseparation of amino acids by co-extractants with di(2-ethylhexyl)phosphoric acid and tartaric acid derivates: Tetrahedron: Asymmetry 17 (2006) 883-891.

Tan B., Luo G. and Wang J., Extractive separation of amino acids enantiomers with coextractants of tartaric acid derivate and Aliquat-336: Separation and Purification Technology 53 (2007) 330-336.

Thalasso F., Van der Burgt J., O'Flaherty V. and Colleran E., Large-scale anaerobic degradation of betaine: Journal of Chemical Technology and Biotechnology 74 (1999) 1176-1182.

Thien M. P., Hatton T. A. and Wang D. I. C., Separation and Concentration of Amino Acid Using Liquid Emulsion Membranes: Biotechnol. Bioeng. 32 (1988) 604 - 615. 
Traving M. and Bart H-J., Recovery of Organic Acids Using lon-Exchanger-Impregnated Resins, Chem. Eng. Technol., 25 (2002) 997-1003.

Treybal R. E.,. Ingeniería Química II. Operaciones Básicas, McGraw-Hill, Mexico, 1980.

Trochimczuk A. W., Kabay N., Arda M., Streat M., Stabilization of solvent impregnated resins (SIRs) by coating with water soluble polymes and chemical crosslinking: Reactive \& Functional Polymers, 59 (2004) 1-7.

Uddin M. S., Hidajat K., Lim B. G. and Ching C. B., Interfacial Mass Transfer in Extraction of Amino Acid: J. Chem. Tech. Biotechnol. 48 (1990) 415 - 426.

Uddin M. S., Hidajat K., Lim B. G and Ching C. B., Interfacial Mass Transfer in Stripping of Phenylalanine in a Liquid - Liquid Extraction Process: J. Chem. Tech. Biotechnol. 53 (1992) 353 - 357.

Vaughan T., Seo C. W., Marshall W. E., Removal of selected metal ions from aqueous solution using modified corncobs: Bioresource Technology 78 (2001) 133-139.

Venkatesh G., Singh A. K. and Venkataramani B., Silica Gel Loaded with oDihydroxybenzene: Design, Metal Sorption Equilibrium Studies and Aplication to Metal Enrichment Prior to Determination by Flame Atomic Spectrometry: Microchim. Acta 144 (2004) 233-241.

Villaescusa I., Salvadó V. and De Pablo J., Liquid-liquid and Solid-liquid Extraction of Gold by Trioctylmethylammonium Chloride (TOMACl) Dissolved in Toluene and Impregnated on Amberlite XAD-2 Resin: Hydrometallurgy, 41 (1996) 303-311.

Ward O.P., Biotecnología de la Fermentación. Principios, Procesos y Productos, Ed. Zaragoza, 1989.

Warshawsky A., Extraction with Solvent-Impregnated Resins. In Ion Exchange and Solvent Extraction. vol. 8, pp 229 - 310, J. A. Marinsky and Y. Marcus (Eds), MarcelDekker, New York, 1981.

Weast R. C., CRC Handbook of Chemistry and Physics. 75 th CRC, D. R. Lide, H. P. R. Frederikse (Eds.), Press Inc. Boca Ratón, Florida, 1994 - 1995.

Won C.Y., Chu C.C. and Lee J. D., Synthesis and Characterization of Biodegradable poly(L-Aspartic-Acid-Co-Peg): Journal of Polymer Science Part A-Polymer Chemistry, Vol. 36 (16) (1998) 2949-2959.

Yang R. T., Gas Separation by Adsorption Processes, Butterworth Publishers, 1987.

Yang B. L., Yang S. B., Yao R. Q., Synthesis of ethyl tert-butyl ether from tert-butyl alcohol and ethanol on strong acid cation-exchange resins: Reactive \& Functional polymers 44 (2000) 167-175.

Yang S. T., White S. A.and Hsu S. T., Extraction of Carboxylic Acids with Tertiary and Quaternary Amines; Effect of pH: Ind. Eng. Chem. Res. 30 (6) (1991) 1335 - 1342.

Yang S. A., Pyle D. L., The Adsorption Kinetics of Cephalosphrin-c on Non-ionic Polymeric Macropore Amberlite XAD-16 Resin.: J Chem. Tech. Biotechnol. 74 (1999) 216-220. 
Yoshida H., Kataoka T. and Ruthven D. M., Analytical Solution of the Breakthrough Curva for Rectangular Isotherm Systems: Chem. Eng. Sci. 19 (10) (1984) 1489 - 1497.

Yoshida H., Yoshikawa M. and Kataoka T., Parallel Transport of BSA by Surface and Pore Diffusion in Strongly Basic Chitosan: AIChE J. 40 (12) (1994) 2034 - 2044.

Yoshida H., Kataoka T. and Ikeda S., Intraparticle Mass Transfer in Bidispersed Porous Ion Exchanger. Part I: Isotopic Ion Exchange: Can. J. Chem. Eng. 63 (6) (1985) 422 435.

Youshko M. I., Van Langen L.M., de Vroom E., van Rantwijk F., Sheldon R. A. and Svedas V. K., Highly Efficient Synthesis of Ampicillin in an "Aqueous Solution-Precipitate" System: Repetitive Addition of Substrates in a Semicontinuous Process: Biotechnol. Bioeng., Communication to the Editor, 73 (5), 2001.

Zwart F. J.; Slow S.; Payne R.J.; Lever M., George P.M.; Gerrard J.A. and Chambers S.T. "Glycine betaine and glycine betaine analogues in common foods": Food Chemistry 83 (2003) 197-204. 


\section{NOMENCLATURA}





\section{LISTA DE SÍMBOLOS}

a

b

$\mathrm{A}^{+}$

$\mathrm{A}^{+/-}$

$A^{-}$

$\mathrm{A}^{2-}$

$A^{b-}$

$\mathrm{B}^{+}$

$\mathrm{B}^{+/-}$

$\mathrm{Cl}^{-}$

$\mathrm{H}^{+}$

$\mathrm{OH}^{-}$

$\mathrm{Q}^{+} \mathrm{Cl}^{-}$

$\mathrm{Q}^{+} \mathrm{A}^{-}$

$\mathrm{Q}_{2}^{+} \mathrm{A}^{2-}$

$\mathrm{Q}^{+} \mathrm{OH}^{-}$

C

$\mathrm{C}_{\mathrm{A}}$

$\mathrm{C}_{\mathrm{Ap}}$

$\mathrm{C}_{\mathrm{B}}$

$\mathrm{C}_{\mathrm{S}}$

D

$D_{e}$ actividad de las especies, y radio de la resina sin impregnar expresada en $\mathrm{m}$

coeficiente estequiométrico de la reacción de intercambio iónico del aminoácido o carga de la forma aniónica

forma catiónica del aminoácido

forma anfótera del aminoácido

forma aniónica del aminoácido con una carga

forma aniónica del aminoácido con dos cargas

forma aniónica del aminoácido con $d$ cargas

forma catiónica de betaína

forma anfótera de betaína

iones cloruro

protones

iones hidroxilo

Tomac

complejo aminoácido -Tomac

complejo aminoácido -Tomac

complejo iones hidroxilo -Tomac

concentración total de soluto

concentración total de aminoácido en $\mathrm{mol} / \mathrm{m}^{3}$

concentración de soluto en el fluido que llena los poros de la resina definida en la Ec. (4.17)

concentración total de betaína en $\mathrm{mol} / \mathrm{m}^{3}$

concentración total de sacarosa en $\mathrm{mol} / \mathrm{m}^{3}$

coeficiente de dispersión axial definido en la Ec. (4.20)

coeficiente de difusión efectivo definido en las Ecs. (4.12) y (4.13) 
$\mathrm{D}_{\mathrm{L}}$

$D_{p}$

$D_{s}$

$D_{m}$

$g_{n}$

G

h

i

j

$J_{A p}$

$J_{\text {As }}$

k

$\mathrm{K}$

$\mathrm{K}_{\mathrm{a} 1}, \mathrm{~K}_{\mathrm{a} 2}, \mathrm{~K}_{\mathrm{a} 3}$

$k_{f}$

$\mathrm{K}_{\mathrm{h}}$

$\mathrm{K}_{\mathrm{p} 1}$

$\mathrm{K}_{\mathrm{p} 2}$

$\mathrm{K}_{\mathrm{ep}}$

$\mathrm{K}_{\mathrm{eh}}$

$\mathrm{K}_{\mathrm{w}}$

$\mathrm{m}$ coeficiente de difusión en la película líquida externa

coeficiente de difusión en el poro definido en la Ec. (4.10)

coeficiente de difusión en la superficie definido en la Ec. (4.11)

coeficiente de difusión en la superficie del microporo

número adimensional definido en las Ecs. (5.60), (5.91), (5.92) y (6.32)

parámetro de las Ecs. (5.38) y (5.39) definido en la Ec. (5.40)

parámetro de las Ecs. (5.38) y (5.39) definido en la Ec. (5.41)

parámetro de las Ecs. (5.38) y (5.39) definido en la Ec. (5.42)

número de puntos experimentales de las Ecs. (5.15) y (6.16)

densidad de flujo difusivo en el poro de la especie A definido en la Ec. (4.10)

densidad de flujo difusivo en la superficie de la especie A definido en la Ec. (4.11)

constante de la ecuación de Freundlich definida en las Ecs. (4.4) y (5.20)

coeficiente de distribución de la forma aniónica de aminoácido definido en las Ecs. (5.51), (5.75) y (5.76); y coeficiente de distribución de la concentración total de betaína definido en la Ec. (6.23)

constantes de disociación de los aminoácidos o de la betaína

coeficiente de transferencia de masa de la película líquida externa definido en la Ec. (4.9)

constante de equilibrio expresada en términos de concentración de la Ec. (5.10)

constante de equilibrio expresada en términos de concentración de las Ecs. (5.9), (5.23) y (6.12)

constante de equilibrio expresada en términos de concentración de la Ec. (5.30)

constante de equilibrio definida en la Ec. (3.8)

constante de equilibrio definida en la Ec (3.9)

constante de disociación del agua $\left(\mathrm{mol}^{2} / \mathrm{l}^{2}\right)$

masa de resina expresada en $\mathrm{kg}$ 


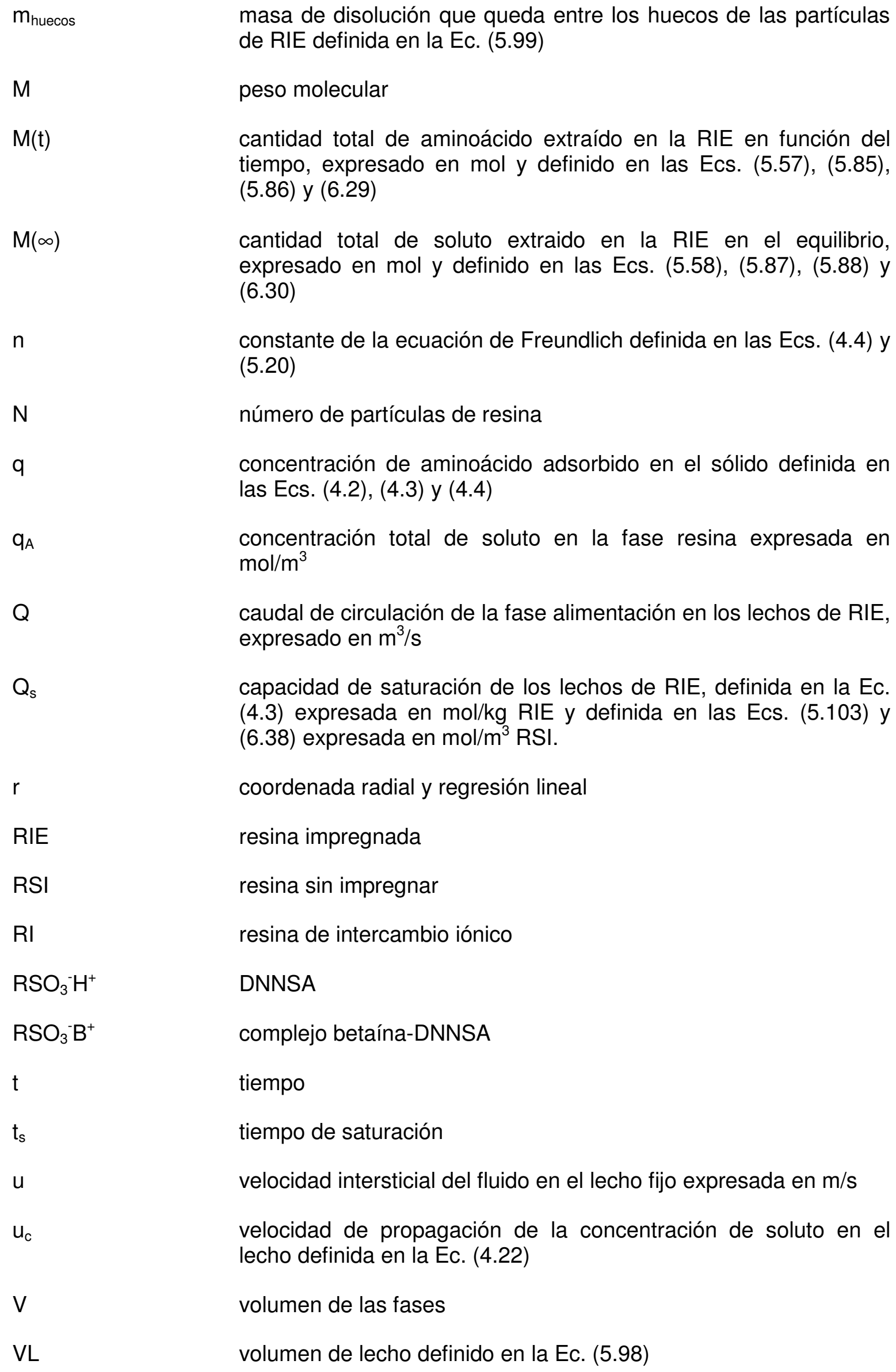
tiempo, expresado en mol y definido en las Ecs. (5.57), (5.85), (5.86) y (6.29)

cantidad total de soluto extraido en la RIE en el equilibrio, expresado en mol y definido en las Ecs. (5.58), (5.87), (5.88) y (6.30)

$\mathrm{n}$

constante de la ecuación de Freundlich definida en las Ecs. (4.4) y (5.20)

$\mathrm{N}$

número de partículas de resina

q

concentración de aminoácido adsorbido en el sólido definida en las Ecs. (4.2), (4.3) y (4.4)

$\mathrm{q}_{\mathrm{A}}$

concentración total de soluto en la fase resina expresada en $\mathrm{mol} / \mathrm{m}^{3}$

caudal de circulación de la fase alimentación en los lechos de RIE, expresado en $\mathrm{m}^{3} / \mathrm{s}$

$Q_{s}$

capacidad de saturación de los lechos de RIE, definida en la Ec. (4.3) expresada en $\mathrm{mol} / \mathrm{kg}$ RIE y definida en las Ecs. (5.103) y (6.38) expresada en $\mathrm{mol} / \mathrm{m}^{3} \mathrm{RSI}$.

coordenada radial y regresión lineal

RIE

resina impregnada

$\mathrm{RSI}$

resina sin impregnar

$\mathrm{Rl}$

resina de intercambio iónico

$\mathrm{RSO}_{3} \mathrm{H}^{+} \quad$ DNNSA

$\mathrm{RSO}_{3}{ }^{-} \mathrm{B}^{+} \quad$ complejo betaína-DNNSA

t tiempo

$t_{s} \quad$ tiempo de saturación

u

velocidad intersticial del fluido en el lecho fijo expresada en $\mathrm{m} / \mathrm{s}$

$\mathrm{u}_{\mathrm{c}}$ velocidad de propagación de la concentración de soluto en el lecho definida en la Ec. (4.22)

$\mathrm{V} \quad$ volumen de las fases

VL volumen de lecho definido en la Ec. (5.98) 
$V_{L} \quad$ volumen de columna empleada

$X$

variable definida en las Ecs. (5.47), (5.48), (5.67) (5.68), (5.69), (5.70), (6.19) y (6.20)

$\mathrm{Xe}$

variable definida en las Ecs. (5.52), (5.77), (5.78) y (6.24)

variable definida en las Ecs. (5.49), (5.71), (5.72) y (6.21)

Z

variable definida en las Ecs. (5.50), (5.73), (5.74) y (6.22)

Z

posición axial en el lecho expresada en m

Otros

concentración molar

$\alpha$

constante definida en las Ecs. (5.61), (5.93), (5.94) y (6.33)

$\beta$

selectividad del disolvente definida en la Ec. (3.2)

$\lambda$

parámetro de la longitud definido en las Ecs. (5.113) y (6.40)

$\tau$

parámetro del tiempo definido en las Ecs. (5.114) y (6.41)

$\psi$

parámetro de las resistencias definido en las Ecs. (5.115) y (6.42)

$\gamma$

coeficiente de actividad

parámetro de ajuste de la Ec. (5.13)

parámetro de ajuste de la Ec. (5.13)

porosidad de la partícula

porosidad del lecho fijo

$\rho$

densidad

$\sigma$

desviación estándar

\section{Subíndices}

A

asp

pgly

I

i

calc aminoácido

ácido aspártico

a-fenilglicina

impregnación

condiciones iniciales

calculada 


$\begin{array}{ll}\text { exp } & \text { experimental } \\ o & \text { fase orgánica } \\ \mathrm{p} & \text { en el poro de la resina } \\ \mathrm{s} & \text { muestra sacada } \\ \mathrm{w} & \text { fase acuosa }\end{array}$

\section{Superíndices}

fase resina 



\section{APÉNDICES}





\section{APÉNDICE A. Equilibrios de extracción de aminoácidos}

TABLAS A. Impregnación de Amberlita XAD-4 con Tomac. (Apartado 5.2.1)

Tabla A1. Datos de impregnación de Amberlita XAD-4 con disoluciones de Tomac disuelto en n-hexano.

\begin{tabular}{ccc}
\hline $\begin{array}{c}\text { \% peso Tomac } \\
\text { en n-hexano }\end{array}$ & $\begin{array}{c}{\left[\overline{\mathrm{Q}^{+} \mathrm{Cl}^{-}}\right.} \\
(\mathrm{mol} \mathrm{Tomac} / \mathrm{Kg} \mathrm{RIE})\end{array}$ & $\begin{array}{c}\overline{\mathrm{Q}^{+} \mathrm{Cl}^{-}} \\
\left(\mathrm{mol} \mathrm{Tomac} / \mathrm{m}^{3} \mathrm{RSI}\right)\end{array}$ \\
\hline 2,02 & 0,10 & 57,69 \\
3,92 & 0,16 & 90,47 \\
5,04 & 0,21 & 122,54 \\
5,88 & 0,22 & 124,57 \\
7,20 & 0,29 & 174,91 \\
11,49 & 0,52 & 349,81 \\
16,18 & 0,66 & 471,46 \\
21,28 & 0,81 & 640,03 \\
27,80 & 0,91 & 766,21 \\
34,94 & 1,00 & 892,39 \\
38,31 & 1,05 & 960,15 \\
41,36 & 1,14 & 1110,39 \\
44,63 & 1,14 & 1109,63 \\
\hline
\end{tabular}

TABLAS B. Isotermas de equilibrio de extracción individual de $\alpha$-fenilglicina con RIE a 30드. (Apartado 5.2.2)

Tabla B1. Datos de equilibrio de extracción individual de a-fenilglicina para el experimento II de la Tabla 2. $\left.\left(\mathrm{pH}_{\mathrm{i}}=\mathbf{5 , 0 6} \pm 0,05 ; \overline{\mathrm{Q}^{+} \mathrm{Cl}^{-}}\right]_{\mathrm{i}}=791,56 \pm 6,99 \mathrm{~mol} / \mathrm{m}^{3} \mathrm{RSI}\right)$.

\begin{tabular}{cccccc}
\hline $\begin{array}{c}\mathrm{C}_{\mathrm{A}(\mathrm{plgly})} \\
\left(\mathrm{mol} / \mathrm{m}^{3}\right)\end{array}$ & $\mathrm{pH}$ & $\begin{array}{c}{\left[\mathrm{A}_{\mathrm{pgly}}^{+}\right]} \\
\left(\mathrm{mol} / \mathrm{m}^{3}\right) \\
\text { Ec. }(5.4)\end{array}$ & $\begin{array}{c}{\left[\mathrm{A}^{+/-} \mathrm{ply}\right]} \\
\left(\mathrm{mol} / \mathrm{m}^{3}\right) \\
\text { Ec. }(5.5)\end{array}$ & $\begin{array}{c}{\left[\mathrm{A}_{\mathrm{pgly}}^{-}\right]} \\
\left(\mathrm{mol} / \mathrm{m}^{3}\right)\end{array}$ & $\begin{array}{c}\overline{\mathrm{C}}_{\mathrm{A}(\mathrm{pgly})} \\
\left(\mathrm{mol} / \mathrm{m}^{3} \mathrm{RSI}\right) \\
\mathrm{Ec} .(5.6)\end{array}$ \\
\hline 1,695 & 5,66 & 0,000 & 1,694 & 0,001 & 0,000 \\
3,448 & 6,04 & 0,000 & 3,444 & 0,004 & 0,000 \\
5,013 & 5,76 & 0,000 & 5,010 & 0,003 & 0,000 \\
6,683 & 5,82 & 0,001 & 6,678 & 0,004 & 0,000 \\
8,386 & 5,84 & 0,001 & 8,379 & 0,006 & 0,000 \\
9,999 & 5,5 & 0,002 & 9,995 & 0,003 & 0,000 \\
10,398 & 5,39 & 0,002 & 10,393 & 0,003 & 0,000 \\
11,376 & 5,47 & 0,002 & 11,371 & 0,003 & 0,000 \\
\hline
\end{tabular}


Tabla B2. Datos de equilibrio de extracción individual de a-fenilglicina para el experimento III de la Tabla 2. $\left(\mathrm{pH}_{\mathrm{i}}=\mathbf{9 , 1 2} \pm 0,02 ;\left[\overline{\mathrm{Q}^{+} \mathrm{Cl}^{-}}\right]_{\mathrm{i}}=791,56 \pm 6,99 \mathrm{~mol} / \mathrm{m}^{3} \mathrm{RSI}\right)$.

\begin{tabular}{|c|c|c|c|c|c|c|c|}
\hline $\begin{array}{l}\mathrm{C}_{\mathrm{A}(\mathrm{plgly})} \\
\left(\mathrm{mol} / \mathrm{m}^{3}\right)\end{array}$ & $\mathrm{pH}$ & $\begin{array}{l}{\left[\mathrm{A}_{\mathrm{pgly}}^{+}\right]} \\
\left(\mathrm{mol} / \mathrm{m}^{3}\right) \\
\text { Ec. }(5.4)\end{array}$ & $\begin{array}{l}{\left[\mathrm{A}^{+/-}{ }_{\mathrm{pgly}}\right]} \\
\left(\mathrm{mol} / \mathrm{m}^{3}\right) \\
\text { Ec. }(5.5)\end{array}$ & $\begin{array}{c}{\left[\mathrm{A}_{\mathrm{pgly}}^{-}\right]} \\
\left(\mathrm{mol} / \mathrm{m}^{3}\right) \\
\text { Ec. }(5.6)\end{array}$ & $\begin{array}{c}\overline{\mathrm{C}}_{\mathrm{A}(\mathrm{pgly})} \\
\left(\mathrm{mol} / \mathrm{m}^{3} \mathrm{RSI}\right) \\
\text { Ec. }(5.3)\end{array}$ & $\begin{array}{c}\left|\overline{\mathrm{Q}^{+} \mathrm{A}_{\mathrm{pgly}}^{-}}\right|\left[\mathrm{Cl}^{-}\right] \\
\left(\mathrm{mol}^{2} / \mathrm{m}^{3} \mathrm{~m}^{3}\right. \\
\mathrm{RSI})\end{array}$ & $\begin{array}{c}{\left[\overline{\mathrm{Q}^{+} \mathrm{Cl}^{-}}\right]\left[\mathrm{A}_{\mathrm{pgly}}\right]} \\
\left(\mathrm{mol}^{2} / \mathrm{m}^{3} \mathrm{~m}^{3}\right. \\
\mathrm{RSI})\end{array}$ \\
\hline 1,283 & 8,11 & 0,000 & 1,137 & 0,146 & 32,381 & 12,584 & 105,838 \\
\hline 2,663 & 8,37 & 0,000 & 2,157 & 0,506 & 68,065 & 54,717 & 347,499 \\
\hline 3,888 & 8,52 & 0,000 & 2,921 & 0,967 & 98,718 & 114,584 & 635,176 \\
\hline 5,408 & 8,60 & 0,000 & 3,868 & 1,540 & 127,675 & 191,829 & 966,781 \\
\hline 6,478 & 8,58 & 0,000 & 4,694 & 1,784 & 137,827 & 222,950 & 1102,322 \\
\hline 7,872 & 8,70 & 0,000 & 5,244 & 2,628 & 170,515 & 339,176 & 1537,745 \\
\hline 8,909 & 8,73 & 0,000 & 5,796 & 3,113 & 182,111 & 386,613 & 1785,153 \\
\hline
\end{tabular}

TABLAS C. Isotermas de equilibrio de extracción individual de ácido aspártico con RIE a $30^{\circ} \mathrm{C}$. (Apartado 5.2.3)

Tabla C1. Datos de equilibrio de extracción individual de ácido aspártico para el experimento l-a de la Tabla 3. $\left.\left(\mathrm{pH}_{\mathrm{i}}=\mathbf{5 , 0 4} \pm 0,04 ; \overline{\mathrm{Q}^{+} \mathrm{Cl}^{-}}\right]_{\mathrm{i}}=0 \mathrm{~mol} / \mathrm{m}^{3} \mathrm{RSI}\right)$.

\begin{tabular}{cccccc}
\hline $\begin{array}{c}\mathrm{C}_{\mathrm{A}(\text { asp })} \\
\left(\mathrm{mol} / \mathrm{m}^{3}\right)\end{array}$ & $\mathrm{pH}$ & $\begin{array}{c}{\left[\mathrm{A}_{\text {asp }}^{+}{ }^{3}\right)} \\
\left(\mathrm{mol} / \mathrm{m}^{3}\right) \\
\text { Ec. }(5.16)\end{array}$ & $\begin{array}{c}{\left[\mathrm{A}^{+/-}{ }_{\text {asp }}\right]} \\
\left(\mathrm{mol} / \mathrm{m}^{3}\right) \\
\text { Ec. }(5.17)\end{array}$ & $\begin{array}{c}{\left[\mathrm{A}_{\text {asp }}^{-}\right]^{3}} \\
\left(\mathrm{~mol} / \mathrm{m}^{3}\right)\end{array}$ & $\begin{array}{c}\overline{\mathrm{C}}_{\mathrm{A} \text { (asp) }} \\
\left(\mathrm{mol} / \mathrm{m}^{3} \mathrm{RSI}\right) \\
\mathrm{Ec} .(5.18)\end{array}$ \\
\hline 7,630 & 5,3 & 0,000 & 0,292 & 7,337 & 0,000 \\
11,587 & 5,36 & 0,000 & 0,388 & 11,198 & 0,000 \\
15,426 & 5,18 & 0,000 & 0,769 & 14,656 & 2,561 \\
18,573 & 5,22 & 0,000 & 0,848 & 17,723 & 6,004 \\
22,888 & 5,16 & 0,001 & 1,192 & 21,694 & 12,368 \\
26,440 & 5,17 & 0,001 & 1,347 & 25,091 & 25,909 \\
30,015 & 5,18 & 0,001 & 1,496 & 28,516 & 40,823 \\
\hline
\end{tabular}

Tabla C2. Datos de equilibrio de extracción individual de ácido aspártico para el experimento II de la Tabla 3. $\left(\mathrm{pH}_{\mathrm{i}}=\mathbf{5 , 0 7 \pm 0 , 0 4 ;}\left[\overline{\mathrm{Q}^{+} \mathrm{Cl}^{-}}\right]_{\mathrm{i}}=791,56 \pm 6,99 \mathrm{~mol} / \mathrm{m}^{3} \mathrm{RSI}\right)$.

\begin{tabular}{|c|c|c|c|c|c|c|c|}
\hline $\begin{array}{c}\mathrm{C}_{\mathrm{A}(\text { asp })} \\
\left(\mathrm{mol} / \mathrm{m}^{3}\right)\end{array}$ & $\mathrm{pH}$ & $\begin{array}{c}{\left[\mathrm{A}^{+}{ }_{\text {asp }}\right]} \\
\left(\mathrm{mol} / \mathrm{m}^{3}\right) \\
\text { Ec. }(5.16)\end{array}$ & $\begin{array}{c}{\left[\mathrm{A}^{+/-}{ }_{\text {asp }}\right]} \\
\left(\mathrm{mol} / \mathrm{m}^{3}\right) \\
\text { Ec. }(5.17)\end{array}$ & $\begin{array}{c}{\left[\mathrm{A}_{\text {asp }}^{-}\right]} \\
\left(\mathrm{mol} / \mathrm{m}^{3}\right) \\
\text { Ec. }(5.18)\end{array}$ & $\begin{array}{c}\overline{\mathrm{C}}_{\mathrm{A}(\mathrm{asp})} \\
\left(\mathrm{mol} / \mathrm{m}^{3} \mathrm{RSI}\right) \\
\text { Ec. }(5.3)\end{array}$ & $\begin{array}{c}\left|\overline{\mathrm{Q}^{+} \mathrm{A}_{\mathrm{asp}}^{-}}\right|\left[\mathrm{Cl}^{-}\right] \\
\left(\mathrm{mol}^{2} / \mathrm{m}^{3} \mathrm{~m}^{3}\right. \\
\mathrm{RSI})\end{array}$ & $\begin{array}{c}{\left[\overline{\mathrm{Q}^{+} \mathrm{Cl}^{-}}\right]\left[\mathrm{A}_{\mathrm{asp}}^{-}\right]} \\
\left(\mathrm{mol}^{2} / \mathrm{m}^{3} \mathrm{~m}^{3}\right. \\
\quad \mathrm{RSI})\end{array}$ \\
\hline 3,064 & 5,00 & 0,000 & 0,225 & 2,838 & 58,410 & 40,245 & 2071,600 \\
\hline 6,280 & 4,99 & 0,000 & 0,472 & 5,808 & 91, & 98,342 & 4048,342 \\
\hline 13,484 & 4,96 & 0,000 & 1,080 & 12,403 & 120,895 & 172,407 & 8278,628 \\
\hline 20,473 & 5,00 & 0,000 & 1,506 & 18,965 & 146,289 & 252,439 & 12177,245 \\
\hline 24,059 & 4,97 & 0,000 & 1,887 & 22,169 & 156,693 & 289,625 & 14004,353 \\
\hline 27,601 & 5,00 & 0,000 & 2,031 & 25,567 & 166,844 & 328,364 & 15891,286 \\
\hline
\end{tabular}


Tabla C3. Datos de equilibrio de extracción individual de ácido aspártico para el experimento III de la Tabla 3. $\left.\left(\mathrm{pH}_{\mathrm{i}}=\mathbf{9 , 0 5} \pm 0,04 ; \overline{\mathrm{Q}^{+} \mathrm{Cl}^{-}}\right]_{\mathrm{i}}=791,56 \pm 6,99 \mathrm{~mol} / \mathrm{m}^{3} \mathrm{RSI}\right)$.

\begin{tabular}{|c|c|c|c|c|c|c|c|}
\hline $\begin{array}{c}\mathrm{C}_{\mathrm{A}(\mathrm{asp})} \\
\left(\mathrm{mol} / \mathrm{m}^{3}\right)\end{array}$ & $\mathrm{pH}$ & $\begin{array}{c}{\left[\mathrm{A}^{+/}{ }_{\text {asp }}\right]} \\
\left(\mathrm{mol} / \mathrm{m}^{3}\right) \\
\text { Ec. }(5.17)\end{array}$ & $\begin{array}{c}{\left[\mathrm{A}_{\text {asp }}^{-}\right]} \\
\left(\mathrm{mol} / \mathrm{m}^{3}\right) \\
\text { Ec. }(5.18)\end{array}$ & $\begin{array}{c}{\left[\mathrm{A}^{2-}{ }^{2-a p}\right]} \\
\left(\mathrm{mol} / \mathrm{m}^{3}\right) \\
\text { Ec. }(5.19)\end{array}$ & $\begin{array}{c}\overline{\mathrm{C}}_{\mathrm{A}(\mathrm{asp})} \\
\left(\mathrm{mol} / \mathrm{m}^{3} \mathrm{RSI}\right) \\
\text { Ec. }(5.3)\end{array}$ & $\begin{array}{c}\left|\overline{\mathrm{Q}^{+} \mathrm{A}_{\mathrm{asp}}^{-}}\right|\left[\mathrm{Cl}^{-}\right] \\
\left(\mathrm{mol}^{2} / \mathrm{m}^{3} \mathrm{~m}^{3}\right. \\
\mathrm{RSI})\end{array}$ & $\begin{array}{c}{\left[\overline{\mathrm{Q}^{+} \mathrm{Cl}^{-}}\right]\left[\mathrm{A}_{\mathrm{asp}}^{-}\right]} \\
\left(\mathrm{mol}^{2} / \mathrm{m}^{3} \mathrm{~m}^{3}\right. \\
\mathrm{RSI})\end{array}$ \\
\hline 6.3 & & 0.001 & & .046 & & & 436 \\
\hline 9,786 & 8,13 & 0,001 & 9,581 & 0,205 & 114 & 155,764 & 6452,363 \\
\hline 13,306 & 8,39 & 0,000 & 12,807 & 0,498 & 133,352 & 209,767 & 8389,083 \\
\hline 20,493 & 8,65 & 0,000 & 19,138 & 1,355 & 155,063 & 283,631 & 12120,751 \\
\hline 27,825 & 8,79 & 0,000 & 25,347 & 2,477 & 171,207 & 345,761 & 15643,969 \\
\hline
\end{tabular}

Tabla C4. Datos de equilibrio de extracción individual de ácido aspártico para el experimento IV de la Tabla 3. $\left.\left(\mathrm{pH}_{\mathrm{i}}=\mathbf{1 1 , 0 2} \pm 0,04 ; \overline{\mathrm{Q}^{+} \mathrm{Cl}^{-}}\right]_{\mathrm{i}}=791,56 \pm 6,99 \mathrm{~mol} / \mathrm{m}^{3} \mathrm{RSI}\right)$.

\begin{tabular}{|c|c|c|c|c|c|c|c|}
\hline $\begin{array}{c}\mathrm{C}_{\mathrm{A}(\mathrm{asp})} \\
\left(\mathrm{mol} / \mathrm{m}^{3}\right)\end{array}$ & $\mathrm{pH}$ & $\begin{array}{c}{\left[\mathrm{A}^{+/-} \text {asp }\right]} \\
\left(\mathrm{mol} / \mathrm{m}^{3}\right) \\
\text { Ec. }(5.17)\end{array}$ & $\begin{array}{c}{\left[\mathrm{A}_{\text {asp }}^{-}\right]} \\
\left(\mathrm{mol} / \mathrm{m}^{3}\right) \\
\text { Ec. }(5.18)\end{array}$ & $\begin{array}{c}{\left[\mathrm{A}^{2-}{ }_{\text {asp }}\right]} \\
\left(\mathrm{mol} / \mathrm{m}^{3}\right) \\
\text { Ec. }(5.19)\end{array}$ & $\begin{array}{c}\overline{\mathrm{C}}_{\mathrm{A}(\text { asp })} \\
\left(\mathrm{mol} / \mathrm{m}^{3} \mathrm{RSI}\right) \\
\text { Ec. }(5.3)\end{array}$ & $\begin{array}{c}\left|\overline{\mathrm{Q}_{2}^{+} \mathrm{A}_{\mathrm{asp}}^{2-}}\right|\left[\mathrm{Cl}^{-}\right]^{2} \\
\left(\mathrm{~mol}^{3} / \mathrm{m}^{6} \mathrm{~m}^{3}\right. \\
\mathrm{RSI})\end{array}$ & $\begin{array}{c}{\left[\overline{\mathrm{Q}^{+} \mathrm{Cl}^{-}}\right]^{2}\left[\mathrm{~A}_{\text {asp }}^{2-}\right]} \\
\left(\mathrm{mol}^{3} / \mathrm{m}^{3} \mathrm{~m}^{6}\right. \\
\mathrm{RSI})\end{array}$ \\
\hline 0,679 & 10,3 & 0,000 & 0,163 & 0,516 & 103 & 598,810 & 196771,868 \\
\hline 2,102 & 10,57 & 0,000 & 0,305 & 1,797 & 133,560 & 1277,941 & 559888,541 \\
\hline 5,510 & 10,76 & 0,000 & 0,544 & 4,965 & & 2233,342 & 1258874,225 \\
\hline 16,068 & 10,89 & 0,000 & 1,208 & 14,860 & 203,371 & 4511,747 & 2603070,521 \\
\hline
\end{tabular}

Tabla C5. Datos de equilibrio de extracción individual de ácido aspártico para el experimento $V$ de la Tabla 3. $\left.\left(\mathrm{pH}_{\mathrm{i}}=12,06 \pm 0,05 ; \overline{\mathrm{Q}^{+} \mathrm{Cl}^{-}}\right]_{\mathrm{i}}=791,56 \pm 6,99 \mathrm{~mol} / \mathrm{m}^{3} \mathrm{RSI}\right)$.

\begin{tabular}{|c|c|c|c|c|c|c|c|}
\hline $\begin{array}{c}\mathrm{C}_{\mathrm{A} \text { (asp })} \\
\left(\mathrm{mol} / \mathrm{m}^{3}\right)\end{array}$ & $\mathrm{pH}$ & $\begin{array}{c}{\left[\mathrm{A}^{+/-} \text {asp }\right]} \\
\left(\mathrm{mol} / \mathrm{m}^{3}\right) \\
\text { Ec. }(5.17)\end{array}$ & $\begin{array}{c}{\left[\mathrm{A}_{\text {asp }}^{-}\right]} \\
\left(\mathrm{mol} / \mathrm{m}^{3}\right) \\
\text { Ec. }(5.18)\end{array}$ & $\begin{array}{c}{\left[\mathrm{A}^{2-}{ }_{\text {asp }}\right]} \\
\left(\mathrm{mol} / \mathrm{m}^{3}\right) \\
\text { Ec. }(5.19)\end{array}$ & $\begin{array}{c}\overline{\mathrm{C}}_{\mathrm{A}(\mathrm{asp})} \\
\left(\mathrm{mol} / \mathrm{m}^{3} \mathrm{RSI}\right) \\
\text { Ec. }(5.3)\end{array}$ & $\begin{array}{c}\left|\overline{\mathrm{Q}_{2}^{+} \mathrm{A}_{\text {asp }}^{2-}}\right|\left[\mathrm{Cl}^{-}\right]^{2} \\
\left(\mathrm{~mol}^{3} / \mathrm{m}^{6} \mathrm{~m}^{3}\right. \\
\text { RSI })\end{array}$ & $\begin{array}{c}{\left[\overline{\mathrm{Q}^{+} \mathrm{Cl}^{-}}\right]^{2}\left[\mathrm{~A}_{\mathrm{asp}}^{2-}\right]} \\
\left(\mathrm{mol}^{3} / \mathrm{m}^{3} \mathrm{~m}^{6}\right. \\
\mathrm{RSI})\end{array}$ \\
\hline 0,750 & $\overline{0}$ & 50 & 0,005 & 0,745 & 10671 & 65 & $\overline{278 \varepsilon}$ \\
\hline 2,233 & 12,00 & 0,000 & 0,014 & 2,219 & 141, & 1505,408 & 654717,424 \\
\hline 5,570 & 12,00 & 0,000 & 0,035 & 5,536 & 169,850 & 2628,283 & 1305209,357 \\
\hline 9,112 & & & & 9,0 & & 3454 & 1856768,951 \\
\hline 12,604 & 12,00 & 00 & 0,079 & 12,525 & 198 & $41 \varepsilon$ & 2302229,924 \\
\hline 16,014 & 12,00 & 0,000 & 0,100 & 15,914 & 207,781 & 4811,639 & 2671441,525 \\
\hline 19,648 & 11,90 & 0,000 & 0,155 & 19,493 & 217,917 & 5550,719 & 2956535,655 \\
\hline 26,434 & 12,00 & 0,000 & 0,166 & 26,268 & 231,048 & 6615,846 & 3464819,343 \\
\hline
\end{tabular}


TABLAS D. Isotermas de equilibrio de extracción de ácido aspártico y $\alpha$-fenilglicina de sus mezclas binarias con RIE. $\left[\overline{\mathrm{Q}^{+} \mathrm{Cl}^{-}}\right]_{\mathrm{i}}=791,56 \pm 6,99 \mathrm{~mol} / \mathrm{m}^{3} \mathrm{RSI} ; 30^{\circ} \mathrm{C}$. (Apartado 5.2.4).

Tabla D1. Datos de equilibrio de extracción de ácido aspártico para el experimento I de la

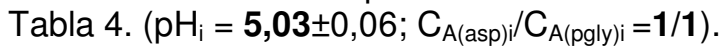

\begin{tabular}{|c|c|c|c|c|c|c|c|}
\hline $\begin{array}{c}\mathrm{C}_{\mathrm{A} \text { (asp) }} \\
\left(\mathrm{mol} / \mathrm{m}^{3}\right)\end{array}$ & $\mathrm{pH}$ & $\begin{array}{c}{\left[\mathrm{A}_{\text {asp }}^{+}\right]} \\
\left(\mathrm{mol} / \mathrm{m}^{3}\right) \\
\text { Ec. }(5.16)\end{array}$ & $\begin{array}{c}{\left[\mathrm{A}_{\text {asp }}^{+/-}\right]} \\
\left(\mathrm{mol} / \mathrm{m}^{3}\right) \\
\text { Ec. }(5.17)\end{array}$ & $\begin{array}{c}{\left[\mathrm{A}_{\text {asp }}^{-}\right]} \\
\left(\mathrm{mol} / \mathrm{m}^{3}\right) \\
\text { Ec. }(5.18)\end{array}$ & $\begin{array}{c}\overline{\mathrm{C}}_{\mathrm{A}(\mathrm{asp})} \\
\left(\mathrm{mol} / \mathrm{m}^{3} \mathrm{RSI}\right) \\
\text { Ec. (5.3) }\end{array}$ & $\begin{array}{c}\left|\overline{\mathrm{Q}^{+} \mathrm{A}_{\text {asp }}^{-}}\right|\left[\mathrm{Cl}^{-}\right] \\
\left(\mathrm{mol}^{2} / \mathrm{m}^{3} \mathrm{~m}^{3}\right. \\
\mathrm{RSI})\end{array}$ & $\begin{array}{l}{\left[\overline{\mathrm{Q}^{+} \mathrm{Cl}^{-}}\right]\left[\mathrm{A}_{\text {asp }}^{-}\right]} \\
\left(\mathrm{mol}^{2} / \mathrm{m}^{3} \mathrm{~m}^{3}\right. \\
\quad \mathrm{RSI})\end{array}$ \\
\hline$\overline{1,405}$ & 4,95 & 0,000 & 0,115 & $\overline{1,290}$ & $\overline{4}$ & $\overline{84}$ & 958,341 \\
\hline 2,854 & 4,92 & 0,000 & 0,249 & 2, & 69 , & 57,830 & 1863,760 \\
\hline 4,819 & 4,78 & 0,001 & 0,561 & 4,257 & 82,695 & 80,803 & 2991,099 \\
\hline 6,600 & 4,88 & 0,001 & 0,625 & 5,973 & 92,897 & 101,970 & 4136,224 \\
\hline 8,516 & 4,93 & 0,001 & 0,727 & 7,788 & 102,813 & 124,902 & 5315,669 \\
\hline
\end{tabular}

Tabla D2. Datos de equilibrio de extracción de ácido aspártico para el experimento I de la

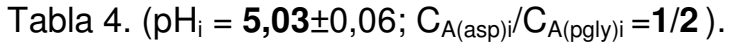

\begin{tabular}{|c|c|c|c|c|c|c|c|}
\hline $\begin{array}{c}\mathrm{C}_{\mathrm{A}(\mathrm{asp})} \\
\left(\mathrm{mol} / \mathrm{m}^{3}\right)\end{array}$ & $\mathrm{pH}$ & $\begin{array}{c}{\left[\mathrm{A}^{+}{ }_{\text {asp }}\right]} \\
\left(\mathrm{mol} / \mathrm{m}^{3}\right) \\
\text { Ec. }(5.16)\end{array}$ & $\begin{array}{c}{\left[\mathrm{A}^{+/-} \text {asp }\right]} \\
\left(\mathrm{mol} / \mathrm{m}^{3}\right) \\
\text { Ec. }(5.17)\end{array}$ & $\begin{array}{c}{\left[\mathrm{A}_{\text {asp }}^{-}\right]} \\
\left(\mathrm{mol} / \mathrm{m}^{3}\right) \\
\text { Ec. }(5.18)\end{array}$ & $\begin{array}{c}\overline{\mathrm{C}}_{\mathrm{A}(\mathrm{asp})} \\
\left(\mathrm{mol} / \mathrm{m}^{3} \mathrm{RSI}\right) \\
\text { Ec. }(5.3)\end{array}$ & $\begin{array}{c}\overline{\mathrm{Q}^{+} \mathrm{A}_{\mathrm{asp}}^{-}} \mid\left[\mathrm{Cl}^{-}\right] \\
\left(\mathrm{mol}^{2} / \mathrm{m}^{3} \mathrm{~m}^{3}\right. \\
\mathrm{RSI})\end{array}$ & $\begin{array}{c}{\left[\overline{\mathrm{Q}^{+} \mathrm{Cl}^{-}}\right]\left[\mathrm{A}_{\text {asp }}^{-}\right]} \\
\left(\mathrm{mol}^{2} / \mathrm{m}^{3} \mathrm{~m}^{3}\right. \\
\mathrm{RSI})\end{array}$ \\
\hline 1,086 & 5,06 & 0,000 & 0,070 & 1,016 & 39,025 & 17,995 & 758,326 \\
\hline 1,691 & 5,20 & 0,000 & 0,081 & 1,611 & 50,908 & 30,623 & 1182,848 \\
\hline 2,335 & 4,93 & 0,000 & 0,199 & 2,135 & 59,989 & 42,522 & 1548,652 \\
\hline 3,032 & 4,91 & 0,000 & 0,270 & 2,762 & 66,458 & 52,187 & 1985,356 \\
\hline 3,688 & 4,86 & 0,001 & 0,364 & 3,323 & 74,336 & 65,294 & 2362,546 \\
\hline 4,346 & 4,94 & 0,001 & 0,363 & 3,982 & 79,591 & 74,852 & 2810,357 \\
\hline 4,997 & 4,99 & 0,000 & 0,376 & 4,621 & 82,534 & 80,489 & 3247,681 \\
\hline 5,584 & 5,01 & 0,000 & 0,402 & 5,182 & 86,297 & 87,996 & 3622,247 \\
\hline
\end{tabular}

Tabla D3. Datos de equilibrio de extracción de ácido aspártico para el experimento I de la

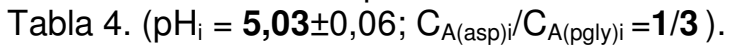

\begin{tabular}{|c|c|c|c|c|c|c|c|}
\hline $\begin{array}{c}\mathrm{C}_{\mathrm{A}(\mathrm{asp})} \\
\left(\mathrm{mol} / \mathrm{m}^{3}\right)\end{array}$ & $\mathrm{pH}$ & $\begin{array}{c}{\left[\mathrm{A}_{\text {asp }}^{+}\right]} \\
\left(\mathrm{mol} / \mathrm{m}^{3}\right) \\
\text { Ec. }(5.16)\end{array}$ & $\begin{array}{c}{\left[\mathrm{A}_{\text {asp }}^{+/-}\right]} \\
\left(\mathrm{mol} / \mathrm{m}^{3}\right) \\
\text { Ec. }(5.17)\end{array}$ & $\begin{array}{c}{\left[\mathrm{A}_{\mathrm{asp}}^{-}\right]} \\
\left(\mathrm{mol} / \mathrm{m}^{3}\right) \\
\text { Ec. }(5.18)\end{array}$ & $\begin{array}{c}\overline{\mathrm{C}}_{\mathrm{A}(\mathrm{asp})} \\
\left(\mathrm{mol} / \mathrm{m}^{3} \mathrm{RSI}\right) \\
\text { Ec. }(5.3)\end{array}$ & $\begin{array}{c}\left|\overline{\mathrm{Q}^{+} \mathrm{A}_{\mathrm{asp}}^{-}}\right|\left[\mathrm{Cl}^{-}\right] \\
\left(\mathrm{mol}^{2} / \mathrm{m}^{3} \mathrm{~m}^{3}\right. \\
\mathrm{RSI})\end{array}$ & $\begin{array}{c}{\left[\overline{\left.\mathrm{Q}^{+} \mathrm{Cl}^{-}\right]}\left[\mathrm{A}_{\text {asp }}^{-}\right]\right.} \\
\left(\mathrm{mol}^{2} / \mathrm{m}^{3} \mathrm{~m}^{3}\right. \\
\mathrm{RSI})\end{array}$ \\
\hline 0,650 & 5,09 & 0,000 & 0,039 & 0,610 & 19,301 & 4,402 & 467,661 \\
\hline 1,248 & 4,96 & 0,000 & 0,100 & 1,148 & 36,955 & 16,137 & 859,131 \\
\hline 1,827 & 5,02 & 0,000 & 0,129 & 1,698 & 51,417 & 31,238 & 1246,113 \\
\hline 2,527 & 5,27 & 0,000 & 0,103 & 2,423 & 56,861 & 38,204 & 1765,315 \\
\hline 2,851 & 4,97 & 0,000 & 0,224 & 2,627 & 63,082 & 47,019 & 1897,467 \\
\hline 3,253 & 4,91 & 0,000 & 0,290 & 2,963 & 65,303 & 50,389 & 2133,544 \\
\hline 3,816 & 4,93 & 0,000 & 0,326 & 3,489 & 71,437 & 60,300 & 2491,099 \\
\hline 4,261 & 4,94 & 0,001 & 0,356 & 3,904 & 73,318 & 63,517 & 2779,971 \\
\hline
\end{tabular}


Tabla D4. Datos de equilibrio de extracción de ácido aspártico para el experimento I de la

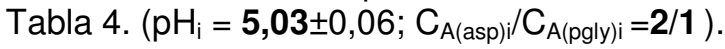

\begin{tabular}{cccccccc}
\hline $\begin{array}{c}\mathrm{C}_{\mathrm{A}(\operatorname{asp})} \\
\left(\mathrm{mol} / \mathrm{m}^{3}\right)\end{array}$ & $\mathrm{pH}$ & $\begin{array}{c}{\left[\mathrm{A}_{\text {asp }}^{+}\right]} \\
\left(\mathrm{mol} / \mathrm{m}^{3}\right) \\
\text { Ec. }(5.16)\end{array}$ & $\begin{array}{c}{\left[\mathrm{A}^{+/-}{ }_{\text {asp }}\right]} \\
\left(\mathrm{mol} / \mathrm{m}^{3}\right)\end{array}$ & $\begin{array}{c}{\left[\mathrm{A}_{\text {asp }}^{-}\right]} \\
\left(\mathrm{mol} / \mathrm{m}^{3}\right)\end{array}$ & $\begin{array}{c}\overline{\mathrm{C}}_{\mathrm{A}(\text { asp })} \\
\left(\mathrm{mol} / \mathrm{m}^{3} \mathrm{RSI}\right) \\
\mathrm{Ec} .(5.18)\end{array}$ & $\begin{array}{c}{\left[\mathrm{Q}^{+} \mathrm{A}_{\text {asp }}^{-}\right.} \\
\left(\mathrm{mol}^{2} / \mathrm{m}^{3} \mathrm{~m}^{3}\right. \\
\mathrm{RSI})\end{array}$ & $\begin{array}{c}{\left[\mathrm{Cl}^{-}\right]} \\
\left(\mathrm{mol}^{2} / \mathrm{m}^{3} \mathrm{~m}^{3}\right. \\
\mathrm{RSI})\end{array}$ \\
\hline 3,202 & 5,04 & 0,000 & 0,216 & 2,985 & 51,741 & 31,633 & 2190,037 \\
6,674 & 4,88 & 0,001 & 0,633 & 6,041 & 89,604 & 94,869 & 4202,731 \\
10,013 & 4,90 & 0,001 & 0,910 & 9,101 & 106,120 & 133,065 & 6181,957 \\
13,909 & 4,89 & 0,002 & 1,291 & 12,616 & 131,229 & 203,484 & 8252,221 \\
17,655 & 4,92 & 0,002 & 1,539 & 16,114 & 135,155 & 215,843 & 10477,274 \\
23,150 & 5,02 & 0,002 & 1,632 & 21,516 & 159,553 & 300,803 & 13464,384 \\
25,344 & 4,99 & 0,002 & 1,905 & 23,436 & 168,607 & 335,907 & 14454,283 \\
\hline
\end{tabular}

Tabla D5. Datos de equilibrio de extracción de ácido aspártico para el experimento I de la

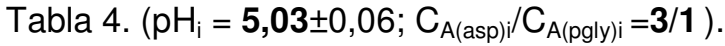

\begin{tabular}{|c|c|c|c|c|c|c|c|}
\hline $\begin{array}{c}\mathrm{C}_{\mathrm{A} \text { (asp) }} \\
\left(\mathrm{mol} / \mathrm{m}^{3}\right)\end{array}$ & $\mathrm{pH}$ & $\begin{array}{c}{\left[\mathrm{A}_{\text {asp }}^{+}\right]} \\
\left(\mathrm{mol} / \mathrm{m}^{3}\right) \\
\text { Ec. }(5.16)\end{array}$ & $\begin{array}{c}{\left[\mathrm{A}^{+/-} \text {asp }\right]} \\
\left(\mathrm{mol} / \mathrm{m}^{3}\right) \\
\text { Ec. }(5.17)\end{array}$ & $\begin{array}{c}{\left[\mathrm{A}_{\text {asp }}^{-}\right]} \\
\left(\mathrm{mol}^{3}\right) \\
\text { Ec. }(5.18)\end{array}$ & $\begin{array}{c}\overline{\mathrm{C}}_{\mathrm{A}(\mathrm{asp})} \\
\left(\mathrm{mol} / \mathrm{m}^{3} \mathrm{RSI}\right) \\
\text { Ec. (5.3) }\end{array}$ & $\begin{array}{c}\left.\mathrm{Q}^{+} \mathrm{A}_{\text {asp }}^{-}\right]\left[\mathrm{Cl}^{-}\right] \\
\left(\mathrm{mol}^{2} / \mathrm{m}^{3} \mathrm{~m}^{3}\right. \\
\mathrm{RSI})\end{array}$ & $\begin{array}{c}\left.\mathrm{Q}^{+} \mathrm{Cl}^{-}\right]\left[\mathrm{A}_{\text {asp }}\right] \\
\left(\mathrm{mol}^{2} / \mathrm{m}^{3} \mathrm{~m}^{3}\right. \\
\mathrm{RSI})\end{array}$ \\
\hline 1,835 & 5,00 & 0,000 & 135 & 1,700 & 35,380 & 14 & 1275,030 \\
\hline 3,630 & 4,85 & 0,001 & 0,366 & 3,263 & 61,958 & 45,359 & 2360,566 \\
\hline 5,837 & 4,86 & 0,001 & 0,577 & 5,259 & 73,701 & 64,183 & 3742,532 \\
\hline 9,759 & 4,90 & 0,001 & 0,887 & 8,870 & 109,697 & 142,187 & 5993,150 \\
\hline 15,246 & 4,85 & 0,003 & 1,538 & 13,705 & 130,330 & 200,707 & 8977,167 \\
\hline 21,294 & 4,86 & 0,004 & 2,104 & 19,187 & 148,198 & 259,510 & 12224,890 \\
\hline 25,023 & 4,89 & 0,004 & 2,322 & 22,696 & 157,277 & 292,282 & 14254,773 \\
\hline 26,925 & 4,88 & 0,004 & 2,552 & 24,369 & 162,017 & 310,166 & 15190,031 \\
\hline
\end{tabular}

Tabla D6. Datos de equilibrio de extracción de ácido aspártico y a-fenilglicina para el experimento II de la Tabla 4. $\left(\mathrm{pH}_{\mathrm{i}}=\mathbf{1 1 , 0 6} \pm 0,04 ; \mathrm{C}_{\mathrm{A}(\text { asp })} / \mathrm{C}_{\mathrm{A}(\mathrm{pgly}) \mathrm{i}}=\mathbf{1 / 1}\right)$.

a) Ácido aspártico

\begin{tabular}{|c|c|c|c|c|c|c|c|}
\hline $\begin{array}{l}\mathrm{C}_{\mathrm{A}(\text { asp })} \\
\left(\mathrm{mol} / \mathrm{m}^{3}\right)\end{array}$ & $\mathrm{pH}$ & $\begin{array}{c}{\left[\mathrm{A}^{+/ /}{ }_{\text {asp }}\right]} \\
\left(\mathrm{mol} / \mathrm{m}^{3}\right) \\
\text { Ec. }(5.17)\end{array}$ & $\begin{array}{c}{\left[\mathrm{A}_{\text {asp }}^{-}\right]} \\
\left(\mathrm{mol} / \mathrm{m}^{3}\right) \\
\text { Ec. }(5.18)\end{array}$ & $\begin{array}{c}{\left[\mathrm{A}^{2-}{ }_{\text {asp }}\right]} \\
\left(\mathrm{mol} / \mathrm{m}^{3}\right) \\
\text { Ec. }(5.19)\end{array}$ & $\begin{array}{c}\overline{\mathrm{C}}_{\mathrm{A}(\mathrm{asp})} \\
\left(\mathrm{mol} / \mathrm{m}^{3} \mathrm{RSI}\right) \\
\text { Ec. (5.3) }\end{array}$ & $\begin{array}{c}\left.\overline{\mathrm{Q}_{2}^{+} \mathrm{A}_{\mathrm{asp}}^{2-}}\right]\left[\mathrm{Cl}^{-2}\right]^{2} \\
\left(\mathrm{~mol}^{3} / \mathrm{m}^{6} \mathrm{~m}^{3}\right. \\
\text { RSI })\end{array}$ & $\begin{array}{c}{\left[\overline{\mathrm{Q}^{+} \mathrm{Cl}^{-}}\right]^{2}\left[\mathrm{~A}_{\mathrm{asp}}^{2-}\right]} \\
\left(\mathrm{mol}^{3} / \mathrm{m}^{3} \mathrm{~m}^{6}\right. \\
\mathrm{RSI})\end{array}$ \\
\hline 0,965 & 10,67 & 0,000 & 0115 & 0,850 & $\overline{9}$ & 715,916 & 256733,795 \\
\hline 2,685 & 10,53 & 0,000 & 0 & 3 & 20 & 1320,150 & 543296,593 \\
\hline 6,285 & 10,6 & 0,000 & 0,7 & 5,4 & & 2053,198 & 1037855,001 \\
\hline 7,939 & 10,60 & 0,000 & 1,086 & 6,853 & 125, & 2555,363 & 1130997,364 \\
\hline 9,865 & 10,63 & 0,000 & 1,271 & 8,593 & 126,765 & 2755,075 & 1328434,532 \\
\hline 12,006 & 10,65 & 0,000 & 1,4 & 10,520 & 134,737 & 3412,275 & 1376842,071 \\
\hline 17,594 & 10,81 & 0,000 & 1,566 & 16,028 & 135,600 & 3750,141 & 1880944,780 \\
\hline
\end{tabular}


Tabla D6. (Continuación)

b) a-Fenilglicina

\begin{tabular}{|c|c|c|c|c|c|c|}
\hline $\begin{array}{l}\mathrm{C}_{\mathrm{A}(\mathrm{plgly})} \\
\left(\mathrm{mol} / \mathrm{m}^{3}\right)\end{array}$ & $\mathrm{pH}$ & $\begin{array}{l}{\left[\mathrm{A}^{+-} \text {pgly }\right]} \\
\left(\mathrm{mol} / \mathrm{m}^{3}\right) \\
\text { Ec. }(5.5)\end{array}$ & $\begin{array}{l}{\left[\mathrm{A}_{\mathrm{pgly}}^{-}\right]} \\
\left(\mathrm{mol} / \mathrm{m}^{3}\right) \\
\text { Ec. }(5.6)\end{array}$ & $\begin{array}{c}\overline{\mathrm{C}}_{\mathrm{A}(\mathrm{pgly})} \\
\left(\mathrm{mol} / \mathrm{m}^{3} \mathrm{RSI}\right) \mathrm{Ec} . \\
(5.3)\end{array}$ & $\begin{array}{c}\left.\overline{\mathrm{Q}^{+} \mathrm{A}_{\mathrm{pgly}}^{-}}\right]\left[\mathrm{Cl}^{-}\right] \\
\left(\mathrm{mol}^{2} / \mathrm{m}^{3} \mathrm{~m}^{3}\right. \\
\mathrm{RSI})\end{array}$ & $\begin{array}{c}{\left[\overline{\mathrm{Q}^{+} \mathrm{Cl}^{-}}\right]\left[\mathrm{A}_{\mathrm{pgly}}\right]} \\
\left(\mathrm{mol}^{2} / \mathrm{m}^{3} \mathrm{~m}^{3} \mathrm{RSI}\right)\end{array}$ \\
\hline 1,285 & 10,67 & 0,027 & 1,258 & 58,263 & 176,684 & 668,272 \\
\hline 2,819 & 10,53 & 0,081 & 2,738 & 85,402 & 331,703 & 1257,279 \\
\hline 5,744 & 10,64 & 0,129 & 5,615 & 117,702 & 533,589 & 2268,957 \\
\hline 7,166 & 10,60 & 0,176 & 6,991 & 130,620 & 557,596 & 2981,565 \\
\hline 8,631 & 10,63 & 0,198 & 8,433 & 141,685 & 660,740 & 3314,698 \\
\hline 10,218 & 10,65 & 0,224 & 9,994 & 157,149 & 720,039 & 3997,232 \\
\hline 14,189 & 10,81 & 0,216 & 13,973 & 174,618 & 881,854 & 5033,889 \\
\hline
\end{tabular}

Tabla D7. Datos de equilibrio de extracción de ácido aspártico y a-fenilglicina para el experimento II de la Tabla 4. $\left(\mathrm{pH}_{\mathrm{i}}=\mathbf{1 1 , 0 6} \pm 0,04 ; \mathrm{C}_{\mathrm{A}(\text { asp }) /} / \mathrm{C}_{\mathrm{A}(\mathrm{pgly}) \mathrm{i}}=\mathbf{1 / 2}\right)$.

a) Ácido aspártico

\begin{tabular}{|c|c|c|c|c|c|c|c|}
\hline $\begin{array}{c}\mathrm{C}_{\mathrm{A}(\mathrm{asp})} \\
\left(\mathrm{mol} / \mathrm{m}^{3}\right)\end{array}$ & $\mathrm{pH}$ & $\begin{array}{c}{\left[\mathrm{A}^{+-}{ }_{\text {asp }}\right]} \\
\left(\mathrm{mol} / \mathrm{m}^{3}\right) \\
\text { Ec. }(5.17)\end{array}$ & $\begin{array}{c}{\left[\mathrm{A}_{\text {asp }}^{-}\right]} \\
\left(\mathrm{mol} / \mathrm{m}^{3}\right) \\
\text { Ec. }(5.18)\end{array}$ & $\begin{array}{c}{\left[\mathrm{A}^{2-}{ }_{\text {asp }}^{2}\right]} \\
\left(\mathrm{mol} / \mathrm{m}^{3}\right) \\
\text { Ec. }(5.19)\end{array}$ & $\begin{array}{c}\bar{C}_{\mathrm{A}(\text { asp })} \\
\left(\mathrm{mol} / \mathrm{m}^{3} \mathrm{RSI}\right) \\
\text { Ec. }(5.3)\end{array}$ & $\begin{array}{c}\left.\overline{\mathrm{Q}_{2}^{+} \mathrm{A}_{\text {asp }}^{2-}}\right]\left[\mathrm{Cl}^{-}\right]^{2} \\
\left(\mathrm{~mol}^{3} / \mathrm{m}^{6} \mathrm{~m}^{3}\right. \\
\mathrm{RSI})\end{array}$ & $\begin{array}{c}{\left[\overline{\mathrm{Q}^{+} \mathrm{Cl}^{-}}\right]^{2}\left[\mathrm{~A}_{\mathrm{asp}}^{2-}\right]} \\
\left(\mathrm{mol}^{3} / \mathrm{m}^{3} \mathrm{~m}^{6}\right. \\
\mathrm{RSI})\end{array}$ \\
\hline 2,716 & 10,93 & & & & & 27 & 5960 \\
\hline 4,504 & 11,08 & 0 & 225 & 4,280 & 35 & 1742,732 & 793887,425 \\
\hline 5,226 & 10,92 & 0,000 & 0,368 & 4,857 & 95,720 & 1849,674 & 839474,267 \\
\hline 6,470 & 10,89 & 0,000 & 0,486 & 5,984 & 100,000 & 2126,844 & 945131,346 \\
\hline 7,070 & 10,89 & 0,000 & & & 98,556 & 2091,126 & 1035251,203 \\
\hline 8,277 & 10,95 & 0,000 & 0,547 & 7,730 & 99,286 & 2318,929 & 1108478,760 \\
\hline
\end{tabular}

b) a-Fenilglicina

\begin{tabular}{|c|c|c|c|c|c|c|}
\hline $\begin{array}{c}\left.\mathrm{C}_{\mathrm{A}(\mathrm{plgly})}\right) \\
\left(\mathrm{mol} / \mathrm{m}^{3}\right)\end{array}$ & $\mathrm{pH}$ & $\begin{array}{l}{\left[\mathrm{A}_{\mathrm{pgly}}^{+/-}\right]} \\
\left(\mathrm{mol} / \mathrm{m}^{3}\right) \\
\text { Ec. }(5.5)\end{array}$ & $\begin{array}{c}{\left[\mathrm{A}_{\mathrm{pgly}}^{-}\right]} \\
\left(\mathrm{mol} / \mathrm{m}^{3}\right) \\
\text { Ec. }(5.6)\end{array}$ & $\begin{array}{c}\overline{\mathrm{C}}_{\mathrm{A}(\mathrm{pgly})} \\
\left(\mathrm{mol} / \mathrm{m}^{3} \mathrm{RSI}\right) \mathrm{Ec} . \\
(5.3)\end{array}$ & $\begin{array}{c}\left|\overline{\mathrm{Q}^{+} \mathrm{A}_{\mathrm{pgly}}^{-}}\right|\left[\mathrm{Cl}^{-}\right] \\
\left(\mathrm{mol}^{2} / \mathrm{m}^{3} \mathrm{~m}^{3}\right. \\
\mathrm{RSI})\end{array}$ & $\begin{array}{c}{\left[\overline{\mathrm{Q}^{+} \mathrm{Cl}^{-}}\right]\left[\mathrm{A}_{\mathrm{pgly}}^{-}\right]} \\
\left(\mathrm{mol}^{2} / \mathrm{m}^{3} \mathrm{~m}^{3}\right. \\
\text { RSI })\end{array}$ \\
\hline 5,493 & 10,93 & 0,064 & 5,429 & 136,209 & 486,580 & 2636,051 \\
\hline 8,384 & 11,08 & 0,069 & 8,315 & 161,896 & 678,963 & 3599,333 \\
\hline 9,458 & 10,92 & 0,113 & 9,345 & 181,218 & 818,426 & 3789,841 \\
\hline 11,200 & 10,89 & 0,141 & 11,058 & 190,962 & 888,811 & 4354,625 \\
\hline 12,118 & 10,89 & 0,155 & 11,964 & 193,381 & 867,796 & 4881,029 \\
\hline 13,790 & 10,95 & 0,153 & 13,637 & 211,126 & 1000,585 & 5272,436 \\
\hline
\end{tabular}


Tabla D8. Datos de equilibrio de extracción de ácido aspártico y a-fenilglicina para el experimento II de la Tabla 4. $\left(\mathrm{pH}_{\mathrm{i}}=\mathbf{1 1 , 0 6} \pm 0,04 ; \mathrm{C}_{\mathrm{A}(\text { asp })} / \mathrm{C}_{\mathrm{A}(\mathrm{pgly}) \mathrm{i}}=\mathbf{1 / 3}\right)$.

a) Ácido aspártico

\begin{tabular}{|c|c|c|c|c|c|c|c|}
\hline $\begin{array}{c}\mathrm{C}_{\mathrm{A} \text { (asp) }}{ } \\
\left(\mathrm{mol} / \mathrm{m}^{3}\right)\end{array}$ & $\mathrm{pH}$ & 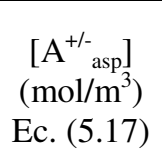 & $\begin{array}{c}{\left[\mathrm{A}_{\text {asp }}^{-}\right]} \\
\left(\mathrm{mol} / \mathrm{m}^{3}\right) \\
\text { Ec. }(5.18)\end{array}$ & $\begin{array}{c}{\left[\mathrm{A}_{\text {asp }}^{2-}\right]} \\
\left(\mathrm{mol} / \mathrm{m}^{3}\right) \\
\text { Ec. }(5.19)\end{array}$ & $\begin{array}{c}\overline{\mathrm{C}}_{\mathrm{A}(\mathrm{asp})} \\
\left(\mathrm{mol} / \mathrm{m}^{3} \mathrm{RSI}\right) \\
\text { Ec. }(5.3)\end{array}$ & $\begin{array}{c}\left.\mid \overline{\mathrm{Q}_{2}^{+} \mathrm{A}_{\text {asp }}^{2-}}\right]\left[\mathrm{Cl}^{-2}\right]^{2} \\
\left(\mathrm{~mol}^{3} / \mathrm{m}^{6} \mathrm{~m}^{3}\right. \\
\mathrm{RSI})\end{array}$ & $\begin{array}{c}{\left[\overline{\mathrm{Q}^{+} \mathrm{Cl}^{-}}\right]^{2}\left[\mathrm{~A}_{\text {asp }}^{2-}\right]} \\
\left(\mathrm{mol}^{3} / \mathrm{m}^{3} \mathrm{~m}^{6}\right. \\
\mathrm{RSI})\end{array}$ \\
\hline & & & & & & & 31 \\
\hline & T & & & & & & 569 \\
\hline 3,914 & 10,94 & 0,000 & 0,264 & 3,6 & 76 , & 1356,306 & 680761,987 \\
\hline 4,614 & 10,72 & 0.000 & 0,495 & 4,118 & 82,741 & 1718,219 & 665789,096 \\
\hline 6,279 & 11,09 & 0,000 & 0,306 & 5,972 & 82,833 & 1953,781 & 847368,065 \\
\hline
\end{tabular}

b) a-Fenilglicina

\begin{tabular}{|c|c|c|c|c|c|c|}
\hline $\begin{array}{l}\mathrm{C}_{\mathrm{A}(\mathrm{plgly})} \\
\left(\mathrm{mol} / \mathrm{m}^{3}\right)\end{array}$ & $\mathrm{pH}$ & $\begin{array}{l}{\left[\mathrm{A}^{+/-} \text {ply }\right]} \\
\left(\mathrm{mol} / \mathrm{m}^{3}\right) \\
\text { Ec. }(5.5)\end{array}$ & $\begin{array}{c}{\left[\mathrm{A}_{\mathrm{pgly}}^{-}\right]} \\
\left(\mathrm{mol} / \mathrm{m}^{3}\right) \\
\text { Ec. }(5.6)\end{array}$ & $\begin{array}{c}\overline{\mathrm{C}}_{\mathrm{A}(\mathrm{pgly})} \\
\left(\mathrm{mol} / \mathrm{m}^{3} \mathrm{RSI}\right) \mathrm{Ec} . \\
(5.3)\end{array}$ & $\begin{array}{c}\left.\overline{\mathrm{Q}^{+} \mathrm{A}_{\mathrm{pgly}}^{-}}\right]\left[\mathrm{Cl}^{-}\right] \\
\left(\mathrm{mol}^{2} / \mathrm{m}^{3} \mathrm{~m}^{3}\right. \\
\mathrm{RSI})\end{array}$ & 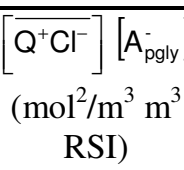 \\
\hline 4,138 & 10,50 & 0,127 & 4,012 & 140,455 & 526,219 & 1888,562 \\
\hline 8,595 & 10,74 & 0,154 & 8.441 & 189,148 & 801,156 & 3623,910 \\
\hline 10,398 & 10,94 & 0,118 & 10,280 & 203,128 & 849,716 & 4458,965 \\
\hline 11,977 & 10,72 & 0,224 & 11,753 & 220,836 & 1018,426 & 4671,169 \\
\hline 15,387 & 11,09 & 0,124 & 15,263 & 246,053 & 1207,201 & 5684,915 \\
\hline
\end{tabular}

Tabla D9. Datos de equilibrio de extracción de ácido aspártico y a-fenilglicina para el experimento II de la Tabla 4. $\left(\mathrm{pH}_{\mathrm{i}}=\mathbf{1 1}, \mathbf{0 6} \pm 0,04 ; \mathrm{C}_{\mathrm{A}(\text { asp })} / \mathrm{C}_{\mathrm{A}(\mathrm{pg} \mid \mathrm{y}) \mathrm{i}} \mathrm{i}=\mathbf{2} / \mathbf{1}\right)$.

a) Ácido aspártico

\begin{tabular}{|c|c|c|c|c|c|c|c|}
\hline $\begin{array}{c}\mathrm{C}_{\mathrm{A}(\text { asp })} \\
\left(\mathrm{mol} / \mathrm{m}^{3}\right)\end{array}$ & $\mathrm{pH}$ & 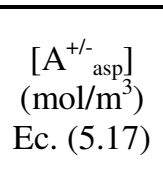 & $\begin{array}{c}{\left[\mathrm{A}_{\text {asp }}^{-}\right]} \\
\left(\mathrm{mol} / \mathrm{m}^{3}\right) \\
\text { Ec. }(5.18)\end{array}$ & $\begin{array}{c}{\left[\mathrm{A}_{\text {asp }}^{2-}\right]} \\
\left(\mathrm{mol} / \mathrm{m}^{3}\right) \\
\text { Ec. }(5.19)\end{array}$ & $\begin{array}{c}\overline{\mathrm{C}}_{\mathrm{A}(\mathrm{asp})} \\
\left(\mathrm{mol} / \mathrm{m}^{3} \mathrm{RSI}\right) \\
\text { Ec. }(5.3)\end{array}$ & $\begin{array}{c}\left.\mid \overline{\mathrm{Q}_{2}^{+} \mathrm{A}_{\mathrm{asp}}^{2-}}\right]\left[\mathrm{Cl}^{-}\right]^{2} \\
\left(\mathrm{~mol}^{3} / \mathrm{m}^{6} \mathrm{~m}^{3}\right. \\
\mathrm{RSI})\end{array}$ & $\begin{array}{c}{\left[\overline{\mathrm{Q}^{+} \mathrm{Cl}^{-}}\right]^{2}\left[\mathrm{~A}_{\mathrm{asp}}^{2-}\right]} \\
\left(\mathrm{mol}^{3} / \mathrm{m}^{3} \mathrm{~m}^{6}\right. \\
\mathrm{RSI})\end{array}$ \\
\hline 2,313 & 10,56 & 0,000 & 0,342 & 1,971 & 2,940 & 119 & 517800,702 \\
\hline 5,983 & 10,82 & 0,000 & 0,522 & 5,462 & 132 & 2098,550 & 1109077,606 \\
\hline 9,348 & 10,72 & 0,000 & 1,003 & 8,345 & 143,793 & 2786,283 & 1438657,087 \\
\hline 13,127 & 10,80 & 0,000 & 1,193 & 11,933 & 149,837 & 3356,890 & 1788426,586 \\
\hline 20,624 & 10,85 & 0,000 & 1,688 & 18,936 & 154,363 & 4095,189 & 2342824,864 \\
\hline 24,231 & 10,85 & 0,000 & 1,983 & 22,248 & 157,180 & 4544,062 & 2460802,381 \\
\hline 27,820 & 10,94 & 0,000 & 1,879 & 25,941 & 162,005 & 4934,010 & 2665407,951 \\
\hline
\end{tabular}

b) a-Fenilglicina

\begin{tabular}{|c|c|c|c|c|c|c|}
\hline $\begin{array}{l}\mathrm{C}_{\mathrm{A}(\mathrm{plgly})} \\
\left(\mathrm{mol} / \mathrm{m}^{3}\right)\end{array}$ & $\mathrm{pH}$ & $\begin{array}{l}{\left[\mathrm{A}_{\mathrm{pgly}}^{+/-}\right]} \\
\left(\mathrm{mol} / \mathrm{m}^{3}\right) \\
\text { Ec. }(5.5)\end{array}$ & $\begin{array}{c}{\left[\mathrm{A}_{\mathrm{pgly}}^{-}\right]} \\
\left(\mathrm{mol} / \mathrm{m}^{3}\right) \\
\text { Ec. }(5.6)\end{array}$ & $\begin{array}{c}\overline{\mathrm{C}}_{\mathrm{A}(\mathrm{pgly})} \\
\left(\mathrm{mol} / \mathrm{m}^{3} \mathrm{RSI}\right) \mathrm{Ec} . \\
(5.3)\end{array}$ & $\begin{array}{c}\left|\overline{\mathrm{Q}^{+} \mathrm{A}_{\mathrm{pgly}}^{-}}\right|\left[\mathrm{Cl}^{-}\right] \\
\left(\mathrm{mol}^{2} / \mathrm{m}^{3} \mathrm{~m}^{3}\right. \\
\mathrm{RSI})\end{array}$ & $\begin{array}{c}{\left[\overline{\mathrm{Q}^{+} \mathrm{Cl}^{-}}\right]\left[\mathrm{A}_{\mathrm{pgly}}^{-}\right]} \\
\left(\mathrm{mol}^{2} / \mathrm{m}^{3} \mathrm{~m}^{3}\right. \\
\mathrm{RSI})\end{array}$ \\
\hline 1,390 & 10,56 & 0,037 & 1,353 & 49,932 & 178,114 & 657,393 \\
\hline 3,000 & 10,82 & 0,045 & 2,955 & 73,371 & 292,328 & 1331,772 \\
\hline 4,400 & 10,72 & 0,082 & 4,318 & 85,586 & 383,234 & 1765,101 \\
\hline 5,958 & 10,80 & 0,093 & 5,865 & 101,585 & 531,355 & 2023,209 \\
\hline 8,944 & 10,85 & 0,125 & 8,819 & 127,922 & 640,539 & 3209,364 \\
\hline 10,249 & 10,85 & 0,143 & 10,106 & 141,455 & 817,484 & 3016,293 \\
\hline 11,739 & 10,94 & 0,133 & 11,605 & 143,834 & 844,648 & 3372,061 \\
\hline
\end{tabular}


Tabla D10. Datos de equilibrio de extracción de ácido aspártico y a-fenilglicina para el experimento II de la Tabla 4. $\left(\mathrm{pH}_{\mathrm{i}}=\mathbf{1 1 , 0 6} \pm 0,04 ; \mathrm{C}_{\mathrm{A}(\mathrm{asp}) \mathrm{i}} / \mathrm{C}_{\mathrm{A}(\mathrm{pgly}) \mathrm{i}}=\mathbf{3} / \mathbf{1}\right)$.

a) Ácido aspártico

\begin{tabular}{|c|c|c|c|c|c|c|c|}
\hline $\begin{array}{c}\mathrm{C}_{\mathrm{A} \text { (asp) }} \\
\left(\mathrm{mol} / \mathrm{m}^{3}\right)\end{array}$ & $\mathrm{pH}$ & $\begin{array}{c}{\left[\mathrm{A}^{+/-}{ }_{\text {asp }}\right]} \\
\left(\mathrm{mol} / \mathrm{m}^{3}\right) \\
\text { Ec. }(5.17)\end{array}$ & $\begin{array}{c}{\left[\mathrm{A}_{\text {asp }}^{-}\right]} \\
\left(\mathrm{mol} / \mathrm{m}^{3}\right) \\
\text { Ec. }(5.18)\end{array}$ & $\begin{array}{c}{\left[\mathrm{A}^{2-}{ }_{\text {asp }}^{2}\right]} \\
\left(\mathrm{mol} / \mathrm{m}^{3}\right) \\
\text { Ec. }(5.19)\end{array}$ & $\begin{array}{c}\overline{\mathrm{C}}_{\mathrm{A}(\mathrm{asp})} \\
\left(\mathrm{mol} / \mathrm{m}^{3} \mathrm{RSI}\right) \\
\text { Ec. }(5.3)\end{array}$ & $\begin{array}{c}\left.\overline{\mathrm{Q}_{2}^{+} \mathrm{A}_{\text {asp }}^{2-}}\right]\left[\mathrm{Cl}^{-2}\right]^{2} \\
\left(\mathrm{~mol}^{3} / \mathrm{m}^{6} \mathrm{~m}^{3}\right. \\
\mathrm{RSI})\end{array}$ & $\begin{array}{c}{\left[\overline{\mathrm{Q}^{+} \mathrm{Cl}^{-}}\right]^{2}\left[\mathrm{~A}_{\text {asp }}^{2-}\right]} \\
\left(\mathrm{mol}^{3} / \mathrm{m}^{3} \mathrm{~m}^{6}\right. \\
\mathrm{RSI})\end{array}$ \\
\hline 2,082 & 10,52 & 0,000 & 0,333 & 1,749 & 109,599 & 978,412 & 500692,728 \\
\hline 5,056 & 10,61 & 0,000 & 0,678 & 4,378 & 138,621 & 2066,922 & 930588,536 \\
\hline 9,454 & 10,84 & 0,000 & 0,790 & 8,664 & 154,314 & 2996,161 & 1491039,685 \\
\hline 11,509 & 10,83 & 0,000 & 0,982 & 10,526 & 157,963 & 3271,721 & 1706005,007 \\
\hline 14,711 & 10,80 & 0,000 & 1,337 & 13,374 & 159,521 & 3518,502 & 2036713,576 \\
\hline 20,068 & 10,79 & 0,000 & 1,863 & 18,205 & 168,634 & 4243,089 & 2400890,224 \\
\hline 23,497 & 10,91 & 0,000 & 1,693 & 21,805 & 171,782 & 4643,717 & 2634882,884 \\
\hline 27,091 & 10,86 & 0,000 & 2,171 & 24,921 & 174,586 & 4945,725 & 2833282,198 \\
\hline
\end{tabular}

b) $\alpha$-Fenilglicina

\begin{tabular}{|c|c|c|c|c|c|c|}
\hline $\begin{array}{l}\mathrm{C}_{\mathrm{A}(\mathrm{plgly})} \\
\left(\mathrm{mol} / \mathrm{m}^{3}\right)\end{array}$ & $\mathrm{pH}$ & $\begin{array}{l}{\left[\mathrm{A}_{\mathrm{pgly}}^{+/-}\right]} \\
\left(\mathrm{mol} / \mathrm{m}^{3}\right) \\
\text { Ec. }(5.5)\end{array}$ & $\begin{array}{c}{\left[\mathrm{A}_{\mathrm{pgly}}^{-}\right]} \\
\left(\mathrm{mol} / \mathrm{m}^{3}\right) \\
\text { Ec. }(5.6)\end{array}$ & $\begin{array}{c}\overline{\mathrm{C}}_{\mathrm{A}(\mathrm{pgly})} \\
\left(\mathrm{mol} / \mathrm{m}^{3} \mathrm{RSI}\right) \mathrm{Ec} . \\
(5.3)\end{array}$ & $\begin{array}{c}\overline{\left[\mathrm{Q}^{+} \mathrm{A}_{\mathrm{pgly}}^{-}\right.} \mid\left[\mathrm{Cl}^{-}\right] \\
\left(\mathrm{mol}^{2} / \mathrm{m}^{3} \mathrm{~m}^{3}\right. \\
\mathrm{RSI})\end{array}$ & $\begin{array}{c}{\left[\overline{\mathrm{Q}^{+} \mathrm{Cl}^{-}}\right]\left[\mathrm{A}_{\mathrm{pgly}}^{-}\right]} \\
\left(\mathrm{mol}^{2} / \mathrm{m}^{3} \mathrm{~m}^{3}\right. \\
\mathrm{RSI})\end{array}$ \\
\hline 0,838 & 10,52 & 0,025 & 0,813 & 34,094 & 108,495 & 421,802 \\
\hline 1,753 & 10,61 & 0,042 & 1,711 & 50,107 & 207,822 & 747,130 \\
\hline 2,989 & 10,84 & 0,043 & 2,946 & 64,918 & 282,047 & 1237,567 \\
\hline 3,654 & 10,83 & 0,053 & 3,601 & 69,886 & 295,051 & 1550,061 \\
\hline 4,539 & 10,80 & 0,071 & 4,468 & 79,098 & 334,476 & 1920,751 \\
\hline 6,050 & 10,79 & 0,097 & 5,954 & 87,970 & 376,709 & 2532,535 \\
\hline 6,985 & 10,91 & 0,085 & 6,900 & 97,203 & 443,873 & 2768,695 \\
\hline 7,979 & 10,86 & 0,109 & 7,870 & 102,036 & 629,966 & 2085,494 \\
\hline
\end{tabular}

Tabla D11. Datos de equilibrio de extracción de ácido aspártico y a-fenilglicina para el experimento III de la Tabla 4. $\left(\mathrm{pH}_{\mathrm{i}}=\mathbf{1 2 , 0 2} \pm 0,06 ; \mathrm{C}_{\mathrm{A}(\text { asp })} / \mathrm{C}_{\mathrm{A}(\text { pgly }) \mathrm{i}}=\mathbf{1 / 1}\right)$.

a) Ácido aspártico

\begin{tabular}{|c|c|c|c|c|c|c|c|}
\hline 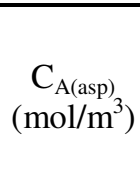 & $\mathrm{pH}$ & $\begin{array}{c}{\left[\mathrm{A}^{+/-}{ }_{\text {asp }}\right]} \\
\left(\mathrm{mol} / \mathrm{m}^{3}\right) \\
\text { Ec. }(5.17)\end{array}$ & $\begin{array}{c}{\left[\mathrm{A}_{\text {asp }}^{-}\right]} \\
\left(\mathrm{mol} / \mathrm{m}^{3}\right) \\
\text { Ec. }(5.18)\end{array}$ & $\begin{array}{c}{\left[\mathrm{A}_{\text {asp }}^{2-}\right]} \\
\left(\mathrm{mol} / \mathrm{m}^{3}\right) \\
\text { Ec. }(5.19)\end{array}$ & $\begin{array}{c}\overline{\mathrm{C}}_{\mathrm{A}(\mathrm{asp})} \\
\left(\mathrm{mol} / \mathrm{m}^{3} \mathrm{RSI}\right) \\
\text { Ec. }(5.3)\end{array}$ & $\begin{array}{c}\overline{\mathrm{Q}_{2}^{+} \mathrm{A}_{\text {asp }}^{2-}} \mid\left[\mathrm{Cl}^{-}\right]^{2} \\
\left(\mathrm{~mol}^{3} / \mathrm{m}^{6} \mathrm{~m}^{3}\right. \\
\text { RSI })\end{array}$ & $\begin{array}{c}{\left[\overline{\mathrm{Q}^{+} \mathrm{Cl}^{-}}\right]^{2}\left[\mathrm{~A}_{\mathrm{asp}}^{2-}\right]} \\
\left(\mathrm{mol}^{3} / \mathrm{m}^{3} \mathrm{~m}^{6}\right. \\
\mathrm{RSI})\end{array}$ \\
\hline 0,911 & 11,90 & 0,000 & 0,007 & 0,904 & 87,471 & 665,919 & 289747,145 \\
\hline 6,324 & 11,97 & 0,000 & 0,042 & 6,281 & 126,527 & 2384,248 & 1170909,450 \\
\hline 10,377 & 11,95 & 0,000 & 0,073 & 10,304 & 133,062 & 3122,814 & 1558768,578 \\
\hline 14,185 & 11,95 & 0,000 & 0,100 & 14,085 & 137,083 & 3581,034 & 1889513,230 \\
\hline 18,001 & 12,01 & 0,000 & 0,110 & 17,891 & 136,319 & 3970,582 & 2091953,487 \\
\hline 21,796 & 12,02 & 0,000 & 0,131 & 21,666 & 138,222 & 4317,529 & 2297171,373 \\
\hline 25,629 & 12,01 & 0,000 & 0,157 & 25,472 & 143,003 & 4860,830 & 2371158,860 \\
\hline
\end{tabular}


Tabla D11. (Continuación).

b) $\alpha$-Fenilglicina

\begin{tabular}{ccccccc}
\hline $\begin{array}{c}\mathrm{C}_{\mathrm{A}(\mathrm{plgly})} \\
\left(\mathrm{mol} / \mathrm{m}^{3}\right)\end{array}$ & $\mathrm{pH}$ & $\begin{array}{c}{\left[\mathrm{A}_{\mathrm{pgly}}^{+/-}\right]} \\
\left(\mathrm{mol} / \mathrm{m}^{3}\right)\end{array}$ & $\begin{array}{c}{\left[\mathrm{A}_{\mathrm{pgly}}^{-}\right]} \\
\left(\mathrm{mol} / \mathrm{m}^{3}\right)\end{array}$ & $\begin{array}{c}\overline{\mathrm{C}}_{\mathrm{A}(\mathrm{pgly})} \\
\left(\mathrm{mol} / \mathrm{m}^{3} \mathrm{RSI}\right) \mathrm{Ec} . \\
(5.3)\end{array}$ & $\begin{array}{c}\left.\overline{\mathrm{Q}^{+} \mathrm{A}_{\mathrm{pgly}}^{-}}\right]\left[\mathrm{Cl}^{-}\right] \\
\left(\mathrm{mol}^{2} / \mathrm{m}^{3} \mathrm{~m}^{3}\right. \\
\mathrm{RSI})\end{array}$ & $\begin{array}{c}{\left[\overline{\mathrm{Q}^{+} \mathrm{Cl}^{-}}\right]\left[\mathrm{A}_{\mathrm{pgly}}\right]} \\
\left(\mathrm{mol}^{2} / \mathrm{m}^{3} \mathrm{~m}^{3}\right. \\
\mathrm{RSI})\end{array}$ \\
\hline 1,336 & 11,90 & 0,002 & 1,334 & 59,720 & 164,778 & 755,467 \\
5,923 & 11,97 & 0,006 & 5,917 & 116,137 & 540,461 & 2397,273 \\
8,997 & 11,95 & 0,010 & 8,987 & 145,890 & 706,759 & 3495,191 \\
11,888 & 11,95 & 0,013 & 11,874 & 160,522 & 813,635 & 4391,981 \\
14,743 & 12,01 & 0,014 & 14,729 & 186,365 & 1000,040 & 5075,219 \\
17,506 & 12,02 & 0,017 & 17,490 & 198,885 & 1111,552 & 5694,955 \\
20,161 & 12,01 & 0,020 & 20,142 & 209,841 & 1209,340 & 6260,096 \\
\hline
\end{tabular}

Tabla D12. Datos de equilibrio de extracción de ácido aspártico y a-fenilglicina para el experimento III de la Tabla 4. $\left(\mathrm{pH}_{\mathrm{i}}=\mathbf{1 2 , 0 2} \pm 0,06 ; \mathrm{C}_{\mathrm{A}(\text { asp })} / \mathrm{C}_{\mathrm{A}(\text { pgly) }}=\mathbf{1 / 2}\right)$.

a) Ácido aspártico

\begin{tabular}{|c|c|c|c|c|c|c|c|}
\hline $\begin{array}{c}\mathrm{C}_{\mathrm{A}(\mathrm{asp})}{ } \\
\left(\mathrm{mol} / \mathrm{m}^{3}\right)\end{array}$ & $\mathrm{pH}$ & $\begin{array}{c}{\left[\mathrm{A}^{+/-}{ }_{\text {asp }}\right]} \\
\left(\mathrm{mol} / \mathrm{m}^{3}\right) \\
\text { Ec. }(5.17)\end{array}$ & $\begin{array}{c}{\left[\mathrm{A}_{\text {asp }}^{-}\right]} \\
\left(\mathrm{mol} / \mathrm{m}^{3}\right) \\
\text { Ec. }(5.18)\end{array}$ & $\begin{array}{c}{\left[\mathrm{A}^{2-}{ }_{\text {asp }}\right]} \\
\left(\mathrm{mol} / \mathrm{m}^{3}\right) \\
\text { Ec. }(5.19)\end{array}$ & $\begin{array}{c}\overline{\mathrm{C}}_{\mathrm{A}(\mathrm{asp})} \\
\left(\mathrm{mol} / \mathrm{m}^{3} \mathrm{RSI}\right) \\
\text { Ec. }(5.3)\end{array}$ & $\begin{array}{c}\left.\overline{\mathrm{Q}_{2}^{+} \mathrm{A}_{\mathrm{asp}}^{2-}}\right]\left[\mathrm{Cl}^{-}\right]^{2} \\
\left(\mathrm{~mol}^{3} / \mathrm{m}^{6} \mathrm{~m}^{3}\right. \\
\mathrm{RSI})\end{array}$ & $\begin{array}{c}{\left[\overline{\mathrm{Q}^{+} \mathrm{Cl}^{-}}\right]^{2}\left[\mathrm{~A}_{\text {asp }}^{2-}\right]} \\
\left(\mathrm{mol}^{3} / \mathrm{m}^{3} \mathrm{~m}^{6}\right. \\
\mathrm{RSI})\end{array}$ \\
\hline 2.886 & 11.80 & 0.000 & 0,029 & 2.858 & 97.310 & 1488.048 & 626924.647 \\
\hline 4,776 & 11,83 & 0,000 & 0,044 & 4,732 & 102,795 & 2027,764 & 847602,699 \\
\hline 5,754 & 11,84 & 0,000 & 0,052 & 5,702 & 104,748 & 2253,951 & 941817,337 \\
\hline 6,751 & 11,98 & 0,000 & 0,044 & 6,707 & 101,614 & 2210,122 & 1096348,844 \\
\hline 7,459 & 11,92 & 0,000 & 0,056 & 7,403 & 102,493 & 2401,861 & 1121612,763 \\
\hline 8,815 & 11,90 & 0,000 & 0,069 & 8,746 & 101,200 & 2418,017 & 1297891,397 \\
\hline 10,895 & 11,91 & 0,000 & 0,084 & 10,811 & 100,883 & 2674,020 & 1425286,346 \\
\hline 12,546 & 11,93 & 0,000 & 0,092 & 12,453 & 102,553 & 2901,934 & 1512798,875 \\
\hline
\end{tabular}

b) $\alpha-F e n i l g l i c i n a$

\begin{tabular}{|c|c|c|c|c|c|c|}
\hline $\begin{array}{l}\mathrm{C}_{\mathrm{A}(\mathrm{plgly})} \\
\left(\mathrm{mol} / \mathrm{m}^{3}\right)\end{array}$ & $\mathrm{pH}$ & $\begin{array}{l}{\left[\mathrm{A}_{\mathrm{pgly}}^{+/-}\right]} \\
\left(\mathrm{mol} / \mathrm{m}^{3}\right) \\
\text { Ec. }(5.5)\end{array}$ & $\begin{array}{l}{\left[\mathrm{A}_{\mathrm{pgly}}^{-}\right]} \\
\left(\mathrm{mol} / \mathrm{m}^{3}\right) \\
\text { Ec. }(5.6)\end{array}$ & $\begin{array}{c}\overline{\mathrm{C}}_{\mathrm{A}(\mathrm{pgly})} \\
\left(\mathrm{mol} / \mathrm{m}^{3} \mathrm{RSI}\right) \mathrm{Ec} . \\
(5.3)\end{array}$ & $\begin{array}{c}\overline{\mathrm{Q}^{+} \mathrm{A}_{\mathrm{pgly}}^{-}} \mid\left[\mathrm{Cl}^{-}\right] \\
\left(\mathrm{mol}^{2} / \mathrm{m}^{3} \mathrm{~m}^{3} \mathrm{RSI}\right)\end{array}$ & $\begin{array}{c}{\left[\overline{\mathrm{Q}^{+} \mathrm{Cl}^{-}}\right]\left[\mathrm{A}_{\mathrm{pgly}}^{-}\right]} \\
\left(\mathrm{mol}^{2} / \mathrm{m}^{3} \mathrm{~m}^{3} \mathrm{RSI}\right)\end{array}$ \\
\hline 5,780 & 11,80 & 0,009 & 5,771 & 137,962 & 564,048 & 2615,609 \\
\hline 8,618 & 11,83 & 0,013 & 8,605 & 172,146 & 781,069 & 3571,571 \\
\hline 10,028 & 11,84 & 0,014 & 10,014 & 185,023 & 881,185 & 3964,502 \\
\hline 11,567 & 11,98 & 0,012 & 11,555 & 193,413 & 927,800 & 4540,734 \\
\hline 12,509 & 11,92 & 0,015 & 12,494 & 206,726 & 1032,467 & 4700,203 \\
\hline 14,380 & 11,90 & 0,018 & 14,362 & 213,323 & 1033,872 & 5583,320 \\
\hline 17,185 & 11,91 & 0,021 & 17,164 & 236,098 & 1215,526 & 6231,865 \\
\hline 19,522 & 11,93 & 0,023 & 19,499 & 247,306 & 1315,539 & 6796,117 \\
\hline
\end{tabular}


Tabla D13. Datos de equilibrio de extracción de ácido aspártico y a-fenilglicina para el experimento III de la Tabla 4. $\left(\mathrm{pH}_{\mathrm{i}}=\mathbf{1 2 , 0 2} \pm 0,06 ; \mathrm{C}_{\mathrm{A}(\text { asp })} / \mathrm{C}_{\mathrm{A}(\mathrm{pg} \mid \mathrm{y}) \mathrm{i}}=\mathbf{1 / 3}\right)$.

a) Ácido aspártico

\begin{tabular}{|c|c|c|c|c|c|c|c|}
\hline $\begin{array}{c}\mathrm{C}_{\mathrm{A}(\mathrm{asp})} \\
\left(\mathrm{mol} / \mathrm{m}^{3}\right)\end{array}$ & $\mathrm{pH}$ & $\begin{array}{c}{\left[\mathrm{A}^{+/-}{ }_{\text {asp }}\right]} \\
\left(\mathrm{mol} / \mathrm{m}^{3}\right) \\
\text { Ec. }(5.17)\end{array}$ & $\begin{array}{c}{\left[\mathrm{A}_{\text {asp }}^{-}\right]} \\
\left(\mathrm{mol} / \mathrm{m}^{3}\right) \\
\text { Ec. }(5.18)\end{array}$ & $\begin{array}{c}{\left[\mathrm{A}^{2-}{ }_{\text {asp }}\right]} \\
\left(\mathrm{mol} / \mathrm{m}^{3}\right) \\
\text { Ec. }(5.19)\end{array}$ & $\begin{array}{c}\overline{\mathrm{C}}_{\mathrm{A}(\mathrm{asp})} \\
\left(\mathrm{mol} / \mathrm{m}^{3} \mathrm{RSI}\right) \\
\text { Ec. }(5.3)\end{array}$ & $\begin{array}{c}\left|\overline{\mathrm{Q}_{2}^{+} \mathrm{A}_{\text {asp }}^{2-}}\right|\left[\mathrm{Cl}^{-}\right]^{2} \\
\left(\mathrm{~mol}^{3} / \mathrm{m}^{6} \mathrm{~m}^{3}\right. \\
\mathrm{RSI})\end{array}$ & $\begin{array}{c}{\left[\overline{\mathrm{Q}^{+} \mathrm{Cl}^{-}}\right]^{2}\left[\mathrm{~A}_{\text {asp }}^{2-}\right]} \\
\left(\mathrm{mol}^{3} / \mathrm{m}^{3} \mathrm{~m}^{6}\right. \\
\mathrm{RSI})\end{array}$ \\
\hline 1,160 & 11,94 & 0,000 & 0,008 & 1,151 & 69,276 & 769,790 & 308230,243 \\
\hline 2,925 & 11,94 & 0,000 & 0,021 & 2,904 & 71,228 & 1151,228 & 611933,544 \\
\hline 3,933 & 11,98 & 0,000 & 0,026 & 3,907 & 77,776 & 1438,993 & 739762,576 \\
\hline 4,641 & 11,93 & 0,000 & 0,034 & 4,607 & 78,754 & 1608,593 & 799541,339 \\
\hline 5,478 & 11,99 & 0,000 & 0,035 & 5,442 & 80,706 & 1762,443 & 886132,086 \\
\hline 6,247 & 11,96 & 0,000 & 0,043 & 6,204 & 74,847 & 1643,308 & 1004865,232 \\
\hline 7,109 & 12,01 & 0,000 & 0,044 & 7,066 & 73,797 & 1680,551 & 1102962,675 \\
\hline 7,871 & 11,92 & 0,000 & 0,059 & 7,812 & 80,476 & 2060,417 & 1073002,714 \\
\hline
\end{tabular}

b) $\alpha$-Fenilglicina

\begin{tabular}{|c|c|c|c|c|c|c|}
\hline $\begin{array}{l}\left.\mathrm{C}_{\mathrm{A}(\mathrm{plgly})}\right) \\
\left(\mathrm{mol} / \mathrm{m}^{3}\right)\end{array}$ & $\mathrm{pH}$ & $\begin{array}{l}{\left[\mathrm{A}^{+/-}{ }_{\mathrm{pgly}}\right]} \\
\left(\mathrm{mol} / \mathrm{m}^{3}\right) \\
\text { Ec. }(5.5)\end{array}$ & $\begin{array}{c}{\left[\mathrm{A}_{\mathrm{pgly}}^{-}\right]} \\
\left(\mathrm{mol} / \mathrm{m}^{3}\right) \\
\text { Ec. }(5.6)\end{array}$ & $\begin{array}{c}\overline{\mathrm{C}}_{\mathrm{A}(\mathrm{pgly})} \\
\left(\mathrm{mol} / \mathrm{m}^{3} \mathrm{RSI}\right) \mathrm{Ec} . \\
(5.3)\end{array}$ & $\begin{array}{c}\overline{\mathrm{Q}^{+} \mathrm{A}_{\mathrm{pgly}}^{-}} \mid\left[\mathrm{Cl}^{-}\right] \\
\left(\mathrm{mol}^{2} / \mathrm{m}^{3} \mathrm{~m}^{3}\right. \\
\mathrm{RSI})\end{array}$ & $\begin{array}{c}\overline{\left[\mathrm{Q}^{+} \mathrm{Cl}^{-}\right]}\left[\mathrm{A}_{\mathrm{pgly}}^{-}\right] \\
\left(\mathrm{mol}^{2} / \mathrm{m}^{3} \mathrm{~m}^{3}\right. \\
\mathrm{RSI})\end{array}$ \\
\hline 4,071 & 11,94 & 0,005 & 4,066 & 144,954 & 488,200 & 2091,908 \\
\hline 8,368 & 11,94 & 0,010 & 8,359 & 199,461 & 833,575 & 3723,973 \\
\hline 10,333 & 11,98 & 0,011 & 10,322 & 210,274 & 898,353 & 4517,096 \\
\hline 11,973 & 11,93 & 0,014 & 11,959 & 226,864 & 1025,301 & 4981,657 \\
\hline 13,818 & 11,99 & 0,014 & 13,803 & 236,028 & 1102,985 & 5569,815 \\
\hline 15,342 & 11,96 & 0,017 & 15,325 & 248,814 & 1140,282 & 6301,313 \\
\hline 17,158 & 12,01 & 0,017 & 17,141 & 258,261 & 1214,126 & 6875,837 \\
\hline 18,853 & 11,92 & 0,023 & 18,830 & 269,387 & 1340,961 & 7110,075 \\
\hline
\end{tabular}

Tabla D14. Datos de equilibrio de extracción de ácido aspártico y a-fenilglicina para el experimento III de la Tabla 4. $\left(\mathrm{pH}_{\mathrm{i}}=\mathbf{1 2 , 0 2} \pm 0,06 ; \mathrm{C}_{\mathrm{A}(\text { asp }) /} / \mathrm{C}_{\mathrm{A}(\text { (pgly) }}=\mathbf{2} / \mathbf{1}\right)$.

a) Ácido aspártico

\begin{tabular}{|c|c|c|c|c|c|c|c|}
\hline $\begin{array}{c}\mathrm{C}_{\mathrm{A}(\mathrm{asp})} \\
\left(\mathrm{mol} / \mathrm{m}^{3}\right)\end{array}$ & $\mathrm{pH}$ & $\begin{array}{c}{\left[\mathrm{A}^{+/-} \text {asp }\right]} \\
\left(\mathrm{mol} / \mathrm{m}^{3}\right) \\
\text { Ec. }(5.17)\end{array}$ & $\begin{array}{c}\left.\left[\mathrm{A}_{\text {asp }}^{-}\right]^{3}\right) \\
\left(\mathrm{mol} / \mathrm{m}^{3}\right) \\
\text { Ec. }(5.18)\end{array}$ & $\begin{array}{c}{\left[\mathrm{A}_{\text {asp }}^{2-}\right]} \\
\left(\mathrm{mol} / \mathrm{m}^{3}\right) \\
\text { Ec. }(5.19)\end{array}$ & $\begin{array}{c}\overline{\mathrm{C}}_{\mathrm{A}(\text { asp })} \\
\left(\mathrm{mol} / \mathrm{m}^{3} \mathrm{RSI}\right) \\
\text { Ec. }(5.3)\end{array}$ & $\begin{array}{c}\left.\overline{\mathrm{Q}_{2}^{+} \mathrm{A}_{\text {asp }}^{2-}}\right]\left[\mathrm{Cl}^{-}\right]^{2} \\
\left(\mathrm{~mol}^{3} / \mathrm{m}^{6} \mathrm{~m}^{3}\right. \\
\mathrm{RSI})\end{array}$ & $\begin{array}{c}{\left[\overline{\mathrm{Q}^{+} \mathrm{Cl}^{-}}\right]^{2}\left[\mathrm{~A}_{\mathrm{asp}}^{2-}\right]} \\
\left(\mathrm{mol}^{3} / \mathrm{m}^{3} \mathrm{~m}^{6}\right. \\
\mathrm{RSI})\end{array}$ \\
\hline 6,147 & 12,00 & 0,000 & 0,039 & 6,109 & 142,435 & 2494,006 & 1210076,197 \\
\hline 9,871 & 12,00 & 0,000 & 0,062 & 9,809 & 15 & 3202,830 & 1658937,575 \\
\hline 13,365 & 11,99 & 0,000 & 0,086 & 13,280 & 158,791 & 3731,116 & 2006274,243 \\
\hline 17,726 & 12,07 & 0,000 & 0,095 & 17,631 & 161,386 & 4209,013 & 2369721,976 \\
\hline 21,321 & 12,12 & 0,000 & 0,102 & 21,219 & 170,515 & 5055,724 & 2421961,766 \\
\hline 25,290 & 12,06 & 0,000 & 0,138 & 25,151 & 170,899 & 5273,161 & 2714564,692 \\
\hline
\end{tabular}


Tabla D14. (Continuación).

b) $\alpha$-Fenilglicina

\begin{tabular}{|c|c|c|c|c|c|c|}
\hline $\begin{array}{c}\mathrm{C}_{\mathrm{A}(\mathrm{plgl} \mathrm{l})} \\
\left(\mathrm{mol} / \mathrm{m}^{3}\right)\end{array}$ & $\mathrm{pH}$ & $\begin{array}{l}{\left[\mathrm{A}^{+-} \mathrm{pgly}\right]} \\
\left(\mathrm{mol} / \mathrm{m}^{3}\right) \\
\text { Ec. }(5.5)\end{array}$ & $\begin{array}{c}{\left[\mathrm{A}_{\mathrm{pgly}}^{-}\right]} \\
\left(\mathrm{mol} / \mathrm{m}^{3}\right) \\
\text { Ec. }(5.6)\end{array}$ & $\begin{array}{c}\overline{\mathrm{C}}_{\mathrm{A}(\mathrm{pggly})} \\
\left(\mathrm{mol} / \mathrm{m}^{3} \mathrm{RSI}\right) \mathrm{Ec} . \\
(5.3)\end{array}$ & $\begin{array}{c}\left.\overline{\mathrm{Q}^{+} \mathrm{A}_{\mathrm{pgly}}^{-}}\right]\left[\mathrm{Cl}^{-}\right] \\
\left(\mathrm{mol}^{2} / \mathrm{m}^{3} \mathrm{~m}^{3} \mathrm{RSI}\right)\end{array}$ & $\begin{array}{c}{\left[\overline{\mathrm{Q}^{+} \mathrm{Cl}^{-}}\right]\left[\mathrm{A}_{\mathrm{pgly}}\right]} \\
\left(\mathrm{mol}^{2} / \mathrm{m}^{3} \mathrm{~m}^{3} \mathrm{RSI}\right)\end{array}$ \\
\hline 3,002 & 12,00 & 0,003 & 2,999 & 71,012 & 306,413 & 1274,528 \\
\hline 4,537 & 12,00 & 0,004 & 4,533 & 84,598 & 387,635 & 1782,327 \\
\hline 5,979 & 11,99 & 0,006 & 5,973 & 94,680 & 444,808 & 2383,336 \\
\hline 7,814 & 12,07 & 0,007 & 7,807 & 111,562 & 522,201 & 3174,278 \\
\hline 9,205 & 12,12 & 0,007 & 9,198 & 122,071 & 625,607 & 3358,107 \\
\hline 10,691 & 12,06 & 0,009 & 10,682 & 130,626 & 674,371 & 3966,590 \\
\hline
\end{tabular}

Tabla D15. Datos de equilibrio de extracción de ácido aspártico y a-fenilglicina para el experimento III de la Tabla 4. $\left(\mathrm{pH}_{\mathrm{i}}=\mathbf{1 2 , 0 2} \pm 0,06 ; \mathrm{C}_{\mathrm{A}(\text { asp })} / \mathrm{C}_{\mathrm{A}(\text { (pgly) })}=\mathbf{3 / 1}\right)$.

a) Ácido aspártico

\begin{tabular}{|c|c|c|c|c|c|c|c|}
\hline $\begin{array}{c}\mathrm{C}_{\mathrm{A}(\mathrm{asp})} \\
\left(\mathrm{mol} / \mathrm{m}^{3}\right)\end{array}$ & $\mathrm{pH}$ & $\begin{array}{c}{\left[\mathrm{A}^{+/-}{ }_{\text {asp }}\right]} \\
\left(\mathrm{mol} / \mathrm{m}^{3}\right) \\
\text { Ec. }(5.17)\end{array}$ & $\begin{array}{c}{\left[\mathrm{A}_{\text {asp }}^{-}\right]} \\
\left(\mathrm{mol} / \mathrm{m}^{3}\right) \\
\text { Ec. }(5.18)\end{array}$ & $\begin{array}{c}{\left[\mathrm{A}^{2-}{ }_{\text {asp }}\right]} \\
\left(\mathrm{mol} / \mathrm{m}^{3}\right) \\
\text { Ec. }(5.19)\end{array}$ & $\begin{array}{c}\overline{\mathrm{C}}_{\mathrm{A}(\text { asp })} \\
\left(\mathrm{mol} / \mathrm{m}^{3} \mathrm{RSI}\right) \\
\text { Ec. }(5.3)\end{array}$ & $\begin{array}{c}\overline{\mathrm{Q}_{2}^{+} \mathrm{A}_{\mathrm{asp}}^{2-}} \mid\left[\mathrm{Cl}^{-}\right]^{2} \\
\left(\mathrm{~mol}^{3} / \mathrm{m}^{6} \mathrm{~m}^{3}\right. \\
\mathrm{RSI})\end{array}$ & $\begin{array}{c}{\left[\overline{\mathrm{Q}^{+} \mathrm{Cl}^{-}}\right]^{2}\left[\mathrm{~A}_{\text {asp }}^{2-}\right]} \\
\left(\mathrm{mol}^{3} / \mathrm{m}^{3} \mathrm{~m}^{6}\right. \\
\mathrm{RSI})\end{array}$ \\
\hline 2,052 & 12,05 & 0,000 & 0,011 & 2,040 & 128,120 & 1489,669 & 532645,616 \\
\hline 5,449 & 12,07 & 0,000 & 9 & 5,420 & & 2524,003 & 1105334,891 \\
\hline 9,929 & 12,10 & 0,000 & 0,050 & 9,879 & 16 & 3447,994 & 1664410,905 \\
\hline 11,961 & 12,16 & 0,000 & 0,052 & 11,909 & 168,680 & 3825,122 & 1867109,153 \\
\hline 15,889 & 12,14 & 0,000 & 0,072 & 15,816 & 175,291 & 4403,896 & 2220126,297 \\
\hline 21,374 & 12,08 & 0,000 & 0,112 & 21,262 & & 5223,774 & 2570641,633 \\
\hline 25,073 & 12,12 & 0,000 & 0,119 & 24,954 & 181,496 & 5210,490 & 2974537,213 \\
\hline
\end{tabular}

b) a-Fenilglicina

\begin{tabular}{|c|c|c|c|c|c|c|}
\hline $\begin{array}{c}\mathrm{C}_{\mathrm{A}(\mathrm{plgly})} \\
\left(\mathrm{mol} / \mathrm{m}^{3}\right)\end{array}$ & $\mathrm{pH}$ & $\begin{array}{l}{\left[\mathrm{A}^{+/-}{ }_{\mathrm{pgly}}\right]} \\
\left(\mathrm{mol} / \mathrm{m}^{3}\right) \\
\text { Ec. }(5.5)\end{array}$ & $\begin{array}{l}{\left[\mathrm{A}_{\mathrm{pgly}}^{-}\right]} \\
\left(\mathrm{mol} / \mathrm{m}^{3}\right) \\
\text { Ec. }(5.6)\end{array}$ & $\begin{array}{c}\overline{\mathrm{C}}_{\mathrm{A}(\mathrm{pgly})} \\
\left(\mathrm{mol} / \mathrm{m}^{3} \mathrm{RSI}\right) \mathrm{Ec} . \\
(5.3)\end{array}$ & $\begin{array}{c}\left.\overline{\mathrm{Q}^{+} \mathrm{A}_{\mathrm{pgly}}^{-}}\right]\left[\mathrm{Cl}^{-}\right] \\
\left(\mathrm{mol}^{2} / \mathrm{m}^{3} \mathrm{~m}^{3}\right. \\
\text { RSI })\end{array}$ & $\begin{array}{c}{\left[\overline{\mathrm{Q}^{+} \mathrm{Cl}^{-}}\right]\left[\mathrm{A}_{\mathrm{pgly}}^{-}\right]} \\
\left(\mathrm{mol}^{2} / \mathrm{m}^{3} \mathrm{~m}^{3} \mathrm{RSI}\right)\end{array}$ \\
\hline 0,875 & 12,05 & 0,001 & 0,874 & 33,763 & 124,521 & 425,791 \\
\hline 1,806 & 12,07 & 0,002 & 1,805 & 50,231 & 226,699 & 752,773 \\
\hline 3,063 & 12,10 & 0,002 & 3,061 & 63,379 & 316,795 & 1150,399 \\
\hline 3,621 & 12,16 & 0,003 & 3,618 & 67,641 & 343,973 & 1333,242 \\
\hline 4,797 & 12,14 & 0,003 & 4,793 & 75,708 & 388,932 & 1744,836 \\
\hline 6,293 & 12,08 & 0,005 & 6,288 & 85,373 & 429,573 & 2345,506 \\
\hline 7,249 & 12,12 & 0,005 & 7,244 & 92,700 & 480,241 & 2610,307 \\
\hline
\end{tabular}




\section{APÉNDICE B. Cinéticas de extracción de aminoácidos en baños agitados}

TABLAS A. Resultados experimentales de las cinéticas de extracción individual de ácido aspártico con RIE en baños agitados. $\mid \overline{\mathrm{Q}^{+} \mathrm{Cl}^{-}}{ }_{\mathrm{i}}=782,93 \pm 19,04 \mathrm{~mol} / \mathrm{m}^{3} \mathrm{RSI} ; \mathrm{T}=30^{\circ} \mathrm{C}$. (Apartado 5.3.1).

Tabla A1. Datos cinéticos de extracción de ácido aspártico con RIE en baños agitados para el experimento I $\left(\mathrm{pH}_{\mathrm{i}}=\mathbf{5 , 0 6} \pm 0,07 ; \mathrm{C}_{\mathrm{A}(\text { asp })} \mathrm{i}=\mathbf{7 , 3 7} \mathrm{mol} / \mathrm{m}^{3}\right)$ de la Tabla 5 .

\begin{tabular}{cccccc}
\hline $\mathrm{t}(\mathrm{s})$ & $\mathrm{pH}(\mathrm{t})$ & $\begin{array}{c}\mathrm{C}_{\mathrm{A}(\text { asp })}(\mathrm{t}) \\
\left(\mathrm{mol}^{3}\right)\end{array}$ & $\mathrm{C}_{\mathrm{A} \text { (asp) }} / \mathrm{C}_{\mathrm{A}(\text { asp }) \mathrm{i}}$ & $\begin{array}{c}{\left[\mathrm{A}_{\text {asp }}^{-}\right](\mathrm{t})} \\
\left(\mathrm{mol} / \mathrm{m}^{3}\right) \mathrm{Ec} . \\
(5.43)\end{array}$ & $\begin{array}{c}\overline{\mathrm{C}}_{\mathrm{A}(\text { asp })}(\mathrm{t}) \\
\left(\mathrm{mol} / \mathrm{m}^{3} \mathrm{RSI}\right) \\
\mathrm{Ec} .(5.45)\end{array}$ \\
\hline 0 & 5,15 & 7,370 & 1,000 & 6,977 & 0,000 \\
31 & 5,08 & 6,923 & 0,939 & 6,493 & 40,881 \\
72 & 5,07 & 6,614 & 0,897 & 6,195 & 66,077 \\
107 & 5,07 & 6,514 & 0,884 & 6,101 & 74,042 \\
150 & 5,06 & 6,386 & 0,866 & 5,972 & 84,899 \\
243 & 5,07 & 6,217 & 0,844 & 5,823 & 97,499 \\
361 & 5,07 & 6,216 & 0,843 & 5,822 & 97,563 \\
540 & 5,10 & 6,221 & 0,844 & 5,851 & 95,104 \\
785 & 5,16 & 6,217 & 0,844 & 5,893 & 91,614 \\
1048 & 5,25 & 6,265 & 0,850 & 5,996 & 82,852 \\
1202 & 5,28 & 6,285 & 0,853 & 6,033 & 79,724 \\
1501 & 5,35 & 6,256 & 0,849 & 6,041 & 79,078 \\
1800 & 5,43 & 6,254 & 0,849 & 6,074 & 76,255 \\
2106 & 5,49 & 6,262 & 0,850 & 6,105 & 73,700 \\
2416 & 5,56 & 6,268 & 0,850 & 6,133 & 71,270 \\
2910 & 5,66 & 6,280 & 0,852 & 6,172 & 67,994 \\
3619 & 5,72 & 6,308 & 0,856 & 6,214 & 64,499 \\
5254 & 5,84 & 6,301 & 0,855 & 6,229 & 63,235 \\
\hline
\end{tabular}

Tabla A2. Datos cinéticos de extracción de ácido aspártico con RIE en baños agitados para el experimento I $\left(\mathrm{pH}_{\mathrm{i}}=\mathbf{5 , 0 6} \pm 0,07 ; \mathrm{C}_{\mathrm{A}(\mathrm{asp}) \mathrm{i}}=\mathbf{1 1 , 1 1} \mathrm{mol} / \mathrm{m}^{3}\right)$ de la Tabla 5 .

\begin{tabular}{cccccc}
\hline $\mathrm{t}(\mathrm{s})$ & $\mathrm{pH}(\mathrm{t})$ & $\begin{array}{c}\mathrm{C}_{\mathrm{A}(\text { asp }}(\mathrm{t}) \\
\left(\mathrm{mol} / \mathrm{m}^{3}\right)\end{array}$ & $\mathrm{C}_{\mathrm{A}(\text { asp })} / \mathrm{C}_{\mathrm{A} \text { (asp)i }}$ & $\begin{array}{c}{\left[\mathrm{A}_{\text {asp }}^{-}\right](\mathrm{t})} \\
\left(\mathrm{mol} / \mathrm{m}^{3}\right) \\
(5.43)\end{array}$ & $\begin{array}{c}\overline{\mathrm{C}}_{\mathrm{A}(\text { asp })}(\mathrm{t}) \\
\left(\mathrm{mol} / \mathrm{m}^{3} \mathrm{RSI}\right) \\
\mathrm{Ec} .(5.45)\end{array}$ \\
\hline 0 & 5,03 & 11,114 & 1,000 & 10,346 & 0,000 \\
34 & 4,99 & 10,607 & 0,954 & 9,808 & 45,375 \\
62 & 4,98 & 10,243 & 0,922 & 9,455 & 75,200 \\
92 & 4,98 & 10,051 & 0,904 & 9,278 & 90,170 \\
151 & 4,97 & 9,892 & 0,890 & 9,115 & 103,964 \\
240 & 4,97 & 9,753 & 0,878 & 8,987 & 114,786 \\
362 & 4,99 & 9,701 & 0,873 & 8,970 & 116,169 \\
547 & 5,03 & 9,737 & 0,876 & 9,064 & 108,260 \\
787 & 5,09 & 9,750 & 0,877 & 9,158 & 100,331 \\
1022 & 5,17 & 9,714 & 0,874 & 9,218 & 95,239 \\
1201 & 5,24 & 9,718 & 0,874 & 9,293 & 88,915 \\
1500 & 5,34 & 9,751 & 0,877 & 9,409 & 79,157 \\
\hline
\end{tabular}


Tabla A2. (Continuación)

\begin{tabular}{cccccc}
\hline $\mathrm{t}(\mathrm{s})$ & $\mathrm{pH}(\mathrm{t})$ & $\begin{array}{c}\mathrm{C}_{\mathrm{A}(\text { asp })}(\mathrm{t}) \\
\left(\mathrm{mol} / \mathrm{m}^{3}\right)\end{array}$ & $\begin{array}{c}\mathrm{C}_{\mathrm{A} \text { (asp })} / \mathrm{C}_{\mathrm{A}(\text { as }} \\
\mathrm{p}) \mathrm{i}\end{array}$ & $\begin{array}{c}{\left[\mathrm{A}_{\text {asp }}^{-}(\mathrm{t})\right.} \\
\left(\mathrm{mol} / \mathrm{m}^{3}\right) \\
\mathrm{Ec} .(5.43)\end{array}$ & $\begin{array}{c}\overline{\mathrm{C}}_{\mathrm{A}(\text { asp })}(\mathrm{t}) \\
\left(\mathrm{mol} / \mathrm{m}^{3} \mathrm{RSI}\right) \mathrm{Ec} .(5.45)\end{array}$ \\
\hline 1803 & 5,43 & 9,766 & 0,879 & 9,485 & 72,664 \\
2100 & 5,50 & 9,753 & 0,878 & 9,514 & 70,262 \\
2403 & 5,54 & 9,740 & 0,876 & 9,521 & 69,647 \\
3608 & 5,60 & 9,840 & 0,885 & 9,647 & 59,025 \\
\hline
\end{tabular}

Tabla A3. Datos cinéticos de extracción de ácido aspártico con RIE en baños agitados para el experimento I $\left(\mathrm{pH}_{\mathrm{i}}=\mathbf{5 , 0 6} \pm 0,07 ; \mathrm{C}_{\mathrm{A}(\mathrm{asp}) \mathrm{i}}=\mathbf{1 4 , 6 4} \mathrm{mol} / \mathrm{m}^{3}\right)$ de la Tabla 5 .

\begin{tabular}{|c|c|c|c|c|c|}
\hline $\mathrm{t}(\mathrm{s})$ & $\mathrm{pH}(\mathrm{t})$ & $\begin{array}{l}\mathrm{C}_{\mathrm{A}(\text { asp })}(\mathrm{t}) \\
\left(\mathrm{mol} / \mathrm{m}^{3}\right)\end{array}$ & $\mathrm{C}_{\mathrm{A} \text { (asp) }} / \mathrm{C}_{\mathrm{A} \text { (asp)i }}$ & $\begin{array}{c}{\left[\mathrm{A}_{\text {asp }}^{-}\right](\mathrm{t})} \\
\left(\mathrm{mol} / \mathrm{m}^{3}\right) \mathrm{Ec} . \\
(5.43)\end{array}$ & $\begin{array}{c}\overline{\mathrm{C}}_{\mathrm{A}(\mathrm{asp})}(\mathrm{t}) \\
\left(\mathrm{mol} / \mathrm{m}^{3} \mathrm{RSI}\right) \\
\text { Ec. }(5.45)\end{array}$ \\
\hline 0 & 4,99 & 14,636 & 1,000 & 13,534 & 0,000 \\
\hline 31 & 4,96 & 13,976 & 0,955 & 12,855 & 57,388 \\
\hline 62 & 4,94 & 13,615 & 0,930 & 12,475 & 89,461 \\
\hline 96 & 4,93 & 13,374 & 0,914 & 12,231 & 110,130 \\
\hline 153 & 4,93 & 13,261 & 0,906 & 12,128 & 118,850 \\
\hline 240 & 4,92 & 13,119 & 0,896 & 11,974 & 131,836 \\
\hline 366 & 4,93 & 13,080 & 0,894 & 11,962 & 132,826 \\
\hline 541 & 4,95 & 13,075 & 0,893 & 12,004 & 129,303 \\
\hline 795 & 4,99 & 13,076 & 0,893 & 12,092 & 121,846 \\
\hline 1030 & 5,04 & 13,088 & 0,894 & 12,203 & 112,475 \\
\hline 1200 & 5,06 & 13,039 & 0,891 & 12,194 & 113,216 \\
\hline 1505 & 5,11 & 13,006 & 0,889 & 12,249 & 108,560 \\
\hline 1800 & 5,17 & 13,107 & 0,895 & 12,438 & 92,642 \\
\hline 2146 & 5,21 & 13,057 & 0,892 & 12,447 & 91,905 \\
\hline 2400 & 5,25 & 13,101 & 0,895 & 12,540 & 84,039 \\
\hline 3604 & 5,36 & 13,208 & 0,902 & 12,765 & 65,038 \\
\hline
\end{tabular}

Tabla A4. Datos cinéticos de extracción de ácido aspártico con RIE en baños agitados para el experimento I $\left(\mathrm{pH}_{\mathrm{i}}=\mathbf{5 , 0 6} \pm 0,07 ; \mathrm{C}_{\mathrm{A}(\text { asp) }}=\mathbf{2 1}, \mathbf{8 5} \mathrm{mol} / \mathrm{m}^{3}\right)$ de la Tabla 5 .

\begin{tabular}{cccccc}
\hline $\mathrm{t}(\mathrm{s})$ & $\mathrm{pH}(\mathrm{t})$ & $\begin{array}{c}\mathrm{C}_{\mathrm{A} \text { (aspp }}(\mathrm{t}) \\
\left(\mathrm{mol} / \mathrm{m}^{3}\right)\end{array}$ & $\mathrm{C}_{\mathrm{A} \text { (asp) }} / \mathrm{C}_{\mathrm{A} \text { (asp) }}$ & $\begin{array}{c}{\left[\mathrm{A}_{\text {asp }}^{-}\right](\mathrm{t})} \\
\left(\mathrm{mol} / \mathrm{m}^{3}\right) \\
(5.43)\end{array}$ & $\begin{array}{c}\overline{\mathrm{C}}_{\mathrm{A} \text { (asp) }}(\mathrm{t}) \\
\left(\mathrm{mol} / \mathrm{m}^{3} \mathrm{RSI}\right) \\
\mathrm{Ec} .(5.45)\end{array}$ \\
\hline 0 & 5,11 & 21,856 & 1,000 & 20,585 & 0,000 \\
45 & 5,07 & 20,840 & 0,954 & 19,519 & 90,057 \\
88 & 5,06 & 20,522 & 0,939 & 19,193 & 117,601 \\
120 & 5,06 & 20,413 & 0,934 & 19,091 & 126,199 \\
160 & 5,06 & 20,143 & 0,922 & 18,838 & 147,569 \\
240 & 5,06 & 20,106 & 0,920 & 18,804 & 150,460 \\
360 & 5,08 & 20,121 & 0,921 & 18,872 & 144,666 \\
550 & 5,11 & 20,057 & 0,918 & 18,890 & 143,145 \\
798 & 5,17 & 20,077 & 0,919 & 19,052 & 129,475 \\
1024 & 5,20 & 20,046 & 0,917 & 19,088 & 126,422 \\
1205 & 5,24 & 20,120 & 0,921 & 19,239 & 113,651 \\
1504 & 5,27 & 20,082 & 0,919 & 19,260 & 111,944 \\
2101 & 5,39 & 20,134 & 0,921 & 19,502 & 91,456 \\
2400 & 5,40 & 20,225 & 0,925 & 19,604 & 82,830 \\
3602 & 5,43 & 20,285 & 0,928 & 19,703 & 74,520 \\
\hline
\end{tabular}


Tabla A5. Datos cinéticos de extracción de ácido aspártico con RIE en baños agitados para el experimento II $\left(\mathrm{pH}_{\mathrm{i}}=\mathbf{8 , 9 6} \pm 0,02 ; \mathrm{C}_{\mathrm{A}(\mathrm{asp}) \mathrm{i}}=\mathbf{1 5 , 2 9} \mathrm{mol} / \mathrm{m}^{3}\right)$ de la Tabla 5 .

\begin{tabular}{|c|c|c|c|c|c|c|}
\hline $\mathrm{t}(\mathrm{s})$ & $\mathrm{pH}(\mathrm{t})$ & $\begin{array}{l}\mathrm{C}_{\mathrm{A}(\mathrm{asp})}(\mathrm{t}) \\
\left(\mathrm{mol} / \mathrm{m}^{3}\right)\end{array}$ & $\mathrm{C}_{\mathrm{A} \text { (asp) }} / \mathrm{C}_{\mathrm{A} \text { (asp)i }}$ & $\begin{array}{c}{\left[\mathrm{A}_{\text {asp }}^{-}\right](\mathrm{t})} \\
\left(\mathrm{mol} / \mathrm{m}^{3}\right) \mathrm{Ec} . \\
(5.43)\end{array}$ & $\begin{array}{c}{\left[\mathrm{A}^{2-}{ }_{\text {asp }}\right](\mathrm{t})} \\
\left(\mathrm{mol} / \mathrm{m}^{3}\right) \mathrm{Ec} \\
(5.44)\end{array}$ & $\begin{array}{c}\overline{\mathrm{C}}_{\mathrm{A}(\mathrm{asp})}(\mathrm{t}) \\
\left(\mathrm{mol} / \mathrm{m}^{3} \mathrm{RSI}\right) \\
\text { Ec. }(5.45)\end{array}$ \\
\hline 0 & 8,96 & 15,289 & 1,000 & 13,358 & 1,931 & 0,000 \\
\hline 30 & 8,85 & 14,183 & 0,928 & 12,752 & 1,431 & 93,368 \\
\hline 60 & 8,78 & 13,854 & 0,906 & 12,646 & 1,208 & 121,164 \\
\hline 90 & 8,72 & 13,663 & 0,894 & 12,613 & 1,049 & 137,309 \\
\hline 150 & 8,63 & 13,454 & 0,880 & 12,602 & 0,852 & 154,956 \\
\hline 240 & 8,54 & 13,169 & 0,861 & 12,482 & 0,686 & 179,043 \\
\hline 360 & 8,48 & 13,176 & 0,862 & 12,574 & 0,602 & 178,412 \\
\hline 540 & 8,48 & 13,197 & 0,863 & 12,594 & 0,603 & 176,668 \\
\hline 785 & 8,52 & 13,193 & 0,863 & 12,535 & 0,658 & 176,984 \\
\hline 1023 & 8,58 & 13,143 & 0,860 & 12,396 & 0,747 & 181,186 \\
\hline 1200 & 8,62 & 13,233 & 0,866 & 12,412 & 0,820 & 173,644 \\
\hline 1520 & 8,66 & 13,131 & 0,859 & 12,244 & 0,887 & 182,196 \\
\hline 1802 & 8,69 & 13,232 & 0,866 & 12,279 & 0,953 & 173,658 \\
\hline 2102 & 8,70 & 13,248 & 0,867 & 12,273 & 0,975 & 172,367 \\
\hline 2400 & 8,76 & 13,205 & 0,864 & 12,101 & 1,104 & 175,996 \\
\hline 3730 & 8,83 & 13,231 & 0,865 & 11,950 & 1,280 & 173,810 \\
\hline
\end{tabular}

Tabla A6. Datos cinéticos de extracción de ácido aspártico con RIE en baños agitados para el experimento III $\left(\mathrm{pH}_{\mathrm{i}}=\mathbf{1 1 , 0 4} \pm 0,06 ; \mathrm{C}_{\mathrm{A}(\text { asp }) i}=\mathbf{7 , 4 5} \mathrm{mol} / \mathrm{m}^{3}\right)$ de la Tabla 5.

\begin{tabular}{|c|c|c|c|c|c|}
\hline $\mathrm{t}(\mathrm{s})$ & $\mathrm{pH}(\mathrm{t})$ & $\begin{array}{l}\mathrm{C}_{\mathrm{A}(\text { asp })}(\mathrm{t}) \\
\left(\mathrm{mol} / \mathrm{m}^{3}\right)\end{array}$ & $\mathrm{C}_{\mathrm{A} \text { (asp) }} / \mathrm{C}_{\mathrm{A}(\text { asp) }}$ & $\begin{array}{c}{\left[\mathrm{A}_{\text {ass }}^{2-}\right](\mathrm{t})} \\
\left(\mathrm{mol} / \mathrm{m}^{3}\right) \mathrm{Ec} . \\
(5.44)\end{array}$ & $\begin{array}{c}\overline{\mathrm{C}}_{\mathrm{A}(\text { asp })}(\mathrm{t}) \\
\left(\mathrm{mol} / \mathrm{m}^{3} \mathrm{RSI}\right) \\
\text { Ec. }(5.46)\end{array}$ \\
\hline 0 & 11,05 & 7,449 & 1,000 & 7,053 & 0,000 \\
\hline 30 & 11,02 & 7,274 & 0,977 & 6,861 & 19,355 \\
\hline 70 & 11,00 & 6,894 & 0,926 & 6,485 & 50,370 \\
\hline 130 & 10,97 & 6,575 & 0,883 & 6,159 & 76,239 \\
\hline 219 & 10,95 & 6,397 & 0,859 & 5,974 & 90,555 \\
\hline 317 & 10,97 & 6,166 & 0,828 & 5,776 & 108,911 \\
\hline 470 & 10,98 & 5,849 & 0,785 & 5,486 & 134,035 \\
\hline 720 & 10,97 & 5,616 & 0,754 & 5,261 & 152,215 \\
\hline 916 & 10,95 & 5,632 & 0,756 & 5,260 & 150,987 \\
\hline 1163 & 11,03 & 5,597 & 0,751 & 5,286 & 153,675 \\
\hline 1380 & 11,04 & 5,604 & 0,752 & 5,299 & 153,167 \\
\hline 1665 & 11,04 & 5,563 & 0,747 & 5,260 & 156,265 \\
\hline 1860 & 10,99 & 5,611 & 0,753 & 5,271 & 152,653 \\
\hline 2065 & 11,05 & 5,569 & 0,748 & 5,272 & 155,799 \\
\hline 2405 & 11,01 & 5,596 & 0,751 & 5,271 & 153,784 \\
\hline 2656 & 10,96 & 5,573 & 0,748 & 5,213 & 160,302 \\
\hline 2656 & 10,96 & 5,593 & 0,751 & 5,254 & 163,428 \\
\hline
\end{tabular}


Tabla A7. Datos cinéticos de extracción de ácido aspártico con RIE en baños agitados para el experimento III $\left(\mathrm{pH}_{\mathrm{i}}=\mathbf{1 1 , 0 4} \pm 0,06 ; \mathrm{C}_{\mathrm{A}(\text { asp })}=\mathbf{1 1}, \mathbf{4 6} \mathrm{mol} / \mathrm{m}^{3}\right)$ de la Tabla 5 .

\begin{tabular}{cccccc}
\hline $\mathrm{t}(\mathrm{s})$ & $\mathrm{pH}(\mathrm{t})$ & $\begin{array}{c}\mathrm{C}_{\mathrm{A}(\text { asp })}(\mathrm{t}) \\
\left(\mathrm{mol} / \mathrm{m}^{3}\right)\end{array}$ & $\mathrm{C}_{\mathrm{A} \text { (asp) }} / \mathrm{C}_{\mathrm{A} \text { (asp)i }}$ & $\begin{array}{c}{\left[\mathrm{A}^{2-}{ }_{\text {asp }}\right](\mathrm{t})} \\
\left(\mathrm{mol} / \mathrm{m}^{3}\right) \\
(5.44)\end{array}$ & $\begin{array}{c}\overline{\mathrm{C}}_{\mathrm{A}(\text { asp })}(\mathrm{t}) \\
\left(\mathrm{mol} / \mathrm{m}^{3} \mathrm{RSI}\right) \\
\mathrm{Ec} .(5.46)\end{array}$ \\
\hline 0 & 11,14 & 11,459 & 1,000 & 10,958 & 0,000 \\
21 & 11,11 & 11,197 & 0,977 & 10,675 & 29,849 \\
50 & 11,11 & 10,805 & 0,943 & 10,301 & 62,671 \\
80 & 11,08 & 10,611 & 0,926 & 10,082 & 78,813 \\
143 & 11,09 & 10,377 & 0,906 & 9,871 & 98,027 \\
245 & 11,14 & 9,846 & 0,859 & 9,416 & 141,370 \\
385 & 11,10 & 9,617 & 0,839 & 9,158 & 159,937 \\
604 & 11,18 & 9,458 & 0,825 & 9,079 & 172,751 \\
854 & 11,15 & 9,293 & 0,811 & 8,895 & 185,873 \\
1096 & 11,13 & 9,118 & 0,796 & 8,711 & 199,654 \\
1344 & 11,10 & 9,041 & 0,789 & 8,610 & 205,674 \\
1574 & 11,09 & 9,081 & 0,793 & 8,638 & 202,551 \\
1821 & 11,12 & 9,012 & 0,786 & 8,600 & 207,883 \\
2058 & 11,12 & 9,065 & 0,791 & 8,651 & 203,853 \\
2406 & 11,04 & 8,858 & 0,773 & 8,376 & 219,500 \\
2652 & 11,05 & 8,952 & 0,781 & 8,475 & 220,094 \\
3613 & 11,08 & 9,116 & 0,796 & 8,662 & 215,238 \\
\hline
\end{tabular}

Tabla A8. Datos cinéticos de extracción de ácido aspártico con RIE en baños agitados para el experimento III $\left(\mathrm{pH}_{\mathrm{i}}=\mathbf{1 1 , 0 4} \pm 0,06 ; \mathrm{C}_{\mathrm{A}(\text { asp })}=\mathbf{1 8}, \mathbf{9 4} \mathrm{mol} / \mathrm{m}^{3}\right)$ de la Tabla 5 .

\begin{tabular}{cccccc}
\hline $\mathrm{t}(\mathrm{s})$ & $\mathrm{pH}(\mathrm{t})$ & $\begin{array}{c}\mathrm{C}_{\mathrm{A} \text { (asp) }}(\mathrm{t}) \\
\left(\mathrm{mol} / \mathrm{m}^{3}\right)\end{array}$ & $\mathrm{C}_{\mathrm{A} \text { (asp) }} / \mathrm{C}_{\mathrm{A}(\text { (asp }) \mathrm{i}}$ & $\begin{array}{c}{\left[\mathrm{A}^{2-}{ }_{\text {ass }}\right](\mathrm{t})} \\
\left(\mathrm{mol}^{3}\right) \mathrm{mc} \\
(5.44)\end{array}$ & $\begin{array}{c}\overline{\mathrm{C}}_{\mathrm{A} \text { (asp) }}(\mathrm{t}) \\
\left(\mathrm{mol}^{3} / \mathrm{m}^{3} \mathrm{RSI}\right) \\
\mathrm{Ec} .(5.46)\end{array}$ \\
\hline 0 & 11,01 & 18,939 & 1,000 & 17,839 & 0,000 \\
55 & 10,99 & 18,080 & 0,955 & 16,983 & 77,700 \\
135 & 10,98 & 17,805 & 0,940 & 16,701 & 100,452 \\
247 & 10,97 & 17,522 & 0,925 & 16,388 & 123,744 \\
357 & 10,96 & 17,375 & 0,917 & 16,201 & 135,818 \\
530 & 10,95 & 17,122 & 0,904 & 15,941 & 156,479 \\
878 & 10,94 & 16,950 & 0,895 & 15,754 & 170,560 \\
1230 & 10,93 & 16,788 & 0,886 & 15,579 & 183,644 \\
1850 & 10,93 & 17,051 & 0,900 & 15,797 & 162,386 \\
2693 & 10,93 & 16,820 & 0,888 & 15,501 & 181,011 \\
3598 & 10,92 & 16,7946 & 0,887 & 16,795 & 189,074 \\
5455 & 10,91 & 17,2094 & 0,909 & 17,209 & 161,924 \\
7240 & 10,91 & 16,8415 & 0,889 & 16,841 & 196,998 \\
9044 & 10,90 & 16,7479 & 0,884 & 16,748 & 210,196 \\
10815 & 10,88 & 16,5827 & 0,876 & 16,583 & 228,927 \\
12664 & 10,88 & 16,9518 & 0,895 & 16,952 & 205,635 \\
14375 & 10,87 & 16,7454 & 0,884 & 16,745 & 227,351 \\
\hline
\end{tabular}


Tabla A9. Datos cinéticos de extracción de ácido aspártico con RIE en baños agitados

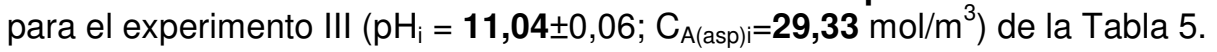

\begin{tabular}{|c|c|c|c|c|c|}
\hline $\mathrm{t}(\mathrm{s})$ & $\mathrm{pH}(\mathrm{t})$ & $\begin{array}{l}\mathrm{C}_{\mathrm{A}(\text { asp })}(\mathrm{t}) \\
\left(\mathrm{mol} / \mathrm{m}^{3}\right)\end{array}$ & $\mathrm{C}_{\mathrm{A} \text { (asp) }} / \mathrm{C}_{\mathrm{A} \text { (asp)i }}$ & $\begin{array}{c}{\left[\mathrm{A}_{\text {asp }}^{2-}\right](\mathrm{t})} \\
\left(\mathrm{mol} / \mathrm{m}^{3}\right) \mathrm{Ec} . \\
(5.44)\end{array}$ & $\begin{array}{c}\overline{\mathrm{C}}_{\mathrm{A}(\mathrm{asp})}(\mathrm{t}) \\
\left(\mathrm{mol} / \mathrm{m}^{3} \mathrm{RSI}\right) \\
\text { Ec. }(5.46)\end{array}$ \\
\hline 0 & 11,00 & 29,331 & 1,000 & 27,590 & 0,000 \\
\hline 26 & 10,96 & 28,808 & 0,982 & 26,944 & 64,093 \\
\hline 64 & 10,95 & 28,376 & 0,967 & 26,500 & 100,210 \\
\hline 114 & 10,97 & 28,096 & 0,958 & 26,317 & 123,477 \\
\hline 172 & 10,97 & 27,927 & 0,952 & 26,159 & 137,391 \\
\hline 291 & 10,95 & 27,495 & 0,937 & 25,677 & 172,725 \\
\hline 411 & 10,94 & 27,136 & 0,925 & 25,303 & 201,739 \\
\hline 605 & 10,94 & 26,883 & 0,917 & 25,067 & 222,133 \\
\hline 810 & 10,94 & 26,787 & 0,913 & 24,978 & 229,729 \\
\hline 1044 & 10,95 & 26,715 & 0,911 & 24,948 & 235,456 \\
\hline 1274 & 10,93 & 26,639 & 0,908 & 24,801 & 241,370 \\
\hline 1510 & 10,91 & 26,497 & 0,903 & 24,588 & 252,403 \\
\hline 1750 & 10,93 & 26,510 & 0,904 & 24,681 & 251,368 \\
\hline 2009 & 10,93 & 26,454 & 0,902 & 24,628 & 255,692 \\
\hline 2352 & 10,93 & 26,361 & 0,899 & 24,541 & 262,709 \\
\hline 2578 & 10,91 & 26,274 & 0,896 & 24,381 & 269,216 \\
\hline 3422 & 10,90 & 26,445 & 0,902 & 24,499 & 256,508 \\
\hline
\end{tabular}

Tabla A10. Datos cinéticos de extracción de ácido aspártico con RIE en baños agitados para el experimento IV $\left(\mathrm{pH}_{\mathrm{i}}=\mathbf{1 2 , 0 2} \pm 0,07 ; \mathrm{C}_{\mathrm{A}(\text { asp })}=\mathbf{9 , 5 8} \mathrm{mol} / \mathrm{m}^{3}\right)$ de la Tabla 5.

\begin{tabular}{|c|c|c|c|c|c|}
\hline $\mathrm{t}(\mathrm{s})$ & $\mathrm{pH}(\mathrm{t})$ & $\begin{array}{l}\mathrm{C}_{\mathrm{A}(\text { asp })}(\mathrm{t}) \\
\left(\mathrm{mol} / \mathrm{m}^{3}\right)\end{array}$ & $\mathrm{C}_{\mathrm{A} \text { (asp) }} / \mathrm{C}_{\mathrm{A} \text { (asp)i }}$ & $\begin{array}{c}{\left[\mathrm{A}^{2-}{ }_{\text {asp }}\right](\mathrm{t})} \\
\left(\mathrm{mol} / \mathrm{m}^{3}\right) \mathrm{Ec} . \\
(5.44)\end{array}$ & $\begin{array}{c}\overline{\mathrm{C}}_{\mathrm{A}(\mathrm{asp})}(\mathrm{t}) \\
\left(\mathrm{mol} / \mathrm{m}^{3} \mathrm{RSI}\right) \\
\text { Ec. }(5.46) \\
\end{array}$ \\
\hline 0 & 12,05 & 9,578 & 1,000 & 9,524 & 0,000 \\
\hline 30 & 11,73 & 8,552 & 0,893 & 8,453 & 88,570 \\
\hline 60 & 11,75 & 8,129 & 0,849 & 8,038 & 125,165 \\
\hline 95 & 11,71 & 7,813 & 0,816 & 7,718 & 152,396 \\
\hline 140 & 11,76 & 7,437 & 0,776 & 7,356 & 184,901 \\
\hline 290 & 11,91 & 7,105 & 0,742 & 7,051 & 213,527 \\
\hline 320 & 11,95 & 7,113 & 0,743 & 7,063 & 212,856 \\
\hline 371 & 11,86 & 7,011 & 0,732 & 6,950 & 221,691 \\
\hline 563 & 11,84 & 7,036 & 0,735 & 6,972 & 219,521 \\
\hline 860 & 11,82 & 7,017 & 0,733 & 6,950 & 221,173 \\
\hline 1250 & 11,88 & 6,879 & 0,718 & 6,822 & 233,069 \\
\hline 1354 & 11,85 & 6,965 & 0,727 & 6,903 & 225,677 \\
\hline 1600 & 11,83 & 6,919 & 0,722 & 6,855 & 229,625 \\
\hline 1815 & 11,89 & 6,851 & 0,715 & 6,796 & 235,449 \\
\hline 2109 & 11,83 & 6,865 & 0,717 & 6,802 & 234,235 \\
\hline 2405 & 11,79 & 6,885 & 0,719 & 6,815 & 232,582 \\
\hline 2900 & 11,79 & 6,998 & 0,731 & 6,927 & 222,787 \\
\hline 3640 & 11,79 & 6,961 & 0,727 & 6,890 & 225,995 \\
\hline 7000 & 11,79 & 6,927 & 0,723 & 6,857 & 228,896 \\
\hline
\end{tabular}


Tabla A11. Datos cinéticos de extracción de ácido aspártico con RIE en baños agitados para el experimento IV $\left(\mathrm{pH}_{\mathrm{i}}=\mathbf{1 2 , 0 2} \pm 0,07 ; \mathrm{C}_{\mathrm{A}(\text { asp })}=\mathbf{1 1}, \mathbf{1 9} \mathrm{mol} / \mathrm{m}^{3}\right)$ de la Tabla 5.

\begin{tabular}{cccccc}
\hline $\mathrm{t}(\mathrm{s})$ & $\mathrm{pH}(\mathrm{t})$ & $\begin{array}{c}\mathrm{C}_{\mathrm{A}(\text { (asp })}(\mathrm{t}) \\
\left(\mathrm{mol} / \mathrm{m}^{3}\right)\end{array}$ & $\mathrm{C}_{\mathrm{A} \text { (asp })} / \mathrm{C}_{\mathrm{A} \text { (asp)i })}$ & $\begin{array}{c}{\left[\mathrm{A}_{\text {asp }}^{2-}(\mathrm{t})\right.} \\
\left(\mathrm{mol} / \mathrm{m}^{3}\right) \mathrm{Ec} . \\
(5.44)\end{array}$ & $\begin{array}{c}\overline{\mathrm{C}}_{\mathrm{A} \text { (asp) }}(\mathrm{t}) \\
\left(\mathrm{mol}^{3} / \mathrm{m}^{3} \mathrm{RSI}\right) \\
\mathrm{Ec} .(5.46)\end{array}$ \\
\hline 0 & 11,94 & 11,198 & 1,000 & 11,117 & 0,000 \\
33 & 11,70 & 10,393 & 0,928 & 10,264 & 68,000 \\
80 & 11,70 & 10,001 & 0,893 & 9,876 & 101,133 \\
145 & 11,69 & 9,613 & 0,858 & 9,491 & 133,899 \\
200 & 11,74 & 9,438 & 0,843 & 9,331 & 148,695 \\
260 & 11,76 & 9,376 & 0,837 & 9,274 & 153,933 \\
360 & 11,73 & 9,268 & 0,828 & 9,160 & 163,062 \\
550 & 11,69 & 9,232 & 0,824 & 9,114 & 166,078 \\
788 & 11,70 & 9,130 & 0,815 & 9,016 & 174,718 \\
1023 & 11,77 & 9,155 & 0,818 & 9,058 & 172,602 \\
1202 & 11,79 & 9,171 & 0,819 & 9,078 & 171,236 \\
1500 & 11,75 & 9,172 & 0,819 & 9,070 & 171,120 \\
1802 & 11,75 & 9,180 & 0,820 & 9,078 & 170,490 \\
2102 & 11,76 & 9,193 & 0,821 & 9,094 & 169,334 \\
2400 & 11,75 & 9,191 & 0,821 & 9,089 & 169,515 \\
3610 & 11,74 & 9,202 & 0,822 & 9,098 & 168,579 \\
\hline
\end{tabular}

Tabla A12. Datos cinéticos de extracción de ácido aspártico con RIE en baños agitados para el experimento IV $\left(\mathrm{pH}_{\mathrm{i}}=\mathbf{1 2 , 0 2} \pm 0,07 ; \mathrm{C}_{\mathrm{A}(\text { asp })}=\mathbf{1 4 , 6 4} \mathrm{mol} / \mathrm{m}^{3}\right)$ de la Tabla 5 .

\begin{tabular}{cccccc}
\hline $\mathrm{t}(\mathrm{s})$ & $\mathrm{pH}(\mathrm{t})$ & $\begin{array}{c}\mathrm{C}_{\mathrm{A}(\text { asp })}(\mathrm{t}) \\
\left(\mathrm{mol} / \mathrm{m}^{3}\right)\end{array}$ & $\mathrm{C}_{\mathrm{A} \text { (asp) }} / \mathrm{C}_{\mathrm{A}(\text { asp }) \mathrm{i}}$ & $\begin{array}{c}{\left[\mathrm{A}_{\text {asp }}^{2-}(\mathrm{t})\right.} \\
\left(\mathrm{mol} / \mathrm{m}^{3}\right) \\
(5.44)\end{array}$ & $\begin{array}{c}\overline{\mathrm{C}}_{\mathrm{A}(\text { asp })}(\mathrm{t}) \\
\left(\mathrm{mol}^{3} / \mathrm{m}^{3} \mathrm{RSI}\right) \\
\mathrm{Ec} .(5.46)\end{array}$ \\
\hline 0 & 12,03 & 14,639 & 1,000 & 14,553 & 0,000 \\
30 & 11,99 & 14,121 & 0,965 & 14,030 & 43,750 \\
67 & 11,99 & 13,580 & 0,928 & 13,493 & 89,403 \\
104 & 11,99 & 13,450 & 0,919 & 13,364 & 100,370 \\
150 & 11,99 & 13,285 & 0,908 & 13,200 & 114,355 \\
251 & 11,99 & 12,982 & 0,887 & 12,898 & 139,974 \\
360 & 11,99 & 12,847 & 0,878 & 12,765 & 151,336 \\
545 & 12,00 & 12,894 & 0,881 & 12,813 & 147,367 \\
790 & 12,01 & 12,779 & 0,873 & 12,700 & 157,108 \\
1053 & 12,02 & 12,880 & 0,880 & 12,803 & 148,548 \\
1200 & 12,03 & 12,899 & 0,881 & 12,823 & 146,958 \\
1500 & 12,04 & 12,878 & 0,880 & 12,804 & 148,758 \\
1800 & 12,04 & 12,867 & 0,879 & 12,793 & 149,691 \\
2101 & 12,05 & 12,832 & 0,877 & 12,760 & 152,624 \\
2460 & 12,05 & 12,827 & 0,876 & 12,756 & 153,011 \\
3604 & 12,06 & 12,857 & 0,878 & 12,786 & 150,534 \\
\hline
\end{tabular}


Tabla A13. Datos cinéticos de extracción de ácido aspártico con RIE en baños agitados para el experimento IV $\left(\mathrm{pH}_{\mathrm{i}}=\mathbf{1 2 , 0 2} \pm 0,07 ; \mathrm{C}_{\mathrm{A}(\mathrm{asp}) \mathrm{i}}=\mathbf{2 4 , 6 9} \mathrm{mol} / \mathrm{m}^{3}\right)$ de la Tabla 5.

\begin{tabular}{cccccc}
\hline $\mathrm{t}(\mathrm{s})$ & $\mathrm{pH}(\mathrm{t})$ & $\begin{array}{c}\mathrm{C}_{\mathrm{A}(\text { asp })}(\mathrm{t}) \\
\left(\mathrm{mol} / \mathrm{m}^{3}\right)\end{array}$ & $\mathrm{C}_{\mathrm{A} \text { (asp) }} / \mathrm{C}_{\mathrm{A}(\text { asp }) \mathrm{i}}$ & $\begin{array}{c}{\left[\mathrm{A}^{2-}{ }_{\text {asp }}\right](\mathrm{t})} \\
\left(\mathrm{mol}^{3} / \mathrm{m}^{3}\right) \mathrm{Ec} . \\
(5.44)\end{array}$ & $\begin{array}{c}\overline{\mathrm{C}}_{\mathrm{A}(\text { asp })}(\mathrm{t}) \\
\left(\mathrm{mol} / \mathrm{m}^{3} \mathrm{RSI}\right) \\
\mathrm{Ec} .(5.46)\end{array}$ \\
\hline 0 & 11,95 & 24,692 & 1,000 & 24,518 & 0,000 \\
30 & 11,92 & 23,521 & 0,953 & 23,344 & 99,058 \\
60 & 11,92 & 23,314 & 0,944 & 23,139 & 116,585 \\
94 & 11,92 & 23,134 & 0,937 & 22,959 & 131,878 \\
152 & 11,93 & 22,906 & 0,928 & 22,737 & 151,148 \\
241 & 11,93 & 22,550 & 0,913 & 22,384 & 181,284 \\
386 & 11,93 & 22,290 & 0,903 & 22,126 & 203,246 \\
540 & 11,92 & 22,185 & 0,898 & 22,018 & 212,141 \\
780 & 11,92 & 22,261 & 0,902 & 22,093 & 205,722 \\
1023 & 11,92 & 22,258 & 0,901 & 22,091 & 205,944 \\
1200 & 11,92 & 22,214 & 0,900 & 22,047 & 209,694 \\
1505 & 11,92 & 22,192 & 0,899 & 22,025 & 211,568 \\
1801 & 11,92 & 22,317 & 0,904 & 22,149 & 200,951 \\
2106 & 11,91 & 22,419 & 0,908 & 22,247 & 192,313 \\
2401 & 11,91 & 22,285 & 0,903 & 22,114 & 203,636 \\
3610 & 11,90 & 22,568 & 0,914 & 22,390 & 179,707 \\
\hline
\end{tabular}


Tabla A14. Determinación de la etapa controlante del proceso de extracción de ácido aspártico con RIE en baños agitados para los experimentos de la Tabla 5. Apartado (5.3.1.1)

a) $\frac{\text { Experimento I }\left(\mathrm{pH}_{\mathrm{i}}=\mathbf{5 , 0 6 \pm 0 , 0 7 ;} \mathrm{C}_{\mathrm{A}(\text { asp })}=\mathbf{7 , 3 7} \mathrm{mol} / \mathrm{m}^{3}\right)}{\mathrm{Y}}$

\begin{tabular}{cccc}
\hline$X$ & $Y$ & $Z$ & \\
Ec. $(5.48)$ & Ec. $(5.49)$ & Ec. $(5.50)$ & $\int_{0}^{t}\left[A_{\text {asp }}^{-}\right] d t$ \\
\hline 0,000 & 0,000 & 0,000 & 0,000 \\
0,052 & 0,000 & 0,009 & 208,789 \\
0,084 & 0,002 & 0,018 & 468,895 \\
0,094 & 0,002 & 0,021 & 684,066 \\
0,108 & 0,004 & 0,029 & 943,629 \\
0,124 & 0,007 & 0,060 & 1492,097 \\
\hline
\end{tabular}

b) Experimento I $\left(\mathrm{pH}_{\mathrm{i}}=\mathbf{5 , 0 6 \pm 0 , 0 7 ; \mathrm { C } _ { \mathrm { A } ( \text { asp } ) \mathrm { i } } = \mathbf { 1 1 , 1 1 } \mathrm { mol } / \mathrm { m } ^ { 3 } )} \mathrm{Y}\right.$

\begin{tabular}{cccc}
\hline$X$ & $Y$ & $Z$ & \\
Ec. $(5.48)$ & Ec. $(5.49)$ & Ec. $(5.50)$ & $\int_{0}^{t}\left[A_{\text {asp }}^{-}\right] \mathrm{dt}$ \\
\hline 0,000 & 0,000 & 0,000 & 0,000 \\
0,058 & 0,001 & 0,011 & 342,620 \\
0,095 & 0,002 & 0,023 & 612,315 \\
0,114 & 0,004 & 0,031 & 893,320 \\
0,132 & 0,007 & 0,044 & 1435,917 \\
0,146 & 0,011 & 0,080 & 2241,444 \\
\hline
\end{tabular}

c) Experimento I $\left(\mathrm{pH}_{\mathrm{i}}=\mathbf{5 , 0 6 \pm 0 , 0 7 ; \mathrm { C } _ { \mathrm { A } ( \text { asp } ) \mathrm { i } } = \mathbf { 1 4 , 6 4 \mathrm { mol } / \mathrm { m } ^ { 3 } ) }} \mathrm{Y}\right.$

\begin{tabular}{cccc}
\hline$X$ & $Y$ & $Z$ & \\
Ec. $(5.48)$ & Ec. $(5.49)$ & Ec. $(5.50)$ & $\int_{0}^{t}\left[A_{\text {asp }}^{-}\right] \mathrm{dt}$ \\
\hline 0,000 & 0,000 & 0,000 & 0,000 \\
0,073 & 0,001 & 0,015 & 409,039 \\
0,113 & 0,003 & 0,027 & 801,663 \\
0,140 & 0,006 & 0,040 & 1221,668 \\
0,151 & 0,008 & 0,048 & 1915,880 \\
0,167 & 0,015 & 0,091 & 2964,288 \\
\hline
\end{tabular}

d) Experimento I $\left(\mathrm{pH}_{\mathrm{i}}=\mathbf{5 , 0 6 \pm 0 , 0 7 ; \mathrm { C } _ { \mathrm { A } ( \text { asp } ) \mathrm { i } } = \mathbf { 2 1 , 8 5 } \mathrm { mol } / \mathrm { m } ^ { 3 } )}\right.$

\begin{tabular}{cccc}
\hline$X$ & $Y$ & $Z$ & \\
Ec. $(5.48)$ & Ec. $(5.49)$ & Ec. $(5.50)$ & $\int_{0}^{t}\left[A_{\text {asp }}^{-}\right] \mathrm{dt}$ \\
\hline 0,000 & 0,000 & 0,000 & 0,000 \\
0,114 & 0,004 & 0,033 & 902,330 \\
0,149 & 0,009 & 0,051 & 1734,625 \\
0,160 & 0,011 & 0,060 & 2347,162 \\
0,187 & 0,024 & 0,128 & 3105,738 \\
\hline
\end{tabular}

e) Experimento II $\left(\mathrm{pH}_{\mathrm{i}}=\mathbf{8 , 9 6} \pm 0,02 ; \mathrm{C}_{\mathrm{A}(\text { asp }) \mathrm{i}}=\mathbf{1 5 , 2 9} \mathrm{mol} / \mathrm{m}^{3}\right)$

\begin{tabular}{cccc}
\hline$X$ & $Y$ & $Z$ & \\
Ec. $(5.48)$ & Ec. $(5.49)$ & Ec. $(5.50)$ & $\int_{0}^{t}\left[A_{\text {asp }}^{-}\right] d t$ \\
\hline 0,000 & 0,000 & 0,000 & 0,000 \\
0,120 & 0,002 & 0,021 & 391,647 \\
0,155 & 0,005 & 0,032 & 772,620 \\
0,176 & 0,007 & 0,042 & 1151,513 \\
0,199 & 0,014 & 0,081 & 1907,967 \\
0,229 & 0,016 & 0,081 & 3036,751 \\
\hline
\end{tabular}


f) Experimento III $\left(\mathrm{pH}_{\mathrm{i}}=\mathbf{1 1 , 0 4 \pm 0 , 0 6 ; \mathrm { C } _ { \mathrm { A } ( \text { asp } ) \mathrm { i } } = \mathbf { 7 , 4 5 } \mathrm { mol } / \mathrm { m } ^ { 3 } )}\right.$

\begin{tabular}{cccc}
\hline$X$ & $Y$ & $Z$ & \\
Ec. $(5.48)$ & Ec. $(5.49)$ & Ec. $(5.50)$ & $\int_{0}^{t}\left[A_{\text {asp }}^{2-}\right] \mathrm{dt}$ \\
\hline 0,000 & 0,000 & 0,000 & 0,000 \\
0,052 & 0,000 & 0,001 & 208,699 \\
0,136 & 0,000 & 0,003 & 475,618 \\
0,206 & 0,001 & 0,006 & 854,933 \\
0,245 & 0,002 & 0,007 & 1394,833 \\
0,295 & 0,003 & 0,010 & 1970,577 \\
0,000 & 0,000 & 0,000 & 0,000 \\
\hline
\end{tabular}

g) Experimento III $\left(\mathrm{pH}_{\mathrm{i}}=\mathbf{1 1 , 0 4 \pm 0 , 0 6 ; \mathrm { C } _ { \mathrm { A } ( \text { asp } ) \mathrm { i } } = \mathbf { 1 1 } , \mathbf { 4 6 } \mathrm { mol } / \mathrm { m } ^ { 3 } )}\right.$

\begin{tabular}{cccc}
\hline$X$ & $Y$ & $Z$ & $\int_{0}^{t}\left[A_{\text {asp }}^{2-}\right] d t$ \\
Ec. $(5.48)$ & Ec. $(5.49)$ & Ec. $(5.50)$ & 0,000 \\
\hline 0,000 & 0,000 & 0,000 & 227,141 \\
0,076 & 0,000 & 0,002 & 531,281 \\
0,159 & 0,001 & 0,004 & 837,016 \\
0,200 & 0,001 & 0,005 & 1465,525 \\
0,249 & 0,002 & 0,007 & 2449,167 \\
0,359 & 0,004 & 0,011 & 3749,359 \\
0,406 & 0,006 & 0,014 & 5746,327 \\
0,438 & 0,008 & 0,016 & 7993,121 \\
0,471 & 0,011 & 0,020 & \\
\hline
\end{tabular}

h) Experimento III $\left(\mathrm{pH}_{\mathrm{i}}=\mathbf{1 1 , 0 4 \pm 0 , 0 6 ; \mathrm { C } _ { \mathrm { A } ( \text { asp } ) \mathrm { i } } = \mathbf { 1 8 , 9 4 } \mathrm { mol } / \mathrm { m } ^ { 3 } )}\right.$

\begin{tabular}{cccc}
\hline$X$ & $Y$ & $Z$ & \\
Ec. $(5.48)$ & Ec. $(5.49)$ & Ec. $(5.50)$ & $\int_{0}^{t}\left[A_{\text {asp }}^{2-}\right] \mathrm{dt}$ \\
\hline 0,000 & 0,000 & 0,000 & 0,000 \\
0,206 & 0,003 & 0,013 & 957,603 \\
0,266 & 0,005 & 0,018 & 2304,985 \\
0,327 & 0,009 & 0,024 & 4158,014 \\
0,359 & 0,011 & 0,029 & 5950,460 \\
0,414 & 0,018 & 0,038 & 8730,767 \\
0,451 & 0,025 & 0,048 & 14245,741 \\
0,486 & 0,039 & 0,073 & 19760,418 \\
\hline
\end{tabular}

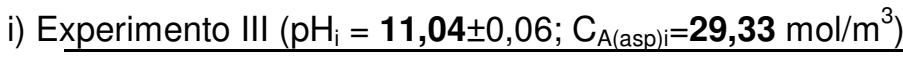

\begin{tabular}{cccc}
\hline$X$ & $Y$ & $Z$ & \\
Ec. $(5.48)$ & Ec. $(5.49)$ & Ec. $(5.50)$ & $\int_{0}^{t}\left[A_{\text {app }}^{2-}\right] d t$ \\
\hline 0,000 & 0,000 & 0,000 & 0,000 \\
0,163 & 0,001 & 0,008 & 708,937 \\
0,254 & 0,003 & 0,013 & 1724,373 \\
0,313 & 0,006 & 0,017 & 3044,804 \\
0,348 & 0,007 & 0,020 & 4566,597 \\
0,438 & 0,013 & 0,027 & 7650,812 \\
0,512 & 0,021 & 0,036 & 10709,625 \\
0,563 & 0,028 & 0,044 & 15595,510 \\
\hline
\end{tabular}


j) Experimento IV $\left(\mathrm{pH}_{\mathrm{i}}=\mathbf{1 2 , 0 2} \pm 0,07 ; \mathrm{C}_{\mathrm{A}(\text { asp }) \mathrm{i}}=\mathbf{9 , 5 8 \mathrm { mol } / \mathrm { m } ^ { 3 } )}\right.$

\begin{tabular}{cccc}
\hline$X$ & $Y$ & $Z$ & \\
Ec. $(5.48)$ & Ec. $(5.49)$ & Ec. $(5.50)$ & $\int_{0}^{t}\left[A_{\text {asp }}^{2-}\right] \mathrm{dt}$ \\
\hline 0,000 & 0,000 & 0,000 & 0,000 \\
0,215 & 0,001 & 0,004 & 0,215 \\
0,303 & 0,002 & 0,006 & 0,303 \\
0,369 & 0,003 & 0,008 & 0,369 \\
0,448 & 0,006 & 0,011 & 0,448 \\
0,517 & 0,010 & 0,017 & 0,517 \\
0,516 & 0,010 & 0,017 & 0,516 \\
0,537 & 0,013 & 0,020 & 0,537 \\
\hline
\end{tabular}

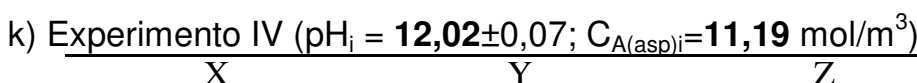

\begin{tabular}{cccc}
\hline$X$ & $Y$ & $Z$ & \\
Ec. $(5.48)$ & Ec. $(5.49)$ & Ec. $(5.50)$ & $\int_{0}^{1}\left[A_{\text {asp }}^{2-}\right] \mathrm{dt}$ \\
\hline 0,000 & 0,000 & 0,000 & 0,000 \\
0,172 & 0,001 & 0,007 & 352,789 \\
0,256 & 0,003 & 0,012 & 826,081 \\
0,339 & 0,007 & 0,020 & 1455,507 \\
0,377 & 0,011 & 0,025 & 1973,088 \\
0,390 & 0,012 & 0,027 & 2531,223 \\
0,413 & 0,016 & 0,033 & 3452,921 \\
0,421 & 0,018 & 0,037 & 5188,995 \\
\hline
\end{tabular}

I) Experimento IV $\left(\mathrm{pH}_{\mathrm{i}}=\mathbf{1 2 , 0 2 \pm 0 , 0 7 ; \mathrm { C } _ { \mathrm { A } ( \mathrm { asp } ) \mathrm { i } } = \mathbf { 1 4 , 6 4 \mathrm { mol } / \mathrm { m } ^ { 3 } ) }} \mathrm{Y}\right.$

\begin{tabular}{cccc}
\hline$X$ & $Y$ & $Z$ & \\
Ec. (5.48) & Ec. (5.49) & Ec. $(5.50)$ & $\int_{0}^{1}\left[A_{\text {asp }}^{2-}\right] d t$ \\
\hline 0,000 & 0,000 & 0,000 & 0,000 \\
0,111 & 0,001 & 0,008 & 428,746 \\
0,227 & 0,005 & 0,020 & 937,927 \\
0,254 & 0,007 & 0,024 & 1434,787 \\
0,290 & 0,010 & 0,030 & 2045,755 \\
0,355 & 0,020 & 0,049 & 3363,705 \\
0,384 & 0,032 & 0,085 & 4762,340 \\
\hline
\end{tabular}

m) Experimento IV $\left(\mathrm{pH}_{\mathrm{i}}=\mathbf{1 2 , 0 2 \pm 0 , 0 7 ; \mathrm { C } _ { \mathrm { A } ( \text { asp } ) \mathrm { i } } = \mathbf { 2 4 , 6 9 } \mathrm { mol } / \mathrm { m } ^ { 3 } )}\right.$

\begin{tabular}{cccc}
\hline$X$ & $Y$ & $Z$ & \\
Ec. $(5.48)$ & Ec. (5.49) & Ec. $(5.50)$ & $\int_{0}^{1}\left[A_{\text {app }}^{2-}\right] d t$ \\
\hline 0,000 & 0,000 & 0,000 & 0,000 \\
0,252 & 0,005 & 0,020 & 717,941 \\
0,297 & 0,008 & 0,025 & 1415,186 \\
0,336 & 0,011 & 0,030 & 2198,852 \\
0,385 & 0,016 & 0,037 & 3524,053 \\
0,462 & 0,028 & 0,053 & 5531,934 \\
0,518 & 0,049 & 0,084 & 8758,893 \\
0,540 & 0,056 & 0,108 & 12157,983 \\
\hline
\end{tabular}


TABLAS B. Resultados experimentales de las cinéticas de extracción de mezclas de ácido aspártico y a-fenilglicina con RIE en baños agitados. $\left[\overline{\mathrm{Q}^{+} \mathrm{Cl}^{-}}\right]_{\mathrm{i}}=765,07 \pm 10,24$ $\mathrm{mol} / \mathrm{m}^{3} \mathrm{RSI}$; 30으. (Apartado 5.3.2).

Tabla B1. Datos cinéticos de extracción de mezclas de ácido aspártico y a-fenilglicina con

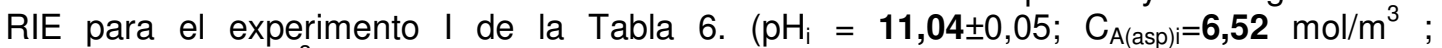

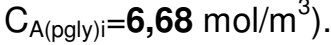

a) Ácido aspártico

\begin{tabular}{|c|c|c|c|c|c|}
\hline $\mathrm{t}(\mathrm{s})$ & $\mathrm{pH}(\mathrm{t})$ & $\begin{array}{l}\mathrm{C}_{\mathrm{A} \text { (asp) }}(\mathrm{t}) \\
\left(\mathrm{mol} / \mathrm{m}^{3}\right)\end{array}$ & $\mathrm{C}_{\mathrm{A} \text { (asp) }} / \mathrm{C}_{\mathrm{A} \text { (asp) } \mathrm{i}}$ & $\begin{array}{c}{\left[\mathrm{A}^{2-} \text { asp }\right]} \\
\left(\mathrm{mol} / \mathrm{m}^{3}\right) \mathrm{Ec} . \\
(5.44)\end{array}$ & $\begin{array}{c}\overline{\mathrm{C}}_{\mathrm{A} \text { (asp) }}(\mathrm{t}) \\
\left(\mathrm{mol} / \mathrm{m}^{3} \mathrm{RSI}\right) \\
\text { Ec. }(5.46) \\
\end{array}$ \\
\hline 0 & 11,01 & 6,522 & 1,000 & 6,144 & 0,000 \\
\hline 30 & 10,98 & 6,288 & 0,964 & 5,898 & 23,800 \\
\hline 72 & 11,97 & 6,035 & 0,925 & 5,995 & 48,791 \\
\hline 187 & 10,96 & 5,460 & 0,837 & 5,107 & 101,544 \\
\hline 250 & 10,91 & 5,339 & 0,819 & 4,955 & 114,954 \\
\hline 374 & 10,89 & 5,235 & 0,803 & 4,841 & 126,888 \\
\hline 612 & 10,80 & 5,048 & 0,774 & 4,589 & 145,178 \\
\hline 864 & 10,83 & 4,944 & 0,758 & 4,522 & 156,746 \\
\hline 1098 & 10,83 & 4,940 & 0,757 & 4,519 & 160,309 \\
\hline 1341 & 10,84 & 4,902 & 0,751 & 4,492 & 166,591 \\
\hline 1577 & 10,84 & 4,893 & 0,750 & 4,484 & 170,510 \\
\hline 1786 & 10,85 & 4,921 & 0,754 & 4,518 & 171,706 \\
\hline 2060 & 10,91 & 4,952 & 0,759 & 4,595 & 172,650 \\
\hline 2415 & 10,87 & 4,893 & 0,750 & 4,509 & 180,337 \\
\hline 2682 & 10,86 & 4,856 & 0,745 & 4,467 & 186,327 \\
\hline 3577 & 10,88 & 4,953 & 0,759 & 4,573 & 182,474 \\
\hline 5401 & 10,87 & 4,972 & 0,762 & 4,582 & 184,458 \\
\hline 7227 & 10,84 & 4,996 & 0,766 & 4,578 & 186,057 \\
\hline \multicolumn{6}{|c|}{ b) $\alpha$-Fenilglicina } \\
\hline $\mathrm{t}(\mathrm{s})$ & $\mathrm{pH}(\mathrm{t})$ & $\begin{array}{l}\mathrm{C}_{\mathrm{A}(\mathrm{pgly})}(\mathrm{t}) \\
\left(\mathrm{mol} / \mathrm{m}^{3}\right)\end{array}$ & $\begin{array}{l}\left.\mathrm{C}_{\mathrm{A}(\mathrm{pg} l y)}\right) \\
\mathrm{C}_{\mathrm{A}(\mathrm{pgly}) \mathrm{i}}\end{array}$ & $\begin{array}{c}{\left[\mathrm{A}_{\mathrm{pgly}}^{-}\right]} \\
\left(\mathrm{mol} / \mathrm{m}^{3}\right) \mathrm{Ec} . \\
(5.65)\end{array}$ & $\begin{array}{c}\overline{\mathrm{C}}_{\mathrm{A}(\mathrm{pgly})}(\mathrm{t}) \\
\left(\mathrm{mol} / \mathrm{m}^{3} \mathrm{RSI}\right) \\
\text { Ec. }(5.66) \\
\end{array}$ \\
\hline 0 & 11,01 & 6,685 & 1,000 & 6,620 & 0,000 \\
\hline 30 & 10,98 & 6,488 & 0,971 & 6,421 & 20,777 \\
\hline 72 & 11,97 & 6,327 & 0,946 & 6,320 & 38,384 \\
\hline 187 & 10,96 & 6,057 & 0,906 & 5,991 & 66,626 \\
\hline 250 & 10,91 & 5,944 & 0,889 & 5,872 & 79,764 \\
\hline 374 & 10,89 & 5,898 & 0,882 & 5,823 & 87,415 \\
\hline 612 & 10,80 & 5,741 & 0,859 & 5,651 & 103,812 \\
\hline 864 & 10,83 & 5,575 & 0,834 & 5,494 & 120,690 \\
\hline 1098 & 10,83 & 5,506 & 0,824 & 5,426 & 129,757 \\
\hline 1341 & 10,84 & 5,435 & 0,813 & 5,357 & 138,972 \\
\hline 1577 & 10,84 & 5,387 & 0,806 & 5,310 & 146,252 \\
\hline 1786 & 10,85 & 5,355 & 0,801 & 5,280 & 152,312 \\
\hline 2060 & 10,91 & 5,332 & 0,798 & 5,267 & 157,623 \\
\hline 2415 & 10,87 & 5,260 & 0,787 & 5,190 & 166,547 \\
\hline 2682 & 10,86 & 5,221 & 0,781 & 5,150 & 172,941 \\
\hline 3577 & 10,88 & 5,214 & 0,780 & 5,146 & 176,938 \\
\hline 5401 & 10,87 & 5,214 & 0,780 & 5,145 & 180,385 \\
\hline 7227 & 10,84 & 5,121 & 0,766 & 5,048 & 190,604 \\
\hline
\end{tabular}


Tabla B2. Datos cinéticos de extracción de mezclas de ácido aspártico y a-fenilglicina con RIE para el experimento I de la Tabla 6. $\left(\mathrm{pH}_{\mathrm{i}}=\mathbf{1 1 , 0 4} \pm 0,05 ; \mathrm{C}_{\mathrm{A}(\text { asp })}=\mathbf{1 3}, \mathbf{1 1} \mathrm{mol} / \mathrm{m}^{3}\right.$; $\mathrm{C}_{\mathrm{A}(\mathrm{pg} \mid \mathrm{y}) \mathrm{i}}=6,74 \mathrm{~mol} / \mathrm{m}^{3}$ ).

a) Ácido aspártico

\begin{tabular}{cccccc}
\hline $\mathrm{t}(\mathrm{s})$ & $\mathrm{pH}(\mathrm{t})$ & $\begin{array}{c}\mathrm{C}_{\mathrm{A} \text { (asp) }}(\mathrm{t}) \\
\left(\mathrm{mol} / \mathrm{m}^{3}\right)\end{array}$ & $\mathrm{C}_{\mathrm{A} \text { (asp) }} / \mathrm{C}_{\mathrm{A} \text { (asp)i }}$ & $\begin{array}{c}{\left[\mathrm{A}_{\text {ass }}^{2-}\right]} \\
\left(\mathrm{mol} / \mathrm{m}^{3}\right) \\
(5.44)\end{array}$ & $\begin{array}{c}\overline{\mathrm{C}}_{\mathrm{A} \text { (asp) }}(\mathrm{t}) \\
\left(\mathrm{mol}^{2} / \mathrm{m}^{3} \mathrm{RSI}\right) \\
\mathrm{Ec} .(5.46)\end{array}$ \\
\hline 0 & 11,01 & 13,108 & 1,000 & 12,346 & 0,000 \\
20 & 10,99 & 12,799 & 0,976 & 12,023 & 34,302 \\
76 & 10,94 & 12,520 & 0,955 & 11,674 & 65,875 \\
129 & 10,95 & 12,267 & 0,936 & 11,456 & 94,878 \\
192 & 10,94 & 12,062 & 0,920 & 11,247 & 119,647 \\
264 & 10,95 & 11,919 & 0,909 & 11,131 & 139,174 \\
369 & 10,94 & 11,812 & 0,901 & 11,014 & 155,636 \\
612 & 10,94 & 11,593 & 0,884 & 10,810 & 180,840 \\
856 & 10,92 & 11,504 & 0,878 & 10,693 & 195,520 \\
1098 & 10,92 & 11,426 & 0,872 & 10,621 & 209,243 \\
1342 & 10,92 & 11,494 & 0,877 & 10,684 & 211,678 \\
1569 & 10,91 & 11,376 & 0,868 & 10,556 & 228,390 \\
1825 & 10,93 & 11,471 & 0,875 & 10,679 & 228,805 \\
2080 & 10,96 & 11,414 & 0,871 & 10,675 & 240,747 \\
2424 & 10,93 & 11,438 & 0,873 & 10,649 & 246,563 \\
2674 & 10,94 & 11,465 & 0,875 & 10,690 & 252,270 \\
3596 & 10,92 & 11,443 & 0,873 & 10,636 & 261,483 \\
7241 & 10,89 & 11,400 & 0,870 & 10,543 & 272,284 \\
10805 & 10,90 & 11,423 & 0,872 & 10,583 & 278,204 \\
14366 & 10,86 & 11,414 & 0,871 & 10,499 & 286,537 \\
\hline
\end{tabular}

b) $\alpha$-Fenilglicina

\begin{tabular}{cccccc}
\hline $\mathrm{t}(\mathrm{s})$ & $\mathrm{pH}(\mathrm{t})$ & $\begin{array}{c}\mathrm{C}_{\mathrm{A}(\mathrm{pgly})}(\mathrm{t}) \\
\left(\mathrm{mol} / \mathrm{m}^{3}\right)\end{array}$ & $\begin{array}{c}\left.\mathrm{C}_{\mathrm{A}(\mathrm{pgly})}\right) \\
\mathrm{C}_{\mathrm{A}(\mathrm{pgly}) \mathrm{i}}\end{array}$ & $\begin{array}{c}{\left[\mathrm{A}_{\mathrm{pgly}}^{-}\right]} \\
\left(\mathrm{mol} / \mathrm{m}^{3}\right) \\
(5.65)\end{array}$ & $\begin{array}{c}\overline{\mathrm{C}}_{\mathrm{A}(\mathrm{pgly})}(\mathrm{t}) \\
\left(\mathrm{mol} / \mathrm{m}^{3} \mathrm{RSI}\right) \\
\mathrm{Ec} .(5.66)\end{array}$ \\
\hline 0 & 11,01 & 6,736 & 1,000 & 6,671 & 0,0000 \\
20 & 10,99 & 6,588 & 0,978 & 6,521 & 16,7724 \\
76 & 10,94 & 6,513 & 0,967 & 6,439 & 27,3712 \\
129 & 10,95 & 6,344 & 0,942 & 6,274 & 45,4919 \\
192 & 10,94 & 6,309 & 0,937 & 6,237 & 52,5573 \\
264 & 10,95 & 6,255 & 0,929 & 6,185 & 61,1359 \\
369 & 10,94 & 6,160 & 0,914 & 6,090 & 72,8818 \\
612 & 10,94 & 6,098 & 0,905 & 6,029 & 81,8839 \\
856 & 10,92 & 5,950 & 0,883 & 5,879 & 97,5290 \\
1098 & 10,92 & 5,888 & 0,874 & 5,818 & 106,2947 \\
1342 & 10,92 & 5,878 & 0,873 & 5,808 & 111,0424 \\
1569 & 10,91 & 5,795 & 0,860 & 5,725 & 121,2366 \\
1825 & 10,93 & 5,804 & 0,862 & 5,737 & 124,4635 \\
2080 & 10,96 & 5,730 & 0,851 & 5,668 & 133,8821 \\
2424 & 10,93 & 5,692 & 0,845 & 5,626 & 140,5074 \\
2674 & 10,94 & 5,674 & 0,842 & 5,609 & 145,6872 \\
3596 & 10,92 & 5,613 & 0,833 & 5,546 & 153,9109 \\
7241 & 10,89 & 5,540 & 0,822 & 5,470 & 162,8934 \\
10805 & 10,90 & 5,524 & 0,820 & 5,455 & 167,7617 \\
14366 & 10,86 & 5,502 & 0,817 & 5,428 & 172,9890 \\
\hline
\end{tabular}


Tabla B3. Datos cinéticos de extracción de mezclas de ácido aspártico y a-fenilglicina con

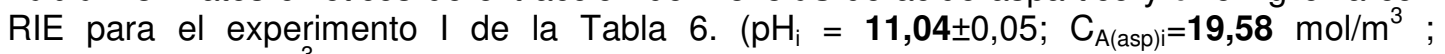

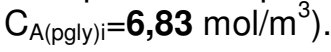

a) Ácido aspártico

\begin{tabular}{cccccc}
\hline $\mathrm{t}(\mathrm{s})$ & $\mathrm{pH}(\mathrm{t})$ & $\begin{array}{c}\mathrm{C}_{\mathrm{A}(\text { asp })}(\mathrm{t}) \\
\left(\mathrm{mol}^{3}\right)\end{array}$ & $\mathrm{C}_{\mathrm{A} \text { (asp) }} / \mathrm{C}_{\mathrm{A} \text { (asp)i })}$ & $\begin{array}{c}{\left[\mathrm{A}^{2-} \text { asp }\right]} \\
\left(\mathrm{mol} / \mathrm{m}^{3}\right) \\
(5.44)\end{array}$ & $\begin{array}{c}\overline{\mathrm{C}}_{\mathrm{A} \text { (asp) }}(\mathrm{t}) \\
\left(\mathrm{mol} / \mathrm{m}^{3} \mathrm{RSI}\right) \\
\mathrm{Ec} .(5.46)\end{array}$ \\
\hline 0 & 11,01 & 19,584 & 1,000 & 18,447 & 0,000 \\
17 & 10,95 & 19,321 & 0,987 & 18,043 & 34,957 \\
56 & 10,95 & 18,898 & 0,965 & 17,648 & 82,650 \\
90 & 10,96 & 18,688 & 0,954 & 17,479 & 112,378 \\
139 & 10,99 & 18,292 & 0,934 & 17,182 & 156,947 \\
281 & 10,98 & 17,887 & 0,913 & 16,779 & 201,650 \\
382 & 10,97 & 17,732 & 0,905 & 16,609 & 225,956 \\
618 & 10,96 & 17,571 & 0,897 & 16,434 & 250,535 \\
871 & 10,98 & 17,363 & 0,887 & 16,287 & 278,508 \\
1107 & 10,97 & 17,374 & 0,887 & 16,274 & 289,291 \\
1339 & 10,95 & 17,360 & 0,886 & 16,212 & 301,958 \\
1559 & 10,93 & 17,414 & 0,889 & 16,212 & 309,458 \\
1816 & 10,94 & 17,421 & 0,890 & 16,245 & 320,541 \\
2068 & 10,93 & 17,392 & 0,888 & 16,192 & 334,371 \\
2428 & 10,93 & 17,479 & 0,893 & 16,273 & 339,548 \\
2668 & 10,92 & 17,417 & 0,889 & 16,189 & 355,804 \\
3598 & 10,93 & 17,526 & 0,895 & 16,317 & 359,498 \\
7224 & 10,90 & 17,566 & 0,897 & 16,273 & 368,341 \\
10835 & 10,88 & 17,646 & 0,901 & 16,291 & 374,344 \\
14367 & 10,85 & 17,662 & 0,902 & 16,217 & 385,008 \\
\hline
\end{tabular}

b) $\alpha$-Fenilglicina

\begin{tabular}{|c|c|c|c|c|c|}
\hline $\mathrm{t}(\mathrm{s})$ & $\mathrm{pH}(\mathrm{t})$ & $\begin{array}{c}\mathrm{C}_{\mathrm{A}(\mathrm{pgly})}(\mathrm{t}) \\
\left(\mathrm{mol} / \mathrm{m}^{3}\right)\end{array}$ & $\begin{array}{l}\mathrm{C}_{\mathrm{A}(\mathrm{pg} l \mathrm{y})} / \\
\mathrm{C}_{\mathrm{A}(\mathrm{pg} \mathrm{g}) \mathrm{i}}\end{array}$ & $\begin{array}{c}{\left[\mathrm{A}_{\mathrm{pgly}}^{-}\right]} \\
\left(\mathrm{mol} / \mathrm{m}^{3}\right) \mathrm{Ec} . \\
(5.65)\end{array}$ & $\begin{array}{c}\overline{\mathrm{C}}_{\mathrm{A}(\mathrm{pgly})}(\mathrm{t}) \\
\left(\mathrm{mol} / \mathrm{m}^{3} \mathrm{RSI}\right) \\
\text { Ec. }(5.66)\end{array}$ \\
\hline 0 & 11,01 & 6,830 & 1,000 & 6,764 & 0,000 \\
\hline 17 & 10,95 & 6,715 & 0,983 & 6,640 & 14,086 \\
\hline 56 & 10,95 & 6,580 & 0,963 & 6,507 & 29,638 \\
\hline 90 & 10,96 & 6,512 & 0,954 & 6,442 & 39,583 \\
\hline 139 & 10,99 & 6,367 & 0,932 & 6,303 & 55,682 \\
\hline 281 & 10,98 & 6,252 & 0,915 & 6,187 & 69,193 \\
\hline 382 & 10,97 & 6,149 & 0,900 & 6,084 & 81,525 \\
\hline 618 & 10,96 & 6,050 & 0,886 & 5,984 & 93,501 \\
\hline 871 & 10,98 & 5,917 & 0,866 & 5,855 & 107,934 \\
\hline 1107 & 10,97 & 5,880 & 0,861 & 5,818 & 114,748 \\
\hline 1339 & 10,95 & 5,833 & 0,854 & 5,768 & 122,280 \\
\hline 1559 & 10,93 & 5,814 & 0,851 & 5,747 & 127,597 \\
\hline 1816 & 10,94 & 5,779 & 0,846 & 5,714 & 134,145 \\
\hline 2068 & 10,93 & 5,735 & 0,840 & 5,668 & 141,328 \\
\hline 2428 & 10,93 & 5,716 & 0,837 & 5,650 & 146,543 \\
\hline 2668 & 10,92 & 5,676 & 0,831 & 5,608 & 153,350 \\
\hline 3598 & 10,93 & 5,649 & 0,827 & 5,583 & 159,111 \\
\hline 7224 & 10,90 & 5,625 & 0,824 & 5,556 & 164,569 \\
\hline 10835 & 10,88 & 5,604 & 0,821 & 5,531 & 169,885 \\
\hline 14367 & 10,85 & 5,577 & 0,817 & 5,499 & 175,559 \\
\hline
\end{tabular}


Tabla B4. Datos cinéticos de extracción de mezclas de ácido aspártico y a-fenilglicina con

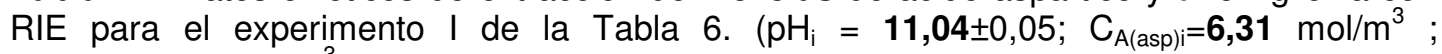
$\left.\mathrm{C}_{\mathrm{A}(\mathrm{pg} \mid \mathrm{y}) \mathrm{i}}=12,38 \mathrm{~mol} / \mathrm{m}^{3}\right)$.

a) Ácido aspártico

\begin{tabular}{cccccc}
\hline $\mathrm{t}(\mathrm{s})$ & $\mathrm{pH}(\mathrm{t})$ & $\begin{array}{c}\mathrm{C}_{\mathrm{A}(\text { asp })}(\mathrm{t}) \\
\left(\mathrm{mol}^{3}\right)\end{array}$ & $\mathrm{C}_{\mathrm{A} \text { (asp) }} / \mathrm{C}_{\mathrm{A} \text { (asp)i })}$ & $\begin{array}{c}{\left[\mathrm{A}^{2-} \mathrm{asp}\right]} \\
\left(\mathrm{mol} / \mathrm{m}^{3}\right) \\
(5.44)\end{array}$ & $\begin{array}{c}\overline{\mathrm{C}}_{\mathrm{A} \text { (asp) }}(\mathrm{t}) \\
\left(\mathrm{mol} / \mathrm{m}^{3} \mathrm{RSI}\right) \\
\mathrm{Ec} .(5.46)\end{array}$ \\
\hline 0 & 11,09 & 6,306 & 1,000 & 5,998 & 0,000 \\
20 & 11,04 & 6,167 & 0,978 & 5,832 & 15,699 \\
58 & 11,03 & 5,801 & 0,920 & 5,478 & 49,975 \\
109 & 11,03 & 5,640 & 0,894 & 5,326 & 66,987 \\
149 & 10,99 & 5,620 & 0,891 & 5,279 & 72,382 \\
267 & 11,01 & 5,459 & 0,866 & 5,142 & 88,991 \\
409 & 11,00 & 5,234 & 0,830 & 4,924 & 110,555 \\
641 & 10,99 & 5,153 & 0,817 & 4,840 & 120,495 \\
905 & 10,97 & 5,083 & 0,806 & 4,761 & 129,365 \\
1125 & 10,94 & 5,051 & 0,801 & 4,710 & 135,300 \\
1363 & 10,88 & 5,060 & 0,802 & 4,671 & 137,990 \\
1598 & 10,90 & 5,128 & 0,813 & 4,750 & 136,187 \\
1823 & 10,91 & 5,118 & 0,812 & 4,749 & 140,364 \\
2070 & 10,90 & 5,135 & 0,814 & 4,757 & 142,495 \\
2460 & 10,89 & 5,154 & 0,817 & 4,766 & 144,540 \\
2676 & 10,91 & 5,121 & 0,812 & 4,752 & 150,413 \\
3620 & 10,89 & 5,157 & 0,818 & 4,769 & 151,189 \\
7216 & 10,86 & 5,213 & 0,827 & 4,795 & 150,611 \\
10910 & 10,88 & 5,272 & 0,836 & 4,868 & 149,836 \\
14475 & 10,86 & 5,248 & 0,832 & 4,827 & 155,121 \\
\hline
\end{tabular}

b) $\alpha$-Fenilglicina

\begin{tabular}{cccccc}
\hline $\mathrm{t}(\mathrm{s})$ & $\mathrm{pH}(\mathrm{t})$ & $\begin{array}{c}\mathrm{C}_{\mathrm{A}(\mathrm{pgly})}(\mathrm{t}) \\
\left(\mathrm{mol} / \mathrm{m}^{3}\right)\end{array}$ & $\begin{array}{c}\left.\mathrm{C}_{\mathrm{A}(\mathrm{pgly})}\right) \\
\mathrm{C}_{\mathrm{A}(\mathrm{pgly}) \mathrm{i}}\end{array}$ & $\begin{array}{c}{\left[\mathrm{A}_{\mathrm{pgly}}^{-}\right]} \\
\left(\mathrm{mol} / \mathrm{m}^{3}\right) \\
(5.65)\end{array}$ & $\begin{array}{c}\overline{\mathrm{C}}_{\mathrm{A}(\mathrm{pgly})}(\mathrm{t}) \\
\left(\mathrm{mol} / \mathrm{m}^{3} \mathrm{RSI}\right) \\
\mathrm{Ec} .(5.66)\end{array}$ \\
\hline 0 & 11,09 & 12,379 & 1,000 & 12,279 & 0,000 \\
20 & 11,04 & 12,267 & 0,991 & 12,156 & 17,621 \\
58 & 11,03 & 11,819 & 0,955 & 11,709 & 62,675 \\
109 & 11,03 & 11,658 & 0,942 & 11,550 & 83,711 \\
149 & 10,99 & 11,664 & 0,942 & 11,546 & 91,015 \\
267 & 11,01 & 11,437 & 0,924 & 11,326 & 117,028 \\
409 & 11,00 & 11,030 & 0,891 & 10,920 & 157,079 \\
641 & 10,99 & 10,870 & 0,878 & 10,760 & 177,060 \\
905 & 10,97 & 10,674 & 0,862 & 10,561 & 199,625 \\
1125 & 10,94 & 10,607 & 0,857 & 10,487 & 211,988 \\
1363 & 10,88 & 10,554 & 0,853 & 10,417 & 223,165 \\
1598 & 10,90 & 10,622 & 0,858 & 10,490 & 225,046 \\
1823 & 10,91 & 10,511 & 0,849 & 10,383 & 240,547 \\
2070 & 10,90 & 10,393 & 0,840 & 10,264 & 256,393 \\
2460 & 10,89 & 10,368 & 0,838 & 10,236 & 265,192 \\
2676 & 10,91 & 10,256 & 0,828 & 10,131 & 280,371 \\
3620 & 10,89 & 10,226 & 0,826 & 10,096 & 289,377 \\
7216 & 10,86 & 10,279 & 0,830 & 10,139 & 292,435 \\
10910 & 10,88 & 10,237 & 0,827 & 10,104 & 302,271 \\
14475 & 10,86 & 10,142 & 0,819 & 10,004 & 315,844 \\
\hline
\end{tabular}


Tabla B5.Datos cinéticos de extracción de mezclas de ácido aspártico y a-fenilglicina con RIE para el experimento II de la Tabla 6. $\left(\mathrm{pH}_{\mathrm{i}}=12,02 \pm 0,02 ; \mathrm{C}_{\mathrm{A}(\mathrm{asp}) \mathrm{i}}=7,65 \mathrm{~mol} / \mathrm{m}^{3}\right.$; $\left.\mathrm{C}_{\mathrm{A}(\mathrm{pg} \mid \mathrm{y}) \mathrm{i}}=\mathbf{8 , 1 0} \mathrm{mol} / \mathrm{m}^{3}\right)$.

a) Ácido aspártico

\begin{tabular}{cccccc}
\hline $\mathrm{t}(\mathrm{s})$ & $\mathrm{pH}(\mathrm{t})$ & $\begin{array}{c}\mathrm{C}_{\mathrm{A} \text { (asp) }}(\mathrm{t}) \\
\left(\mathrm{mol} / \mathrm{m}^{3}\right)\end{array}$ & $\mathrm{C}_{\mathrm{A} \text { (asp) }} / \mathrm{C}_{\mathrm{A} \text { (asp)i })}$ & $\begin{array}{c}{\left[\mathrm{A}^{2-}{ }_{\text {asp }}\right]} \\
\left(\mathrm{mol}^{3} / \mathrm{m}^{3}\right) \\
(5.44)\end{array}$ & $\begin{array}{c}\overline{\mathrm{C}}_{\mathrm{A} \text { (asp) }}(\mathrm{t}) \\
\left(\mathrm{mol} / \mathrm{m}^{3} \mathrm{RSI}\right) \\
\mathrm{Ec} .(5.46)\end{array}$ \\
\hline 0 & 12,02 & 7,655 & 1 & 7,609 & 0,000 \\
60 & 11,99 & 6,821 & 0,891 & 6,778 & 70,371 \\
120 & 12,00 & 6,549 & 0,856 & 6,508 & 93,371 \\
180 & 12,01 & 6,476 & 0,846 & 6,436 & 99,569 \\
300 & 12,02 & 6,174 & 0,807 & 6,137 & 125,060 \\
600 & 12,05 & 6,128 & 0,801 & 6,094 & 128,916 \\
900 & 12,08 & 6,162 & 0,805 & 6,130 & 126,078 \\
1200 & 12,12 & 6,203 & 0,810 & 6,174 & 122,560 \\
1800 & 12,18 & 6,203 & 0,810 & 6,177 & 122,620 \\
2713 & 12,23 & 6,287 & 0,821 & 6,263 & 115,521 \\
3602 & 12,27 & 6,239 & 0,815 & 6,218 & 119,543 \\
7215 & 12,26 & 6,195 & 0,809 & 6,173 & 123,302 \\
14419 & 12,18 & 6,170 & 0,806 & 6,144 & 125,396 \\
21847 & 12,08 & 6,259 & 0,818 & 6,226 & 117,892 \\
28800 & 12,00 & 6,276 & 0,820 & 6,237 & 116,422 \\
83155 & 12,01 & 6,271 & 0,819 & 6,233 & 116,830 \\
\hline
\end{tabular}

b) $\alpha$-Fenilglicina

\begin{tabular}{cccccc}
\hline $\mathrm{t}(\mathrm{s})$ & $\mathrm{pH}(\mathrm{t})$ & $\begin{array}{c}\mathrm{C}_{\mathrm{A}(\mathrm{pgly})}(\mathrm{t}) \\
\left(\mathrm{mol} / \mathrm{m}^{3}\right)\end{array}$ & $\begin{array}{c}\left.\mathrm{C}_{\mathrm{A}(\mathrm{pgly})}\right) \\
\mathrm{C}_{\mathrm{A}(\mathrm{pgly}) \mathrm{i}}\end{array}$ & $\begin{array}{c}{\left[\mathrm{A}_{\mathrm{pgly}}^{-}\right]} \\
\left(\mathrm{mol} / \mathrm{m}^{3}\right) \mathrm{Ec} . \\
(5.65)\end{array}$ & $\begin{array}{c}\overline{\mathrm{C}}_{\mathrm{A}(\mathrm{pgly})}(\mathrm{t}) \\
\left(\mathrm{mol} / \mathrm{m}^{3} \mathrm{RSI}\right) \\
\mathrm{Ec} .(5.66)\end{array}$ \\
\hline 0 & 12,02 & 8,101 & 1 & 8,094 & 0,000 \\
60 & 11,99 & 7,382 & 0,911 & 7,374 & 60,790 \\
120 & 12,00 & 7,279 & 0,898 & 7,271 & 69,479 \\
180 & 12,01 & 7,267 & 0,897 & 7,260 & 70,470 \\
300 & 12,02 & 6,907 & 0,853 & 6,900 & 100,881 \\
600 & 12,05 & 6,644 & 0,820 & 6,638 & 123,051 \\
900 & 12,08 & 6,583 & 0,813 & 6,578 & 128,205 \\
1200 & 12,12 & 6,477 & 0,799 & 6,472 & 137,215 \\
1800 & 12,18 & 6,460 & 0,797 & 6,455 & 138,662 \\
2713 & 12,23 & 6,489 & 0,801 & 6,485 & 136,185 \\
3602 & 12,27 & 6,479 & 0,800 & 6,475 & 137,048 \\
7215 & 12,26 & 6,390 & 0,789 & 6,387 & 144,525 \\
14419 & 12,18 & 6,316 & 0,780 & 6,311 & 150,815 \\
21847 & 12,08 & 6,435 & 0,794 & 6,429 & 140,750 \\
28800 & 12,00 & 6,378 & 0,787 & 6,372 & 145,545 \\
83155 & 12,01 & 6,347 & 0,783 & 6,340 & 148,194 \\
\hline
\end{tabular}


Tabla B6. Determinación de la etapa controlante del proceso de extracción conjunta de ácido aspártico y a-fenilglicina con RIE para los experimentos I y II de la Tabla 6.

a) Experimento I $\left(\mathrm{pH}_{\mathrm{i}}=\mathbf{1 1 , 0 4} \pm 0,05 ; \mathrm{C}_{\mathrm{A}(\text { asp }) \mathrm{i}}=\mathbf{6 , 5 2} \mathrm{mol} / \mathrm{m}^{3} ; \mathrm{C}_{\mathrm{A}(\mathrm{pgly}) \mathrm{i}}=\mathbf{6 , 6 8} \mathrm{mol} / \mathrm{m}^{3}\right)$

a1) Ácido aspártico

\begin{tabular}{cccc}
\hline $\mathrm{X}$ & $\mathrm{Y}$ & $\mathrm{Z}$ & \\
Ec. $(5.69)$ & Ec. $(5.71)$ & Ec. $(5.73)$ & $\int_{0}^{t}\left[A_{\text {asp }}^{2-}\right] d t$ \\
\hline 0,000 & 0,000 & 0,000 & 0,000 \\
0,063 & 0,000 & 0,001 & 180,630 \\
0,128 & 0,000 & 0,003 & 430,384 \\
0,267 & 0,002 & 0,008 & 1068,734 \\
0,303 & 0,003 & 0,010 & 1385,675 \\
0,334 & 0,005 & 0,012 & 1993,002 \\
0,3821 & 0,009 & 0,019 & 3115,164 \\
\hline
\end{tabular}

a2) a-Fenilglicina

\begin{tabular}{cccc}
\hline$X$ & $Y$ & $Z$ & \\
Ec. $(5.70)$ & Ec. $(5.72)$ & Ec. $(5.74)$ & $\int_{0}^{t}\left[A_{\text {pgly }}^{-}\right] d t$ \\
\hline 0,000 & 0,000 & 0,000 & 0,000 \\
0,027 & 0,000 & 0,001 & 195,608 \\
0,051 & 0,000 & 0,002 & 463,157 \\
0,088 & 0,000 & 0,004 & 1171,041 \\
0,105 & 0,001 & 0,005 & 1544,731 \\
0,115 & 0,001 & 0,006 & 2269,823 \\
0,137 & 0,001 & 0,007 & 3635,287 \\
0,159 & 0,002 & 0,009 & 5039,563 \\
0,171 & 0,002 & 0,011 & 6317,182 \\
0,183 & 0,002 & 0,012 & 7627,368 \\
0,192 & 0,003 & 0,014 & 8886,149 \\
0,200 & 0,003 & 0,015 & 9992,852 \\
0,207 & 0,004 & 0,017 & 11437,793 \\
0,219 & 0,005 & 0,020 & 13293,854 \\
\hline
\end{tabular}

b) Experimento I $\left(\mathrm{pH}_{\mathrm{i}}=\mathbf{1 1}, \mathbf{0 4} \pm 0,05 ; \mathrm{C}_{\mathrm{A}(\mathrm{asp}) \mathrm{i}}=\mathbf{1 3 , 1 1} \mathrm{mol} / \mathrm{m}^{3} ; \mathrm{C}_{\mathrm{A}(\text { pgly) }}=\mathbf{6}, \mathbf{7 4} \mathrm{mol} / \mathrm{m}^{3}\right)$

b1) Ácido aspártico

\begin{tabular}{cccc}
\hline$X$ & $Y$ & $Z$ & $\int_{0}^{t}\left[A_{\text {asp }}^{2-}\right] d t$ \\
Ec. $(5.69)$ & Ec. $(5.71)$ & Ec. $(5.73)$ & \\
\hline 0,000 & 0,000 & 0,000 & 0,000 \\
0,090 & 0,000 & 0,003 & 243,695 \\
0,173 & 0,001 & 0,005 & 907,213 \\
0,250 & 0,002 & 0,008 & 1520,144 \\
0,315 & 0,004 & 0,011 & 2235,276 \\
0,366 & 0,006 & 0,014 & 3040,880 \\
0,410 & 0,008 & 0,017 & 4203,497 \\
0,476 & 0,013 & 0,024 & 6855,095 \\
0,515 & 0,017 & 0,029 & 9478,415 \\
0,551 & 0,026 & 0,043 & 12057,369 \\
\hline
\end{tabular}


b2) a-Fenilglicina

\begin{tabular}{cccc}
\hline$X$ & $Y$ & $Z$ & $\int_{0}^{t}\left[A_{\text {pgly }}^{-}\right] d t$ \\
Ec. $(5.70)$ & Ec. $(5.72)$ & Ec. $(5.74)$ & \\
\hline 0,000 & 0,000 & 0,000 & 0,000 \\
0,022 & 0,000 & 0,001 & 131,923 \\
0,036 & 0,000 & 0,003 & 494,811 \\
0,060 & 0,000 & 0,004 & 831,691 \\
0,069 & 0,000 & 0,005 & 1225,791 \\
0,080 & 0,001 & 0,007 & 1673,012 \\
0,096 & 0,001 & 0,008 & 2317,453 \\
0,108 & 0,001 & 0,010 & 3789,820 \\
0,128 & 0,002 & 0,013 & 5242,557 \\
0,140 & 0,002 & 0,015 & 6657,931 \\
0,146 & 0,003 & 0,017 & 8076,286 \\
0,160 & 0,004 & 0,020 & 9385,240 \\
0,164 & 0,004 & 0,022 & 10852,302 \\
0,176 & 0,006 & 0,027 & 12306,352 \\
\hline
\end{tabular}

c) Experimento I $\left(\mathrm{pH}_{\mathrm{i}}=\mathbf{1 1}, \mathbf{0 4} \pm 0,05 ; \mathrm{C}_{\mathrm{A}(\text { asp }) \mathrm{i}}=\mathbf{1 9 , 5 8} \mathrm{mol} / \mathrm{m}^{3} ; \mathrm{C}_{\mathrm{A}(\mathrm{pgly} \mid \mathrm{y})}=\mathbf{6 , 8 3} \mathrm{mol} / \mathrm{m}^{3}\right)$

c1) Ácido aspártico

\begin{tabular}{|c|c|c|c|}
\hline $\mathrm{X}$ & $\mathrm{Y}$ & $\bar{Z}$ & \multirow{2}{*}{$\int_{0}^{t}\left[A_{\text {asp }}^{2-}\right] d t$} \\
\hline Ec. (5.69) & Ec. (5.71) & Ec. (5.73) & \\
\hline 0,000 & 0,000 & 0,000 & 0,000 \\
\hline 0,092 & 0,000 & 0,003 & 310,168 \\
\hline 0,218 & 0,002 & 0,008 & 1006,158 \\
\hline 0,296 & 0,003 & 0,011 & 1603,325 \\
\hline 0,413 & 0,008 & 0,017 & 2452,531 \\
\hline 0,531 & 0,016 & 0,027 & 4863,756 \\
\hline 0,595 & 0,023 & 0,034 & 6549,822 \\
\hline 0,659 & 0,043 & 0,066 & 10448,847 \\
\hline \multicolumn{4}{|c|}{ 2) a-Fenilglicina } \\
\hline $\mathrm{X}$ & $\bar{Y}$ & $\bar{Z}$ & \multirow{2}{*}{$\int_{0}^{t}\left[A_{p g l y}^{-}\right] d t$} \\
\hline Ec. $(5.70)$ & Ec. (5.72) & Ec. (5.74) & \\
\hline 0,000 & 0,000 & 0,000 & 0,000 \\
\hline 0,019 & 0,000 & 0,001 & 113,932 \\
\hline 0,039 & 0,000 & 0,003 & 370,309 \\
\hline 0,052 & 0,000 & 0,004 & 590,439 \\
\hline 0,073 & 0,000 & 0,006 & 902,673 \\
\hline 0,091 & 0,001 & 0,008 & 1789,429 \\
\hline 0,107 & 0,001 & 0,010 & 2409,116 \\
\hline 0,123 & 0,002 & 0,012 & 3833,145 \\
\hline 0,142 & 0,002 & 0,015 & 5330,831 \\
\hline 0,151 & 0,003 & 0,018 & 6708,249 \\
\hline 0,161 & 0,004 & 0,020 & 8052,218 \\
\hline 0,168 & 0,004 & 0,023 & 9318,903 \\
\hline 0,177 & 0,006 & 0,028 & 10791,594 \\
\hline
\end{tabular}


d) Experimento I $\left(\mathrm{pH}_{\mathrm{i}}=\mathbf{1 1}, \mathbf{0 4} \pm 0,05 ; \mathrm{C}_{\mathrm{A}(\mathrm{asp}) \mathrm{i}}=\mathbf{6 , 3 1} \mathrm{mol} / \mathrm{m}^{3} ; \mathrm{C}_{\mathrm{A}(\mathrm{pgly}) \mathrm{i}}=\mathbf{1 2 , 3 8} \mathrm{mol} / \mathrm{m}^{3}\right)$ d1) Ácido aspártico

\begin{tabular}{cccc}
\hline$X$ & $Y$ & $Z$ & \\
Ec. $(5.69)$ & Ec. $(5.71)$ & Ec. $(5.73)$ & $\int_{0}^{t}\left[A_{\text {asp }}^{2-}\right] d t$ \\
\hline 0,000 & 0,000 & 0,000 & 0,000 \\
0,041 & 0,000 & 0,002 & 118,297 \\
0,132 & 0,001 & 0,006 & 333,180 \\
0,176 & 0,002 & 0,008 & 608,683 \\
0,190 & 0,002 & 0,009 & 820,779 \\
0,234 & 0,003 & 0,013 & 1435,624 \\
0,291 & 0,007 & 0,022 & 2150,311 \\
0,317 & 0,013 & 0,040 & 3282,920 \\
\hline & & & \\
a-Fenilglicina & & & \\
\hline$X$ & $Y$ & $Z$ & $\int_{0}^{t}\left[A_{\text {pgly }}^{-}\right] d t$ \\
Ec. $(5.70)$ & Ec. $(5.72)$ & Ec. $(5.74)$ & \\
\hline 0,000 & 0,000 & 0,000 & 0,000 \\
0,023 & 0,000 & 0,001 & 244,352 \\
0,082 & 0,000 & 0,004 & 697,788 \\
0,110 & 0,001 & 0,005 & 1290,896 \\
0,120 & 0,001 & 0,006 & 1752,804 \\
0,154 & 0,001 & 0,008 & 3102,227 \\
0,207 & 0,003 & 0,012 & 4681,720 \\
0,233 & 0,004 & 0,015 & 7196,602 \\
0,263 & 0,006 & 0,019 & 10010,951 \\
0,279 & 0,007 & 0,022 & 12326,194 \\
0,294 & 0,009 & 0,026 & 14813,656 \\
0,296 & 0,009 & 0,027 & 17270,133 \\
\hline
\end{tabular}

e) Experimento II $\left(\mathrm{pH}_{\mathrm{i}}=\mathbf{1 2 , 0 2} \pm 0,02 ; \mathrm{C}_{\mathrm{A}(\text { asp })}=\mathbf{7 , 6 5} \mathrm{mol} / \mathrm{m}^{3} ; \mathrm{C}_{\mathrm{A}(\mathrm{pgly}) \mathrm{i}}=\mathbf{8 , 1 0} \mathrm{mol} / \mathrm{m}^{3}\right)$

e1) Ácido aspártico

\begin{tabular}{cccc}
\hline$X$ & $Y$ & $Z$ & \\
Ec. $(5.69)$ & Ec. $(5.71)$ & Ec. $(5.73)$ & $\int_{0}^{t}\left[A_{\text {asp }}^{2-}\right] d t$ \\
\hline 0,000 & 0,000 & 0,000 & 0,000 \\
0,180 & 0,002 & 0,011 & 431,587 \\
0,239 & 0,005 & 0,018 & 830,153 \\
0,255 & 0,006 & 0,020 & 1218,470 \\
\hline
\end{tabular}

e2) a-Fenilglicina

\begin{tabular}{cccc}
\hline$X$ & $Y$ & $Z$ & $\int_{0}^{t}\left[A_{\text {pgly }}^{-}\right] d t$ \\
Ec. $(5.70)$ & Ec. $(5.72)$ & Ec. $(5.74)$ & 0,000 \\
\hline 0,000 & 0,000 & 0,000 & 464,026 \\
0,078 & 0,001 & 0,009 & 903,386 \\
0,089 & 0,001 & 0,010 & 1339,322 \\
0,090 & 0,001 & 0,011 & 2188,927 \\
0,129 & 0,003 & 0,019 & 4219,733 \\
0,158 & 0,006 & 0,033 & 6202,177 \\
0,164 & 0,008 & 0,051 & \\
\hline
\end{tabular}




\section{APÉnDICE C. Extracción de aminoácidos en lechos fijos de RIE}

TABLAS A. Curvas de ruptura de extracción de ácido aspártico. (Apartado 5.4.1)

Tabla A1. Datos experimentales de extracción de ácido aspártico en columna rellena de RIE para el experimento I de la Tabla 7 . $\left(\mathrm{pH}_{\mathrm{i}}=5,05 ; \mathrm{C}_{\mathrm{A}(\mathrm{asp}) \mathrm{i}}=7,40 \mathrm{~mol} / \mathrm{m}^{3} ; \mathrm{Q}=0,022 \times 10^{-6} \mathrm{~m}^{3} / \mathrm{s}\right.$; $\left.\left[\overline{\mathrm{Q}^{+} \mathrm{Cl}^{-}}\right]_{\mathrm{i}}=773,72 \pm 3,78 \mathrm{~mol} / \mathrm{m}^{3} \mathrm{RSI}\right)$.

\begin{tabular}{ccccc}
\hline $\mathrm{t}(\mathrm{s})$ & $\mathrm{VL}$ & $\mathrm{C}_{\mathrm{A}(\text { asp })} / \mathrm{C}_{\mathrm{A} \text { (asp)i }}$ & {$\left[\mathrm{A}^{2-}{ }_{\text {asp }}\right] /\left[\mathrm{A}^{2-}{ }_{\text {asp }}\right] \mathrm{i}$} & $\mathrm{pH} / \mathrm{pH} \mathrm{H}_{\mathrm{i}}$ \\
\hline 400 & 1,378 & 0,130 & 0,081 & 0,802 \\
1010 & 3,480 & 0,209 & 0,129 & 0,800 \\
1619 & 5,578 & 0,277 & 0,193 & 0,826 \\
2233 & 7,693 & 0,348 & 0,273 & 0,859 \\
2827 & 9,740 & 0,400 & 0,330 & 0,877 \\
3437 & 11,842 & 0,471 & 0,425 & 0,917 \\
3773 & 13,125 & 0,524 & 0,485 & 0,933 \\
4354 & 15,246 & 0,645 & 0,632 & 0,976 \\
4644 & 16,491 & 0,740 & 0,737 & 0,994 \\
5225 & 18,341 & 0,806 & 0,812 & 1,010 \\
5515 & 19,242 & 0,838 & 0,841 & 1,006 \\
5805 & 20,312 & 0,873 & 0,878 & 1,008 \\
6531 & 22,500 & 0,917 & 0,924 & 1,010 \\
7256 & 25,413 & 0,942 & 0,947 & 1,006 \\
8708 & 30,012 & 0,957 & 0,965 & 1,012 \\
11610 & 40,001 & 0,957 & 0,970 & 1,020 \\
\hline
\end{tabular}


Tabla A2. Datos experimentales de extracción de ácido aspártico en columna rellena de RIE para el experimento II de la Tabla 7. $\left(\mathbf{p H}_{\mathrm{i}}=10,99 ; \mathrm{C}_{\mathrm{A}(\text { asp })}=7,55 \mathrm{~mol} / \mathrm{m}^{3} ; \mathrm{Q}=0,022 \times 10^{-6}\right.$ $\left.\left.\mathrm{m}^{3} / \mathrm{s} ; \overline{\mathrm{Q}^{+} \mathrm{Cl}^{-}}\right]_{\mathrm{i}}=773,72 \pm 3,78 \mathrm{~mol} / \mathrm{m}^{3} \mathrm{RSI}\right)$.

\begin{tabular}{|c|c|c|c|c|}
\hline $\mathrm{t}(\mathrm{s})$ & VL & $\mathrm{C}_{\mathrm{A}(\text { asp })} / \mathrm{C}_{\mathrm{A} \text { (asp) } \mathrm{i}}$ & {$\left[\mathrm{A}^{2-}{ }_{\text {asp }}\right] /\left[\mathrm{A}_{\text {asp }}^{2-}\right] \mathrm{i}$} & $\mathrm{pH} / \mathrm{pH}_{\mathrm{i}}$ \\
\hline 750 & 1,003 & 0,023 & 0,020 & 0,953 \\
\hline 1353 & 2,094 & 0,004 & 0,002 & 0,911 \\
\hline 1954 & 3,180 & 0,008 & 0,004 & 0,886 \\
\hline 2564 & 4,283 & 0,020 & 0,004 & 0,838 \\
\hline 3166 & 5,372 & 0,049 & 0,006 & 0,810 \\
\hline 4301 & 7,424 & 0,115 & 0,006 & 0,775 \\
\hline 4916 & 8,536 & 0,102 & 0,008 & 0,794 \\
\hline 5499 & 9,590 & 0,088 & 0,011 & 0,813 \\
\hline 6907 & 12,136 & 0,074 & 0,010 & 0,817 \\
\hline 7533 & 13,267 & 0,072 & 0,012 & 0,826 \\
\hline 8120 & 14,329 & 0,073 & 0,014 & 0,832 \\
\hline 9019 & 15,954 & 0,076 & 0,015 & 0,833 \\
\hline 9917 & 17,578 & 0,079 & 0,014 & 0,830 \\
\hline 10809 & 19,191 & 0,083 & 0,015 & 0,831 \\
\hline 11722 & 20,841 & 0,082 & 0,016 & 0,833 \\
\hline 12605 & 22,438 & 0,094 & 0,028 & 0,855 \\
\hline 13511 & 24,076 & 0,082 & 0,037 & 0,879 \\
\hline 14407 & 25,696 & 0,209 & 0,155 & 0,924 \\
\hline 15998 & 28,572 & 0,500 & 0,476 & 0,975 \\
\hline 17199 & 30,744 & 0,663 & 0,649 & 0,988 \\
\hline 18242 & 32,630 & 0,741 & 0,731 & 0,991 \\
\hline 19149 & 34,270 & 0,790 & 0,783 & 0,995 \\
\hline 20054 & 35,906 & 0,830 & 0,825 & 0,996 \\
\hline 20960 & 37,544 & 0,860 & 0,857 & 0,997 \\
\hline 21857 & 39,166 & 0,887 & 0,886 & 0,999 \\
\hline 22768 & 40,813 & 0,905 & 0,905 & 1,000 \\
\hline 23668 & 42,440 & 0,926 & 0,927 & 1,000 \\
\hline 24581 & 44,091 & 0,946 & 0,949 & 1,001 \\
\hline 25826 & 46,342 & 0,967 & 0,967 & 1,000 \\
\hline 26720 & 47,958 & 0,975 & 0,975 & 1,000 \\
\hline 27817 & 49,942 & 0,996 & 0,994 & 0,999 \\
\hline 28703 & 51,544 & 1,005 & 1,003 & 0,999 \\
\hline 29610 & 53,183 & 1,014 & 1,013 & 0,999 \\
\hline 30708 & 55,169 & 1,024 & 1,024 & 1,000 \\
\hline 32438 & 58,297 & 1,033 & 1,033 & 1,000 \\
\hline
\end{tabular}


Tabla A3. Datos experimentales de extracción de ácido aspártico en columna rellena de RIE para el experimento III de la Tabla 7. $\left(\mathbf{p H}_{\mathrm{i}}=\mathbf{1 1 , 2 4} ; \mathrm{C}_{\mathrm{A}(\text { asp })}=7,29 \mathrm{~mol} / \mathrm{m}^{3} ; \mathbf{Q}=\mathbf{0 , 0 1 7 \times 1 0 ^ { - 6 }}\right.$ $\left.\mathrm{m}^{3} / \mathrm{s} ; \overline{\mathrm{Q}^{+} \mathrm{Cl}^{-}}{ }_{\mathrm{i}}=773,72 \pm 3,78 \mathrm{~mol} / \mathrm{m}^{3} \mathrm{RSI}\right)$.

\begin{tabular}{|c|c|c|c|c|}
\hline $\mathrm{t}(\mathrm{s})$ & VL & $\mathrm{C}_{\mathrm{A}(\text { asp })} / \mathrm{C}_{\mathrm{A}(\mathrm{asp}) \mathrm{i}}$ & {$\left[\mathrm{A}^{2-}{ }_{\text {asp }}\right] /\left[\mathrm{A}_{\text {asp }}^{2-}\right] \mathrm{i}$} & $\mathrm{pH} / \mathrm{pH}_{\mathrm{i}}$ \\
\hline 935 & 1,006 & 0,000 & 0,000 & 0,936 \\
\hline 1578 & 1,589 & 0,011 & 0,007 & 0,887 \\
\hline 2226 & 2,527 & 0,011 & 0,005 & 0,866 \\
\hline 2880 & 3,473 & 0,012 & 0,006 & 0,872 \\
\hline 3606 & 4,524 & 0,014 & 0,008 & 0,886 \\
\hline 4211 & 5,399 & 0,014 & 0,010 & 0,906 \\
\hline 5107 & 6,696 & 0,013 & 0,011 & 0,931 \\
\hline 5990 & 7,973 & 0,014 & 0,012 & 0,948 \\
\hline 6665 & 8,950 & 0,015 & 0,014 & 0,944 \\
\hline 7324 & 9,904 & 0,015 & 0,013 & 0,943 \\
\hline 8212 & 11,189 & 0,015 & 0,013 & 0,948 \\
\hline 8972 & 12,289 & 0,016 & 0,015 & 0,948 \\
\hline 9686 & 13,322 & 0,015 & 0,014 & 0,952 \\
\hline 10558 & 14,584 & 0,017 & 0,016 & 0,955 \\
\hline 11412 & 15,819 & 0,020 & 0,018 & 0,947 \\
\hline 12309 & 17,117 & 0,024 & 0,022 & 0,951 \\
\hline 13500 & 18,841 & 0,032 & 0,030 & 0,952 \\
\hline 14284 & 19,975 & 0,031 & 0,029 & 0,955 \\
\hline 15400 & 21,590 & 0,051 & 0,047 & 0,958 \\
\hline 16382 & 23,011 & 0,086 & 0,081 & 0,963 \\
\hline 16995 & 23,898 & 0,109 & 0,104 & 0,968 \\
\hline 18000 & 25,353 & 0,205 & 0,200 & 0,979 \\
\hline 18600 & 26,221 & 0,265 & 0,259 & 0,979 \\
\hline 19440 & 27,436 & 0,329 & 0,323 & 0,983 \\
\hline 20460 & 28,912 & 0,438 & 0,433 & 0,988 \\
\hline 21180 & 29,954 & 0,484 & 0,478 & 0,987 \\
\hline 22036 & 31,193 & 0,575 & 0,569 & 0,989 \\
\hline 22974 & 32,550 & 0,631 & 0,624 & 0,989 \\
\hline 23760 & 33,688 & 0,709 & 0,704 & 0,992 \\
\hline 24559 & 34,844 & 0,743 & 0,737 & 0,992 \\
\hline 25320 & 35,945 & 0,781 & 0,776 & 0,993 \\
\hline 26280 & 37,334 & 0,834 & 0,831 & 0,996 \\
\hline 27006 & 38,385 & 0,864 & 0,862 & 0,998 \\
\hline 27720 & 39,418 & 0,885 & 0,882 & 0,997 \\
\hline 28626 & 40,729 & 0,893 & 0,889 & 0,994 \\
\hline 29100 & 41,415 & 0,917 & 0,909 & 0,992 \\
\hline
\end{tabular}


Tabla A4. Datos experimentales de extracción de ácido aspártico en columna rellena de RIE para el experimento IV de la Tabla 7. $\left(\mathbf{p H}_{\mathrm{i}}=\mathbf{1 2 , 0 5} ; \mathrm{C}_{\mathrm{A}(\text { asp })}=7,57 \mathrm{~mol} / \mathrm{m}^{3} ; \mathbf{Q}=\mathbf{0 , 0 2 3 \times 1 0 ^ { - 6 }}\right.$ $\left.\left.\mathrm{m}^{3} / \mathrm{s} ; \overline{\mathrm{Q}^{+} \mathrm{Cl}^{-}}\right]_{\mathrm{i}}=773,72 \pm 3,78 \mathrm{~mol} / \mathrm{m}^{3} \mathrm{RSI}\right)$.

\begin{tabular}{|c|c|c|c|c|}
\hline $\mathrm{t}(\mathrm{s})$ & VL & $\mathrm{C}_{\mathrm{A}(\text { asp })} / \mathrm{C}_{\mathrm{A}(\text { asp }) \mathrm{i}}$ & {$\left[\mathrm{A}_{\text {asp }}^{2-}\right] /\left[\mathrm{A}_{\text {asp }}^{2-}\right] \mathrm{i}$} & $\mathrm{pH} / \mathrm{pH}_{\mathrm{i}}$ \\
\hline 573 & 1,005 & 0,005 & 0,002 & 0,805 \\
\hline 1191 & 2,213 & 0,004 & 0,001 & 0,781 \\
\hline 1821 & 3,445 & 0,007 & 0,007 & 0,936 \\
\hline 2430 & 4,635 & 0,010 & 0,010 & 0,990 \\
\hline 3047 & 5,841 & 0,012 & 0,012 & 0,998 \\
\hline 3740 & 7,196 & 0,012 & 0,012 & 0,999 \\
\hline 4452 & 8,588 & 0,013 & 0,013 & 1,000 \\
\hline 5087 & 9,829 & 0,014 & 0,014 & 1,000 \\
\hline 5700 & 11,028 & 0,014 & 0,014 & 1,001 \\
\hline 7204 & 13,968 & 0,013 & 0,013 & 1,001 \\
\hline 8072 & 15,665 & 0,015 & 0,015 & 0,999 \\
\hline 8754 & 16,998 & 0,013 & 0,013 & 1,000 \\
\hline 9602 & 18,656 & 0,014 & 0,014 & 1,000 \\
\hline 10504 & 20,419 & 0,017 & 0,017 & 1,001 \\
\hline 11401 & 22,173 & 0,041 & 0,041 & 1,001 \\
\hline 12302 & 23,934 & 0,145 & 0,145 & 1,000 \\
\hline 13216 & 25,721 & 0,326 & 0,326 & 1,000 \\
\hline 14119 & 27,486 & 0,476 & 0,476 & 1,001 \\
\hline 15323 & 29,840 & 0,625 & 0,625 & 1,000 \\
\hline 16219 & 31,591 & 0,687 & 0,687 & 1,002 \\
\hline 17132 & 33,376 & 0,747 & 0,747 & 1,000 \\
\hline 18030 & 35,132 & 0,800 & 0,800 & 1,000 \\
\hline 18935 & 36,901 & 0,843 & 0,843 & 0,999 \\
\hline 19742 & 38,479 & 0,875 & 0,875 & 0,997 \\
\hline 21006 & 40,950 & 0,906 & 0,905 & 0,998 \\
\hline 22222 & 43,327 & 0,940 & 0,941 & 1,001 \\
\hline 23421 & 45,671 & 0,960 & 0,960 & 1,002 \\
\hline 24640 & 48,054 & 0,974 & 0,975 & 1,000 \\
\hline 25765 & 50,253 & 0,986 & 0,987 & 1,001 \\
\hline 27162 & 52,984 & 1,000 & 1,001 & 1,002 \\
\hline 28884 & 56,350 & 1,010 & 1,010 & 1,001 \\
\hline
\end{tabular}


Tabla A5. Datos experimentales de extracción de ácido aspártico en columna rellena de

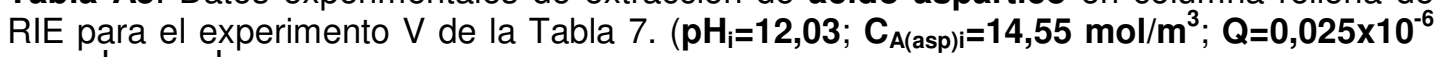
$\left.\mathrm{m}^{3} / \mathrm{s} ; \overline{\mathrm{Q}^{+} \mathrm{Cl}^{-}}{ }_{\mathrm{i}}=773,72 \pm 3,78 \mathrm{~mol} / \mathrm{m}^{3} \mathrm{RSI}\right)$.

\begin{tabular}{ccccc}
\hline $\mathrm{t}(\mathrm{s})$ & $\mathrm{VL}$ & $\mathrm{C}_{\mathrm{A}(\text { asp })} / \mathrm{C}_{\mathrm{A}(\text { asp }) \mathrm{i}}$ & {$\left[\mathrm{A}^{2-}{ }_{\text {asp }}\right] /\left[\mathrm{A}^{2-}{ }_{\text {asp }}\right] \mathrm{i}$} & $\mathrm{pH} / \mathrm{pH}_{\mathrm{i}}$ \\
\hline 552 & & 0,007 & 0,003 & 0,806 \\
1129 & 1,006 & 0,001 & 0,001 & 0,865 \\
1685 & 2,366 & 0,004 & 0,004 & 0,985 \\
2298 & 3,532 & 0,009 & 0,009 & 0,993 \\
2906 & 4,817 & 0,015 & 0,015 & 0,991 \\
3515 & 6,091 & 0,018 & 0,018 & 0,994 \\
4090 & 7,368 & 0,039 & 0,039 & 0,991 \\
4660 & 8,573 & 0,099 & 0,099 & 0,994 \\
5529 & 9,768 & 0,284 & 0,284 & 0,994 \\
6190 & 11,589 & 0,426 & 0,426 & 0,992 \\
6835 & 12,975 & 0,539 & 0,539 & 0,992 \\
7551 & 14,327 & 0,639 & 0,639 & 0,995 \\
8692 & 15,828 & 0,745 & 0,745 & 0,995 \\
9242 & 18,219 & 0,785 & 0,785 & 0,994 \\
9899 & 19,372 & 0,833 & 0,832 & 0,995 \\
10443 & 20,749 & 0,865 & 0,864 & 0,993 \\
11342 & 21,889 & 0,883 & 0,882 & 0,995 \\
12230 & 23,774 & 0,896 & 0,896 & 0,994 \\
13102 & 25,635 & 0,928 & 0,927 & 0,995 \\
14065 & 27,463 & 0,941 & 0,940 & 0,995 \\
14983 & 29,481 & 0,950 & 0,949 & 0,995 \\
16174 & 31,406 & 0,965 & 0,965 & 0,997 \\
17335 & 33,902 & 0,989 & 0,988 & 0,995 \\
18274 & 36,336 & 0,999 & 0,995 \\
\hline
\end{tabular}


Tabla A6. Datos experimentales de extracción de ácido aspártico en columna rellena de RIE para el experimento VI de la Tabla $7 .\left(p_{i}=12,08 ; C_{A(a s p) i}=15,00 ~ m o l / m^{3} ; Q=0,022 \times 10^{-6}\right.$ $\left.\left.\mathrm{m}^{3} / \mathrm{s} ; \overline{\mathrm{Q}^{+} \mathrm{Cl}^{-}}\right]_{\mathrm{i}}=618,00 \pm 0,39 \mathrm{~mol} / \mathrm{m}^{3} \mathrm{RSI}\right)$.

\begin{tabular}{ccccc}
\hline $\mathrm{t}(\mathrm{s})$ & $\mathrm{VL}$ & $\mathrm{C}_{\mathrm{A}(\text { asp })} / \mathrm{C}_{\mathrm{A}(\text { asp }) \mathrm{i}}$ & {$\left[\mathrm{A}^{2-}{ }_{\text {asp }}\right] /\left[\mathrm{A}^{2-}{ }_{\text {asp }}\right] \mathrm{i}$} & $\mathrm{pH} / \mathrm{pH}_{\mathrm{i}}$ \\
\hline 624 & & 0,001 & 0,001 & 0,900 \\
1315 & 1,011 & 0,005 & 0,005 & 0,957 \\
1858 & 2,334 & 0,008 & 0,008 & 0,995 \\
2460 & 3,373 & 0,016 & 0,016 & 1,000 \\
3138 & 4,526 & 0,059 & 0,059 & 0,999 \\
3746 & 5,824 & 0,211 & 0,211 & 1,000 \\
4376 & 6,988 & 0,394 & 0,394 & 1,000 \\
4930 & 8,194 & 0,565 & 0,565 & 0,995 \\
5571 & 9,254 & 0,682 & 0,682 & 0,998 \\
6314 & 10,481 & 0,781 & 0,781 & 0,997 \\
6918 & 11,904 & 0,840 & 0,840 & 0,998 \\
7522 & 13,060 & 0,872 & 0,872 & 1,000 \\
8156 & 14,216 & 0,909 & 0,908 & 0,997 \\
8825 & 15,430 & 0,920 & 0,920 & 1,000 \\
9426 & 16,711 & 0,937 & 0,937 & 0,998 \\
10125 & 17,862 & 0,959 & 0,959 & 0,999 \\
10750 & 19,200 & 0,961 & 0,961 & 0,997 \\
11401 & 20,396 & 0,974 & 0,973 & 0,996 \\
12007 & 21,643 & 0,980 & 0,980 & 1,000 \\
12615 & 22,803 & 0,988 & 0,987 & 0,994 \\
13530 & 23,967 & 0,995 & 0,995 & 1,000 \\
14633 & 25,718 & 1,000 & 0,999 & 0,996 \\
\hline
\end{tabular}

Tabla A7. Datos experimentales de extracción de ácido aspártico en columna rellena de RIE para el experimento VII de la Tabla 7 . $\left(\mathrm{pH}_{\mathrm{i}}=\mathbf{1 2 , 0 3} ; \mathrm{C}_{\mathrm{A}(\text { asp }) \mathrm{i}}=15,72 \mathrm{~mol} / \mathrm{m}^{3} ; \mathrm{Q}=\mathbf{0 , 0 6 3 \times 1 0 ^ { - 6 }}\right.$ $\left.\left.\mathrm{m}^{3} / \mathrm{s} ; \overline{\mathrm{Q}^{+} \mathrm{Cl}^{-}}\right]_{\mathrm{i}}=618,00 \pm 0,39 \mathrm{~mol} / \mathrm{m}^{3} \mathrm{RSI}\right)$.

\begin{tabular}{ccccc}
\hline $\mathrm{t}(\mathrm{s})$ & $\mathrm{VL}$ & $\mathrm{C}_{\mathrm{A}(\text { asp })} / \mathrm{C}_{\mathrm{A}(\text { asp }) \mathrm{i}}$ & {$\left[\mathrm{A}^{2-}{ }_{\text {asp }}\right] /\left[\mathrm{A}^{2-}{ }_{\text {asp }}\right] \mathrm{i}$} & $\mathrm{pH} / \mathrm{pH} \mathrm{i}_{\mathrm{i}}$ \\
\hline 208 & 1,003 & 0,055 & 0,031 & 0,823 \\
529 & 2,735 & 0,070 & 0,069 & 0,990 \\
892 & 4,693 & 0,179 & 0,179 & 0,997 \\
1441 & 7,655 & 0,501 & 0,501 & 0,997 \\
2041 & 10,891 & 0,715 & 0,714 & 0,998 \\
2641 & 14,128 & 0,850 & 0,850 & 0,998 \\
3243 & 17,375 & 0,936 & 0,935 & 0,996 \\
3849 & 20,644 & 0,955 & 0,955 & 0,997 \\
4484 & 24,070 & 0,980 & 0,980 & 1,000 \\
5057 & 27,161 & 0,990 & 0,990 & 0,999 \\
5655 & 30,387 & 0,991 & 0,991 & 1,000 \\
6402 & 34,416 & 0,996 & 0,995 & 0,998 \\
7230 & 38,883 & 0,997 & 0,996 & 0,996 \\
\hline
\end{tabular}


TABLAS B. Curvas de ruptura de extracción y reextracción de ácido aspártico.

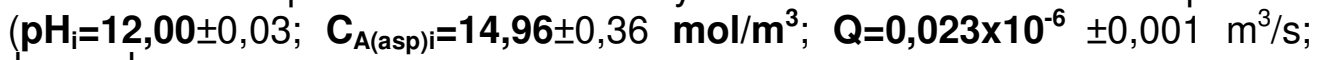
$\left[\overline{\mathrm{Q}^{+} \mathrm{Cl}^{-}}\right]_{\mathrm{i}}=\mathbf{7 7 1 , 7 5} \mathrm{mol} / \mathrm{m}^{3} \mathrm{RSI}$ ). (Apartado 5.4.1.1).

Tabla B1. Datos experimentales de $1^{\text {er }}$ ciclo de extracción de ácido aspártico para el experimento I-a de la Tabla 9.

\begin{tabular}{ccc}
\hline $\mathrm{t}(\mathrm{s})$ & $\mathrm{VL}$ & $\mathrm{C}_{\mathrm{A}(\text { asp })} / \mathrm{C}_{\mathrm{A}(\text { asp }) \mathrm{i}}$ \\
\hline 552 & 1,006 & 0,007 \\
1129 & 2,366 & 0,001 \\
1685 & 3,532 & 0,004 \\
2298 & 4,817 & 0,009 \\
2906 & 6,091 & 0,015 \\
3515 & 7,368 & 0,018 \\
4090 & 8,573 & 0,039 \\
4660 & 9,768 & 0,099 \\
5529 & 11,589 & 0,284 \\
6190 & 12,975 & 0,426 \\
6835 & 14,327 & 0,539 \\
7551 & 15,828 & 0,639 \\
8692 & 18,219 & 0,745 \\
9242 & 19,372 & 0,785 \\
9899 & 20,749 & 0,833 \\
10443 & 21,889 & 0,865 \\
11342 & 23,774 & 0,883 \\
12230 & 25,635 & 0,896 \\
13102 & 27,463 & 0,928 \\
14065 & 29,481 & 0,941 \\
14983 & 31,406 & 0,950 \\
16174 & 33,902 & 0,965 \\
17335 & 36,336 & 0,989 \\
\hline
\end{tabular}


Tabla B2. Datos experimentales de $2^{\circ}$ ciclo de extracción de ácido aspártico para el experimento I-b de la Tabla 9.

\begin{tabular}{ccc}
\hline $\mathrm{t}(\mathrm{s})$ & $\mathrm{VL}$ & $\mathrm{C}_{\mathrm{A}(\text { asp })} / \mathrm{C}_{\mathrm{A} \text { (asp)i }}$ \\
\hline 620 & 1,054 & 0,011 \\
1037 & 1,884 & 0,022 \\
1642 & 3,088 & 0,004 \\
2242 & 4,281 & 0,006 \\
2840 & 5,471 & 0,012 \\
3441 & 6,667 & 0,011 \\
4042 & 7,863 & 0,016 \\
4656 & 9,084 & 0,069 \\
5416 & 10,596 & 0,321 \\
6052 & 11,861 & 0,520 \\
6766 & 13,282 & 0,646 \\
7340 & 14,424 & 0,710 \\
8030 & 15,797 & 0,773 \\
8745 & 17,219 & 0,823 \\
9670 & 19,060 & 0,853 \\
10499 & 20,709 & 0,887 \\
11584 & 22,867 & 0,914 \\
12424 & 24,539 & 0,942 \\
13375 & 26,431 & 0,959 \\
14226 & 28,124 & 0,964 \\
15302 & 30,264 & 0,976 \\
16202 & 32,055 & 0,982 \\
17133 & 33,907 & 0,990 \\
18079 & 35,789 & 0,991 \\
18922 & 37,466 & 0,998 \\
\hline
\end{tabular}

Tabla B3. Datos experimentales de $3^{\text {er }}$ ciclo de extracción de ácido aspártico para el experimento I-c de la Tabla 9.

\begin{tabular}{ccc}
\hline $\mathrm{t}(\mathrm{s})$ & $\mathrm{VL}$ & $\mathrm{C}_{\mathrm{A} \text { (asp) }} / \mathrm{C}_{\mathrm{A} \text { (asp) } \mathrm{i}}$ \\
\hline 1142 & 1,931 & 0,001 \\
1752 & 3,168 & 0,005 \\
2375 & 4,432 & 0,008 \\
2979 & 5,657 & 0,009 \\
3600 & 6,917 & 0,009 \\
4221 & 8,176 & 0,015 \\
4846 & 9,444 & 0,113 \\
5450 & 10,669 & 0,355 \\
6052 & 11,890 & 0,566 \\
6681 & 13,166 & 0,690 \\
7320 & 14,462 & 0,763 \\
7907 & 15,652 & 0,809 \\
8668 & 17,196 & 0,853 \\
9517 & 18,918 & 0,882 \\
10361 & 20,630 & 0,908 \\
11300 & 22,535 & 0,929 \\
12187 & 24,334 & 0,945 \\
13085 & 26,155 & 0,955 \\
14004 & 28,019 & 0,967 \\
14889 & 29,814 & 0,973 \\
15945 & 31,956 & 0,984 \\
17105 & 34,309 & 0,986 \\
18000 & 36,124 & 0,989 \\
18931 & 38,013 & 0,999 \\
\hline
\end{tabular}


Tabla B4. Datos experimentales de $1^{\text {er }}$ ciclo de reextracción de ácido aspártico para el experimento I-a de la Tabla 9.

\begin{tabular}{ccc}
\hline $\mathrm{t}(\mathrm{s})$ & $\mathrm{VL}$ & $\mathrm{C}_{\mathrm{A} \text { (asp) }}$ \\
\hline 843 & 1,567 & 39,073 \\
1449 & 2,694 & 130,876 \\
2054 & 3,818 & 6,261 \\
2656 & 4,937 & 4,937 \\
3256 & 6,053 & 5,354 \\
3871 & 7,196 & 4,856 \\
4244 & 7,890 & 2,346 \\
5090 & 9,462 & 1,307 \\
5701 & 10,598 & 0,965 \\
6304 & 11,719 & 1,019 \\
6937 & 12,896 & 2,325 \\
7348 & 13,660 & 1,524 \\
7940 & 14,760 & 0,096 \\
8558 & 15,909 & 0,044 \\
9286 & 17,263 & 0,000 \\
9859 & 18,328 & 0,007 \\
10537 & 19,588 & 0,005 \\
11267 & 20,945 & 0,003 \\
12258 & 22,787 & 0,007 \\
13295 & 24,715 & 0,001 \\
\hline
\end{tabular}

Tabla B5. Datos experimentales de $2^{\circ}$ ciclo de reextracción de ácido aspártico para el experimento I-b de la Tabla 9.

\begin{tabular}{ccc}
\hline $\mathrm{t}(\mathrm{s})$ & $\mathrm{VL}$ & $\mathrm{C}_{\mathrm{A} \text { (asp) }}$ \\
\hline 852 & 1,477 & 31,810 \\
1463 & 2,714 & 114,700 \\
2068 & 3,939 & 11,655 \\
2671 & 5,159 & 4,590 \\
3328 & 6,489 & 4,018 \\
3935 & 7,717 & 1,321 \\
4536 & 8,934 & 1,174 \\
5137 & 10,150 & 2,585 \\
5764 & 11,419 & 0,893 \\
6532 & 12,973 & 2,264 \\
6893 & 13,704 & 3,437 \\
7590 & 15,115 & 1,119 \\
7992 & 15,928 & 0,045 \\
8889 & 17,744 & 0,005 \\
9808 & 19,604 & 0,003 \\
10629 & 21,265 & 0,002 \\
11646 & 23,324 & 0,134 \\
12770 & 25,599 & 0,217 \\
\hline
\end{tabular}


TABLAS C. Curvas de ruptura de extracción de ácido aspártico y de a-fenilglicina de sus mezclas binarias $\left(\mathrm{pH}_{\mathrm{i}}=12,01 \pm 0,07 ; \mathrm{Q}=0,018 \times 10^{-6} \mathrm{~m}^{3} / \mathrm{s}\right)$ (Apartado 5.4.2).

Tabla C1. Datos experimentales de extracción de ácido aspártico y a-fenilglicina de sus mezclas binarias en columna rellenas de RIE para el experimento I de la Tabla 8. $\left.\left(\mathrm{C}_{\mathrm{A}(\text { asp })} / \mathrm{C}_{\mathrm{A}(\text { pgly) })}=\mathbf{1} / \mathbf{1} ; \overline{\mathrm{Q}^{+} \mathrm{Cl}^{-}}\right]_{\mathrm{i}}=787,62 \mathrm{~mol} / \mathrm{m}^{3} \mathrm{RSI}\right)$.

\begin{tabular}{|c|c|c|c|c|c|c|}
\hline $\mathrm{t}(\mathrm{s})$ & VL & $\begin{array}{l}\left.\mathrm{C}_{\mathrm{A}(\text { asp }}\right) \\
\mathrm{C}_{\mathrm{A} \text { (asp) } \mathrm{i}}\end{array}$ & $\begin{array}{l}{\left[\mathrm{A}^{2-}{ }^{2-}{ }_{\text {asp }}\right] /} \\
{\left[\mathrm{A}^{2-}{ }_{\text {asp }}\right] \mathrm{i}}\end{array}$ & $\begin{array}{l}\mathrm{C}_{\mathrm{A}(\mathrm{pgly} y)} / \\
\mathrm{C}_{\mathrm{A}(\mathrm{pgly}) \mathrm{i}}\end{array}$ & $\begin{array}{l}{\left[\mathrm{A}_{\text {pgly }}^{-}\right] /} \\
{\left[\mathrm{A}_{\mathrm{pgly}}^{-}\right] \mathrm{i}}\end{array}$ & $\mathrm{pH} / \mathrm{pH}_{\mathrm{i}}$ \\
\hline 281 & 0,703 & 0,000 & 0,000 & 0,026 & 0,000 & 0,581 \\
\hline 963 & 2,410 & 0,000 & 0,000 & 0,007 & 0,007 & 0,939 \\
\hline 1943 & 4,862 & 0,000 & 0,000 & 0,022 & 0,022 & 0,986 \\
\hline 2563 & 6,414 & 0,028 & 0,028 & 0,057 & 0,057 & 0,993 \\
\hline 3219 & 8,055 & 0,028 & 0,028 & 0,115 & 0,115 & 0,994 \\
\hline 3882 & 9,714 & 0,020 & 0,020 & 0,191 & 0,191 & 0,996 \\
\hline 4713 & 11,794 & 0,115 & 0,115 & 0,299 & 0,299 & 0,995 \\
\hline 5363 & 13,421 & 0,188 & 0,188 & 0,362 & 0,362 & 0,993 \\
\hline 6081 & 15,217 & 0,369 & 0,369 & 0,449 & 0,449 & 0,992 \\
\hline 6653 & 16,649 & 0,488 & 0,487 & 0,493 & 0,493 & 0,993 \\
\hline 7343 & 18,375 & 0,632 & 0,631 & 0,545 & 0,545 & 0,992 \\
\hline 8010 & 20,045 & 0,732 & 0,731 & 0,589 & 0,589 & 0,992 \\
\hline 8673 & 21,704 & 0,804 & 0,803 & 0,630 & 0,630 & 0,993 \\
\hline 9473 & 23,706 & 0,866 & 0,864 & 0,670 & 0,670 & 0,991 \\
\hline 10243 & 25,632 & 0,919 & 0,918 & 0,720 & 0,720 & 0,993 \\
\hline 11068 & 27,697 & 0,953 & 0,952 & 0,766 & 0,766 & 0,992 \\
\hline 11703 & 29,286 & 0,973 & 0,972 & 0,798 & 0,798 & 0,993 \\
\hline 12393 & 31,013 & 0,983 & 0,982 & 0,819 & 0,819 & 0,993 \\
\hline 13113 & 32,814 & 0,987 & 0,986 & 0,845 & 0,845 & 0,992 \\
\hline 14018 & 35,079 & 1,014 & 1,013 & 0,893 & 0,893 & 0,993 \\
\hline 14798 & 37,031 & 1,025 & 1,023 & 0,918 & 0,918 & 0,993 \\
\hline 15544 & 38,898 & 1,014 & 1,013 & 0,928 & 0,928 & 0,993 \\
\hline 16421 & 41,093 & 1,017 & 1,016 & 0,939 & 0,938 & 0,993 \\
\hline 17346 & 43,407 & 1,028 & 1,027 & 0,962 & 0,962 & 0,993 \\
\hline 18273 & 45,727 & 1,022 & 1,021 & 0,968 & 0,968 & 0,992 \\
\hline 19241 & 48,149 & 1,036 & 1,035 & 0,989 & 0,989 & 0,993 \\
\hline 20493 & 51,282 & 1,042 & 1,041 & 1,007 & 1,007 & 0,993 \\
\hline 21583 & 54,010 & 1,028 & 1,027 & 1,003 & 1,002 & 0,993 \\
\hline 22733 & 56,888 & 1,046 & 1,045 & 1,023 & 1,023 & 0,993 \\
\hline 24700 & 61,810 & 1,033 & 1,032 & 1,014 & 1,014 & 0,993 \\
\hline
\end{tabular}

Tabla C2. Datos experimentales de extracción de ácido aspártico y a-fenilglicina de sus mezclas binarias en columna rellena de RIE para el experimento II de la Tabla 8. $\left.\left(\mathrm{C}_{\mathrm{A}(\text { asp })} / \mathrm{C}_{\mathrm{A}(\text { pgly) })}=\mathbf{2} / \mathbf{1} ; \quad \overline{\mathrm{Q}^{+} \mathrm{Cl}^{-}}\right]_{\mathrm{i}}=787,62 \mathrm{~mol} / \mathrm{m}^{3} \mathrm{RSI}\right)$.

\begin{tabular}{|c|c|c|c|c|c|c|}
\hline $\mathrm{t}(\mathrm{s})$ & VL & $\begin{array}{l}\left.\mathrm{C}_{\mathrm{A}(\mathrm{asp}}\right) \\
\mathrm{C}_{\mathrm{A}(\mathrm{asp}) \mathrm{i}}\end{array}$ & $\begin{array}{c}{\left[\mathrm{A}^{2-}{ }^{2-}\right] \mathrm{asp}} \\
{\left[\mathrm{A}^{2-}{ }_{\text {asp }}\right] \mathrm{i}}\end{array}$ & $\begin{array}{l}\mathrm{C}_{\mathrm{A}(\mathrm{pgly})} / \\
\mathrm{C}_{\mathrm{A}(\mathrm{pg} \mathrm{y}) \mathrm{i}}\end{array}$ & $\begin{array}{l}{\left[\mathrm{A}_{\mathrm{pgly}}^{-}\right] /} \\
{\left[\mathrm{A}_{\mathrm{pgly}}^{-}\right] \mathrm{i}}\end{array}$ & $\mathrm{pH} / \mathrm{pH}_{\mathrm{i}}$ \\
\hline 257 & 0,664 & 0,000 & 0,000 & 0,022 & 0,000 & 0,552 \\
\hline 957 & 2,472 & 0,023 & 0,022 & 0,008 & 0,008 & 0,944 \\
\hline 1556 & 4,019 & 0,029 & 0,029 & 0,021 & 0,021 & 0,987 \\
\hline
\end{tabular}


Tabla C2. (Continuación)

\begin{tabular}{ccccccc}
\hline $\mathrm{t}(\mathrm{s})$ & $\mathrm{VL}$ & $\begin{array}{c}\mathrm{C}_{\mathrm{A}(\text { asp })} / \\
\mathrm{C}_{\mathrm{A}(\text { asp }) \mathrm{i}}\end{array}$ & $\begin{array}{c}{\left[\mathrm{A}^{2-}{ }_{\text {asp }}\right] /} \\
{\left[\mathrm{A}^{2-}{ }_{\text {as }}\right] \mathrm{i}}\end{array}$ & $\begin{array}{c}\mathrm{C}_{\mathrm{A}(\mathrm{pgly})} / \\
\mathrm{C}_{\mathrm{A}(\mathrm{pgly}) \mathrm{i}}\end{array}$ & $\begin{array}{c}{\left[\mathrm{A}_{\mathrm{pgly}}^{-}\right] /} \\
{\left[\mathrm{A}_{\mathrm{pgly}}^{-}\right] \mathrm{i}}\end{array}$ & $\mathrm{pH} / \mathrm{pH}_{\mathrm{i}}$ \\
\hline 2206 & 5,697 & 0,066 & 0,066 & 0,053 & 0,053 & 0,988 \\
2946 & 7,608 & 0,148 & 0,148 & 0,108 & 0,108 & 0,990 \\
3462 & 8,941 & 0,262 & 0,261 & 0,158 & 0,158 & 0,990 \\
4080 & 10,537 & 0,426 & 0,425 & 0,216 & 0,216 & 0,991 \\
4681 & 12,089 & 0,550 & 0,549 & 0,264 & 0,264 & 0,991 \\
5332 & 13,771 & 0,717 & 0,716 & 0,331 & 0,331 & 0,992 \\
6015 & 15,535 & 0,804 & 0,803 & 0,410 & 0,410 & 0,990 \\
6614 & 17,082 & 0,871 & 0,870 & 0,453 & 0,453 & 0,992 \\
7336 & 18,946 & 0,909 & 0,908 & 0,506 & 0,506 & 0,993 \\
8170 & 21,100 & 0,935 & 0,934 & 0,558 & 0,557 & 0,993 \\
8880 & 22,934 & 0,969 & 0,968 & 0,616 & 0,616 & 0,992 \\
9595 & 24,780 & 0,990 & 0,988 & 0,669 & 0,668 & 0,992 \\
10269 & 26,521 & 1,003 & 1,002 & 0,717 & 0,716 & 0,992 \\
11043 & 28,520 & 1,011 & 1,010 & 0,775 & 0,775 & 0,993 \\
12018 & 31,038 & 1,017 & 1,016 & 0,822 & 0,822 & 0,993 \\
12910 & 33,342 & 1,028 & 1,027 & 0,874 & 0,874 & 0,993 \\
13761 & 35,540 & 1,013 & 1,012 & 0,903 & 0,903 & 0,993 \\
14506 & 37,464 & 1,027 & 1,026 & 0,937 & 0,937 & 0,993 \\
15454 & 39,912 & 1,034 & 1,033 & 0,954 & 0,954 & 0,992 \\
16266 & 42,009 & 1,025 & 1,024 & 0,971 & 0,971 & 0,993 \\
17014 & 43,941 & 1,037 & 1,036 & 0,992 & 0,992 & 0,991 \\
17911 & 46,258 & 1,028 & 1,027 & 0,993 & 0,992 & 0,993 \\
18834 & 48,642 & 1,033 & 1,032 & 1,002 & 1,001 & 0,993 \\
20021 & 51,707 & 1,035 & 1,034 & 1,012 & 1,011 & 0,991 \\
21291 & 54,987 & 1,057 & 1,056 & 1,018 & 1,017 & 0,993 \\
\hline
\end{tabular}

Tabla C3. Datos experimentales de extracción de ácido aspártico y a-fenilglicina de sus mezclas binarias en columna de lecho fijo para el experimento III de la

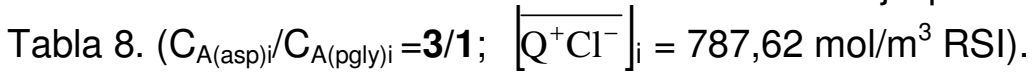

\begin{tabular}{|c|c|c|c|c|c|c|}
\hline $\mathrm{t}(\mathrm{s})$ & VL & $\begin{array}{l}\mathrm{C}_{\mathrm{A} \text { (asp) }} / \\
\mathrm{C}_{\mathrm{A} \text { (asp)i }}\end{array}$ & $\begin{array}{l}{\left[\mathrm{A}^{2-} \text { asp }\right] /} \\
{\left[\mathrm{A}^{-2-}{ }_{\text {asp }}\right] \mathrm{i}}\end{array}$ & $\begin{array}{l}\mathrm{C}_{\mathrm{A}(\mathrm{pgly} / \mathrm{l})} \\
\mathrm{C}_{\mathrm{A}(\mathrm{pg} \mathrm{y}) \mathrm{i}}\end{array}$ & $\begin{array}{l}{\left[\mathrm{A}_{\mathrm{pgly}}^{-}\right] /} \\
{\left[\mathrm{A}_{\mathrm{pgly}}^{-}\right] \mathrm{i}}\end{array}$ & $\mathrm{pH} / \mathrm{pH}_{\mathrm{i}}$ \\
\hline 333 & 0,914 & 0,044 & 0,000 & 0,023 & 0,000 & 0,606 \\
\hline 906 & 2,488 & 0,043 & 0,039 & 0,011 & 0,011 & 0,904 \\
\hline 1455 & 3,995 & 0,113 & 0,112 & 0,036 & 0,036 & 0,977 \\
\hline 2078 & 5,705 & 0,323 & 0,322 & 0,104 & 0,104 & 0,984 \\
\hline 2655 & 7,290 & 0,523 & 0,522 & 0,172 & 0,172 & 0,987 \\
\hline 3304 & 9,072 & 0,689 & 0,687 & 0,253 & 0,253 & 0,990 \\
\hline 3938 & 10,812 & 0,789 & 0,788 & 0,303 & 0,303 & 0,992 \\
\hline 4548 & 12,487 & 0,892 & 0,891 & 0,366 & 0,366 & 0,992 \\
\hline 5183 & 14,231 & 0,940 & 0,938 & 0,439 & 0,439 & 0,992 \\
\hline 5946 & 16,325 & 0,979 & 0,977 & 0,499 & 0,499 & 0,992 \\
\hline 6650 & 18,258 & 0,992 & 0,990 & 0,554 & 0,554 & 0,992 \\
\hline 7245 & 19,892 & 1,011 & 1,009 & 0,628 & 0,628 & 0,992 \\
\hline 7864 & 21,592 & 1,031 & 1,030 & 0,695 & 0,695 & 0,992 \\
\hline 8555 & 23,489 & 1,046 & 1,044 & 0,744 & 0,744 & 0,992 \\
\hline 9218 & 25,309 & 1,048 & 1,046 & 0,795 & 0,795 & 0,993 \\
\hline
\end{tabular}


Tabla C3. (Continuación de la Tabla C3)

\begin{tabular}{|c|c|c|c|c|c|c|}
\hline $\mathrm{t}(\mathrm{s})$ & VL & $\begin{array}{l}\left.\mathrm{C}_{\mathrm{A}(\text { asp }}\right) \\
\mathrm{C}_{\mathrm{A}(\text { asp }) \mathrm{i}}\end{array}$ & $\begin{array}{l}{\left[\mathrm{A}^{2-}{ }^{2-}{ }_{\text {asp }}\right] /} \\
{\left[\mathrm{A}^{2-}{ }_{\text {asp }}\right] \mathrm{i}}\end{array}$ & $\begin{array}{l}\mathrm{C}_{\mathrm{A}(\mathrm{pg} l y} / \\
\mathrm{C}_{\mathrm{A}(\mathrm{pg} g \mathrm{ly}) \mathrm{i}} /\end{array}$ & $\begin{array}{l}{\left[\mathrm{A}_{\mathrm{pgly}}^{-}\right] /} \\
{\left[\mathrm{A}_{\mathrm{pgly}}^{-}\right] \mathrm{i}}\end{array}$ & $\mathrm{pH} / \mathrm{pH}_{\mathrm{i}}$ \\
\hline 9918 & 27,231 & 1,052 & 1,050 & 0,843 & 0,843 & 0,992 \\
\hline 10733 & 29,469 & 1,060 & 1,058 & 0,893 & 0,893 & 0,992 \\
\hline 11648 & 31,981 & 1,064 & 1,062 & 0,915 & 0,915 & 0,993 \\
\hline 12372 & 33,969 & 1,055 & 1,053 & 0,943 & 0,943 & 0,992 \\
\hline 13290 & 36,489 & 1,059 & 1,058 & 0,983 & 0,983 & 0,992 \\
\hline 14203 & 38,996 & 1,059 & 1,057 & 1,001 & 1,001 & 0,992 \\
\hline 15041 & 41,297 & 1,060 & 1,059 & 1,017 & 1,017 & 0,992 \\
\hline 15998 & 43,925 & 1,060 & 1,058 & 1,022 & 1,022 & 0,992 \\
\hline 16875 & 46,332 & 1,050 & 1,049 & 1,020 & 1,020 & 0,992 \\
\hline 18533 & 50,885 & 1,043 & 1,041 & 1,020 & 1,019 & 0,992 \\
\hline
\end{tabular}

Tabla C4. Datos experimentales de extracción de ácido aspártico y a-fenilglicina de sus mezclas binarias en columna de lecho fijo para el experimento IV de la Tabla 8. $\left.\left(\mathrm{C}_{\mathrm{A}(\mathrm{asp}) \mathrm{i}} / \mathrm{C}_{\mathrm{A}(\mathrm{pgly}) \mathrm{i}}=1 / 2 ; \quad \overline{\mathrm{Q}^{+} \mathrm{Cl}^{-}}\right]_{\mathrm{i}}=787,62 \mathrm{~mol} / \mathrm{m}^{3} \mathrm{RSI}\right)$.

\begin{tabular}{|c|c|c|c|c|c|c|}
\hline $\mathrm{t}(\mathrm{s})$ & VL & $\begin{array}{l}\left.\mathrm{C}_{\mathrm{A}(\mathrm{asp})}\right) \\
\mathrm{C}_{\mathrm{A}(\mathrm{asp}) \mathrm{i}}\end{array}$ & $\begin{array}{l}{\left[\mathrm{A}^{2-}{ }^{2-}\right] /} \\
{\left[\mathrm{A}^{2-}{ }_{\text {asp }}\right]}\end{array}$ & $\begin{array}{l}\mathrm{C}_{\mathrm{A}(\mathrm{pg} l \mathrm{y})} / \\
\mathrm{C}_{\mathrm{A}(\mathrm{pgly}) \mathrm{i}}\end{array}$ & $\begin{array}{l}{\left[\mathrm{A}_{\mathrm{pgly}}^{-}\right] /} \\
{\left[\mathrm{A}_{\mathrm{pgly}}^{-}\right] \mathrm{i}}\end{array}$ & $\mathrm{pH} / \mathrm{pH}_{\mathrm{i}}$ \\
\hline 284 & 0,771 & 0,000 & 0,000 & 0,023 & 0,000 & 0,612 \\
\hline 896 & 2,431 & 0,000 & 0,000 & 0,006 & 0,006 & 0,832 \\
\hline 1549 & 4,204 & 0,000 & 0,000 & 0,006 & 0,006 & 0,978 \\
\hline 2203 & 5,978 & 0,000 & 0,000 & 0,017 & 0,017 & 0,988 \\
\hline 2943 & 7,986 & 0,000 & 0,000 & 0,064 & 0,064 & 0,992 \\
\hline 3508 & 9,520 & 0,000 & 0,000 & 0,129 & 0,129 & 0,992 \\
\hline 4280 & 11,615 & 0,171 & 0,170 & 0,296 & 0,296 & 0,991 \\
\hline 5154 & 13,986 & 0,402 & 0,401 & 0,431 & 0,431 & 0,992 \\
\hline 5746 & 15,593 & 0,625 & 0,624 & 0,549 & 0,549 & 0,992 \\
\hline 6335 & 17,191 & 0,744 & 0,743 & 0,617 & 0,617 & 0,992 \\
\hline 6988 & 18,963 & 0,837 & 0,836 & 0,674 & 0,674 & 0,992 \\
\hline 7593 & 20,605 & 0,897 & 0,896 & 0,715 & 0,715 & 0,993 \\
\hline 8233 & 22,342 & 0,935 & 0,933 & 0,751 & 0,751 & 0,992 \\
\hline 8938 & 24,255 & 0,978 & 0,976 & 0,794 & 0,794 & 0,992 \\
\hline 9601 & 26,054 & 1,002 & 1,001 & 0,823 & 0,823 & 0,992 \\
\hline 10275 & 27,883 & 1,017 & 1,016 & 0,860 & 0,859 & 0,993 \\
\hline 10987 & 29,815 & 1,024 & 1,023 & 0,896 & 0,896 & 0,992 \\
\hline 11708 & 31,772 & 1,042 & 1,040 & 0,929 & 0,929 & 0,992 \\
\hline 12549 & 34,054 & 1,044 & 1,042 & 0,955 & 0,955 & 0,993 \\
\hline 13281 & 36,041 & 1,033 & 1,031 & 0,964 & 0,964 & 0,992 \\
\hline 14225 & 38,602 & 1,056 & 1,054 & 0,995 & 0,995 & 0,992 \\
\hline 15143 & 41,094 & 1,050 & 1,049 & 0,998 & 0,998 & 0,992 \\
\hline 16092 & 43,669 & 1,040 & 1,038 & 1,001 & 1,001 & 0,992 \\
\hline 17088 & 46,372 & 1,060 & 1,059 & 1,025 & 1,025 & 0,992 \\
\hline 18503 & 50,212 & 1,067 & 1,066 & 1,033 & 1,033 & 0,992 \\
\hline
\end{tabular}


Tabla C5. Datos experimentales de extracción de ácido aspártico y a-fenilglicina de sus mezclas binarias en columna de lecho fijo para el experimento $\mathrm{V}$ de la Tabla 8. $\left.\left(\mathrm{C}_{\mathrm{A}(\mathrm{asp}))} / \mathrm{C}_{\mathrm{A}(\mathrm{pgly}) \mathrm{i}}=\mathbf{1} / \mathbf{3} ; \overline{\mathrm{Q}^{+} \mathrm{Cl}^{-}}\right]_{\mathrm{i}}=787,62 \mathrm{~mol} / \mathrm{m}^{3} \mathrm{RSI}\right)$.

\begin{tabular}{|c|c|c|c|c|c|c|}
\hline $\mathrm{t}(\mathrm{s})$ & VL & $\begin{array}{l}\mathrm{C}_{\mathrm{A} \text { (asp) }} / \\
\mathrm{C}_{\mathrm{A} \text { (asp)i })}\end{array}$ & $\begin{array}{l}{\left[\mathrm{A}^{2-}{ }^{2-}{ }_{\text {asp }}\right] /} \\
{\left[\mathrm{A}^{-2}{ }_{\text {asp }}\right] \mathrm{i}}\end{array}$ & $\begin{array}{l}\mathrm{C}_{\mathrm{A}(\mathrm{pgly} / \mathrm{y})} / \\
\mathrm{C}_{\mathrm{A}(\mathrm{pgly}) \mathrm{i}}\end{array}$ & $\begin{array}{l}{\left[\mathrm{A}_{\mathrm{pgly}}^{-}\right]} \\
{\left[\mathrm{A}_{\mathrm{pgly}}^{-}\right] \mathrm{i}}\end{array}$ & $\mathrm{pH} / \mathrm{pH}_{\mathrm{i}}$ \\
\hline 296 & 0,786 & 0,000 & 0,000 & 0,025 & 0,000 & 0,585 \\
\hline 950 & 2,522 & 0,000 & 0,000 & 0,009 & 0,009 & 0,936 \\
\hline 1589 & 4,218 & 0,000 & 0,000 & 0,034 & 0,034 & 0,992 \\
\hline 2270 & 6,025 & 0,000 & 0,000 & 0,107 & 0,107 & 0,993 \\
\hline 2857 & 7,583 & 0,161 & 0,160 & 0,202 & 0,202 & 0,992 \\
\hline 3483 & 9,245 & 0,350 & 0,350 & 0,325 & 0,325 & 0,993 \\
\hline 4190 & 11,121 & 0,556 & 0,555 & 0,448 & 0,448 & 0,993 \\
\hline 4795 & 12,727 & 0,705 & 0,704 & 0,545 & 0,545 & 0,992 \\
\hline 5637 & 14,962 & 0,850 & 0,848 & 0,657 & 0,657 & 0,992 \\
\hline 6291 & 16,698 & 0,910 & 0,908 & 0,711 & 0,711 & 0,992 \\
\hline 6918 & 18,362 & 0,956 & 0,954 & 0,762 & 0,762 & 0,993 \\
\hline 7625 & 20,239 & 0,998 & 0,997 & 0,821 & 0,821 & 0,993 \\
\hline 8252 & 21,903 & 1,018 & 1,017 & 0,860 & 0,860 & 0,993 \\
\hline 8865 & 23,530 & 1,017 & 1,015 & 0,881 & 0,881 & 0,992 \\
\hline 9608 & 25,502 & 1,031 & 1,029 & 0,920 & 0,920 & 0,992 \\
\hline 10355 & 27,485 & 1,036 & 1,035 & 0,944 & 0,944 & 0,992 \\
\hline 11065 & 29,370 & 1,029 & 1,027 & 0,958 & 0,958 & 0,992 \\
\hline 11801 & 31,323 & 1,040 & 1,039 & 0,980 & 0,980 & 0,995 \\
\hline 12505 & 33,192 & 1,040 & 1,038 & 0,995 & 0,995 & 0,992 \\
\hline 13349 & 35,432 & 1,044 & 1,042 & 1,001 & 1,001 & 0,992 \\
\hline 14258 & 37,845 & 1,021 & 1,020 & 1,004 & 1,004 & 0,992 \\
\hline 15203 & 40,353 & 1,029 & 1,028 & 1,011 & 1,011 & 0,992 \\
\hline 16119 & 42,784 & 1,037 & 1,036 & 1,012 & 1,012 & 0,992 \\
\hline 17485 & 46,410 & 1,025 & 1,023 & 1,006 & 1,006 & 0,992 \\
\hline
\end{tabular}


Tabla C6. Datos experimentales de extracción de ácido aspártico y a-fenilglicina de sus mezclas binarias en columna de lecho fijo para el experimento VI de la Tabla 8.

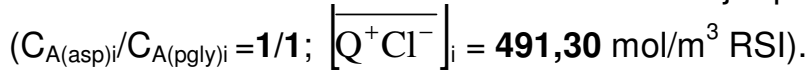

\begin{tabular}{|c|c|c|c|c|c|c|}
\hline $\mathrm{t}(\mathrm{s})$ & VL & $\begin{array}{l}\mathrm{C}_{\mathrm{A}(\text { (asp })} / \\
\mathrm{C}_{\mathrm{A} \text { (asp)i }}\end{array}$ & $\begin{array}{l}{\left[\mathrm{A}^{2-}{ }^{2-}{ }^{2 \text { asp }}\right] /} \\
{\left[\mathrm{A}^{-2}{ }_{\text {asp }}\right]}\end{array}$ & $\begin{array}{l}\mathrm{C}_{\mathrm{A}(\mathrm{pgly} / \mathrm{l})} \\
\mathrm{C}_{\mathrm{A}(\mathrm{pg} \mathrm{y}) \mathrm{i}}\end{array}$ & $\begin{array}{l}{\left[\mathrm{A}_{\mathrm{pgly}}^{-}\right] /} \\
{\left[\mathrm{A}_{\mathrm{pgly}}^{-}\right] \mathrm{i}}\end{array}$ & $\mathrm{pH} / \mathrm{pH}_{\mathrm{i}}$ \\
\hline 290 & 0,811 & 0,000 & 0,000 & 0,029 & 0,001 & 0,616 \\
\hline 913 & 2,554 & 0,000 & 0,000 & 0,006 & 0,006 & 0,936 \\
\hline 1629 & 4,557 & 0,000 & 0,000 & 0,008 & 0,008 & 0,995 \\
\hline 2295 & 6,420 & 0,000 & 0,000 & 0,019 & 0,019 & 0,998 \\
\hline 2883 & 8,064 & 0,000 & 0,000 & 0,054 & 0,054 & 1,000 \\
\hline 3690 & 10,322 & 0,248 & 0,248 & 0,141 & 0,141 & 1,000 \\
\hline 4334 & 12,123 & 0,480 & 0,480 & 0,186 & 0,186 & 0,998 \\
\hline 4848 & 13,561 & 0,754 & 0,754 & 0,254 & 0,254 & 0,999 \\
\hline 5414 & 15,144 & 0,895 & 0,895 & 0,319 & 0,319 & 0,998 \\
\hline 6032 & 16,873 & 1,017 & 1,017 & 0,395 & 0,395 & 0,998 \\
\hline 6613 & 18,498 & 1,023 & 1,023 & 0,472 & 0,472 & 0,997 \\
\hline 7345 & 20,545 & 1,033 & 1,033 & 0,545 & 0,545 & 1,000 \\
\hline 7938 & 22,204 & 1,031 & 1,031 & 0,660 & 0,660 & 1,000 \\
\hline 8556 & 23,933 & 1,029 & 1,029 & 0,717 & 0,717 & 0,998 \\
\hline 9295 & 26,000 & 1,020 & 1,020 & 0,783 & 0,783 & 0,999 \\
\hline 9980 & 27,916 & 1,031 & 1,031 & 0,862 & 0,862 & 1,000 \\
\hline 10804 & 30,221 & 1,021 & 1,021 & 0,918 & 0,918 & 0,999 \\
\hline 11691 & 32,702 & 1,032 & 1,032 & 0,944 & 0,944 & 0,998 \\
\hline 12496 & 34,954 & 1,047 & 1,047 & 0,960 & 0,960 & 0,999 \\
\hline 13298 & 37,197 & 1,043 & 1,043 & 0,984 & 0,984 & 0,998 \\
\hline 14137 & 39,544 & 1,046 & 1,045 & 0,978 & 0,978 & 0,998 \\
\hline 14965 & 41,860 & 1,046 & 1,045 & 0,987 & 0,987 & 0,998 \\
\hline 15550 & 43,497 & 1,049 & 1,049 & 0,995 & 0,995 & 0,999 \\
\hline 16696 & 46,702 & 1,031 & 1,031 & 0,992 & 0,991 & 0,998 \\
\hline 17947 & 50,201 & 1,054 & 1,054 & 1,006 & 1,006 & 0,998 \\
\hline 19740 & 55,217 & 1,037 & 1,036 & 0,994 & 0,993 & 0,998 \\
\hline
\end{tabular}




\section{APÉNDICE D. Extracción de betaina}

TABLAS A. Equilibrios de extracción de betaína con RI. (Apartado 6.2)

Tabla A1. Datos de equilibrio de extracción de betaína con $\mathrm{Rl}$ a $\mathrm{pH}_{\mathrm{i}}=6,08 \pm 0,29$ y $28^{\circ} \mathrm{C}$. (Apartado 6.2.2)

\begin{tabular}{ccccc}
\hline $\begin{array}{c}\mathrm{C}_{\mathrm{B}} \\
\left(\mathrm{mol} / \mathrm{m}^{3}\right)\end{array}$ & $\mathrm{pH}$ & $\begin{array}{c}{\left[\mathrm{B}^{+}\right]} \\
\left(\mathrm{mol} / \mathrm{m}^{3}\right) \\
\text { Ec. }(6.3)\end{array}$ & $\begin{array}{c}{\left[\mathrm{B}^{+/}\right]} \\
\left(\mathrm{mol} / \mathrm{m}^{3}\right) \\
\text { Ec. }(6.4)\end{array}$ & $\begin{array}{c}\overline{\mathrm{C}}_{\mathrm{B}} \\
(\mathrm{mol} / \mathrm{Kg} \mathrm{RI}) \\
\text { Ec. }(6.2)\end{array}$ \\
\hline 0,163 & 1,68 & 0,0957 & 4,1875 & 0,017 \\
0,206 & 1,66 & 0,1228 & 7,6669 & 0,032 \\
0,394 & 1,67 & 0,2329 & 42,5301 & 0,176 \\
0,736 & 1,69 & 0,4265 & 79,4598 & 0,329 \\
5,007 & 1,73 & 2,7903 & 289,8306 & 1,197 \\
15,093 & 1,85 & 7,3726 & 474,7856 & 1,944 \\
\hline
\end{tabular}

Tabla A2. Datos de equilibrio de extracción de mezclas binarias de betaína y sacarosa con $\mathrm{RI}$ a pH $\mathrm{i}=6,32 \pm 0,07$ y $28^{\circ} \mathrm{C}$. $\left(\mathrm{C}_{\mathrm{Bi}}=280\right.$ y $\left.456 \mathrm{~mol} / \mathrm{m}^{3}\right)($ Apartado 6.2.3)

\begin{tabular}{ccccc}
\hline $\begin{array}{c}\mathrm{C}_{\mathrm{B}} \\
\left(\mathrm{mol} / \mathrm{m}^{3}\right)\end{array}$ & $\begin{array}{c}\mathrm{C}_{\mathrm{S}} \\
\left(\mathrm{mol} / \mathrm{m}^{3}\right)\end{array}$ & $\mathrm{pH}$ & $\begin{array}{c}\overline{\mathrm{C}}_{\mathrm{B}} \\
(\mathrm{mol} / \mathrm{kg} \mathrm{RI}) \\
\text { Ec. }(6.2)\end{array}$ & $\begin{array}{c}\overline{\mathrm{C}}_{\mathrm{S}} \\
(\mathrm{mol} / \mathrm{kg} \mathrm{RI}) \\
\text { Ec. (6.6) }\end{array}$ \\
\hline 4,066 & 33,364 & 1,86 & 1,117 & 0,000 \\
13,837 & 32,999 & 1,99 & 1,821 & 0,000 \\
4,067 & 97,390 & 1,84 & 1,135 & 0,000 \\
16,583 & 99,966 & 2,01 & 1,844 & 0,000 \\
5,137 & 163,352 & 1,78 & 1,131 & 0,000 \\
16,149 & 158,562 & 1,96 & 1,850 & 0,000 \\
\hline
\end{tabular}


TABLAS B. Equilibrios de extracción de betaína con RIE.

Tabla B1. Datos de impregnación de Amberlita XAD-4 con disoluciones de DNNSA disuelto en nhexano. (Apartado 6.3.2)

\begin{tabular}{|c|c|c|}
\hline $\begin{array}{l}\% \text { peso DNNSA } \\
\text { en n-hexano }\end{array}$ & $\begin{array}{c}{\left[\overline{\mathrm{RSO}_{3}{ }^{-} \mathrm{H}^{+}}\right]} \\
(\mathrm{mol} \mathrm{DNNSA} / \mathrm{kg} \text { RIE) }\end{array}$ & $\begin{array}{c}{\left[\overline{\mathrm{RSO}_{3}{ }^{-} \mathrm{H}^{+}}\right] \mathrm{Ec}(6.8)} \\
\left(\mathrm{mol} \mathrm{DNNSA} / \mathrm{m}^{3} \mathrm{RSI}\right)\end{array}$ \\
\hline 3,972 & 0,18 & 107,311 \\
\hline 6,025 & 0,27 & 166,332 \\
\hline 7,696 & 0,33 & 210,598 \\
\hline 10,474 & 0,44 & 296,447 \\
\hline 19,271 & 0,67 & 539,238 \\
\hline 25,768 & 0,67 & 539,238 \\
\hline
\end{tabular}

Tabla B2. Datos de impregnación de Amberlita XAD-4 con disoluciones de DNNSA disuelto en nheptano. (Apartado 6.3.2)

\begin{tabular}{ccc}
\hline $\begin{array}{c}\text { \% peso DNNSA } \\
\text { en n-heptano }\end{array}$ & $\begin{array}{c}{\left[\overline{\mathrm{RSO}_{3}{ }^{-} \mathrm{H}^{+}}\right.} \\
(\mathrm{mol} \mathrm{DNNSA} / \mathrm{kg} \mathrm{RIE})\end{array}$ & $\begin{array}{c}\overline{\mathrm{RSO}_{3}{ }^{-} \mathrm{H}^{+}} \\
\left(\mathrm{mol} \mathrm{DNNSA} / \mathrm{m}^{3} \mathrm{RSI}\right)\end{array}$ \\
\hline 1,83 & 0,09 & 49,631 \\
4,35 & 0,20 & 119,383 \\
7,80 & 0,33 & 209,256 \\
5,65 & 0,25 & 152,918 \\
11,10 & 0,45 & 313,885 \\
20,05 & 0,65 & 543,262 \\
34,24 & 0,65 & 543,262 \\
50,00 & 0,65 & 543,262 \\
\hline
\end{tabular}

Tabla B3. Datos de equilibrio de extracción de betaína con RIE a $28^{\circ} \mathrm{C}$. $\left(\mathrm{pH}_{\mathrm{i}}=6,50\right.$; $\left.\left|\overline{\mathrm{RSO}_{3}{ }^{-} \mathrm{H}^{+}}\right|_{\mathrm{i}}=500,14 \mathrm{~mol} / \mathrm{m}^{3} \mathrm{RSI}\right) .($ Apartado 6.3 .4 )

\begin{tabular}{ccccc}
\hline $\begin{array}{c}\mathrm{C}_{\mathrm{B}} \\
\left(\mathrm{mol} / \mathrm{m}^{3}\right)\end{array}$ & $\mathrm{pH}$ & $\begin{array}{c}{\left[\mathrm{B}^{+}\right]} \\
\left(\mathrm{mol} / \mathrm{m}^{3}\right) \mathrm{Ec} . \\
(6.3)\end{array}$ & $\begin{array}{c}{\left[\mathrm{B}^{+/}\right]} \\
\left(\mathrm{mol} / \mathrm{m}^{3}\right) \\
(6.4)\end{array}$ & $\begin{array}{c}\overline{\mathrm{C}}_{\mathrm{B}} \\
\left(\mathrm{mol} / \mathrm{m}^{3} \mathrm{RSI}\right) \\
\mathrm{Ec} .(6.10)\end{array}$ \\
\hline 0,305 & 2,08 & 0,107 & 3,645 & 11,318 \\
0,519 & 2,12 & 0,171 & 7,086 & 22,180 \\
3,600 & 2,25 & 0,959 & 39,313 & 120,748 \\
17,413 & 2,42 & 3,432 & 80,681 & 219,620 \\
171,831 & 3,10 & 8,383 & 253,074 & 294,760 \\
296,608 & 3,25 & 10,392 & 381,350 & 313,034 \\
\hline
\end{tabular}


Tabla B4. Datos de equilibrio de extracción de mezclas binarias de betaína y sacarosa con RIE a pH $\mathrm{i}_{\mathrm{i}}=6,50 \pm 0,27$ y $28^{\circ} \mathrm{C}$. $\left(\left[\overline{\mathrm{RSO}_{3}{ }^{-} \mathrm{H}^{+}}\right]_{i}=500,14 \mathrm{~mol} / \mathrm{m}^{3} \mathrm{RSI} ; \mathrm{C}_{\mathrm{Bi}}=280\right.$ y $\left.456 \mathrm{~mol} / \mathrm{m}^{3}\right)$ (Apartado 6.3.5)

\begin{tabular}{ccccccc}
\hline $\begin{array}{c}\mathrm{C}_{\mathrm{B}} \\
\left(\mathrm{mol} / \mathrm{m}^{3}\right)\end{array}$ & $\begin{array}{c}\mathrm{C}_{\mathrm{S}} \\
\left(\mathrm{mol} / \mathrm{m}^{3}\right)\end{array}$ & $\begin{array}{c}{\left[\mathrm{B}^{+}\right]} \\
\left(\mathrm{mol} / \mathrm{m}^{3}\right) \\
\text { Ec. }(6.3)\end{array}$ & $\begin{array}{c}{\left[\mathrm{B}^{+/}\right]} \\
\left(\mathrm{mol} / \mathrm{m}^{3}\right) \\
\text { Ec. }(6.4)\end{array}$ & $\mathrm{pH}$ & $\begin{array}{c}\overline{\mathrm{C}}_{\mathrm{B}} \\
\left(\mathrm{mol} / \mathrm{m}^{3} \mathrm{RSI}\right) \\
\text { Ec. }(6.10)\end{array}$ & $\begin{array}{c}\overline{\mathrm{C}}_{\mathrm{S}} \\
\left(\mathrm{mol} / \mathrm{m}^{3} \mathrm{RSI}\right) \\
\text { Ec. }(6.17)\end{array}$ \\
\hline 169,566 & 29,503 & 9,028 & 160,539 & 3,06 & 343,695 & 4,974 \\
348,353 & 30,281 & 10,442 & 337,910 & 3,32 & 355,749 & 5,494 \\
168,220 & 87,319 & 9,355 & 158,865 & 3,04 & 359,910 & 22,779 \\
346,700 & 87,483 & 11,880 & 334,820 & 3,26 & 372,015 & 14,773 \\
168,480 & 145,945 & 8,587 & 159,893 & 3,08 & 356,887 & 25,708 \\
348,056 & 145,855 & 10,910 & 337,146 & 3,30 & 369,192 & 24,795 \\
\hline
\end{tabular}

TABLAS C. Cinéticas de extracción de betaína en baños agitados con RIE. (Apartado 6.3.6)

Tabla C1. Datos cinéticos de extracción de betaína con RIE en baños agitados a $\mathrm{pH}_{\mathrm{i}}=$ $6,50 \pm 0,27$ y $28^{\circ} \mathrm{C}$. $\left(\left.\overline{\mathrm{RSO}_{3}{ }^{-} \mathrm{H}^{+}}\right|_{\mathrm{i}}=500,14 \mathrm{~mol} / \mathrm{m}^{3} \mathrm{RSI} ; \mathrm{C}_{\mathrm{Bi}}=\mathbf{4 5 , 3 7} \mathrm{mol} / \mathrm{m}^{3}\right.$ ) (Apartado 6.3.6)

\begin{tabular}{|c|c|c|c|c|}
\hline $\mathrm{t}(\mathrm{s})$ & $\mathrm{pH}(\mathrm{t})$ & $\begin{array}{c}\mathrm{C}_{\mathrm{B}}(\mathrm{t}) \\
\left(\mathrm{mol} / \mathrm{m}^{3}\right)\end{array}$ & $\mathrm{C}_{\mathrm{B}} / \mathrm{C}_{\mathrm{Bi}}$ & $\begin{array}{c}\overline{\mathrm{C}}_{\mathrm{B}}(\mathrm{t}) \\
\left(\mathrm{mol} / \mathrm{m}^{3} \mathrm{RSI}\right) \\
\text { Ec. }(6.18)\end{array}$ \\
\hline 0 & 5,94 & 45,371 & 1,000 & 0,000 \\
\hline 32 & 3,98 & 43,847 & 0,966 & 121,202 \\
\hline 75 & 3,93 & 43,693 & 0,963 & 133,467 \\
\hline 125 & 3,9 & 43,119 & 0,950 & 179,104 \\
\hline 190 & 3,88 & 42,876 & 0,945 & 198,425 \\
\hline 301 & 3,85 & 42,077 & 0,927 & 261,969 \\
\hline 430 & 3,83 & 41,651 & 0,918 & 295,822 \\
\hline 530 & 3,83 & 41,206 & 0,908 & 331,239 \\
\hline 615 & 3,82 & 41,021 & 0,904 & 345,952 \\
\hline 732 & 3,82 & 40,575 & 0,894 & 381,422 \\
\hline 920 & 3,82 & 40,332 & 0,889 & 400,748 \\
\hline 1290 & 3,81 & 39,400 & 0,868 & 474,869 \\
\hline 1480 & 3,81 & 39,655 & 0,874 & 454,589 \\
\hline 1995 & 3,8 & 39,265 & 0,865 & 485,605 \\
\hline 2380 & 3,8 & 39,726 & 0,876 & 448,982 \\
\hline 2702 & 3,79 & 39,270 & 0,866 & 485,208 \\
\hline 3130 & 3,79 & 39,620 & 0,873 & 457,372 \\
\hline 4220 & 3,77 & 39,831 & 0,878 & 440,592 \\
\hline 4815 & 3,77 & 40,005 & 0,882 & 426,754 \\
\hline 5490 & 3,77 & 40,049 & 0,883 & 423,254 \\
\hline 6330 & 3,77 & 39,568 & 0,872 & 461,508 \\
\hline 7215 & 3,76 & 39,844 & 0,878 & 439,574 \\
\hline 8450 & 3,76 & 40,357 & 0,889 & 398,759 \\
\hline 9605 & 3,76 & 40,076 & 0,883 & 421,107 \\
\hline 11190 & 3,76 & 40,257 & 0,887 & 406,729 \\
\hline
\end{tabular}


Tabla C2. Determinación de la etapa controlante del proceso de extracción de betaína con RIE en baños agitados a $28^{\circ} \mathrm{C}$ para la. $\left(\mathrm{pH}_{\mathrm{i}}=6,50 ; \quad\left[\overline{\mathrm{RSO}_{3}{ }^{-} \mathrm{H}^{+}}\right]_{i}=500,14 \mathrm{~mol} / \mathrm{m}^{3} \mathrm{RSI}\right.$; $\mathrm{C}_{\mathrm{Bi}}=\mathbf{4 5}, \mathbf{3 7} \mathrm{mol} / \mathrm{m}^{3}$ ). Apartado (6.3.6.1).

\begin{tabular}{cccc}
\hline $\mathrm{X}$ & $\mathrm{Y}$ & $\mathrm{Z}$ & \\
Ec. $(6.20)$ & Ec. $(6.21)$ & Ec. $(6.22)$ & $\int_{0}^{\mathrm{t}} \mathrm{C}_{\mathrm{B}}(\mathrm{t}) \mathrm{dt}$ \\
\hline 0,000 & 0,000 & 0,000 & 0,000 \\
0,241 & 0,002 & 0,007 & 1427,488 \\
0,266 & 0,002 & 0,008 & 3309,593 \\
0,357 & 0,004 & 0,011 & 5479,887 \\
0,395 & 0,005 & 0,013 & 8274,723 \\
0,521 & 0,010 & 0,019 & 12989,614 \\
0,589 & 0,014 & 0,022 & 18390,091 \\
0,659 & 0,020 & 0,027 & 22532,958 \\
0,759 & 0,030 & 0,035 & 26027,605 \\
0,798 & 0,035 & 0,039 & 30800,971 \\
0,945 & 0,078 & 0,085 & 38406,229 \\
\hline
\end{tabular}

TABLAS D. Extracción de betaína en lechos fijos de RIE. (Apartado 6.3.7)

Tabla D1. Datos experimentales de extracción de betaína en columna rellena de RIE para el experimento I de la Tabla 24. $\left(\mathrm{pH}_{\mathrm{i}}=6,50 ; \mathrm{C}_{\mathrm{Bi}}=41,01 \mathrm{~mol} / \mathrm{m}^{3} ; \mathrm{Q}=0,018 \times 10^{-6} \mathrm{~m}^{3} / \mathrm{s} ; \mathrm{RSO}_{3}^{-} \mathrm{H}^{+}\right]_{\mathrm{i}}=$ $\left.500,14 \pm 1,21 \mathrm{~mol} / \mathrm{m}^{3} \mathrm{RSI}\right)$.

\begin{tabular}{|c|c|c|c|}
\hline$t(s)$ & VL & $\mathrm{C}_{\mathrm{B}} / \mathrm{C}_{\mathrm{Bi}}$ & $\mathrm{pH} / \mathrm{pH}_{\mathrm{i}}$ \\
\hline 460 & 0,849 & 0,001 & 0,272 \\
\hline 1070 & 1,975 & 0,010 & 0,348 \\
\hline 1564 & 2,887 & 0,006 & 0,405 \\
\hline 1970 & 3,637 & 0,009 & 0,456 \\
\hline 2607 & 4,813 & 0,036 & 0,519 \\
\hline 3190 & 5,889 & 0,169 & 0,561 \\
\hline 3830 & 7,071 & 0,420 & 0,618 \\
\hline 4450 & 8,215 & 0,644 & 0,651 \\
\hline 5057 & 9,336 & 0,818 & 0,643 \\
\hline 5819 & 10,743 & 0,900 & 0,669 \\
\hline 6470 & 11,945 & 0,937 & 0,677 \\
\hline 7230 & 13,348 & 0,952 & 0,683 \\
\hline 7922 & 14,625 & 0,965 & 0,692 \\
\hline 8699 & 16,060 & 0,971 & 0,683 \\
\hline 9634 & 17,786 & 0,981 & 0,677 \\
\hline 10570 & 19,514 & 0,983 & 0,691 \\
\hline 11670 & 21,545 & 0,985 & 0,706 \\
\hline 12589 & 23,241 & 0,985 & 0,689 \\
\hline 13637 & 25,176 & 0,984 & 0,696 \\
\hline 14734 & 27,201 & 0,989 & 0,683 \\
\hline
\end{tabular}


Tabla D2. Datos experimentales de extracción de betaína en columna rellena de RIE para el experimento II de la Tabla 24. $\left(\mathbf{p H}_{\mathrm{i}}=\mathbf{2}, 13 ; \mathrm{C}_{\mathrm{Bi}}=41,14 \mathrm{~mol} / \mathrm{m}^{3} ; \quad \mathrm{Q}=0,018 \times 10^{-6} \mathrm{~m}^{3} / \mathrm{s}\right.$; $\left.\left.\mid \overline{\mathrm{RSO}_{3}^{-} \mathrm{H}^{+}}\right]_{\mathrm{i}}=500,14 \pm 1,21 \mathrm{~mol} / \mathrm{m}^{3} \mathrm{RSI}\right)$.

\begin{tabular}{cccc}
\hline $\mathrm{t}(\mathrm{s})$ & $\mathrm{VL}$ & $\mathrm{C}_{\mathrm{B}} / \mathrm{C}_{\mathrm{Bi}}$ & $\mathrm{pH} / \mathrm{pH}_{\mathrm{i}}$ \\
& & & \\
\hline 346 & 0,639 & 0,063 & 0,681 \\
1021 & 1,885 & 0,082 & 0,751 \\
1655 & 3,055 & 0,091 & 0,793 \\
2391 & 4,414 & 0,232 & 0,817 \\
2886 & 5,328 & 0,566 & 0,883 \\
3389 & 6,257 & 0,839 & 0,939 \\
3907 & 7,213 & 0,996 & 0,953 \\
4383 & 8,092 & 1,001 & 0,962 \\
5065 & 9,351 & 0,997 & 0,962 \\
5676 & 10,479 & 1,024 & 0,977 \\
6379 & 11,777 & 1,044 & 0,967 \\
7061 & 13,036 & 1,022 & 0,967 \\
8171 & 15,085 & 1,028 & 0,967 \\
9096 & 16,793 & 1,012 & 0,972 \\
10656 & 19,673 & 1,006 & 0,972 \\
\hline
\end{tabular}

Tabla D3. Datos experimentales de extracción de betaína en columna rellena de RIE para el experimento III de la Tabla 24. $\left(\mathrm{pH}_{\mathrm{i}}=6,50 ; \quad \mathrm{C}_{\mathrm{Bi}}=\mathbf{8 2 , 6 5} \mathrm{mol} / \mathrm{m}^{3} ; \quad \mathrm{Q}=0,017 \times 10^{-6} \mathrm{~m}^{3} / \mathrm{s}\right.$; $\left.\left[\overline{\mathrm{RSO}_{3}^{-} \mathrm{H}^{+}}\right]_{\mathrm{i}}=500,14 \pm 1,21 \mathrm{~mol} / \mathrm{m}^{3} \mathrm{RSI}\right)$.

\begin{tabular}{cccc}
\hline $\mathrm{t}(\mathrm{s})$ & $\mathrm{VL}$ & $\mathrm{C}_{\mathrm{B}} / \mathrm{C}_{\mathrm{Bi}}$ & $\mathrm{pH} / \mathrm{pH}_{\mathrm{i}}$ \\
& & 0,000 & 0,272 \\
\hline 545 & 0,863 & 0,100 & 0,318 \\
899 & 1,424 & 0,227 & 0,373 \\
1376 & 2,179 & 0,416 & 0,455 \\
1788 & 2,831 & 0,649 & 0,535 \\
2120 & 3,357 & 0,809 & 0,590 \\
2590 & 4,101 & 0,924 & 0,600 \\
3096 & 4,903 & 0,992 & 0,615 \\
3429 & 5,430 & 0,992 & 0,632 \\
3808 & 6,030 & 1,031 & 0,639 \\
4568 & 7,234 & 1,039 & 0,673 \\
5688 & 9,007 & 1,003 & 0,669 \\
6682 & 10,581 & 0,998 & 0,666 \\
8702 & 13,780 & 1,011 & 0,669 \\
9942 & 15,743 & 1,037 & 0,670 \\
11054 & 17,504 & & \\
\hline
\end{tabular}


Tabla D4. Datos experimentales de extracción de betaína en columna rellena de RIE para el experimento IV de la Tabla 24. $\left(\mathrm{pH}_{\mathrm{i}}=6,50 ; \mathrm{C}_{\mathrm{B} i}=19,85 \mathrm{~mol} / \mathrm{m}^{3} ; \quad \mathrm{Q}=0,018 \times 10^{-6} \mathrm{~m}^{3} / \mathrm{s}\right.$; $\left.\left.\mid \overline{\mathrm{RSO}_{3}^{-} \mathrm{H}^{+}}\right]_{\mathrm{i}}=500,14 \pm 1,21 \mathrm{~mol} / \mathrm{m}^{3} \mathrm{RSI}\right)$.

\begin{tabular}{cccc}
\hline $\mathrm{t}(\mathrm{s})$ & $\mathrm{VL}$ & $\mathrm{C}_{\mathrm{B}} / \mathrm{C}_{\mathrm{Bi}}$ & $\mathrm{pH} / \mathrm{pH}_{\mathrm{i}}$ \\
\hline 632 & & 0,031 & 0,322 \\
1109 & 1,296 & 0,026 & 0,409 \\
1605 & 3,275 & 0,052 & 0,463 \\
1991 & 4,084 & 0,089 & 0,496 \\
2498 & 5,124 & 0,139 & 0,509 \\
2921 & 5,992 & 0,159 & 0,530 \\
3395 & 6,964 & 0,239 & 0,550 \\
3876 & 7,951 & 0,353 & 0,557 \\
4369 & 8,962 & 0,501 & 0,576 \\
4927 & 10,107 & 0,705 & 0,591 \\
5471 & 11,223 & 0,887 & 0,589 \\
6055 & 12,421 & 1,001 & 0,612 \\
6663 & 13,668 & 1,006 & 0,626 \\
7393 & 15,165 & 1,031 & 0,634 \\
8206 & 16,833 & 1,033 & 0,633 \\
9093 & 18,652 & 1,022 & 0,644 \\
10225 & 20,974 & 1,008 & 0,647 \\
11359 & 23,301 & 1,018 & 0,655 \\
\hline
\end{tabular}

Tabla D5. Datos experimentales de extracción de betaína en columna rellena de RIE para el experimento $V$ de la Tabla 24. $\left(\mathrm{pH}_{\mathrm{i}}=6,50 ; \quad \mathrm{C}_{\mathrm{Bi}}=38,09 \mathrm{~mol} / \mathrm{m}^{3} ; \quad \mathrm{Q}=\mathbf{0}, \mathbf{0 3 2 \times 1 0 ^ { - 6 }} \mathrm{m}^{3} / \mathrm{s}\right.$; $\left.\left[\overline{\mathrm{RSO}_{3}^{-} \mathrm{H}^{+}}\right]_{\mathrm{i}}=500,14 \pm 1,21 \mathrm{~mol} / \mathrm{m}^{3} \mathrm{RSI}\right)$.

\begin{tabular}{cccc}
\hline $\mathrm{t}(\mathrm{s})$ & $\mathrm{VL}$ & $\mathrm{C}_{\mathrm{B}} / \mathrm{C}_{\mathrm{Bi}}$ & $\mathrm{pH} / \mathrm{pH}_{\mathrm{i}}$ \\
\hline 238 & 0,830 & 0,021 & 0,284 \\
423 & 1,475 & 0,047 & 0,344 \\
673 & 2,347 & 0,121 & 0,415 \\
940 & 3,278 & 0,278 & 0,496 \\
1230 & 4,289 & 0,376 & 0,539 \\
1480 & 5,161 & 0,503 & 0,571 \\
1671 & 5,827 & 0,667 & 0,592 \\
2003 & 6,985 & 0,781 & 0,612 \\
2374 & 8,279 & 0,927 & 0,615 \\
2789 & 9,726 & 0,959 & 0,637 \\
3182 & 11,096 & 0,993 & 0,644 \\
3604 & 12,568 & 1,015 & 0,650 \\
3990 & 13,914 & 0,986 & 0,649 \\
4557 & 15,891 & 0,995 & 0,683 \\
5142 & 17,931 & 0,984 & 0,689 \\
\hline
\end{tabular}


TABLAS E. Curvas de ruptura de extracción y reextracción de betaína. $\left(\mathbf{Q}=\mathbf{0}, \mathbf{0 3 5 \times 1 0 ^ { - 6 }}\right.$ $\left.\pm 0,003 \mathrm{~m} / \mathrm{s} ; \overline{\mathrm{RSO}_{3}^{-} \mathrm{H}^{+}}\right]_{\mathrm{i}}=\mathbf{5 0 0 , 1 4} \pm 1,21 \mathrm{~mol} / \mathrm{m}^{3} \mathrm{RSI}$ ). (Apartado 6.3.7.2).

Tabla E1. Datos experimentales de $1^{\text {er }}$ ciclo de extracción de betaína para el experimento I-a de la Tabla 25. $\left(\mathrm{pH}_{\mathrm{i}}=6,50 ; \mathrm{C}_{\mathrm{Bi}}=38,09 \mathrm{~mol} / \mathrm{m}^{3}\right)$

\begin{tabular}{ccc}
\hline $\mathrm{t}(\mathrm{s})$ & $\mathrm{VL}$ & $\mathrm{C}_{\mathrm{B}} / \mathrm{C}_{\mathrm{Bi}}$ \\
\hline 238 & 0,830 & 0,021 \\
423 & 1,475 & 0,047 \\
673 & 2,347 & 0,121 \\
940 & 3,278 & 0,278 \\
1230 & 4,289 & 0,376 \\
1480 & 5,161 & 0,503 \\
1671 & 5,827 & 0,667 \\
2003 & 6,985 & 0,781 \\
2374 & 8,279 & 0,927 \\
2789 & 9,726 & 0,959 \\
3182 & 11,096 & 0,993 \\
3604 & 12,568 & 1,015 \\
3990 & 13,914 & 0,986 \\
4557 & 15,891 & 0,995 \\
5142 & 17,931 & 0,984 \\
\hline
\end{tabular}

Tabla E2. Datos experimentales de $2^{\circ}$ ciclo de extracción de betaína para el experimento Ib de la Tabla 25. $\left(\mathrm{pH}_{\mathrm{i}}=6,50 ; \mathrm{C}_{\mathrm{Bi}}=48,16 \mathrm{~mol} / \mathrm{m}^{3}\right)$

\begin{tabular}{ccc}
\hline $\mathrm{t}(\mathrm{s})$ & $\mathrm{VL}$ & $\mathrm{C}_{\mathrm{B}} / \mathrm{C}_{\mathrm{Bi}}$ \\
\hline 190 & 0,721 & 0,001 \\
478 & 1,814 & 0,001 \\
640 & 2,429 & 0,001 \\
847 & 3,214 & 0,007 \\
1103 & 4,186 & 0,036 \\
1365 & 5,180 & 0,099 \\
1630 & 6,186 & 0,301 \\
1905 & 7,229 & 0,655 \\
2229 & 8,459 & 0,872 \\
2580 & 9,791 & 0,955 \\
2959 & 11,229 & 0,977 \\
3362 & 12,758 & 0,987 \\
3600 & 13,662 & 0,987 \\
3926 & 14,899 & 0,990 \\
4465 & 16,944 & 0,993 \\
5197 & 19,722 & 0,993 \\
\hline
\end{tabular}


Tabla E3. Datos experimentales de $3^{\text {er }}$ ciclo de extracción de betaína para el experimento I-c de la Tabla 25. $\left(\mathrm{pH}_{\mathrm{i}}=6,50 ; \mathrm{C}_{\mathrm{Bi}}=47,73 \mathrm{~mol} / \mathrm{m}^{3}\right)$

\begin{tabular}{ccc}
\hline $\mathrm{t}(\mathrm{s})$ & $\mathrm{VL}$ & $\mathrm{C}_{\mathrm{B}} / \mathrm{C}_{\mathrm{Bi}}$ \\
\hline 107 & 0,384 & 0,001 \\
418 & 1,501 & 0,002 \\
727 & 2,610 & 0,004 \\
909 & 3,263 & 0,011 \\
1108 & 3,977 & 0,028 \\
1358 & 4,875 & 0,063 \\
1593 & 5,718 & 0,210 \\
1796 & 6,447 & 0,472 \\
2026 & 7,273 & 0,726 \\
2318 & 8,321 & 0,899 \\
2703 & 9,703 & 0,974 \\
3017 & 10,830 & 0,987 \\
3388 & 12,162 & 0,987 \\
3825 & 13,731 & 0,992 \\
4416 & 15,852 & 0,994 \\
5129 & 18,412 & 0,997 \\
\hline
\end{tabular}


Tabla E4. Datos experimentales de $1^{\text {er }}$ ciclo de reextracción de betaína para el experimento I-a de la Tabla 25. $\left(\mathrm{pH}_{\mathrm{i}}=6,50 ; \mathrm{C}_{\mathrm{Bi}}=38,09 \mathrm{~mol} / \mathrm{m}^{3}\right)$

\begin{tabular}{|c|c|c|}
\hline $\mathrm{t}(\mathrm{s})$ & $\mathrm{VL}$ & $\mathrm{C}_{\mathrm{B}} / \mathrm{C}_{\mathrm{Bi}}$ \\
\hline 90 & 0,166 & 2,694 \\
\hline 152 & 0,281 & 5,203 \\
\hline 211 & 0,390 & 4,132 \\
\hline 271 & 0,500 & 6,968 \\
\hline 332 & 0,613 & 6,697 \\
\hline 396 & 0,731 & 5,355 \\
\hline 468 & 0,864 & 3,956 \\
\hline 511 & 0,943 & 3,420 \\
\hline 566 & 1,045 & 3,325 \\
\hline 628 & 1,159 & 3,271 \\
\hline 690 & 1,274 & 2,281 \\
\hline 750 & 1,385 & 2,056 \\
\hline 811 & 1,497 & 1,813 \\
\hline 872 & 1,610 & 1,440 \\
\hline 931 & 1,719 & 1,407 \\
\hline 1040 & 1,920 & 1,332 \\
\hline 1127 & 2,081 & 1,227 \\
\hline 1231 & 2,273 & 1,216 \\
\hline 1327 & 2,450 & 0,974 \\
\hline 1477 & 2,727 & 1,120 \\
\hline 1583 & 2,922 & 0,840 \\
\hline 1672 & 3,087 & 0,957 \\
\hline 1777 & 3,281 & 0,676 \\
\hline 1926 & 3,556 & 0,686 \\
\hline 2060 & 3,803 & 0,610 \\
\hline 2171 & 4,008 & 0,488 \\
\hline 2335 & 4,311 & 0,592 \\
\hline 2466 & 4,553 & 0,444 \\
\hline 2597 & 4,794 & 0,527 \\
\hline 2794 & 5,158 & 0,410 \\
\hline 3034 & 5,601 & 0,241 \\
\hline 3220 & 5,945 & 0,163 \\
\hline 3485 & 6,434 & 0,125 \\
\hline 3645 & 6,729 & 0,083 \\
\hline 3908 & 7,215 & 0,051 \\
\hline 4216 & 7,783 & 0,041 \\
\hline 4596 & 8,485 & 0,028 \\
\hline
\end{tabular}


Tabla E5. Datos experimentales de $\mathbf{2}^{\circ}$ ciclo de reextracción de betaína para el experimento I-b de la Tabla $25 .\left(\mathrm{pH}_{\mathrm{i}}=6,50 ; \mathrm{C}_{\mathrm{Bi}}=48,16 \mathrm{~mol} / \mathrm{m}^{3}\right)$

\begin{tabular}{ccc}
\hline $\mathrm{t}(\mathrm{s})$ & $\mathrm{VL}$ & $\mathrm{C}_{\mathrm{B}} / \mathrm{C}_{\mathrm{Bi}}$ \\
\hline 95 & 0,205 & 1,092 \\
169 & 0,364 & 1,735 \\
255 & 0,549 & 2,660 \\
336 & 0,724 & 3,779 \\
420 & 0,905 & 3,918 \\
475 & 1,023 & 2,983 \\
611 & 1,316 & 1,971 \\
715 & 1,540 & 1,513 \\
818 & 1,762 & 1,336 \\
950 & 2,046 & 0,809 \\
1095 & 2,358 & 0,728 \\
1221 & 2,630 & 0,673 \\
1373 & 2,957 & 0,618 \\
1486 & 3,201 & 0,462 \\
1605 & 3,457 & 0,218 \\
1760 & 3,791 & 0,180 \\
1930 & 4,157 & 0,137 \\
2198 & 4,734 & 0,051 \\
2327 & 5,012 & 0,048 \\
2535 & 5,460 & 0,029 \\
2770 & 5,966 & 0,023 \\
3080 & 6,634 & 0,017 \\
3427 & 7,381 & 0,016 \\
3839 & 8,269 & 0,012 \\
4440 & 9,563 & 0,009 \\
\hline
\end{tabular}

